\title{
Income, Cost, Time, and Convenience of Food: A Series of Rapid Reviews and Evidence Scans
}

Emily Callahan, MS, a Marlana Bates, MPH, RD, b Laural Kelly English, PhD, ${ }^{b}$ Molly Higgins, MLIS, ${ }^{c}$ Julia H Kim, PhD, $\mathrm{MPH}, \mathrm{RD},{ }^{\mathrm{b}}$ Julie Nevins, PhD, ${ }^{\mathrm{b}}$ Sara Scinto-Madonich, MS

a Project Lead, NESR team, Nutrition Guidance and Analysis Division (NGAD), Center for Nutrition Policy and Promotion (CNPP), Food and Nutrition Service (FNS), U.S. Department of Agriculture (USDA)

${ }^{b}$ Analyst, NESR team; Panum Group, under contract with the FNS, USDA

c Librarian, NESR team; Panum Group, under contract with the FNS, USDA

Suggested citation: Nutrition Evidence Systematic Review Team. Income, Cost, Time, and Convenience of Food: A Series of Rapid Reviews and Evidence Scans. USDA Food Plans Rapid Reviews and Evidence Scans. Alexandria, VA: U.S. Department of Agriculture, Food and Nutrition Service, Center for Nutrition Policy and Promotion, August 2021. Available at: https://nesr.usda.gov/usda-foodplans-rapid-reviews-and-evidence-scans.

Related citation: U.S. Department of Agriculture. Thrifty Food Plan, 2021. August 2021. Available at: https://FNS.usda.gov/TFP. 
The contents of this document may be used and reprinted without permission. Endorsements by NESR, CNPP, FNS, or USDA of derivative products developed from this work may not be stated or implied.

In accordance with Federal civil rights law and U.S. Department of Agriculture (USDA) civil rights regulations and policies, the USDA, its Agencies, offices, and employees, and institutions participating in or administering USDA programs are prohibited from discriminating based on race, color, national origin, religion, sex, gender identity (including gender expression), sexual orientation, disability, age, marital status, family/parental status, income derived from a public assistance program, political beliefs, or reprisal or retaliation for prior civil rights activity, in any program or activity conducted or funded by USDA (not all bases apply to all programs). Remedies and complaint filing deadlines vary by program or incident.

Persons using assistive technology should be able to access information in this report. For further assistance please email SM.FN.NESR@USDA.gov.

Persons with disabilities who require alternative means of communication for program information (e.g., Braille, large print, audiotape, American Sign Language, etc.) should contact the responsible Agency or USDA's TARGET Center at (202) 720-2600 (voice and TTY) or contact USDA through the Federal Relay Service at (800) 877-8339. Additionally, program information may be made available in languages other than English.

To file a program discrimination complaint, complete the USDA Program Discrimination Complaint Form, AD-3027, found online at How to File a Program Discrimination Complaint and at any USDA office or write a letter addressed to USDA and provide in the letter all of the information requested in the form. To request a copy of the complaint form, call (866) 632-9992. Submit your completed form or letter to USDA by: (1) mail: U.S. Department of Agriculture, Office of the Assistant Secretary for Civil Rights, 1400 Independence Avenue, SW, Washington, D.C. 20250-9410; (2) fax: (202) 690-7442; or (3) email: program.intake@usda.gov.

USDA is an equal opportunity provider, employer, and lender. 


\section{Table of contents}

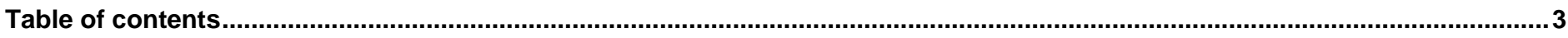

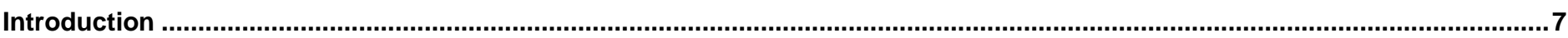

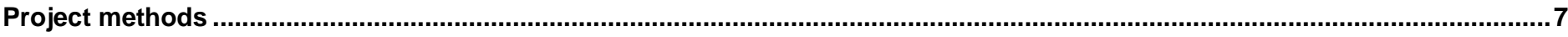

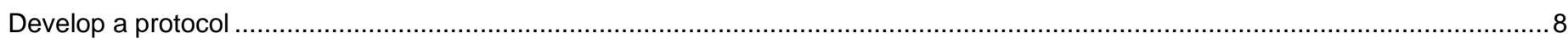

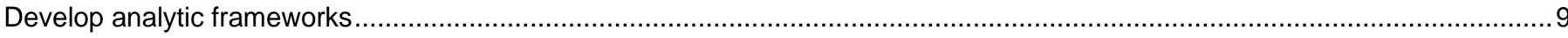

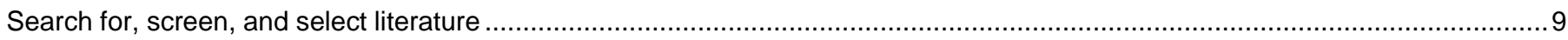

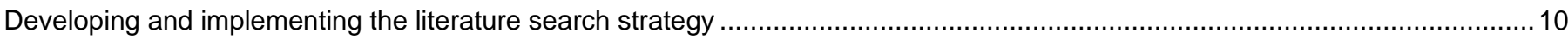

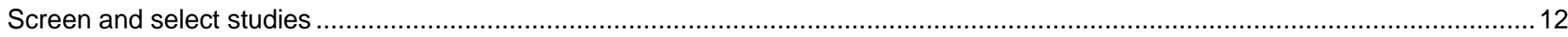

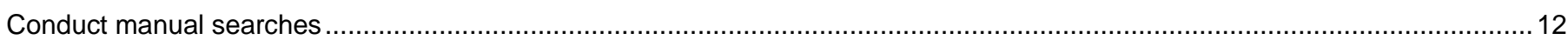

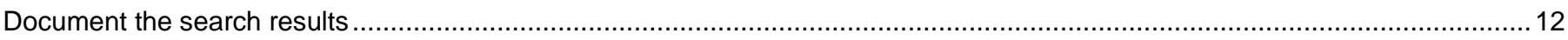

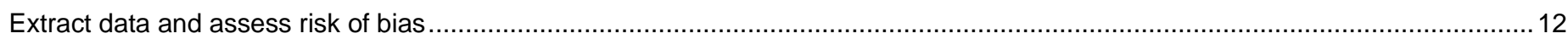

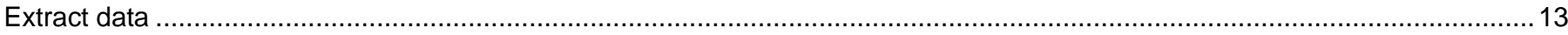

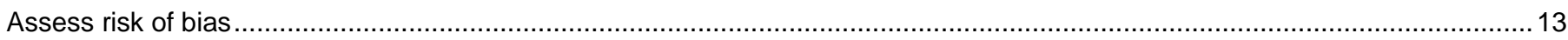

Synthesize evidence, assessment of evidence, develop summary statements, and identify research recommendations ..................14

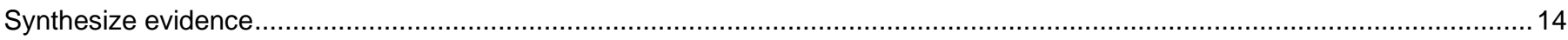

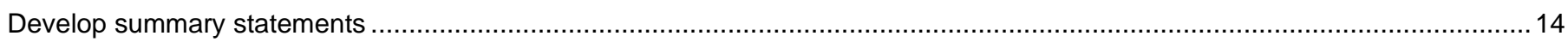

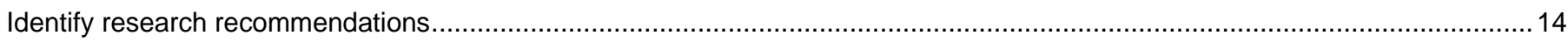

Chapter 1 - What is the relationship between income and prices for food items/baskets? ....................................................15

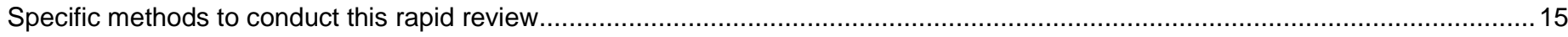

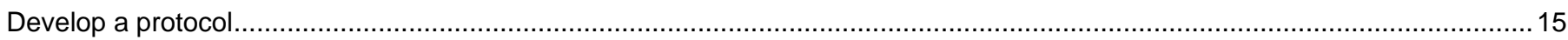

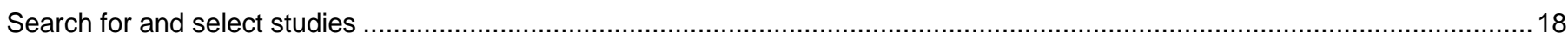

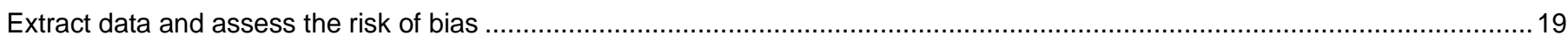

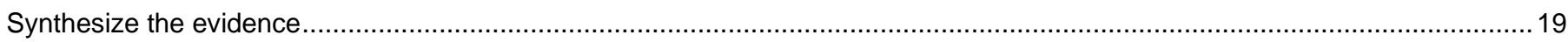

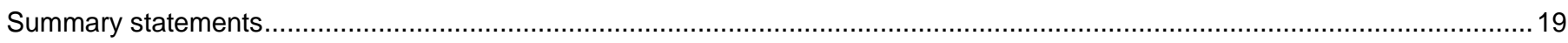

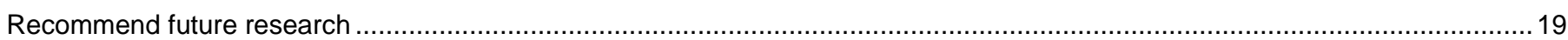

Results n...1.

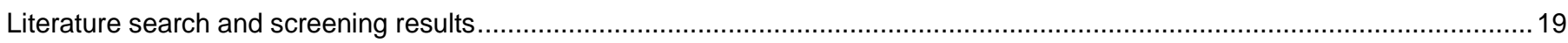

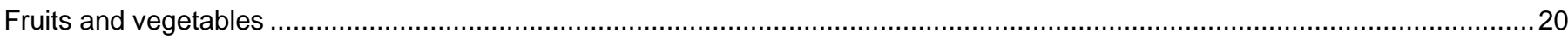

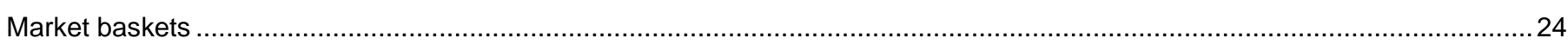

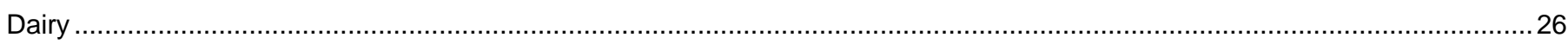

Grains .

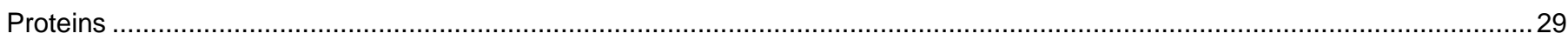

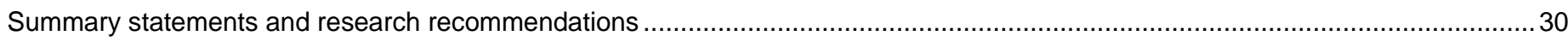

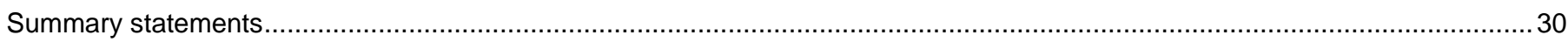

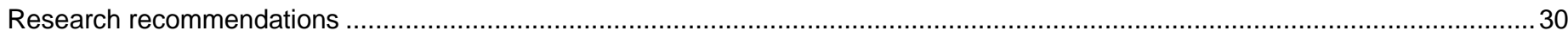

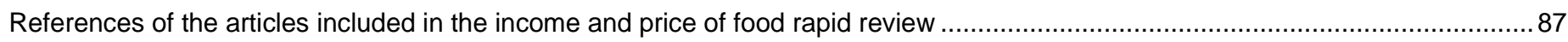

Chapter $\mathbf{2}$ - What is the relationship between income or Federal Assistance participation/eligibility and following a dietary pattern that aligns with the Dietary Guidelines for Americans, as measured by the Healthy Eating Index (HEI)? .......................89

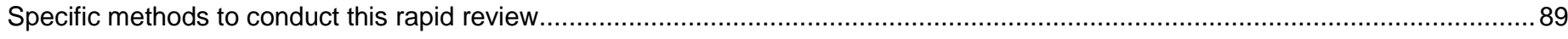

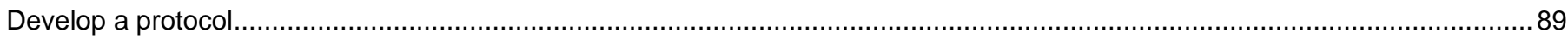

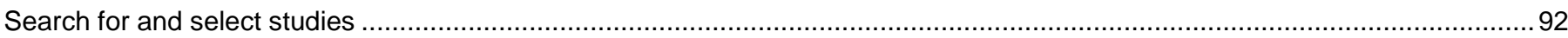




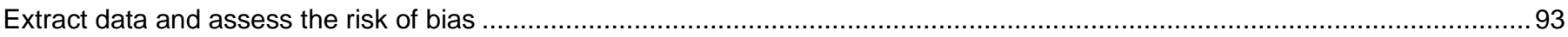

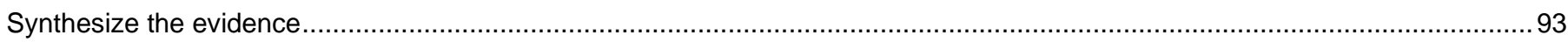

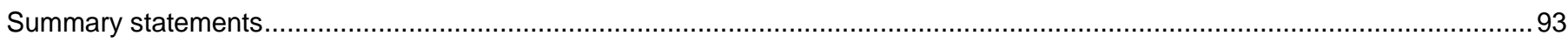

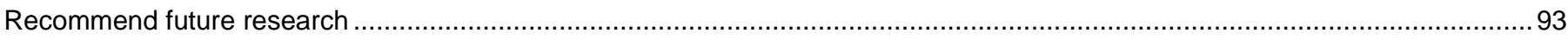

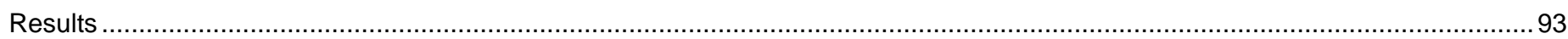

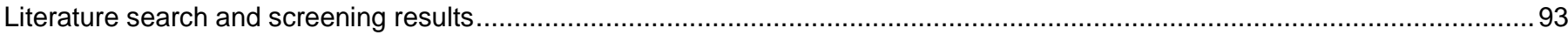

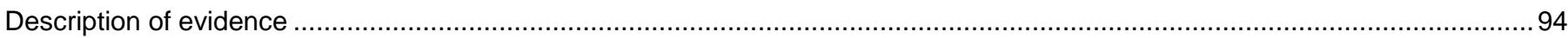

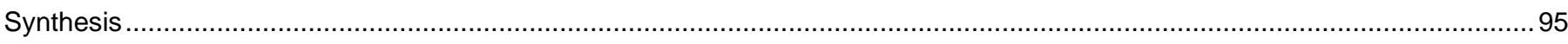

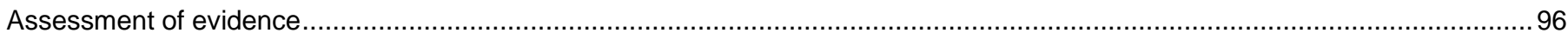

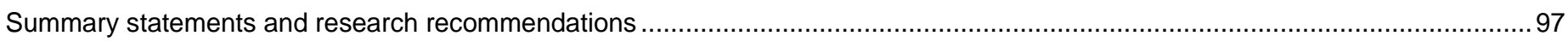

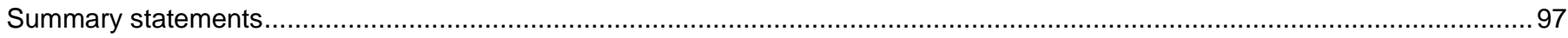

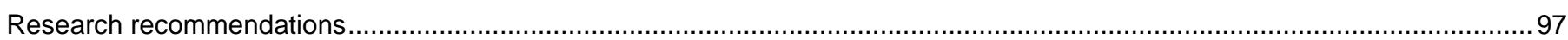

References of the articles included in the income and HEI rapid review ....................................................................... 119

Chapter 3 - What is the relationship between overall diet cost and following a dietary pattern that aligns with the Dietary Guidelines for Americans, as measured by the Healthy Eating Index (HEI)? ........................................................................122

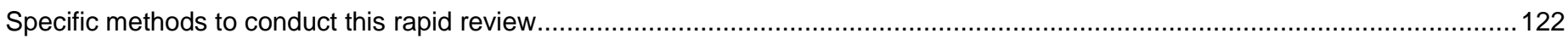

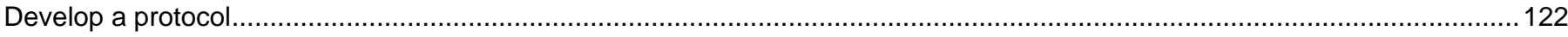

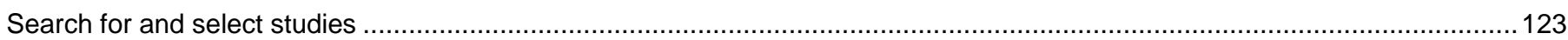

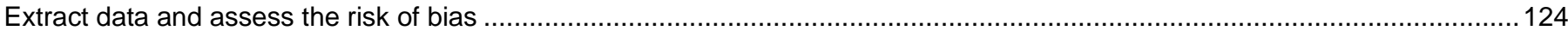

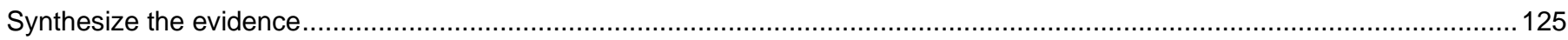

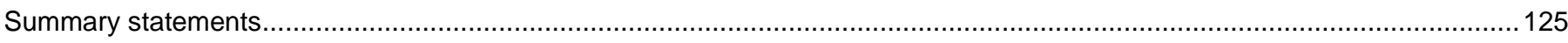

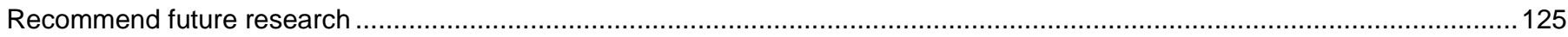

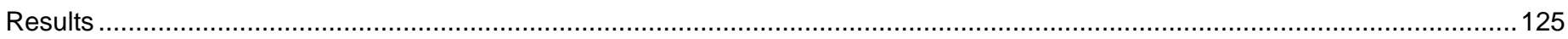

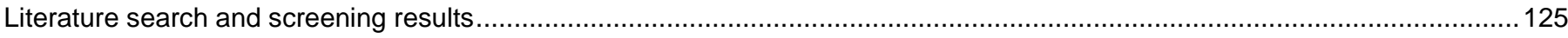

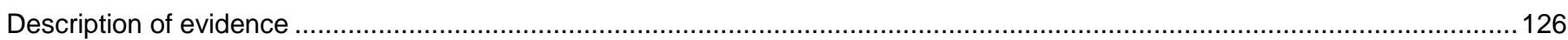

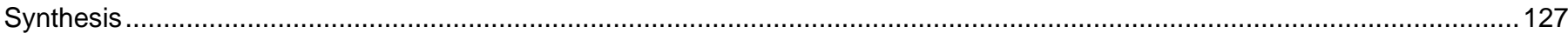

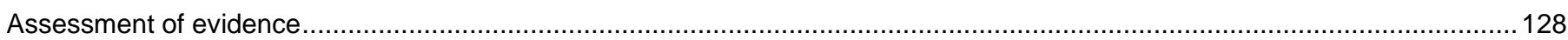

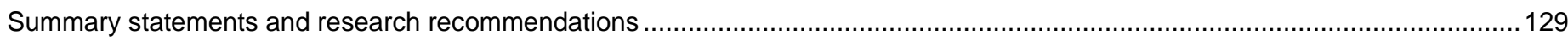

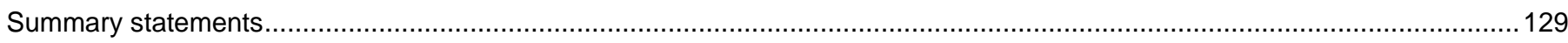

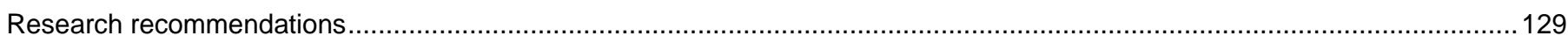

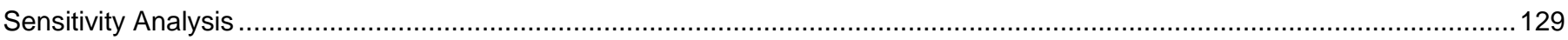

References of the articles included in the diet cost and HEI rapid review ....................................................................... 137

Chapter 4 - What is the relationship between income and time spent on food-at-home-related activities? ............................ 138

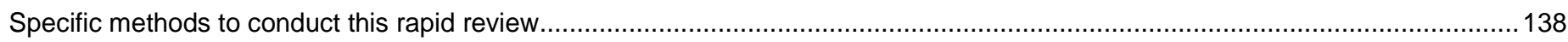

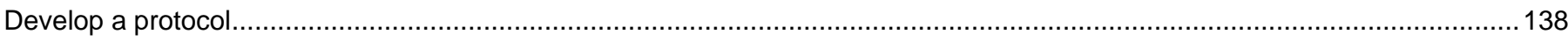

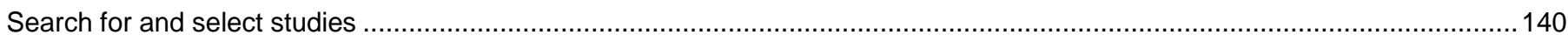

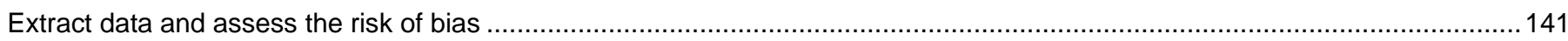

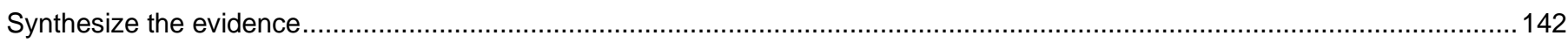

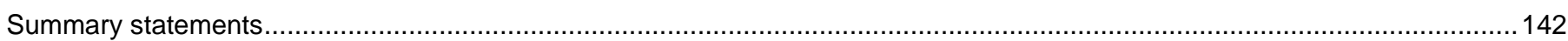

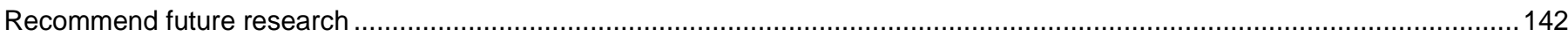

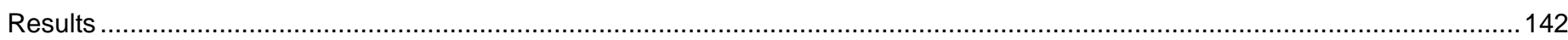

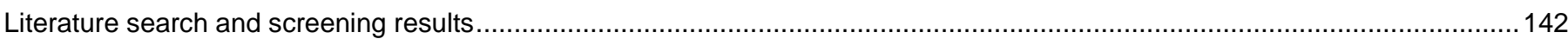

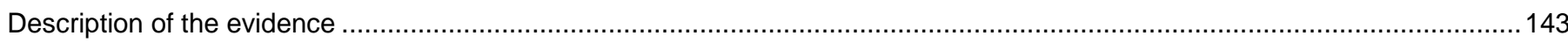


Synthesis of the evidence

Summary statements and research recommendations

Summary statements

Research recommendations.

References of the articles included in the income and time spent on food-at-home-related activities rapid review

158

Chapter 5 - What factors influence the purchase and/or consumption of at-home convenience foods? How are these foods described in the literature?

Specific methods to conduct this evidence scan. 159

Develop a protocol. 159

Search for and select studies 160

Extract data 161

Describe the evidence 163

Recommend future research 163

Results 163

Literature search and screening results. 163

Description of the evidence 164

Research recommendations. 172

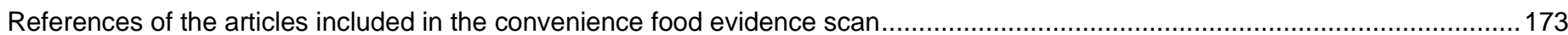

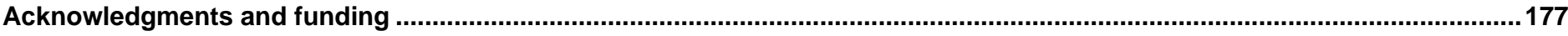

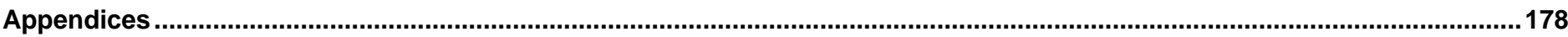

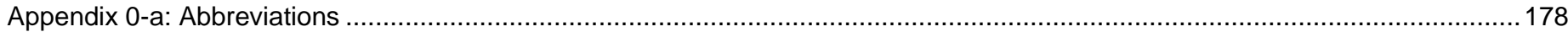

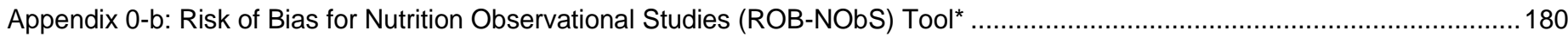

Appendix 1-a: Literature search strategy for the rapid review on income and food prices .................................................... 188

Appendix 1-b: Excluded articles for the rapid review on income and food prices ............................................................. 194

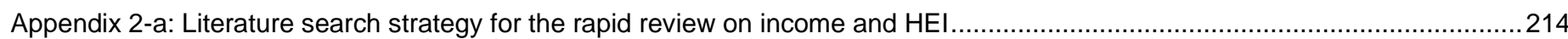

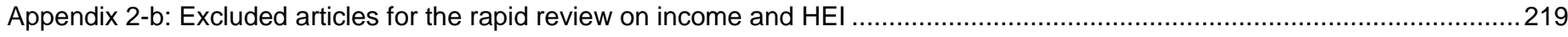

Appendix 3-a: Literature search strategy for the rapid review on diet cost and HEI ..........................................................235

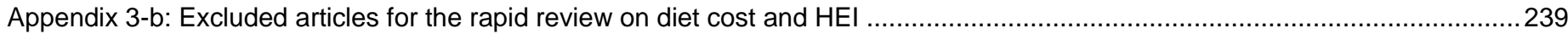

Appendix 4-a: Literature search strategy for the rapid review on income and time spent on food-at-home-related activities ............249

Appendix 4-b: Excluded articles for the rapid review on income and time spent on food-at-home-related activities.......................253

Appendix 5-a: Literature search strategy for the evidence scan on factors that influence the purchase and/or consumption of convenience foods

Appendix 5-b: Excluded articles for the evidence scan on factors that influence the purchase and/or consumption of convenience foods

Table 1-a. Inclusion and exclusion criteria for the rapid review on income and price of food............................................................

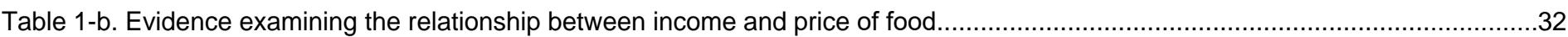

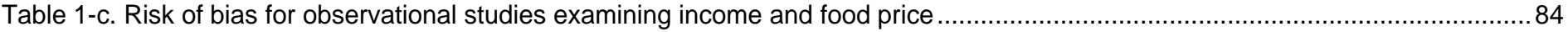

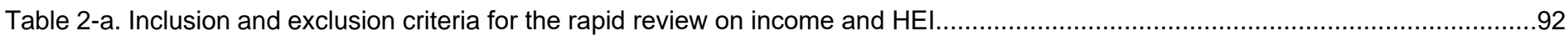

Table 2-b. Evidence examining the relationship between income and/or Federal assistance participation/eligibility and $\mathrm{HEI}$................99

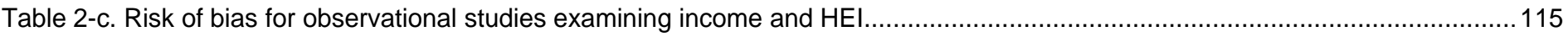

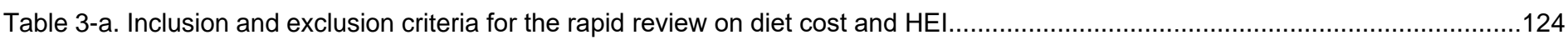

Table 3-b. Evidence examining the relationship between diet cost and HEl score .....................................................................131 
Table 3-c. Evidence examining the relationship between food expenditures and HEI scores .............................................. 133

Table 3-d. Risk of bias for the randomized controlled trial examining diet cost or expenditures and HEI....................................... 135

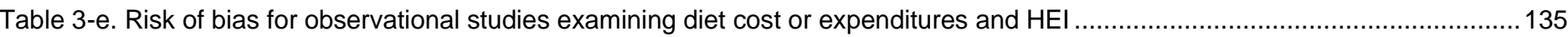

Table 4-a. Inclusion and exclusion criteria for the rapid review on income and time spent on food-at-home-related activities..............140

Table 4-b. Cross-sectional evidence examining the relationship between income and time spent on food-at-home-related activities .. 148

Table 4-c. Cross-sectional evidence examining the relationship between income proxy and time spent on food-at-home-related

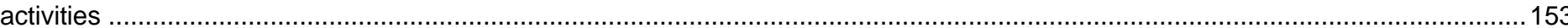

Table 4-d. Risk of bias for observational studies examining income and time spent on food-at-home-related activities..................... 156

Table 5-a. Inclusion and exclusion criteria for the evidence scan on the purchase/consumption of at-home convenience foods.......... 161

Figure 1-a. Analytic frameworkfortherapidreviewonincomeandprice of food

Figure 1-b. Literature search and screen flowchart for the rapid review on income and price of food...............................................20

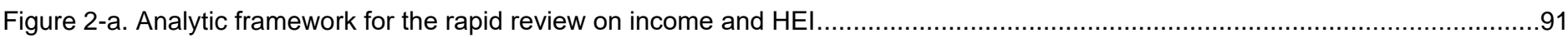

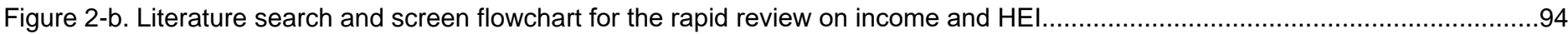

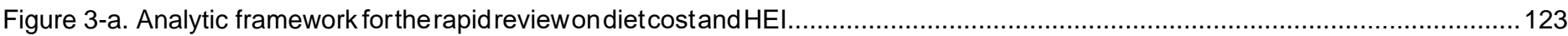

Figure 3-b. Literature search and screen flowchart for the rapid review on diet cost and HEl................................................126

Figure 4-a. Analytic framework for the rapid review on income and time spent on food-at-home-related activities ............................139

Figure 4-b. Literature search and screen flowchart for the rapid review on income and time-spent on food-at-home-related activities. 143

Figure 5-a. Analytic framework for the evidence scan on purchase/consumption of at-home convenience foods. .160

Figure 5-b. Literature search and screen flowchart for the evidence scan on purchase/consumption of at-home convenience foods...164

Figure 5-c. Qualitative study factors identified related to the purchase/consumption of at-home convenience foods .166

Figure 5-d. Quantitative study factors examined related to the purchase/consumption of at-home convenience foods..... 167

Figure 5-e. Ready-to-Eat Food Groups 169

Figure 5-f. Ready-to-Heat Food Groups 170

Figure 5-g. Ready-to-Cook/Ready-to-Bake Food Groups

Figure 5-h. Ready-to-Prepare Food Groups.... 


\section{Introduction}

The U.S. Department of Agriculture (USDA) develops four USDA Food Plans (the Thrifty, Low-Cost, ModerateCost, and Liberal Food Plans), each of which shows how a nutritious diet may be achieved at various cost levels. Each Food Plan includes a set of market baskets applicable to 1 of 15 age-sex groups. Each market basket is a selection of foods in purchasable food categories that together can be used in meals that reflect current dietary recommendations.

The Thrifty Food Plan (TFP) serves as the basis for the maximum allotment for the Supplemental Nutrition Assistance Program (SNAP), formerly known as the Food Stamp Program. The 2018 Farm Bill mandated an update to the TFP market baskets by 2022 and every five years thereafter to reflect "current prices, composition data, consumption patterns, and dietary guidance". The importance of updating the TFP was further reiterated in Executive Order 14002 issued by President Joseph R. Biden on January 22, 2021.

To meet this mandate, the Thrifty Food Plan, 2021 has been updated using a rigorous scientific process. USDA's Center for Nutrition Policy and Promotion's (CNPP) Nutrition Evidence Systematic Review (NESR) team completed a series of rapid reviews and evidence scans as a source of information to support systematic and rigorous decisions throughout the process.

The staff at NESR specializes in conducting food- and nutrition-related systematic reviews and evidence syntheses. The NESR staff collaborated with USDA's CNPP Nutrition and Economic Analysis Team (NEAT), who conduct the analyses to develop the USDA Food Plans, to complete a series of rapid reviews and evidence scans to address the following research questions:

1. Rapid Review: What is the relationship between income and prices for food items/baskets?

2. Rapid Review: What is the relationship between income or Federal Assistance participation/eligibility and following a dietary pattern that aligns with the Dietary Guidelines for Americans, as measured by the Healthy Eating Index (HEI)?

3. Rapid Review: What is the relationship between overall diet cost and following a dietary pattern that aligns with the Dietary Guidelines for Americans, as measured by the Healthy Eating Index (HEI)?

4. Rapid Review: What is the relationship between income and time spent on food-at-home-related activities?

5. Evidence Scan: What factors influence the purchase and/or consumption of at-home convenience foods? How are these foods described in the literature?

The methods for the rapid reviews and evidence scan are detailed below.

\section{Project methods}

Herein, we present an overview of the methods specific to the rapid reviews and evidence scans to inform the Thrifty Food Plan, 2021, including all deviations or modifications made to NESR standard systematic review methods.

Four rapid reviews were conducted to support the Thrifty Food Plan, 2021 project. A rapid review is a type of evidence synthesis project in which the methods of a systematic review are modified or streamlined to produce 
results in a timely and cost-effective manner. ${ }^{a}$ Although systematic review methods are modified to expedite the process, a rapid review is still characterized by rigorous, transparent, and reproducible methods. The methodology utilized for each rapid review is informed by and tailored to the scientific question being answered and the specific needs of the requester (e.g., timeline, purpose, scope, circumstances, and stakeholders) while retaining scientific integrity. Best practices and recommendations from other research and health organizations, including the World Health Organization, Cochrane, the Agency for Healthcare Research and Quality, and the Center for Evidence-Based Medicine at the University of Oxford, inform the process by which NESR conducts rapid reviews. ${ }^{a, b, c, d}$

Three evidence scans were conducted for the Thrifty Food Plan, 2021 project. A NESR evidence scan is a systematic and exploratory process used to provide objective data on the volume and characteristics of research available on a topic or question. Evidence scans involve the following: development/refinement of the research question, evidence scan protocol development, search for and screen studies, minimal data extraction, and summarizing study characteristics. NESR evidence scans do not include: 1) data extraction of study results, 2) assessment of risk of bias, 3) synthesis of the evidence, 4) development of conclusion statements, or 5) grading the strength of the evidence. Two of the evidence scans were conducted to inform protocol development for 2 of the rapid reviews and 1 to describe the volume and characteristics of studies available on a topic of interest related to the Thrifty Food Plan, 2021.

The process by which NESR developed rigorous a priori methods and protocols for this series of rapid reviews and evidence scans, and the type and extent of modifications made to NESR systematic review methods, are transparently documented and described below. Any additional methodological modifications made for individual reviews are acknowledged under their respective sections of the report. The summary statements in this series of rapid reviews should be interpreted in light of these modifications, and noted limitations.

\section{Develop a protocol}

For each rapid review question or evidence scan, the NESR team collaborated with the NEAT team to develop a protocol. A rapid review or evidence scan protocol has the same elements as a systematic review protocol, and is a plan for how a specific review will be conducted. The protocol includes:

- Analytic framework

- Literature search and screening plan

- Inclusion and exclusion criteria

- Electronic databases and search terms

- Literature search and screening results

\footnotetext{
a Tricco AC, Langlois EV, Straus SE, editors. Rapid reviews to strengthen health policy and systems: a practical guide. Geneva: World Health Organization. 2017. https://apps.who.int/iris/handle/10665/258698.

${ }^{b}$ Garritty C, Gartlehner G, Nussbaumer-Streit B, King VJ, Hamel C, Kamel C, Affengruber L, Stevens A. Cochrane Rapid Reviews Methods Group offers evidence-informed guidance to conduct rapid reviews. J Clin Epi. 2020;130:13-22.

${ }^{c}$ Hartling L, Guise J-M, Kato E, Anderson J, Aronson N, Belinson S, Berliner E, Dryden D, Featherstone R, Foisy M, Mitchell M, Motu'apuaka M, Noorani H, Paynter R, Robinson KA, Schoelles K, Umscheid CA, Whitlock E. EPC Methods: An Exploration of Methods and Context for the Production of Rapid Reviews. Research White Paper. (Prepared by the Scientific Resource Center under Contract No. 290-2012-00004-C.) AHRQ Publication No. 15-EHC008-EF. Rockville, MD: Agency for Healthcare Research and Quality; February 2015. www.effectivehealthcare.ahrq.gov/reports/final.cfm.

d Plüddemann A, Aronson JK, Onakpoya I, Heneghan C, Mahtani KR. Redefining rapid reviews: a flexible framework for restricted systematic reviews. BMJ Evid Based Med. 2018;23(6):201-203. doi:10.1136/bmjebm-2018-110990
} 
- Flow chart of literature search and screening results

- List of included articles

- List of excluded articles, with rationale

The protocols were established before any evidence was reviewed and synthesized. This allowed the establishment of protocols that would capture the most appropriate, relevant, and direct body of evidence to answer each question. Any revisions to protocols that occurred after the start of a specific review were documented and are noted in the below report.

A description of NESR's methodology for developing an analytic framework is below. NESR's methodology for developing inclusion and exclusion criteria and the search strategy, as well as processes related to screening and selecting studies for inclusion in a review, is described, below, in "Search for, screen, and select literature."

\section{Develop analytic frameworks}

Analytic frameworks were developed for each rapid review and evidence scan question. An analytic framework defines the core elements of the review question, includes definitions for key terms, identifies key confounders and other factors that could affect the relationships examined, and helps to ensure that important contributing elements in the causal chain will be examined and evaluated. The analytic framework serves as the foundation for the rest of the review process, and informs the inclusion/exclusion criteria and literature search strategy, data extraction and risk of bias assessments, and the strategy for synthesizing the evidence to develop summary statements.

A standard framework, called the PICO framework, was used to define core elements of each review question. The elements of the PICO framework are the Population (for both the intervention/exposure and for the outcome), Intervention and/or exposure, Comparator (i.e., the alternative being compared to the intervention or exposure), and Outcomes. Key terms, key confounders, and other factors to be considered (i.e., mediators, moderators, covariates) were also identified and included in the analytic framework where appropriate. Key confounders are considered during review and evaluation of the evidence, particularly during risk of bias assessment (see "Assess risk of bias," below) and evidence synthesis.

\section{Search for, screen, and select literature}

Systematic searching, screening, and selecting the scientific literature is a process through which NESR sought to identify the most complete and relevant body of evidence to answer the rapid review and evidence scan questions. The process started with defining inclusion and exclusion criteria a priori, followed by developing and implementing literature search strategies, and finally screening and identifying search results. The entire process was documented, including a complete list of articles that met criteria for inclusion in each rapid review or scan, and a list of excluded articles, with the rationale for exclusion.

\section{Define inclusion and exclusion criteria}

Inclusion and exclusion criteria provide an objective, consistent, and transparent framework for determining which articles to include in each review. These criteria were developed before any studies were reviewed to guide selection of the most relevant and appropriate body of evidence for each review question. Additionally, these criteria were framed to increase the utility for Thrifty Food Plan, 2021. To minimize bias, revisions to the criteria after studies had been reviewed were discouraged. Any revisions to the criteria that occurred after studies were reviewed are documented in the individual reviews in this report. 
NESR analysts worked jointly with the NEAT staff to establish inclusion and exclusion criteria that were tailored to the specific review question addressed.

Criteria were established for a number of study characteristics, and although criteria were tailored to the unique characteristics of each review question being addressed, NESR also applied several standard criteria across this project. Deviations from the standard criteria that were appropriate for individual questions are documented in the report section for that question. The following is a description of criteria applied across this project:

- Study Design: Any study design that was not a narrative review, systematic review, or meta-analysis was included.

- Language: Articles published in English were included. Articles published in languages other than English were excluded.

- Publication status: Articles that had been peer-reviewed or grey literature in the form of reports that had not been peer reviewed, but were available from government and nongovernmental organizations were included.

- Publication date and data years: Studies published between January 2008 to present and had data collected inclusive of 2008 (e.g., 2000-2012; 2008-2009) were included. Articles published before January 2008 or articles with data collected prior to 2008 (e.g., 2000-2007; 1999-2005), regardless of publication date, were excluded. NESR and NEAT chose 2008 because of national and policy-relevant changes. The Food, Conservation, Energy Act of 2008 (which was a continuation of the 2002 Farm Bill that restored food and nutrition program eligibility of legal immigrants) increased benefits and eligibility for the Food Stamp Program (FSP), and increased funding and eligibility for free/reduced-price lunch and other food-assistance programs. In 2009, the FSP was renamed to the Supplemental Nutrition Assistance Program (SNAP). Therefore, the NEAT and NESR teams determined that the preponderance of the evidence most relevant to factors such as income, price, cost and Federal assistance would be captured by searching literature starting in the year 2008. For consistency, a starting date of 2008 was selected for multiple questions addressed in this project.

- Country: Studies were only included if they were conducted in the U.S.

- Study participants: Human participants/populations were included and all non-human participants (i.e., animal studies, in-vitro) were excluded.

\section{Developing and implementing the literature search strategy}

Once the inclusion and exclusion criteria were set, the NESR librarian used the analytic framework and inclusion/exclusion criteria to guide development of a comprehensive literature search strategy. The literature search strategy included selecting and using the appropriate bibliographic databases (e.g., PubMed/MEDLINE, Business Source Premier, Web of Science), identifying search terms appropriate for the databases being searched, and employing search refinements, such as search filters. The librarian worked in collaboration with NESR staff to construct a preliminary search strategy using PubMed operators and search terms. This was used to conduct a test search, preview the results, and correct any syntax, spelling, or grammatical errors. The search strategy underwent multiple revisions to refine and adjust the search before it was finalized for use. The search strategies are included in this report for all rapid reviews completed. Unlike NESR systematic reviews, the search strategies for these rapid reviews were not peer-reviewed by a $2^{\text {nd }}$ librarian as a time-savings concession. 
Literature search strategies for rapid reviews and evidence scans are developed with the same methods and were specific to each question. Evidence scans generally have broader questions and therefore broader search strategies. For the 2 questions where an evidence scan was conducted to inform the rapid review, the evidence scan confirmed that the scope of the question was adequate and the same search that was run for the evidence scan was used for the rapid review.

\section{Identify bibliographic databases}

The NESR librarian selected electronic bibliographic databases based on the systematic review topic. A team of staff at Economic Research Service consulted on appropriate databases on the topic of income and prices of food/food baskets, including a grey literature approach. This insight was applied across the project for additional questions and topics. PubMed/MEDLINE, Business Source Premier, Web of Science were the primary databases used for the project, and AgEcon, Google Scholar, and Google were used for the grey literature search.

\section{Develop search terms and apply search filters}

NESR analysts helped identify initial key terms and/or relevant articles to ensure that the NESR librarian had an understanding of the scope and intent of the systematic review question. The librarian was responsible for checking each bibliographic database's search features to ensure that all related search terms for a particular review question were captured.

For this project, filters that were used include: English language, human studies, date, study design, and publication type (e.g., to filter out news, editorials, and comments).

\section{Implement the literature search strategy}

After finalizing the search strategies for each of the databases, the NESR librarian began the process of conducting all of the electronic searches. When searching multiple databases, overlap in the literature identified is common; the librarian electronically eliminated duplicate records at the search level using a citation management program (EndNote X9; Clarivate Analytics, Philadelphia, PA). Additional duplicates were identified by NESR analysts during the course of screening, and were removed from the search results. In addition, because some journals publish articles electronically, in advance of the print journal, the search captured these articles, and they were eligible for inclusion in the review, even though there was a possibility that they would be assigned an official publication date outside the window of the search date range.

In addition to the peer-reviewed primary studies retrieved from major biomedical databases, a complementary search of the grey literature was conducted in order to ensure that published and unpublished studies and reports relevant to the research questions were included in the search process. The grey literature search strategy included a broad search using similar key terms. More information about the sources selected and the searches conducted are included in each individual review. To determine which results to select for screening, the librarian limited the export of results to $n$ pages where $n=$ [pages with relevant results] +1 . Relevant results were determined by the result's title.

Once the electronic searches were done, the librarian documented the total number of unique articles identified, indicating how many were identified from each database searched. This documentation included the total, raw search results, as well as search results after removal of duplicates. 


\section{Screen and select studies}

The screening of search results was facilitated by the use of a web-based tool (i.e., DistillerSR) and screening forms that were developed based on the inclusion and exclusion criteria identified for each systemic review. For the rapid reviews and evidence scan included in this project, generally, 1 NESR analyst screened $100 \%$ of records and a $2^{\text {nd }}$ analyst screened $20 \%$ of records. In some cases, 1 analyst screened $100 \%$ of records, and a $2^{\text {nd }}$ analyst verified the decisions. A re-ranking function was utilized in DistillerSR to reorder the most relevant articles first. The goal of screening was to review the search results and exclude those that did not meet the inclusion criteria. Screening was generally completed at 3 levels. The first level of screening was completed using only the title of each article. If an article was not excluded at this level, it moved forward to the $2^{\text {nd }}$ level, where the abstract was screened. Finally, if an article passed the first 2 levels, it moved to the third level, where the full text of the article was screened. In this project, title and abstract screening were sometimes combined into 1 level. Any disagreements between analysts were reconciled between the 2 screenings. If necessary, a third analyst was consulted to resolve differences. These screening distinctions are noted in each individual review section of this report.

If multiple articles were identified that presented effectively the same data from the same study or cohort, the article that most directly addressed the review question was included to avoid duplicative data. However, if the articles addressed unique data related to the question, or were needed to comprehensively present information from a study or cohort, then all articles were included. Included articles from the same study or cohort were noted in the review, and this was taken in consideration when weighing the amount of evidence to answer a question.

Screening for rapid reviews and evidence scans for this project used consistent methods in order to ensure that the screening completed for the scan could also be applied to the rapid review. In cases where the focus of the rapid review question was narrowed after the evidence scan, additional screening was completed to exclude any studies that would no longer be included when the rapid review protocol elements were applied to the body of evidence.

\section{Conduct manual searches}

NESR analysts also completed manual searches on the rapid reviews in this project. Manual searching was done to find articles not identified through the electronic database search. This was typically due to inadequate indexing or filtering limitations of a database. The primary approach used for the manual search was hand searching, in which an analyst systematically searched the reference sections of included articles and related systematic reviews and meta-analyses. Potential articles also may have been suggested by others engaged in the process. Any identified citations were then screened for inclusion or exclusion as outlined above.

\section{Document the search results}

After the electronic and manual searches were completed, NESR analysts and the librarian documented the literature search and screening results by compiling lists of the included and excluded citations, along with the rationale for exclusion at the full-text level.

\section{Extract data and assess risk of bias}

NESR analysts extracted and summarized data from each included article to objectively describe the body of evidence available to answer a rapid review question or inform an evidence scan. For rapid reviews, NESR analysts assessed the risk of bias for each included article. Risk of bias assessments were not completed for 
evidence scans. The extracted data and assessment of risk of bias were used to populate evidence tables to present the key data used in the synthesis for the review.

\section{Extract data}

To expedite data extraction, only the most essential data for answering the question were extracted. For the rapid reviews, information on the following elements were generally extracted: Study design, analytic $\mathrm{N}$, geographic location and/or population description, intervention/exposure, outcomes, results, key confounders, and data source. For evidence scans, only minimal descriptive information was extracted, and no results were included.

Once the types of data to be extracted were determined, a data extraction form was developed and used to facilitate accurate, consistent, and efficient data extraction. This form ensured that the same information from each article was formatted consistently, which made the content easier to compare and contrast during synthesis. NESR analysts used DistillerSR to extract data.

One NESR analyst extracted data from each included article using the data extraction form. In some cases, the required data were not reported in the article. In those situations, the data were recorded as "not reported." However, if the required data were reported in an article's protocol or related publication, the analyst extracted the data and noted the publication from which it was extracted. Next, a $2^{\text {nd }}$ analyst reviewed only the extracted results for completeness, accuracy, and consistent presentation and formatting. Evidence tables were created by NESR analysts using the extracted data.

\section{Assess risk of bias}

Each article included in a rapid review underwent a formal risk of bias assessment. Risk of bias assessments were not completed for evidence scans. Risk of bias is the likelihood of a systematic error or deviation from the truth, in results or interferences, which can lead to underestimation or overestimation of either the true effect of an intervention on an outcome or the true association between an exposure and outcome.

NESR assessed the risk of bias of RCTs, including parallel group trials, cluster-randomized trials, and crossover trials, using the "Cochrane risk-of-bias tool for randomized trials" (RoB 2.0; August 2016 version). ${ }^{a}$ NESR assessed the risk of bias of non-RCTs using the "Risk of Bias in Non-randomized Studies. ${ }^{b}$ NESR assessed the risk of bias of observational studies using the Risk of Bias for Nutrition Observational Studies tool (RoBNObs) (Appendix 0-b).

For each article included in a rapid review, 1 NESR analyst completed the risk of bias tool appropriate for the study's design and the assessment was verified by a $2^{\text {nd }}$ analyst. Analysts answered the signaling questions based only on the data that was extracted for the rapid review for a specific result, and determined domainlevel risk of bias judgements (e.g., Low, Moderate, Serious, Critical). If necessary, analysts referred to previous and/or related publications to obtain information to complete items in the tool. The analysts' reconciled disagreements and if a disagreement could not be resolved by the 2 analysts, an additional member of the NESR staff was asked to provide a third-party consultation.

\footnotetext{
a Higgins JPT, Sterne JAC, Savović J, et al. A revised tool for assessing risk of bias in randomized trials. In: Chandler J, Clarke M, McKenzie J, Boutron I, Welch V, eds. Cochrane Methods. Vol 10(Suppl 1): Cochrane Database of Syst Rev.; 2016. doi: 10.1002/14651858.CD201601.

b Sterne JAC, Hernán MA, Reeves BC, et al. ROBINS-I: a tool for assessing risk of bias in nonrandomised studies of interventions. BMJ. 2016;355:i4919. doi:10.1136/bmj.i4919.
} 
The results of each risk of bias assessment were displayed in a risk of bias table. This table provides transparency to the domain-level risk of bias judgements for each included article using a color-coded system. Limitations identified during risk of bias assessments were also described and considered.

\section{Synthesize evidence, assessment of evidence, develop summary statements, and identify research recommendations}

\section{Synthesize evidence}

Evidence synthesis was conducted for each rapid review, which is the process by which evidence from multiple studies is described, compared and contrasted, and combined qualitatively, or narratively, to answer the review question. This synthesis of the body of evidence involves identifying overarching themes or key concepts from the findings, identifying and explaining similarities and differences between studies, and determining whether certain factors may have affected the relationships being examined. Evidence synthesis conducted as part of the rapid reviews in this project align with that of NESR systematic reviews, but are more concise.

NESR analysts drafted a description of the studies included in the review to begin the process of synthesizing the evidence using the analytic framework and review protocol to guide how the evidence was organized and described.

Next, NESR analysts reviewed the included articles individually, and the body of evidence collectively. The following were considered in each review: study design, key associations between the intervention/exposure and outcome(s) of interest in the review question, along with considerations of key factors for assessing the body of evidence (risk of bias, consistency, directness, precision, and generalizability). Patterns of agreement and disagreement among the findings were examined, and methodological differences between the studies were assessed to potentially help explain disagreement. Gaps in the body of evidence also were identified.

Synthesis, assessment of evidence, and developing summary statements were not completed for evidence scans because no results were extracted nor was risk of bias assessed. However, research recommendations were developed based on the type and amount of literature included in the scan.

\section{Develop summary statements}

NESR analysts developed summary statements outlining the main themes from the synthesis. Because modifications were made to NESR's standard systematic review methods and these reviews included limited expert involvement, conclusion statements and grades were not developed to answer the research questions. However, the grading elements (i.e., risk of bias, consistency, precision, directness, generalizability) were referenced to assess the evidence, determine limitations, and inform the development of summary statements.

\section{Identify research recommendations}

Research gaps and methodological limitations identified during data extraction, synthesis, and discussions with the NEAT team are documented and included in this report for each question. They are framed as research recommendations that detail areas where further research is needed to strengthen the body of evidence on the research question of interest. 


\section{Chapter 1 - What is the relationship between income and prices for food items/baskets?}

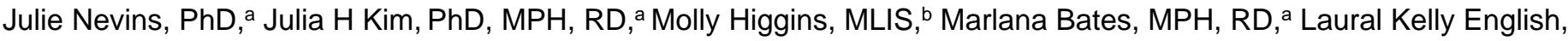
$\mathrm{PhD},{ }^{\mathrm{a}}$ Sara Scinto-Madonich, MS, ${ }^{a}$ Emily Callahan, $\mathrm{MS}^{\mathrm{c}}$

\section{Specific methods to conduct this rapid review}

\section{Develop a protocol}

The research question, "What is the relationship between income and the price of food items/baskets?", was answered using a rapid review that was informed by an evidence scan.

The analytic framework for the rapid review examining the relationship between income and prices for food items/baskets is presented in Figure 1-a. This analytic framework visually represents the overall scope of the rapid review question and depicts the contributing elements that were examined and evaluated. The intervention or exposure of interest is income (e.g., household, city, regional income) and socioeconomic and geographic proxies for income in U.S. households or populations. The comparators are different levels/categories of income or socioeconomic factor proxy or different geographic areas. The outcomes are the difference in prices of similar food items/baskets of similar items (e.g., jar of spaghetti sauce, unit of banana) in U.S. households or populations. The key confounders are seasonal differences, urban versus rural areas, and cultural/racial diversity or disparities. The other factors to be considered are cultural food choices and neighborhood characteristics (access to healthy foods/distance to store/access to car/type of store). The confounders and other factors to be considered may impact the relationships of interest.

An evidence scan was conducted before the rapid review, and it included any paper that described socioeconomic status (SES) or geographic region for the intervention/exposure. The evidence scan also included education, time (e.g., cooking time), and neighborhood characteristics as key confounders. Based on the evidence scan, the following updates were made to the analytic framework for the rapid review:

- SES and geographic region had to relate directly to income to meet the inclusion criteria for the intervention/exposure.

- Because education is so closely linked to SES, and often included in indices of SES, it was not included as a key confounder in the present rapid review.

- While time (e.g., cooking time) may relate to income and/or food price, it was addressed in a separate rapid review presented in - . Therefore, time was not included as a key confounder in the present rapid review.

- Neighborhood characteristics, including access to foods, were determined to relate to income and/or food price, but were beyond the scope of the present rapid review. Therefore, neighborhood characteristics were not included as a key confounder in the present rapid review.

\footnotetext{
a Analyst, NESR team; Panum Group, under contract with the FNS, USDA

b Librarian, NESR team; Panum Group, under contract with the FNS, USDA

c Project Lead, NESR team, NGAD, CNPP, FNS, USDA
} 
Further clarifications were made for the rapid review based on the evidence scan, although this did not change the analytic framework or inclusion/exclusion criteria:

- The price of alcoholic beverages does not meet the outcome criterion of "food price" because SNAP funds cannot be spent on alcohol.

- The Nutrition Environment Measures Survey in stores (NEMS-S) tool did not meet the outcome criteria because the price subscore compares price of "regular" foods versus healthy alternatives but does not include food prices. 
Figure 1-a. Analytic Framework for the rapid review on income and price of food

\section{Interventions/exposures}

Income (e.g., household, city, regiona income)

Socioeconomic factor proxy for income

Geographic area proxy for income vs

Comparators

Different levels/categories of income or socioeconomic factor proxy

Different geographic areas

Population: U.S. households or populations

\section{Outcomes}

Difference in prices of similar food items/basket of similar food items (e.g., fruits, vegetables, jar of spaghetti sauce, unit of bananas, etc.)

Population: U.S. households or populations

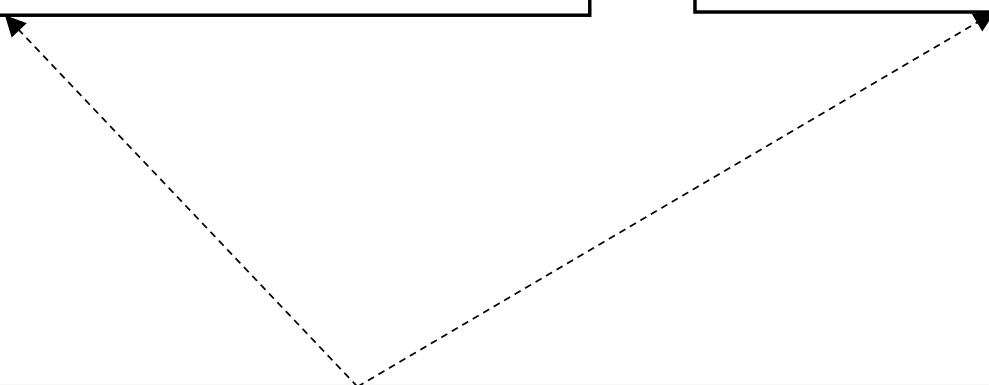

Key confounders: Seasonal differences; Urban vs. Rural; Cultural/racial diversity or disparities

Other factors to be considered: Cultural food choices; Neighborhood characteristics (Access to food/distance to stores/access to car/type of store)

\section{Key definitions}

Low income: before-tax income at or below 130 percent of the U.S. poverty guidelines Higher income: before-tax income above 130 percent of the U.S. poverty guidelines

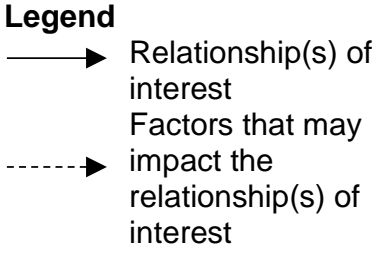




\section{Search for and select studies}

NESR analysts worked jointly with NEAT staff to establish the final inclusion and exclusion criteria, which are detailed in Table 1-a.

Table 1-a. Inclusion and exclusion criteria for the rapid review on income and price of food

\begin{tabular}{|c|c|c|}
\hline Category & Inclusion Criteria & Exclusion Criteria \\
\hline Study design & $\begin{array}{l}\text { - Any study design that is not a narrative review, } \\
\text { systematic review, or meta-analysis }\end{array}$ & $\begin{array}{ll}\text { - } & \text { Narrative reviews } \\
\text { - } & \text { Systematic reviews } \\
\text { - } & \text { Meta-analyses }\end{array}$ \\
\hline $\begin{array}{l}\text { Intervention/ } \\
\text { exposure }\end{array}$ & $\begin{array}{l}\text { Income (e.g., household, city, regional income); } \\
\text { socioeconomic factor proxy for income (e.g., } \\
\text { education); geographic area proxy for income }\end{array}$ & $\begin{array}{l}\text { - Socioeconomic factors or geographic areas that } \\
\text { are not a direct proxy for income determined by the } \\
\text { author }\end{array}$ \\
\hline Comparator & $\begin{array}{l}\text { - Different levels or categories of income or SES } \\
\text { factor proxy for income } \\
\text { - Higher vs. lower geographic areas }\end{array}$ & $\begin{array}{l}\text { - N/A } \\
\text { - Comparison of geographic areas without a proxy } \\
\text { for income }\end{array}$ \\
\hline Outcomes & $\begin{array}{l}\text { Difference in price of similar food item/basket of } \\
\text { similar food items (food items include food item or } \\
\text { food category) } \\
\text { - Difference in price of basket of similar food items }\end{array}$ & - Total food/grocery expenditures \\
\hline $\begin{array}{l}\text { Publication } \\
\text { date }\end{array}$ & $\begin{array}{l}\text { Published January } 1995 \text { - February } 2021 \text { with data } \\
\text { from January } 1995 \text { - February } 2021\end{array}$ & $\begin{array}{l}\text { - } \quad \text { Before January 1995, after February } 2021 \\
\text { - } \quad \text { Data prior to January } 1995\end{array}$ \\
\hline $\begin{array}{l}\text { Publication } \\
\text { status }\end{array}$ & $\begin{array}{l}\text { - } \quad \text { Articles that have been peer-reviewed } \\
\text { - Grey literature: reports that have not been peer- } \\
\text { reviewed but are reports available from } \\
\text { government and nongovernmental organizations } \\
\text { (e.g., National Bureau of Economic Research) }\end{array}$ & $\begin{array}{l}\text { - Articles that have not been peer-reviewed and are } \\
\text { not published in peer-reviewed journals, other than } \\
\text { reports from government and nongovernmental } \\
\text { organizations }\end{array}$ \\
\hline Language & - $\quad$ Articles published in English & - Articles published in languages other than English \\
\hline Country & - $\quad$ Studies conducted in the U.S. & - $\quad$ Studies conducted outside the U.S. \\
\hline $\begin{array}{l}\text { Study } \\
\text { participants }\end{array}$ & - Human participants & $\begin{array}{l}\text { - Non-human participants (e.g., animal studies, in- } \\
\text { vitro models) }\end{array}$ \\
\hline
\end{tabular}

The final search terms for all databases as well as documentation included in the total, raw search results from each database, as well as search results after removal of duplicates are included in Appendix 1-a. Literature search strategy.

The following outlines any departures from the screen and select studies project methods for this specific rapid review.

- Screening was done at 2 levels. The first level of screening was done using only the title and abstract of each article. If an article was not excluded, it moved forward to the $2^{\text {nd }}$ level, where the full text of the 
article was screened. After NESR analysts completed screening of both levels, the analysts reconciled any discrepancies between the 2 screenings for the 20 percent of articles which were dual screened. If necessary, a third analyst was consulted to resolve differences.

- Based on the literature, NESR analysts updated the analytic framework to include "type of store" as a commonly-reported measure of the other factor to be considered, "access to healthy foods."

The compiled list of the included citations, can be found in the References section.

\section{Extract data and assess the risk of bias}

NESR analysts extracted and summarized data from each included article to objectively describe the body of evidence available to answer a rapid review question or inform an evidence scan. The following outlines any departures from the project methods for this specific rapid review:

- Data extraction by single analyst, with quality control conducted by a $2^{\text {nd }}$ analyst. Reconciliation was completed as needed

- Data extracted in Distiller, including author, year of data collection and data source for exposure and outcome, study design, analytic N, geographic location, population description, intervention/exposure and comparator descriptions, outcome description, results, key confounders

- Standard NESR risk of bias forms used in Distiller (dual, independent risk of bias)

\section{Synthesize the evidence}

Evidence synthesis was completed by describing the evidence and evaluating the included studies individually and collectively as previously described in the project methods.

\section{Summary statements}

NESR analysts formed summary statements, as previously described in the project methods, outlining the themes observed during the data synthesis of studies examining income and price of food.

\section{Recommend future research}

Recommendations for future research evaluating the relationship between income and the price of food were determined based on the gaps and limitations observed during data extraction and synthesis, as previously described in the project methods. Future work addressing these gaps and limitations may contribute to the body of evidence available to answer this research question.

\section{Results}

\section{Literature search and screening results}

The literature search yielded 7,313 search results after the removal of duplicates (see Figure 1-b). Dualscreening resulted in the exclusion of 7,043 titles/abstracts and 274 full-texts articles. Reasons for full-text exclusion are in Appendix 1-b. Eight additional articles were identified from the manual search. The body of evidence included 37 articles from 32 studies (31 cross-sectional studies ${ }^{1-36}$ and 1 prospective cohort study ${ }^{37}$ ). The included articles are listed in Table 1-b.

Evidence was provided for each food group, and most studies evaluated price data from multiple food groups: 
- $\quad$ Fruits and Vegetables: 23 studies $^{1-5,7,9,12-19,22,23,25,27,29,30,32,33,35,36}$

- $\quad$ Market Baskets: 11 studies $^{2,6,8,9,11,18,20,22-24,27,34,37}$

- Dairy: 11 studies $1,7,10,14,18,22,23,26,27,29-32$

- $\quad$ Grains: 8 studies $1,7,14,18,22,23,29,30,32$

- Proteins: 2 studies ${ }^{14,23}$

Studies also reported prices of beverages (e.g., energy drinks, sports drinks, ready-to-drink tea and coffee), salty snacks, and sweets (e.g., sugar-sweetened beverages, ice cream), but were not specifically examined in this rapid review.

Figure 1-b. Literature search and screen flowchart for the rapid review on income and price of food

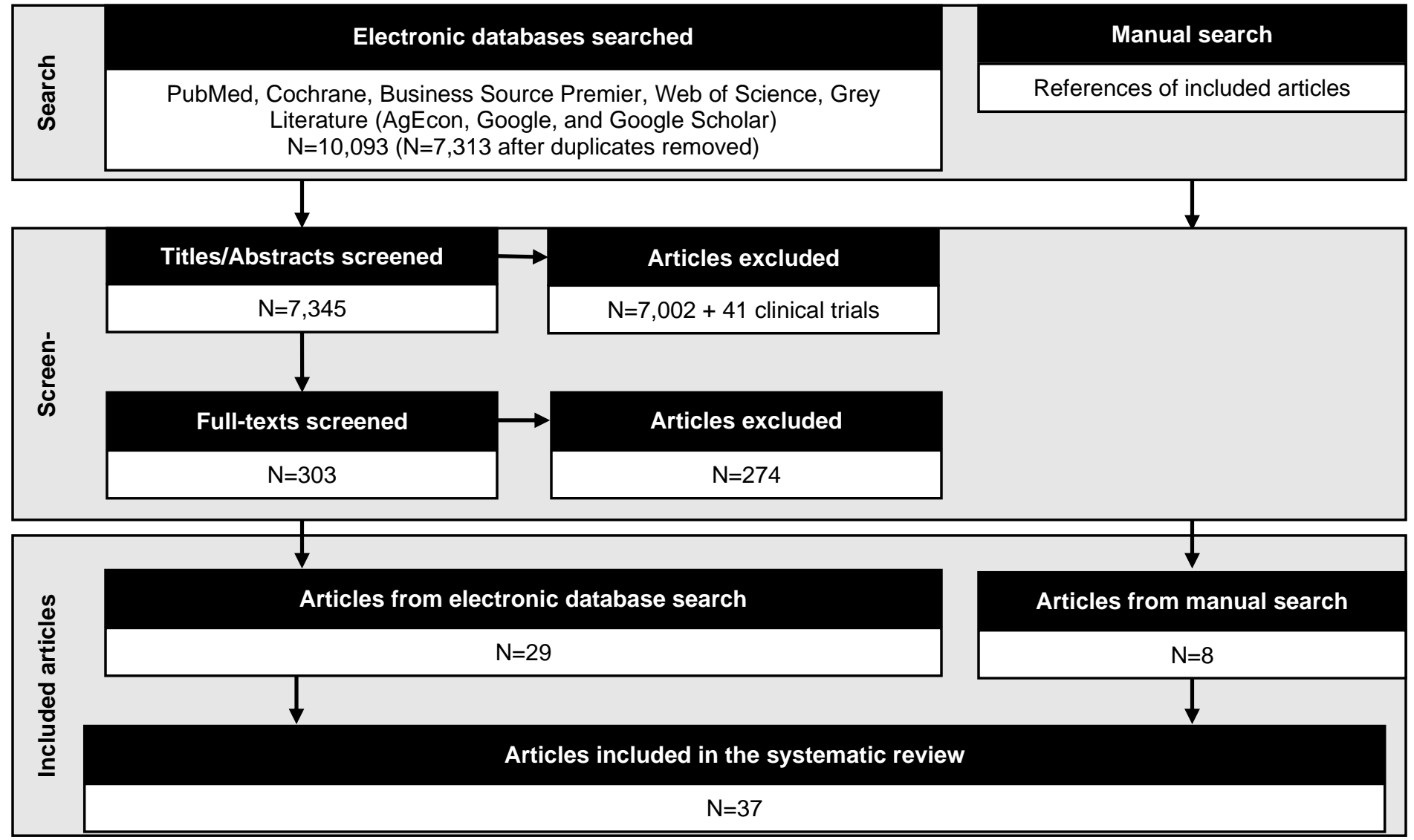

\section{Fruits and vegetables}

\section{Description of the evidence}

\section{Population}

Twenty-three cross-sectional studies reported fruit and/or vegetable outcomes as individual foods or food group(s), including 19 studies examining price in stores ${ }^{1-3,7,9,12,13,15,16,18,19,22,23,25,27,29,30,32,35,36}$ ( $\mathrm{N}=6^{1}$ to $1953^{27}$ stores), and 4 examining prices purchased by households $4,5,14,17,33$ ( $N=90^{17}$ to $43,000^{14}$ households). The body 
of evidence included samples from across the U.S. and 3 household studies had nationally representative samples. ${ }^{4,5,14,33}$ Five studies that examined prices in stores included small or convenience stores. ${ }^{7,13,15,32,35}$

Thirteen of the studies $3,7,9,12,15,16,18,19,22,23,30,32,35,36$ examined the price of fruit alone as individual foods or food group(s) in stores. No studies examined the price of fruit alone in households.

Twelve of the studies $1,3,9,12,13,16,18,19,22,30,32,35,36$ reported the price of vegetables alone as individual foods or food group(s) in stores and two ${ }^{14,33}$ in households.

\section{Intervention/exposure}

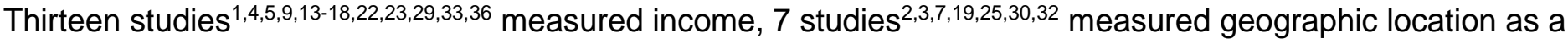
proxy for income, and 3 studies ${ }^{12,26,27,35}$ measured a socioeconomic proxy for income.

Of the 13 studies of fruit, 6 studies $^{9,15,16,18,22,23,36}$ measured income, 5 studies $^{3,7,19,30,32}$ measured geographic proxies of income, and 2 studies $^{12,35}$ measured socioeconomic proxies of income.

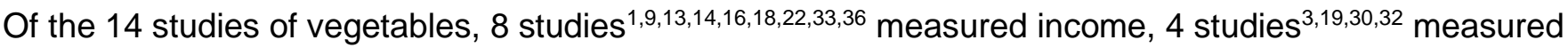
geographic proxies of income, and 2 studies $^{12,35}$ measured socioeconomic proxies of income.

\section{Outcome}

Outcomes included prices of fruit (apples, bananas, berries, fruit juice, grapefruit, grapes, lemons, limes, mangoes, melons, oranges, peaches, pears, pineapple, plums, strawberries, total fruit), prices of vegetables (asparagus, avocados, beans, broccoli, cabbage, carrots, cauliflower, celery, corn, cruciferous vegetables, cucumbers, eggplant, green beans, greens, lettuce, mushrooms, okra, onions, peppers, potatoes, squash, tomatoes, frozen vegetables, total vegetables), prices of fruits and vegetables combined, and prices of produce.

\section{Synthesis of the evidence}

Higher income related to higher prices of fruits and vegetables

Among the studies of income and prices paid by households, 3 studies ${ }^{4,17,33}$ of households found a statistically significant relationship between income and price of fruits and vegetables: households with higher incomes tended to pay higher prices for fruits and vegetables compared to households with lower incomes. The effect size ranged from less than 1 cent price index difference between poverty groups to 2 to 3 cents per ounce or cup.

Of the 19 studies examining prices of fruits and vegetables in stores, 14 studies 1,3,7,9,12,13,16,22,23,25,27,32,35,36 found a statistically significant relationship between income and price: prices of fruits and vegetables were higher in stores located in neighborhoods with higher incomes compared to stores located in neighborhoods with lower incomes. The evidence included samples from states across the U.S. and 4 studies in stores explicitly included small or convenience stores. ${ }^{7,13,32,35}$ Two studies $^{12,32}$ were relatively small (less than 50 stores) and had critical ratings for risk of bias due to exposure classification (Table 1-c); thus the studies could not provide useful information on the relationship between income and price.

Seven studies that examined prices in stores ${ }^{3,7,9,12,22,23,32}\left(\mathrm{~N}=25^{9}\right.$ to 65 stores $\left.^{7}\right)$ reported a statistically significant relationship between income and the prices of fruits alone: prices were higher in stores located in neighborhoods with higher incomes compared to stores located in neighborhoods with lower incomes. All but 1 study $^{32}$ included groceries or supermarkets and 2 studies $^{7,32}$ included convenience stores. Stores were located in the southern and eastern U.S. 
One ${ }^{33}$ of the two studies of income and prices paid by households for vegetables found statistically significant relationship, such that households with higher incomes paid higher prices for vegetables compared to households with lower incomes. The study was nationally representative and included 7,143 households. Eight studies in stores ${ }^{1,9,12,13,16,32,35,36}\left(\mathrm{~N}=6^{1}\right.$ to 364 stores $\left.^{36}\right)$ reported a statistically significant finding that stores in higher income neighborhoods had higher vegetable prices than stores in lower income neighborhoods. Three studies $^{13,32,35}$ included convenience stores, and all others included groceries or supermarkets. Stores were primarily located in New York and in the southern and midwestern U.S.

\section{Higher income related to lower prices of fruits and vegetables}

One study of households ${ }^{5}$ found a small, but statistically significant, relationship between income and price of fruits and vegetables: households with higher incomes paid lower prices for fruits and vegetables.

Five studies ${ }^{12,16,19,30,35}$ found a statistically significant relationship between income and price of fruits and vegetables in stores. Stores located in neighborhoods with higher incomes had lower prices of fruits and vegetables than stores located in neighborhoods with lower incomes. One study ${ }^{19}$ took place exclusively in low-income neighborhoods and another ${ }^{35}$ included only small or non-traditional stores. Two studies ${ }^{12,19}$ had critical ratings for risk of bias due to exposure classification (Table 1-c) and thus could not provide useful information on the relationship between income and price.

Two studies in stores $\left(\mathrm{N}=32^{30}\right.$ to 1,474 stores $\left.^{19}\right)$ reported a statistically significant relationship between income and the prices of fruits alone, such that stores in higher income neighborhoods had lower fruit prices than stores in lower income neighborhoods. Additionally, four studies in stores $\left(N=23^{16}\right.$ to 1,474 stores $\left.^{19}\right)$ reported a statistically significant finding that stores in higher income neighborhoods had lower prices of vegetables compared to stores in lower income neighborhoods. Store types were mixed and were located in California, New York, and Texas.

\section{Non-significant associations between income and prices of fruits and vegetables}

Two studies ${ }^{4,14}$ found no relationship between income and the price households paid for fruits and vegetables among adolescents (not children) ${ }^{4}$ or for dried beans/peas. ${ }^{14}$

Fifteen studies $2,3,7,9,12,13,15,16,18,19,22,29,30,32,35,36$ found no relationship between income and the price of fruits and vegetables in stores. Although none of the studies were nationally representative, results overall cover much of the country. Six studies $2,7,13,15,32,35$ included convenience or small stores explicitly. Three studies ${ }^{12,19,32}$ had critical ratings for risk of bias due to exposure classification (Table 1c) and thus could not provide useful information on the relationship between income and price.

Nine studies in stores $7,12,15,16,18,30,32,35,36\left(\mathrm{~N}=23^{16}\right.$ to 364 stores $\left.^{36}\right)$ found no relationship between income and the prices of fruits alone. Four studies ${ }^{7,15,32,35}$ included small or convenience stores. Stores were located in the southern and eastern U.S.

One ${ }^{14}$ of the two studies of income and prices paid by households for vegetables found no relationship. The study was nationally representative and included 43,000 households. Seven studies in stores $3,13,16,18,19,22,30,35$ (N $=23^{16}$ to 1,474 stores $^{19}$ ) reported no relationship between income and the prices of vegetables alone. Two studies $^{13,35}$ included convenience stores, and overall the studies were distributed across the U.S.

\section{Assessment of the evidence}

Risk of bias 
The body of evidence was comprised of cross-sectional studies, with moderate to serious concerns of risk of bias. While the studies generally had low risk of bias related to selection of participants into the study, deviations from intended exposures, and measurement of the outcomes, other domains had generally higher risk of bias. The major concerns are listed below, which limited the ability to draw clear summary statements:

- Most of the studies ${ }^{1-5,7,9,12,14-19,22,23,25,27,29,30,32,33,35,36}$ did not account for all key confounders, resulting in a serious risk of bias.

- The studies of stores had risk of bias related to the exposure classification because each study examined the exposure of income levels of neighborhoods near the stores, but could not provide evidence that residents of those neighborhoods in fact shopped at the study stores and thus may not have faced the food prices in those stores. The risk of bias was critical in 3 studies $^{12,19,32}$.

- Concerns emerged regarding risk of bias due to potential selection of reported results because none of the studies had pre-registered data analysis plans. However, given that the reported domains were generally consistent with reported methods and that most of the studies reported at least 1 nonstatistically significant result, the risk was judged to be moderate.

- Several studies ${ }^{12,15,25,29,30,32,35}$ had missing data that differed between exposure groups, often due to a lack of availability of certain foods or food groups in 1 exposure group, resulting in risk of bias due to missing data. Another 3 studies ${ }^{1,14,33}$ did not provide sufficient information to evaluate risk of bias due to missing data.

\section{Consistency}

Results were inconsistent for the relationship between income and the price of fruits, vegetables, and fruits and vegetables combined, but overall suggest a direct relationship. Results were less clear when examining individual foods, but this may be due to the variety of individual foods examined which did not necessarily overlap across studies. Within studies of households or stores, the methods were generally similar across studies.

Some studies noted that access to larger stores and/or purchasing behaviors explained prices more than income; more of the studies that adjusted for key confounders and store type/access seemed to find no relationship between income and price.

\section{Precision}

There was an adequate number of studies to investigate the relationship between income and prices of fruits and vegetables, and the studies generally had medium to large sample sizes.

\section{Directness}

Although multiple studies were designed to examine a different outcome (e.g., diet quality, obesity, or differences in access to stores), they directly examined the relationship between income and price of fruits and vegetables. Some studies reported that store size and/or shopping behavior may explain pricing more than income. Further, most of the studies evaluated prices in stores, which made it difficult to answer the review question because the studies could not prove that neighborhood income was measured in the same individuals who purchased food at the study stores.

\section{Generalizability}

Overall the body of evidence was geographically diverse, particularly for the results of vegetables and fruits and vegetables combined, and thus the results were generalizable to the U.S. population. This was most clear 
in the household studies, which were nationally representative; and, the studies in stores were also conducted across the U.S. For the results of fruits there were no nationally representative studies but results overall cover much of the country. There was some racial, ethnic, and socioeconomic diversity across the body of evidence.

\section{Market baskets}

\section{Description of the evidence}

\section{Population}

Ten cross-sectional studies $2,6,8,9,11,18,20-24,26,27,34$ and 1 prospective cohort study ${ }^{37}$ reported market basket outcomes. These included 2 studies examining prices purchased by households $\left(N=3,473^{37}\right.$ to $\left.40,000^{8}\right)$ and 9 studies examining price ${ }^{2,6,9,11,18,20-24,26,27,34}$ in stores $\left(\mathrm{N}=4^{20}\right.$ to $\left.1,953^{27}\right)$. The body of evidence included samples from across the U.S. One study explicitly included small or convenience stores. ${ }^{2}$

\section{Intervention/exposure}

Four studies $8,9,18,22-24$ measured income, 6 studies $^{2,6,11,20,21,34,37}$ measured geographic location as a proxy for income, and 1 study ${ }^{26,27}$ measured a socioeconomic proxy for income.

\section{Outcome}

All market baskets included foods from multiple food groups. Two studies ${ }^{8,23}$ measured the cost of all foods purchased, 4, $4^{90-22}$ measured the cost of a USDA Market Basket meeting the Dietary Guidelines for Americans, and 4,9,11,22,24 measured the cost of a diet based on the Thrift Food Plan. Three studies ${ }^{2,18,26,27}$ reported the prices of regular and healthier food options of market baskets and two studies ${ }^{34,37}$ simply reported foods across multiple food categories.

\section{Synthesis of the evidence}

\section{Higher income related to higher prices of market baskets}

Both studies of households 8,37 found a statistically significant relationship between income and price of market baskets: higher income households paid more for market baskets than lower income households. The data were from households across the country, with large sample sizes ( $N=3,473$ to 43,000). Five studies ${ }^{2,6,9,18,24}$ reported a statistically significant relationship between income and price of market baskets in stores $\left(\mathrm{N}=25^{9,24}\right.$ to 110 stores $^{6}$ ), such that stores in higher income neighborhoods had higher prices than stores in lower income neighborhoods. The studies took place primarily in California and in southern, eastern, and midwestern states. One study ${ }^{2}$ explicitly included convenience stores.

\section{Higher income related to lower prices of market baskets}

Three studies of stores ${ }^{20,21,27,34}$ found a statistically significant finding that price of market baskets was lower in stores from higher versus lower income neighborhoods $\left(\mathrm{N}=4^{20}\right.$ to $\left.1,953^{27}\right)$. The data were collected from across the U.S. None of the studies explicitly included small or convenience stores.

\section{Non-significant associations between income and prices of market baskets}

Six studies of stores ${ }^{2,11,18,22,23,27,34}$ reported no relationship between income and the prices ( $N=55^{11}$ to $1,953^{27}$ ). The data were collected from across the U.S., and 1 study ${ }^{2}$ explicitly included convenience stores. 


\section{Assessment of the evidence}

\section{Risk of bias}

The body of evidence was comprised primarily of cross-sectional studies with moderate to serious concerns of risk of bias. The studies generally had low risk of bias related to selection of participants into the study, deviations from intended exposures, and measurement of the outcomes. The major concerns in other domains are listed below, which limited the ability to draw clear summary statements:

- Two studies had serious ${ }^{21,37}$ ratings for deviations from intended exposures due to unbalanced coexposures between exposure groups.

- Most of the studies $2,6,9,11,20,21,23,24,34$ did not account for all key confounders, resulting in a serious risk of bias.

- The studies of stores had risk of bias related to the exposure classification because each study examined the exposure of income levels of neighborhoods near the stores, but could not provide evidence that residents of those neighborhoods in fact shopped at the study stores and thus may not have faced the food prices in those stores. The risk of bias was critical in 2 studies. ${ }^{21,32}$

- Concerns emerged regarding risk of bias due to potential selection of reported results because none of the studies had pre-registered data analysis plans. However, given that the reported domains were generally consistent with reported methods and that most of the studies reported at least 1 nonstatistically significant result, the risk was judged to be moderate.

- One study ${ }^{8}$ did not provide sufficient information to evaluate risk of bias due to missing data.

\section{Consistency}

Results were inconsistent, but generally suggested a relationship between higher income and higher price of market baskets. Methods were generally similar across studies. Many studies noted that access to larger stores and/or purchasing behaviors explained prices more than income.

\section{Precision}

There was an adequate number of studies to investigate the relationship between income and prices of market baskets, with mostly medium or large sample sizes.

\section{Directness}

Multiple studies were designed to examine a different outcome (e.g., diet quality, obesity, or differences in access to stores), but still directly examined the relationship between income and price of market baskets. Some studies reported that store size and/or shopping behavior may explain pricing more than income. Further, most of the studies evaluated prices in stores, which made it difficult to answer the review question because the studies could not prove that neighborhood income was measured in the same individuals who purchased food at the study stores.

\section{Generalizability}

Overall, the body of evidence was geographically diverse, with more studies in urban than in rural areas, and included large, nationally representative studies. There was some racial, ethnic, and socioeconomic diversity across the body of evidence. Therefore, these studies were generalizable to the U.S. population. 


\section{Dairy}

\section{Description of the evidence}

\section{Population}

Eleven cross-sectional studies reported dairy outcomes, including 10 studies examining price in stores $^{1,7,10,18,22,23,26,27,29-32}$ ( $N=6^{1}$ to $8,793^{31}$ stores), and 1 examining prices purchased by 43,000 households ${ }^{14}$ households). The body of evidence included samples from across the U.S., including two studies with nationally representative data. ${ }^{26,27,31}$

\section{Intervention/exposure}

Six studies 1,14,18,22,23,29,31 measured income, $4^{7,10,30,32}$ measured geographic location as a proxy for income, and 1 study ${ }^{26,27}$ measured a socioeconomic proxy for income.

\section{Outcome}

Outcomes included milk, cheese, and total dairy.

\section{Synthesis of the evidence}

\section{Higher income related to higher prices of dairy}

Four studies found a statistically significant relationship between income and the price of milk ${ }^{1,10,26}$ or low-fat dairy ${ }^{22}$ in grocery stores, such that prices were higher in stores in higher income neighborhoods than in lower income neighborhoods. Study sample sizes ranged from small $(\mathrm{N}=6)^{1,10}$ to large $(\mathrm{N}=1,743) .{ }^{26}$ The study by Kern et al. ${ }^{26}$ was nationally representative.

\section{Higher income related to lower prices of dairy}

Three studies ${ }^{10,27,31}$ including 2 nationally representative studies, ${ }^{27,31}$ reported a statistically significant between income and price of milk or dairy measured at grocery stores: prices of milk and dairy were higher in stores in higher income neighborhoods than stores in lower income neighborhoods. Study sample sizes ranged from small $(\mathrm{N}=6)^{10}$ to large $(\mathrm{N}=8,793) .{ }^{31}$

\section{Non-significant associations between income and prices of dairy}

The study of households ${ }^{14}$ found no relationship between income and the price of milk or cheese. Six studies $7,18,22,23,29,30,32$ found no relationship between income and the price of dairy, specifically milk, measured in stores. Study sample sizes ranged from $28^{32}$ to $73^{29}$ stores, mostly from New York and the southern U.S. Two studies ${ }^{7,32}$ included convenience stores, and 1 of those ${ }^{32}$ had a critical rating for risk of bias due to exposure classification (Table 1-c) and thus could not provide useful information on the relationship between income and price of milk or cheese.

\section{Assessment of the evidence}

\section{Risk of bias}

The body of evidence was comprised of cross-sectional studies with generally moderate to serious concerns of risk of bias. The studies generally had low risk of bias related to selection of participants into the study, deviations from intended exposures, and measurement of the outcomes. The major concerns in other domains are listed below, which limited the ability to draw clear summary statements: 
- Most of the studies ${ }^{1,7,10,14,23,29-32}$ did not account for all key confounders, resulting in a serious risk of bias.

- The studies of stores had risk of bias related to the exposure classification because each study examined the exposure of income levels of neighborhoods near the stores, but could not provide evidence that residents of those neighborhoods shopped at the study stores and thus may not have faced the food prices in those stores. The risk of bias was critical in 1 study. ${ }^{32}$

- Concerns emerged regarding risk of bias due to potential selection of reported results because none of the studies had pre-registered data analysis plans. However, given that the reported domains were generally consistent with reported methods and that most of the studies reported at least 1 nonstatistically significant result, the risk was judged to be moderate.

- Three studies ${ }^{29,30,32}$ had missing data that differed between exposure groups, often due to a lack of availability of certain foods or food groups in 1 exposure group, resulting in risk of bias due to missing data. Another 2 studies ${ }^{1,14}$ did not provide sufficient information to evaluate risk of bias due to missing data.

\section{Consistency}

Results were inconsistent for the relationship between income and the price of dairy, with generally similar methods across studies. Specific food items studies varied across studies. Many studies noted that access to larger stores and/or purchasing behaviors explained prices more than income.

\section{Precision}

There were an adequate number of studies to investigate the relationship between income and prices of dairy, with varied sample sizes.

\section{Directness}

Multiple studies were really designed to examine a different outcome (e.g., diet quality, obesity, or differences in access to stores), but still directly examined the relationship between income and price of dairy. Some studies reported that store size and/or shopping behavior may explain pricing more than income. Further, most of the studies evaluated prices in stores, which made it difficult to answer the review question because the studies could not provide evidence that neighborhood income was measured in the same individuals who faced food prices at the study stores.

\section{Generalizability}

Overall the body of evidence was fairly geographically diverse, and included large, nationally representative studies. There was some racial, ethnic, and socioeconomic diversity across the body of evidence. Therefore, these studies were generalizable to the U.S. population.

\section{Grains}

\section{Description of the evidence}

\section{Population}

Eight cross-sectional studies reported grains as individual foods or food group(s), including 7 studies examining price in stores ${ }^{1,7,18,22,23,29,30,32}\left(\mathrm{~N}=6^{1}\right.$ to $73^{29}$ stores), and 1 examining prices purchased by 43,000 
households. ${ }^{14}$ The body of evidence included samples from across the U.S. Two studies in stores included small or convenience stores. ${ }^{7,32}$

\section{Intervention/exposure}

Five studies ${ }^{1,14,18,22,23,29}$ measured income and $3^{7,30,32}$ measured geographic location as a proxy for income. No studies measured a socioeconomic proxy for income.

\section{Outcome}

Outcomes included bread, breakfast cereals, flour, oatmeal, pasta, rice, and whole grains.

\section{Synthesis of the evidence}

\section{Higher income related to higher prices of grains}

Three studies ${ }^{1,18,32}$ found a statistically significant relationship suggesting that higher income was related to higher grains prices, but the results were difficult to interpret. In 1 study, ${ }_{1}^{1}$ prices did not differ between neighborhoods, shoppers in higher income neighborhoods purchased more expensive grains than shoppers in lower-income neighborhoods, suggesting that the effects reflected consumer behavior rather than prices faced. In a $2^{\text {nd }}$ study, ${ }^{18}$ prices of more nutrient dense grains were reported in comparison to less nutrient dense grains, and the size of the store was a stronger determinant of relative price than income. Further, the third study $^{32}$ had critical ratings for risk of bias due to exposure classification (Table 1-c) and thus could not provide useful information on the relationship between income and price of grains.

\section{Higher income related to lower prices of grains}

Two studies of stores reported a statistically significant relationship between income and the price of bread ${ }^{30}$ and cereal ${ }^{23}$ : stores in higher income neighborhoods had higher prices than stores in lower neighborhoods.

Non-significant associations between income and prices of grains

One study of 43,000 households across the U.S. ${ }^{14}$ found no relationship between income and the price of grains, specifically the price of ready-to-eat breakfast cereal. Six studies in stores ${ }^{1,7,18,22,23,29,32}$ found no relationship between income and the price of grains, specifically the price of whole grain bread. ${ }^{7,18,23,29,32}$ Sample sizes ranged from $6^{1}$ to $73^{29}$ stores, and 2 of the studies ${ }^{7,32}$ included data from convenience stores. Stores were primarily located in the southern and eastern U.S.

\section{Assessment of the evidence}

\section{Risk of bias}

The body of evidence was comprised of cross-sectional studies with generally moderate to serious concerns of risk of bias. While the studies generally had low risk of bias related to selection of participants into the study, deviations from intended exposures, and measurement of the outcomes, other domains had generally higher risk of bias. The major concerns are listed below, which limited the ability to draw clear summary statements:

- Most of the studies $1,7,14,23,29,30,32$ did not account for all key confounders, resulting in a serious risk of bias.

- The studies of stores had serious risk of bias related to the exposure classification because each study examined the exposure of income levels in neighborhoods near the stores but did not provide evidence that residents of those neighborhoods shopped at the study stores. The risk of bias was critical in 1 study because the exposure was not clearly defined. ${ }^{32}$ 
- Risk of bias due to potential selection of reported results was possible because none of the studies had pre-registered data analysis plans. However, the risk was judged to be moderate because the reported domains were generally consistent with reported methods and that most of the studies reported at least 1 non-statistically significant result.

- $\quad$ Three studies ${ }^{29,30,32}$ had missing data that differed between exposure groups, often due to a lack of availability of certain foods or food groups in 1 exposure group, resulting in risk of bias due to missing data. Two additional studies ${ }^{1,14}$ did not provide sufficient information to evaluate risk of bias due to missing data.

\section{Consistency}

Results were inconsistent for the relationship between income and the price of grains, with little overlap in the specific foods studied. Within studies of households or stores, respectively, the methods were generally similar across studies. Some studies noted that access to larger stores and/or purchasing behaviors explained prices more than income; more of the higher-quality studies reported no relationship between income and price.

\section{Precision}

There were a somewhat small number of studies to investigate the relationship between income and grain prices, and the studies generally had small to medium sample sizes.

\section{Directness}

Most of the studies reported that store size and/or shopping behavior may explain pricing more than income. Further, most of the studies evaluated prices in stores, which made it difficult to answer the review question because the studies could not prove that neighborhood income was measured in the same people who purchased food at the study stores.

\section{Generalizability}

There were concerns with generalizability of the evidence as most studies were conducted in the eastern and midwestern regions of the U.S., and studies did not report sufficient information to evaluate the racial, ethnic, and socioeconomic diversity across the body of evidence.

\section{Proteins}

\section{Description of the evidence}

\section{Population}

Two cross-sectional studies reported protein food outcomes, including 1 study examining price in stores ${ }^{23}$ ( $\mathrm{N}=57$ stores), and 1 examining prices purchased by households ${ }^{14}$ ( $\mathrm{N}=43,000$ households). Hayes et al. ${ }^{23}$ was conducted in New York City and Davis et al. ${ }^{14}$ had a nationally representative sample.

\section{Intervention/exposure}

Both studies ${ }^{14,23}$ measured income. No studies measured either geographic or socioeconomic proxies for income.

\section{Outcome}

Outcomes included chicken, eggs, ground beef, peanut butter, and tuna. 
Synthesis of the evidence

There was insufficient evidence to examine the relationship between income and price of protein foods.

\section{Summary statements and research recommendations}

\section{Summary statements}

The findings of the rapid review are presented in the following summary statements.

\section{Fruits and vegetables}

Evidence suggests that a higher income may be associated with a higher price of vegetables and fruits and vegetables combined, but shopping behavior may be an important factor in interpreting the data.

Evidence suggests no relationship between income and price of fruit, although higher income may be associated with a higher price of fruit. Store size and/or shopping behavior may explain pricing more than income.

All studies were cross-sectional, resulting in risk of bias concerns common in that study design. Most of the studies did not account for all key confounders and had risk of bias related to the exposure classification because most studies did not measure the exposure and outcome for the same individuals.

\section{Market baskets}

Evidence indicates that a higher income is associated with a higher price of market baskets. Income was more strongly associated with shopping behaviors and store size/access than the actual prices faced, although shopping behavior may be in response to prices.

Most of the studies did not account for all key confounders and had risk of bias related to the exposure classification because most studies did not measure the exposure and outcome for the same individuals.

\section{Dairy}

Evidence suggests that a higher income may be weakly associated with a lower price of dairy products, although studies were not consistent. Income was more strongly associated with shopping behaviors and store size/access than the actual prices faced, although shopping behavior may be in response to prices.

All studies were cross-sectional, resulting in risk of bias concerns common in that study design. Most of the studies did not account for all key confounders and had risk of bias related to the exposure classification because most studies did not measure the exposure and outcome for the same individuals.

\section{Grains}

Evidence suggests no relationship between income and price of grains, particularly whole-grain breads. There was not enough evidence to examine the relationship with other types of grains. Store size and or shopping behavior may explain pricing more than income.

All studies were cross-sectional, resulting in risk of bias concerns common in that study design. Most of the studies did not account for all key confounders and had risk of bias related to the exposure classification because most studies did not measure the exposure and outcome for the same individuals.

\section{Protein foods}

There was not enough evidence to examine the relationship between income and price of protein foods.

\section{Research recommendations}

1. Conduct well-designed, longitudinal studies that examine the relationship between income and food price over time. In particular, these studies should directly examine the relationship between household-level income and actual prices at stores where household members shop for food. 
2. Assess income exposures using standard definitions and categories to improve comparability across studies.

3. Assess food group prices using standard definitions and categories to improve comparability across studies.

4. Differentiate between participants in Federal assistance programs who are income-eligible, incomeeligible nonparticipants, and income-ineligible nonparticipants.

5. Account for store size/type, access to stores, as well as other potential confounders including urban versus rural setting and cultural/racial diversity or disparities, to better determine the response to income on food price as a function of these factors. 
Table 1-b. Evidence examining the relationship between income and price ${ }^{a}$

\begin{tabular}{|c|c|c|c|c|}
\hline Article & $\begin{array}{l}\text { Study and Participant } \\
\text { Characteristics }\end{array}$ & Intervention & Outcome(s) & Results \\
\hline \multicolumn{5}{|l|}{$\begin{array}{l}\text { Prospective cohort } \\
\text { study }\end{array}$} \\
\hline Colabianchi, $2021^{37}$ & $\begin{array}{l}\mathbf{N}=\mathbf{3 4 7 3} \\
\text { All participants lived in public } \\
\text { housing or project-based assisted } \\
\text { housing located centrally in } 1 \text { of the } \\
\text { five cities in a census tract with high } \\
\text { poverty rates (i.e., } 40 \% \text { or more } \\
\text { persons in the census tract had } \\
\text { incomes < federal poverty threshold) } \\
\text { in } 1995-1998 \text {. }\end{array}$ & $\begin{array}{l}\text { Geographic } \\
\text { location } \\
\text { - Treatment } \\
\text { - Section } 8 \\
\text { - Control }\end{array}$ & Market basket & $\begin{array}{l}\text { Direct relationship, Statistically significant } \\
\text { Mean (log transformed), SE price per unit averaged across } 13 \\
\text { categories, weighted linear regression, F-statistic: } 16.50, \\
\text { p }<0.001 \\
\text { Treatment }(n=1428): 0.30,0.026 \\
\text { Section } 8(n=982): 0.24,0.030 \\
\text { Control }(n=1063): 0.07,0.031\end{array}$ \\
\hline \multicolumn{5}{|l|}{$\begin{array}{l}\text { Cross-sectional } \\
\text { studies }\end{array}$} \\
\hline Akbay, $2005^{1}$ & $\begin{array}{l}\mathbf{N}=6 \\
\text { Analytic N is stores (supermarkets); } \\
\text { Columbus, Ohio metropolitan area }\end{array}$ & $\begin{array}{l}\text { Income } \\
\text { - Lower } \\
\text { - Higher }\end{array}$ & $\begin{array}{l}\text { Breakfast } \\
\text { cereals }\end{array}$ & $\begin{array}{l}\text { Direct relationship, Statistically significant } \\
\text { Mean price paid for food products, cents per ounce } \\
\text { Breakfast cereals, t-test } \\
\text { Private brand price } \\
\text { Lower income: } 14.16 \\
\text { Higher income: } 14.73 \\
\text { t: }-4.72 ; p<0.01 \\
\text { National brand price } \\
\text { Lower income: } 20.02 \\
\text { Higher income: } 21.29 \\
\text { t: }-11.60 ; p<0.01 \\
\end{array}$ \\
\hline
\end{tabular}




\section{USDA United States \\ Department of \\ Agriculture}

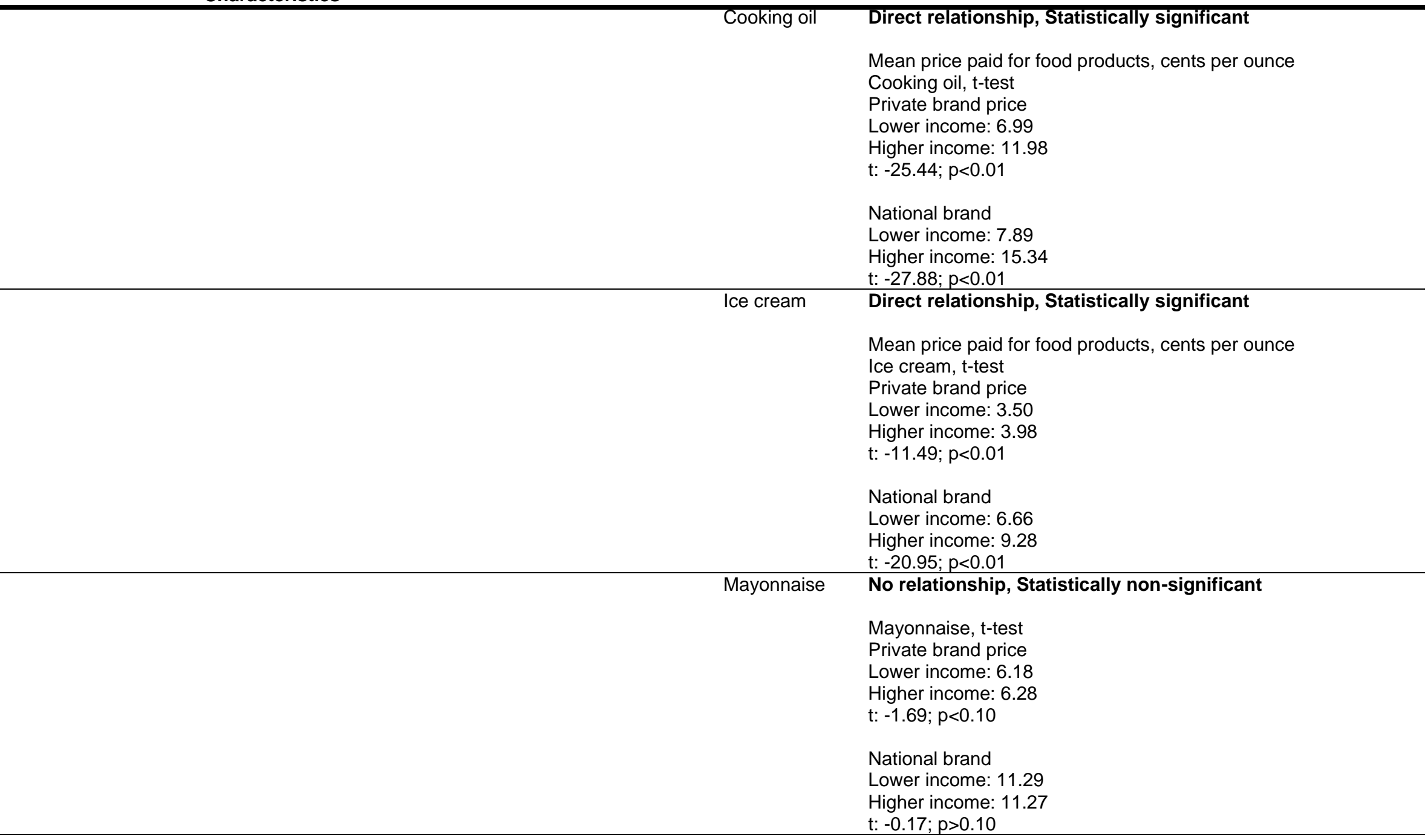




\section{USDA United States \\ Department of \\ Agriculture}

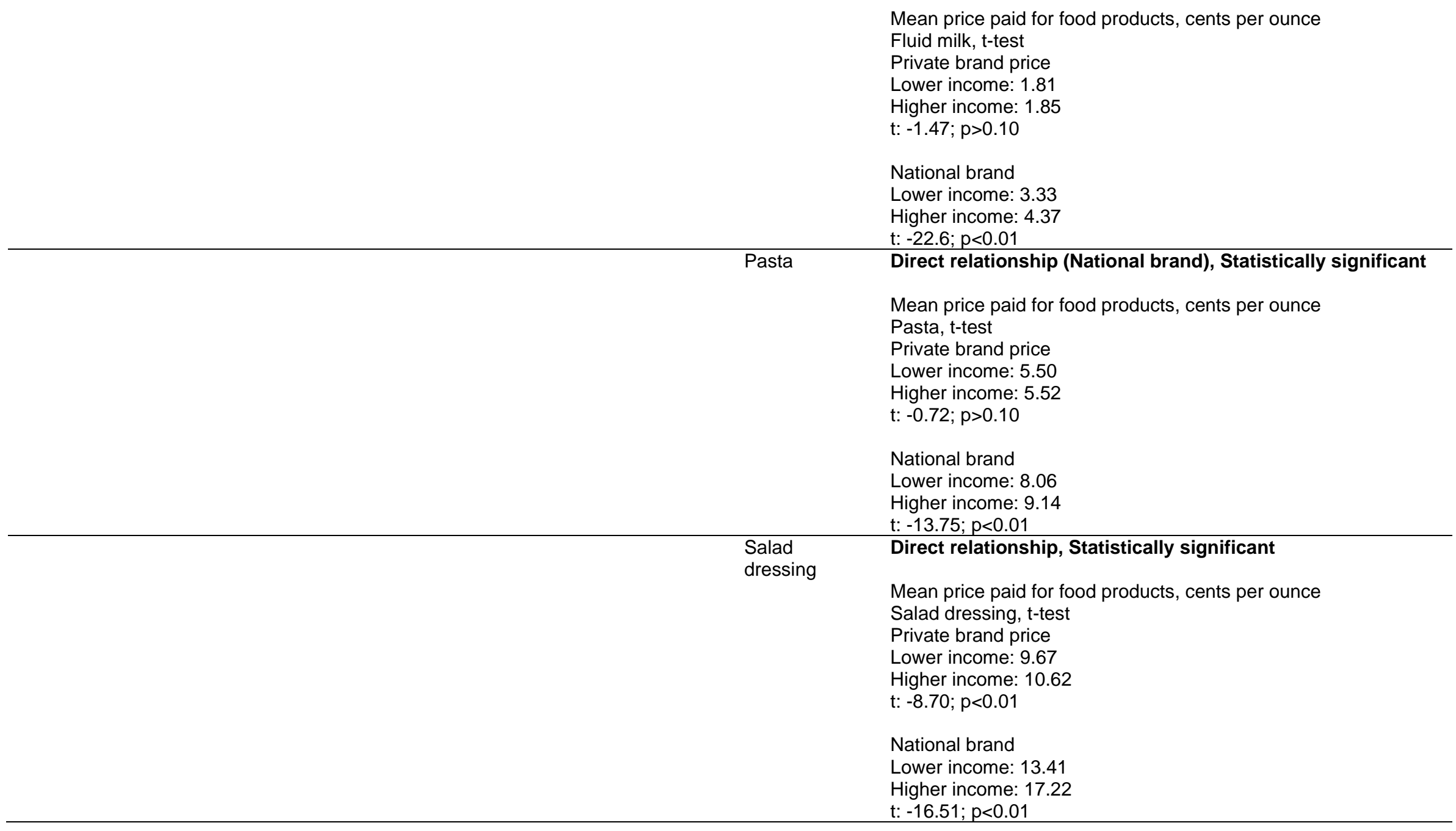


Mean price paid for food products, cents per ounce

Salty snacks, t-test

Private brand price

Lower income: 13.06

Higher income: 12.65

t: 3.02; $p<0.01$

National brand

Lower income: 19.60

Higher income: 20.22

$\mathrm{t}:-5.83 ; \mathrm{p}<0.01$

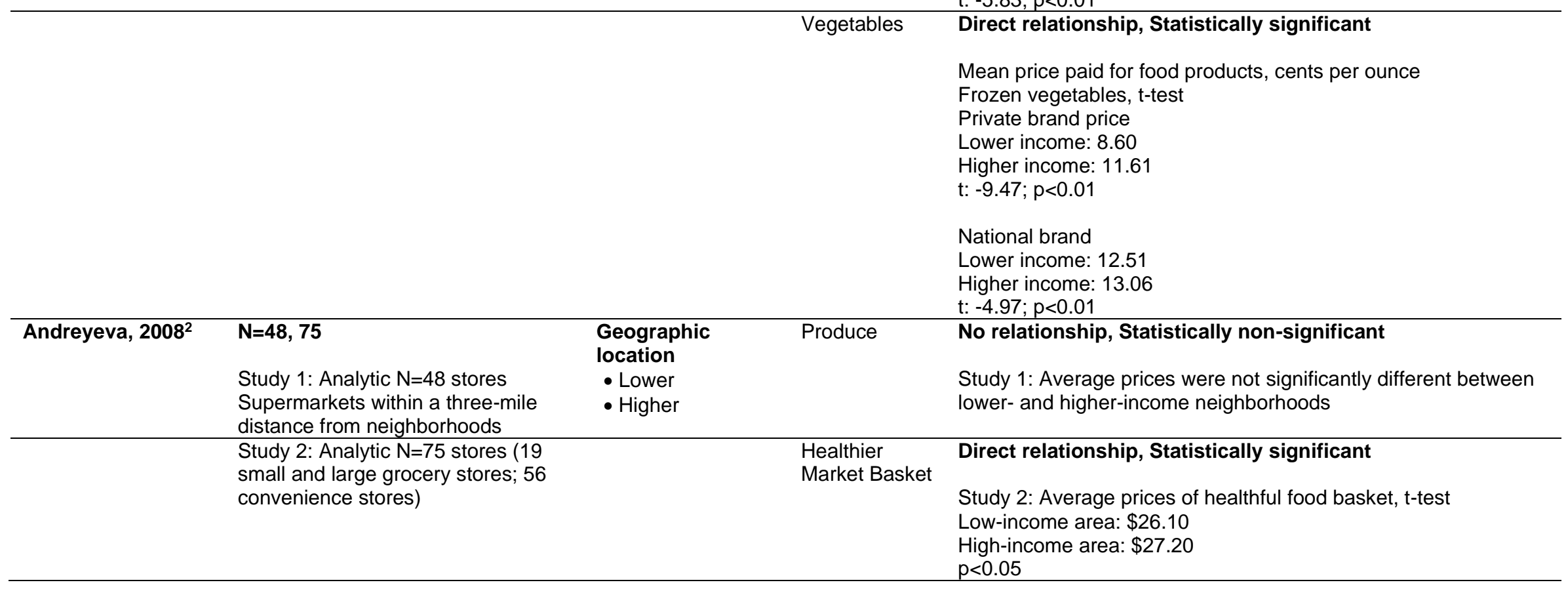


Study 2: Average prices of all-foods basket, t-test

Low-income area: $\$ 46.70$

High-income area: $\$ 48.50$

$\mathrm{p}<0.05$

\begin{tabular}{rr}
\hline & Unhealthy \\
food price
\end{tabular}

Direct relationship, Statistically non-significant

ood price

Study 2: Average prices of regular food basket, t-test

Low-income area: $\$ 20.60$

High-income area: $\$ 21.30$

$p>0.05$

\begin{tabular}{|c|c|c|c|c|}
\hline Ard, $2010^{3}$ & $\begin{array}{l}\mathbf{N}=44 \\
\text { Analytic N is grocery stores in } \\
\text { Jefferson and Shelby counties } \\
\text { Neighborhood median } \\
\text { characteristics: } \\
29 \% \text { African American } \\
80 \% \geq \text { high school diploma } \\
12 \% \mathrm{HH}<\text { poverty level }\end{array}$ & $\begin{array}{l}\text { Geographic } \\
\text { location } \\
\% \text { HH below } \\
\text { poverty level }\end{array}$ & Potatoes & $\begin{array}{l}\text { Direct relationship (t-test), Statistically significant } \\
\text { No relationship (multiple linear regression), Statistically } \\
\text { non-significant } \\
\text { Price/serving of white potatoes during spring months, multiple } \\
\text { linear regression (adjusted for } \% \text { African American and } \% \geq \text { high } \\
\text { school diploma) } \\
\text { Beta coefficient (SE), } \\
\% \mathrm{HH} \text { below poverty level: } 0.000(0.001), p=0.92 \\
\mathrm{~F}(35,3): 4.073, \text { Adjusted } \mathrm{R}^{2}: 0.195 \\
\text { Mean prices for potatoes, t-test, } p=0.004 \\
\text { Highest tertile for \% below poverty level: } \$ 0.09 \\
\text { Lowest tertile for \% below poverty level: } \$ 0.13\end{array}$ \\
\hline & & & Strawberries & $\begin{array}{l}\text { Direct relationship, Statistically significant } \\
\text { Mean price of strawberries, t-test, } p=0.048 \\
\text { Middle tertile for \% below poverty level: } \$ 0.16 \\
\text { Top tertile for \% below poverty level: NR but lower than middle } \\
\text { tertile }\end{array}$ \\
\hline
\end{tabular}




\begin{tabular}{|c|c|c|c|c|}
\hline Article & $\begin{array}{l}\text { Study and Participant } \\
\text { Characteristics }\end{array}$ & Intervention & Outcome(s) & Results \\
\hline Beydoun, 20085 & $\begin{array}{l}\mathrm{N}=7331 \\
\text { Analytic N is nationally } \\
\text { representative sample of } 7331 \\
\text { adults from USDA Continuing } \\
\text { Survey of Food Intakes by } \\
\text { Individuals (CSFII) 1994-1996. } \\
\text { Mean age of } 39.8 \text { (SD: } 0.25) ; 13.3 \\
\text { (SD: } 1.0) \text { years of education, } 51 \% \\
\text { female, } 74 \% \text { non-Hispanic White; } \\
\text { highest proportion lived in the South } \\
(36 \%) ; 47 \% \text { lived in suburban areas }\end{array}$ & $\begin{array}{l}\text { Income } \\
\text { - } P I R \leq 130 \% \\
\text { - } P I R ~ 131-299 \% \\
\text { - } P I R \geq 300 \%\end{array}$ & $\begin{array}{l}\text { Fruits and } \\
\text { Vegetables }\end{array}$ & $\begin{array}{l}\text { Inverse relationship, Statistically significant } \\
\text { FV-PI } \\
\text { Weighted Mean (SEM), ANOVA, } p<0.05 \\
\leq 130 \%(n=1616): \$ 0.728(0.009) \\
131-299 \%(n=2713): \$ 0.722(0.007) \\
\geq 300 \%(n=3002): \$ 0.727(0.007) \\
\text { FV-PI } \\
\text { Weighted Mean (SEM), ANOVA, p<0.05 } \\
\leq 130 \%: \$ 0.728(0.009) \\
131-299 \%: \$ 0.722(0.007) \\
\geq 300 \%: \$ 0.727(0.007)\end{array}$ \\
\hline Beydoun, 20114 & $\begin{array}{l}\mathbf{N}=\mathbf{8 4 3 8} \\
\text { Analytic N is nationally } \\
\text { representative sample of } 6759 \\
\text { children aged } 2-9 \text { y and } 1679 \\
\text { adolescents age } 10-18 \text { y from USDA } \\
\text { Continuing Survey of Food Intakes } \\
\text { by Individuals (CSFII) 1994-1996 } \\
\text { and additional data collected from } \\
\text { children aged } \\
2-9 \text { y in 1998. }\end{array}$ & $\begin{array}{l}\text { Income } \\
\text { - } \mathrm{PIR} \leq 185 \% \\
\text { - } \mathrm{PIR}>185 \%\end{array}$ & $\begin{array}{l}\text { Fruits and } \\
\text { Vegetables }\end{array}$ & $\begin{array}{l}\text { Direct relationship (Children), Statistically significant } \\
\text { No relationship (Adolescents), Statistically non-significant } \\
\text { FV-PI among children (2-9 y) } \\
\text { Weighted Mean (SE), ANOVA, } p<0.05 \\
\leq 185 \%: \$ 0.72(0.01) \\
>185 \%: \$ 0.73(0.01) \\
\text { FV-PI among adolescents }(10-18 \mathrm{y}) \\
\text { Weighted Mean (SE), ANOVA, } \mathrm{p} \geq 0.05 \\
\leq 185 \%: \$ 0.72(0.01) \\
>185 \%: \$ 0.72(0.01)\end{array}$ \\
\hline Block, 2006 6 & $\begin{array}{l}\mathbf{N}=110 \\
\text { Analytic N is stores; } \\
\text { Austin: population } 117,527,42 \% \text { of } \\
\text { the } \mathrm{HH} \text { lived in homes for } \geq 10 \text { years. } \\
24 \% \mathrm{HH}<\text { poverty level; primarily } \\
\text { African American population with } \\
\text { averages lower middle income } \\
\text { Oak Park: population } 52,500 \text {. Upper- } \\
\text { middle-income suburb with a mixed } \\
\text { profile }\end{array}$ & $\begin{array}{l}\text { Geographic } \\
\text { location } \\
\text { - Austin } \\
\text { - Oak Park }\end{array}$ & $\begin{array}{l}\text { USDA Market } \\
\text { Basket }\end{array}$ & $\begin{array}{l}\text { Direct relationship, Statistically significant } \\
\text { Difference of means t-test: } \\
\text { Austin } \$ 110 \text { vs. Oak Park } \$ 122 \\
P<0.001\end{array}$ \\
\hline
\end{tabular}




\begin{tabular}{|c|c|c|c|c|}
\hline Article & $\begin{array}{l}\text { Study and Participant } \\
\text { Characteristics }\end{array}$ & Intervention & Outcome(s) & Results \\
\hline Borja, 20197 & $\begin{array}{l}\mathrm{N}=65 \\
\text { Analytic } \mathrm{N} \text { is stores, including } 25 \\
\text { grocery stores and } 40 \text { convenience } \\
\text { stores } \\
\text { County population of } 1,408,566, \\
75 \% \text { White, } 18 \% \text { African American, } \\
29 \% \text { Hispanic or Latino } \\
\text { Median household income of } \\
\$ 51,681\end{array}$ & $\begin{array}{l}\text { Geographic } \\
\text { location } \\
\text { - low-income } \\
\text { areas } \\
\text { - not-low-income } \\
\text { areas }\end{array}$ & Apples & $\begin{array}{l}\text { Direct relationship (regression), Statistically significant } \\
\text { No relationship (t-test), Statistically non-significant } \\
\text { Mean prices of apples per unit } \\
\text { T-test, } \mathrm{P}=\mathrm{NS} \\
\text { Low-income areas: } \$ 0.78 \\
\text { Not-low-income areas: } \$ 0.79 \\
\text { Beta coefficient }(\mathrm{SE}) \text {, Income and price regression (adjusted for } \\
\text { distance, no car, density, and store type) } \\
\text { Apple: } 0.31(0.13), p<0.05\end{array}$ \\
\hline & & & Bananas & $\begin{array}{l}\text { Direct relationship (regression), Statistically significant } \\
\text { No relationship (t-test), Statistically non-significant } \\
\text { Mean prices of bananas per unit } \\
\text { T-test, } P=N S \\
\text { Low-income areas: } \$ 0.39 \\
\text { Not-low-income areas: } \$ 0.38 \\
\text { Beta coefficient }(\mathrm{SE}) \text {, Income and price regression (adjusted for } \\
\text { distance, no car, density, and store type) } \\
\text { Banana: } 0.22(0.11), p<0.05\end{array}$ \\
\hline & & & Bread & $\begin{array}{l}\text { Direct relationship, Statistically non-significant } \\
\text { Mean prices for white bread } \\
\text { T-test, P=NS } \\
\text { Low-income areas: } \$ 2.73 \\
\text { Not-low-income group: } \$ 2.89 \\
\text { Mean prices for whole wheat bread } \\
\text { T-test, P=NS } \\
\text { Low-income areas: } \$ 2.85 \\
\text { Not-low-income group: } \$ 2.87 \\
\text { Beta coefficient (SE), Income and price regression (adjusted for } \\
\text { distance, no car, density, and store type) } \\
\text { White bread: }-0.02(0.39), N S \\
\text { Wheat bread: } 0.05(0.43), N S\end{array}$ \\
\hline
\end{tabular}




\section{USDA United States

Mean prices of high sugar content cereal per $17 / 18$ oz box T-test, $\mathrm{P}=\mathrm{NS}$

Low-income areas: $\$ 4.44$

Not-low-income areas: $\$ 4.03$

Mean prices of low sugar content cereal per 17/18 oz box T-test, $\mathrm{P}=\mathrm{NS}$

Low-income areas: $\$ 3.96$

Not-low-income areas: $\$ 3.85$

Beta coefficient (SE), Income and price regression (adjusted for distance, no car, density, and store type)

High sugar content cereal: -0.24 (0.39), NS

Low sugar content cereal: $-0.23(0.34)$, NS

No relationship, Statistically non-significant

Mean price of whole milk (1 gallon)

T-test, $\mathrm{P}=\mathrm{NS}$

Low-income areas: $\$ 4.28$

Not-low-income areas: $\$ 4.02$

Mean price of $2 \%$-fat milk ( 1 gallon)

T-test, $\mathrm{P}=\mathrm{NS}$

Low-income areas: $\$ 4.2$

Not-low-income areas: $\$ 3.96$

Mean price of $1 \%$-fat milk ( 1 gallon)

T-test, $\mathrm{P}=\mathrm{NS}$

Low-income areas: $\$ 3.79$

Not-low-income areas: $\$ 3.69$

Mean price of skim milk (1 gallon)

T-test, $\mathrm{P}=\mathrm{NS}$

Low-income areas: $\$ 3.73$

Not-low-income areas: $\$ 3.59$

Beta coefficient (SE), Income and price regression (adjusted for distance, no car, density, and store type)

Whole milk: $0.05(0.27)$, NS

$1 \%$ milk: $0.28(0.28), \mathrm{NS}$

$2 \%$ milk: $0.26(0.27), \mathrm{NS}$ 


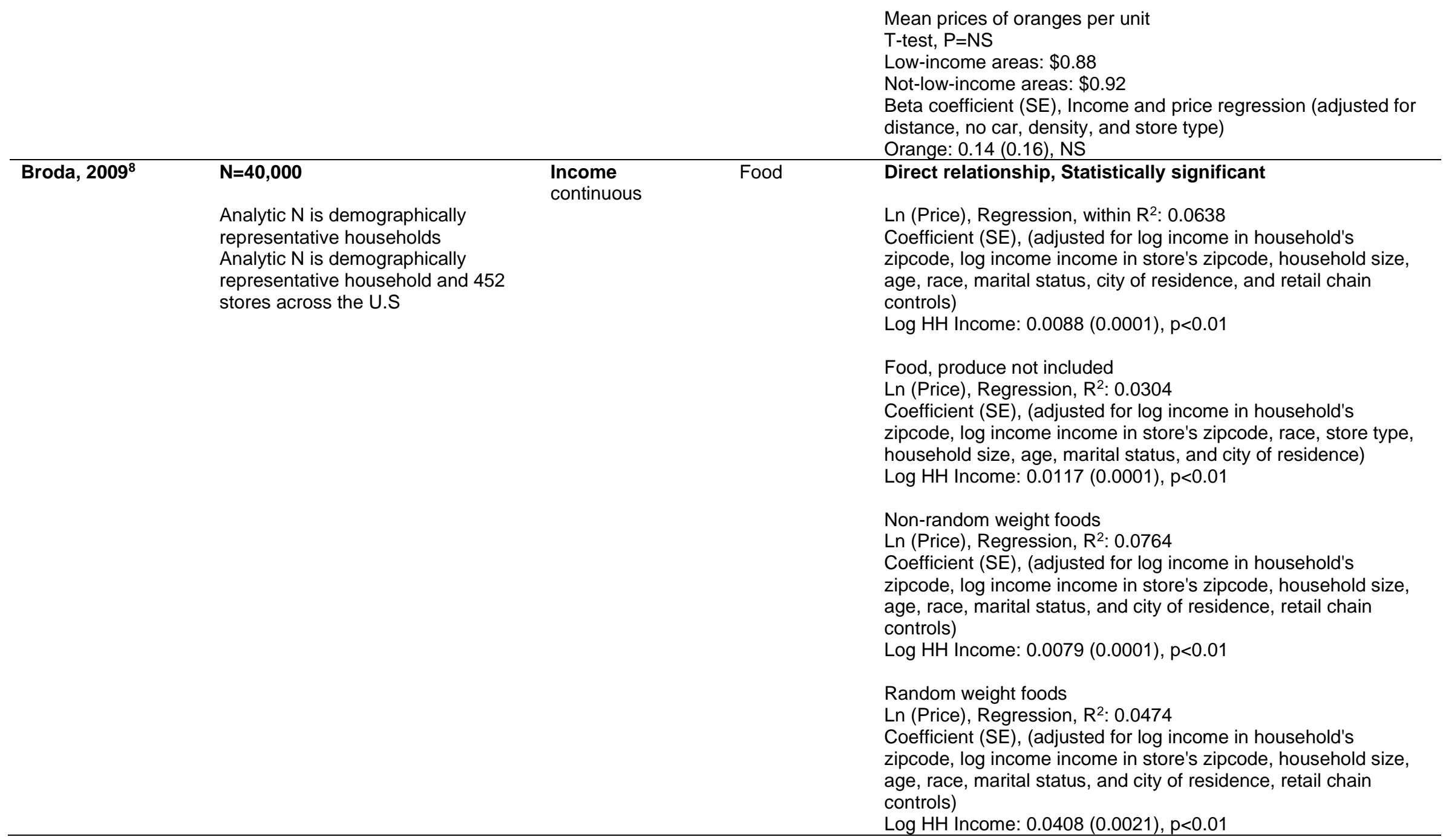




\section{USDA}

United States

Department of

Agriculture

\begin{tabular}{|c|c|c|c|c|}
\hline Article & $\begin{array}{l}\text { Study and Participant } \\
\text { Characteristics }\end{array}$ & Intervention & Outcome(s) & Results \\
\hline \multirow[t]{3}{*}{ Cassady, $2007^{9}$} & $\begin{array}{l}\mathrm{N}=75 \\
\mathrm{~N}=75 \text { observations across } 25 \text { stores } \\
\text { and } 3 \text { timepoints } \\
\text { Number of observations by store } \\
\text { type (N): Bulk (12), Independent (9), } \\
\text { Chain (54) }\end{array}$ & $\begin{array}{l}\text { Income } \\
\text { - Very low } \\
\text { - Low } \\
\text { - Middle } \\
\text { - High }\end{array}$ & $\begin{array}{l}2005 \text { DGA } \\
\text { Market Basket }\end{array}$ & $\begin{array}{l}\text { Direct relationship, Statistically significant } \\
2005 \text { DGA Market Basket } \\
\text { Mean total cost of F\&V, t-test } \\
\text { Very Low : } \$ 64.94 \\
\text { Low: } \$ 66.67 \\
\text { Middle: } \$ 77.82, \text { vs. Very Low } p<0.05, \text { vs. Low } p<0.05 \\
\text { High: } \$ 73.07, \text { vs. Very Low } p<0.05, \text { vs. Low } p<0.05\end{array}$ \\
\hline & & & $\begin{array}{l}\text { TFP Food } \\
\text { Basket }\end{array}$ & $\begin{array}{l}\text { Direct relationship, Statistically significant } \\
\text { TFP market basket } \\
\text { Mean total cost of } F \& V \text {, t-test } \\
\text { Very Low and Low: } \$ 65 \\
\text { Middle and High: } \$ 78, \text { vs. Very Low and Low } p \leq 0.05\end{array}$ \\
\hline & & & Fruit & $\begin{array}{l}\text { Direct relationship (Middle vs. lower), Statistically } \\
\text { significant } \\
\text { No relationship (High vs. lower), Statistically non- } \\
\text { significant } \\
2005 \text { DGA Market Basket } \\
\text { Mean cost of fruit, t-test } \\
\text { Very Low: } \$ 31.60 \\
\text { Low: } \$ 32.84 \\
\text { Middle: } \$ 37.62 \text {, vs. Very Low } p<0.05 \text {, vs. Low } p<0.05 \\
\text { High: } \$ 35.60\end{array}$ \\
\hline
\end{tabular}


2005 DGA Market Basket

Mean cost of vegetables, t-test

Very Low: $\$ 33.34$

Low: $\$ 34.28$

Middle: $\$ 40.19$, vs. Very Low $p<0.05$, vs. Low $p<0.05$

High: $\$ 37.47$, vs. Very Low $p<0.05$, vs. Low $p<0.05$, vs. Middle

$\mathrm{p}<0.05$

Mean cost of dark green vegetables, t-test, $p>0.05$

Very Low: $\$ 4.41$

Low: $\$ 4.70$

Middle: $\$ 4.89$

High: $\$ 4.63$

Mean cost of orange vegetables, t-test

Very Low: $\$ 1.60$

Low: $\$ 1.76$

Middle: $\$ 2.33$, vs. Very Low $p<0.05$, vs. Low $p<0.05$

High: $\$ 2.17$, vs. Very Low $p<0.05$, vs. Low $p<0.05$

Mean cost of legumes, t-test, $p>0.05$

Very Low: $\$ 9.05$

Low: $\$ 8.58$

Middle: $\$ 9.66$

High: $\$ 9.82$

Mean cost of starchy vegetables, t-test

Very Low: $\$ 2.81$

Low: $\$ 2.94$

Middle: $\$ 4.22$, vs. Very Low $p<0.05$, vs. Low $p<0.05$

High: $\$ 3.38$

Mean cost of other vegetables, t-test

Very Low: $\$ 15.77$

Low: $\$ 15.84$

Middle: $\$ 19.09$, vs. Very Low $p<0.05$, vs. Low $p<0.05$

High: $\$ 17.47$

TFP market basket

Mean cost of fruit, t-test, Data NR 
Results

Characteristics

TFP market basket (Prices NR)

Mean cost of vegetables

High more than Very Low and Low, p>0.05

Mean cost of orange vegetables

Middle more than Very Low and Low, $p \leq 0.05$

High more than Very Low and Low, $p \leq 0.05$

Mean cost of starchy vegetables

Middle more than Very Low and Low, $\mathrm{p} \leq 0.05$

Mean cost of other vegetables

Middle more than Very Low and Low, $\mathrm{p} \leq 0.05$ 


\begin{tabular}{|c|c|c|c|c|}
\hline Article & $\begin{array}{l}\text { Study and Participant } \\
\text { Characteristics }\end{array}$ & Intervention & Outcome(s) & Results \\
\hline Chang, 2011'0 & $\begin{array}{l}\mathrm{N}=6 \\
\text { Analytic } \mathrm{N} \text { is stores } \\
\text { Race: } \\
\text { Inner-city: White: } 76.2 \% \text {, Black: } \\
21.7 \% \text {, Other: } 2.0 \% \\
\text { Suburban: White: } 93.6 \% \text {, Black: } \\
3.5 \% \text {, Other: } 3.0 \% \\
\text { Education: } \\
\text { Inner-city: } 30.4 \% \text { at least some } \\
\text { college, } 33.7 \% \text { did not graduate } \\
\text { from high school } \\
\text { Suburban: } 65 \% \text { at least some } \\
\text { college, } 11.3 \% \text { did not graduate } \\
\text { from high school }\end{array}$ & $\begin{array}{l}\text { Geographic } \\
\text { location } \\
\text { - Low Income } \\
\text { - High Income }\end{array}$ & Milk & $\begin{array}{l}\text { Direct relationship (organic milk), Statistically significant } \\
\text { Inverse relationship (conventional skim milk), Statistically } \\
\text { significant } \\
\text { Price per half gallon } \\
\text { Mean conventional whole milk prices, t-test, } p=0.50 \\
\text { Inner-city: } \$ 1.297 \\
\text { Suburban: } \$ 1.305 \\
\text { Mean conventional } 2 \% \text { milk prices, t-test, } p=0.38 \\
\text { Inner-city: } \$ 1.297 \\
\text { Suburban: } \$ 1.308 \\
\text { Mean conventional } 1 \% \text { milk prices, t-test, } p=0.24 \\
\text { Inner-city: } \$ 1.284 \\
\text { Suburban: } \$ 1.269 \\
\text { Mean conventional skim milk prices, t-test, } p=0.00 \\
\text { Inner-city: } \$ 1.363 \\
\text { Suburban: } \$ 1.324 \\
\text { Mean organic whole milk prices, t-test, } p=0.00 \\
\text { Inner-city: } \$ 2.980 \\
\text { Suburban: } \$ 3.251 \\
\text { Mean organic } 2 \% \text { milk prices, t-test, } p=0.00 \\
\text { Inner-city: } \$ 3.117 \\
\text { Suburban: } \$ 3.267 \\
\text { Mean organic } 1 \% \text { milk prices, t-test, } p=0.00 \\
\text { Inner-city: } \$ 3.210 \\
\text { Suburban: } \$ 3.411 \\
\text { Inner-city: } \$ 2.877 \\
\text { Suburban: } \$ 3.271\end{array}$ \\
\hline
\end{tabular}




\begin{tabular}{ll} 
Article & $\begin{array}{l}\text { Study and Participant } \\
\text { Characteristics }\end{array}$ \\
\hline Chung, 199911 & $\mathrm{N}=55$ \\
$\mathrm{~N}$ is stores & Nonpoor $(\mathrm{n}=31)$ : zip codes with \\
& $<10 \%$ below poverty level; $87 \%$ of \\
& chain stores and $60 \%$ of nonchain \\
& stores in these ZIP \\
& Poor $(\mathrm{n}=24):$ zip codes with $\geq 10 \%$ \\
& below poverty level; $13 \%$ of chain \\
& stores and $40 \%$ of nonchain stores \\
& in these ZIP
\end{tabular}

\section{Intervention Outcome(s) Results}

Geographic TFP Food Inverse relationship, Statistically significant

$\begin{array}{ll}\text { location } & \text { Basket }\end{array}$

- Poor

Mean basket price, t-test

- Non-poor

Poor: $\$ 110.36$

Non-poor: $\$ 105.21$

Difference: $\$ 5.15$

Difference (adjusted for chains and availability): $\$ 3.41$

t-value: $1.3076, p>0.10$

Recursive model, Adj $R^{\wedge} 2=0.2535, p=0.0009$

Coefficient, $t$-value

Poor: -1.5223, -0.329 (NS)

Adjusted for chain supermarket, \% stores in ZIP chains,

availability index

$\begin{array}{ll}\text { Cole, 2010 } & \mathbf{N}=\mathbf{4 5} \\ & \text { Analytic N is census tracts } \\ \text { two Brooklyn Community Districts } \\ \text { (BCD). BCD 6 included Carroll } \\ \text { Gardens, Cobble Hill, Park Slope, } \\ \text { Gowanus, and Red Hook. BCD 9 } \\ \text { included Crown Heights South, } \\ \text { Prospect Lefferts Gardens, and } \\ \text { Wingate. }\end{array}$

SES proxy
$\bullet>80 \%$ Black (low
income)
$-20-80 \%$ Black
$\quad$ (middle)
$-<20 \%$ Black
$\quad$ (high income)

\section{Direct relationship, Statistically significant}

Mean (SD) price of apples, statistical method NR, $\mathrm{p}=$ significant Predominantly Black, low-income $(n=3)$ : $\$ 0.44(n / a)$

Mixed race, middle income $(n=7)$ : $\$ 0.52(0.11)$

Predominantly White, high-income $(n=17)$ : $\$ 0.70(0.24)$

Direct relationship, Statistically significant

Mean (SD) price of asparagus, statistical method NR, $\mathrm{p}=$ significant

Predominantly Black, low-income $(n=1)$ : $\$ 2.39$ (n/a)

Mixed race, middle income $(n=1): \$ n / a(n / a)$

Predominantly White, high-income $(n=5): \$ 3.06$ (1.01)

Direct relationship, Statistically significant

Mean (SD) price of avocados, statistical method NR, $\mathrm{p}=$ significant

Predominantly Black, low-income $(n=1): \$ n / a(n / a)$

Mixed race, middle income $(n=6): \$ 1.31(0.41)$

Predominantly White, high-income $(n=11): \$ 1.79(0.38)$ 
Mean (SD) price of yellow bananas, statistical method NR, $\mathrm{p}=$ significant

Predominantly Black, low-income $(n=0): \$ n / a(n / a)$

Mixed race, middle income $(n=10): \$ 0.24(0.06)$

Predominantly White, high-income $(n=18)$ : \$0.29 (0.09)

Berries

\section{Direct relationship, Statistically significant}

Mean (SD) price of berries, statistical method NR, $\mathrm{p}=$ significant

Predominantly Black, low-income $(n=1)$ : $\$ 3.33(n / a)$

Mixed race, middle income $(n=5): \$ 3.24(1.75)$

Predominantly White, high-income $(n=11)$ : $\$ 4.10$ (1.39)

Broccoli

Direct relationship, Statistically significant

Mean (SD) price of broccoli, statistical method NR, $p=$ significant

Predominantly Black, low-income $(n=1): \$ 1.49(n / a)$

Mixed race, middle income $(n=2)$ : $\$ 0.99$ ( $n / a)$

Predominantly White, high-income $(n=7): \$ 2.32(0.71)$

Corn

Direct relationship, Statistically significant

Mean (SD) price of corn, statistical method NR, $p=$ significant Predominantly Black, low-income $(n=1)$ : $\$ n / a(n / a)$

Mixed race, middle income $(n=4)$ : $\$ 0.33(n / a)$

Predominantly White, high-income $(n=8): \$ 0.89(0.44)$

Cucumbers

Direct relationship, Statistically significant

Mean (SD) price of cucumbers, statistical method NR, $\mathrm{p}=$ significant

Predominantly Black, low-income $(n=1): \$ 0.50(n / a)$

Mixed race, middle income $(n=6)$ : $\$ 0.34(0.15)$

Predominantly White, high-income $(n=11)$ : $\$ 0.55(0.42)$

Eggplant

Direct relationship, Statistically significant

Mean (SD) price of eggplants, statistical method NR, $\mathrm{p}=$ significant

Predominantly Black, low-income $(n=1): \$ n / a(n / a)$

Mixed race, middle income $(n=5): \$ 0.63(0.11)$

Predominantly White, high-income $(n=6): \$ 1.09(0.36)$ 
Mean (SD) price of grapefruit, statistical method NR, $\mathrm{p}=$ significant

Predominantly Black, low-income $(\mathrm{n}=1)$ : $\$ 0.65$ (n/a) Mixed race, middle income $(n=5): \$ 0.60(0.24)$

Predominantly White, high-income $(n=12): \$ 1.24(0.75)$

\section{Green beans Direct relationship, Statistically significant}

Mean (SD) price of green beans (lb), statistical method NR, $\mathrm{p}=$ significant

Predominantly Black, low-income $(n=2)$ : $\$ 0.99(n / a)$ Mixed race, middle income $(n=5): \$ 2.94(n / a)$

Predominantly White, high-income $(n=9): \$ 2.31(0.58)$

Lemons Direct relationship, Statistically significant

Mean (SD) price of lemons, statistical method NR, $\mathrm{p}=$ significant Predominantly Black, low-income $(n=4): \$ 0.25(n / a)$

Mixed race, middle income $(n=6)$ : $\$ 0.27(0.04)$

Predominantly White, high-income $(n=15)$ : $\$ 0.42(0.22)$

Lettuce Direct relationship, Statistically significant

Mean (SD) price of greens, lettuce, statistical method NR, $\mathrm{p}=$ significant

Predominantly Black, low-income $(n=3)$ : $\$ 0.99(n / a)$

Mixed race, middle income $(n=6): \$ 1.35(0.51)$

Predominantly White, high-income $(n=11): \$ 1.43(0.96)$

Limes

\section{Direct relationship, Statistically significant}

Mean (SD) price of limes, statistical method NR, $p=$ significant

Predominantly Black, low-income $(n=1): \$ 0.15(n / a)$

Mixed race, middle income $(n=4): \$ 0.17(0.05)$

Predominantly White, high-income $(n=14): \$ 0.42(0.23)$

Mangoes

No relationship, Statistically non-significant

Mean (SD) price of mangoes, statistical method NR, $p=N S$

Predominantly Black, low-income $(\mathrm{n}=1): \$ 1.50(\mathrm{n} / \mathrm{a})$

Mixed race, middle income $(n=5): \$ 1.47(0.35)$

Predominantly White, high-income $(n=14)$ : $\$ 1.39(0.47)$ 
Mean (SD) price of melons, statistical method NR, $p=$ significant

Predominantly Black, low-income $(n=1)$ : $\$ 1.50(n / a)$

Mixed race, middle income $(n=6): \$ 1.60(1.12)$

Predominantly White, high-income $(n=10)$ : \$3.12 (1.39)

Mushrooms

Direct relationship, Statistically non-significant

Mean (SD) price of mushrooms (lb), statistical method NR, $\mathrm{p}=\mathrm{NR}$

Predominantly Black, low-income $(n=1): \$ n / a(n / a)$

Mixed race, middle income $(n=2)$ : $\$ 3.39(n / a)$

Predominantly White, high-income $(n=7): \$ 6.24$ (3.20)

Okra Inverse relationship, Statistically significant

Mean (SD) price of okra (lb), statistical method NR, $p=$ significant

Predominantly Black, low-income $(n=1)$ : $\$ 3.99$ (n/a)

Mixed race, middle income $(\mathrm{n}=2): \$ 2.00(\mathrm{n} / \mathrm{a})$

Predominantly White, high-income $(n=2): \$ 1.54$ (1.34)

Oranges Direct relationship, Statistically significant

Mean (SD) price of oranges, statistical method NR, $\mathrm{p}=$ significant

Predominantly Black, low-income $(\mathrm{n}=3)$ : $\$ 0.33(\mathrm{n} / \mathrm{a})$

Mixed race, middle income $(n=6)$ : $\$ 0.44(0.07)$

Predominantly White, high-income $(n=15)$ : $\$ 0.56(0.24)$

Pears Direct relationship, Statistically significant

Mean (SD) price of pears, statistical method NR, $p=$ significant

Predominantly Black, low-income $(n=0)$ : $\$ n / a(n / a)$

Mixed race, middle income $(n=5): \$ 0.49(0.05)$

Predominantly White, high-income $(\mathrm{n}=9)$ : $\$ 0.76(0.22)$

Peppers Direct relationship, Statistically significant

Mean (SD) price of peppers, statistical method NR, $p=$ significant

Predominantly Black, low-income $(n=1): \$ 0.33(n / a)$

Mixed race, middle income $(n=7): \$ 0.56(0.08)$

Predominantly White, high-income $(n=11): \$ 0.94(0.49)$

Pineapple

Direct relationship, Statistically significant

Mean (SD) price of pineapples, statistical method NR, $\mathrm{p}=$ significant

Predominantly Black, low-income $(n=0): \$ n / a(n / a)$

Mixed race, middle income $(n=4): \$ 1.99(n / a)$

Predominantly White, high-income $(n=9): \$ 4.42(1.13)$ 
Mean (SD) price of plums, statistical method NR, $p=$ significant

Predominantly Black, low-income $(n=0)$ : $\$ n / a(n / a)$

Mixed race, middle income $(n=5): \$ 0.34(0.20)$

Predominantly White, high-income $(n=11)$ : $\$ 0.67(0.30)$

Potatoes

Direct relationship, Statistically significant

Mean (SD) price of potatoes, statistical method NR, $p=$ significant

Predominantly Black, low-income $(\mathrm{n}=6)$ : $\$ 0.33(\mathrm{n} / \mathrm{a})$

Mixed race, middle income $(n=9)$ : $\$ 0.41(0.36)$

Predominantly White, high-income $(n=17): \$ 1.01$ (1.63)

Squash Direct relationship, Statistically significant

Mean (SD) price of squash, statistical method NR, $p=$ significant Predominantly Black, low-income $(n=1)$ : $\$ 1.00$ (n/a)

Mixed race, middle income $(n=6): \$ 1.00(0.49)$

Predominantly White, high-income $(n=8): \$ 1.61(1.30)$

Tomatoes

Direct relationship, Statistically significant

Mean (SD) price of , statistical method NR, $\mathrm{p}=$ significant

Predominantly Black, low-income $(\mathrm{n}=3)$ : $\$ 0.54(\mathrm{n} / \mathrm{a})$

Mixed race, middle income $(n=7)$ : $\$ 0.51(0.07)$

Predominantly White, high-income $(n=17)$ : $\$ 0.77(0.33)$

Daepp, $2015^{13} \quad \mathrm{~N}=40$

No relationship, Statistically non-significant

Analytic $\mathrm{N}=$ stores

- High

Broccoli (bunch) in grocery stores

High vs. Low income

Kruskall Wallis Chi-square: $3.7817, \mathrm{p}=0.0518$

Cabbage No relationship, Statistically non-significant

Cabbage $(1 \mathrm{lb})$ in grocery stores

High vs. Low income

Kruskall Wallis Chi-square: $0.9724, \mathrm{p}=0.3241$

Carrots

No relationship, Statistically non-significant

Carrots $(1 \mathrm{lb})$ in grocery stores

High vs. Low income

Kruskall Wallis Chi-square: $0.3628, \mathrm{p}=0.547$ 
Cauliflower (pc) in grocery stores

High vs. Low income

Kruskall Wallis Chi-square: $5.2067, \mathrm{p}=0.0225$

Celery No relationship, Statistically non-significant

Celery (stalk) in grocery stores

High vs. Low income

Kruskall Wallis Chi-square: $0.2384, \mathrm{p}=0.6254$

Corn

No relationship, Statistically non-significant

Corn (3 pc) in grocery stores

High vs. Low income

Kruskall Wallis Chi-square: $2.1, p=0.1473$

Cucumbers No relationship, Statistically non-significant

Cucumber (pc) in grocery stores

High vs. Low income

Kruskall Wallis Chi-square: $0, p=1.0000$

Lettuce No relationship, Statistically non-significant

Lettuce in grocery stores

High vs. Low income

Kruskall Wallis Chi-square: $1.1126, p=0.2915$

Peppers No relationship, Statistically non-significant

Peppers (pc) in grocery stores

High vs. Low income

Kruskall Wallis Chi-square: $0.7445, \mathrm{p}=0.3882$

Tomatoes

No relationship, Statistically non-significant

Tomatoes $(1 \mathrm{lb})$ in grocery stores

High vs. Low income

Kruskall Wallis Chi-square: $0.5038, \mathrm{p}=0.4778$ 


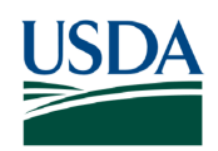

United States

Department of

Agriculture
Income and Price of Food

\begin{tabular}{|c|c|c|c|c|}
\hline Article & $\begin{array}{l}\text { Study and Participant } \\
\text { Characteristics }\end{array}$ & Intervention & Outcome(s) & Results \\
\hline \multirow[t]{5}{*}{ Davis, $2005^{14}$} & $\begin{array}{l}\mathrm{N}=43000 \\
\text { Analytic N = about } 43,000 \\
\text { households from } 24 \text { cities in } 17 \\
\text { States } \\
\text { California (San Francisco/Oakland, } \\
\text { Los Angeles, Visalia), Colorado } \\
\text { (Denver, Grand Junction), Florida } \\
\text { (Tampa/St. Petersburg), Georgia } \\
\text { (Atlanta, Rome); Illinois (Chicago), } \\
\text { lowa (Cedar Rapids) }\end{array}$ & $\begin{array}{l}\text { Tncome } \\
\text { - Low income; } \\
\text { WIC eligible } \\
\text { - High income }\end{array}$ & Beans & $\begin{array}{l}\text { No relationship, Statistically non-significant } \\
\text { Prices for dried beans/peas did not differ between income } \\
\text { classes. (Statistical test NR) }\end{array}$ \\
\hline & & & $\begin{array}{l}\text { Breakfast } \\
\text { cereals }\end{array}$ & $\begin{array}{l}\text { No relationship, Statistically non-significant } \\
\text { Prices for baby cereals and ready-to-eat breakfast cereals did } \\
\text { not differ between income classes. (Statistical test NR) }\end{array}$ \\
\hline & & & Cheese & $\begin{array}{l}\text { No relationship, Statistically non-significant } \\
\text { Prices for cheese did not differ between income classes. } \\
\text { (Statistical test NR) }\end{array}$ \\
\hline & & & Eggs & $\begin{array}{l}\text { No relationship, Statistically non-significant } \\
\text { Prices for eggs did not differ between income classes. (Statistical } \\
\text { test NR) }\end{array}$ \\
\hline & & & Juice & $\begin{array}{l}\text { No relationship, Statistically non-significant } \\
\text { Prices for fruit and vegetable juice did not differ between income } \\
\text { classes. (Statistical test NR) }\end{array}$ \\
\hline
\end{tabular}


Mean milk price (1 gal), Statistical test NR

Low income, WIC eligible, High income, $p=$ non-significant

CA: $\$ 2.61, \$ 2.57, \$ 2.70$

CO: $\$ 2.49, \$ 2.52, \$ 2.43$

$\mathrm{FL}: \$ 2.98, \$ 3.00, \$ 3.00$

GA: $\$ 2.55, \$ 2.61, \$ 2.69$

IA: \$2.33, \$2.36, \$2.30

IL: \$2.52, \$2.46, \$2.54

$\mathrm{KS}: \$ 2.66, \$ 2.64, \$ 2.64$

MA: $\$ 2.62, \$ 2.65, \$ 2.61$

MI: \$2.57, \$2.55, \$2.57

$\mathrm{MN}: \$ 2.89, \$ 2.88, \$ 2.88$

MO: $\$ 2.76, \$ 2.77, \$ 2.76$

NY: $\$ 2.92, \$ 2.87, \$ 2.90$

$\mathrm{PA}: \$ 2.36, \$ 2.48, \$ 2.37$

TN: \$2.82, \$2.81, \$2.85

TX: \$2.43, \$2.37, \$2.40

WA: \$2.52, \$2.52, \$2.62

WI: $\$ 2.51, \$ 2.53, \$ 2.51$

Peanut butter No relationship, Statistically non-significant

Prices for peanut butter did not differ between income classes.

(Statistical test NR)

\begin{tabular}{|c|c|c|c|c|}
\hline DeWeese, $2017^{15}$ & $\begin{array}{l}\mathrm{N}=104 \\
\text { Analytic N is New Jersey corner } \\
\text { stores for metro areas of Camden, } \\
\text { Newark, New Brunswick, and } \\
\text { Trenton, NJ }\end{array}$ & $\begin{array}{l}\text { Income } \\
\text { - Low } \\
\text { - Med } \\
\text { - High }\end{array}$ & Chips & $\begin{array}{l}\text { No relationship, Statistically non-significant } \\
\text { Mean price of chips, ANOVA, } \mathrm{P}=\mathrm{NS} \\
\text { Lowest income }(\geq 54 \%): \$ 0.45 \\
\text { Medium income }(34-<54 \%): \$ 0.49 \\
\text { Highest income }(<34 \%): \$ 0.45\end{array}$ \\
\hline & & & Fruit & $\begin{array}{l}\text { No relationship, Statistically non-significant } \\
\text { Mean price of fruit, ANOVA, P=NS } \\
\text { Lowest income }(\geq 54 \%): \$ 0.49 \\
\text { Medium income }(34-<54 \%): \$ 0.50 \\
\text { Highest income }(<34 \%): \$ 0.47\end{array}$ \\
\hline
\end{tabular}




\begin{tabular}{|c|c|c|c|}
\hline Article & $\begin{array}{l}\text { Study and Participant } \\
\text { Characteristics }\end{array}$ & Intervention & Outcome(s) \\
\hline Dunn, $2011^{16}$ & $\begin{array}{l}\mathbf{N}=23 \\
\text { Analytic } \mathrm{N}=23 \text { stores from } 6 \text { rural } \\
\text { counties in the Brazos Valley, } \\
\text { located between Dallas and } \\
\text { Houston. } \\
\text { Census block group characteristics } \\
\text { of the included stores, Mean (SD): } \\
\text { Median family income: } \$ 30,083 \\
\text { (\$7,290) } \\
\text { Proportion Black: } 21.2 \%(16.1 \%) \\
\text { Proportion Hispanic: } 16.5 \%(9.7 \%)\end{array}$ & $\begin{array}{l}\text { Tncome } \\
\text { Median family } \\
\text { income }\end{array}$ & Fruit \\
\hline
\end{tabular}

\section{Direct relationship (High variety), Statistically non-} significant

No relationship (Basic variety), Statistically non-significant

Fruit Price Index--High Variety

Multivariate regression, $\mathrm{R}^{\wedge} 2=0.19, \mathrm{~N}=21$

Coefficient estimates (robust SE), adjusted for race Median family income (In): $B=10.15$ (5.99), p>0.05

Fruit Price Index--Basic Variety

Multivariate regression, $R^{\wedge} 2=0.02, N=22$

Coefficient estimates (robust SE), adjusted for race Median family income (In): $B=-0.12$ (3.49), p $>0.05$

Direct relationship, Statistically non-significant

Vegetable Price Index--High Variety

Multivariate regression, $\mathrm{R}^{\wedge} 2=0.14, \mathrm{~N}=23$

Coefficient estimates (robust SE), adjusted for race

Median family income (In): $B=13.87$ (6.94), p>0.05

Vegetable Price Index--Basic Variety

Multivariate regression, $\mathrm{R}^{\wedge} 2=0.15, \mathrm{~N}=23$

Coefficient estimates (robust SE), adjusted for race

Median family income (In): $B=16.12$ (8.11), p>0.05

Apples No relationship, Statistically non-significant

Price of apples $(\$ / \mathrm{lb})$

Multivariate regression, $\mathrm{R}^{\wedge} 2=0.09, \mathrm{~N}=21$

Coefficient estimates (robust $\mathrm{SE}$ ), adjusted for race

Median family income (In): B=0.50 (0.45), p>0.05

Avocados

Direct relationship, Statistically significant

Price of avocados $(\$ / \mathrm{lb})$

Multivariate regression, $R^{\wedge} 2=0.48, N=21$

Coefficient estimates (robust SE), adjusted for race

Median family income (In): $B=3.78$ (1.37), $p<0.01$

Bananas
No relationship, Statistically non-significant

Price of bananas $(\$ / \mathrm{lb})$

Multivariate regression, $\mathrm{R}^{\wedge} 2=0.17, \mathrm{~N}=21$

Coefficient estimates (robust SE), adjusted for race

Median family income $(\operatorname{In})$ : $B=-0.16(0.10), p>0.05$ 
Price of green beans $(\$ / \mathrm{lb})$

Multivariate regression, $\mathrm{R}^{\wedge} 2=0.22, \mathrm{~N}=23$

Coefficient estimates (robust $\mathrm{SE}$ ), adjusted for race

Median family income (In): $B=-2.05$ (1.03), $p<0.05$

Berries

No relationship, Statistically non-significant

Price of berries $(\$ / \mathrm{lb})$

Multivariate regression, $\mathrm{R}^{\wedge} 2=0.11, \mathrm{~N}=21$

Coefficient estimates (robust SE), adjusted for race

Median family income (In): B=0.21 (1.04), p>0.05

Carrots

No relationship, Statistically non-significant

Price of carrots $(\$ / \mathrm{lb})$

Multivariate regression, $R^{\wedge} 2=0.15, N=23$

Coefficient estimates (robust SE), adjusted for race

Median family income (In): $B=-0.16(0.44), p>0.05$

Corn

No relationship, Statistically non-significant

Price of corn $(\$ / \mathrm{lb})$

Multivariate regression, $\mathrm{R}^{\wedge} 2=0.16, \mathrm{~N}=23$

Coefficient estimates (robust SE), adjusted for race

Median family income (In): B=0.03 (0.53), p>0.05

Cruciferous

vegetables

No relationship, Statistically non-significant

Price of cruciferous vegetables $(\$ / \mathrm{lb})$

Multivariate regression, $\mathrm{R}^{\wedge} 2=0.15, \mathrm{~N}=23$

Coefficient estimates (robust $\mathrm{SE}$ ), adjusted for race

Median family income (In): $B=0.26(0.30), p>0.05$

Grapes

No relationship, Statistically non-significant

Price of grapes $(\$ / \mathrm{lb})$

Multivariate regression, $\mathrm{R}^{\wedge} 2=0.04, \mathrm{~N}=21$

Coefficient estimates (robust SE), adjusted for race

Median family income (In): B=0.54 (0.60), p>0.05

Greens

Price of greens $(\$ / \mathrm{lb})$

Multivariate regression, $\mathrm{R}^{\wedge} 2=0.11, \mathrm{~N}=23$

Coefficient estimates (robust SE), adjusted for race

Median family income (In): $B=-0.30(0.33)$ 
Price of lettuce $(\$ / \mathrm{lb})$

Multivariate regression, $\mathrm{R}^{\wedge} 2=0.31, \mathrm{~N}=23$

Coefficient estimates (robust $\mathrm{SE}$ ), adjusted for race

Median family income $(\operatorname{In}): B=1.11$ (0.67), $p>0.05$

Melons

No relationship, Statistically non-significant

Price of melons $(\$ / \mathrm{lb})$

Multivariate regression, $\mathrm{R}^{\wedge} 2=0.01, \mathrm{~N}=21$

Coefficient estimates (robust $\mathrm{SE}$ ), adjusted for race

Median family income (In): B=0.09 (0.38), p>0.05

Onions No relationship, Statistically non-significant

Price of onions $(\$ / \mathrm{lb})$

Multivariate regression, $\mathrm{R}^{\wedge} 2=0.06, \mathrm{~N}=23$

Coefficient estimates (robust SE), adjusted for race

Median family income (In): B=0.51 (0.54), p>0.05

Oranges No relationship, Statistically non-significant

Price of oranges $(\$ / \mathrm{lb})$

Multivariate regression, $\mathrm{R}^{\wedge} 2=0.02, \mathrm{~N}=21$

Coefficient estimates (robust SE), adjusted for race

Median family income (In): $B=-0.03(0.40)$, p >0.05

Peaches No relationship, Statistically non-significant

Price of peaches $(\$ / \mathrm{lb})$

Multivariate regression, $\mathrm{R}^{\wedge} 2=0.08, \mathrm{~N}=21$

Coefficient estimates (robust $\mathrm{SE}$ ), adjusted for race

Median family income (In): $B=-0.30$ (0.49), p>0.05

Pears

No relationship, Statistically non-significant

Price of pears $(\$ / \mathrm{lb})$

Multivariate regression, $\mathrm{R}^{\wedge} 2=0.02, \mathrm{~N}=21$

Coefficient estimates (robust SE), adjusted for race

Median family income (In): $B=-0.06$ (0.55), p>0.05

Potatoes No relationship, Statistically non-significant

Price of potatoes $(\$ / \mathrm{lb})$

Multivariate regression, $\mathrm{R}^{\wedge} 2=0.13, \mathrm{~N}=23$

Coefficient estimates (robust SE), adjusted for race

Median family income $(\operatorname{In})$ : $B=0.48(0.39), p>0.05$ 
Price of squash $(\$ / l b)$

Multivariate regression, $R^{\wedge} 2=0.26, N=23$

Coefficient estimates (robust $\mathrm{SE}$ ), adjusted for race

Median family income $(\operatorname{In})$ : $B=1.08$ (0.41), $p<0.01$

Tomatoes

No relationship, Statistically non-significant

Price of tomatoes $(\$ / \mathrm{lb})$

Multivariate regression, $\mathrm{R}^{\wedge} 2=0.07, \mathrm{~N}=23$

Coefficient estimates (robust SE), adjusted for race

Median family income (In): B=0.62 (0.49), p>0.05

\begin{tabular}{|c|c|c|c|c|}
\hline French, $2010^{17}$ & $\begin{array}{l}\mathrm{N}=90 \\
\text { Analytic } \mathrm{N} \text { is households } \\
\text { Mean of four people per household. } \\
\text { Primary shoppers were } 93 \% \text { female; } \\
78 \% \text { White; Mean age } 40.8 \text { y } \\
(\mathrm{SD}=7.3) ; 64 \% \text { married or living with } \\
\text { significant other; } 25.8 \% \text { had more } \\
\text { than a college degree; mean BMI: } \\
29.7(\mathrm{SD}=7.2)\end{array}$ & $\begin{array}{l}\text { Income } \\
\text { - Low } \\
\text { - Med } \\
\text { - High }\end{array}$ & $\begin{array}{l}\text { Fruits and } \\
\text { Vegetables }\end{array}$ & $\begin{array}{l}\text { Direct relationship, Statistically significant } \\
\text { Monthly median price per person per ounce of fruits/vegetables } \\
\text { eaten at home, Jonckheere-Terpstra test, } p=0.007 \\
\text { Low: } \$ 0.08 \\
\text { Med: } \$ 0.08 \\
\text { High: } \$ 0.10\end{array}$ \\
\hline Gillespie, $2015^{18}$ & $\begin{array}{l}\mathrm{N}=60 \\
\text { Analytic } \mathrm{N}=\text { full-service grocery } \\
\text { stores across } 9 \text { parishes } \\
\text { Median HH income: } \$ 45,392 \\
\text { African American population: } 39 \%\end{array}$ & Income & $\begin{array}{l}\text { Healthier } \\
\text { Market Basket }\end{array}$ & $\begin{array}{l}\text { No relationship, Statistically non-significant } \\
\text { Price(Ln) of Nutrient-dense foods } \\
\text { Regression (adjusted for Black, real estate value, urban, chain, } \\
\text { supercenter, services, store size, competition), } N=50, R^{2}: 0.184 \text {, } \\
\text { Prob>F: } 0.070 \\
\text { Coefficient }(S E) \\
\text { Income }(L n): 0.143(0.138), p>0.10\end{array}$ \\
\hline & & & $\begin{array}{l}\text { Unhealthy } \\
\text { food price }\end{array}$ & $\begin{array}{l}\text { Direct relationship, Statistically significant } \\
\text { Price(Ln) of Energy-dense foods, } \\
\text { Regression (adjusted for Black, real estate value, urban, chain, } \\
\text { supercenter, services, store size, competition), } N=40, R^{2}: 0.596 \text {, } \\
\text { Prob>F: } 0.000 \\
\text { Coefficient }(S E) \\
\text { Income }(L n):-0.237(0.131), p \leq 0.10 \\
{[10 \% \text { increase in income was associated with a } 2.37 \% \text { decrease }} \\
\text { in price of energy-dense foods] }\end{array}$ \\
\hline
\end{tabular}


Income was significant ( $p \leq 0.10)$ for $7(26 \%)$ of the 45

regressions for nutrient-dense/energy-dense pricing ratios.

Models adjusted for Black, High or Low real estate value, urban,

chain, supercenter, services, store size, and competition.

4 regressions (15\%) indicated that higher income resulted in relatively higher prices for nutrient-dense foods relative to energy-dense foods: whole-wheat bread, potatoes, and oatmeal, all relative to snack cakes, and oatmeal relative to cola.

3 regressions (11\%) indicated that higher income resulted in relatively lower prices for nutrient-dense foods relative to energydense foods: skim milk and bananas relative to cola and bananas relative to potato chips.

When the nutrient-dense market basket /energy-dense market basket cost ratio was analyzed, income was non-significant

Price (Ln) of bananas (1 lb)

Regression (adjusted for Black, real estate value, urban, chain, supercenter, services, store size, competition), $N=59, R^{2}: 0.128$,

Prob>F: 0.008

Coefficient (SE)

Income(Ln): -0.212 (0.237), p>0.10

Price(Ln) of whole wheat bread (20 oz)

Regression (adjusted for Black, real estate value, urban, chain,

supercenter, services, store size, competition), $N=58, R^{2}: 0.220$,

Prob>F: 0.036

Coefficient (SE)

Income(Ln): 0.167 (0.257), $\mathrm{p}>0.10$ 
Price $(\mathrm{Ln})$ of broccoli $(1 \mathrm{lb})$

Regression (adjusted for Black, real estate value, urban, chain, supercenter, services, store size, competition), $N=59, R^{2}: 0.424$, Prob>F: 0.000

Coefficient (SE)

Income(Ln): 0.207

Chips $\quad$ Direct relationship, Statistically significant

Price(Ln) of potato chips (12 oz)

Regression (adjusted for Black, real estate value, urban, chain, supercenter, services, store size, competition), $N=57, R^{2}: 0.486$, Prob>F: 0.000

Coefficient (SE)

Income(Ln): 0.543 (0.215), $\mathrm{p}<0.05$

$[10 \%$ increase in income was associated with a $5.43 \%$ increase in price of potato chips]

Price $(\mathrm{Ln})$ of ice cream $(0.5 \mathrm{gal})$

Regression (adjusted for Black, real estate value, urban, chain, supercenter, services, store size, competition), $N=59, R^{2}: 0.217$,

Prob>F: 0.018

Coefficient (SE)

Income(Ln): 0.121 (0.186), p>0.10

Milk No relationship, Statistically non-significant

Price(Ln) of skim milk (1 gal)

Regression (adjusted for Black, real estate value, urban, chain, supercenter, services, store size, competition), $N=59, R^{2}: 0.326$,

Prob>F: 0.001

Coefficient (SE)

Income(Ln): 0.117 (0.087), p>0.10

\section{No relationship, Statistically non-significant}

Price(Ln) of oatmeal (18 oz)

Regression (adjusted for Black, real estate value, urban, chain, supercenter, services, store size, competition), $N=58, R^{2}: 0.206$, Prob>F: 0.006

Coefficient (SE)

Income(Ln): 0.401 (0.307), p>0.10 
Price(Ln) of oranges (1 lb)

Regression (adjusted for Black, real estate value, urban, chain, supercenter, services, store size, competition), $N=58, R^{2}: 0.358$, Prob>F: 0.000

Coefficient (SE)

Income(Ln): 0.225 (0.204), p>0.10

Soda No relationship, Statistically non-significant

Price $(\mathrm{Ln})$ of cola $(2 \mathrm{~L})$

Regression (adjusted for Black, real estate value, urban, chain, supercenter, services, store size, competition), $N=58, R^{2}: 0.488$,

Prob>F: 0.000

Coefficient (SE)

Income (Ln): $0.082(0.225), p>0.10$

\begin{tabular}{|c|c|c|}
\hline Gosliner, 2018 & $\begin{array}{l}\mathrm{N}=1474 \\
\text { Analytic } \mathrm{N}=1474 \text { stores in } 470 \\
\text { unique } \\
\text { census tracts within } 225 \text { low-income } \\
\text { neighborhoods in cities and towns } \\
\text { across } 44 \text { California counties. }\end{array}$ & $\begin{array}{l}\text { Geographic } \\
\text { location } \\
\text { - Low-income } \\
\text { neighborhoods } \\
\text { - County average }\end{array}$ \\
\hline
\end{tabular}

Inverse relationship, Statistically significant

Apples Inverse relationship, Statistically significant
Mean (SD, range), Relative price difference from county chain supermarket average, Statistical test NR

Large groceries $(n=218): \$ 1.17(0.39,0.66-2.99), 44 \%$ Small markets $(n=312): \$ 1.18(0.37,0.63-2.59), 53 \%$ Convenience stores $(n=130): \$ 1.58(0.50,0.69-2.80), 110 \%$

\section{Inverse relationship, Statistically significant}

Average lowest price of bananas ( $\$ / \mathrm{lb}$ ) by store type

Mean (SD, range), Relative price difference from county chain supermarket average, Statistical test NR

Large groceries $(n=218): \$ 0.70(0.16,0.49-1.49), 15 \%$

Small markets $(n=336): \$ 0.85(0.31,0.49-2.19), 39 \%$

Convenience stores $(n=150): \$ 1.30(0.46,0.49-2.19), 115 \%$

Average lowest price of broccoli $(\$ / \mathrm{lb})$ by store type

Mean (SD, range), Relative price difference from county chain supermarket average, Statistical test NR

Large groceries $(n=199)$ : $\$ 1.30(0.49,0.68-3.19), 1 \%$

Small markets $(n=142): \$ 1.33(0.56,0.68-3.18), 6 \%$

Convenience stores: Available in too few stores for inclusion 
Average lowest price of cabbage ( $\$ / \mathrm{lb}$ ) by store type

Mean (SD, range), Relative price difference from county chain

supermarket average, Statistical test NR

Large groceries $(n=172): \$ 0.74(0.27,0.38-1.59) 0 \%$

Small markets $(n=261)$ : $\$ 0.66(0.26,0.34-1.50),-1 \%$

Convenience stores: Available in too few stores for inclusion

Carrots Inverse relationship, Statistically significant

Average lowest price of carrots $(\$ / \mathrm{lb})$ by store type

Mean (SD, range), Relative price difference from county chain supermarket average, Statistical test NR

Large groceries $(n=179): \$ 0.84(0.33,0.50-2.14), 33 \%$

Small markets $(n=242): \$ 0.91(0.37,0.50-2.20), 43 \%$

Convenience stores $(n=24): \$ 1.22(0.58,0.50-2.00), 102 \%$

Oranges

Inverse relationship, Statistically significant

Average lowest price of oranges $(\$ / \mathrm{lb})$ by store type Mean (SD, range), Relative price difference from county chain supermarket average, Statistical test NR

Large groceries $(n=200): \$ 0.95(0.40,0.48-1.49)$, 35\% Small markets $(n=249): \$ 0.88(0.41,0.47-2.20), 27 \%$

Convenience stores $(n=88): \$ 1.36(0.59,0.50-2.20), 107 \%$

Average lowest price of tomatoes $(\$ / \mathrm{lb})$ by store type

Mean (SD, range), Relative price difference from county chain

supermarket average, Statistical test NR

Large groceries $(n=197): \$ 1.21(0.45,0.59-2.66), 13 \%$

Small markets $(n=311): \$ 1.12(0.41,0.59-2.79), 6 \%$

Convenience stores $(n=57): \$ 1.21(0.38,0.69-2.19), 23 \%$ 
Article
Study and Participant

Characteristics

Hardin-Fanning, $2015^{20}$

Analytic $\mathrm{N}$ is number of counties 4 counties compared with 1 store/county

All groceries were regional or national chain stores of similar size and food product variety

\section{Intervention Outcome(s) Results}

\section{Geographic \\ location \\ USDA Market \\ Basket \\ Inverse relationship (healthier foods), Statistically significant}

- FD-HP

- U-MP

- U-LP

- HP

Mean price/serving, repeated measures ANOVA identifier (random effect) (adjusted for month and ONQI score (fixed effects) and food item

County: $F(3,1365)=22.9, p<0.0001$

County $x$ Month: $p=0.4$

Mean price/serving, repeated measures ANOVA

(adjusted for month and quartile $\mathrm{x}$ month (fixed effects) and food item identifier (random effect))

County: $F(3,1347)=24.5, p<0.0001$

County $x$ Month: $p>0.0005$

ONQI quartile $x$ County: $F(9,1347)=6.7, p<0.0001$

Mean price/serving, Post-hoc analysis

FD-HP (lower per capita income): $\$ 0.40$ vs. U-MP and U-LP, $\mathrm{p}<0.0001$; vs. HP, $\mathrm{p}=0.0002$

U-MP and U-LP (higher per capita income; average): $\$ 0.36$

HP (higher per capita income): $\$ 0.38$ vs. U-LP $\mathrm{p}=0.003$

\begin{tabular}{|c|c|c|c|}
\hline $\begin{array}{l}\text { Hardin-Fanning, } \\
2017^{21}\end{array}$ & $\begin{array}{l}\mathbf{N}=15 \\
\text { Analytic } \mathrm{N} \text { is number of counties } \\
15 \text { counties compared with } 1 \\
\text { store/county } \\
\text { All groceries were regional or } \\
\text { national chain stores of similar size } \\
\text { and food product variety }\end{array}$ & $\begin{array}{l}\text { Geographic } \\
\text { location } \\
\text { - Least healthy } \\
\text { counties (highest } \\
\text { average poverty } \\
\text { rates) } \\
\text { - Moderately } \\
\text { healthy counties } \\
\text { (lower average } \\
\text { poverty rates) } \\
\text { - Most healthy } \\
\text { counties (lower } \\
\text { average poverty } \\
\text { rates) }\end{array}$ & $\begin{array}{l}\text { USDA Market } \\
\text { Basket }\end{array}$ \\
\hline
\end{tabular}

\section{Inverse relationship, Statistically significan}

GEE Model, Price per serving across health ranking groups, adjusted for ONQI quartile, county population, Appalachian status, and multiple measurements per county. Chi-squared: $12, \mathrm{P}=0.003$

Post-hoc analysis of pairwise differences, mean price/serving: Least healthy (highest poverty) $\$ 0.58$ Moderately healthy (lower poverty) $\$ 0.53$

Most healthy (lower poverty) $\$ 0.50$

Relative price per serving (\$) by health tertiles:

Least healthy (highest poverty) vs. Most healthy (lower poverty): $B=0.08, S E=0.02, Z=3.8, P<0.001$

Least healthy (highest poverty) vs. Moderately healthy (lower poverty): $\mathrm{B}=0.05, \mathrm{SE}=0.02, \mathrm{Z}=2.3, \mathrm{P}=0.024$

Moderately healthy vs. Most healthy, $\mathrm{P}=\mathrm{NS}$ 


\section{USDA \\ (n)}

United States

Department of

Agriculture

\begin{tabular}{|c|c|c|c|}
\hline Article & $\begin{array}{l}\text { Study and Participant } \\
\text { Characteristics }\end{array}$ & Intervention & Outcome(s) \\
\hline $\begin{array}{l}\text { Hatzenbuehler, } \\
\text { 2012 }^{22}\end{array}$ & $\begin{array}{l}\mathrm{N}=59 \\
\text { Analytic N is supermarkets in Baton } \\
\text { Rouge, Louisiana, metropolitan area } \\
\text { Mean income: } \$ 40,704 \text { (range: } \\
\$ 17,170-77,668) \\
\text { Mean household size: } 2.61 \text { (range: } \\
1.87-3.08) \\
\text { Mean \% Black: } 32.53 \% \text { (0.50- } \\
97.00 \%) \\
\text { Mean \% other minority: } 4.55 \%(1.06- \\
11.96 \%)\end{array}$ & $\begin{array}{l}\text { Income } \\
\text { continuous }\end{array}$ & $\begin{array}{l}\text { TFP Food } \\
\text { Basket }\end{array}$ \\
\hline
\end{tabular}

Results

2005 DGA

Market Basket

\section{No relationship, Statistically non-significant}

TFP market basket, Ordinary least squares

Income: B: 0.29 , t-value: $0.76, p>0.05$

$R^{2}$ : 0.3250, Model F-value: $4.10, p<0.01$

Adjusted for population density, household size, chain

supercenter, services, store size, Black, other minority

\section{No relationship, Statistically non-significant}

Stewart DGA market basket, Ordinary least squares Income: B: 0.52 , t-value: $1.50, p>0.05$

$R^{2}$ : 0.3655, Model F-value: $4.71, p<0.01$

Adjusted for population density, household size, chain, supercenter, services, store size, Black, other minority

Dairy Direct relationship (2005 DGA), Statistically significant

No relationship (TFP), Statistically non-significant

Low-fat dairy products for the Stewart 2005 DGA market basket

Ordinary least squares

Income: B: 0.17, t-value: $2.19, \mathrm{p}<0.05$

$R^{2}$ : 0.2407, Model F-value: $3.04, p<0.01$

Adjusted for population density, household size, chain,

supercenter, services, store size, Black, other minority

Low-fat dairy products for the TFP market basket

Ordinary least squares

Income: $B: 0.06$, t-value: $1.43, \mathrm{p}>0.05$

$R^{2}: 0.1491$, Model F-value: $2.13, p<0.05$

Adjusted for population density, household size, chain

supercenter, services, store size, Black, other minority 
Fruit for the Stewart 2005 DGA market basket

Ordinary least squares

Income: $\mathrm{B}: 0.13$, t-value: $2.55, \mathrm{p}<0.05$

$\mathrm{R}^{2}$ : 0.3778, Model F-value: $4.91, \mathrm{p}<0.01$

Adjusted for population density, household size, chain,

supercenter, services, store size, Black, other minority

Fruit for the TFP market basket

Ordinary least squares

Income: $\mathrm{B}: 0.23$, t-value: $1.52, \mathrm{p}>0.05$

$R^{2}: 0.2893$, Model F-value: $3.62, p<0.01$

Adjusted for population density, household size, chain,

supercenter, services, store size, Black, other minority

No relationship, Statistically non-significant

Dark green vegetables for the Stewart 2005 DGA market basket Ordinary least squares

Income: B: 0.02, t-value: $1.00, p>0.05$

$R^{2}: 0.1433$, Model F-value: $2.08, p<0.05$

Adjusted for population density, household size, chain,

supercenter, services, store size, Black, other minority

Dark green vegetables for the TFP market basket

Ordinary least squares

Income: $\mathrm{B}: 0.00$, t-value: $0.87, \mathrm{p}>0.05$

$R^{2}: 0.1135$, Model F-value: $1.83, p>0.05$

Adjusted for population density, household size, chain,

supercenter, services, store size, Black, other minority 
Whole grains for the Stewart 2005 DGA market basket Ordinary least squares

Income: $B:-0.01$, t-value: $-0.17, p>0.05$

$R^{2}: 0.1784$, Model F-value: $2.40, p<0.05$

Adjusted for population density, household size, chain, supercenter, services, store size, Black, other minority

Whole grains for the TFP market basket Ordinary least squares

Income: $B: 0.00$, t-value: $0.35, p>0.05$

$R^{2}$ : 0.1524, Model F-value: $2.16, p<0.05$

Adjusted for population density, household size, chain,

supercenter, services, store size, Black, other minority

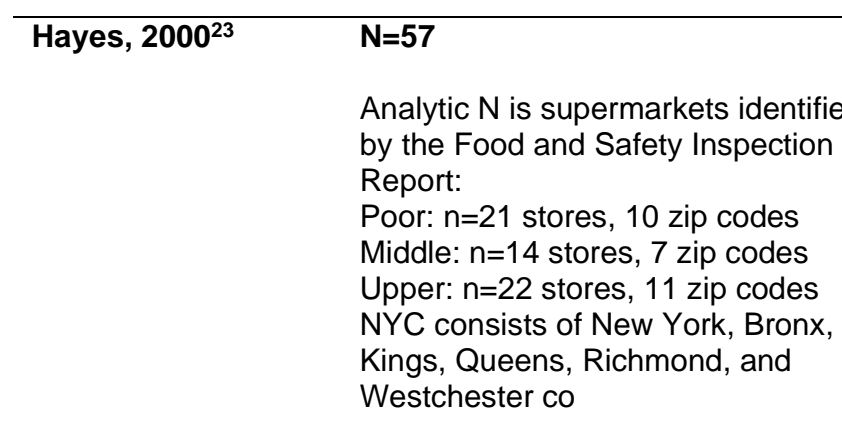

Income

- Poor

- Middle

- Upper

-

Mean (SE) total cost in logarithms of market basket, weighted by expenditure-shares, Mean difference

Poor: 3.955 (0.008) or $\$ 52.20$

Middle: $3.968(0.013)$ or $\$ 52.88$

Upper: 3.971 (0.014) or $\$ 53.04$

Poor-upper difference: $-0.016(0.016)$ or $-\$ 0.84$

$\mathrm{P}=\mathrm{NS}$

Mean (SE) total cost of market basket in logarithms, unweighted Poor: 3.925 (0.008) or $\$ 50.65$

Middle: $3.938(0.014)$ or $\$ 51.32$

Upper: $3.942(0.015)$ or $\$ 51.52$

Poor-upper difference: $-0.016(0.017)$ or $-\$ 0.87$

$\mathrm{P}=\mathrm{NS}$

Mean (SE) price in logarithms of Apples, Mean difference

Poor: $-0.120(0.032)$ or $\$ 0.89$

Middle: $0.058(0.032)$ or $\$ 1.06$

Upper: $0.082(0.028)$ or $\$ 1.09$

Poor-upper difference: $-0.202(0.043)$ or $-\$ 0.20$

Significantly different 
Mean (SE) price in logarithms of Bananas, Mean difference

Poor: $-0.799(0.038)$ or $\$ 0.45$

Middle: $-0.854(0.067)$ or $\$ 0.43$

Upper: $-0.636(0.049)$ or $\$ 0.53$

Poor-upper difference: $-0.163(0.062)$ or $\$ 0.08$

Significantly different

Bread Direct relationship, Statistically non-significant

Mean (SE) price in logarithms of Bread, Mean difference

Poor: $0.468(0.023)$ or $\$ 1.60$

Middle: $0.538(0.12)$ or $\$ 1.71$

Upper: $0.504(0.014)$ or $\$ 1.66$

Poor-upper difference: -0.036 (0.027) or $-\$ 0.06$

$\mathrm{P}=\mathrm{NS}$

Breakfast Inverse relationship, Statistically significant

cereals

Mean (SE) price in logarithms of Cereal, Mean difference

Poor: $0.927(0.005)$ or $\$ 2.53$

Middle: $0.926(0.016)$ or $\$ 2.52$

Upper: $0.876(0.009)$ or $\$ 2.40$

Poor-upper difference: 0.052 (0.010) or $\$ 0.13$

Significantly different

Butter

\section{Inverse relationship, Statistically non-significant}

Mean (SE) price in logarithms of Butter, Mean difference

Poor: $1.106(0.009)$ or $\$ 3.02$

Middle: $1.060(0.030)$ or $\$ 2.89$

Upper: 1.068 (0.027) or $\$ 2.91$

Poor-upper difference: 0.037 (0.028) or $\$ 0.11$

$\mathrm{P}=\mathrm{NS}$

Mean (SE) price in logarithms of Cheese, Mean difference

Poor: $1.180(0.21)$ or $\$ 3.25$

Middle: $1.166(0.046)$ or $\$ 3.21$

Upper: $1.152(0.027)$ or $\$ 3.16$

Poor-upper difference: 0.028 (0.034) or $\$ 0.09$

$\mathrm{P}=\mathrm{NS}$ 
Mean price in logarithms of Chicken, Mean difference

Poor: $0.788(0.044)$ or $\$ 2.20$

Middle: $0.755(0.069)$ or $\$ 2.13$

Upper: 0.862 (0.052) or $\$ 2.37$

Poor-upper difference: -0.074 (0.068) or $-\$ 0.17$

$\mathrm{P}=\mathrm{NS}$

Cooking oil No relationship, Statistically non-significant

Mean (SE) price in logarithms of Oil, Mean difference

Poor: $0.533(0.005)$ or $\$ 1.70$

Middle: $0.570(0.017)$ or $\$ 1.77$

Upper: $0.542(0.009)$ or $\$ 1.72$

Poor-upper difference: $-0.009(0.011)$ or $\$ 0.02$

$\mathrm{P}=\mathrm{NS}$

Direct relationship, Statistically non-significant

Mean (SE) price in logarithms of Eggs, Mean difference Poor: $0.192(0.020)$ or $\$ 1.21$

Middle: $0.222(0.035)$ or $\$ 1.25$

Upper: 0.285 (0.039) or $\$ 1.33$

Poor-upper difference: $-0.074(0.044)$ or $-\$ 0.12$

$\mathrm{P}=\mathrm{NS}$

\section{Flour Direct relationship, Statistically non-significant}

Mean (SE) price in logarithms of Flour, Mean difference

Poor: $0.648(0.046)$ or $\$ 1.91$

Middle: $0.700(0.024)$ or $\$ 2.01$

Upper: $0.676(0.026)$ or $\$ 1.97$

Poor-upper difference: $-0.029(0.052)$ or $-\$ 0.06$

$\mathrm{P}=\mathrm{NS}$

\section{Direct relationship, Statistically non-significant}

Mean (SE) price in logarithms of Ground beef, Mean difference

Poor: $1.444(0.042)$ or $\$ 4.24$

Middle: $1.490(0.077)$ or $\$ 4.44$

Upper: 1.530 (0.044) or $\$ 4.62$

Poor-upper difference: -0.086 (0.061) or $\$ 0.38$

$\mathrm{P}=\mathrm{NS}$ 
Mean (SE) price in logarithms of Orange Juice, Mean difference

Poor: $0.919(0.026)$ or $\$ 2.51$

Middle: $0.915(0.031)$ or $\$ 2.50$

Upper: $1.011(0.022)$ or $\$ 2.75$

Poor-upper difference: $-0.092(0.034)$ or $-\$ 0.24$

Significantly different

Milk No relationship, Statistically non-significant

Mean (SE) price in logarithms of Milk, Mean difference

Poor: $0.932(0.008)$ or $\$ 2.54$

Middle: $0.885(0.029)$ or $\$ 2.42$

Upper: $0.948(0.020)$ or $\$ 2.58$

Poor-upper difference: -0.015 (0.022) or $-\$ 0.04$

$\mathrm{P}=\mathrm{NS}$

Pasta No relationship, Statistically non-significant

Mean (SE) price in logarithms of Spaghetti, Mean difference

Poor: $-0.025(0.044)$ or $\$ 0.98$

Middle: $0.071(0.039)$ or $\$ 1.07$

Upper: 0.002 (0.032) or $\$ 1.00$

Poor-upper difference: -0.027 (0.054) or $\$ 0.02$

$\mathrm{P}=\mathrm{NS}$

Mean (SE) price in logarithms of Long-Grain Rice, Mean difference

Poor: $1.104(0.017)$ or $\$ 3.02$

Middle: $1.116(0.013)$ or $\$ 3.05$

Upper: $1.088(0.018)$ or $\$ 2.97$

Poor-upper difference: 0.016 (0.025) or $\$ 0.05$

$\mathrm{P}=\mathrm{NS}$

Sugar Direct relationship, Statistically non-significant

Mean (SE) price in logarithms of Sugar, Mean difference Poor: 0.957 (0.008) or $\$ 2.60$

Middle: $0.895(0.025)$ or $\$ 2.45$

Upper: 0.990 (0.019) or $\$ 2.69$

Poor-upper difference: $-0.033(0.020)$ or $-\$ 0.09$

$\mathrm{P}=\mathrm{NS}$ 


\begin{tabular}{ll} 
& \\
\hline Jetter, $2006^{24}$ & Analytic $N=$ stores \\
& 12 stores in Los Angeles; 13 stores
\end{tabular}

in Sacramento

\begin{tabular}{ll}
\hline Jewell, 201925 & $\mathbf{N = 2 1}$ \\
& $\begin{array}{l}\text { Analytic } N \text { is neighborhoods. } \\
\text { Stores: } \mathrm{N}=108 \text { from } 710 \text { census } \\
\text { tracts }\end{array}$ \\
\hline Kern, 2016 & $\mathbf{N = 1 7 4 3}$ \\
& $\begin{array}{l}\text { Analytic } \mathrm{N} \text { is stores (large chain } \\
\text { supermarkets and superstores) } \\
\text { across } 41 \text { states and } 1694 \text { census } \\
\text { blocks. }\end{array}$
\end{tabular}

Mean (SE) price in logarithms of Tuna, Mean difference Poor: -0.059 (0.026) or $\$ 0.94$

Middle: $0.034(0.058)$ or $\$ 1.03$ Upper: - $0.051(0.031)$ or $\$ 0.95$

Poor-upper difference: $-0.008(0.040)$ or $\$ 0.01$

$\mathrm{P}=\mathrm{NS}$

Income TFP Food

Continuous and Basket low vs. higher

Direct

(continuous), Statistically significant

No relationship (lower vs. higher), Statistically nonsignificant

Cost of a market basket (either TFP or Healthier)

Regression model (adjusted for: store type, fiber (In), fat (In), store density, store access)

Coefficient

Low-income area: $-0.001, \mathrm{p}>0.1$

Income (In; continuous): $0.079, \mathrm{p}<0.05$

$\begin{array}{lll}\begin{array}{l}\text { Geographic } \\ \text { location }\end{array} & \text { Fruits and } & \text { Direct relationship, Statistically non-significant } \\ \text { - CX3 } & \text { Vegetables } & \\ \text { - Adjan (IQR) produce price, Kruskal-Wallis, } p=0.06\end{array}$

CX3

CX3 neighborhoods: $\$ 1.05(0.63)$

- Adjacent

Adjacent neighborhoods: $\$ 1.50(0.97)$

SES proxy

Direct relationship, Statistically significant

Neighborhood SES

index

Milk

Hierarchical model of price of milk ( $\$ / 12 \mathrm{fl}$. oz) per neighborhood SES z-score

Estimate $(95 \% \mathrm{Cl})$

Adjusted (race, age, region, urbanicity, supermarket density, toilet paper price, soda price, county and state): 0.0149 (0.0104, $0.0193), p<0.0001$

Bivariate regression model of price of milk ( $\$ / 12 \mathrm{fl}$. oz) per neighborhood SES z-score, $p<0.0001$

Mean (SD)

Lowest SES tertile (least advantaged, $\mathrm{n}=581)$ : $\$ 0.60(0.11)$

Middle SES tertile $(n=582)$ : $\$ 0.61(0.11)$

Highest SES tertile (most advantaged, $\mathrm{n}=580)$ : $\$ 0.65(0.10)$ 


\section{USDA United States

Article Study and Participant Characteristics
Intervention

Outcome(s)

Results

Soda

\section{Direct relationship, Statistically significant}

Hierarchical model of price of soda $(\$ / 12 \mathrm{fl}$. oz) per neighborhood SES z-score

Estimate $(95 \% \mathrm{Cl})$

Adjusted (race, age, region, urbanicity, supermarket density,

toilet paper price, milk price, county and state): $0.0024(0.0012$ $0.0035), p<0.0001$

Bivariate regression model of price of soda $(\$ / 12 \mathrm{fl}$. oz) per neighborhood SES z-score, $\mathrm{p}<0.0001$

Mean (SD)

Lowest SES tertile (least advantaged, $n=581)$ : $\$ 0.23(0.02)$

Middle SES tertile $(n=582)$ : $\$ 0.22(0.02)$

Highest SES tertile (most advantaged, $n=580)$ : $\$ 0.23(0.02)$

\begin{tabular}{|c|c|c|c|}
\hline Kern, $2017^{27}$ & $\begin{array}{l}\mathrm{N}=1953 \\
\text { Analytic } \mathrm{N} \text { is stores }\end{array}$ & $\begin{array}{l}\text { SES proxy } \\
\text { Neighborhood SES } \\
\text { index }\end{array}$ & $\begin{array}{l}\text { Healthy food } \\
\text { price }\end{array}$ \\
\hline
\end{tabular}

Direct relationship (unadjusted), Statistically significant

Estimate (95\%): Unadjusted (county and state): 0.00452 $(0.0034,0.0056), p<0.0001$

Partially adjusted (age, region, urbanicity, population density, supermarket density, toilet paper price, county and state):

$0.00085(-0.00027,0.00198), p=0.1370$

Fully adjusted (age, region, urbanicity, population density, supermarket density, toilet paper price, race, county and state): $0.00090(-0.0007,0.0025), p=0.2836$

Price of food by Neighborhood SES quintile, mean (SD):

Lowest quintile (least advantaged): \$0.581 (0.047)

Second quintile: $\$ 0.581(0.048)$

Middle quintile: $\$ 0.589$ (0.053)

Fourth quintile: $\$ 0.590$ (0.057)

Highest quintile (most advantaged): \$0.611 (0.068) 


\section{USDA United States \\ Department of \\ Agriculture}

Estimate $(95 \% \mathrm{Cl})$

Unadjusted (county and state): $0.00057(0.0001,0.0011)$

$\mathrm{p}=0.0234$

Partially adjusted (age, region, urbanicity, population density, supermarket density, toilet paper price, county and state):

$-0.00102(-0.00148,-0.00056), p<0.0001$

Fully adjusted (age, region, urbanicity, population density, supermarket density, toilet paper price, race, county and state) $0.00055(-0.0001,0.0012), p=0.1110$

Price of food by Neighborhood SES quintile, mean (SD):

Lowest quintile (least advantaged): \$0.299 (0.019)

Second quintile: $\$ 0.295(0.020)$

Middle quintile: $\$ 0.295(0.017)$

Fourth quintile: $\$ 0.294$ (0.016)

Highest quintile (most advantaged): $\$ 0.306$ (\$0.039)

Estimate $(95 \% \mathrm{Cl})$

Unadjusted (county and state): $-0.01323(-0.0153,-0.0112)$, $\mathrm{p}<0.0001$

Fully adjusted (age, region, urbanicity, population density, supermarket density, toilet paper price, race, county and state) $-0.01836(-0.0215,-0.0152), p<0.0001$

Fruit Juice and Frozen Vegetables

\section{Direct relationship, Statistically significant}

Estimate $(95 \% \mathrm{Cl})$

Unadjusted (county and state): $0.01386(0.0126,0.0151)$, $\mathrm{p}<0.0001$

Fully adjusted (age, region, urbanicity, population density, supermarket density, toilet paper price, and race, county and state): 0.01096 (0.0091, 0.0128), $\mathrm{p}<0.0001$ 
Estimate $(95 \% \mathrm{Cl})$

Unadjusted (county and state): $-0.00216(-0.0025,-0.0018)$, $\mathrm{p}<0.0001$

Fully adjusted (age, region, urbanicity, population density, supermarket density, toilet paper price, race, county and state): $-0.00125(-0.0018-0.0007), p<0.0001$

\section{No relationship, Statistically non-significant}

Estimate $(95 \% \mathrm{Cl})$

Unadjusted (county and state): $0.00051(-0.0001,0.0011)$, $\mathrm{p}=0.0937$

Fully adjusted (age, region, urbanicity, population density, supermarket density, toilet paper price, either race, county and state): 0.00065 ( $-0.0003,0.0016), p=0.1682$

Estimate $(95 \% \mathrm{Cl})$

Unadjusted (county and state): $0.00267(0.0018,0.0035)$, $\mathrm{p}<0.0001$

Fully adjusted (age, region, urbanicity, population density supermarket density, toilet paper price, race, county and state): $0.00153(0.0005,0.0026), p=0.0054$

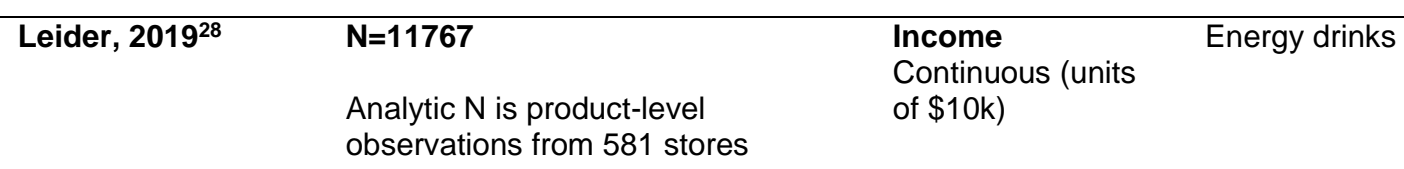

No relationship, Statistically non-significant

observations from 581 stores

Energy drinks $(n=2,276)$

Beta coefficient $(95 \% \mathrm{Cl})$, Multiple linear regression

Median HH income (units of \$10k): $0.02(-0.05,0.10), p>0.05$

$\%$ population <125\% poverty level: $0.02(-0.00,0.04), p>0.05$

Adjusted for beverage size, sale status, store type,

race/ethnicity, site

Juice drinks (non-100\% juice, $n=886$ )

Beta coefficient $(95 \% \mathrm{Cl})$, Multiple linear regression

Median HH income (units of \$10k): $0.02(-0.03,0.07), p>0.05$

$\%$ population <125\% poverty level: $0.00(-0.01,0.02), p>0.05$

Adjusted for beverage size, sale status, store type,

race/ethnicity, site 
Adjusted for beverage size, sale status, store type,

race/ethnicity, site

Soda Direct relationship, Statistically significant

\section{Soda $(n=5,220)$}

Beta coefficient $(95 \% \mathrm{Cl})$, Multivariable linear regression Median HH income (units of \$10k): $0.02(0.00,0.04), p<0.05$

$\%$ population $<125 \%$ poverty level: $0.00(-0.01,0.00), p>0.05$

Adjusted for beverage size, sale status, store type,

race/ethnicity, site

\section{Sports drinks No relationship, Statistically non-significant}

Sports drinks $(n=1,931)$

Beta coefficient $(95 \% \mathrm{Cl})$, Multivariable linear regression

Median $\mathrm{HH}$ income (units of $\$ 10 \mathrm{k}): 0.00(-0.03,0.03), \mathrm{p}>0.05$

$\%$ population $<125 \%$ poverty level: $0.00(-0.00,0.01), p>0.05$ Adjusted for beverage size, sale status, store type,

race/ethnicity, site

All sugar-sweetened beverages $(\mathrm{N}=11,767)$

Beta coefficient $(95 \% \mathrm{Cl})$, Multivariable linear regression

Median HH income (units of $\$ 10 \mathrm{k}): 0.02(-0.01,0.04), p>0.05$

$\%$ population $<125 \%$ poverty level: $0.00(-0.01,0.01), p>0.05$

Adjusted for beverage category, beverage size, sale status, store

type, race/ethnicity, site

\begin{tabular}{|c|c|c|c|}
\hline Leone, $2011^{29}$ & $\begin{array}{l}\mathbf{N}=\mathbf{7 3} \\
\text { Analytic } \mathrm{N} \text { is stores } \\
\text { County population was } 239,452 \text {. } \\
\text { Race: White } 66.4 \% \text {, Black } 29.1 \% \text {, } \\
\text { other race } 4.5 \% \\
18.2 \% \text { lived below poverty }\end{array}$ & $\begin{array}{l}\text { Income } \\
\text { - Low } \\
\text { - High }\end{array}$ & $\begin{array}{l}\text { Fruits and } \\
\text { Vegetables }\end{array}$ \\
\hline
\end{tabular}

No relationship, Statistically non-significant

Neighborhood characteristics (including income) were not significantly related to the price of more healthful foods.

Neighborhood characteristics (including income) were not significantly related to the price of whole-wheat bread. 
Characteristics

\section{Milk}

\section{No relationship, Statistically non-significant}

Neighborhood characteristics (including income) were not significantly related to the price of low-fat milk.

\begin{tabular}{ll}
\hline Lopez-Class, & $\mathbf{N}=\mathbf{3 2}$ \\
& Analytic N is stores \\
& Latino and surrounding \\
& neighborhoods in a city located in \\
& East Central New York, on the \\
& Mohawk River. \\
& Population of $\sim 18,000$ with $16 \%$ \\
& Latino, of those $72 \%$ are Puerto- \\
& Rican. City is divided into four \\
& geographic areas: Cork Hill, South \\
& Side, the Projects, and East End
\end{tabular}

Geographic
location
- Latino
neighborhood
- Non-Latino
neighborhood

\section{Apple, medium}

Mean price (SD), range, t-test, $\mathrm{p}=0.038$

Latino neighborhood: \$0.39 (0.07), 0.30-0.49

Non-Latino neighborhood: \$0.28 (0.08), 0.15-0.36
Inverse relationship, Statistically significant

\section{Bread Inverse relationship, Statistically significant \\ High-fiber bread ( $\geq 2 \mathrm{~g}$ per slice), $24 \mathrm{oz}$ Mean price (SD), range, t-test, $\mathrm{p}=0.028$ \\ Latino neighborhood: $\$ 3.89$ (only mean available) \\ Non-Latino neighborhood: \$2.72 (0.94), 1.44-3.84}

Cucumbers

Inverse relationship, Statistically significant

Cucumber, medium

Mean price (SD), range, t-test, $\mathrm{p}=0.041$

Latino neighborhood: \$0.54 (0.05), 0.49-0.59

Non-Latino neighborhood: $\$ 0.39$ (0.09), 0.33-0.49 
Low-fat ( $\leq 1 \%$ milk), quart

Mean price (SD), range, t-test, $p=0.081$

Latino neighborhood: \$1.08 (0.16), 0.95-1.29

Non-Latino neighborhood: \$0.93 (0.09), 0.80-0.99

Low-fat ( $\leq 1 \%$ milk), half gallon

Mean price (SD), range, $p=0.746$

Latino neighborhood: \$1.51 (0.19), 1.09-1.75

Non-Latino neighborhood: \$1.54 (0.20), 1.29-1.99

Low-fat ( $\leq 1 \%$ milk), gallon

Mean price $(S D)$, range, $\mathrm{p}=0.888$

Latino neighborhood: \$2.59 (0.40), 1.99-2.79

Non-Latino neighborhood: \$2.62 (0.31), 2.25-2.99

Oranges

Inverse relationship, Statistically non-significant

Orange, medium

Mean price (SD), range, t-test, $p=0.267$

Latino neighborhood: $\$ 0.54$ (0.18), 0.33-0.75

Non-Latino neighborhood: $\$ 0.43(0.09), 0.32-0.50$

Tomatoes

No relationship, Statistically non-significant

Tomato, medium

Mean price (SD), range, t-test, $\mathrm{p}=0.315$

Latino neighborhood: \$0.33 (0.11), 0.11-0.40

Non-Latino neighborhood: $\$ 0.51$ (0.29), 0.24-0.99 


\section{Rimkus, 2015 ${ }^{31} \quad \mathrm{~N}=8793$}

Analytic $\mathrm{N}=$ food stores across 468 communities spanning 46 states Communities observed were defined

by school enrollment zones for students surveyed as part of the Monitoring the Future study and were nationally representative of where 8th, 10th, and 12th grade public school students reside.
Income

- High (ref)

- Medium

- Low
Milk

Inverse relationship (various), Statistically significant

No relationship, Statistically non-significant

All stores

Ordinary least squares regression, adjusted for: US Census

Division, year of data collection, store type, race, ethnicity, urbanicity

Beta coefficient (SE) of whole milk prices

High income: Reference

Medium income: $0.067(0.043), p>0.05$

Low income: 0.091 (0.042), $p<0.05$

Beta coefficient (SE) of $2 \%$ milk prices High income: Reference

Medium income: 0.064 (0.041), $\mathrm{p}>0.05$

Low income: 0.075 (0.041), $p>0.05$

Beta coefficient (SE) of $1 \%$ milk prices

High income: Reference

Medium income: $-0.017(0.046), p>0.05$

Low income: -0.006 (0.055), $p>0.05$

Beta coefficient (SE) of skim milk prices

High income: Reference

Medium income: $-0.008(0.045), p>0.05$

Low income: -0.0034 (0.047), p>0.05

Supermarkets

Ordinary least squares regression, adjusted for: US Census

Division, year of data collection, race, ethnicity, urbanicity

Beta coefficient (SE) of whole milk prices

High income: Reference

Medium income: $0.091(0.060), p>0.05$

Low income: 0.069 (0.067), p>0.05

Beta coefficient (SE) of $2 \%$ milk prices

High income: Reference

Medium income: 0.067 (0.063), p>0.05

Low income: 0.032 (0.067), $p>0.05$

Beta coefficient (SE) of $1 \%$ milk prices

High income: Reference

Medium income: 0.084 (0.064), p>0.05 
Low income: $0.036(0.067), p>0.05$

Beta coefficient (SE) of skim milk prices

High income: Reference

Medium income: $0.069(0.068), \mathrm{p}>0.05$

Low income: 0.021 (0.070), $p>0.05$

Grocery stores

Ordinary least squares regression, adjusted for: US Census

Division, year of data collection, race, ethnicity, urbanicity

Beta coefficient (SE) of whole milk prices

High income: Reference

Medium income: 0.058 (0.085), $p>0.05$

Low income: 0.117 (0.098), $p>0.05$

Beta coefficient (SE) of $2 \%$ milk prices

High income: Reference

Medium income: 0.073 (0.086), $\mathrm{p}>0.05$

Low income: 0.122 (0.089), $p>0.05$

Beta coefficient (SE) of $1 \%$ milk prices

High income: Reference

Medium income: $0.217(0.101), \mathrm{p}<0.05$

Low income: $0.212(0.106), p<0.05$

Beta coefficient (SE) of skim milk prices

High income: Reference

Medium income: $0.210(0.108), p>0.05$

Low income: 0.153 (0.111), $p>0.05$

Limited-service stores

Ordinary least squares regression, adjusted for: US Census

Division, year of data collection, race, ethnicity, urbanicity

Beta coefficient (SE) of whole milk prices

High income: Reference

Medium income: 0.064 (0.045), $\mathrm{p}>0.05$

Low income: $0.092(0.041), p<0.05$

Beta coefficient (SE) of $2 \%$ milk prices

High income: Reference

Medium income: $0.061(0.044), p>0.05$

Low income: $0.079(0.043), p>0.05$ 
Beta coefficient (SE) of skim milk prices High income: Reference

Medium income: -0.060 (0.046), $\mathrm{p}>0.05$

Low income: -0.075 (0.050), p>0.05

\begin{tabular}{ll}
\hline Smith, 20132 & $\mathbf{N}=\mathbf{2 8}$ \\
& Analytic $\mathrm{N}=28$ convenience stores \\
from 2 neighborhoods in Bexar \\
County, TX. \\
ZIP A and ZIP B has the highest and \\
lowest city-levels of adults clinically
\end{tabular}

Geographic

location

- Lower income

- Higher income

owest city-levels of adults clinically

diagnosed with diabetes.
No relationship, Statistically non-significant

Apples $\quad$ No relationshipe of apples

Mean (SD), t-test, $p=0.818$

ZIP A (lower income, $\mathrm{n}=5)$ : $\$ 1.12(0.94)$

ZIP B (higher income, $n=5): \$ 1.24(0.53)$

\section{Bananas Direct relationship, Statistically significant}

Price of bananas

Mean (SD), t-test, $\mathrm{p}=0.015$

ZIP A (lower income, $n=5): \$ 0.43(0.15)$

ZIP B (higher income, $\mathrm{n}=6): \$ 1.13(0.43)$

Direct relationship (White bread), Statistically significant No relationship (Whole grain bread), Statistically nonsignificant

Price of whole grain bread

Mean (SD), t-test, $p=0.203$

ZIP A (lower income, $n=3): \$ 2.01(0.77)$

ZIP B (higher income, $\mathrm{n}=7$ ): \$2.83 (0.17)

Price of white bread

Mean (SD), t-test, $p=0.001$

ZIP A $(n=15): \$ 2.06(0.39)$

ZIP B $(n=8): \$ 2.65(0.32)$

Direct relationship, Statistically significant

Broccoli

Price of broccoli

Mean (SD), t-test, $p<0.001$

ZIP A (lower income, $n=1)$ : $\$ 0.07(0.30)$

ZIP B (higher income, $\mathrm{n}=1)$ : $\$ 2.99(0.00)$ 
Price of baked potato chips

Mean (SD), t-test, $p=N R$

ZIP A (lower income, $n=3)$ : $\$ 0.99(0.00)$

ZIP B (higher income, $\mathrm{n}=8$ ): $\$ 0.99(0.00)$

Price of regular potato chips

Mean (SD), t-test, $p=0.868$

ZIP A $(n=18): \$ 2.22(1.43)$

ZIP B $(n=9): \$ 2.32(1.58)$

Cucumbers

Direct relationship, Statistically significant

Price of cucumbers

Mean (SD), t-test, $p<0.001$

ZIP A (lower income, $n=3): \$ 0.14(0.34)$

ZIP B (higher income, $\mathrm{n}=1)$ : $\$ 2.99(0.00)$

Price of $100 \%$ juice (no sugar added; $15.2 \mathrm{oz}$ )

Mean (SD), t-test, $p=0.071$

ZIP A (lower income, $n=13): \$ 1.66(0.19)$

ZIP B (higher income, $\mathrm{n}=7$ ): $\$ 2.00(0.58)$

Price of juice drink (sugar added: $15.2 \mathrm{oz}$ )

Mean (SD), t-test, $p=0.487$

ZIP A $(n=6): \$ 1.55(0.15)$

ZIP B $(n=5): \$ 1.63(0.23)$

Melons No relationship, Statistically non-significant

Price of watermelon

Mean (SD), t-test, $p=0.873$

ZIP A (lower income, $n=2)$ : \$1.99 (0.00)

ZIP B (higher income, $n=5)$ : $\$ 2.19(1.09)$ 
Price of milk: low fat, skim, or $1 \%$ (half gallon)

Mean (SD), t-test, $p=0.130$

ZIP A (lower income, $n=2)$ : \$3.19 (0.28)

ZIP B (higher income, $n=1): \$ 2.29(0.42)$

Price of milk: $2 \%$ (half gallon)

Mean (SD), t-test, $p=0.852$

ZIP A $(n=5): \$ 3.29(0.27)$

ZIP B $(n=8): \$ 3.14(1.30)$

Price of oranges

Mean (SD), t-test, $p=0.018$

ZIP A (lower income, $n=3): \$ 0.45(0.09)$

ZIP B (higher income, $n=4): \$ 0.90(0.21)$

Direct relationship (diet cola), Statistically significant

No relationship (regular cola), Statistically non-significant

Price of diet cola (20 oz)

Mean (SD), t-test, $p=0.044$

ZIP A (lower income, $n=19): \$ 1.35(0.13)$

ZIP B (higher income, $\mathrm{n}=9)$ : $\$ 1.45(0.05)$

Price of regular cola $(20 \mathrm{oz})$

Mean (SD), t-test, $\mathrm{p}=0.060$

ZIP A $(n=19): \$ 1.37(0.11)$

ZIP B $(\mathrm{n}=9): \$ 1.45(0.05)$

Price of tomatoes

Mean (SD), t-test, $p=0.010$

ZIP A (lower income, $\mathrm{n}=7$ ): $\$ 0.18(0.27)$

ZIP B (higher income, $\mathrm{n}=1$ ): $\$ 0.99(0.00)$ 


\begin{tabular}{ll} 
Article & $\begin{array}{l}\text { Study and Participant } \\
\text { Characteristics }\end{array}$ \\
\hline Stewart, 201133 & $\mathrm{N}=7143$ \\
$\mathrm{~N}$ is households who participated in \\
the Nielsen-run panel for all 12 \\
months of 2006 \\
Nielsen provides a sample weight to \\
be nationally representative \\
Mean household income: $\$ 27,000 ;$ \\
Mean age: 54.9 y; Mean household \\
size: 2.32 people; Black: $13 \%$, \\
Hispanic
\end{tabular}

Intervention

Income

continuous

months of 2006

size: 2.32 people; Black: 13\%,

Hispanic

\begin{tabular}{|c|c|c|c|c|}
\hline & & & Vegetables & $\begin{array}{l}\text { Direct relationship, Statistically significant } \\
\text { Fresh vegetables } \\
\text { Coefficient (SE), } R^{\wedge} 2=0.14 \\
\text { Household income: } 0.0293(0.0372), p<0.01 \\
\text { Household income squared: }-0.0019(0.0004), p<0.01 \\
\text { Poverty principal component: }-0.0009(0.0011), p>0.1 \\
\text { Adjusted for household size, age, education, household includes } \\
\text { child, homemaker in household, race/ethnicity, urbanicity, } \\
\text { poverty, residential community, racial composition of community, } \\
\text { geographic region (east, south, west) }\end{array}$ \\
\hline Talukdar, 2008 & $\begin{array}{l}\mathbf{N}=\mathbf{1 1 5} \\
\text { Analytic } \mathrm{N}=115 \text { stores from } 17 \text { of } \\
\text { the } 27 \text { zip codes in of Buffalo city } \\
\text { and immediate surrounding suburbs. } \\
\text { Homes with } \geq \text { Bachelor's degree: } \\
\text { Richest zip codes: } 28.0 \% \\
\text { Medium zip codes: } 27.1 \% \\
\text { Poorest zip codes: } 11.6 \%\end{array}$ & $\begin{array}{l}\text { Geographic } \\
\text { location } \\
\text { - Richest zip } \\
\text { codes (ref) } \\
\text { - Medium zip } \\
\text { codes } \\
\text { - Poorest zip } \\
\text { codes }\end{array}$ & $\begin{array}{l}\text { Branded } \\
\text { foods }\end{array}$ & $\begin{array}{l}\text { Inverse relationship (Richest vs. Poorest), Statistically } \\
\text { significant } \\
\text { Relative price index, regression model (adjusted for store type, } \\
\text { and distance to competitive environment), Adj } R^{\wedge} 2=0.78 \\
\text { Estimates (SE) } \\
\text { Richest: Reference } \\
\text { Medium: } 0.006(0.008), p>0.1 \\
\text { Poorest: } 0.019(0.008), p<0.05\end{array}$ \\
\hline & & & $\begin{array}{l}\text { Non-branded } \\
\text { foods }\end{array}$ & $\begin{array}{l}\text { No relationship, Statistically non-significant } \\
\text { Relative price index, regression model (adjusted for store type, } \\
\text { and distance to competitive environment), Adj } R^{\wedge} 2=0.75 \\
\text { Estimates (SE) } \\
\text { Richest: Reference } \\
\text { Medium: } 0.006(0.009), p>0.1 \\
\text { Poorest: } 0.008(0.014), p>0.1\end{array}$ \\
\hline
\end{tabular}

\section{Outcome(s) Results}

\section{Salty Snacks \\ Direct relationship, Statistically significant}

Salty snacks

Coefficient (SE), $R^{\wedge} 2=0.05$

Household income: 0.005 (0.0015), $\mathrm{p}<0.01$

Household income squared: -0.0003 (0.0002), $p>0.1$

Poverty principal component: 0.0005 (0.0004), $p>0.1$

Adjusted for household size, age, education, household includes

child, homemaker in household, race/ethnicity, urbanicity,

poverty, residential community, racial composition of community,

geographic region (east, south, west)

Direct relationship, Statistically significant

Fresh vegetables

fficient (SE), $R^{\wedge} 2=0.14$

coverty, residential community, racial composition of community,

Poorest: $0.008(0.014), p>0.1$ 


\section{Article Study and Participant Characteristics \\ Winkler, 201935 \\ $\mathrm{N}=140$}

Analytic $\mathrm{N}=$ stores

Small and non-traditional food stores

were randomly selected from lists of

icensed grocery retailers in both

cities. Of 157 eligible stores, 140

agreed to participate

\section{Intervention Outcome(s) Results}

\section{SES proxy}

- Lowest income

- Middle income

- Highest income

\section{Apples}

\section{No relationship, Statistically non-significant}

Price of Apples (\$/item)

Multivariate regression, adjusted for corporate status

Adjusted Mean $(95 \% \mathrm{Cl}), \mathrm{N}=56, \mathrm{p}>0.05$

POC dominant (Lowest income): $\$ 0.83(0.67,1.00)$

Racially mixed (Middle income): $\$ 0.84(0.75,0.93)$

White dominant (Highest income): $\$ 0.92(0.83,1.01)$

Bananas
Price of Bananas (\$/item)

Multivariate regression, adjusted for corporate status Adjusted Mean $(95 \% \mathrm{Cl}), \mathrm{N}=64, \mathrm{p}>0.05$

POC dominant (Lowest income): $\$ 0.52(0.44,0.61)$

Racially mixed (Middle income): $\$ 0.45(0.41,0.49)$

White dominant (Highest income): $\$ 0.51(0.46,0.55$

Lettuce

No relationship, Statistically non-significant

Price of Lettuce (\$/item)

Multivariate regression, adjusted for corporate status

Adjusted Mean (95\% Cl), N=15, p>0.05

POC dominant (Lowest income): $\$ 3.21(1.47,4.94)$

Racially mixed (Middle income): \$3.37 (2.48, 4.27)

White dominant (Highest income): \$3.31 (2.71, 3.90)

Onions

\section{No relationship, Statistically non-significant}

Price of Onions (\$/item)

Multivariate regression, adjusted for corporate status

Adjusted Mean $(95 \% \mathrm{Cl}), \mathrm{N}=25, \mathrm{p}>0.05$

POC dominant (Lowest income): $\$ 0.68(0.13,1.22)$

Racially mixed (Middle income): $\$ 0.70(0.41,0.99)$

White dominant (Highest income): $\$ 0.67(0.38,0.96)$

Price of Oranges (\$/item)

Multivariate regression, adjusted for corporate status Adjusted Mean (95\% Cl), N=47, p>0.05

POC dominant (Lowest income): $\$ 1.25(1.00,1.52)$

Racially mixed (Middle income): $\$ 0.84(0.67,1.01)$

White dominant (Highest income): $\$ 0.94(0.76,1.11)$ 
Price of Tomatoes (\$/item)

Multivariate regression, adjusted for corporate status

Adjusted Mean $(95 \% \mathrm{Cl}), \mathrm{N}=18, \mathrm{p}>0.05$

POC dominant (Lowest income): $\$ 0.79(0.00,1.60)$

Racially mixed (Middle income): $\$ 1.30(0.68,1.93)$

White dominant (Highest income): $\$ 1.06(0.52,1.60)$

Zenk, 2014 ${ }^{36}$

$\mathrm{N}=364$

Income

Fruit

No relationship, Statistically non-significant

Analytic N $=364$ WIC vendors in 7 seven northern Illinois counties (DeKalb, DuPage, Kane, Lee, Ogle,

Winnebago, west suburban Cook

[not including Chicago]).

Data were collected annually from

each vendor. Analysis included all

WIC vendors authorized in 20

Fresh fruit

racial/ethnicity), Adj $R^{\wedge} 2=0.25$

Coefficient (SE)

$\mathrm{p}=0.96$
Multivariate regression, adjusted for vendor type, year of data collection, seasonality, population density, \% other

Neighborhood median HH income (1000s): <-0.01 (0.02),

Canned fruit

Multivariate regression, adjusted for vendor type, year of data

collection, seasonality, population density, \% other

racial/ethnicity), Adj $R^{\wedge} 2=0.17$

Coefficient (SE)

Neighborhood median $\mathrm{HH}$ income (1000s): 0.01 (0.02), $\mathrm{p}=0.36$

Frozen fruit

Multivariate regression, adjusted for vendor type, year of data

collection, seasonality, population density, \% other

racial/ethnicity), Adj $\mathrm{R}^{\wedge} 2=0.29$

Coefficient (SE)

Neighborhood median $\mathrm{HH}$ income (1000s): 0.02 (0.02), $\mathrm{p}=0.17$ 


\section{Fresh vegetables}

Multivariate regression, adjusted for vendor type, year of data

collection, seasonality, population density, \% other

racial/ethnicity), Adj $R^{\wedge} 2=0.35$

Coefficient (SE)

Neighborhood median $\mathrm{HH}$ income (1000s): -0.02 (0.01), $\mathrm{p}=0.19$

\section{Canned vegetables}

Multivariate regression, adjusted for vendor type, year of data

collection, seasonality, population density, \% other

racial/ethnicity), Adj $R^{\wedge} 2=0.61$

Coefficient (SE)

Neighborhood median HH income (1000s): 0.03 (0.01), $p=0.002$

Frozen vegetables

Multivariate regression, adjusted for vendor type, year of data

collection, seasonality, population density, \% other

$\mathrm{racial} /$ ethnicity), Adj $\mathrm{R}^{\wedge} 2=0.26$

Coefficient (SE)

Neighborhood median $\mathrm{HH}$ income (1000s): 0.02 (0.01), $\mathrm{p}=0.14$

${ }^{a}$ Abbreviations: ANOVA: Analysis of Variance; CSFII: USDA Continuing Survey of Food Intakes by Individuals; CX3: Communities of Excellence in Nutrition, Physical Activity and Obesity Prevention Project; DGA: Dietary Guidelines for Americans; F\&V: Fruits and vegetables; FV-PI: Fruits and Vegetables Price Index; g: gram; gal: gallon; GEE: general estimation equation; HH: household; IQR: interquartile range; Ib: pound; Ln: natural log; N: sample size; n/a: not applicable; NR: Not reported; NS: Statistically non-significant; ONQI: overall nutrition quality index; Oz: ounce; pc: piece; PIR: Poverty Income Ratio; POC: person of color; SD: standard deviation; SE: standard error; SEM: standard error of the mean; SES: Socioeconomic status; TFP: Thrifty Food Plan; USDA: United States Department of Agriculture; WIC: Special Supplemental Nutrition Program for Women, Infants, and Children; y: year 
Table 1-c. Risk of bias for observational studies examining income and food price ${ }^{a}$

\begin{tabular}{|c|c|c|c|c|c|c|c|}
\hline Article & Confounding & $\begin{array}{l}\text { Selection of } \\
\text { participants }\end{array}$ & $\begin{array}{l}\text { Classification } \\
\text { of exposures }\end{array}$ & $\begin{array}{l}\text { Deviations from } \\
\text { intended } \\
\text { exposures }\end{array}$ & Missing data & $\begin{array}{c}\text { Outcome } \\
\text { measurement }\end{array}$ & $\begin{array}{c}\text { Selection of } \\
\text { the } \\
\text { reported } \\
\text { result }\end{array}$ \\
\hline Akbay, $2005^{1}$ & SERIOUS & NO INFORMATION & SERIOUS & LOW & NO INFORMATION & LOW & MODERATE \\
\hline Andreyeva, $2008^{2}$ & SERIOUS & LOW & SERIOUS & MODERATE & LOW & LOW & MODERATE \\
\hline Ard, $2010^{3}$ & MODERATE & LOW & SERIOUS & MODERATE & LOW & LOW & MODERATE \\
\hline Beydoun, $2008^{5}$ & SERIOUS & MODERATE & LOW & LOW & LOW & MODERATE & SERIOUS \\
\hline Beydoun, $2011^{4}$ & SERIOUS & MODERATE & LOW & LOW & LOW & MODERATE & SERIOUS \\
\hline Block, $2006^{6}$ & SERIOUS & LOW & SERIOUS & LOW & MODERATE & LOW & MODERATE \\
\hline Borja, $2019^{7}$ & SERIOUS & LOW & SERIOUS & MODERATE & LOW & LOW & MODERATE \\
\hline Broda, $2009^{8}$ & MODERATE & LOW & LOW & LOW & NO INFORMATION & MODERATE & MODERATE \\
\hline Cassady, $2007^{9}$ & SERIOUS & LOW & SERIOUS & LOW & LOW & LOW & SERIOUS \\
\hline Chang, $2011^{10}$ & SERIOUS & LOW & SERIOUS & LOW & LOW & LOW & MODERATE \\
\hline Chung, $1999^{11}$ & SERIOUS & LOW & SERIOUS & LOW & LOW & LOW & MODERATE \\
\hline Colabianchi, $2021^{37}$ & MODERATE & LOW & SERIOUS & SERIOUS & LOW & LOW & MODERATE \\
\hline Cole, $2010^{12}$ & SERIOUS & LOW & CRITICAL & LOW & SERIOUS & LOW & CRITICAL \\
\hline Daepp, $2015^{13}$ & SERIOUS & NO INFORMATION & SERIOUS & LOW & SERIOUS & LOW & SERIOUS \\
\hline
\end{tabular}




\begin{tabular}{|c|c|c|c|c|c|c|c|}
\hline Article & Confounding & $\begin{array}{l}\text { Selection of } \\
\text { participants }\end{array}$ & $\begin{array}{l}\text { Classification } \\
\text { of exposures }\end{array}$ & $\begin{array}{l}\text { Deviations from } \\
\text { intended } \\
\text { exposures }\end{array}$ & Missing data & $\begin{array}{c}\text { Outcome } \\
\text { measurement }\end{array}$ & $\begin{array}{c}\text { Selection of } \\
\text { the } \\
\text { reported } \\
\text { result }\end{array}$ \\
\hline Davis, $2005^{14}$ & SERIOUS & LOW & LOW & NO INFORMATION & NO INFORMATION & LOW & MODERATE \\
\hline DeWeese, $2017^{15}$ & SERIOUS & LOW & SERIOUS & LOW & SERIOUS & LOW & MODERATE \\
\hline Dunn, $2011^{16}$ & MODERATE & LOW & SERIOUS & LOW & MODERATE & LOW & MODERATE \\
\hline French, $2010^{17}$ & SERIOUS & LOW & MODERATE & LOW & LOW & MODERATE & MODERATE \\
\hline Gillespie, $2015^{18}$ & MODERATE & LOW & SERIOUS & LOW & LOW & LOW & SERIOUS \\
\hline Gosliner, $2018^{19}$ & SERIOUS & SERIOUS & CRITICAL & LOW & MODERATE & MODERATE & MODERATE \\
\hline Hardin-Fanning, $2015^{20}$ & SERIOUS & LOW & SERIOUS & LOW & LOW & LOW & SERIOUS \\
\hline Hardin-Fanning, $2017^{21}$ & SERIOUS & LOW & CRITICAL & SERIOUS & LOW & LOW & MODERATE \\
\hline Hatzenbuehler, $2012^{22}$ & MODERATE & LOW & SERIOUS & Low & MODERATE & Low & MODERATE \\
\hline Hayes, $2000^{23}$ & SERIOUS & LOW & SERIOUS & LOW & MODERATE & LOW & MODERATE \\
\hline Jetter, $2006^{24}$ & SERIOUS & LOW & SERIOUS & MODERATE & LOW & LOW & MODERATE \\
\hline Jewell, $2019^{25}$ & MODERATE & LOW & SERIOUS & LOW & SERIOUS & LOW & SERIOUS \\
\hline Kern, $2016^{26}$ & MODERATE & LOW & SERIOUS & LOW & LOW & LOW & SERIOUS \\
\hline Kern, $2017^{27}$ & MODERATE & Low & SERIOUS & Low & Low & Low & SERIOUS \\
\hline Leider, $2019^{28}$ & MODERATE & LOW & SERIOUS & LOW & MODERATE & LOW & SERIOUS \\
\hline
\end{tabular}




\begin{tabular}{llcccc} 
Article & Confounding & $\begin{array}{c}\text { Selection of } \\
\text { participants }\end{array}$ & $\begin{array}{c}\text { Classification } \\
\text { of exposures }\end{array}$ & $\begin{array}{c}\text { Deviations from } \\
\text { intended } \\
\text { exposures }\end{array}$ & $\begin{array}{c}\text { Missing data } \\
\text { Outcome } \\
\text { measurement }\end{array}$ \\
\hline Leone, $2011^{29}$ & SERIOUS & LOW & SERIOUS & MODERATE & SERIOUS \\
result
\end{tabular}

a Possible ratings of low, moderate, serious, critical, or no information determined using the "Risk of Bias for Nutrition Observational Studies" tool (RoB-NObs) (Dietary Guidelines Advisory Committee. 2020. Scientific Report of the 2020 Dietary Guidelines Advisory Committee: Advisory Report to the Secretary of Agriculture and the Secretary of Health and Human Services. U.S. Department of Agriculture, Agricultural Research Service, Washington, DC.) 


\section{References of the articles included in the income and price of food rapid review}

Akbay, C, Jones, E. Food consumption behavior of socioeconomic groups for private labels and national brands. Food Quality and Preference. 2005;16(7):621-631.doi. <Go to ISI>:/WOS:000231006600006.

Connecticut. Health Aff (Millwood). 2008;27(5):1381-1388.doi: 10.1377/hlthaff.27.5.1381.

3. Ard, J D, Perumean C, et al. Fruit and vegetable pricing by demographic factors in the Birmingham, Alabama, metropolitan area, 2004-2005. Prev Chronic Dis. 2010;7(4):A78.doi.

4. Beydoun, M A, Powell, et al. Food prices are associated with dietary quality, fast food consumption, and body mass index among U.S. children and adolescents. J Nutr. 2011;141(2):304-311.doi: 10.3945/jn.110.132613. Epub 2010 Dec 22.

5. Beydoun, M A, Powell, L M, Wang, Y. The association of fast food, fruit and vegetable prices with dietary intakes among US adults: is there modification by family income? Soc Sci Med. 2008;66(11):2218-2229.doi: 10.1016/j.socscimed.2008.01.018. Epub 2008 Mar 3.

6. Block, D, Kouba, J. A comparison of the availability and affordability of a market basket in two communities in the Chicago area. Public Health Nutr. 2006;9(7):837-845.doi: 10.1017/phn2005924.

7. Borja, K, Dieringer, S. Availability of affordable healthy food in Hillsborough County, Florida. Journal of Public Affairs. 2019;19(3).doi. <Go to ISI>:/WOS:000481524400018.

8. Broda, C, Leibtag, E, Weinstein, D E. The role of prices in measuring the poor's living standard. Journal of Economic Perspectives. 2009;23(2):77-97.doi.

9. Cassady, D, Jetter, K M, Culp, J. Is price a barrier to eating more fruits and vegetables for low-income families? J Am Diet Assoc. 2007;107(11):1909-1915.doi: 10.1016/j.jada.2007.08.015. Epub 2007 Oct 18.

10. Chang, $\mathrm{C} \mathrm{H}$, Hooker, et al. Organic and Conventional Milk Purchase Behaviors in Central Ohio. Agribusiness. 2011;27(3):311326.doi. <Go to ISI>://WOS:000293083500004.

11. Chung, Chanjin, Myers, Jr Samuel L. Do the Poor Pay More for Food? An Analysis of Grocery Store Availability and Food Price Disparities. Journal of Consumer Affairs. 1999;33(2):276.doi.

http://ezproxyhhs.nihlibrary.nih.gov/login?url=http://search.ebscohost.com/login.aspx?direct=true\&db=buh\&AN=2440351\&site $=$ ehost-live\&scope=site.

12. Cole, Shaun, Filomena, Susan, Morland, Kimberly. Analysis of Fruit and Vegetable Cost and Quality Among Racially Segregated Neighborhoods in Brooklyn, New York. Journal of Hunger \& Environmental Nutrition. 2010;5(2):202-215.doi.

13. Daepp, M. Prices and availability of healthy foods across St. Louis. American Economist. 2015;60(2):209-224.doi.

14. Davis, David E, Leibtag, Ephraim S. INTERSTATE VARIATION IN WIC FOOD PACKAGE COSTS: THE ROLE OF FOOD PRICES, CASELOAD COMPOSITION, AND COST-CONTAINMENT PRACTICES. 2005:37.doi.

15. DeWeese, R S, Ohri V, P. Cost of Children's Healthy vs. Unhealthy Snacks Does Not Differ at Convenience Stores. J Nutr Educ Behav. 2017;49(3):241-243.e241.doi: 10.1016/j.jneb.2016.11.006. Epub 2017 Jan 7.

16. Dunn, R A, Sharkey, et al. Socio-economic status, racial composition and the affordability of fresh fruits and vegetables in neighborhoods of a large rural region in Texas. Nutr J. 2011;10:6.doi: 10.1186/1475-2891-10-6.

17. French, S A, Wall, M, Mitchell, N R. Household income differences in food sources and food items purchased. Int J Behav Nutr Phys Act. 2010;7:77.doi: 10.1186/1479-5868-7-77.

18. Gillespie, Jeffrey, Hatzenbuehler, et al. The Impact of Neighborhood Income on the Cost of Energy-Dense and Nutrient-Dense Foods in Supermarkets. 2015;46(3):23.doi.

19. Gosliner, W, Brown, et al. Availability, quality and price of produce in low-income neighbourhood food stores in California raise equity issues. Public Health Nutr. 2018;21(9):1639-1648.doi: 10.1017/S1368980018000058. Epub 2018 Mar 15.

20. Hardin-Fanning, F, Rayens, M K. Food cost disparities in rural communities. Health Promot Pract. 2015;16(3):383-391.doi: 10.1177/1524839914554454. Epub 2014 Oct 10.

21. Hardin-Fanning, F, Wiggins, A T. Food Costs Are Higher in Counties With Poor Health Rankings. J Cardiovasc Nurs. 2017;32(2):93-98.doi: 10.1097/JCN.0000000000000329.

22. Hatzenbuehler, P, Gillespie, J, O'Neil, C. Does healthy food cost more in poor neighborhoods? An analysis of retail food cost and spatial competition. Agricultural and Resource Economics Review. 2012;41(1):43-56.doi.

23. Hayes, Lashawn R. Are Prices Higher for the Poor in New York City? Journal of Consumer Policy. 2000;23(2):127-152.doi. http://ezproxyhhs.nihlibrary.nih.gov/login?url=http://search.ebscohost.com/login.aspx?direct=true\&db=buh\&AN=3576727\&site $=$ ehost-live\&scope $=$ site.

24. Jetter, Karen M, Crespi, John M, Cassady, Diana. The Effects of the Spatial Distribution of Grocery Stores on Food Prices on Low Income Neighborhoods. 2006:18.doi.

25. Jewell, M P, Lai, et al. Higher pricing of fresh produce is more likely in SNAP-Ed eligible neighborhoods when adjacent nonprogram eligible neighborhoods are mixed income. Prev Med Rep. 2019;14:100817.doi: 10.1016/j.pmedr.2019.01.021. eCollection 2019 Jun.

26. Kern, D M, Auchincloss, et al. Neighbourhood variation in the price of soda relative to milk and its association with neighbourhood socio-economic status and race. Public Health Nutr. 2016;19(18):3386-3396.doi: 10.1017/S1368980016001579. Epub 2016 Jun 30. 
27. Kern, D M, Auchincloss, et al. Healthy and Unhealthy Food Prices across Neighborhoods and Their Association with Neighborhood Socioeconomic Status and Proportion Black/Hispanic. J Urban Health. 2017;94(4):494-505.doi: 10.1007/s11524-017-0168-8.

28. Leider, J, Powell, L M. Sugar-sweetened beverage prices: Variations by beverage, food store, and neighborhood characteristics, 2017. Prev Med Rep. 2019;15:100883.doi: 10.1016/j.pmedr.2019.100883. eCollection 2019 Sep.

29. Leone, A F, Rigby, et al. Leone et al. Store type and demographic influence on the availability and price of healthful foods, Leon County, Florida, 2008. . 8 (6), A140. Prev Chronic Dis. 2011;8(6):A140.doi.

30. Lopez-Class, M, Hosler, A S. Assessment of community food resources: A Latino neighborhood study in upstate New York. J Poverty. 2010;14(4):369-381.doi: 10.1080/10875549.2010.517070.

31. Rimkus, L, Isgor, et al. Disparities in the Availability and Price of Low-Fat and Higher-Fat Milk in US Food Stores by Community Characteristics. J Acad Nutr Diet. 2015;115(12):1975-1985.doi: 10.1016/j.jand.2015.04.002. Epub 2015 Jun 2.

32. Smith, M L, Sunil, et al. Disparities of food availability and affordability within convenience stores in Bexar County, Texas. J Environ Public Health. 2013;2013:782756.doi: 10.1155/2013/782756. Epub 2013 Jul 1.

33. Stewart, H, Dong, D S. Variation in retail costs for fresh vegetables and salty snacks across communities in the United States. Food Policy. 2011;36(2):128-135.doi. <Go to ISI>://WOS:000289340500004.

34. Talukdar, Debabrata. Cost of Being Poor: Retail Price and Consumer Price Search Differences across Inner-City and Suburban Neighborhoods. Journal of Consumer Research. 2008;35(3):457-471.doi.

35. Winkler, M R, Lenk, et al. Variation in the food environment of small and non-traditional stores across racial segregation and corporate status. Public Health Nutr. 2019;22(9):1624-1634.doi: 10.1017/S1368980019000132. Epub 2019 Mar 8.

36. Zenk, S N, Powell, et al. Impact of the revised Special Supplemental Nutrition Program for Women, Infants, and Children (WIC) food package policy on fruit and vegetable prices. J Acad Nutr Diet. 2014;114(2):288-296.doi: 10.1016/j.jand.2013.08.003. Epub 2013 Oct 30.

37. Colabianchi, N, Antonakos, et al. The role of the built environment, food prices and neighborhood poverty in fruit and vegetable consumption: An instrumental variable analysis of the moving to opportunity experiment. Health Place. 2021;67:102491.doi: 10.1016/j.healthplace.2020.102491. Epub 2020 Dec 18. 


\section{Chapter 2 - What is the relationship between income or Federal Assistance participation/eligibility and following a dietary pattern that aligns with the Dietary Guidelines for Americans, as measured by the Healthy Eating Index (HEI)?}

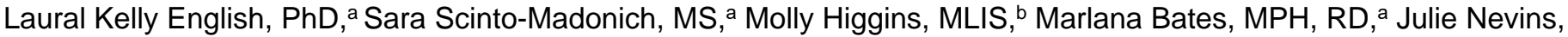
$\mathrm{PhD},{ }^{\text {a }}$ Julia H Kim, PhD, MPH, RD, ${ }^{a}$ Emily Callahan, $\mathrm{MS}^{\mathrm{c}}$

\section{Specific methods to conduct this rapid review}

\section{Develop a protocol}

The research question, "What is the relationship between income and HEl?", was answered using a rapid review that was informed by an evidence scan.

The analytic framework for the rapid review examining the relationship between income and following a dietary pattern that aligns with the Dietary Guidelines for Americans, as measured by the Healthy Eating Index (HEI), is presented in Figure 2-a. This analytic framework visually represents the overall scope of the rapid review question and depicts the contributing elements that were examined and evaluated. The intervention or exposure of interest is income or Federal assistance participation/eligibility in Americans. The comparators are different levels or categories of income or participation/eligibility status. The outcomes are HEI scores in Americans. The key confounders are urban versus rural settings, cultural/racial diversity or disparities, sex, age, food security status. The other factors to be considered are cultural food choices, neighborhood characteristics (e.g., access to food/distance to stores/access to car/type of store), smoking, weight status, chronic disease status, convenience level, and processing level. The confounders and other factors to be considered may impact the relationships of interest.

An evidence scan was conducted before the rapid review, and it included additional intervention/exposures of income proxies including socioeconomic status (SES) factors such as education, marital status, or household assets, food security status, and geographical areas. Based on the evidence scan, the intervention/exposure for the rapid review was narrowed to include only income or Federal assistance participation/eligibility in Americans to produce the strongest body of evidence that would be of most utility for the Thrifty Food Plan, 2021. The evidence scan also included outcomes of either consumption or purchasing of dietary patterns, diet diversity, and other diet quality indicators/scores as the outcomes, regardless of approach or measure used to study the dietary pattern. The outcome for the rapid review was narrowed to include only HEI scores based on consumption as these were by far the most common outcome studied across the evidence scan and the NEAT staff recognized that additional information would not be useful for the Thrifty Food Plan, 2012 by the inclusion of other types of dietary patterns that were not in direct alignment with the Dietary Guidelines for Americans. Comparisons of Federal assistance benefits between states were considered in the scan, but excluded from the rapid review for lack of applicability to the entire U.S. population. Similarly, comparisons of temporality within receipt month of Federal assistance benefits (e.g., 15 days past receipt v. 30 days past receipt) were

\footnotetext{
a Analyst, NESR team; Panum Group, under contract with the FNS, USDA

b Librarian, NESR team; Panum Group, under contract with the FNS, USDA

c Project Lead, NESR team, NGAD, CNPP, FNS, USDA
} 


\section{USDA United States \\ Department of \\ Agriculture}

Income and $\mathrm{HEI}$

considered in the scan, but excluded from the rapid review for lack of directness to the intended exposure of income. 
Figure 2-a. Analytic Framework for the rapid review on income and HEI

\section{Intervention[s]/exposure[s] \\ vs Comparator[s]}

Income (e.g., household, city, regional income) or Federal assistance program participation/eligibility

Population: U.S. households or populations
Different levels/categories of income or participation/eligibility

\section{Outcome[s]}

Dietary pattern that aligns with the Dietary Guidelines for Americans, as measured by the Healthy Eating Index (HEl)

Population: U.S. households or populations

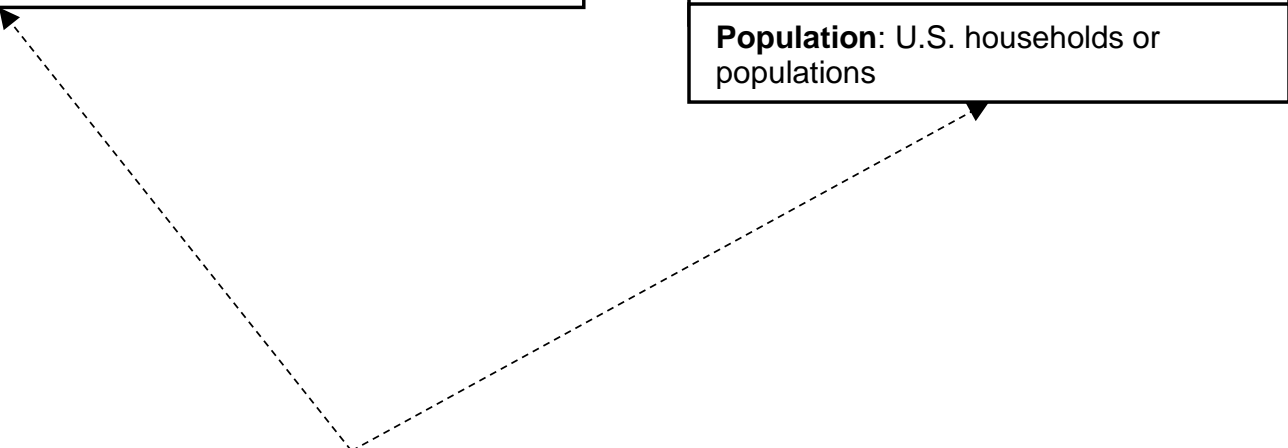

Key confounders: Urban vs. Rural; Cultural/racial diversity or disparities; Sex; Age; Food security status

Other factors to be considered: Cultural food choices; Neighborhood characteristics (e.g., access to food/distance to stores/access to car/type of store); Smoking; Weight status; Chronic disease status; Convenience level; Processing level

\section{Key definitions}

Low income: before-tax income at or below 130 percent of the U.S. poverty guidelines Higher income: before-tax income above 130 percent of the U.S. poverty guidelines Dietary pattern: The quantities, proportions, variety, or combination of different foods, drinks, and nutrients (when available) in diets, and the frequency with which they are habitually consumed.

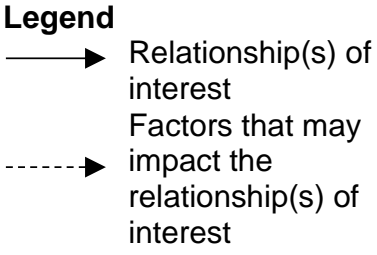




\section{Search for and select studies}

The following outlines any departures from the search and select studies project methods for this specific rapid review:

- $80 \%$ of all records were single-screened at title, abstract, and full-text levels and $20 \%$ of all records were dual-screened, independently at each of these levels.

NESR analysts worked jointly with NEAT staff to establish the final inclusion and exclusion criteria and literature search strategy, which are detailed in Table 2-a and Appendix 2-a, respectively.

Table 2-a. Inclusion and exclusion criteria for the rapid review on income and HEI

$\begin{array}{lll}\text { Category Inclusion Criteria } & \text { Exclusion Criteria }\end{array}$

\begin{tabular}{|c|c|c|}
\hline Study design & $\begin{array}{l}\text { - Any study design that is not a narrative review, } \\
\text { systematic review, or meta-analysis }\end{array}$ & $\begin{array}{ll}\text { - } & \text { Narrative reviews } \\
\text { - } & \text { Systematic reviews } \\
\text { - } & \text { Meta-analyses }\end{array}$ \\
\hline $\begin{array}{l}\text { Intervention/ } \\
\text { exposure }\end{array}$ & $\begin{array}{l}\text { - Income (e.g., household, city, regional income) } \\
\text { - Income-based Federal assistance program } \\
\text { participation/eligibility }\end{array}$ & - Other proxies used for income \\
\hline Comparator & $\begin{array}{l}\text { - Different levels or categories of income } \\
\text { - Different participation/eligibility status in income- } \\
\text { based Federal assistance program(s) }\end{array}$ & $\begin{array}{l}\text { - Comparison of geographic areas without a proxy } \\
\text { for income }\end{array}$ \\
\hline Outcomes & $\begin{array}{l}\text { - } \quad \text { Dietary patterns that specifically align with the } \\
\text { Dietary Guidelines for Americans, as measured by } \\
\text { the total Healthy Eating Index (HEI) } \\
\text { - All versions or variations of HEI (e.g. HEI-2005, } \\
\text { HEI-2010, HEI-2015) } \\
\text { - Change in total HEI over time }\end{array}$ & $\begin{array}{l}\text { - Studies that examine any other dietary pattern or } \\
\text { diet quality indicator that include only individual or } \\
\text { select foods and beverages and do not reflect the } \\
\text { totality of the diet nor the Dietary Guidelines for } \\
\text { Americans. } \\
\text { - Studies that only examine component scores of the } \\
\text { HEI }\end{array}$ \\
\hline $\begin{array}{l}\text { Publication } \\
\text { date }\end{array}$ & $\begin{array}{l}\text { - Jan } 2008 \text { - May } 2021 \text { and data inclusive of } 2008 \\
\text { (e.g., 2000-2012; 2008-2009) }\end{array}$ & $\begin{array}{l}\text { - } \quad \text { Articles published prior to Jan } 2008 \\
\text { - } \quad \text { Data prior to } 2008 \text { (e.g., 2000-2007; 1999-2005) }\end{array}$ \\
\hline $\begin{array}{l}\text { Publication } \\
\text { status }\end{array}$ & $\begin{array}{l}\text { - } \quad \text { Articles that have been peer-reviewed } \\
\text { - } \quad \text { rey literature: reports that have not been peer } \\
\text { reviewed but are available from government and } \\
\text { nongovernmental organizations }\end{array}$ & $\begin{array}{l}\text { Articles that have not been peer reviewed and are } \\
\text { not published in peer-reviewed journals (e.g., } \\
\text { unpublished data, manuscripts, pre-prints, reports, } \\
\text { abstracts, and conference proceedings), other than } \\
\text { reports from government and nongovernmental } \\
\text { organizations }\end{array}$ \\
\hline Language & - $\quad$ Articles published in English & - Articles published in languages other than English \\
\hline Country & - $\quad$ Studies conducted in the U.S. & - $\quad$ Studies conducted outside the U.S. \\
\hline $\begin{array}{l}\text { Study } \\
\text { participants }\end{array}$ & - Human participants/populations & $\begin{array}{l}\text { - Non-human participants (e.g., animal studies, in- } \\
\text { vitro models) }\end{array}$ \\
\hline
\end{tabular}




\section{Category}

Inclusion Criteria

\section{Exclusion Criteria}

\section{Extract data and assess the risk of bias}

NESR analysts extracted and summarized data from each included article to objectively describe the body of evidence available to answer a rapid review question. The following outlines any departures from the extract data and assesses risk of bias project methods for this specific rapid review:

- Data extraction and risk of bias assessment was completed on all included articles and verified by a $2^{\text {nd }}$ analyst

\section{Synthesize the evidence}

Evidence synthesis was completed by describing the evidence and evaluating the included studies individually and collectively as previously described in the project methods.

\section{Summary statements}

NESR analysts formed summary statements, as previously described in the project methods, outlining the themes observed during the data synthesis of studies examining income and HEI.

\section{Recommend future research}

Recommendations for future research evaluating the relationship between income and HEI were determined based on the gaps and limitations observed during data extraction and synthesis, as previously described in the project methods. Future work addressing these gaps and limitations may contribute to the body of evidence available to answer this research question.

\section{Results}

\section{Literature search and screening results}

The literature search yielded 10,692 search results after the removal of duplicates (see Figure 2-b). Dualscreening resulted in the exclusion of 9,719 titles, 646 abstracts, and 183 full-texts articles. Reasons for fulltext exclusion are in Appendix 2-b. Five additional articles were identified from the manual search. The body of evidence for the rapid review included 61 articles. 
Figure 2-b. Literature search and screen flowchart for the rapid review on income and HEI

\begin{tabular}{|c|c|c|}
\hline \multirow{2}{*}{ 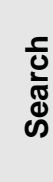 } & Electronic databases searched & Manual search \\
\hline & $\begin{array}{c}\text { PubMed, Business Source Premier, Web of Science, Grey Literature } \\
\text { (AgEcon, Google, Google Scholar) } \\
\mathrm{N}=13,062(\mathrm{~N}=10,692 \text { after duplicates removed) }\end{array}$ & $\begin{array}{l}\text { References of included articles and } \\
\text { existing systematic reviews }\end{array}$ \\
\hline & & I \\
\hline \multirow{6}{*}{ ळ్ } & Articles excluded & \\
\hline & $\mathrm{N}=10,692$ & \\
\hline & Abstracts screened & \\
\hline & $\mathrm{N}=646$ & \\
\hline & Full-texts screened & \\
\hline & $\mathrm{N}=271$ & \\
\hline \multirow{5}{*}{ 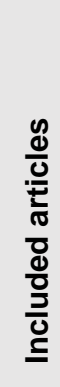 } & Articles from electronic database search & Articles from manual search \\
\hline & $\mathrm{N}=56$ & $\mathrm{~N}=5$ \\
\hline & \multicolumn{2}{|c|}{ Articles included in the rapid review } \\
\hline & \multicolumn{2}{|l|}{$\mathrm{N}=61$, rapid review } \\
\hline & & \\
\hline
\end{tabular}

\section{Description of evidence}

This rapid review included 61 articles that examined the relationship between income and HEl. Four articles came from prospective cohort studies ${ }^{1-4}$ and the rest (57 articles) were from cross-sectional study designs. ${ }^{5-61}$ Common data sources of these studies included the National Health and Nutrition Examination Survey (NHANES) 5,13,14,23,24,26,29,33,37-44,47-49,52-54,56,61 and the Continuing Survey of Food Intake by Individuals (CSFII). ${ }^{7,45}$ Four articles were included from the Healthy Aging in Neighborhoods of Diversity across the Life Span Study (HANDLS) but represented unique data by examining different sub-samples or analytic/assessment methods. 1,6,9,34 


\section{Population characteristics}

Most of the studies ( $41 \%)$ were conducted using data from national databases or by enrolling participants from multiple states, with a few select studies conducted exclusively in rural or urban cities or areas. Across the body of evidence, analytic sample sizes ranged from $n=80$ to $n=43,996$. More information on the location and analytic sample size from each individual article can be found in Table 2-b.

Studies varied across all populations and life stages. Most of the studies examined data in adults ${ }^{1,2,5-7,9-12,15-}$ $18,20,25,28,30,31,34,37,41-46,48-51,54,56-58,60,61$ with a smaller sub-set of articles examining data in children (toddlers through adolescents). 4,8,14,19,21,24,26,27,29,32,33,35,38-40,52,53 In addition, there were 7 articles that studied children and adults $^{13,47}$, or child-adult dyads. ${ }^{3,22,36,55,59}$ One study examined household data. ${ }^{23}$

Most studies enrolled participants regardless of sex, although select studies enrolled only women ${ }^{50}$, or those who were pregnant. ${ }^{16,28,51}$ Most studies enrolled participants regardless of racial/ethnic background, but select studies enrolled only those who were Hispanic, ${ }^{51,61}$ of Mexican-origin, ${ }^{40}$ African-American, ${ }^{46,50}$ HaitianAmerican, ${ }^{30}$ or members of the Confederated Salish, Pend d'Oreille, or Kootenai tribes of Flathead nation. ${ }^{10}$ Select studies exclusively enrolled participants with diagnosed diabetes ${ }^{12,44}$ or cancer..$^{31}$

\section{Exposure and comparator characteristics}

Studies examined household income $8,10,11,15-18,20,22,30,36,46,50,58,60$ or poverty (e.g., poverty-to-income ratio (PIR)). 1,3-5,7,7,12,34,40,43-45,48,52,53,61. Studies varied in the cut-off points used for income, poverty, or thresholds applied, whether or not household/family size was accounted for in the income variable, and/or percentage of residents in living poverty at that address according to Census data.

Both income or poverty and Federal assistance program participation/eligibility were examined in a subset of studies. ${ }^{24-26,28,31-33,39,55,59}$

Studies examined participation and eligibility in various Federal assistance programs, $2,6,13,14,19,21,23,25-33,35,37-$ 39,41,42,47,49,51,52,54-57,59 including Supplemental Nutrition Assistance Program (SNAP, formerly Food Stamps) eligibility and participation, ${ }^{2,6,13,23-25,28,29,31,35,37-39,41,42,47,49,54,56,57}$ National School Lunch Program (NSLP) or School Breakfast Program (SBP) participation, ${ }^{14,19,21,24,26,27,33,39}$ Supplemental Assistance Program for Women, Infants and Children (WIC) participation and duration, ${ }^{25,32,39,51,59}$ and other programs (e.g., Child and Adult Care Food Program (CACFP), ${ }^{55}$ and Medicaid or Supplemental Security Income (SSI ${ }^{25,31}$ ).

\section{Outcome assessment}

All studies examined dietary patterns aligned with the DGA as measured by the HEI 22 , HEl-2005 (14 articles) 7,12-15,18,23,26,30,36-38,56,58 , HEI-2010 (31 articles) 1,2,4-6,9-11,17,19-21,24,25,27-29,31-34,40-44,46,50,54,60,61, and/or HEI-2015 (15 articles) $3,8,16,35,39,45,47-49,51-53,55,57,59$. Scores on the HEl were determined using a variety of dietary assessment methods, including food frequency questionnaires or 24-hour dietary recalls.

\section{Synthesis}

Results from all included studies are provided in Table 2-b. Income was significantly associated with HEI scores in 20 articles. . $^{1,-7,9,13,20,22,30,36,40-44,48,49,54}$ Results were reported as lower income/greater poverty associating with lower HEl scores, higher income/less poverty associating with higher HEl scores, and/or as participation versus non-participation in Federal assistance program(s) associating with lower HEl scores.

Eleven articles reported 'positive' associations (that is, higher income associated with higher HEl scores) with not all results reported reaching statistical significance. ${ }^{2,17,23,25,26,33,37,39,45,50,58}$ Five articles ${ }^{14,21,19,24,59}$ reported at 
least 1 significant 'inverse' association with 3 finding that NSLP participants (compared to non-participants) had significantly higher HEI scores. ${ }^{14,19,21} \mathrm{Gu}$ et al ${ }^{24}$ reported that NSLP was significantly associated with lower HEI scores and WIC participation was significantly associated with higher HEl scores, but comparisons based on income or SNAP status were not significant. Weinfield et al ${ }^{59}$ similarly reported that longer WIC duration was significantly associated with higher HEI scores, but comparisons of HEI by poverty were not significant.

The remaining articles reported no significant association between income, , $10,11,15,16,18,31,32,46,55,60_{\text {poverty-to- }}$ income ratio, ${ }^{12,34,52,53,61}$ Federal assistance participation/eligibility/duration (SNAP, ${ }^{29,35,38,47,51,56,57}$ NSLP, ${ }^{27}$ WIC, ${ }^{51}$ ), or both income and Federal assistance ${ }^{28}$ and HEI scores.

\section{Assessment of evidence}

As outlined and described below, the body of evidence examining the relationship between income and HEI was assessed for the following elements.

\section{Risk of bias}

Risk of bias assessments for each included article are provided in Table 2-c. The preponderance of evidence came from observational studies, particularly cross-sectional data or design, that did not account or adjust for key confounders including food insecurity/hunger and urban/rural setting. Many studies had serious or some concerns with classification of income due to self-selection of Federal assistance program participation/eligibility status and/or proxy calculations. Many studies had serious concerns related to comparisons with little difference between income levels of exposure groups or likelihood that participants' income or Federal participation/eligibility status was assessed at a single point in time but likely instable. Many studies also had concerns with missing data and/or the selection of reported results due to the lack of a priori analysis plans/protocol.

\section{Consistency}

The direction of findings consistently showed that lower income was associated with lower HEI scores and the magnitude of the effect was consistently small, with many reported results not reaching statistical significance. Participation in Federal assistance programs was correlated with lower diet quality, as measured by $\mathrm{HEI}$ scores. However, about half of the articles found no statistically significant relationships between income and $\mathrm{HEl}$.

\section{Directness}

The body of evidence had several concerns regarding directness, particularly the exposures and/or comparators examined by studies were not directly related to the question of interest. For example, studies examining SNAP participation tended to compare groups that had similar or nearly similar income levels. In addition, the population in several articles were all low-income or all participants in specific Federal assistance programs. Outcomes examined in all studies were directly related to the question.

\section{Precision}

Several concerns with precision were identified across the body of evidence. Although sample sizes were relatively large, the reported effects tended to be small in magnitude (of little practical/clinical significance) and have wider confidence intervals indicating limited precision. 


\section{Generalizability}

Although all studies were conducted in the U.S. and many used nationally representative data, the generalizability was limited in several studies particularly related to the selection of participants. For example, several studies examined differences within exclusive populations such as all WIC participants, all low-income participants, only Mexican-origin children, or only Haitian-Americans.

\section{Summary statements and research recommendations}

\section{Summary statements}

The findings of the rapid review are presented in the following summary statement[s].

Evidence suggests lower income or greater poverty is correlated with lower HEI scores. Critical limitations in the design and conduct of most included studies were identified that impact the validity of the reported results. In addition, the findings that reached statistical significance tended to lack meaningful clinical/practical significance (e.g., 1 to 5 point higher HEI scores) but remaining within a range of needing improvement.

Studies widely varied in how they defined and examined income exposures. No clear trends were found between studies that examined similar or different income groupings.

Studies that examined Federal assistance eligibility/participation often reported indirect income exposures or comparisons, and/or treated income constant between participant groups.

Relatively few studies accounted for food security/hunger. No clear trends were found among exposures, outcomes, or significance of results based on whether food security was accounted for or not.

\section{Research recommendations}

1. Conduct well-designed, longitudinal studies that examine the relationship between income and diet quality over time.

2. Assess income exposures using standard definitions and categories to improve comparability across studies.

3. Differentiate between participants in studies who are income-eligible, income-eligible nonparticipants, and income-ineligible nonparticipants of Federal assistance programs.

4. Account for hunger or food security status of participants, as well as other potential confounders including urban/rural setting and cultural/racial diversity or disparities, to better determine the response to income on dietary patterns as a function of these factors. 
Table 2-b. Evidence examining the relationship between income and/or Federal assistance participation/eligibility and $\mathrm{HEI}{ }^{\mathrm{a}}$

\begin{tabular}{|c|c|c|c|c|c|c|}
\hline Article $^{*}$ & $\mathbf{N}$ & Population & Exposure & Outcome & Results $^{\dagger}$ & Summary of Limitations \\
\hline \multicolumn{7}{|c|}{ Income } \\
\hline $\begin{array}{l}\text { Bekelman, } \\
2021^{8}\end{array}$ & 482 & $\begin{array}{l}\text { Children, } 5 \text { y; } \\
\text { Colorado } \\
\text { Data source: Healthy } \\
\text { Start study }\end{array}$ & $\begin{array}{l}\text { Income: }<\$ 75 \mathrm{~K} \text { v. } \geq \\
\$ 75 \mathrm{~K}\end{array}$ & $\begin{array}{l}\mathrm{HEI}- \\
2015\end{array}$ & OR: $0.84,95 \% \mathrm{Cl}: 0.54,1.31, \mathrm{NS}$ & $\begin{array}{l}\text { Did not account for confounders } \\
\text { of: Urban vs. Rural; Food } \\
\text { security; Some concerns with } \\
\text { departure from intended exposure } \\
\text { due to lack of accounting for food } \\
\text { insecurity/hunger }\end{array}$ \\
\hline $\begin{array}{l}\text { Byker } \\
\text { Shanks, } \\
2020^{10}\end{array}$ & 80 & $\begin{array}{l}\text { Adults, } \geq 18 \mathrm{y} \\
\text { Flathead nation, } \\
\text { Montana } \\
\text { Data source: N/A }\end{array}$ & Income, \$ & $\begin{array}{l}\mathrm{HEI}- \\
2010\end{array}$ & data NR, $p<0.21 ; N S$ & $\begin{array}{l}\text { Minimal concerns with selection } \\
\text { into study and selection of } \\
\text { reported results }\end{array}$ \\
\hline Chen, $2018^{11}$ & 298 & $\begin{array}{l}\text { Adults: Parents of } \\
\text { children, } 9 \text { to } 10 \mathrm{y} \text {; } \\
\text { rural Texas } \\
\text { Data source: Student } \\
\text { Wellness Assessment } \\
\text { and Advocacy Project } \\
\text { [SWAAP] }\end{array}$ & $\begin{array}{l}\text { Income: Low } \\
<\$ 40 \mathrm{~K} ; \text { Medium } \\
\$ 40,001-\$ 70 \mathrm{~K} ; \\
\text { High }>\$ 70,001\end{array}$ & $\begin{array}{l}\text { HEI- } \\
2010 \\
\text { adapted }\end{array}$ & $\beta=0.09, r=-0.29189, p=0.268 ; N S$ & $\begin{array}{l}\text { Did not account for confounders } \\
\text { of: Food security; Some concerns } \\
\text { with outcome measurement due } \\
\text { to adaption of HEI-2010 }\end{array}$ \\
\hline $\begin{array}{l}\text { Deierlein, } \\
2014^{15}\end{array}$ & 1306 & $\begin{array}{l}\text { Adults, } 60 \text { to } 99 \text { y; } \\
\text { New York City, New } \\
\text { York } \\
\text { Data source: } \\
\text { Cardiovascular } \\
\text { Health of Seniors and } \\
\text { the Built Environment } \\
\text { Study }\end{array}$ & $\begin{array}{l}\text { Annual HH income: } \\
>\$ 30 \mathrm{~K} \text { (ref) v. } \leq \\
\$ 30 \mathrm{~K}\end{array}$ & $\begin{array}{l}\mathrm{HEI}- \\
2005\end{array}$ & $\begin{array}{l}\mathrm{HEI} \geq 80 \text { v. }<80 \text { RR: } 1.2095 \% \text { Cl: } 0.93 \text {, } \\
1.55\end{array}$ & $\begin{array}{l}\text { Some concerns with selection } \\
\text { bias; Some concerns with } \\
\text { departure from intended exposure }\end{array}$ \\
\hline
\end{tabular}

\footnotetext{
* All study designs and/or data reported were cross-sectional unless indicated by *PCS, which indicates a prospective cohort study design.

† Unless otherwise noted, results are formatted as mean (SD), mean [SE], odds ratio (OR), relative risk (RR), and/or 95\% Confidence Interval (CI). Results that were statistically significant are bolded and those that were not statistically significant are indicated either by the respective $p$ value or NS.
} 


\begin{tabular}{|c|c|c|c|c|c|c|}
\hline Article $^{\star}$ & $\mathbf{N}$ & Population & Exposure & Outcome & Results $^{\dagger}$ & Summary of Limitations \\
\hline $\begin{array}{l}\text { Deierlein, } \\
2021^{16}\end{array}$ & 1016 & $\begin{array}{l}\text { Adults, all pregnant } \\
\text { women, } \geq 18 \text { y; New } \\
\text { York City, New York } \\
\text { Data source: New } \\
\text { York University } \\
\text { Children's Health and } \\
\text { Environment Study } \\
\text { (NYU CHES) }\end{array}$ & $\begin{array}{l}\text { Income: }<\$ 30 \mathrm{~K} \\
\$ 80 \mathrm{~K}-\$ 99.999 \mathrm{~K} \\
\geq \$ 100 \mathrm{~K}\end{array}$ & $\begin{array}{l}\text { HEl- } \\
2015\end{array}$ & $\begin{array}{l}\geq \$ 100 \mathrm{k} \text { (ref) v. <\$30k: } 1.92,95 \% \mathrm{Cl}: \\
-0.41,4.25, \mathrm{NS} \\
\geq \$ 100 \mathrm{k} \text { (ref) v. } \$ 30-\$ 99.999 \mathrm{k}: 1.02,95 \% \\
\mathrm{Cl}:-0.53,2.57, \mathrm{NS}\end{array}$ & $\begin{array}{l}\text { Did not account for confounders } \\
\text { of: Food security; Some concerns } \\
\text { with selection bias; Some } \\
\text { concerns with departure from } \\
\text { intended exposure related to } \\
\text { potential for changes from timing } \\
\text { of assessments; Limited } \\
\text { generalizability to non-pregnant } \\
\text { populations }\end{array}$ \\
\hline $\begin{array}{l}\text { Drewnowski, } \\
2016^{17}\end{array}$ & 1116 & $\begin{array}{l}\text { Adults, } \geq 18 \text { y; Seattle, } \\
\text { Washington } \\
\text { Data source: Seattle } \\
\text { Obesity Study (SOS) }\end{array}$ & $\begin{array}{l}\text { Income, } \leq \$ 50 \mathrm{~K} \text { ref } \\
\text { v. } \$ 50 \mathrm{~K} \text { to }<100 \mathrm{~K} ; \\
\leq \$ 50 \mathrm{~K} \text { ref v. } \\
\geq \$ 100 \mathrm{~K}\end{array}$ & $\begin{array}{l}\mathrm{HEl}- \\
2010 \\
\text { HEI- } \\
2005\end{array}$ & $\begin{array}{l}\text { HEl-2010: } \\
\text { \$50K to <100K: } 1.34,95 \% \mathrm{Cl}:-0.13,2.82 \\
\geq \$ 100 \mathrm{~K}: \mathbf{2 . 5 7 , 9 5 \% ~ C l : ~} \mathbf{0 . 9 6}, \mathbf{4 . 1 9} \\
\text { HEl-2005: } \\
\text { \$50K to <100K: } 0.72,95 \% \mathrm{Cl}:-0.73, \\
2.19 ; \mathrm{NS} \\
\geq \$ 100 \mathrm{~K}: 1.30,95 \% \mathrm{Cl}:-0.28,2.89 ; \mathrm{NS}\end{array}$ & $\begin{array}{l}\text { Did not account for confounders } \\
\text { of: Food security; Some concerns } \\
\text { with departure from intended } \\
\text { exposure }\end{array}$ \\
\hline $\begin{array}{l}\text { Freedman, } \\
2019^{20}\end{array}$ & 101 & $\begin{array}{l}\text { Adults, } 19 \text { to } 92 \mathrm{y}, \\
\text { living in urban food } \\
\text { desert; Ohio } \\
\text { Data source: BRFSS }\end{array}$ & Annual HH Income & $\begin{array}{l}\text { HEl- } \\
2010\end{array}$ & $\begin{array}{l}\text { Path modeling including the collective } \\
\text { influence of individual, social, and built } \\
\text { food environment factors on diet quality } \\
\text { with income included in the models: } \\
\text { Cleveland: Income, } \beta=0.171, p<0.05 \\
\text { Columbus: Income, } \beta=0.300, p<0.10\end{array}$ & $\begin{array}{l}\text { Some concerns with classification } \\
\text { of exposure and departure from } \\
\text { intended exposure; Concerns } \\
\text { with indirectness }\end{array}$ \\
\hline Gibbs, $2016^{22}$ & 177 & $\begin{array}{l}\text { Dyads of Children } 4 \text { to } \\
6 \mathrm{y} \text {, with parents } \\
\text { (primary food } \\
\text { purchaser/preparer); } \\
\text { Kansas }\end{array}$ & $\begin{array}{l}\mathrm{HH} \text { income, } \$ \text {, } \\
\text { mean }\end{array}$ & $\mathrm{HEl}$ & Income: $r=0.218, p<0.05$ & $\begin{array}{l}\text { Did not account for confounders } \\
\text { of: Urban vs. Rural; Food } \\
\text { security }\end{array}$ \\
\hline
\end{tabular}




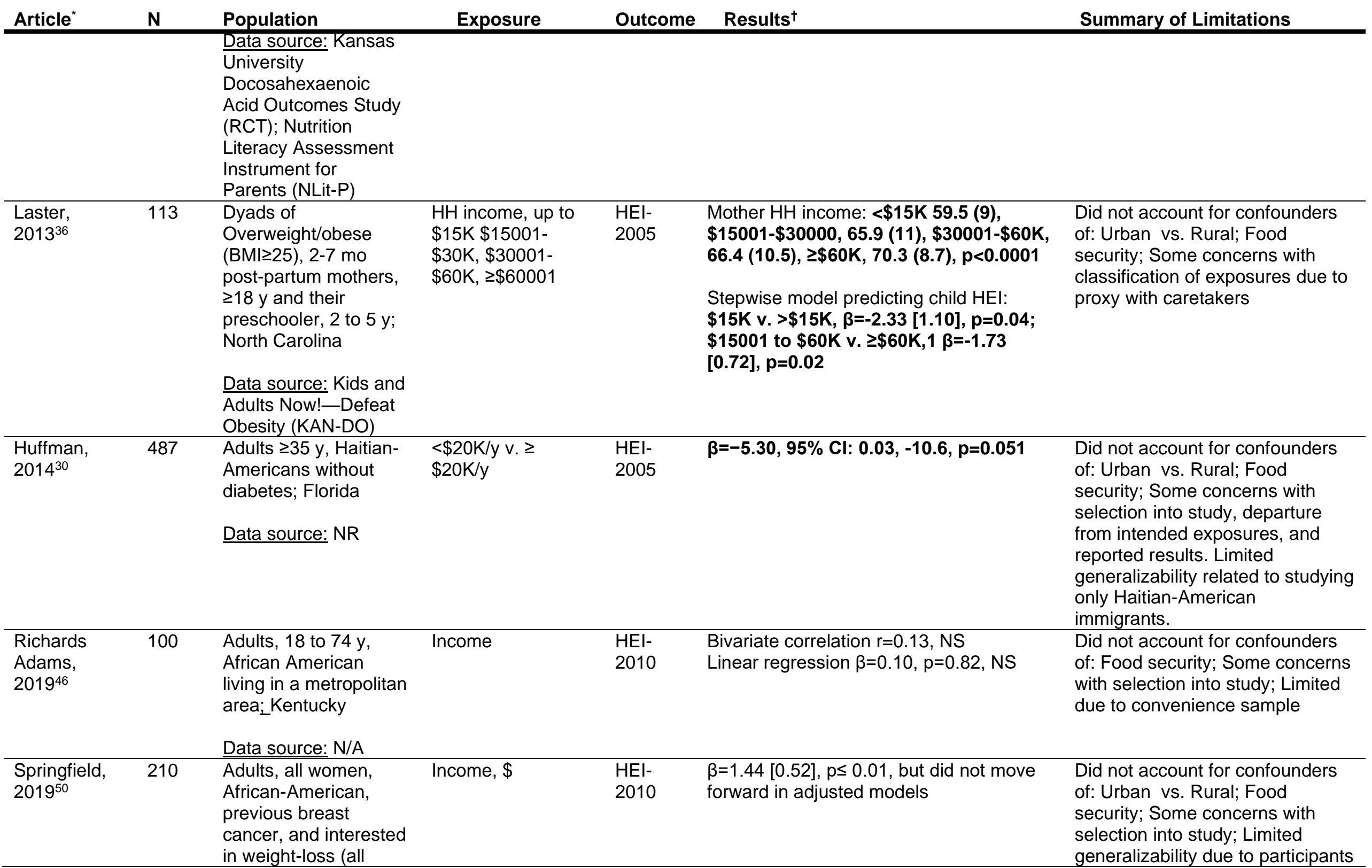




\begin{tabular}{|c|c|c|c|c|c|c|}
\hline Article $^{*}$ & $\mathbf{N}$ & Population & Exposure & Outcome & Results $^{\dagger}$ & Summary of Limitations \\
\hline & & $\begin{array}{l}\text { Overweight or obese); } \\
\text { Chicago, IL } \\
\text { Data source: Moving } \\
\text { forward study, a RCT } \\
\text { for weight loss }\end{array}$ & & & & $\begin{array}{l}\text { self-selecting into study for weight } \\
\text { loss }\end{array}$ \\
\hline $\begin{array}{l}\text { Weatherspoo } \\
n, 2017^{58}\end{array}$ & 2687 & $\begin{array}{l}\text { Adults, } \geq 19 \mathrm{y} ; \\
\text { Michigan } \\
\text { Data source: Michigan } \\
\text { State University } \\
\text { Extension (MSUE) }\end{array}$ & $\begin{array}{l}\text { HH income } \$ 100 \\
\text { and } \$ 500 / p p / m o ~ v . \\
<\$ 100 / p p / m o\end{array}$ & $\begin{array}{l}\mathrm{HEl}- \\
2005\end{array}$ & $\begin{array}{l}\Delta \mathrm{HEl} \text { exit-entry after SNAP-Ed only: }- \\
\mathbf{0 . 6 8}[\mathbf{0 . 0 2}], \mathbf{p}<0.01 \\
\Delta \mathrm{HEl} \text { exit-entry after EFNEP only: }-\mathbf{0 . 8 5} \\
{[0.03], \mathbf{p}<0.01} \\
\text { Data NR: HH income } \$ 100 \text { and } \\
\$ 500 / p p / m o ~ v .<\$ 100 / p p / m o \text { increased in } \\
\Delta H E l \text { scores, } p<0.05 ; \$ 500 \text { or more, NS }\end{array}$ & $\begin{array}{l}\text { Did not account for confounders } \\
\text { of: Food security; Serious } \\
\text { concerns with departure from } \\
\text { intended exposures; Comparator } \\
\text { not directly related to question of } \\
\text { interest }\end{array}$ \\
\hline $\begin{array}{l}\text { Wilcox, } \\
2020^{60}\end{array}$ & 465 & $\begin{array}{l}\text { Adults, } \geq 18 \text { y, } \\
\text { shoppers for } \geq 50 \% \\
\text { household's food; } \\
\text { South Carolina cities } \\
\text { Data source: N/A }\end{array}$ & $\begin{array}{l}\text { Income: <\$10k; } \\
\text { \$10-\$19.999k; } \\
\geq \$ 20 \mathrm{k}\end{array}$ & $\begin{array}{l}\text { HEl- } \\
2010\end{array}$ & $\begin{array}{l}<\$ 10 \mathrm{k}: 47.42 \text { v. } \$ 10-\$ 19.999 \mathrm{k}: 47.26 \mathrm{v} \\
\geq \$ 20 \mathrm{k}: 49.75, \mathrm{NS} \\
\text { Income, } \mathrm{F}(4,448)=6.71, \mathrm{p}<0.001 \\
\text { r2=0.06; } F(2,448)=1.29, \mathrm{p}=0.28\end{array}$ & $\begin{array}{l}\text { Did not account for confounders } \\
\text { of: Cultural/racial diversity or } \\
\text { disparities; Food security; Serious } \\
\text { concerns with departure from } \\
\text { intended exposures }\end{array}$ \\
\hline \multicolumn{7}{|c|}{ Poverty } \\
\hline $\begin{array}{l}\text { Aggarwal, } \\
2016^{5}\end{array}$ & 8957 & $\begin{array}{l}\text { Adults, } \geq 20 \text { y; National } \\
\text { dataset } \\
\text { Data source: } \\
\text { NHANES, 2007-2010 }\end{array}$ & $\begin{array}{l}\text { FIPR: family } \\
\text { income-to-poverty } \\
\text { ratio, adjusted for } \\
\mathrm{HH} \text { size }\end{array}$ & $\begin{array}{l}\text { HEl- } \\
2010\end{array}$ & $\begin{array}{l}\text { FIPR }<130 \%: 45.6,131-184 \%: 47.1,185- \\
399 \%: 48.4, \geq 400 \%: 51.7 \\
<130 \% \text { (ref) v. } 131-184 \%: 1.96[0.86] \\
p=0.030 \\
<130 \% \text { (ref) v. } 185-399 \%: 3.21[0.50] \\
p<0.001 \\
<130 \% \text { (ref) v. } \geq 400 \%: 6.48[0.60] \\
p<0.001\end{array}$ & $\begin{array}{l}\text { Did not account for confounders } \\
\text { of: Urban vs. Rural; Food } \\
\text { security; Some concerns due to } \\
\text { missing data }\end{array}$ \\
\hline Beatty, $2014^{7}$ & 37263 & $\begin{array}{l}\text { Adults, } \geq 20 \mathrm{y} ; \\
\text { National dataset } \\
\text { Data source: CSFII, } \\
\text { 1989-1991, 1994- } \\
\text { 1996; NHANES, 2001- } \\
2008\end{array}$ & $\begin{array}{l}\text { HH Income }<185 \% \\
\text { FPG (low) }\end{array}$ & $\begin{array}{l}\mathrm{HEl}- \\
2005\end{array}$ & $\begin{array}{l}\text { 2005-2008, n=9258: low-income } 51.37 \\
\text { (14.99), } 95 \% \text { Cl: } 8.78,94.60 \text { v. higher- } \\
\text { income } 52.92 \text { (11.29), } 95 \% \mathrm{Cl}: 10.00 \text {, } \\
\text { 95.38, p<0.05 } \\
\text { Data NR (in figures): For HEI below 45, } \\
\text { higher-income individuals experienced a } \\
\text { greater improvement over the period } \\
\text { 1989-2008 than low-income individuals. } \\
\text { Whereas at higher levels of the HEl }\end{array}$ & $\begin{array}{l}\text { Did not account for confounders } \\
\text { of: Urban vs. Rural; Food } \\
\text { security; Some concerns with } \\
\text { departure from intended exposure } \\
\text { due to lack of accounting for food } \\
\text { insecurity/hunger; Some concerns } \\
\text { with outcome measurement due } \\
\text { to timing of dietary data collected } \\
\text { vs.. calculated; Some concerns } \\
\text { with reported results; Limitations }\end{array}$ \\
\hline
\end{tabular}




\begin{tabular}{|c|c|c|c|c|c|c|}
\hline Article $^{\star}$ & $\mathbf{N}$ & Population & Exposure & Outcome & Results $^{\dagger}$ & Summary of Limitations \\
\hline & & & & & $\begin{array}{l}\text { distribution, low-income individuals } \\
\text { experienced greater increases in } \mathrm{HEI} \text {. }\end{array}$ & $\begin{array}{l}\text { related to date range of data } \\
\text { collected }\end{array}$ \\
\hline $\begin{array}{l}\text { Beydoun, } \\
2015^{9}\end{array}$ & 2111 & $\begin{array}{l}\text { Adults, } 30 \text { to } 64 \text { y; } \\
\text { Baltimore, Maryland } \\
\text { Data source: Healthy } \\
\text { Aging in } \\
\text { Neighborhoods of } \\
\text { Diversity across the } \\
\text { Life Span Study } \\
\text { (HANDLS) }\end{array}$ & $\begin{array}{l}\text { PIR: } \geq 125 \% \\
\text { poverty threshold } v \\
<125 \% \text { poverty } \\
\text { threshold }\end{array}$ & $\begin{array}{l}\mathrm{HEl}- \\
2010\end{array}$ & $\begin{array}{l}\text { PIR } \geq 125 \%: 43.82(0.35) \text { v. }<125 \%: 40.93 \\
(0.34), p<0.05\end{array}$ & $\begin{array}{l}\text { Did not account for confounders } \\
\text { of: Sex; Age; Food security; } \\
\text { Some concerns with departure } \\
\text { from intended exposure due to } \\
\text { lack of accounting for food } \\
\text { insecurity/hunger; Some concerns } \\
\text { with outcome measurement }\end{array}$ \\
\hline $\begin{array}{l}\text { Beydoun, } \\
2018^{1 *} \text { PCS }\end{array}$ & 1466 & $\begin{array}{l}\text { Adults, } 30 \text { to } 64 \mathrm{y} ; \\
\text { urban Maryland } \\
\text { Data source: HANDLS }\end{array}$ & $\begin{array}{l}\text { PIR }<125 \% \text { poverty } \\
\text { threshold, } \geq 125 \% \\
\text { poverty threshold }\end{array}$ & $\begin{array}{l}\text { HEl- } \\
2010\end{array}$ & $\begin{array}{l}\text { baseline, } \geq 125 \%, 44.5[0.4] \text { v. }<125 \% \text {, } \\
41.3[0.4], p<0.001 \\
\text { follow-up, } \geq 125 \%, 47.95[0.4] \text { v. }<125 \% \text {, } \\
44.6[0.46], p<0.001 \\
\text { change, } \geq 125 \%,+0.78[0.10] \text { v. }<125 \% \text {, } \\
+0.68[0.10], N S\end{array}$ & $\begin{array}{l}\text { Did not account for confounders } \\
\text { of: Food security; Some concerns } \\
\text { with selection bias; Some } \\
\text { concerns with departure from } \\
\text { intended exposure due to lack of } \\
\text { accounting for food } \\
\text { insecurity/hunger; Some concerns } \\
\text { with reported results due to no } \\
\text { protocol }\end{array}$ \\
\hline $\begin{array}{l}\text { Coltman, } \\
2013^{12}\end{array}$ & 99 & $\begin{array}{l}\text { Adults, } 18 \text { to } 75 \text { y; } \\
\text { diagnosed with type } 2 \\
\text { diabetes; urban Illinois } \\
\text { Data source: N/A }\end{array}$ & $\begin{array}{l}\text { PIR } \leq 130 \% \text {, } \\
>130 \% \text {, based on \# } \\
\text { of people living in } \\
\mathrm{HH}\end{array}$ & $\begin{array}{l}\text { HEl- } \\
2005\end{array}$ & $\begin{array}{l}\text { PIR: } \leq 130 \%, 56.0(11.3) \text { v. }>130 \%, 56.6 \\
\text { (9.6); NS } \\
\text { Correlations with HEI: PIR: }-0.075 ; \text { NS }\end{array}$ & $\begin{array}{l}\text { Critical concerns due to not } \\
\text { accounting for confounders of: } \\
\text { Cultural/racial diversity or } \\
\text { disparities; Sex; Age; Food } \\
\text { security; Serious concerns due to } \\
\text { selection into study based on } \\
\text { diabetic status; Some concerns } \\
\text { with departure from intended } \\
\text { exposure; Limited generalizability }\end{array}$ \\
\hline $\begin{array}{l}\text { Covington, } \\
2020^{3}{ }^{*} \text { PCS }\end{array}$ & 207 & $\begin{array}{l}\text { Dyads of Children, } 12 \\
\text { to } 32 \text { mo with their } \\
\text { mothers; Mid-Atlantic } \\
\text { region } \\
\text { Data source: } \\
\text { NCT02615158 }\end{array}$ & $\begin{array}{l}\text { Poverty based on } \\
\text { parent-reported } \\
\text { income and family } \\
\text { size, }<1.0 \text { indicated } \\
\text { below poverty } \\
\text { threshold }\end{array}$ & $\begin{array}{l}\text { HEl- } \\
2010\end{array}$ & $\begin{array}{l}\text { Between-person indirect effect: } 3.797 \\
\text { [0.842], 95\% Cl: } 2.133,5.460, p<0.05 \\
\text { Within-person indirect effect: }-3.552 \\
{[2.230], 95 \% \mathrm{Cl}:-7.948,0.844, \mathrm{NS}}\end{array}$ & $\begin{array}{l}\text { Did not account for confounders } \\
\text { of: Cultural/racial diversity or } \\
\text { disparities ( } 68 \% \text { Non-Hispanic } \\
\text { Black); Food security; Some } \\
\text { concerns due to missing data } \\
\text { despite methods used to account } \\
\text { for impact; }\end{array}$ \\
\hline $\begin{array}{l}\text { Kuczmarski, } \\
2016^{34}\end{array}$ & 2111 & $\begin{array}{l}\text { Adults, } \sim 48 \mathrm{y}_{i} \\
\text { Baltimore City, } \\
\text { Maryland }\end{array}$ & $\begin{array}{l}\text { PIR: } \geq 125 \% \\
\text { poverty threshold }\end{array}$ & $\begin{array}{l}\text { HEl- } \\
2010\end{array}$ & $\mathrm{PIR} \geq 125 \%$ vs. $<125 \%: 0.70(0.49), \mathrm{NS}$ & $\begin{array}{l}\text { Did not account for confounders } \\
\text { of: Food security; Some concerns }\end{array}$ \\
\hline
\end{tabular}




\begin{tabular}{|c|c|c|c|c|c|c|}
\hline Article $^{\star}$ & $\mathbf{N}$ & Population & Exposure & Outcome & Results $^{\dagger}$ & Summary of Limitations \\
\hline & & Data source: HANDLS & $\begin{array}{l}\text { vs. }<125 \% \text { poverty } \\
\text { threshold }\end{array}$ & & & $\begin{array}{l}\text { with departure from intended } \\
\text { exposure }\end{array}$ \\
\hline $\begin{array}{l}\text { Martin, } \\
2015^{40}\end{array}$ & 4799 & $\begin{array}{l}\text { Children, } 5 \text { to } 17 \text { y of } \\
\text { Mexican-origin; } \\
\text { National dataset } \\
\text { Data source: } \\
\text { NHANES, } 1999-2010\end{array}$ & PIR-squared & $\begin{array}{l}\text { HEl- } \\
2010\end{array}$ & $-1.30, p<0.05$ & $\begin{array}{l}\text { Did not account for confounders } \\
\text { of: Urban vs. Rural; Food } \\
\text { security; Some concerns with } \\
\text { missing data. Limited } \\
\text { generalizability due to sample } \\
\text { being only Mexican-origin } \\
\text { children. }\end{array}$ \\
\hline $\begin{array}{l}\text { Nowlin, } \\
2016^{43}\end{array}$ & 11668 & $\begin{array}{l}\text { Adults, } \geq 20 \text { y not } \\
\text { pregnant; National } \\
\text { dataset } \\
\text { Data source: } \\
\text { NHANES, 2007-2012 }\end{array}$ & PIR & $\begin{array}{l}\text { HEl- } \\
2010\end{array}$ & $\begin{array}{l}\text { Regression coefficient [SE] } \\
\text { PIR: } \geq 3.5 \text { (ref) v. 1.3-3.49; } \geq 3.5 \text { (ref) v. } \\
\leq 1.29 \\
\text { No T2D, } \mathbf{n = 9 , 5 0 9 : - 2 . 4 7 ~ [ 0 . 6 ] , ~} \mathbf{p}<0.01 ;- \\
\text { 3.15 [0.6], } \mathbf{p}<0.01 \\
\text { Undiagnosed T2D, } n=451: 4.68 \text { [2.1] NS; - } \\
\text { 1.47 [2.0] NS; } \\
\text { Diagnosed T2D, } n=1708: 1.00 \text { [1.4] NS; - } \\
0.96[1.4] \text { NS }\end{array}$ & $\begin{array}{l}\text { Did not account for confounders } \\
\text { of: Urban vs. Rural; Food } \\
\text { security; Serious concerns with } \\
\text { departure from intended } \\
\text { exposures and reported results. }\end{array}$ \\
\hline Orr, $2019^{44}$ & 5882 & $\begin{array}{l}\text { Adults, } \geq 20 \text { y with } \\
\text { type } 1 \text { or } 2 \text { diabetes; } \\
\text { National dataset } \\
\text { Data source: } \\
\text { NHANES, } 1999-2014\end{array}$ & $\begin{array}{l}\text { PIR, based on } \% \\
\text { HH income at; } \\
100 \%, 100-200 \% \text {, } \\
>200 \% \text { poverty } \\
\text { threshold }\end{array}$ & $\begin{array}{l}\text { HEl- } \\
2010\end{array}$ & 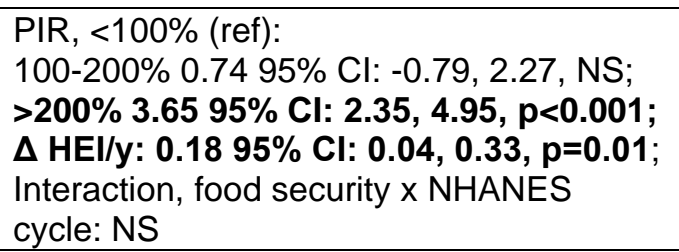 & $\begin{array}{l}\text { Did not account for confounders } \\
\text { of: Urban vs. Rural; Some } \\
\text { concerns with selection into study }\end{array}$ \\
\hline $\begin{array}{l}\text { Patetta, } \\
2019^{45}\end{array}$ & 8012 & $\begin{array}{l}\text { Adults, } 18 \text { to } 39 \text { y; } \\
\text { National dataset } \\
\frac{\text { Data source: NHANES }}{2011-14}\end{array}$ & $\begin{array}{l}<180 \% \text { poverty } \\
\text { threshold (low), } \\
180-350 \% \text { poverty } \\
\text { threshold (middle), } \\
>350 \% \text { poverty } \\
\text { threshold (high) }\end{array}$ & $\begin{array}{l}\text { HEl- } \\
2015\end{array}$ & $\begin{array}{l}\text { Low v. high income and mean HEl: } \\
52.4 \text { v.61.2, p<0.05; low v. middle: } 52.4 \text { v. } \\
55.8 \text {, NS; middle v. high: } 55.8 \text { v. } 61.2, \mathrm{NS}\end{array}$ & $\begin{array}{l}\text { Did not account for confounders } \\
\text { of: Urban vs. Rural; } \\
\text { Cultural/racial diversity or } \\
\text { disparities; Sex; Age; Food } \\
\text { security }\end{array}$ \\
\hline Shan, $2019^{48}$ & 43996 & $\begin{array}{l}\text { Adults, } \geq 20 \text { y; National } \\
\text { dataset } \\
\text { Data source: } \\
\text { NHANES, 1999-2016 }\end{array}$ & $\begin{array}{l}\text { PIR: }<1,1.3-3.49 \\
\geq 3.5\end{array}$ & $\begin{array}{l}\text { HEl- } \\
2015\end{array}$ & $\begin{array}{l}\text { PIR < 1.3: } \\
2009-1055.6,95 \% \text { Cl: 55.0, 56.1; } \\
2011-1256 \text { 95\% Cl: 55.0, 56.9; } \\
2013-1455.795 \% \text { Cl: 55.0, 56.4; } \\
2015-1656.295 \% \text { Cl: } 55.3,57.2 ; \\
2015-16 \text { v. } 1999-00 \text { difference, } 0.81,95 \% \\
\text { Cl: }-0.63,2.26 ; \text { NS }\end{array}$ & $\mathrm{N} / \mathrm{A}$ \\
\hline
\end{tabular}


2015-16 v. $1999-00$ difference: 1.32 ,

95\% Cl: 0.18, $2.46 \mathrm{p}<0.001$

$\mathrm{PIR} \geq 3.5$

2009-10 58.8, 95\% Cl: 58.1, 59.5;

2011-12 59.9, 95\% Cl: 58.9, 60.8;

2013-14 59.5, 95\% Cl: 58.8, 60.2;

2015-16 59.3, 95\% Cl: 58.3, 60.3;

2015-16 v. 1999-00 difference, 3.23 ,

95\% Cl: 1.71, 4.75, $\mathrm{p}<0.001$

\begin{tabular}{|c|c|c|c|c|c|c|}
\hline $\begin{array}{l}\text { Taverno } \\
\text { Ross, } 2020^{4} \\
{ }^{*} \text { PCS }\end{array}$ & 260 & $\begin{array}{l}\text { Children, } 10 \text { to } 17 \mathrm{y} ; \\
\text { South Carolina } \\
\text { Data source: } \\
\text { Transitions and } \\
\text { Activity Changes in } \\
\text { Kids study }\end{array}$ & $\begin{array}{l}\text { Poverty based on } \\
\text { the percentage of } \\
\text { residents living in } \\
\text { poverty in the } \\
\text { census tract for the } \\
\text { child's home } \\
\text { address. }\end{array}$ & $\begin{array}{l}\text { HEI- } \\
2015\end{array}$ & HEl growth curve: $0.2[0.1], p<0.05$ & $\begin{array}{l}\text { Did not account for confounders } \\
\text { of: Urban vs. Rural; Food } \\
\text { security }\end{array}$ \\
\hline $\begin{array}{l}\text { Thomson, } \\
2019^{52}\end{array}$ & 9000 & $\begin{array}{l}\text { Children, } 2 \text { to } 18 \mathrm{y} ; \\
\text { National dataset } \\
\text { Data source: NHANES } \\
\text { 2009-2014 }\end{array}$ & PIR: $<1, \geq 1$ & $\begin{array}{l}\text { HEI- } \\
2015\end{array}$ & $\begin{array}{l}\text { Overall: PIR<1 vs. PIR } \geq 1,53.9,95 \% \\
\mathrm{Cl}: 52.5,55.4 \text { vs.. } 55.1,95 \% \mathrm{Cl}: 54.1 \text {, } \\
56.1, \text { NS } \\
\text { By Race/Ethnicity (in figure): no } \\
\text { significant differences in HEI by PIR in } \\
\text { non-Hispanic black, Mexican American, } \\
\text { other Hispanic or other race groups; } \\
\text { Significant difference in non-Hispanic } \\
\text { white group by PIR } \\
\text { By Age Group and by gender: No } \\
\text { significant differences in HEI by PIR }\end{array}$ & $\begin{array}{l}\text { Did not account for confounders } \\
\text { of: Urban vs. Rural; } \\
\text { Cultural/racial diversity or } \\
\text { disparities; Sex; Age; Food } \\
\text { security; Serious concerns with } \\
\text { departure from intended } \\
\text { exposures }\end{array}$ \\
\hline $\begin{array}{l}\text { Thomson, } \\
2020^{53}\end{array}$ & 8894 & $\begin{array}{l}\text { Children, } 2 \text { to } 18 \mathrm{y} \text {; } \\
\text { National dataset } \\
\text { Data source: } \\
\text { NHANES, 2009-2014 }\end{array}$ & PIR: $<1, \geq 1$ & $\begin{array}{l}\text { HEI- } \\
2015\end{array}$ & $\begin{array}{l}\text { PIR<1 v. PIR } \geq 1, \text { mean, } 95 \% \mathrm{Cl} \\
\text { Underweight: } 47.7,95 \% \mathrm{Cl}: 42.8,52.8 \text { v. } \\
51.1,95 \% \mathrm{Cl}: 46.6,55.8, \mathrm{NS} \\
\text { Normal weight: } 53.9,95 \% \mathrm{Cl}: 52.2,55.6 \\
\text { v. } 55.6,95 \% \mathrm{Cl}: 54.5,56.6, \mathrm{NS} \\
\text { Overweight: } 55.2,95 \% \mathrm{Cl}: 52.5,57.9 \mathrm{v} . \\
54.4,95 \% \mathrm{Cl}: 52.0,56.7, \mathrm{NS}\end{array}$ & $\begin{array}{l}\text { Did not account for confounders } \\
\text { of: Urban vs. Rural; } \\
\text { Cultural/racial diversity or } \\
\text { disparities; Sex; Age; Food } \\
\text { security; Serious concerns due to } \\
\text { missing data }\end{array}$ \\
\hline
\end{tabular}




\begin{tabular}{|c|c|c|c|c|c|c|}
\hline Article $^{\star}$ & $\mathbf{N}$ & Population & Exposure & Outcome & Results $^{\dagger}$ & Summary of Limitations \\
\hline & & & & & $\begin{array}{l}\text { Obese: } 53.3,95 \% \text { Cl: } 51.1,55.5 \text { v. } 54.3 \text {, } \\
95 \% \text { Cl: } 51.2,57.6, \text { NS }\end{array}$ & \\
\hline $\begin{array}{l}\text { Wilson, } \\
2018^{61}\end{array}$ & 3555 & $\begin{array}{l}\text { Adults, } \geq 19 \text { y, all } \\
\text { Hispanic; National } \\
\text { dataset } \\
\text { Data source: } \\
\text { NHANES, 2007/08; } \\
2009 / 10 \text { Consumer } \\
\text { Behavior Phone } \\
\text { Follow-Up Modules }\end{array}$ & $\begin{array}{l}\mathrm{PIR} \leq 130 \% \mathrm{v} . \\
>130 \% \text { poverty } \\
\text { threshold }\end{array}$ & $\begin{array}{l}\mathrm{HEl}- \\
2010\end{array}$ & $\mathrm{HEl}<51.6: 1.18,95 \% \mathrm{Cl}: 0.99,1.44 ; \mathrm{NS}$ & $\begin{array}{l}\text { Did not account for confounders } \\
\text { of: Urban vs. Rural; Food } \\
\text { security; Serious concerns due to } \\
\text { missing data }\end{array}$ \\
\hline \multicolumn{7}{|c|}{ Both income and Federal assistance program participation/eligibility } \\
\hline Gu, $2017^{24}$ & $\begin{array}{l}\text { All y: } \\
38,48 \\
7 \\
Y \text { in or } \\
\text { after } \\
2008 \text { : } \\
16,80 \\
2\end{array}$ & $\begin{array}{l}\text { Children, } 2 \text { to } 18 \text { y; } \\
\text { National dataset } \\
\text { Data source: } \\
\text { NHANES, 1999-2012 }\end{array}$ & $\begin{array}{l}\text { Income: PIR } \\
\text { NSLP/SBP; SBP; } \\
\text { SNAP; }\end{array}$ & $\begin{array}{l}\mathrm{HEl}- \\
2010\end{array}$ & 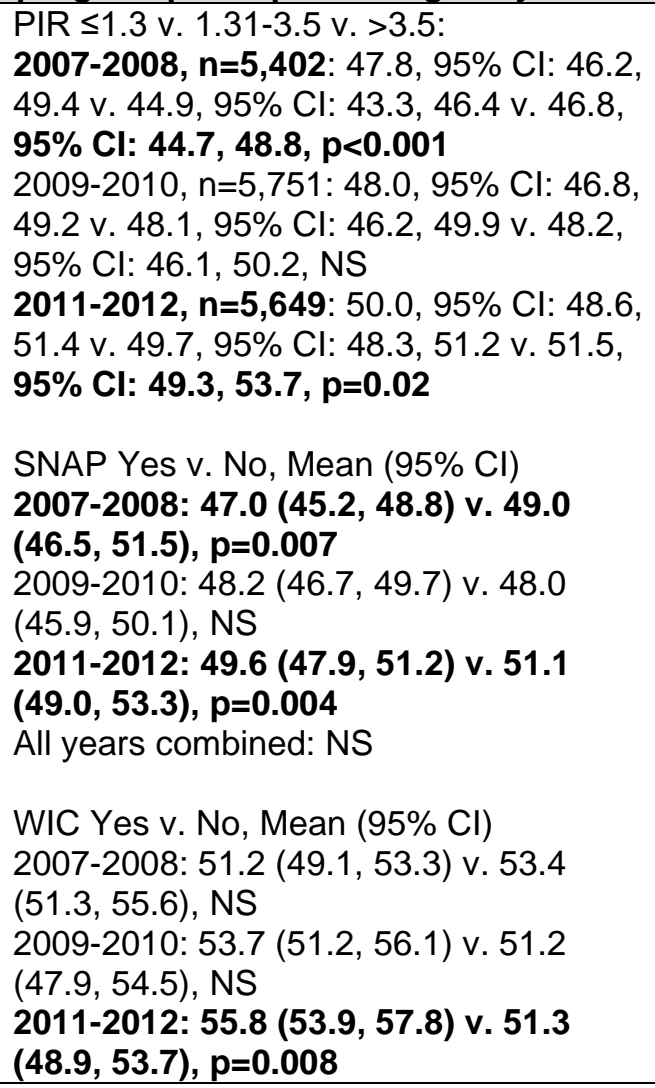 & $\begin{array}{l}\text { Did not account for confounders } \\
\text { of: Urban vs. Rural; Food } \\
\text { security; Some concerns with } \\
\text { departure from intended exposure }\end{array}$ \\
\hline
\end{tabular}


Results $^{\dagger}$

All years combined: Higher v. Lower (numbers not reported), $\mathrm{p}=\mathbf{0 . 0 0 6}$

NSLP/SBP Yes v. No, Mean $(95 \% \mathrm{Cl})$ 2007-2008: $45.2(44.2,46.2)$ v. 47.5

$(43.8,51.3), p<0.001$

2009-2010: $46.8(45.6,48.1)$ v. 43.2

$(40.2,46.2), \mathrm{NS}$

2011-2012: $49.0(47.8,50.3)$ v. 46.8

$(43.2,50.4)$, NS

All years combined: Lower v. Higher (numbers not reported). $\mathrm{p}=\mathbf{0 . 0 0 3}$

\begin{tabular}{|c|c|c|c|c|c|c|}
\hline $\begin{array}{l}\text { Gupta, } \\
2020^{25}\end{array}$ & 450 & $\begin{array}{l}\text { Adults, } 51.1 \mathrm{y}, \\
\text { primary food shoppers } \\
\text { with low access to } \\
\text { healthy food retail; } \\
\text { Ohio } \\
\text { Data source: N/A }\end{array}$ & $\begin{array}{l}\text { SNAP participation } \\
\text { in past } 12 \text { mo; WIC } \\
\text { participation in past } \\
12 \text { mo; Other } \\
\text { federal assistance } \\
\text { in past } 12 \text { mo } \\
\text { (TANF, Medicaid, } \\
\text { disability, or SSI) } \\
\text { Income: }<\$ 10 \mathrm{~K}, \\
\$ 10,001-\$ 20 \mathrm{~K}, \\
\$ 20,001-\$ 30 \mathrm{~K}, \\
\$ 30,001-\$ 40 \mathrm{~K}, \\
>\$ 40,001 \text { (ref). }\end{array}$ & $\begin{array}{l}\mathrm{HEl}- \\
2010\end{array}$ & $\begin{array}{l}\text { Income, > } \$ 40,001 \text { (ref): }<\$ 10 \mathrm{~K} \beta=-2.3 \text {, } \\
\text { NS; } \$ 10,001-\$ 20 \mathrm{~K} \beta=-2.9, \mathrm{NS} ; \$ 20,001- \\
\$ 30 \mathrm{~K} \beta=-0.7 ; \$ 30,001-\$ 40 \mathrm{~K} \beta=-1.8, \mathrm{NS} ; \\
\text { SNAP, non-participation (ref): } \beta=-2.5 \text {, } \\
\mathbf{p = 0 . 0 4 ;} \\
\text { WIC, non-participation (ref): } \beta=-2.2, N S \\
\text { Other: } \beta=0.4, N S ;\end{array}$ & $\begin{array}{l}\text { Some concerns with departure } \\
\text { from intended exposure; Serious } \\
\text { concerns with selection of } \\
\text { reported results; Limited } \\
\text { generalizability to those with } \\
\text { higher access to healthy food } \\
\text { retail. }\end{array}$ \\
\hline $\begin{array}{l}\text { Hanson, } \\
2013^{26}\end{array}$ & 2376 & $\begin{array}{l}\text { Children, } 6 \text { to } 17 \text { y; } \\
\text { National dataset } \\
\text { Data source: } \\
\text { NHANES, } 2003-2008\end{array}$ & $\begin{array}{l}\text { Family Income: } \\
<200 \% \text { poverty } \\
\text { threshold (ref), } \\
>200 \% \text { poverty } \\
\text { threshold; } \\
\text { NSLP: no meals } \\
\text { (ref), school lunch } \\
\text { only, school } \\
\text { breakfast and } \\
\text { lunch; }\end{array}$ & $\begin{array}{l}\mathrm{HEl}- \\
2005\end{array}$ & 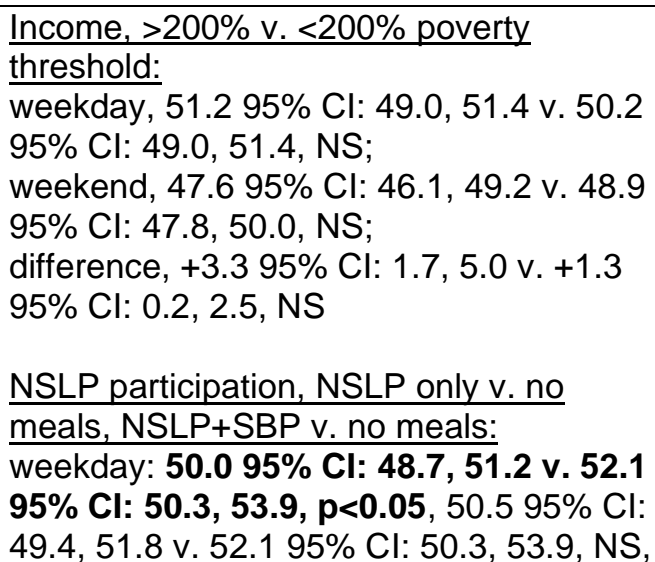 & $\begin{array}{l}\text { Serious concerns due to not } \\
\text { accounting for confounders of: } \\
\text { Urban vs. Rural; Cultural/racial } \\
\text { diversity or disparities; Sex; Age; } \\
\text { Food security; Serious concerns } \\
\text { with classification of exposure, } \\
\text { departure from intended } \\
\text { exposure, missing data, and } \\
\text { selection of reported results } \\
\text { related to intent of study to } \\
\text { capture weekday/weekend } \\
\text { changes in HEl. }\end{array}$ \\
\hline
\end{tabular}

\section{Summary of Limitations}




\section{Outcome Results ${ }^{\dagger}$}

weekend, $48.595 \%$ CI: $46.8,50.2$ v. 46.9 $95 \%$ Cl: $45.0,48.9$, NS, $48.595 \%$ Cl: $47.4,49.7$ v. $46.995 \%$ Cl: $45.0,48.9$, NS; difference, $+1.495 \% \mathrm{Cl}:-0.3,3.2$ v. +5.2 95\% Cl: 2.8, 7.6, $\mathrm{p}<0.05,+1.995 \% \mathrm{Cl}:$ $0.7,3.1$ v. $+5.295 \% \mathrm{Cl}: 2.8,7.6, \mathrm{p}<0.05$;

Hill, $2020^{28}$
Adult, $\geq 18 \mathrm{y}$, pregnant women in 2 nd trimester recruited

from WIC clinic: North Carolina

Data source: N/A
Monthly income: $\$ 0-1,000$ SNAP: Receives benefits or not

2010 Monthly income: $\$ 0-\$ 1000,54.96(14.16)$ $95 \% \mathrm{Cl}: 52.19,57.72$, v. $\geq \$ 1001,57.36$ (13.11) $95 \% \mathrm{Cl}: 54.68,60.05$; NS

SNAP: receives benefits, 56.61 (13.36) $95 \% \mathrm{Cl}: 54.05,59.17$ v. not receiving benefits, 55.51 (14.05) 95\% Cl: 52.63, 58.48; NS

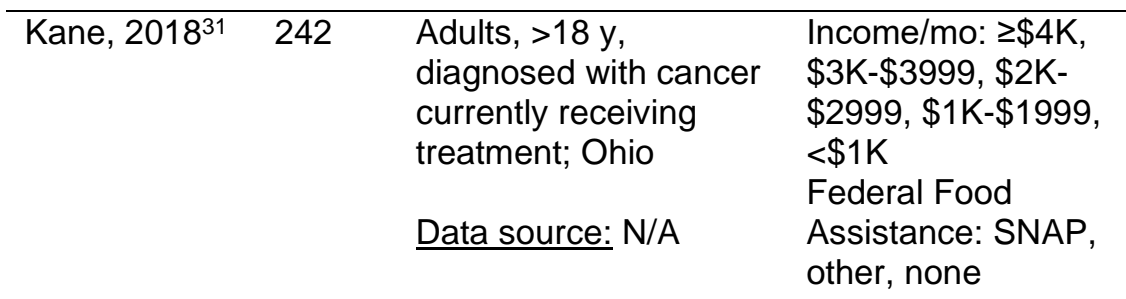

\section{HEI- \\ 2010 \\ Bivariate-Income/mo, $\geq \$ 4 \mathrm{~K} 64.69$ (10.52) (ref): \$3K-\$3999 63.61 (12.66), \$2K-\$2999 60.63 (11.01), \$1K-\$1999 57.25 (11.55), <\$1K 56.44 (12.12), $\mathrm{p} \leq 0.001$}

Bivariate-Fed Food Assistance: None 62.55 (11.61) (ref): SNAP 55.18 (9.59), Other 55.73 (16.39), $p \leq 0.01$

\section{Summary of Limitations}

Regression - Income/mo, $\geq \$ 4 \mathrm{~K}$ (ref): $\$ 3 \mathrm{~K}$ $\$ 3999 / \mathrm{mo}, \beta=0.79,95 \% \mathrm{Cl}:-2.97,4.55$, $\mathrm{p}=0.68$

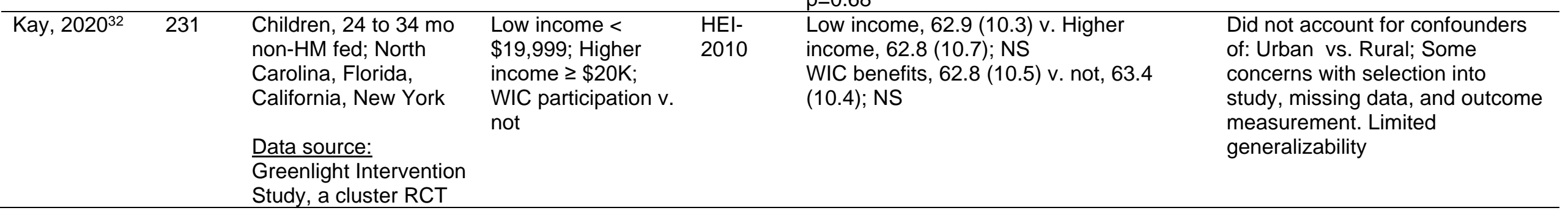




\begin{tabular}{|c|c|c|c|c|c|c|}
\hline Article $^{*}$ & $\mathbf{N}$ & Population & Exposure & Outcome & Results $^{\dagger}$ & Summary of Limitations \\
\hline $\begin{array}{l}\text { Kinderknecht, } \\
2020^{33}\end{array}$ & 6389 & $\begin{array}{l}\text { Children, } 5 \text { to } 18 \mathrm{y} \text {, } \\
\text { participating in NSL; } \\
\text { National dataset } \\
\text { Data source: } \\
\text { NHANES, 2007-2016 }\end{array}$ & $\begin{array}{l}\text { NSLP participation } \\
\text { or not, before and } \\
\text { after Healthy, } \\
\text { Hunger-Free Kids } \\
\text { Act (HHFKA); } \\
\text { Income: } \leq 130 \% \\
\text { poverty threshold } \\
\text { (low); >130\%- } \\
\leq 185 \% \text { poverty } \\
\text { threshold (low- } \\
\text { middle); and } \\
>185 \% \text { poverty } \\
\text { threshold (middle- } \\
\text { high) }\end{array}$ & $\begin{array}{l}\text { HEl- } \\
2010\end{array}$ & $\begin{array}{l}\text { Stratified by income, difference between } \\
\text { before and after HHFKA for NSLP } \\
\text { participants v. nonparticipants: } \\
\text { low income, } 3.495 \% \mathrm{Cl}: \mathbf{0 . 5 , 6 . 3 , p = 0 . 0 2 ;} \\
\text { low-middle income, } 4.795 \% \mathrm{Cl}: \mathbf{0 . 8 , 8 . 7} \\
\text { p=0.02; } \\
\text { middle-high income, } 1.995 \% \mathrm{Cl} \text { : - } \\
0.08,4.5 ; \mathrm{NS}\end{array}$ & $\begin{array}{l}\text { Did not account for confounders } \\
\text { of: Urban vs. Rural; Food } \\
\text { security; Serious or some } \\
\text { concerns with selection into } \\
\text { study, classification of exposures, } \\
\text { departure from intended } \\
\text { exposures, missing data, and } \\
\text { reported results. Limited } \\
\text { generalizability }\end{array}$ \\
\hline Liu, $2020^{39}$ & 31420 & $\begin{array}{l}\text { Children, } 2 \text { to } 19 \mathrm{y}_{i} \\
\text { National dataset } \\
\frac{\text { Data source: NHANES }}{1999-2016}\end{array}$ & $\begin{array}{l}\text { PIR: }<1.30,1.30- \\
1.849,1.85-2.99 \\
\geq 3.00 \\
\text { SNAP: Yes/No } \\
\text { WIC: Yes/No } \\
\text { NSLP/SBP: Yes/No }\end{array}$ & $\begin{array}{l}\text { HEl- } \\
2015\end{array}$ & 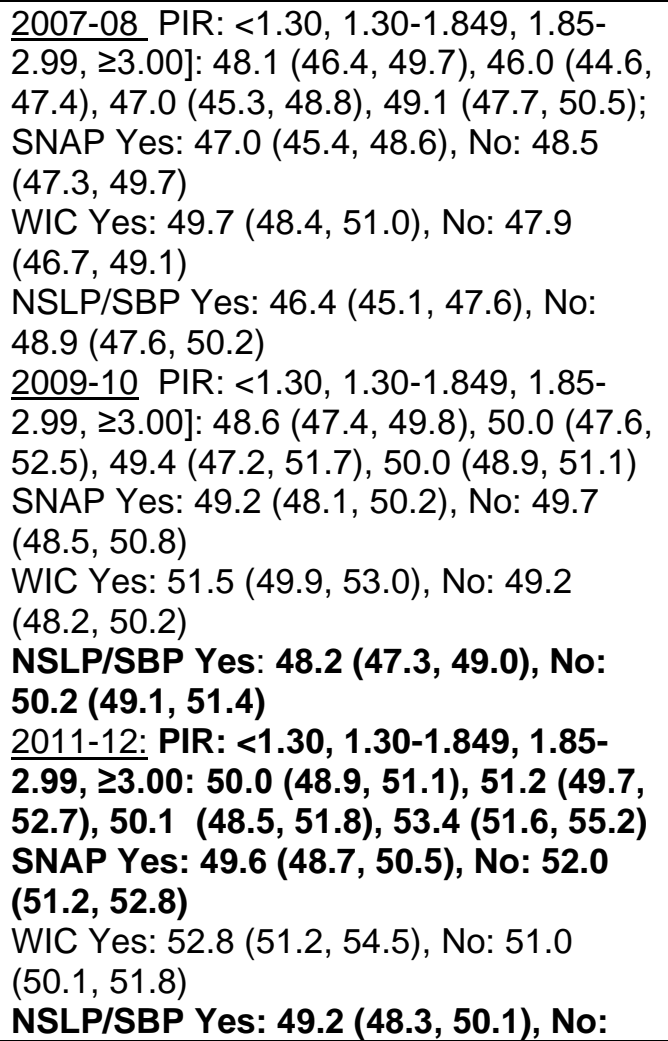 & $\begin{array}{l}\text { Serious risk due to confounding } \\
\text { due to not accounting for } \\
\text { confounders of: Urban vs. Rural; } \\
\text { Cultural/racial diversity or } \\
\text { disparities; Sex; Age; Food } \\
\text { security }\end{array}$ \\
\hline
\end{tabular}



2.99, $\geq 3.00: 49.6(48.2,51.1), 49.9$ (48.2 $51.7), 49.3(47.6,50.9), 50.7(48.7,52.8)$ SNAP Yes: 50.1 (48.9, 51.2), No: 49.9

$(48.8,51.1)$

WIC Yes: 51.3 (49.3, 53.2), No: 49.7

$(48.8,50.6)$

NSLP/SBP Yes: $49.2(48.0,50.3)$, No:

50.4 (49.2-51.5)

2015-16 (no SNAP or WIC data this cycle):

PIR: $<1.30,1.30-1.849,1.85-2.99, \geq 3.00$ :

$48.3(46.7,49.9), 48.8(47.2,50.4), 50.7$

$(48.8,52.7), 50.1(48.3,51.9)$

NSLP/SBP Yes: 47.9 (46.6, 49.2), No:

$50.8(49.5,52.1)$

\begin{tabular}{|c|c|c|c|c|c|c|}
\hline Tovar, $2020^{55}$ & 119 & $\begin{array}{l}\text { Child-care centers } \\
\text { with providers and } 374 \\
\text { children; Providence, } \\
\text { Rhode Island } \\
\text { Data source: Healthy } \\
\text { Start/Comienzos } \\
\text { Sanos }\end{array}$ & $\begin{array}{l}\text { Income: }<\$ 25 \mathrm{k}, \\
\$ 25,001-\$ 50 \mathrm{k}, \\
\$ 75 \mathrm{k}+ \\
\text { Federal: Receives } \\
\text { CACFP subsidies } \\
\text { (Yes/No) }\end{array}$ & $\begin{array}{l}\text { HEI- } \\
2015\end{array}$ & $\begin{array}{l}\text { Income: }<\$ 25 \mathrm{k}(\mathrm{ref}) ; \$ 25,001-\$ 50 \mathrm{k}, \beta=2.9 \\
{[3.0], p=0.3 ; \$ 75 \mathrm{k}+, \beta=-5.6[4.0] p=0.17} \\
\text { NS } \\
\text { CACFP: No (ref); Yes; } \beta=4.6[2.6] \\
p=0.08, \text { NS }\end{array}$ & $\begin{array}{l}\text { Did not account for confounders } \\
\text { of: Urban vs. Rural; Age; Food } \\
\text { security; Serious/some concerns } \\
\text { on most domains of bias }\end{array}$ \\
\hline $\begin{array}{l}\text { Weinfield, } \\
2021^{59}\end{array}$ & 1223 & $\begin{array}{l}\text { Dyads of Mothers with } \\
\text { child } 3 \text { y;National } \\
\text { dataset } \\
\text { Data source: Special } \\
\text { Supplemental Nutrition } \\
\text { Program for WIC } \\
\text { Infant and Toddler } \\
\text { Feeding Practices } \\
\text { Study-2 }\end{array}$ & $\begin{array}{l}\text { Poverty: }>130 \% \\
\text { poverty threshold, } \\
75 \% \text { or less, }>75 \% \\
\text { and }<130 \% \text { poverty } \\
\text { threshold } \\
\text { WIC Duration: Low, } \\
\text { Intermediate, High }\end{array}$ & $\begin{array}{l}\mathrm{HEI}- \\
2015\end{array}$ & 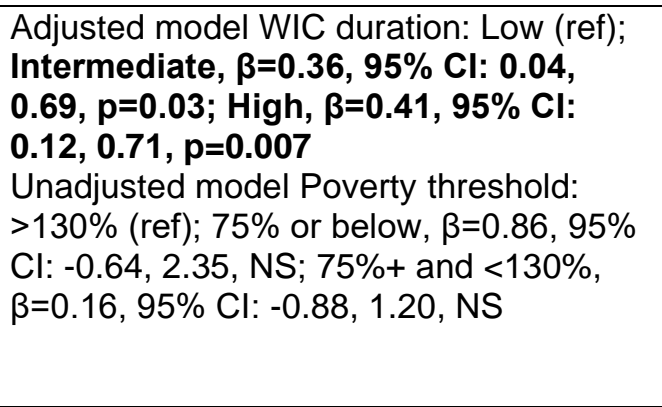 & $\begin{array}{l}\text { Did not account for confounders } \\
\text { of: Urban vs. Rural; Food } \\
\text { security; Serious concerns with } \\
\text { departure from intended } \\
\text { exposures; Indirectly compared } \\
\text { exposure via WIC duration }\end{array}$ \\
\hline \multicolumn{7}{|c|}{ Federal participation/ eligibility } \\
\hline Allen, $2016^{6}$ & 1741 & $\begin{array}{l}\text { Adults, } 30 \text { to } 64 \mathrm{y} ; \\
\text { Baltimore, Maryland }\end{array}$ & $\begin{array}{l}\text { SNAP participation } \\
\text { V. not }\end{array}$ & $\begin{array}{l}\mathrm{HEI}- \\
2010\end{array}$ & $\begin{array}{l}\text { SNAP: } \mathbf{- 2 . 7 4}[\mathbf{0 . 9 0}], \mathbf{p}=\mathbf{0 . 0 0 2} \\
\text { Food insecurity * SNAP: }-0.80[0.39] \text {, }\end{array}$ & $\begin{array}{l}\text { Some concerns with selection } \\
\text { bias due to missing } \mathrm{f} / \mathrm{u} \text {; Methods }\end{array}$ \\
\hline
\end{tabular}


Article*

$\mathbf{N}$ Population

Exposure

Data source: HANDLS

Condon,
$2015 a^{13}$ 16689

Children and Adults, $\geq 2$ y; National dataset

SNAP: eligibility and participation

HEI-

Data source:

NHANES, 2007-2010;

MPED 2.0; CNPP Fact

Sheet No. 1, 2006

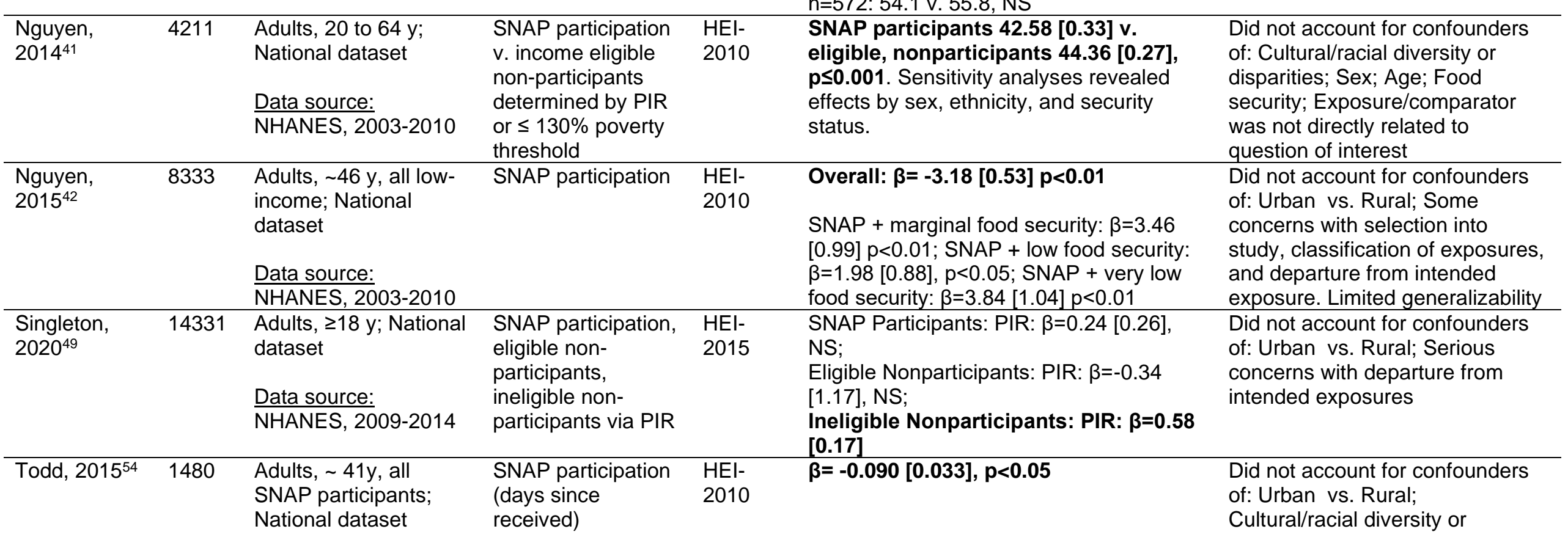

Summary of Limitations

used to assess exposure not well defined; Some concerns with departure from intended exposure due to SNAP status instability

Did not account for confounders of: Urban vs. Rural; Some concerns with selection into study, departure from intended exposure, and missing data

All ages: 56.8 v. $60.3, p<0.05$ v. 60.2 $p<0.05$;

Children: 57.9 v. $61.0, \mathrm{p}<0.05$ v. $59.0, \mathrm{NS}$

Adults: 53.9 v. $58.2, p<0.05$ v. 59.0 ,

p<0.05;

Older adults: 64.0 v. 65.6 , NS v. $65.6, \mathrm{NS}$;

$\geq 16 \mathrm{y}$, matched SNAP-eligible

participants, $n=975$ v. nonparticipants,

$n=572: 54.1$ v. 55.8 , NS

eligible, nonparticipants 44.36 [0.27]

disparities; Sex; Age; Food security; Exposure/comparator

not directly related to

of: Urban vs. Rural; Some concerns with selection into and departure from intended exposure. Limited generalizability Cultural/racial diversity or 


\begin{tabular}{|c|c|c|c|c|c|c|}
\hline Article $^{\star}$ & $\mathbf{N}$ & Population & Exposure & Outcome & Results $^{\dagger}$ & Summary of Limitations \\
\hline & & $\begin{array}{l}\text { Data source: } \\
\text { NHANES, 2007-2010 }\end{array}$ & & & & $\begin{array}{l}\text { disparities; Sex; Age; Limited } \\
\text { generalizability }\end{array}$ \\
\hline $\begin{array}{l}\text { Bremer, } \\
2018^{2}\end{array}$ & 146 & $\begin{array}{l}\text { Adults, > } 18 \text { y, from } \\
\text { the intervention group } \\
\text { of the trial; } \\
\text { southwestern Virginia } \\
\text { Data source: } \\
\text { SIPsmartER trial }\end{array}$ & $\begin{array}{l}\text { SNAP-participants, } \\
\text { SNAP-eligible } \\
\text { nonparticipants, } \\
\text { and Ineligible- } \\
\text { nonparticipants }\end{array}$ & $\begin{array}{l}\text { HEl- } \\
2010\end{array}$ & $\begin{array}{l}\text { At baseline, SNAP participants v. Eligible, } \\
\text { nonparticipants v. Ineligible: } 39.2(10.8) \mathrm{v} \text {. } \\
42.1 \text { (13.6) v. } 45.7 \text { (12.5), } \mathrm{p}=0.160 ; \mathrm{NS} \\
\text { After } 6 \text { mo, SNAP participants v. Eligible, } \\
\text { nonparticipants v. Ineligible: } 41.3 \text { (10.7) v. } \\
42.2(11.3) \text { v. } 50.8(14.0), p=0.160 ; \mathrm{NS}\end{array}$ & $\begin{array}{l}\text { Did not account for confounders } \\
\text { of: Urban vs. Rural; Food } \\
\text { security; Some concerns with } \\
\text { classification of exposure due to } \\
\text { self-selection/proxy calculations; } \\
\text { Some concerns with departure } \\
\text { from intended exposure due to } \\
\text { lack of accounting for food } \\
\text { insecurity/hunger; }\end{array}$ \\
\hline $\begin{array}{l}\text { Condon, } \\
2015 b^{14}\end{array}$ & 5814 & $\begin{array}{l}\text { Children in school, } 5 \\
\text { to } 18 \text { y; National } \\
\text { dataset } \\
\text { Data source: } \\
\text { NHANES, 2005-2010 }\end{array}$ & $\begin{array}{l}\text { NSLP participants } \\
\text { v. nonparticipants } \\
\text { (all income eligible } \\
\text { for free/RP meals) } \\
\text { NSLP participants } \\
\text { v. nonparticipants } \\
\text { (all higher income) }\end{array}$ & $\begin{array}{l}\mathrm{HEl}- \\
2005\end{array}$ & $\begin{array}{l}\text { NSLP participants v. nonparticipants } \\
\text { (all free/RP meals): } 60.5 \text { [1.24] v. } 55.1 \\
\text { [1.23], } p<0.05 \\
\text { In 5-8 y, NS; In 9-13 y, } 61.3 \text { [1.75] v. } 54.2 \\
\text { [1.78], p<0.01 (similar results by sex in } \\
\text { boys and girls); In 14-18 y, NS } \\
\text { NSLP participants v. nonparticipants (all } \\
\text { higher income): } 56.8 \text { [1.19] v. } 57.1 \text { [1.31], } \\
\text { NS } \\
\text { In } 5-8 \text { y, NS; In 9-13 y, NS; In } 14-18 \text { y, NS }\end{array}$ & $\begin{array}{l}\text { Did not account for confounders } \\
\text { of: Urban/rural, Cultural/racial } \\
\text { diversity or disparities; Food } \\
\text { security; Some concerns with } \\
\text { selection into study (excluded } \\
\text { children who bring lunch from } \\
\text { home), departure from intended } \\
\text { exposure, and missing data. }\end{array}$ \\
\hline Fox, $2019^{19}$ & 4141 & $\begin{array}{l}\text { Children in } \\
\text { Elementary, Middle, } \\
\text { and High school; } \\
\text { National dataset } \\
\text { Data source: School } \\
\text { Nutrition and Meal } \\
\text { Cost Study }\end{array}$ & $\begin{array}{l}\text { NSLP participation } \\
\text { v. not; SBP } \\
\text { participation v. not }\end{array}$ & $\begin{array}{l}\text { HEl- } \\
2010\end{array}$ & $\begin{array}{l}\text { NSLP vs.. nonparticipants: } \\
\text { Elementary-school: } 65.1 \text { v. } 60.8, \mathrm{NS} \\
\text { Middle-school: } 65.9 \text { v. } 62.9, \mathrm{NS} \\
\text { High-school: } 63.6 \text { v. } 59.7, \mathrm{NS} \\
\text { All students: } 65.2 \text { v. } 60.6, \mathrm{p}<0.05 \\
\text { SBP vs.. nonparticipants: } \\
\text { Elementary-school: } 66.4 \text { v. } 63.4, \mathrm{NS} \\
\text { Middle-school: } 63.7 \text { v. } 64.9, \mathrm{NS} \\
\text { High-school: } 63.8 \text { v. } 59.8, \mathrm{p}<0.05 \\
\text { All students: } 65.5 \text { v. } 62.8, \mathrm{NS}\end{array}$ & $\begin{array}{l}\text { Did not account for confounders } \\
\text { of: Food security }\end{array}$ \\
\hline $\begin{array}{l}\text { Gearan, } \\
2020^{21}\end{array}$ & 2165 & $\begin{array}{l}\text { Children, } 6 \text { to } 19 \text { y; } \\
\text { National dataset } \\
\text { Data source: School } \\
\text { Nutrition and Meal } \\
\text { Cost Study }\end{array}$ & $\begin{array}{l}\text { NSLP participation } \\
\text { or not on day of } 24 \\
\text { hour recall ( } 9 \% \\
\text { missing data } \\
\text { imputed) }\end{array}$ & $\begin{array}{l}\text { HEl- } \\
2010\end{array}$ & $\begin{array}{l}\text { NSLP v. nonparticipants: } 65 \% \text { v. } 61 \% \text {, } \\
\text { p<0.05 } \\
24 \mathrm{~h} \text { intake, both lower-income: } 65.3 \mathrm{v} . \\
61.4 \text {; difference: } 3.9 ; \text { NS } \\
\text { 24h intake, both higher-income: } 65 \text { v. } \\
\text { 60.9, difference: } 4 \text {, p<0.05 } \\
\text { Lunch intakes, both lower-income: }\end{array}$ & $\begin{array}{l}\text { Did not account for confounders } \\
\text { of: Urban vs. Rural; Food } \\
\text { security; Some concerns related } \\
\text { to missing data }\end{array}$ \\
\hline
\end{tabular}


Article $^{*}$

$\mathbf{N}$ Population

\section{Outcome Results ${ }^{\dagger}$}

79.8 v. 68.0, difference: 11.8, $\mathrm{p}<0.05$

Lunch intakes, both higher-income:

80.5 v. 62.1, difference: $18.4, p<0.05$

Gregory

201323

5105

Households of all low-

income participants $\leq$

$200 \%$ poverty

threshold; National

dataset

Data source:

NHANES, 2003-2008;

ERS

\begin{tabular}{lll}
\hline Hearst, & 739 & Children/Adolescents, \\
$2016^{27}$ & & 9th to 10th grade; rural \\
& Minnesota
\end{tabular}

Data source: Fueling

Academics and

Strengthening Teens

Study (Break-FAST)

Hudak, $2797 \quad$ Children, 2 to $18 \mathrm{y}$;

$2021^{29}$

National dataset

Data source:

NHANES, 2007-2008;

2011-2012

\section{SNAP participation $\mathrm{HEl}-$}

v. nonparticipation

over 12 mo

2005

SNAP: 51.02 v. Non-SNAP 47.49,

$p<0.01$

SNAP v. Non-SNAP: OLS marginal

effects -0.66 [0.65], NS

SNAP v. Non-SNAP: MFX Tx effects

MLE -1.56 [0.25], $p<0.01$

\section{HEl- $\quad$ Free/Red. cost lunch v. Full-price lunch:}

$2010 \beta=-0.60$ [0.79], $p=0.45$, NS

ree/reduced

lunch v. full-price

lunch

SNAP-eligible
$<150 \%$ poverty
threshold; Nearly
SNAP-eligible
between $150 \%$ and
$250 \%$ poverty
threshold
cost lunch, $n=267: 52.1$, NS

\section{Pre-ARRA: SNAP-eligible, 46.4 [1.02] v. \\ 2010 nearly eligible 43.7 [1.00]; NS}

post-ARRA: SNAP-eligible, 47.3 [0.73] v nearly eligible 46.6 [0.73]; NS

SNAP benefit increase, overall before v. after ARRA: -1.99
Summary of Limitations

Did not account for confounders of: Urban vs. Rural; Food security; Some concerns with classification of exposure and departure from intended exposure; Limited generalizability

Full-price lunch, $\mathrm{n}=472: 51.8 \mathrm{v}$. Free/Red.

Did not account for confounders of: Food security; Some concerns with selection into study, departure from intended exposures, and missing data.

ARRA-increase by age: Toddlers 2-3y, n=665: 2.55 [3.47]; Preschoolers 4-5y, $\mathrm{n}=550:-2.61$ [3.01]; Children 6-11 y, $\mathrm{n}=1186$ : -2.86 [2.48]; Adolescents 1218y, $n=1186:-4.61$ (2.21), $p<0.05$

\begin{tabular}{|c|c|c|c|c|c|c|}
\hline $\begin{array}{l}\text { Landry, } \\
2019^{35}\end{array}$ & 598 & $\begin{array}{l}\text { Children, 3rd to 5th } \\
\text { grade; Austin, Texas } \\
\text { Data source: TX } \\
\text { Sprouts }\end{array}$ & $\begin{array}{l}\text { SNAP Participation: } \\
\text { Yes/No }\end{array}$ & $\begin{array}{l}\mathrm{HEl}- \\
2015\end{array}$ & $\begin{array}{l}\text { Unadjusted: SNAP Participation: Yes } \\
\text { (ref); No, } \beta=1.6, \text { SE: } 1.25,95 \% \mathrm{Cl}:-0.85 \text {, } \\
4.05, p=0.200 \text {, NS }\end{array}$ & $\begin{array}{l}\text { Did not account for confounders } \\
\text { of: Urban vs. Rural; Some } \\
\text { concerns with departure from } \\
\text { intended exposures, missing } \\
\text { data, outcome measurement, and } \\
\text { reported results. }\end{array}$ \\
\hline
\end{tabular}

nesr.usda.gov | 112
Dot account for confounders of: Urban vs. Rural; Some concerns with selection into study and classification of exposures; Serious concerns due to departure from intended exposures. reported results. 


\begin{tabular}{|c|c|c|c|c|c|c|}
\hline Article $^{*}$ & $\mathbf{N}$ & Population & Exposure & Outcome & Results $^{\dagger}$ & Summary of Limitations \\
\hline $\begin{array}{l}\text { Leung, } \\
2012^{37}\end{array}$ & 3835 & $\begin{array}{l}\text { Adults, non-elderly; } \\
\text { National dataset } \\
\text { Data source: NHANES } \\
\text { 1999-2008 }\end{array}$ & $\begin{array}{l}\text { SNAP Participants } \\
\text { vs. non-participants }\end{array}$ & $\begin{array}{l}\text { HEl- } \\
2005\end{array}$ & $\begin{array}{l}\text { HEl: SNAP Nonparticipants (ref), SNAP } \\
\text { Participants, RD=0.98, 95\% Cl: } 0.94, \\
\text { 1.02, NS }\end{array}$ & $\begin{array}{l}\text { Accounted for confounders; } \\
\text { Some concerns with departure } \\
\text { from intended exposures (i.e. } \\
\text { variation in SNAP status), missing } \\
\text { data, and reported results. }\end{array}$ \\
\hline $\begin{array}{l}\text { Leung, } \\
2013^{38}\end{array}$ & 5193 & $\begin{array}{l}\text { Children, } 4 \text { to } 19 \text { y, all } \\
\text { low-income } \leq 130 \% \\
\text { poverty threshold; } \\
\text { National dataset } \\
\text { Data source: } \\
\text { NHANES, } 1999-2008\end{array}$ & $\begin{array}{l}\text { SNAP participants } \\
\text { v. income eligible } \\
\text { non-participants } \\
\text { (former participants } \\
\text { within last } 12 \text { mo } \\
\text { were excluded) }\end{array}$ & $\begin{array}{l}\text { HEl- } \\
2005\end{array}$ & $\begin{array}{l}\text { SNAP Nonparticipants, } 47.2(0.5) \mathrm{v} . \\
\text { participants, } 45.6(0.6), \mathrm{NS}\end{array}$ & $\begin{array}{l}\text { Did not account for confounders } \\
\text { of: Urban vs. Rural; Some } \\
\text { concerns with departure from } \\
\text { intended exposures, missing } \\
\text { data, and reported results. }\end{array}$ \\
\hline $\begin{array}{l}\text { Sanjeevi, } \\
2021^{47}\end{array}$ & $\begin{array}{l}\text { Adult: } \\
2784 \text {; } \\
\text { Child: } \\
2553\end{array}$ & $\begin{array}{l}\text { Adults and Children, } 3 \\
\text { to } 75 \mathrm{y} \text {, all low- } \\
\text { income; National } \\
\text { dataset } \\
\frac{\text { Data source: NHANES }}{2011-2016}\end{array}$ & $\begin{array}{l}\text { SNAP current v. } \\
\text { former participants } \\
\text { with benefits cut off } \\
\text { in past year; cut off } \\
\text { for }>1 \mathrm{y}\end{array}$ & $\begin{array}{l}\text { HEl- } \\
2015\end{array}$ & $\begin{array}{l}\text { Adults: Current SNAP (ref); Benefits cut } \\
\text { off in past year: } \beta=0.02 \text { [1.25], } p=0.99 \text {, } \\
\text { NS; Benefits cut off }>1 \text { y: } \beta=-0.66[0.94] \text {, } \\
p=0.49, N S \\
\text { Children: Current SNAP (ref); Benefits cut } \\
\text { off in past year: } \beta=-0.03 \text { [1.58], } p=0.99 \text {, } \\
\text { NS; Benefits cut off }>1 \text { y: } \beta=-1.34[0.99] \text {, } \\
p=0.18, N S\end{array}$ & $\begin{array}{l}\text { Did not account for confounders } \\
\text { of: Urban vs. Rural; Serious } \\
\text { concerns with departure from } \\
\text { intended exposures; Limited } \\
\text { generalizability }\end{array}$ \\
\hline $\begin{array}{l}\text { Thomas } \\
\text { Berube, } \\
2019^{51}\end{array}$ & 519 & $\begin{array}{l}\text { Adults, all Hispanic } \\
\text { women who are } \\
\text { pregnant; New York } \\
\text { City, New York } \\
\text { Data source: Starting } \\
\text { Early Trial }\end{array}$ & $\begin{array}{l}\text { WIC Participation } \\
\text { (yes/no) } \\
\text { SNAP Participation } \\
\text { (yes/no) }\end{array}$ & $\begin{array}{l}\mathrm{HEl-} \\
2015\end{array}$ & $\begin{array}{l}\text { WIC Participation: No (ref), Yes, } \beta=2.1 \text {, } \\
95 \% \mathrm{Cl}:-0.1,4.4, p=0.06, \mathrm{NS} \\
\text { SNAP: No (ref), Yes, } \beta=-0.3,95 \% \mathrm{Cl} \text { - } \\
\text { 1.9, 1.3, } p=0.73, \mathrm{NS}\end{array}$ & $\begin{array}{l}\text { Did not account for confounders } \\
\text { of: Urban vs. Rural; } \\
\text { Cultural/racial diversity or } \\
\text { disparities; Food security; Limited } \\
\text { generalizability }\end{array}$ \\
\hline $\begin{array}{l}\text { Waehrer, } \\
2015^{56}\end{array}$ & 4158 & $\begin{array}{l}\text { Adults, } \geq 19 \text { y; } \\
\text { National dataset } \\
\text { Data source: } \\
\text { NHANES, } 2007-2010\end{array}$ & $\begin{array}{l}\text { SNAP eligible ( } \leq \\
150 \% \text { poverty } \\
\text { threshold) v. } \\
\text { ineligible (150- } \\
250 \% \text { poverty } \\
\text { threshold) }\end{array}$ & $\begin{array}{l}\mathrm{HEl}- \\
2005\end{array}$ & $\begin{array}{l}\text { pre-ARRA } \leq 150 \%: 53.9 ; \text { post-ARRA } \leq \\
\text { 150\%: } 53.5, \mathrm{NS} \\
\text { pre-ARRA } 150-250 \%: 54.9 \text {; post-ARRA } \\
\text { 150-250\%: 56.6, NS }\end{array}$ & $\begin{array}{l}\text { Did not account for confounders } \\
\text { of: Urban vs. Rural; Food } \\
\text { security; Exposure was not } \\
\text { directly related to the question of } \\
\text { interest }\end{array}$ \\
\hline
\end{tabular}


Article $^{*}$

a Abbreviations: ARRA, American Recovery and Reinvestment Act of 2008; EFNEP, Expanded Food and Nutrition Education Program; FPG, Federal Poverty Guidelines; HANDLS, Healthy Aging in Neighborhoods of Diversity across the Life Span Study; HEl, healthy eating index; Healthy, Hunger-Free Kids Act (HHFKA); HH, household; mo, months; N/A, not applicable or available; NHANES, National Health and Nutrition Examination Survey; NSLP, National School Lunch Program; NS, not statistically significant; \% percent; PIR:

poverty-to-income ratio; SBP, School Breakfast Program; SNAP, Supplemental Nutrition Assistance Program; SSI, Supplemental Security Income; WIC, Supplemental Assistance Program for Women, Infants and Children; $y$, years 
Table 2-c. Risk of bias for observational studies examining income and $\mathrm{HEI}^{\mathrm{a}}$

\begin{tabular}{|c|c|c|c|c|c|c|c|}
\hline Article & Confounding & $\begin{array}{l}\text { Selection of } \\
\text { participants }\end{array}$ & $\begin{array}{l}\text { Classification } \\
\text { of exposures }\end{array}$ & $\begin{array}{l}\text { Deviations } \\
\text { from intended } \\
\text { exposures }\end{array}$ & Missing data & $\begin{array}{c}\text { Outcome } \\
\text { measurement }\end{array}$ & $\begin{array}{l}\text { Selection of } \\
\text { the reported } \\
\text { result }\end{array}$ \\
\hline Beydoun, $2018^{1 *}$ PCS & SERIOUS & LOW & MODERATE & SERIOUS & MODERATE & MODERATE & SERIOUS \\
\hline Bremer, $2018^{2 *}$ PCS & SERIOUS & MODERATE & MODERATE & SERIOUS & MODERATE & MODERATE & LOW \\
\hline Covington, $2020^{3}{ }^{*} \mathrm{PCS}$ & SERIOUS & MODERATE & LOW & LOW & MODERATE & LOW & MODERATE \\
\hline Taverno Ross, $2020^{4}$ *PCS & SERIOUS & MODERATE & MODERATE & LOW & MODERATE & MODERATE & MODERATE \\
\hline Aggarwal, $2016^{5}$ & SERIOUS & MODERATE & LOW & MODERATE & MODERATE & LOW & MODERATE \\
\hline Allen, $2016^{6}$ & SERIOUS & SERIOUS & MODERATE & SERIOUS & MODERATE & LOW & LOW \\
\hline Beatty, $2014^{7}$ & SERIOUS & MODERATE & MODERATE & MODERATE & LOW & SERIOUS & SERIOUS \\
\hline Bekelman, $2021^{8}$ & SERIOUS & MODERATE & LOW & MODERATE & MODERATE & LOW & LOW \\
\hline Beydoun, $2015^{9}$ & MODERATE & SERIOUS & LOW & MODERATE & MODERATE & LOW & MODERATE \\
\hline Byker Shanks, $2020^{10}$ & MODERATE & MODERATE & LOW & LOW & LOW & LOW & MODERATE \\
\hline Chen, $2018^{11}$ & MODERATE & MODERATE & LOW & LOW & LOW & MODERATE & LOW \\
\hline Coltman, $2013^{12}$ & CRITICAL & SERIOUS & LOW & MODERATE & MODERATE & LOW & MODERATE \\
\hline Condon, $2015 \mathrm{a}^{13}$ & MODERATE & MODERATE & LOW & MODERATE & SERIOUS & MODERATE & MODERATE \\
\hline Condon, 2015b ${ }^{14}$ & SERIOUS & MODERATE & LOW & MODERATE & MODERATE & LOW & MODERATE \\
\hline Deierlein, $2014^{15}$ & LOW & MODERATE & LOW & MODERATE & LOW & LOW & MODERATE \\
\hline Deierlein, $2021^{16}$ & MODERATE & SERIOUS & LOW & SERIOUS & LOW & LOW & MODERATE \\
\hline
\end{tabular}


Article

\begin{tabular}{|l|l}
\hline Drewnowski, 2016 & LOW \\
\hline
\end{tabular}

Flórez, $2015^{18}$

Fox, $2019^{19}$

Freedman, 201920

Gearan, 202021

Gibbs, $2016^{22}$

Gregory, $2013^{23}$

Gu, $2017^{24}$

Gupta, $2020^{25}$

Hanson, $2013^{26}$

Hearst, $2016^{27}$

Hill, $2020^{28}$

Hudak, $2021^{29}$

Huffman, $2014^{30}$

Kane, $2018^{31}$

Kay, $2020^{32}$

Kinderknecht, $2020^{33}$

S

STE

MODE
Confounding $\begin{aligned} & \text { Selection of } \\ & \text { participants }\end{aligned}$
Classification of exposures
Deviations

from intended Missing data exposures
Outcome measurement

LOW

Selection of

the reported result

MODERATE

\begin{tabular}{|l|l|l} 
MODERATE & MODERATE & MODERATE \\
\hline
\end{tabular}

LOW

LOW

MODERATE

\begin{tabular}{|c|c|}
\hline MODERATE & MODERATE \\
\hline MODERATE & MODERATE \\
\hline MODERATE & LOW \\
\hline
\end{tabular}

LOW

\begin{tabular}{|c|c|}
\hline MODERATE & LOW \\
\hline
\end{tabular}

MODERAT

MODERAT

SERIOUS

SERIOUS SERIOUS SERIOUS

MODERATE

MODERAT

MODERATE

MODERATE

MODERAT

Low

SERIOUS

MODERATE

MODERATE

SERIOUS

SERIOUS

\begin{tabular}{|c|c|c|}
\hline SERIOUS & MODERATE & MOD \\
\hline MODERATE & MODERATE & S \\
\hline MODERATE & LOW & MOD \\
\hline SERIOUS & MODERATE & MOD \\
\hline MODERATE & LOW & \\
\hline MODERATE & SERIOUS & MOD \\
\hline
\end{tabular}

MODERATE

SERIOUS

\begin{tabular}{|l|l|}
\hline SERIOUS \\
\hline SERIOUS \\
\hline SERIOUS
\end{tabular}

MODERATE

\begin{tabular}{|c|c|c|c|}
\hline MODERATE & MODERATE & MODERATE & MOD \\
\hline LOW & MODERATE & MODERATE & \\
\hline MODERATE & MODERATE & LOW & \\
\hline
\end{tabular}

\begin{tabular}{c|c|c|c|}
\hline LOW & MODERATE & MI \\
\hline LOW & MI \\
\hline
\end{tabular}

\begin{tabular}{|c|c|c|c|c|}
\hline MODERATE & MODERATE & LOW & LOW & MODERATE \\
\hline LOW & LOW & MODERATE & LOW & LOW \\
\hline LOW & LOW & LOW & LOW & LOW \\
\hline
\end{tabular}

\begin{tabular}{|c|c|c|c|c|}
\hline LOW & LOW & LOW & LOW & LOW \\
\hline MODERATE & MODERATE & LOW & LOW & MODERATE \\
\hline LOW & SERIOUS & LOW & LOW & MODERATE \\
\hline
\end{tabular}

\begin{tabular}{|c|c|c|c|c|}
\hline LOW & SERIOUS & LOW & LOW & MODERATE \\
\hline LOW & MODERATE & LOW & LOW & SERIOUS \\
\hline SERIOUS & SERIOUS & MODERATE & LOW & SERIOUS \\
\hline LOW & MODERATE & MODERATE & LOW & MODERATE \\
\hline MODERATE & MODERATE & MODERATE & LOW & MODERATE \\
\hline MODERATE & SERIOUS & MODERATE & LOW & LOW \\
\hline LOW & MODERATE & MODERATE & LOW & MODERATE \\
\hline MODERATE & MODERATE & MODERATE & LOW & SERIOUS \\
\hline LOW & LOW & MODERATE & MODERATE & LOW \\
\hline SERIOUS & MODERATE & SERIOUS & LOW & SERIOUS \\
\hline
\end{tabular}


Article

Kuczmarski, $2016^{34}$ Kuczmarski, 2016 34 Landry, 201935

Laster, $2013^{36}$

Leung, $2013^{38}$

Leung, $2012^{37}$

Liu, 202039

Martin, $2015^{40}$

Nguyen, 2014 41

Nyguen, $2015^{42}$

Nowlin, $2016^{43}$

Orr, $2019^{44}$

Patetta, $2019^{45}$

Richards Adams, $2019^{46}$

Sanjeevi, $2021^{47}$

Shan, $2019^{48}$

Singleton, $2020^{49}$

Springfield, $2019^{50}$
Confounding

Selection of participants

Classification of exposures
Deviations

from intended Missing data exposures
Outcome measurement
Selection of

the reported result

\begin{tabular}{|c|c|c|c|c|c|c|}
\hline MODERATE & MODERATE & LOW & MODERATE & LOW & LOW & LOW \\
\hline MODERATE & MODERATE & LOW & MODERATE & MODERATE & MODERATE & MODERATE \\
\hline SERIOUS & MODERATE & MODERATE & LOW & LOW & LOW & LOW \\
\hline MODERATE & MODERATE & LOW & MODERATE & SERIOUS & LOW & MODERATE \\
\hline LOW & MODERATE & LOW & MODERATE & MODERATE & LOW & MODERATE \\
\hline SERIOUS & MODERATE & MODERATE & MODERATE & MODERATE & LOW & MODERATE \\
\hline SERIOUS & MODERATE & LOW & LOW & MODERATE & LOW & LOW \\
\hline MODERATE & MODERATE & MODERATE & MODERATE & LOW & LOW & LOW \\
\hline MODERATE & MODERATE & LOW & MODERATE & MODERATE & LOW & MODERATE \\
\hline SERIOUS & MODERATE & LOW & SERIOUS & MODERATE & LOW & SERIOUS \\
\hline MODERATE & SERIOUS & LOW & MODERATE & MODERATE & LOW & MODERATE \\
\hline SERIOUS & MODERATE & LOW & MODERATE & MODERATE & LOW & MODERATE \\
\hline MODERATE & SERIOUS & LOW & MODERATE & LOW & LOW & MODERATE \\
\hline MODERATE & MODERATE & LOW & SERIOUS & MODERATE & LOW & SERIOUS \\
\hline SERIOUS & MODERATE & LOW & MODERATE & SERIOUS & LOW & LOW \\
\hline MODERATE & MODERATE & MODERATE & SERIOUS & MODERATE & LOW & MODERATE \\
\hline SERIOUS & SERIOUS & LOW & LOW & LOW & LOW & LOW \\
\hline
\end{tabular}




\begin{tabular}{|c|c|c|c|c|c|c|c|}
\hline Article & Confounding & $\begin{array}{l}\text { Selection of } \\
\text { participants }\end{array}$ & $\begin{array}{l}\text { Classification } \\
\text { of exposures }\end{array}$ & $\begin{array}{l}\text { Deviations } \\
\text { from intended } \\
\text { exposures }\end{array}$ & Missing data & $\begin{array}{c}\text { Outcome } \\
\text { measurement }\end{array}$ & $\begin{array}{l}\text { Selection of } \\
\text { the reported } \\
\text { result }\end{array}$ \\
\hline Thomas Berube, $2019^{51}$ & SERIOUS & MODERATE & LOW & MODERATE & MODERATE & LOW & MODERATE \\
\hline Thomson, $2020^{53}$ & SERIOUS & MODERATE & LOW & MODERATE & SERIOUS & LOW & LOW \\
\hline Thomson, $2019^{52}$ & SERIOUS & LOW & MODERATE & SERIOUS & MODERATE & LOW & LOW \\
\hline Todd, $2015^{54}$ & SERIOUS & MODERATE & SERIOUS & MODERATE & MODERATE & LOW & MODERATE \\
\hline Tovar, 202055 & SERIOUS & MODERATE & MODERATE & MODERATE & No Information & LOW & SERIOUS \\
\hline Waehrer, $2015^{56}$ & MODERATE & SERIOUS & LOW & MODERATE & LOW & LOW & LOW \\
\hline Wang, $2021^{57}$ & SERIOUS & LOW & LOW & LOW & LOW & LOW & MODERATE \\
\hline Weatherspoon, $2017^{58}$ & MODERATE & SERIOUS & MODERATE & SERIOUS & MODERATE & MODERATE & MODERATE \\
\hline Weinfield, $2021^{59}$ & SERIOUS & MODERATE & LOW & SERIOUS & MODERATE & LOW & LOW \\
\hline Wilcox, $2020^{60}$ & SERIOUS & MODERATE & LOW & SERIOUS & MODERATE & LOW & MODERATE \\
\hline
\end{tabular}

a Possible ratings of low, moderate, serious, critical, or no information determined using the "Risk of Bias for Nutrition Observational Studies" tool (RoB-NObs) (Dietary Guidelines Advisory Committee. 2020. Scientific Report of the 2020 Dietary Guidelines Advisory Committee: Advisory Report to the Secretary of Agriculture and the Secretary of Health and Human Services. U.S. Department of Agriculture, Agricultural Research Service, Washington, DC.) 


\section{References of the articles included in the income and $\mathrm{HEI}$ rapid}

\section{review}

1. Beydoun MA, Fanelli-Kuczmarski MT, Poti J, et al. Longitudinal change in the diet's monetary value is associated with its change in quality and micronutrient adequacy among urban adults. PLoS One. 2018;13(10):e0204141. doi: 10.1371/journal.pone.0204141. eCollection 2018.

2. Bremer MC, Zoellner JM, Misyak SA, Hedrick VE. Dietary intake changes in response to a sugar-sweetened beverage reduction trial for various supplemental nutrition assistance program (SNAP) eligibility groups. J Nutr Educ Behav. 2018;50(9):931-936. doi: 10.1016/j.jneb.2018.07.010.

3. Covington L, Armstrong B, Trude ACB, Black MM. Longitudinal associations among diet quality, physical activity and sleep onset consistency with body mass index z-score among toddlers in low-income families. Ann Behav Med. 2020. doi: 10.1093/abm/kaaa100.

4. Taverno Ross SE, Militello G, Dowda M, Pate RR. Changes in diet quality in youth living in south carolina from fifth to 11 th grade. J Nutr Educ Behav. 2020;52(10):928-934. doi: 10.1016/j.jneb.2020.03.001. Epub 2020 Apr 23.

5. Aggarwal A, Rehm CD, Monsivais $P$, Drewnowski A. Importance of taste, nutrition, cost and convenience in relation to diet quality: Evidence of nutrition resilience among US adults using National Health and Nutrition Examination Survey (NHANES) 2007-2010. Prev Med. 2016;90:184-192. doi: 10.1016/j.ypmed.2016.06.030. Epub 2016 Jun 29.

6. Allen AJ, Kuczmarski MF, Evans MK, Zonderman AB, Waldstein SR. Race differences in diet quality of urban food-insecure blacks and whites reveals resiliency in blacks. J Racial Ethn Health Disparities. 2016;3(4):706-712. doi: 10.1007/s40615-0150189-5. Epub 2015 Dec 10.

7. Beatty TKM, Lin B-H, Smith TA. Is diet quality improving? Distributional changes in the United States, 1989-2008. American Journal of Agricultural Economics. 2014;96(3):769-789. http://search.ebscohost.com/login.aspx?direct=true\&db=buh\&AN=95479693\&site=ehost-live.

8. Bekelman TA, Sauder KA, Rockette-Wagner B, Glueck DH, Dabelea D. Sociodemographic predictors of adherence to national diet and physical activity guidelines at age 5 years: the healthy start study. Am J Health Promot. 2021;35(4):514-524. doi: 10.1177/0890117120968654. Epub 2020 Oct 29.

9. Beydoun MA, Fanelli-Kuczmarski MT, Allen A, et al. Monetary value of diet Is associated with dietary quality and nutrient adequacy among urban adults, differentially by sex, race and poverty status. PLoS One. 2015;10(11):e0140905. doi: 10.1371/journal.pone.0140905. eCollection 2015.

10. Byker Shanks C, Ahmed S, Dupuis V, et al. Dietary quality varies among adults on the Flathead Nation of the Confederated Salish and Kootenai tribes in Montana. J Community Health. 2020;45(2):388-399. doi: 10.1007/s10900-019-00753-3.

11. Chen XW, Cisse-Egbuonye N, Spears EC, Mkuu R, McKyer ELJ. Children's healthy eating habits and parents' sociodemographic characteristics in rural Texas, USA. Health Educ J. 2018;77(4):444-457. <Go to ISI>://WOS:000436036400005.

12. Coltman AE, Keim KS, Chapman-Novakofski KM, Taylor CA. Assessing diet quality of a type 2 diabetes sample using the Healthy Eating Index 2005. Top Clin Nutr. 2013;28(2):145-153. <Go to ISI>://WOS:000209552700005.

13. Condon E, Drilea S, Jowers K, et al. Diet quality of americans by SNAP participation status: Data from the National Health and Nutrition Examination Survey, 2007-2010. Mathematica Policy Research;2015.

14. Condon E, Drilea S, Lichtenstein C, Mabli J, Madden E, Niland K. Diet quality of Americans by NSLP participation status: Data from the National Health and Nutrition Examination Survey, 2005-2010. Walter R. McDonald \& Associates, Inc, and Mathematica Policy Research;2015.

15. Deierlein AL, Morland KB, Scanlin K, Wong S, Spark A. Diet quality of urban older adults age 60 to 99 years: the Cardiovascular Health of Seniors and Built Environment Study. J Acad Nutr Diet. 2014;114(2):279-287. doi: 10.1016/j.jand.2013.09.002. Epub 2013 Nov 18.

16. Deierlein AL, Ghassabian A, Kahn LG, et al. Dietary quality and sociodemographic and health behavior characteristics among pregnant women participating in the New York university children's health and environment study. Front Nutr. 2021;8:639425. doi: 10.3389/fnut.2021.639425. eCollection 2021.

17. Drewnowski A, Aggarwal A, Cook A, Stewart O, Moudon AV. Geographic disparities in Healthy Eating Index scores (HEI-2005 and 2010) by residential property values: Findings from Seattle Obesity Study (SOS). Prev Med. 2016;83:46-55. doi: 10.1016/j.ypmed.2015.11.021. Epub 2015 Dec 3.

18. Flórez KR, Dubowitz T, Ghosh-Dastidar MB, Beckman R, Collins RL. Associations between depressive symptomatology, diet, and body mass index among participants in the supplemental nutrition assistance program. J Acad Nutr Diet. 2015;115(7):1102-1108. doi: 10.1016/j.jand.2015.01.001. Epub 2015 Mar 10.

19. Fox MK, Gearan E, Cabili C, et al. School nutrition and meal cost study final report volume 4: Student participation, satisfaction, plate waste, and dietary intakes. Mathematica Policy Research;2019.

20. Freedman DA, Bell BA, Clark JK, et al. Socioecological path analytic model of diet quality among residents in two urban food deserts. J Acad Nutr Diet. 2019;119(7):1150-1159. doi: 10.1016/j.jand.2019.02.012. Epub 2019 Apr 25.

21. Gearan EC, Monzella K, Jennings L, Fox MK. Differences in diet quality between school lunch participants and nonparticipants in the United States by income and race. Nutrients. 2020;12(12). doi: 10.3390/nu12123891.

22. Gibbs HD, Kennett AR, Kerling EH, et al. Assessing the nutrition literacy of parents and its relationship with child diet quality. $J$ Nutr Educ Behav. 2016;48(7):505-509.e501. doi: 10.1016/j.jneb.2016.04.006. Epub 2016 May 20. 
23. Gregory C, Ver Ploeg M, Andrews M, Coleman-Jensen A. Supplemental Nutrition Assistance Program (SNAP) participation leads to modest changes in diet quality. 2013:36.

24. Gu X, Tucker KL. Dietary quality of the US child and adolescent population: trends from 1999 to 2012 and associations with the use of federal nutrition assistance programs. Am J Clin Nutr. 2017;105(1):194-202. doi: 10.3945/ajcn.116.135095. Epub 2016 Nov 23.

25. Gupta NR, Freedman DA. Food security moderates relationship between perceived food environment and diet quality among adults in communities with low access to healthy food retail. Pub Health Nutr. 2020:1-12. doi: 10.1017/S1368980020001317.

26. Hanson KL, Olson CM. School meals participation and weekday dietary quality were associated after controlling for weekend eating among U.S. school children aged 6 to 17 years. $J$ Nutr. 2013;143(5):714-721. doi: 10.3945/jn.112.170548. Epub 2013 Mar 13.

27. Hearst MO, Harnack LJ, Wang Q, Nanney MS. Dietary quality of diverse, rural adolescents using the Healthy Eating Index 2010. Health Behav Policy Rev. 2016;3(6):519-527. doi: 10.14485/HBPR.3.6.1.

28. Hill AM, Nunnery DL, Ammerman A, Dharod JM. Racial/ethnic differences in diet quality and eating habits among WIC pregnant women: Implications for policy and practice. Am J Health Promot. 2020;34(2):169-176. doi: 10.1177/0890117119883584. Epub 2019 Oct 28.

29. Hudak KM, Racine EF, Schulkind L. An increase in SNAP benefits did not impact food security or diet quality in youth. $J$ Acad Nutr Diet. 2021;121(3):507-519.e512. doi: 10.1016/j.jand.2020.09.030. Epub 2020 Nov 10.

30. Huffman FG, Vaccaro JA, Zarini GG, Dixon Z. Comparison of two indices of diet quality with acculturation factors and demographics in Haitian Americans. Ecol Food Nutr. 2014;53(1):42-57. <Go to ISI>://WOS:000329775200003.

31. Kane K, llic S, Paden H, et al. An evaluation of factors predicting diet quality among cancer patients. Nutrients. 2018;10(8). doi: 10.3390/nu10081019.

32. Kay MC, Silver HJ, Yin HS, et al. Assessing diet quality in a racially and ethnically diverse cohort of low-income toddlers. $J$ Pediatr Gastroenterol Nutr. 2020;71(5):679-685. doi: 10.1097/MPG.0000000000002871.

33. Kinderknecht K, Harris C, Jones-Smith J. Association of the Healthy, Hunger-Free Kids Act with dietary quality among children in the US National School Lunch Program. Jama. 2020;324(4):359-368. doi: 10.1001/jama.2020.9517.

34. Kuczmarski MF, Beydoun MA, Cotugna N, et al. Literacy contributes to greater higher diet quality in a socioeconomically diverse urban prospective cohort. Top Clin Nutr. 2016;31(1):47-58. <Go to ISI>://WOS:000373300300005.

35. Landry MJ, van den Berg AE, Asigbee FM, Vandyousefi S, Ghaddar R, Davis JN. Child-report of food insecurity is associated with diet quality in children. Nutrients. 2019;11(7). doi: 10.3390/nu11071574.

36. Laster LE, Lovelady CA, West DG, et al. Diet quality of overweight and obese mothers and their preschool children. $J$ Acad Nutr Diet. 2013;113(11):1476-1483. doi: 10.1016/j.jand.2013.05.018. Epub 2013 Jul 16.

37. Leung CW, Ding EL, Catalano PJ, Villamor E, Rimm EB, Willett WC. Dietary intake and dietary quality of low-income adults in the Supplemental Nutrition Assistance Program. Am J Clin Nutr. 2012;96(5):977-988. doi: 10.3945/ajcn.112.040014. Epub 2012 Oct 3.

38. Leung CW, Blumenthal SJ, Hoffnagle EE, et al. Associations of food stamp participation with dietary quality and obesity in children. Pediatrics. 2013;131(3):463-472. doi: 10.1542/peds.2012-0889. Epub 2013 Feb 25.

39. Liu J, Rehm CD, Onopa J, Mozaffarian D. Trends in diet quality among youth in the United States, 1999-2016. Jama. 2020;323(12):1161-1174. doi: 10.1001/jama.2020.0878.

40. Martin MA, Van Hook JL, Quiros S. Is socioeconomic incorporation associated with a healthier diet? Dietary patterns among Mexican-origin children in the United States. Soc Sci Med. 2015;147:20-29. <Go to ISI>://WOS:000367637100003.

41. Nguyen BT, Shuval K, Njike VY, Katz DL. The Supplemental Nutrition Assistance Program and dietary quality among US adults: findings from a nationally representative survey. Mayo Clin Proc. 2014;89(9):1211-1219. doi: 10.1016/j.mayocp.2014.05.010. Epub 2014 Aug 5.

42. Nguyen BT, Shuval K, Bertmann F, Yaroch AL. The Supplemental Nutrition Assistance Program, food insecurity, dietary quality, and obesity among U.S. adults. Am J Public Health. 2015;105(7):1453-1459. doi: 10.2105/AJPH.2015.302580. Epub 2015 May 14.

43. Nowlin SY, Cleland CM, Vadiveloo M, D'Eramo Melkus G, Parekh N, Hagan H. Explaining racial/ethnic dietary patterns in relation to type 2 diabetes: an analysis of NHANES 2007-2012. Ethn Dis. 2016;26(4):529-536. doi: 10.18865/ed.26.4.529.

44. Orr CJ, Keyserling TC, Ammerman AS, Berkowitz SA. Diet quality trends among adults with diabetes by socioeconomic status in the U.S.: 1999-2014. BMC Endocr Disord. 2019;19(1):54. doi: 10.1186/s12902-019-0382-3.

45. Patetta MA, Pedraza LS, Popkin BM. Improvements in the nutritional quality of US young adults based on food sources and socioeconomic status between 1989-1991 and 2011-2014. Nutr J. 2019;18(1):32. doi: 10.1186/s12937-019-0460-4.

46. Richards Adams IK, Figueroa W, Hatsu I, et al. An examination of demographic and psychosocial factors, barriers to healthy eating, and diet quality among African American adults. Nutrients. 2019;11(3). doi: 10.3390/nu11030519.

47. Sanjeevi N, Freeland-Graves JH, Sachdev PK. Association of loss of Supplemental Nutrition Assistance Program benefits with food insecurity and dietary intake of adults and children. Am J Clin Nutr. 2021. doi: 10.1093/ajcn/nqab082.

48. Shan Z, Rehm CD, Rogers G, et al. Trends in dietary carbohydrate, protein, and fat intake and diet quality among US adults, 1999-2016. Jama. 2019;322(12):1178-1187. doi: 10.1001/jama.2019.13771

49. Singleton CR, Young SK, Kessee N, Springfield SE, Sen BP. Examining disparities in diet quality between SNAP participants and non-participants using Oaxaca-Blinder decomposition analysis. Prev Med Rep. 2020;19:101134. doi:

10.1016/j.pmedr.2020.101134. eCollection 2020 Sep. 
50. Springfield S, Odoms-Young A, Tussing-Humphreys LM, Freels S, Stolley MR. A step toward understanding diet quality in urban african-american breast cancer survivors: a cross-sectional analysis of baseline data from the moving forward study. Nutr Cancer. 2019;71(1):61-76. doi: 10.1080/01635581.2018.1557217. Epub 2019 Feb 18.

51. Thomas Berube L, Messito MJ, Woolf K, Deierlein A, Gross R. Correlates of prenatal diet quality in low-income hispanic women. J Acad Nutr Diet. 2019;119(8):1284-1295. doi: 10.1016/j.jand.2019.02.004. Epub 2019 Apr 5.

52. Thomson JL, Tussing-Humphreys LM, Goodman MH, Landry AS. Diet quality in a nationally representative sample of American children by sociodemographic characteristics. Am J Clin Nutr. 2019;109(1):127-138. doi: 10.1093/ajen/nqy284.

53. Thomson JL, Landry AS, Tussing-Humphreys LM, Goodman MH. Diet quality of children in the United States by body mass index and sociodemographic characteristics. Obes Sci Pract. 2020;6(1):84-98. doi: 10.1002/osp4.388. eCollection 2020 Feb.

54. Todd JE. Revisiting the Supplemental Nutrition Assistance Program cycle of food intake: Investigating heterogeneity, diet quality, and a large boost in benefit amounts. Applied Economic Perspectives and Policy. 2015;37(3):437-458. doi: https://doi.org/10.1093/aepp/ppu039

55. Tovar A, Risica PM, Ramirez A, et al. Exploring the provider-level socio-demographic determinants of diet quality of preschoolaged children attending family childcare homes. Nutrients. 2020;12(5). doi: 10.3390/nu12051368.

56. Waehrer G, Deb P, Decker SL. Did the 2009 American Recovery and Reinvestment Act affect dietary intake of low-income individuals? Econ Hum Biol. 2015;19:170-183. doi: 10.1016/j.ehb.2015.08.006. Epub 2015 Aug 29.

57. Wang M, Levi R, Seligman H. New SNAP eligibility in california associated with improved food security and health. Prev Chronic Dis. 2021;18:E28. doi: 10.5888/pcd18.200587.

58. Weatherspoon DD, Miller SR, Steele ME, et al. What social, program, and behavioral factors influence the healthy eating index for EFNEP and SNAP-Ed adult participants? Am J Lifestyle Med. 2017;11(4):344-353. doi: 10.1177/1559827615607194. eCollection 2017 Jul-Aug.

59. Weinfield NS, Borger C, Gola AA. Breastfeeding duration in a low-income sample is associated with child diet quality at age three. J Hum Lact. 2021;37(1):183-193. doi: 10.1177/0890334420903029. Epub 2020 Feb 24.

60. Wilcox S, Sharpe PA, Liese AD, Dunn CG, Hutto B. Socioeconomic factors associated with diet quality and meeting dietary guidelines in disadvantaged neighborhoods in the Southeast United States. Ethn Health. 2020;25(8):1115-1131. doi: 10.1080/13557858.2018.1493434. Epub 2018 Jul 2.

61. Wilson MD, Ramírez AS, Arsenault JE, Miller LMS. Nutrition label use and its association with dietary quality among latinos: the roles of poverty and acculturation. J Nutr Educ Behav. 2018;50(9):876-887. doi: 10.1016/j.jneb.2018.05.019. 


\section{Chapter 3 - What is the relationship between overall diet cost and following a dietary pattern that aligns with the Dietary Guidelines for Americans, as measured by the Healthy Eating Index (HEI)?}

Emily Callahan, MS, ${ }^{a}$ Molly Higgins, MLIS, ${ }^{b}$ Marlana Bates, MPH, RD, ${ }^{c}$ Laural Kelly English, $\mathrm{PhD},{ }^{\mathrm{c}}$ Julie Nevins, $\mathrm{PhD},{ }^{\mathrm{c}}$ Julia H Kim, PhD, MPH, RD, ${ }^{\mathrm{c}}$ Sara Scinto-Madonich, $\mathrm{MS}^{\mathrm{c}}$

\section{Specific methods to conduct this rapid review}

\section{Develop a protocol}

The research question, "What is the relationship between overall diet cost and following a dietary pattern that aligns with the Dietary Guidelines for Americans, as measured by the Healthy Eating Index (HEI)?", was answered using a rapid review.

The analytic framework for the rapid review examining the relationship between diet cost and HEI is presented in Figure 3-a. This analytic framework visually represents the overall scope of the rapid review question, and depicts the contributing elements that were examined and evaluated. The intervention or exposure of interest is overall diet cost in U.S. households or populations. The comparators are different levels or categories of overall diet cost, or the overall cost of a different diet(s). The outcomes are dietary patterns that align with the Dietary Guidelines for Americans, as measured by the HEI in U.S. households or populations. The key confounders are urban versus rural, cultural/racial diversity or disparities, sex, age, energy, and SES. The other factors to be considered are cultural food choices, neighborhood characteristics (e.g., access to food/distance to stores/access to car/type of store), smoking, weight status, chronic disease status, convenience level, processing level, and food security status. The confounders and other factors to be considered may impact the relationships of interest.

\footnotetext{
a Project Lead, NESR team, NGAD, CNPP, FNS, USDA

b Librarian, NESR team; Panum Group, under contract with the FNS, USDA

${ }^{c}$ Analyst, NESR team; Panum Group, under contract with the FNS, USDA
} 
Figure 3-a. Analytic framework

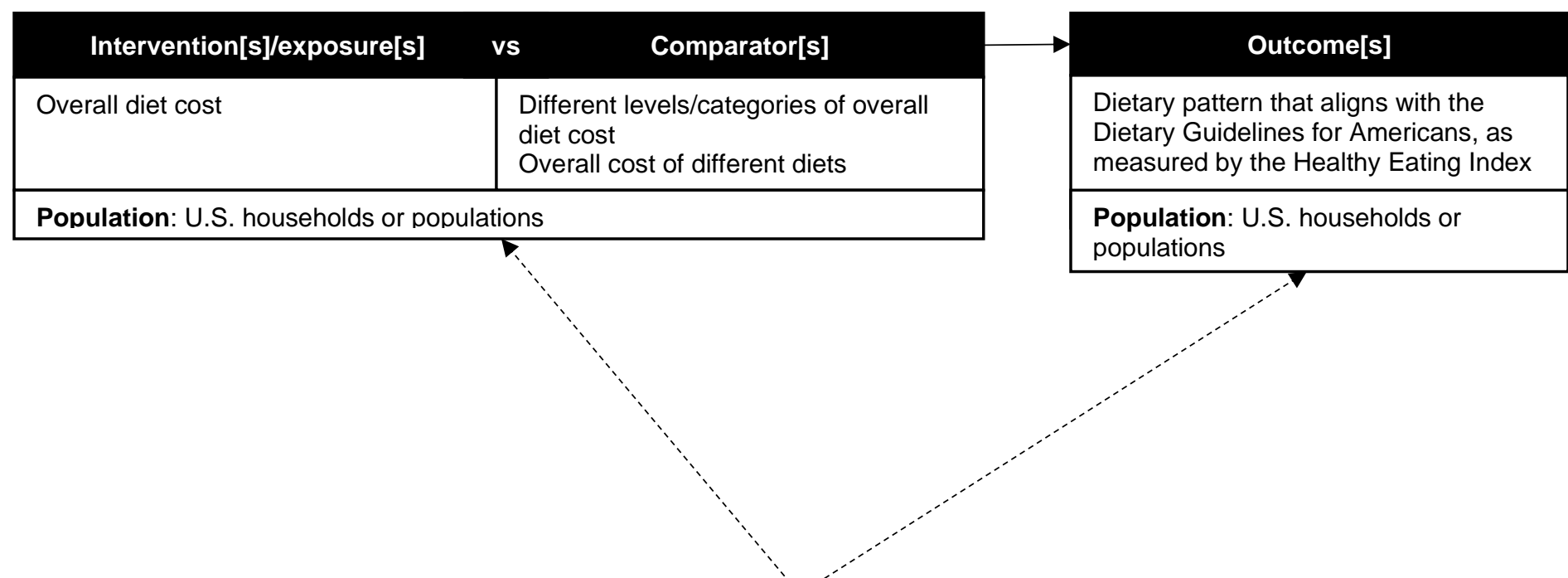

Key confounders: Urban vs. Rural; Cultural/racial diversity or disparities; Sex; Age; Energy; SES

Other factors to be considered: Cultural food choices; Neighborhood characteristics (e.g., access to food/distance to stores/access to car/type of store); Smoking; Weight status; Chronic disease status; Convenience level; Processing level; Food security status

Key definitions

Dietary pattern: The quantities, proportions, variety, or combination of different foods, drinks, and nutrients (when available) in diets, and the frequency with which they are habitually consumed.

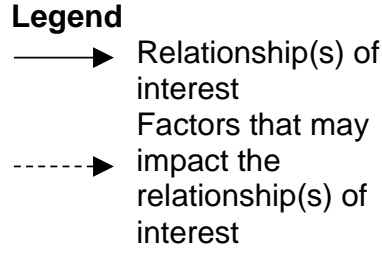

Legend

interest Factors that may relationship(s) of interest

\section{Search for and select studies}

The following outlines any departures from the search and select studies project methods for this specific rapid review:

- Title and abstract screening was completed together in 1 level and full text screening was at a separate level.

- For title and abstract screening, $80 \%$ of all records were single-screened and $20 \%$ of all records were dual-screened, independently. For the full-text screening level all records were dual-screened, independently by 2 analysts.

NESR analysts worked jointly with NEAT staff to establish the final inclusion and exclusion criteria and literature search strategy, which are detailed in Table 3-a and Appendix 3-a, respectively. 
Table 3-a. Inclusion and exclusion criteria

\begin{tabular}{|c|c|c|}
\hline Category & Inclusion Criteria & Exclusion Criteria \\
\hline Study design & $\begin{array}{l}\text { - Any study design that is not a narrative review, } \\
\text { systematic review, or meta-analysis }\end{array}$ & $\begin{array}{l}\text { - } \quad \text { Narrative reviews } \\
\text { - } \quad \text { Systematic reviews } \\
\text { - } \quad \text { Meta-analyses }\end{array}$ \\
\hline $\begin{array}{l}\text { Intervention/ } \\
\text { exposure }\end{array}$ & 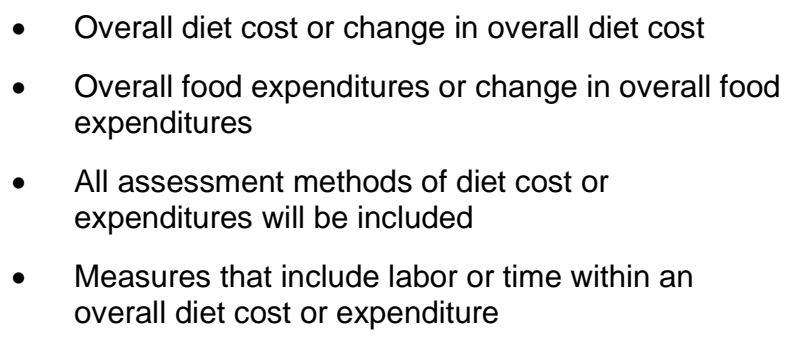 & $\begin{array}{l}\text { - Individual food, beverage, food group, or multiple } \\
\text { food group costs } \\
\text { - Costs of labor or time alone, that are not part of an } \\
\text { overall diet cost measure }\end{array}$ \\
\hline Comparator & $\begin{array}{l}\text { - } \quad \text { Different levels/categories of overall diet cost } \\
\text { - } \quad \text { Overall cost of a different diet }\end{array}$ & - $\quad \mathrm{N} / \mathrm{A}$ \\
\hline Outcomes & $\begin{array}{l}\text { Dietary patterns that specifically align with the } \\
\text { Dietary Guidelines for Americans, as measured by } \\
\text { the total Healthy Eating Index (HEI) } \\
\text { - All versions or variations of HEI (e.g. HEI-2005, } \\
\text { HEl-2010, HEI-2015) } \\
\text { - Change in total HEl over time }\end{array}$ & $\begin{array}{l}\text { - Studies that examine any other dietary pattern or } \\
\text { diet quality indicator that include only individual or } \\
\text { select foods and beverages and do not reflect the } \\
\text { totality of the diet nor the Dietary Guidelines for } \\
\text { Americans. } \\
\text { - Studies that only examine component scores of the } \\
\mathrm{HEI}\end{array}$ \\
\hline $\begin{array}{l}\text { Publication } \\
\text { date }\end{array}$ & $\begin{array}{l}\text { - Jan } 2008 \text { - May } 2021 \text { and data inclusive of } 2008 \\
\text { (e.g., 2000-2012; 2008-2009) }\end{array}$ & $\begin{array}{l}\text { - } \quad \text { Articles published prior to Jan } 2008 \\
\text { - } \quad \text { Data prior to } 2008 \text { (e.g., 2000-2007; 1999-2005) }\end{array}$ \\
\hline $\begin{array}{l}\text { Publication } \\
\text { status }\end{array}$ & $\begin{array}{l}\text { - } \quad \text { Articles published in peer-reviewed journals } \\
\text { - Grey literature: reports that have not been peer } \\
\text { reviewed but are available from government and } \\
\text { nongovernmental organizations }\end{array}$ & $\begin{array}{l}\text { - Articles that have not been peer-reviewed and are } \\
\text { not published in peer-reviewed journals, other than } \\
\text { reports from government and nongovernmental } \\
\text { organizations }\end{array}$ \\
\hline Language & - $\quad$ Articles published in English & - Articles published in languages other than English \\
\hline Country & - $\quad$ Studies conducted the U.S. & - $\quad$ Studies conducted in countries outside the U.S. \\
\hline $\begin{array}{l}\text { Study } \\
\text { participants }\end{array}$ & $\begin{array}{l}\text { - Human participants/populations } \\
\circ \text { Males } \\
\circ \text { Females }\end{array}$ & $\begin{array}{l}\text { - Non-human participants (e.g., animal studies, in- } \\
\text { vitro models) }\end{array}$ \\
\hline
\end{tabular}

\section{Extract data and assess the risk of bias}

NESR analysts extracted and summarized data from each included article to objectively describe the body of evidence available to answer a rapid review question. The following outlines any departures from the extract data and assess risk of bias project methods for this specific rapid review:

- Data extraction and risk of bias assessment was completed on all included articles and verified by a $2^{\text {nd }}$ analyst. 


\section{Synthesize the evidence}

Evidence synthesis was completed by describing the evidence and evaluating the included studies individually and collectively as previously described in the project methods.

\section{Summary statements}

NESR analysts formed summary statements, as previously described in the project methods, outlining the themes observed during the data synthesis of studies examining diet cost and HEl.

\section{Recommend future research}

Recommendations for future research evaluating the relationship between diet cost and $\mathrm{HEI}$ were determined based on the gaps and limitations observed during data extraction and synthesis, as previously described in the project methods. Future work addressing these gaps and limitations may contribute to the body of evidence available to answer this research question.

\section{Results}

\section{Literature search and screening results}

The literature search yielded 3,335 search results after the removal of duplicates (see Figure 3-b). Screening resulted in the exclusion of 3,182 titles and abstracts, and 140 full-texts articles. Reasons for full-text exclusion are in Appendix 3-b. One additional article was identified for inclusion from the manual search. The body of evidence included 12 articles. 
Figure 3-b. Literature search and screen flowchart

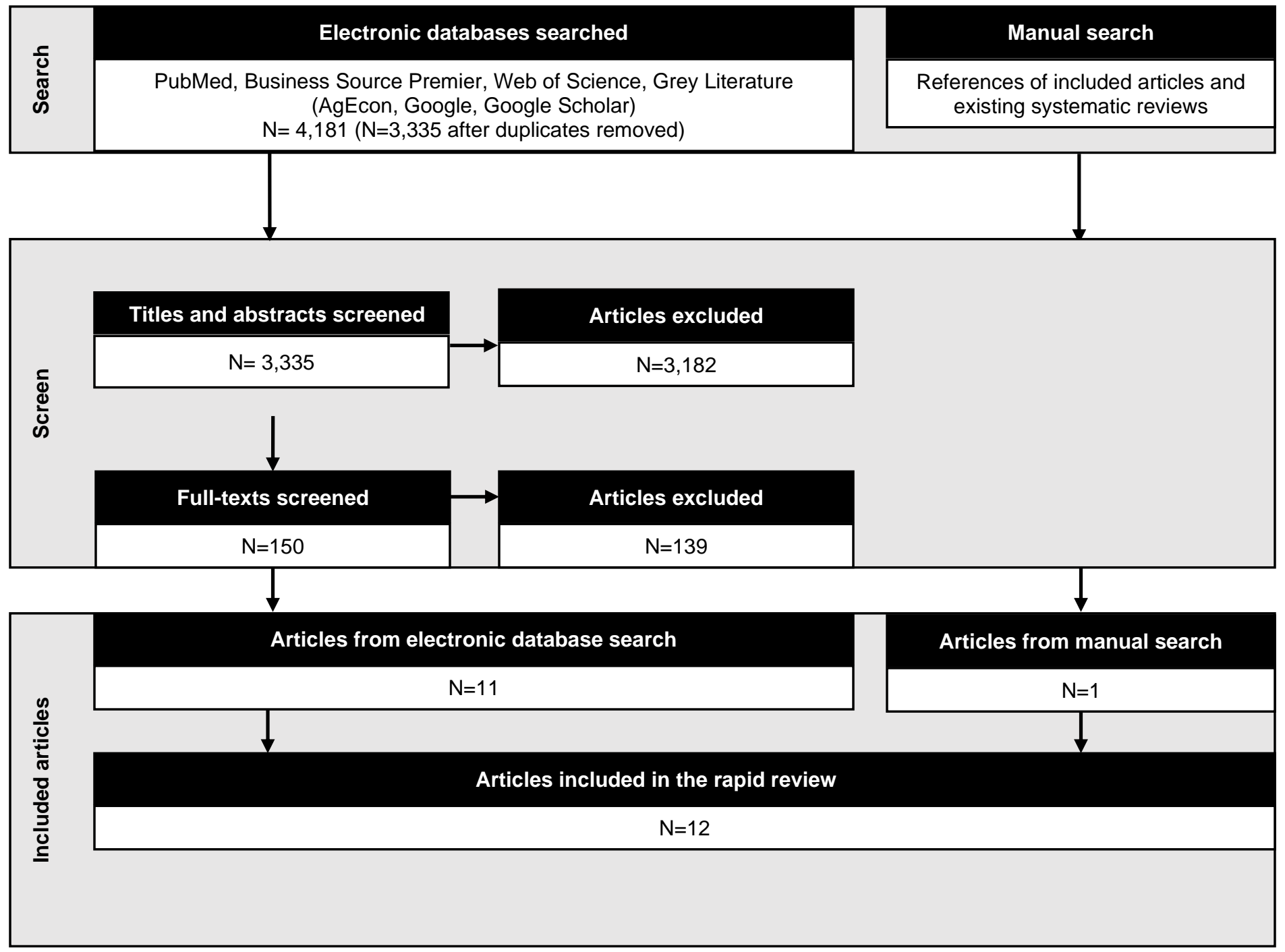

\section{Description of evidence}

This rapid review included 12 articles that examined the relationship between diet cost and HEl. ${ }^{1-12}$ One article was an $\mathrm{RCT}^{9}, 2$ were prospective cohort studies ${ }^{3,12}$, and the remaining 9 were cross-sectional studies. ${ }^{1,2,4-8,10,11}$ The sample sizes of the studies ranged from $134^{9}$ to $11,181^{10}$ participants or dyads. One sample size was unreported but used data from NHANES. ${ }^{1}$

\section{Population characteristics}

Seven independent study populations were examined in the 12 articles. Two articles used nationally representative data (NHANES), ${ }^{1,10} 3$ articles were from the population included in the Seattle Obesity Study III (SOS III) study, ${ }^{6,7,11} 2$ articles were from populations from the Healthy Aging in Neighborhoods of Diversity across the Life Span (HANDLS) study, ${ }^{2,3}$ and 2 articles came from the same population from Massachusetts. ${ }^{8,9}$ The remaining 3 articles were individual populations from Texas and Pennsylvania. ${ }^{4,5,12}$ Ten articles assessed 
only adults, ${ }^{1-7,10-12} 1$ article assessed only children, ${ }^{8}$ and 1 article assessed child-parent dyads. ${ }^{9}$ While similar data were analyzed in the articles from the same study populations, each article contributed unique subanalyses or analytic/assessment methods.

\section{Exposure and comparator characteristics: diet cost and food expenditures}

There were 2 categories of the exposure examined in the included articles, diet cost and food expenditures.

Eight articles assessed diet cost ${ }^{6-11}$ or monetary value of the diet ${ }^{2,3}$ that was based on the cost of the diet that was consumed by the participant. In this subset of studies, diet cost was estimated from consumption data, which were linked to external food prices, and used to calculate a diet cost. While this method most directly answers the question, it has the limitation that costs were estimated using databases that may not be reflective of what the participants paid for the food, the geographic locations that they lived or from the same period of time that the diet data was collected. The food price databases that were used varied across the studies, and included the CNPP Food Prices Database, ${ }^{2,10}$ UNC's Packaged Food Purchase and Price Database ${ }^{3}$ local retail prices from a large supermarket (i.e., Safeway), ${ }^{6,7,11}$ or national online supermarket prices. ${ }^{8,9}$ Diet costs were estimated either per day ${ }^{2,3,8,9}$ or per month. . $, 7,10,11^{-1}$

Seven articles assessed food expenditures ${ }^{4-7,11,12}$ or grocery spending ${ }^{1}$ that were based on the amount spent on purchases of food at home and/or food away from home. Two articles reported only expenditures from food at home, ${ }^{7,11}$ while the other 5 articles reported total food expenditures which included both food at home and food away from home. ${ }^{4-6,12}$ Expenditures were estimated from purchase data, either grocery receipts ${ }^{12}$ or a selfreported estimate of how much money they spent on food per capita ${ }^{1,5-7,11,12}$ or per household. ${ }^{4}$ One article did not report the method used for collecting expenditure data. ${ }^{1}$ Expenditures were generally adjusted to be reflective of the amount of time and number of people the expenditures represent. Two articles reported expenditures per week, ${ }^{4,5}$ while 4 articles reported expenditures per month.,7,11,12 However, what is purchased by the study participant may not reflect what was actually consumed, and therefore, this approach is an indirect measure of the relationship being examined.

\section{Outcome assessment: HEI score}

All studies examined dietary patterns aligned with the DGA as measured by the HEI. Four articles assessed HEl-2015, 4,6,7,11 4 articles assessed HEl-2010,2,3,10,12 3 articles assessed HEl-2005, 5,8,9 and 1 article did not report which version of $\mathrm{HEI}$ was used in the analysis. ${ }^{1}$ Scores on the HEl were determined using a variety of validated dietary assessment methods, including food frequency questionnaires, 24-hour dietary recalls, or 3 day diet records.

\section{Synthesis}

\section{Diet cost}

Eight articles assessed the cost of the diet and HEI by measuring diet cost as the exposure and results from these studies are provided in Table 3-b. . $^{2,3,6-11}$ Six $^{2,3,6,7,10,11}$ of these 8 articles reported that higher cost diets had higher HEl scores or that lower cost diets had lower HEI scores. Three of the 6 articles with significant findings were from the SOS III cohort and included unique data that answered this question but were from the same population of participants. ${ }^{6,7,11}$

The 2 other articles (using data from $1 \mathrm{RCT}$ ) showed non-significant associations between diet cost and $\mathrm{HEI}$ scores. ${ }^{8,9}$ One article showed a non-significant time-varying association between higher diet costs and lower $\mathrm{HEI}$ scores over the 18 month intervention in both children and their parents. The other article, which was a cross sectional analysis of baseline data, showed a non-significant association between higher diet costs and 
higher HEI scores in children. However, this trial was in a population of children with type 1 diabetes and their parents that were generally high income, and may not be generalizable to the U.S. population.

\section{Food expenditures}

Seven articles assessed the relationship between the cost of the diet and $\mathrm{HEl}$ by measuring food expenditures as the exposure and results from these studies are provided in Table 3-c., ${ }^{1,4-71,12}$ Four, ${ }^{4,6,7,12}$ out of 7 articles reported that higher food expenditures were significantly associated with higher HEI scores, or that lower food expenditures were significantly associated with lower $\mathrm{HEI}$ scores. Two of the 4 articles with significant findings were from the SOS III cohort and contributed unique analyses that answered this question but were from the same population of participants. ${ }^{6,7}$ The 3 other articles found relationships in the same direction but did not reach statistical significance..$^{1,5,11}$

Total food expenditures were generally calculated by summing together expenditures from food at home and food away from home. One of the studies looked at the relationship between all three of these variables and $\mathrm{HEI}$, and saw a positive association with both total and food at home expenditures, but an inverse association with food away from home and HEl. ${ }^{4}$ This means that the total expenditure relationship is being driven by food at home related expenditures. Although this is only 1 study, it is an important consideration when looking at this data.

\section{Assessment of evidence}

As outlined and described below, the body of evidence examining the relationship between diet cost or expenditures and HEI was assessed for the following elements.

\section{Risk of bias}

Risk of bias assessments for each included article are provided in Table 3-d and Table 3-e. The majority of studies were cross-sectional or cohort studies and did not account for at least 1 key confounder. Many studies had serious concerns with deviations from intended exposures because of using price data that was not specific to what participants paid. Most studies had concerns with missing data and/or the selection of reported results due to the lack of a priori analysis plans or reporting very similar results from the same cohort of participants. One article with non-significant findings had many serious risks of bias for confounding, classification and deviations from intended exposures and outcome measurement due to the fact that they did not adequately describe how the exposure or outcomes were collected or handled and they did not adjust for any confounding factors in the analysis included in this rapid review ${ }^{1}$.

\section{Consistency}

The direction of the findings were very consistent and the magnitude was consistently small. Most studies reported at least 1 significant association between higher diet cost or expenditures and higher HEI scores. All articles, but one, showed either a significant or non-significant association in a consistent direction, with higher diet cost or expenditures and higher HEl.

\section{Directness}

There were serious concerns with the directness of exposure measurements. Food expenditure represented purchasing costs that are generally self-reported and are not limited to individual diets. Diet cost is more direct and measures cost of the foods that were consumed but are linked to price databases or sources that were not where the participants actually shopped with a lack of adjustment for geographic location. 


\section{Precision}

There were some concerns with precision across the body of evidence. The effects were relatively consistent with large sample sizes; however, samples may not be large enough to detect small differences in HEl scores.

\section{Generalizability}

All studies in the body of evidence were conducted in the U.S. and the majority of studies were generalizable to the U.S. population. However, those studies with convenience samples in children with type 1 diabetes and their families, have very limited generalizability. Additionally, multiple studies were completed in the same population of participants (SOS III; HANDLS) and while each contributed unique data, they should not be interpreted as completely independent.

\section{Summary statements and research recommendations}

\section{Summary statements}

The findings of the rapid review are presented in the following summary statements.

\section{Diet cost}

Evidence suggests a relationship between higher diet costs of foods consumed by participants and higher HEI scores. There were critical limitations including that the prices used were generally not the prices that the participants actually paid, from the same location, or at the same time point as the purchase.

\section{Food expenditures}

Evidence suggests a relationship between higher total expenditures of food purchases and higher HEI scores. There were critical limitations including that total expenditures were generally self-reported and may not be specific to the foods consumed by the participants.

Total expenditures from food includes both food at home and food away from home. The relationship between total expenditures and $\mathrm{HEI}$ scores may be driven by expenditures from food at home, and attenuated by expenditures from food away from home.

\section{Research recommendations}

1. Conduct well-designed longitudinal studies that examine the relationship between diet cost or food expenditures and diet quality over time.

2. Standardize and update national food price databases to increase comparability across studies.

3. Assess diet cost by using prices specific to individuals or standardized national food price databases that are adjusted for participant location and time period of diet data collection.

4. Assess food expenditures that are specific to food at home and food away from home separately, since expenditures from food at home may have a positive relationship with diet quality as where expenditures from food away from home may have an inverse relationship with diet quality.

5. Account for potential confounders to better determine the relationship between diet cost and diet quality.

\section{Sensitivity Analysis}

Articles using data collected prior to 2008 (e.g., 2000-2007; 1999-2005), regardless of publication date, were excluded for this rapid review for the reasons stated in the project methods. However, national price databases are commonly used to determine diet cost, and NESR analysts recognized that articles may not have been included as a result of using the most up to date national data that was available at the time of the authors 
analyses. A sensitivity anslyses was completed that included articles published in 2008 or later, but that used data from prior to 2008.

There were 5 articles included in the sensitivity analyses, of which 4 found an association between higher diet costs or expenditures and higher HEI scores and were in general agreement with the results of the rapid review. ${ }^{\text {abcde }}$ All 5 articles used NHANES data and either the CNPP Food Price Database or Consumer Expenditure Survey Data.

a Carlson, A, Dong, D, Lino, M. Are the total daily cost of food and diet quality related: a random effects panel data analysis. 2010.

b Carlson, A, Dong, D.,Lino, M.. Association between Total Diet Cost and Diet Quality Is Limited. Journal of Agricultural and Resource Economics. 2014. 39:47-68

c Carlson, A, Lino, M, Fungwe, TV, Guenther, PM.. Eating a Healthy Diet: Is Cost a Major Factor? 2009.

d Malbi, J, Castner, L, Ohls, J, Fox, MK, Crepinsek, MK, Condon, E. Food Expenditures and Diet Quality Among Low-Income Households and Individuals," Final Report submitted to USDA, FNS for Contract Number AG-3198-D-07-0114, 2010, http://www.fns.usda.gov/sites/default/files/FoodExpendDietQuality.pdf.

e Rehm, C. D., Monsivais, P., Drewnowski, A.. The quality and monetary value of diets consumed by adults in the United States. Am J Clin Nutr. 2011. 94:1333-9 
Table 3-b. Evidence examining the relationship between diet cost and HEl score ${ }^{a}$

$\begin{array}{llll}\text { Author, Year } & \text { Population } & \text { Outcome } & \text { Results }\end{array}$

\begin{tabular}{|c|c|c|c|c|}
\hline \multirow[t]{2}{*}{$\begin{array}{l}\text { Beydoun, } 2015^{2} \\
\text { Cross-sectional }\end{array}$} & $\begin{array}{l}\text { Healthy Aging in } \\
\text { Neighborhoods of } \\
\text { Diversity across the } \\
\text { Life Span (HANDLS) }\end{array}$ & $\begin{array}{l}\text { Monetary Value of the } \\
\text { Diet }(\$ / d)\end{array}$ & HEI-2010 & $\begin{array}{l}\text { MVD per } \$ 1 / d: \beta=-\$ 1.65[0.12], p<0.0001 \\
\text { MVD per } \$ 3 / d: \beta=-\$ 4.98[0.35],(I Q R: \$ 3.70 / d(Q 1) \text { to } \$ 6.62 / d(Q 4)), p<0.0001\end{array}$ \\
\hline & Analytic N: 2,111 & $\begin{array}{l}\text { Data source: CNPP } \\
\text { Food Prices Database, } \\
2003-2004 \text { (updated } \\
\text { for inflation) }\end{array}$ & & \\
\hline \multirow[t]{2}{*}{ Beydoun, $2018^{3}$} & $\begin{array}{l}\text { Healthy Aging in } \\
\text { Neighborhoods of } \\
\text { Diversity across the } \\
\text { Life Span (HANDLS) }\end{array}$ & $\begin{array}{l}\text { Monetary Value of the } \\
\text { Diet }(\$ / d)\end{array}$ & HEI-2010 & T2 v. T1: $\beta=0.71[0.19]$, T3 v. T1: $\beta=1.33[0.22], p<0.001$ \\
\hline & Analytic N: 1,466 & $\begin{array}{l}\text { Data source: UNC's } \\
\text { Packaged Food } \\
\text { Purchase and Price } \\
\text { Database, 2004-2013 }\end{array}$ & & \\
\hline Gupta, $2020^{6}$ & $\begin{array}{l}\text { Seattle Obesity Study } \\
\text { III (SOS III) }\end{array}$ & Diet Cost $(\$ / \mathrm{mo})$ & HEI-2015 & $\begin{array}{l}\text { Mean HEI (SD): Lowest cost T1 }(n=252) 62.57(9.91) \text { v. middle cost T2 }(n=252) \\
67.18 \text { (9.70) v. highest cost T3 }(n=251) 71.55(7.87), p<0.0001\end{array}$ \\
\hline Cross-sectional & Analytic N: 755 & $\begin{array}{l}\text { Data source: local } \\
\text { retail prices from a } \\
\text { large supermarket (i.e. } \\
\text { Safeway) }\end{array}$ & & \\
\hline Gupta, $2021^{7}$ & $\begin{array}{l}\text { Seattle Obesity Study } \\
\text { III (SOS III) }\end{array}$ & Diet Cost $(\$ / \mathrm{mo})$ & HEI-2015 & $\begin{array}{l}\text { Mean HEI (SD): } \leq \$ 252: 62.6(10) \text { (ref) v. }>\$ 253-\leq \$ 299: 67.1 \text { (9.77), } p<0.0001 \text { v. } \\
\geq \$ 300: 71.5(7.81), p<0.0001\end{array}$ \\
\hline Cross-sectional & Analytic N: 747 & $\begin{array}{l}\text { Data source: local } \\
\text { retail prices from a } \\
\text { large supermarket (i.e. } \\
\text { Safeway) }\end{array}$ & & \\
\hline
\end{tabular}



Author, Year
Population
Exposure
Outcome
Results

\begin{tabular}{|c|c|c|c|c|}
\hline Rose, 202011 & $\begin{array}{l}\text { Seattle Obesity Study } \\
\text { III (SOS III) } \\
\text { Analytic N: } 768\end{array}$ & $\begin{array}{l}\text { Diet Cost }(\$ / \mathrm{mo}) \\
\text { Data source: local } \\
\text { retail prices from a } \\
\text { large supermarket (i.e. } \\
\text { Safeway) }\end{array}$ & HEI-2015 & $\begin{array}{l}\text { Linear models: } \\
\text { Mean HEl per } \$ 100: 5.33,95 \% \mathrm{Cl}: 4.15,6.50, \mathrm{p}<0.0001 \\
\text { Curvilinear models: } \\
\text { 17.82, 95\% Cl: } 9.76,25.88, \mathrm{p}<0.0001 \\
\text { Quadratic model: }-2.06,95 \% \mathrm{Cl}:-3.35,-0.78, \mathrm{p}<0.0002\end{array}$ \\
\hline $\begin{array}{l}\text { Rehm, } 2015^{10} \\
\text { Cross-sectional }\end{array}$ & $\begin{array}{l}\text { NHANES } \\
\text { Analytic N:11,181 }\end{array}$ & $\begin{array}{l}\text { Diet Cost }(\$ / \mathrm{mo}) \\
\text { Data source: CNPP } \\
\text { Food Prices Database, } \\
\text { 2003-2004 (updated } \\
\text { for inflation) }\end{array}$ & HEI-2010 & $\begin{array}{l}Q 1, n=2545: 44.2,95 \% \mathrm{Cl}: 42.7,45.7 \text { (ref) } \\
Q 2, n=2348: 50.1,95 \% \mathrm{Cl}: 48.7,51.5, p<0.001 \\
Q 3, n=2231: 55.8,95 \% \mathrm{Cl}: 54.1,57.6, p<0.001 \\
Q 4, n=2073: 60.2,95 \% \mathrm{Cl}: 58.2,62.1, p<0.001 \\
Q 5, n=1984: 66.6,95 \% \mathrm{Cl}: 65.3,67.9, p<0.001\end{array}$ \\
\hline Nansel, $2015^{8}$ & $\begin{array}{l}\text { Youth with Type } 1 \\
\text { Diabetes }\end{array}$ & Diet Cost $(\$ / d)$ & HEI-2005 & $\begin{array}{l}\text { Mean HEI (SD): T1 (lowest) } \$ 6.67 \text { [0.37] v. T2 \$6.80 [0.36] v. T3 \$7.35 [0.37], p- } \\
\text { trend=0.20, NS }\end{array}$ \\
\hline $\begin{array}{l}\text { Cross-sectional } \\
\text { (baseline data from } \\
\text { RCT) }\end{array}$ & Analytic N: 252 & $\begin{array}{l}\text { Data source: National } \\
\text { online supermarket } \\
\text { prices }\end{array}$ & & \\
\hline Nansel, $2016^{9}$ & $\begin{array}{l}\text { Youth with Type } 1 \\
\text { Diabetes and their } \\
\text { parents }\end{array}$ & Diet Cost $(\$ / d)$ & HEI-2005 & $\begin{array}{l}\text { Youth: } \beta=-0.0005,95 \% \mathrm{Cl}:-0.02,0.02, p=0.96, \mathrm{NS} \\
\text { Adults: } \beta=-0.06,95 \% \mathrm{Cl}:-0.13,0.01, p=0.11, \mathrm{NS}\end{array}$ \\
\hline RCT & Analytic N: 136 & $\begin{array}{l}\text { Data source: National } \\
\text { online supermarket } \\
\text { prices }\end{array}$ & & \\
\hline
\end{tabular}

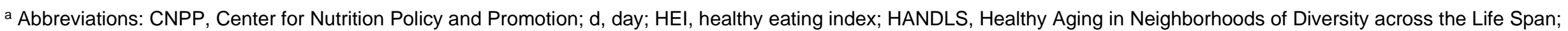
$\mathrm{HH}$, household; mo, month; NS, not significant; PCS, prospective cohort study; RCT, randomized controlled trial; SOS III, Seattle Obesity Study III 
Table 3-c. Evidence examining the relationship between food expenditures and HEl scores ${ }^{a}$

$\begin{array}{llll}\text { Population } & \text { Exposure } & \text { Outcome Results }\end{array}$

\begin{tabular}{|c|c|c|c|c|}
\hline \multirow{2}{*}{$\begin{array}{l}\text { Carpio, } 20204 \\
\text { Cross-sectional }\end{array}$} & \multirow{3}{*}{$\begin{array}{l}\text { Staff and Faculty at } \\
\text { Public University in } \\
\text { West Texas } \\
\text { Analytic N: } 142\end{array}$} & \multirow[t]{2}{*}{$\begin{array}{l}\text { Weekly food } \\
\text { expenditures }(\$ / \text { wk; } \\
\text { HH) }\end{array}$} & \multirow[t]{2}{*}{ HEI-2015 } & \multirow{3}{*}{$\begin{array}{l}\text { Total food expenditures: } \beta=0.058[0.03], p<0.10 \\
\text { Food at home expenditures (natural log): } \beta=0.085[0.029], p<0.01 \\
\text { Food away-from-home expenditures (natural log): Coefficient }-0.002[0.010] \text {, NS; }\end{array}$} \\
\hline & & & & \\
\hline & & \multicolumn{2}{|l|}{ Diet source: self report } & \\
\hline Sanjeevi, $2018^{12}$ & $\begin{array}{l}\text { Low-income women in } \\
\text { Texas }\end{array}$ & \multirow{2}{*}{$\begin{array}{l}\text { Food expenditures } \\
\text { relative to TFP cost } \\
\text { ( } \$ / \text { mo; per capita) }\end{array}$} & \multirow[t]{3}{*}{ HEI-2010 } & \multirow[t]{3}{*}{$\beta=5.29$, SE: $2.60, p=0.04$} \\
\hline \multirow{2}{*}{ PCS } & Analytic N: 144 & & & \\
\hline & & $\begin{array}{l}\text { Diet source: monthly } \\
\text { grocery receipts }\end{array}$ & & \\
\hline Gupta, $2020^{6}$ & $\begin{array}{l}\text { Seattle Obesity Study } \\
\text { III }\end{array}$ & $\begin{array}{l}\text { Food expenditures } \\
(\$ / \text { mo; per capita) }\end{array}$ & HEI-2015 & $\begin{array}{l}\text { Mean HEI (SD): Lowest expenditure T1 } 65.23 \text { (9.53) v. middle expenditure T2 } \\
(\mathrm{n}=271) 66.80 \text { (10.04) v. highest expenditure T3 }(\mathrm{n}=232) 69.45(9.68), \mathrm{p}<0.0001\end{array}$ \\
\hline \multirow{2}{*}{ Cross-sectional } & Analytic N: 755 & & & \\
\hline & & \multicolumn{2}{|l|}{ Diet source: self report } & \\
\hline \multirow{3}{*}{$\begin{array}{l}\text { Gupta, } 2021^{7} \\
\text { Cross-sectional }\end{array}$} & $\begin{array}{l}\text { Seattle Obesity Study } \\
\text { III }\end{array}$ & \multirow{2}{*}{$\begin{array}{l}\text { Food expenditures at } \\
\text { home }(\$ / \mathrm{mo} \text {; per } \\
\text { capita) }\end{array}$} & \multirow[t]{3}{*}{ HEI-2015 } & \multirow[t]{3}{*}{$\begin{array}{l}\text { Mean HEI (SD): } \leq \$ 100: 65.2(9.96) \text { (ref) v. }>\$ 100-\leq \$ 175: 66.4(9.88), p=0.177 \mathrm{v} \text {. } \\
\geq \$ 175: 69.9(9.27), p=0.0001 ;\end{array}$} \\
\hline & Analytic N: 747 & & & \\
\hline & & Diet source: self-report & & \\
\hline \multirow[t]{2}{*}{ Rose, $2020^{11}$} & Seattle Obesity Study & \multirow{3}{*}{$\begin{array}{l}\text { Food expenditures at } \\
\text { home ( } \$ / \mathrm{mo} \text {; per } \\
\text { capita) }\end{array}$} & \multirow[t]{3}{*}{ HEI-2015 } & \multirow{3}{*}{$\begin{array}{l}\text { Linear model, Mean HEl per } \$ 100: 0.09,95 \% \mathrm{Cl}:-0.49,0.67, \mathrm{NS} \\
\text { Curvilinear model, NR, NS }\end{array}$} \\
\hline & & & & \\
\hline \multirow[t]{2}{*}{ Cross-sectional } & Analytic N: 768 & & & \\
\hline & & \multicolumn{2}{|l|}{ Diet source: self report } & \\
\hline
\end{tabular}



Population
Exposure
Outcome
Results

\begin{tabular}{|c|c|c|c|c|}
\hline Anderson, $2016^{1}$ & $\begin{array}{l}\text { NHANES; SNAP } \\
\text { participants }\end{array}$ & $\begin{array}{l}\text { Grocery Spending (per } \\
\text { capita) }\end{array}$ & $\begin{array}{l}\text { HEI } \\
\text { (unspecified) }\end{array}$ & $\beta=0.004(0.004), N S$ \\
\hline Cross-sectional & Analytic N: NR & Diet source: NR & & \\
\hline $\begin{array}{l}\text { Dubowitz, } 2015^{5} \\
\text { Cross-sectional }\end{array}$ & $\begin{array}{l}\text { PHRESH: majority } \\
\text { African-American } \\
\text { population near } \\
\text { Pittsburgh }\end{array}$ & $\begin{array}{l}\text { Weekly food } \\
\text { expenditures ( } \$ / w k \text {; } \\
\text { per capita) }\end{array}$ & HEI-2005 & $\beta=0.004 ; \mathrm{NS}$ \\
\hline & Analytic N: 1,372 & Diet source: self-report & & \\
\hline
\end{tabular}

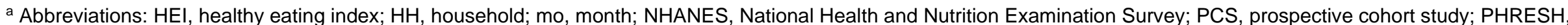

Pittsburgh Hill/Homewood Research on Neighborhood Change and Health; NR, not reported; NS, not significant; RCT, randomized controlled trial; wk, week 
Table 3-d. Risk of bias for the randomized controlled trial examining diet cost or expenditures and $\mathrm{HEI}^{\mathrm{a}}$

\begin{tabular}{|lcccc} 
Article & Randomization & $\begin{array}{c}\text { Deviations from intended } \\
\text { interventions } \\
\text { (effect of assignment) and } \\
\text { (per-protocol) }\end{array}$ & $\begin{array}{c}\text { Missing outcome data } \\
\text { Outcome } \\
\text { measurement }\end{array}$ & $\begin{array}{c}\text { Selection of the reported } \\
\text { result }\end{array}$ \\
\hline Nansel, $2016^{9}$ & LOW & SOME CONCERNS & SOME & LOW \\
\hline
\end{tabular}

a Possible ratings of low, some concerns, or high determined using the "Cochrane Risk-of-bias 2.0" (RoB 2.0) (August 2016 version)" (Higgins JPT, Sterne JAC, Savović J, Page MJ, Hróbjartsson A, Boutron I, Reeves B, Eldridge S. A revised tool for assessing risk of bias in randomized trials In: Chandler J, McKenzie J, Boutron I, Welch V (editors). Cochrane Methods. Cochrane Database of Systematic Reviews 2016, Issue 10 (Suppl 1). dx.doi.org/10.1002/14651858.CD201601.)

Table 3-e. Risk of bias for observational studies examining diet cost or expenditures and HEI ${ }^{a}$

\begin{tabular}{|c|c|c|c|c|c|c|c|}
\hline Article & Confounding & $\begin{array}{l}\text { Selection of } \\
\text { participants }\end{array}$ & $\begin{array}{l}\text { Classification } \\
\text { of exposures }\end{array}$ & $\begin{array}{l}\text { Deviations } \\
\text { from intended } \\
\text { exposures }\end{array}$ & Missing data & $\begin{array}{c}\text { Outcome } \\
\text { measurement }\end{array}$ & $\begin{array}{l}\text { Selection of } \\
\text { the reported } \\
\text { result }\end{array}$ \\
\hline Anderson, $2016^{1}$ & SERIOUS & LOW & SERIOUS & SERIOUS & NI & SERIOUS & MODERATE \\
\hline Beydoun, $2018^{3}$ & LOW & MODERATE & MODERATE & SERIOUS & MODERATE & LOW & MODERATE \\
\hline Beydoun, $2015^{2}$ & LOW & MODERATE & SERIOUS & SERIOUS & MODERATE & LOW & MODERATE \\
\hline Carpio, 20204 & SERIOUS & SERIOUS & MODERATE & SERIOUS & MODERATE & LOW & MODERATE \\
\hline Dubowitz, $2015^{5}$ & MODERATE & MODERATE & LOW & LOW & MODERATE & LOW & MODERATE \\
\hline Gupta, $2020^{6}$ & SERIOUS & MODERATE & LOW & MODERATE & MODERATE & LOW & SERIOUS \\
\hline
\end{tabular}




\begin{tabular}{lccccccc} 
Article & Confounding & $\begin{array}{c}\text { Selection of } \\
\text { participants }\end{array}$ & $\begin{array}{c}\text { Classification } \\
\text { of exposures }\end{array}$ & $\begin{array}{c}\text { Deviations } \\
\text { from intended } \\
\text { exposures }\end{array}$ & $\begin{array}{c}\text { Missing data } \\
\text { Outcome } \\
\text { measurement }\end{array}$ & $\begin{array}{c}\text { Selection of } \\
\text { the reported } \\
\text { result }\end{array}$ \\
\hline Gupta, $2021^{7}$ & LOW & MODERATE & LOW & MODERATE & MODERATE & LOW & SERIOUS \\
\hline Nansel, $2015^{8}$ & SERIOUS & SERIOUS & LOW & MODERATE & MODERATE & LOW & MODERATE \\
\hline Rehm, $2015^{10}$ & MODERATE & LOW & LOW & SERIOUS & LOW & LOW & LOW \\
\hline Rose, $2020^{11}$ & LOW & MODERATE & LOW & MODERATE & MODERATE & LOW & SERIOUS \\
\hline Sanjeevi, $2018{ }^{12}$ & SERIOUS & MODERATE & MODERATE & LOW & LOW & LOW & LOW
\end{tabular}

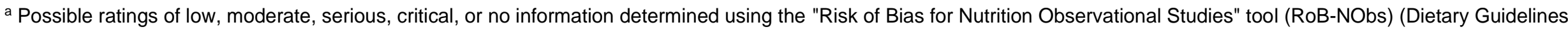

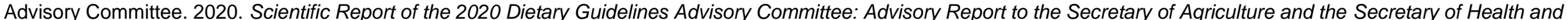
Human Services. U.S. Department of Agriculture, Agricultural Research Service, Washington, DC.) 


\section{References of the articles included in the diet cost and $\mathrm{HEI}$ rapid review}

1. Anderson PM, Butcher KF. The Relationships Among SNAP Benefits, Grocery Spending, Diet Quality, and the Adequacy of Low-Income Families' Resources. Center on Budget and Policy Priorities. 2016.

2. Beydoun MA, Fanelli-Kuczmarski MT, Allen A, et al. Monetary Value of Diet Is Associated with Dietary Quality and Nutrient Adequacy among Urban Adults, Differentially by Sex, Race and Poverty Status. PLoS One. 2015;10(11):e0140905 doi:10.1371/journal.pone.0140905. eCollection 2015.

3. Beydoun MA, Fanelli-Kuczmarski MT, Poti J, et al. Longitudinal change in the diet's monetary value is associated with its change in quality and micronutrient adequacy among urban adults. PLoS One. 2018;13(10):e0204141 doi:10.1371/journal.pone.0204141. eCollection 2018.

4. Carpio CE, Kalenkoski CM, Moyeda-Carabaza AF, Murimi M. The effect of time use and food cost on dietary quality. Public Health Nutr. 2020;23(18):3284-3294 doi:10.1017/S1368980020001615. Epub 2020 Jul 13.

5. Dubowitz T, Zenk SN, Ghosh-Dastidar B, et al. Healthy food access for urban food desert residents: examination of the food environment, food purchasing practices, diet and BMI. Public Health Nutr. 2015;18(12):2220-2230 doi:10.1017/S1368980014002742. Epub 2014 Dec 5.

6. Gupta S, Rose CM, Buszkiewicz J, et al. Characterising percentage energy from ultra-processed foods by participant demographics, diet quality and diet cost: findings from the Seattle Obesity Study (SOS) III. Br J Nutr. 2020:1-9 doi:10.1017/S0007114520004705.

7. Gupta S, Rose CM, Buszkiewicz J, Otten J, Spiker ML, Drewnowski A. Inedible Food Waste Linked to Diet Quality and Food Spending in the Seattle Obesity Study SOS III. Nutrients. 2021;13(2) doi:10.3390/nu13020479.

8. Nansel T, Haynie D, Lipsky L, Mehta S, Laffel L. Little variation in diet cost across wide ranges of overall dietary quality among youth with type 1 diabetes. J Acad Nutr Diet. 2015;115(3):433-439 e431 doi:10.1016/j.jand.2014.07.035. Epub 2014 Sep 27.

9. Nansel TR, Lipsky LM, Eisenberg MH, Liu A, Mehta SN, Laffel LM. Can Families Eat Better Without Spending More? Improving Diet Quality Does Not Increase Diet Cost in a Randomized Clinical Trial among Youth with Type 1 Diabetes and Their Parents. J Acad Nutr Diet. 2016;116(11):1751-1759 e1751 doi:10.1016/j.jand.2016.07.005. Epub 2016 Aug 31.

10. Rehm CD, Monsivais P, Drewnowski A. Relation between diet cost and Healthy Eating Index 2010 scores among adults in the United States 2007-2010. Prev Med. 2015;73:70-75 doi:10.1016/j.ypmed.2015.01.019. Epub 2015 Jan 24.

11. Rose CM, Gupta S, Buszkiewicz J, et al. Small increments in diet cost can improve compliance with the Dietary Guidelines for Americans. Soc Sci Med. 2020;266:113359 doi:10.1016/j.socscimed.2020.113359. Epub 2020 Sep 11.

12. Sanjeevi N, Freeland-Graves JH. Association of Grocery Expenditure Relative to Thrifty Food Plan Cost with Diet Quality of Women Participating in the Supplemental Nutrition Assistance Program. J Acad Nutr Diet. 2018;118(12):2315-2323 doi:10.1016/j.jand.2018.07.015. Epub 2018 Sep 28. 


\section{Chapter 4 - What is the relationship between income and time spent on food-at-home-related activities?}

Julia H Kim, PhD, MPH, RD, a Julie Nevins, PhD, a Molly Higgins, MLIS, ${ }^{b}$ Marlana Bates, MPH, RD, a Laural Kelly English, $\mathrm{PhD},{ }^{a}$ Sara Scinto-Madonich, MS, ${ }^{a}$ Emily Callahan, $\mathrm{MS}^{\mathrm{c}}$

\section{Specific methods to conduct this rapid review}

\section{Develop a protocol}

The research question, "What is the relationship between income and time spent on food-at-home-related activities?" was answered using a rapid review.

The analytic framework for the rapid review examining the relationship between income and time spent on food-at-home-related activities is presented in Figure 4-a. This analytic framework visually represents the overall scope of the rapid review question, and depicts the contributing elements that were examined and evaluated. The intervention or exposure of interest is income (e.g., household, city, regional income) and income proxy (i.e., socioeconomic factor; geographic area; income-based federal assistance program participation/eligibility) in U.S. households or populations. The comparators are different levels/categories of income or income proxy. The outcome is time spent on food-at-home-related activities, including preparation, cooking, and cleaning in U.S. households or populations. The key confounders are food-away-from-home and household characteristics (e.g., household size (e.g., number of children, number of adults), single or dual head of household; marital status; level of employment; workload division). NESR analysts made a posthoc change when assessing the risk of bias for confounding. NESR analysts determined that adjusting for food-away-from-home would be over controlling for the outcome due to the collinearity of time spent on foodat-home-related activities and time spent on food-away-from-home activities. Therefore, articles that did not account for food-away-from-home in their analyses were not rated differently for risk of bias due to confounding. The other factors to be considered are food security; race/ethnicity; sex; seasonal differences; urban/rural; cultural food choices; neighborhood characteristics (e.g., access to food/distance to stores/ access to car/type of store); use of convenience foods; time preferences/value of food-related activities or cooking skills or cooking equipment. The confounders and other factors to be considered may impact the relationships of interest.

a Analyst, NESR team; Panum Group, under contract with the FNS, USDA

b Librarian, NESR team; Panum Group, under contract with the FNS, USDA

c Project Lead, NESR team, NGAD, CNPP, FNS, USDA 
Figure 4-a. Analytic framework for the rapid review on income and time spent on food-at-home-related activities

\begin{tabular}{|c|c|c|}
\hline Interventions/exposures & Comparators & Outcome \\
\hline \multirow[t]{2}{*}{$\begin{array}{l}\text { Income (e.g., household, city, regional } \\
\text { income) } \\
\text { Income proxy (i.e., Socioeconomic } \\
\text { factor; Geographic area; Income- } \\
\text { based Federal assistance program } \\
\text { participation/eligibility) }\end{array}$} & \multirow[t]{2}{*}{$\begin{array}{l}\text { Different levels/categories of income } \\
\text { or income proxy }\end{array}$} & $\begin{array}{l}\text { Time spent on food-at-home-related } \\
\text { activities: } \\
\text { - Preparation } \\
\text { - Cooking } \\
\text { - Cleaning }\end{array}$ \\
\hline & & Population: U.S. households or \\
\hline \multicolumn{2}{|c|}{ Population: U.S. households or populations } & populations \\
\hline
\end{tabular}

Key confounders: Household characteristics (e.g., Household size (e.g., number of children; number of adults), single or dual head of household; marital status; level of employment; workload division)

Other factors to be considered: Food security; Race/ethnicity; Sex; Seasonal differences; Urban/rural; Cultural food choices; Neighborhood characteristics (e.g., access to food/distance to stores/access to car/type of store); Use of convenience foods; Time preferences/value of food-related activities or cooking skills or cooking equipment

\section{Key definitions}

Low income: before-tax income at or below 130 percent of the U.S. poverty guidelines Higher income: before-tax income above 130 percent of the U.S. poverty guidelines Food-at-home: Food that is prepared at home and includes ready-to-eat and non-ready-to-eat foods that are brought from grocery stores, food pantries, super centers, mass merchandisers, convenience stores, drug stores, farmers markets, and food co-ops (ERS, 2018)
Legend

Relationship of interest

Factors that may impact the relationship of interest 


\section{Search for and select studies}

The following outlines any departures from the search and select studies project methods for this specific rapid review:

- Articles were screened at the title, abstract, and the full-text level, separately.

- One person screened $100 \%$ of the articles and a $2^{\text {nd }}$ person screened $20 \%$ of articles at the title and abstract screening levels. All articles were dual-screened at the full-text level $\left(2^{\text {nd }}\right.$ person verified excluded articles). Included articles were hand-searched.

NESR analysts worked jointly with NEAT staff to establish the final inclusion and exclusion criteria and literature search strategy, which are detailed in Table 4-a and Appendix 4-a, respectively.

Table 4-a. Inclusion and exclusion criteria for the rapid review on income and time spent on food-athome-related activities

Category Inclusion Criteria

Study design

- Any study design that is not a narrative review, systematic review, or meta-analysis

\section{Exclusion Criteria}

- $\quad$ Narrative reviews

- Systematic reviews

- Meta-analyses
- Income proxies that are not a direct proxy for income determined by the author

- Socioeconomic factor (e.g., education)

- Geographic area

- Income-based Federal assistance program participation/eligibility

Comparator
- Comparison of geographic areas without a proxy for income

- Higher vs. lower income geographic areas

- Different participation/eligibility status in incomebased Federal assistance program(s) 


\section{Exclusion Criteria}

Outcomes

- Time spent on food-at-home-related activities:

- Preparation (e.g., cutting food, setting table, transportation, shopping)

- Cooking

- Cleaning, including storing and putting away food/drinks

- Studies that examine transportation, shopping, and/or eating as part of a combined measure that also includes either preparation, cooking, and/or cleaning

- Studies that only examine time spent on transportation, shopping, and/or eating

- Studies that only examine time spent on snacking

- Time spent on food-away-from-home-related activities, including fast-food (FF) or full-service (FS) restaurants

Definitions (ERS, 2018):

- Food-away-from-home: Food prepared outside of home and includes food from FS restaurants and FF restaurants

- $\quad$ Fast-food restaurants: Eating places where consumers pay before they eat (e.g., bakery, burger restaurant, and sandwich or coffee shop)

- Full-service restaurants: Eating places where consumers eat before they pay

\begin{tabular}{llll}
\hline $\begin{array}{l}\text { Date of } \\
\text { publication and } \\
\text { data examined }\end{array}$ & $\begin{array}{l}\text { Published January 2008 - April 2021 and data } \\
\text { inclusive of } 2008 \text { (e.g., 2000-2012; 2008-2009) }\end{array}$ & $\bullet$ & $\begin{array}{l}\text { Articles published prior to January 2008 } \\
\text { Data prior to 2008 (e.g., 2000-2007; 1999-2005) }\end{array}$ \\
\hline $\begin{array}{l}\text { Publication } \\
\text { status }\end{array}$ & $\bullet$ & $\begin{array}{l}\text { Articles published in peer-review journals } \\
\text { Grey literature: reports that have not been peer- } \\
\text { reviewed but are available from government and } \\
\text { non-governmental organizations }\end{array}$ & $\begin{array}{l}\text { Articles that have not been peer-reviewed and are } \\
\text { not published in peer-reviewed journals, other than } \\
\text { reports from government and non-governmental } \\
\text { organizations }\end{array}$ \\
\hline $\begin{array}{llll}\text { Language } \\
\text { Country }\end{array}$ & Articles published in English & Studies in the U.S. & Articles published in languages other than English \\
\hline $\begin{array}{l}\text { Study } \\
\text { participants }\end{array}$ & Human participants/populations & Studies conducted outside the U.S. \\
\hline
\end{tabular}

\section{Extract data and assess the risk of bias}

NESR analysts extracted and summarized data from each included article to objectively describe the body of evidence available to answer a rapid review question. The following outlines any departures from the extract data and assess risk of bias project methods for this specific rapid review:

- One NESR analyst extracted data (author, year, study design, cohort, year that time data were collected, data source for time, year that income data were collected, data source for income, analytic $\mathrm{N}$, geographic location, location description, population description, intervention/exposure description, comparator, outcome type (preparation, cooking, and/or cleaning), outcome description, outcome definition, results, results summary, key confounders, other factors to be considered) and a $2^{\text {nd }}$ analyst verified the results.

- Risk of bias assessment was completed by 1 NESR analyst and verified by a $2^{\text {nd }}$ analyst. 


\section{Synthesize the evidence}

Evidence synthesis was completed by describing the evidence and evaluating the included studies individually and collectively as previously described in the project methods.

\section{Summary statements}

NESR analysts formed summary statements, as previously described in the project methods, outlining the themes observed during the data synthesis of studies examining income and time spent on food-at-homerelated activities.

\section{Recommend future research}

Recommendations for future research evaluating the relationship between income and time spent on food-athome-related activities were determined based on the gaps and limitations observed during data extraction and synthesis, as previously described in the project methods. Future work addressing these gaps and limitations may contribute to the body of evidence available to answer this research question.

\section{Results}

\section{Literature search and screening results}

The literature search yielded 5,499 search results after the removal of duplicates (see Figure 4-b). Dual screening resulted in the exclusion of 5,271 titles, 136 abstracts, and 79 full-texts articles. Reasons for full-text exclusion are in Appendix 4-b. One additional article was identified from the manual search. The body of evidence included 13 articles. 
Figure 4-b. Literature search and screen flowchart for the rapid review on income and time spent on food-at-homerelated activities

\begin{tabular}{|c|c|c|}
\hline \multirow{2}{*}{ 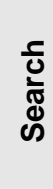 } & Electronic databases searched & Manual search \\
\hline & $\begin{array}{l}\text { PubMed, Business Source Premier \& Web of Science; Grey literature: } \\
\text { AgEcon, Google, and Google Scholar } \\
\mathrm{N}=7,006(\mathrm{~N}=5,499 \text { after duplicates removed) }\end{array}$ & References of included articles \\
\hline \multirow{6}{*}{ 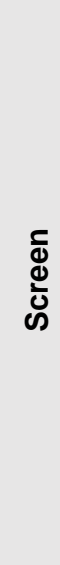 } & Articles excluded & \\
\hline & $N=5,271$ & \\
\hline & Abstracts screened & \\
\hline & $\mathrm{N}=136$ & \\
\hline & Full-texts screened & \\
\hline & $\mathrm{N}=91$ & \\
\hline \multirow{4}{*}{ 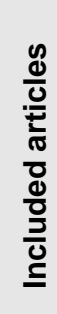 } & Articles from electronic database search & Articles from manual search \\
\hline & $\mathrm{N}=12$ & $\mathrm{~N}=1$ \\
\hline & \multicolumn{2}{|c|}{ Articles included in the rapid review } \\
\hline & \multicolumn{2}{|l|}{$\mathrm{N}=13$} \\
\hline
\end{tabular}

\section{Description of the evidence}

Thirteen studies (13 articles) were included in the body of evidence that addressed the relationship between income, including income proxy, and time spent on food-at-home-related activities (see Figure 4-b). Basic characteristics and results are shown in Table 4-b. All studies were cross-sectional. The majority (85\%) of studies included populations that were nationally representative..$^{111}$ One study each was conducted in Seattle, Washington, ${ }^{12}$ and Minneapolis and St. Paul, Minnesota. ${ }^{13}$ Studies generally included men and women with and without children. Of the five studies that reported race/ethnicity, $, 3,6,7,12,13$ all but one ${ }^{13}$ had predominantly (>65\%) non-Hispanic White populations. The study conducted in Minneapolis and St. Paul, Minnesota had 28\% White, 23\% African American, 21\% Asian, 17\% Hispanic, and 11\% mixed or other race/ethnicity participants. ${ }^{13}$ Therefore, the study populations for the majority of studies represent the racial/ethnic diversity of the U.S. population. The sample sizes in these 13 studies were large, ranging from $1,078^{1}$ to $118,635 .^{10}$ 


\section{Study characteristics}

The majority of studies included participants who completed the survey of interest and were adults 18 years and older, regardless of marital status. Some exceptions were 1 study that only included adults aged 45-75 without children, ${ }^{1}$ another study that excluded participants with a child aged 16 to $17,{ }^{8}$ and another study that only included Hispanic women with a child less than age $13 .{ }^{9}$ The years in which data were collected for analyses varied widely ranging from 2001-2018, and included 2006-2008 $3,4,8$ and 2003-2011.9,10 Mean age of participants ranged from $32.8^{9}$ to 64.3 years. ${ }^{1}$

\section{Exposure}

Eight ${ }^{1-4,8,10-12}$ of the 13 included articles examined the effect of income on time spent on food-at-home-related activities. Gough et al., ${ }^{3}$ Hamrick et al., ${ }^{4}$ and Senia et al., ${ }^{8}$ assessed time data from the American Time Use Survey (ATUS) from 2006-2008, and therefore, likely include some of the same data in their analyses. However, data eligibility criteria differed between these studies and all were included, given that their samples may not be entirely overlapping. Gough et al., ${ }^{3}$ only included women and also included participants who completed 2014-2015 ATUS, Hamrick et al., ${ }^{4}$ included anyone who completed the $8^{\text {th }}$ Current Population Survey, and Senia et al., ${ }^{8}$ included anyone who are the only adult members ( $\geq 18$ years) in the household and with no children age 16-17.

One study examined both income above or below the poverty threshold and SNAP participation and eligibility. Of the studies that examined income, 1 study examined labor income (income from wages, salary, tips, commissions, bonuses, and military pay) and non-labor income (income from government transfers (e.g., social security, disability, welfare), pension benefits, and any income from assets) separately. ${ }^{1}$ The federal poverty threshold, $130 \%$, and $185 \%$ were used as cut-off points in numerous articles, possibly with overlapping data. . $^{3,8}$ For example, a study compared moderate/upper income, defined as $\geq 185 \%$ the poverty threshold to low income ( 130 to $<185 \%$ poverty threshold) and to sub-poverty $\left(<130 \%\right.$ poverty threshold). ${ }^{3}$ Two studies had different income cut-offs of $<\$ 50,000$ versus $\$ 50,000-99,999$ versus $\geq \$ 100,000^{12}$ and $<\$ 25,000$ versus $\$ 25,000-59,000$ versus $\geq \$ 60,000 .{ }^{11}$ Three $e^{2,3,10}$ of these studies collected income data from the American Time Use Survey during various years from 2003-2012 and two from the Eating and Health Module, ${ }^{4,8}$ a supplement of the ATUS. Studies also used income data from the Health and Retirement Survey, ${ }^{1}$ the Home Cooking Survey, ${ }^{11}$ and a study-specific survey. ${ }^{12}$

$\mathrm{Six}^{4-7,9,13}$ of the 13 included articles examined the effect of income proxies on time spent on food-at-homerelated activities. Although there may be overlapping data between Raschke et al., ${ }^{6}$ Hamrick et al., ${ }^{4}$ and Sliwa et al., ${ }^{9}$ all of these studies had different date ranges of 2003-2009, 2006-2008, and 2003-2011 and therefore, the samples may not be entirely overlapping. Three ${ }^{4-6}$ of these studies examined SNAP participation and/or eligibility, 1 study compared different levels of employment (i.e., not employed versus part-time versus fulltime), ${ }^{13} 1$ study compared those who worked from home (higher income) to those who worked away from home (lower income), ${ }^{7}$ and 1 study compared US-born Hispanic mothers (higher income) to immigrant or migrant Hispanic mothers (lower income). ${ }^{9}$ The data source and years for the income proxies varied from 2003-2018 and included the American Time Use Survey, ${ }^{6,9}$ Eating and Health Module, ${ }^{4}$ Consumer Expenditure Quarterly Interview Survey, ${ }^{5}$ Leave and Job Flexibilities Module, ${ }^{7}$ and a study-specific survey. ${ }^{13}$

\section{$\underline{\text { Outcome }}$}

The studies differed in their definition of the outcome of time spent on food-at-home-related activities. Twelve ${ }^{1-}$ $10,12,13$ of the 13 included articles had "preparation" as part of their definition for food-at-home-related activities. As part of the outcome definition, 9 studies ${ }^{1,4,6-12}$ included "cleaning," 6 studies $5,6,8,9,11,12$ included "cooking," 5 studies $^{2,4,6,7,9}$ included "presentation," and 3 studies $5,7,8$ included both grocery shopping and transportation. Nine of the articles assessed time spent on food-at-home-related activities using the American Time Use 
Survey ${ }^{2,3,5-10}$ and/or the Eating and Health Module, ${ }^{4,8} 2$ studies used a study-specific survey, ${ }^{12,13}$ and 1 study each used the Consumption and Activities Mail Survey ${ }^{1}$ and the Home Cooking Survey. ${ }^{11}$

\section{Synthesis of the evidence}

\section{Income}

Among the 4 studies from 5 articles $2,4,8,11,12$ that included men and women, there were mixed findings. Three studies $2,8,11$ found no association between income (log family income or $\$ 25,000-59,999$ versus $\geq \$ 60,000$ ) and time spent on preparing and/or cooking, cleaning, food-related travel and grocery shopping. One of these studies did not describe how income was assessed and did not report model adjustments. ${ }^{2}$ Two studies found a significant and positive relationship between income and time spent on cooking and cleaning ${ }^{11}$ and preparing, cooking, and cleaning. ${ }^{12}$ It is important to note that the income comparators $(<\$ 25,000$ to $\$ 25,000$ 59,000 and to $\geq \$ 60,000^{11}$ and $<\$ 50,000$ to $\geq \$ 50,000^{12}$ ) were higher than the exposure and comparators in studies that found an inverse relationship between income and time spent on food-at-home-related activities. The 2 studies that found a significant and inverse relationship (i.e., higher income associated with less time spent on food-at-home-related activities) compared below or above $185 \%$ poverty threshold 4 and below $130 \%$ poverty threshold to $130-185 \%$ poverty threshold. ${ }^{8}$

Three studies ${ }^{1,3,10}$ assessed the relationship between income among women only and time spent on food-athome-related activities. There were mixed findings within these 3 studies. All 3 studies ${ }^{1,3,10}$ found a significant, inverse relationship between income in mothers and child-free women and time spent on food preparation and clean-up afterwards. Additionally, those with lower income levels tended to spend more time on food preparation. In 1 study, mothers with sub-poverty income (<130\% poverty threshold) spent an average of 8.16 more minutes and mothers with low income (130\% to <185\% poverty threshold) spent 3.28 more minutes in food preparation per day than mothers with middle/upper income ( $\geq 185 \%$ poverty threshold). ${ }^{3}$ This was no longer significant among childfree women. ${ }^{3}$ Another study ${ }^{1}$ found an inverse relationship but this was between non-labor income, defined as income from government transfers (e.g., social security, disability, welfare), pension benefits, and any income from assets. No studies found a direct relationship. Overall, women, especially those with children, spend less time on food-at-home-related activities as income increases.

Two studies ${ }^{1,10}$ assessed the relationship between income among men only and time spent on food-at-homerelated activities. One study found an inverse relationship and 1 study found no relationship. Due to a limited number of studies and mixed findings, it is unclear whether there is a relationship between income and time spent on food-at-home-related activities for men.

\section{Income proxies}

Five studies from 6 articles ${ }^{4-7,9,13}$ examined income proxies, 2 (from 3 articles) of which examined SNAP participation and/or eligibility, ${ }^{4-6} 1$ examined employment level (not employed versus part-time versus fulltime), ${ }^{13} 1$ examined immigrant or migrant Hispanic mothers compared to U.S.-born Hispanic mothers, ${ }^{9}$ and working away from home compared to working at home (higher income). ${ }^{6}$

\section{SNAP participation/eligibility}

All 2 studies from 3 articles $^{4-6}$ that examined SNAP participation and/or eligibility found that those who participated in SNAP spent more time on food preparation, presentation, clean-up, cooking, food-related travel and/or grocery shopping than SNAP non-participants, ${ }^{6}$ and SNAP-eligible non-participants, ${ }^{5}$ and SNAP noneligible ${ }^{4}$ non-participants. One of two studies that compared SNAP participation to SNAP eligible nonparticipants did not find a significant difference in time spent on food preparation, including travel time related to food preparation, cooking time, and grocery shopping time. ${ }^{4}$ Specifically, SNAP participants spent 74.7 
minutes per day on meal preparation, compared to 72.8 minutes per day among SNAP-eligible nonparticipants, and 57.6 minutes per day among non-SNAP, non-eligible (income above the 130\% poverty threshold) participants $(\mathrm{N}=37,832, \mathrm{p}<0.10) .{ }^{4}$ Therefore, individuals who were ineligible for SNAP due to income spent significantly less time on meal preparation than SNAP participants or SNAP-eligible non-participants. ${ }^{4}$ Although there is a small body of evidence, there is consistent evidence that SNAP participants spent significantly more time on food-at-home-related activities than SNAP non-participants. It is less clear whether there is a difference between SNAP participants and SNAP-eligible non-participants on time spent on meal preparation and/or cooking, cleaning, presentation, grocery shopping, and food-related travel.

\section{Other income proxies}

Two of three studies that examined income proxies found a significant association with participants with lower income based on income proxies spending more time on food preparation only, ${ }^{13}$ food preparation, cooking, serving, and clean-up. ${ }^{9}$ U.S.-born Hispanic mothers (higher income, $n=1,345$ ) spent significantly less time (70.8 min/day) on food preparation, cooking, presentation, and clean-up than immigrant or migrant Hispanic mothers (lower income, $n=2,277$ ) of 107.8 minutes per day. ${ }^{9}$ There was a dose-response relationship between mother's employment level (unemployed versus part-time versus full-time) and time spent on food preparation, with time spent on food preparation decreasing as level of employment increases. ${ }^{13}$ For men, those who worked full-time spent less time than those who worked part-time or who were unemployed. However, there was no significant difference between men who were unemployed and men who worked part-time and time spent on food preparation per week. ${ }^{13}$

One study found a significant, positive relationship, with those who worked away from home (higher income) spending more time on food preparation, presentation, clean-up, grocery shopping, and travel to grocery store (mean: $40.7 \mathrm{~min} /$ day, SE: 5.4) than those who worked at home (lower income; Mean: $30.3 \mathrm{~min} /$ day, SE: 1.2) ${ }^{7}$

\section{Summary}

The results of all 13 articles suggest that at lower income levels (i.e., $185 \%, 130 \%$ or poverty threshold cutoffs), particularly women, spent more time on food-at-home-related activities. When comparing income levels higher than $185 \%$ poverty threshold (i.e., $<\$ 50,000$ versus $\geq \$ 50,000 ;<25,000$ versus $\$ 25,000-50,000$ or $\geq \$ 60,000$ ), there is a significant, positive association between income and time spent on preparation, cooking, and/or cleaning. ${ }^{11,12}$ There is also a consistent pattern of SNAP participants spending significantly more time on food preparation, presentation, clean-up, grocery shopping, and/or food-related travel than SNAP nonparticipants, regardless of SNAP-eligibility.

\section{Assessment of the evidence}

Risk of bias: Half of the studies did not account for household characteristics, which included 1 of the following: household size, single or dual head of household, marital status, level of employment, or workload division (Table 4-d).

Consistency: There was some consistency of an inverse relationship between income and time spent on food-at-home-related activities, especially among women and when comparing at $130 \%$ and $185 \%$ poverty thresholds. Additionally, evidence was consistent with those who participated in SNAP spending significant more time on food-at-home-related activities than those who were SNAP non-participants, including those who were SNAP-eligible.

Directness: The majority of studies (62\%) directly measured the income, comparator, outcomes, and population that are outlined in the Analytic Framework (Figure 4-a). The remaining studies measured income proxies, rather than income directly. 
Precision: All studies had large sample sizes and relatively small measures of variance.

Generalizability: All studies were conducted in the U.S., with the majority (85\%) of studies using nationallyrepresented data. Therefore, studies are representative of the U.S. population.

\section{Summary statements and research recommendations}

\section{Summary statements}

The findings of the rapid review are presented in the following summary statements.

\section{$\underline{\text { Income }}$}

Evidence indicates that those with lower income spend more time on food-at-home-related activities, particularly among women in the U.S.

Among all women, participants with higher income ( $\geq 185 \%$ poverty threshold or above the poverty threshold) spend significantly less time on food preparation or food preparation and clean-up.

Among women without children, there was no association between income and time spent on food preparation or food preparation and clean-up.

Among men, there is not enough evidence to determine whether there is an association between income and time spent on food preparation and cleaning due to inconsistent findings.

$\underline{\text { Income proxies }}$

SNAP participation/eligibility: A small but consistent body of evidence suggests that those who participate in SNAP, compared to those who do not participate in SNAP, spend significantly more time on food-at-home-related activities.

It is less clear whether there is a difference between SNAP participants and SNAP-eligible non-participants on meal preparation due to few studies and inconsistent findings.

Studies had serious risks of bias for confounding due to not adjusting for household characteristics. One study also had a serious risk of bias for deviations from intended exposures due to unbalanced co-exposures (i.e., education, race, marital status) between exposure and comparator groups.

Other income proxies: There is not enough evidence to determine whether there is a relationship between income proxies and time spent on food-at-home-related activities.

\section{Research recommendations}

- Account for household characteristics (e.g., household size, single or dual head of household, marital status, level of employment, workload division) when examining the relationship between income and time spent on food-at-home-related activities.

- Increase use of consistent definition, assessment, and measurement of time spent on food-at-homerelated activities.

- More research is needed to examine the effect of income on food-at-home-related activities, particularly in men.

- Determine eligibility in SNAP among SNAP non-participants when examining the effect of SNAP participation/eligibility on time spent on food-at-home-related activities. 
Table 4-b. Cross-sectional evidence examining the relationship between income and time spent on food-at-home-related activities ${ }^{a}$

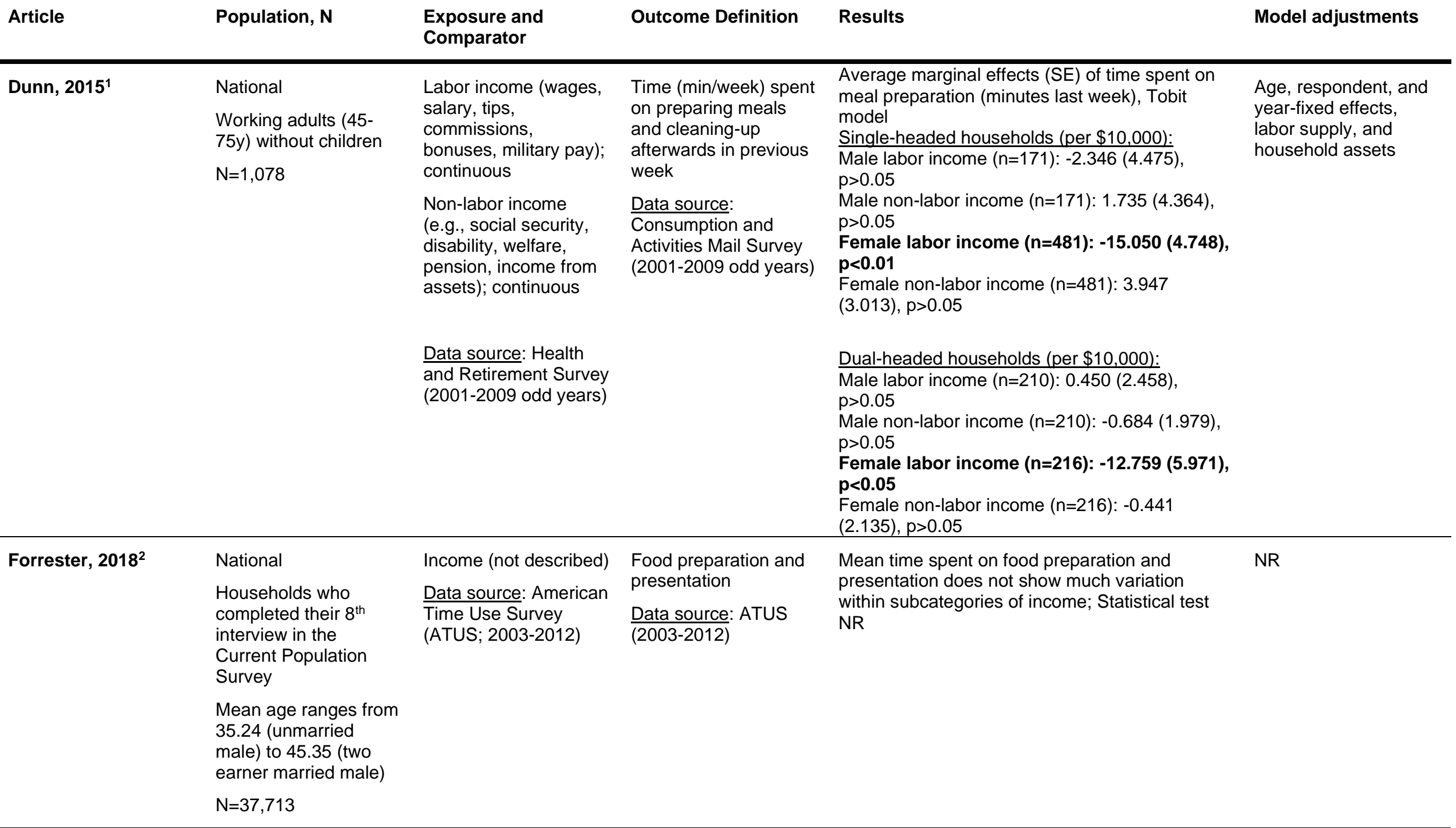




\begin{tabular}{|c|c|c|c|}
\hline \multirow[t]{2}{*}{ Gough, $2019^{3}$} & $\begin{array}{l}\text { National } \\
\text { Women aged 18-55; } \\
65 \% \text { non-Hispanic } \\
\text { White, } 13 \% \text { non- } \\
\text { Hispanic Black, } 15 \% \\
\text { Hispanic; Married } \\
55 \% \text {; Employment } \\
\text { status: employed full } \\
\text { time } 54 \% \text {, employed } \\
\text { part time } 19 \% \text {, out of } \\
\text { the labor force } 21 \% \text {, } \\
\text { unemployed } 6 \%\end{array}$ & $\begin{array}{l}\text { Poverty Threshold } \\
\text { (categorical): } \\
\text { - } \geq 185 \% \text { poverty } \\
\text { threshold } \\
\text { - } 130 \text { to <185\% } \\
\text { poverty threshold } \\
\text { - }<130 \% \text { poverty } \\
\text { threshold } \\
\text { Data source: ATUS } \\
\text { (2006-2008, 2014- } \\
2015)\end{array}$ & $\begin{array}{l}\text { Time spent in food } \\
\text { preparation (yes/no } \\
\text { and min/day among } \\
\text { those who prepared } \\
\text { food) } \\
\text { Data source: ATUS } \\
\text { (2006-2008, 2014- } \\
2015)\end{array}$ \\
\hline & $\mathrm{N}=17,914$ & & \\
\hline
\end{tabular}

$65 \%$ of women spent any time preparing food (mean (SE): 54.38 (43.35) min/day, range: 1-210 $\min /$ day)

Mothers' Likelihood of preparing food, $\mathrm{n}=8517$ OR $(95 \% \mathrm{Cl})$, logistic regression

Middle/Upper income: Ref

Low income (130-185\% poverty threshold): $1.38(1.15,1.65), p<0.01$

Sub-poverty income (<130\% poverty threshold): 1.64 (1.39, 1.94), $p<0.001$

Childfree Women's Likelihood of preparing food, $\mathrm{n}=3198$

OR $(95 \% \mathrm{Cl})$, logistic regression

Middle/Upper income: Ref

Low income: $1.16(0.89,1.51), p>0.10$

Sub-poverty income: $1.07(0.86,1.35), p>0.10$

Mothers' average min/day in food preparation, $\underline{\mathrm{n}=8517}$

Coefficient (SE), OLS regression

Middle/Upper income: Ref

Low income: 3.28 (1.91), p<0.10

Sub-poverty income: 8.16 (1.83), $p<0.001$

Low income vs. sub-poverty income, $p$ is statistically significant

Childfree Women's average min/day in food preparation, $\mathrm{n}=3198$

Coefficient (SE), OLS regression (adjusted for age, marital status, education, race/ethnicity,

citizenship, employment, urban residence

weekend day, and year)

Middle/Upper income: Ref

Low income: 2.94 (3.21), $\mathrm{p}>0.10$

Sub-poverty income: 4.91 (3.40), $p>0.10$
Age, marital status,

education,

race/ethnicity,

citizenship,

employment, urban

residence, weekend

day, and year (all

models) 


\begin{tabular}{|c|c|c|c|c|c|}
\hline Hamrick, $2011^{4}$ & $\begin{array}{l}\text { National } \\
\text { Participants who } \\
\text { completed the ATUS } \\
\text { data and Eating and } \\
\text { Health Module for } \\
2006-2008 \\
\mathrm{~N}=37,832\end{array}$ & $\begin{array}{l}\text { Income (categorical): } \\
\text { - }<185 \% \text { poverty } \\
\text { threshold } \\
\text { - }>185 \% \text { poverty } \\
\text { threshold } \\
\text { - Income missing } \\
\text { Data source: Eating } \\
\text { and Health Module } \\
\text { (2006-2008) }\end{array}$ & $\begin{array}{l}\text { Meal preparation } \\
\text { defined as food and } \\
\text { drink preparation, food } \\
\text { presentation, kitchen } \\
\text { and food cleanup } \\
\text { Data source: } \\
\text { ATUS/Eating and } \\
\text { Health Module (2006- } \\
\text { 2008) }\end{array}$ & $\begin{array}{l}\text { Mean meal prep time (minutes), total population, } \\
\frac{\mathrm{p}<0.10}{\text { Income }<185 \% \text { poverty threshold: } 40.3} \\
\text { Income }>185 \% \text { poverty threshold: } 29.5 \\
\text { Income missing: } 40.2 \\
\frac{\text { Mean meal prep time (minutes), participants, }}{\mathrm{p}<0.10} \\
\text { Income }<185 \% \text { poverty threshold: } 70.8 \\
\text { Income }>185 \% \text { poverty threshold: } 56.4 \\
\text { Income missing: } 75.3\end{array}$ & None \\
\hline $\begin{array}{l}\text { Monsivais, } 2014^{12} \\
\text { Seattle Obesity } \\
\text { Study }\end{array}$ & $\begin{array}{l}\text { Seattle, WA } \\
\text { Participants who } \\
\text { completed survey; } \\
\text { mean age } 54 y, 67.4 \% \\
\text { women, } 81 \% \text { White, } \\
7.5 \% \text { African } \\
\text { American, } 6.7 \% \text { Asian, } \\
2.7 \% \text { Hispanic, } 2 \% \\
\text { other } \\
\mathrm{N}=1,319\end{array}$ & $\begin{array}{l}\text { Household income } \\
\text { (categorical): } \\
\text { - }<\$ 50,000 / \text { year } \\
\text { - } \$ 50,000- \\
\quad \$ 99,999 / \text { year } \\
\text { - } \geq \$ 100,000 / \text { year } \\
\text { Data source: Study- } \\
\text { specific survey (2008- } \\
2009)\end{array}$ & $\begin{array}{l}\text { Average hours spent } \\
\text { on preparing, cooking, } \\
\text { and cleaning up from } \\
\text { meals each time. } \\
\text { Responses stratified } \\
\text { into three groups: } \\
<1 \mathrm{hr} / \text { day ( } \mathrm{n}=212 \text {, } \\
16 \% \text { ) } \\
1-2 \mathrm{hrs} / \text { day ( } \mathrm{n}=566 \text {, } \\
43 \% \text { ) } \\
>2 \mathrm{hrs} / \text { day ( } \mathrm{n}=541 \text {, } \\
41 \% \text { ) } \\
\text { Data source: Study- } \\
\text { specific survey (2008- } \\
2009)\end{array}$ & $\begin{array}{l}\text { Household income }>\$ 50,000 / \text { year }(\%) \text {, Pearson } \\
\text { chi-square } \\
\text { Hours/day spent preparing, cooking, and } \\
\text { cleaning up from meals, } p=0.005 \\
<1 \text { hr/day }(n=212): 46.7 \% \\
1-2 \text { hrs/day }(n=566): 58.3 \% \\
>2 \text { hrs/day }(n=541): 57.1 \%\end{array}$ & None \\
\hline Senia, $2017^{8}$ & $\begin{array}{l}\text { National } \\
\text { Participants who } \\
\text { completed } \\
\text { ATUS/Eating and } \\
\text { Health module, are the } \\
\text { only adult member } \\
\text { ( } \geq 18 y \text { ) in a household } \\
\text { with no children 16- } \\
17 y \\
\mathrm{~N}=11,070\end{array}$ & $\begin{array}{l}\text { Income (continuous) } \\
\text { Income (categorical): } \\
\text { - } 130-185 \% \text { poverty } \\
\text { - <130\% poverty } \\
\text { Data source: ATUS } \\
\text { (2006-2008) }\end{array}$ & $\begin{array}{l}\text { Preparing, cooking, } \\
\text { cleaning time, food- } \\
\text { related travel, grocery } \\
\text { shopping } \\
\frac{\text { Data source: ATUS }}{(2006-2008)}\end{array}$ & $\begin{array}{l}\text { Marginal effect (SE) of probability of positive } \\
\text { food preparation duration } \\
\text { Double-hurdle model: } \\
<130 \% \text { poverty: } 0.04(0.01), p<0.01 \\
130-185 \% \text { poverty: } 0.01(0.01), p \geq 0.1 \\
\text { Log of real family income: }-0.01(0.00), p<0.01 \\
\text { Marginal effect (SE) of expected duration of food } \\
\text { preparation (min/day) } \\
\text { Double-hurdle model } \\
<130 \% \text { poverty: } 5.30(1.35), p<0.01 \\
130-185 \% \text { poverty: } 3.72(1.86), p<0.05 \\
\text { Log of real family income: }-1.09(0.68), p \geq 0.10\end{array}$ & $\begin{array}{l}\text { Food-at-home and fast } \\
\text { food price indices, } \\
\text { age, sex, } \\
\text { race/ethnicity, foreign- } \\
\text { born, missing income, } \\
\text { education, presence of } \\
\text { child (0-5 and } 6-15 \text { y), } \\
\text { metropolitan area, } \\
\text { holiday, day of the } \\
\text { week, region, year, } \\
\text { season }\end{array}$ \\
\hline
\end{tabular}




\begin{tabular}{|c|c|c|c|c|c|}
\hline Smith, $2014^{10}$ & $\begin{array}{l}\text { National } \\
\text { Free-living residents of } \\
\text { households in all } 50 \\
\text { states and District of } \\
\text { Columbia } \geq 18 \mathrm{y} \\
\mathrm{N}=118,635\end{array}$ & $\begin{array}{l}\text { Income (categorical): } \\
\text { - Below poverty } \\
\text { (family income < } \\
\text { weighted average } \\
\text { poverty threshold } \\
\text { for relevant year) } \\
\text { - Above poverty } \\
\text { threshold } \\
\text { Data source: ATUS } \\
\text { (2003-2011) }\end{array}$ & $\begin{array}{l}\text { Any time spent in food } \\
\text { preparation or meal- } \\
\text { related cleaning into } 3 \\
\text { categorical variables } \\
\text { by gender: } \\
\text { Female: } \\
\text { Not cooking: } 32 \% \\
\text { Cooking } 1-59 \mathrm{~min} / \text { day: } \\
35 \% \\
\text { Cooking } \geq 60 \mathrm{~min} / \text { day: } \\
33 \% \\
\text { Male: } \\
\text { Not cooking: } 60 \% \\
\text { Cooking } 1-39 \mathrm{~min} / \text { day: } \\
23 \% \\
\text { Cooking } \geq 40 \mathrm{~min} / \text { day: } \\
17 \% \\
\text { Data source: ATUS } \\
(2003-2011)\end{array}$ & $\begin{array}{l}\text { Men ( } \mathrm{n}=51,139) \text { : } \\
\text { Percentage of men in each cooking category } \\
\text { from } 2003-2007 \text { to } 2008-2011 \text { (post-recession), } \\
\text { Multinomial logistic regression } \\
\text { Below poverty: } \\
0 \text { minutes/day: } 2003-2007: 62 \%, 2008-2011: \\
56 \% \text {, Change: }-6 \% \\
1-39 \text { minutes/day: } 2003-2007: 22 \%, 2008-2011: \\
24 \% \text {, Change: } 2 \% \\
>=40 \text { min/day: } 2003-2007: 16 \%, 2008-2011: \\
20 \% \text {, Change: } 4 \% \\
\text { Above poverty: } \\
0 \text { minutes/day: } 2003-2007: 61 \%, 2008-2011: \\
59 \%, \text { Change: }-2 \% \\
1-39 \text { minutes/day: } 2003-2007: 22 \%, 2008-2011: \\
23 \%, \text { Change: } 1 \% \\
>=40 \text { min/day: } 2003-2007: 16 \%, 2008-2011: \\
18 \%, \text { Change: } 2 \% \\
\text { Change in percentage of men cooking below } \\
(6 \%) \text { vs. above (2\%) poverty: } p<0.01 \\
\text { Women ( } n=67,496): \text { Household income below } \\
\text { federal poverty threshold was associated } \\
\text { with a strong and consistent increase in } \\
\text { likelihood of women cooking for longer } \\
\text { durations. }\end{array}$ & $\begin{array}{l}\text { Holidays, age, } \\
\text { education, } \\
\text { race/ethnicity, } \\
\text { household type, } \\
\text { individual employment } \\
\text { status, and state-level } \\
\text { unemployment }\end{array}$ \\
\hline
\end{tabular}




\begin{tabular}{|c|c|c|c|c|c|}
\hline Wolfson, $2019^{11}$ & $\begin{array}{l}\text { National } \\
\text { Participants of the GfK } \\
\text { KnowledgePanel } \\
\text { ( } 55,000 \text { US adults } \\
\text { recruited through } \\
\text { equal probability, with } \\
\text { sampling frame } \\
\text { covering } 97 \% \text { of US } \\
\text { households) } \\
\mathrm{N}=1,112\end{array}$ & $\begin{array}{l}\text { Income (categorical): } \\
\text { - Low income: } \\
<\$ 25,000 \\
\text { - Middle income: } \\
\$ 25,000-\$ 59,000 \\
\text { - Highest income: } \\
\geq \$ 60,000 \\
\text { Data source: Home } \\
\text { Cooking Survey }\end{array}$ & $\begin{array}{l}\text { Cooking and cleaning } \\
\text { time defined as } \\
\text { minutes that the } \\
\text { participant, or } \\
\text { someone in their } \\
\text { household, typically } \\
\text { spends cooking dinner } \\
\text { and cleaning up after } \\
\text { dinner on weekdays } \\
\text { and on weekends. } \\
\text { Data source: Home } \\
\text { Cooking Survey }\end{array}$ & 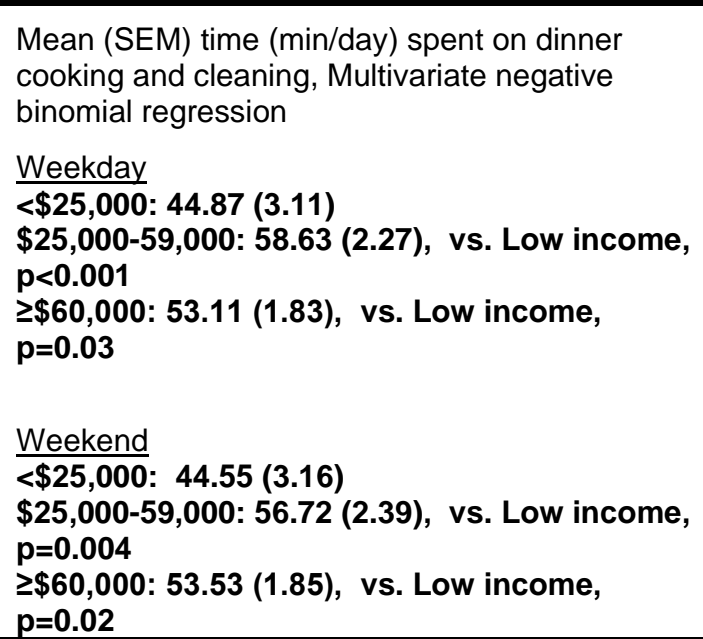 & $\begin{array}{l}\text { Income, gender, age, } \\
\text { race/ethnicity, } \\
\text { education, SNAP/WIC } \\
\text { status, employment } \\
\text { status, primary grocery } \\
\text { shopper status }\end{array}$ \\
\hline
\end{tabular}

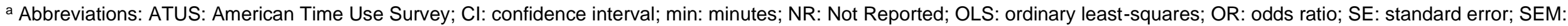
standard error of mean; SNAP: Supplemental Nutrition Assistance Program; WIC: Special Supplemental Nutrition Program for Women, Infants and Children

Bold indicates statistically significant findings 
Table 4-c. Cross-sectional evidence examining the relationship between income proxy and time spent on food-at-home-related activities ${ }^{\text {a }}$

\begin{tabular}{|c|c|c|c|c|c|}
\hline Article & Population, $\mathbf{N}$ & $\begin{array}{l}\text { Exposure and } \\
\text { Comparator(s) }\end{array}$ & Outcome Definition & Results & Model adjustments \\
\hline $\begin{array}{l}\text { Bauer, } 2012^{13} \\
\text { Project F-EAT }\end{array}$ & $\begin{array}{l}\text { Minneapolis and St. } \\
\text { Paul, MN } \\
\text { Parents of adolescents } \\
\text { who participated in the } \\
\text { EAT } 2010 \text { study; age } \\
\text { mean ranged from } \\
40.6 \text { to } 45.4 y ; 71 \% \text { in } \\
\text { married/committed } \\
\text { relationship; White } \\
n=961(28 \%), \text { African } \\
\text { American/Black } n=817 \\
(23 \%), \text { Hispanic } n=592 \\
(17 \%), \text { Asian } n=728 \\
(21 \%), \text { Mixed/other } \\
n=395(11 \%) \\
N=3,256\end{array}$ & $\begin{array}{l}\text { SES proxy: } \\
\text { Employment } \\
\text { - Not employed } \\
\text { (lowest income) } \\
\text { - Part time (middle } \\
\text { income) } \\
\text { - Full time (highest } \\
\quad \text { income) } \\
\text { Data source: Study- } \\
\text { specific survey (2009- } \\
\text { 2010) }\end{array}$ & $\begin{array}{l}\text { Food preparation time } \\
\text { (hours/week) } \\
\text { Data source: Study- } \\
\text { specific survey (2009- } \\
2010 \text { ) }\end{array}$ & $\begin{array}{l}\text { Adjusted means (SE) Time spent on food } \\
\text { preparation (hours/week), Linear regression } \\
\text { Fathers, } p<0.001^{*} \\
\text { Not employed }(n=298): 7.4(0.39) \text { a } \\
\text { Part time }(n=133): 6.8(0.56) \text { a } \\
\text { Full time }(n=752): 4.7(0.23) b(p<0.05) \\
\text { Mothers, } p<0.001 \\
\text { Not employed (lowest income, } n=760): 11.5 \\
(0.30) \text { a }(p<0.05) \\
\text { Part time (middle income, } n=368): 10.1(0.41) \\
b \text { ( } p<0.05) \\
\text { Full time (highest income, } n=945): 8.8(0.26) c \\
(p<0.05) \\
{ }^{* D i f f e r e n t ~ l e t t e r s ~ i n d i c a t e ~ s t a t i s t i c a l l y ~ s i g n i f i c a n t ~} \\
\text { differences }\end{array}$ & $\begin{array}{l}\text { Relationship status, } \\
\text { race/ethnicity, } \\
\text { education, age, } \\
\text { language spoken at } \\
\text { home, and number of } \\
\text { children in home }\end{array}$ \\
\hline Hamrick, $2011^{4}$ & $\begin{array}{l}\text { National } \\
\text { Participants who } \\
\text { completed the ATUS } \\
\text { data and the Eating } \\
\text { and Health Module for } \\
2006-2008 \\
\mathrm{~N}=37,832\end{array}$ & $\begin{array}{l}\text { SES proxy: } \\
\text { Participation and } \\
\text { eligibility in SNAP/food } \\
\text { stamps: } \\
\text { - SNAP participation } \\
\text { - Non-SNAP, income- } \\
\text { eligible } \\
\text { - Non-SNAP, income } \\
\text { >130\% poverty } \\
\text { threshold } \\
\text { Data source: Eating } \\
\text { and Health Module } \\
\text { (2006-2008) }\end{array}$ & $\begin{array}{l}\text { Meal preparation } \\
\text { defined as food and } \\
\text { drink preparation, food } \\
\text { presentation, kitchen } \\
\text { and food cleanup } \\
\frac{\text { Data source: ATUS }}{(2006-2008)}\end{array}$ & $\begin{array}{l}\text { Mean meal prep time (min/day), total population, } \\
\mathrm{p}<0.10 \\
\text { SNAP/FSP participation household: } 47.9 \\
\text { Non-SNAP but income eligible: } 39.9 \\
\text { Non-SNAP, income }>130 \% \text { poverty threshold: } \\
30.4 \\
\text { Mean meal prep time (min/day), participants, } \\
\text { p }<0.10 \\
\text { SNAP/FSP participation household: } 74.7 \\
\text { Non-SNAP but income eligible: } 72.8 \\
\text { Non-SNAP, income }>130 \% \text { poverty threshold: } \\
57.6\end{array}$ & None \\
\hline
\end{tabular}




\begin{tabular}{|c|c|c|c|c|c|}
\hline Kim, $2020^{5}$ & $\begin{array}{l}\text { National } \\
\text { Households with } \\
\text { annual incomes } \\
<130 \% \text { poverty } \\
\text { threshold } \\
\mathrm{N}=8,408\end{array}$ & $\begin{array}{l}\text { SES proxy: } \\
\text { - SNAP participant } \\
\text { - SNAP eligible non- } \\
\text { participants } \\
\text { Data source: } \\
\text { Consumer Expenditure } \\
\text { Quarterly Interview } \\
\text { Survey (2013-2014) }\end{array}$ & $\begin{array}{l}\text { Time (min/day) spent } \\
\text { in food preparation, } \\
\text { including travel time } \\
\text { related to food } \\
\text { preparation, cooking } \\
\text { time, and grocery } \\
\text { shopping time } \\
\frac{\text { Data source: ATUS }}{(2013-2014)}\end{array}$ & $\begin{array}{l}\text { Time (min/day) spent in food preparation, } \\
\text { Regression difference-in-differences model } \\
\text { Predicted mean (robust SE) } \\
\text { Any SNAP: } 8.065(2.695), p<0.01 \\
\text { After: }-0.104(4.768), p>0.05 \\
\text { SNAP }{ }^{\star} \text { After benefit decrease: }-\mathbf{1 3 . 8 9 2 ~ ( 4 . 1 2 7 ) ,} \\
\text { p<0.01 } \\
R^{\wedge} 2=0.159 \\
\frac{\text { Time (min/day) spent cooking, Regression }}{\text { difference-in-differences model }} \\
\text { Predicted mean (robust SE) } \\
\text { Any SNAP: } 5.824(2.156), p<0.01 \\
R^{\wedge} 2=0.162 \\
\text { Additionally adjusted for after SNAP benefit } \\
\text { decrease }\end{array}$ & $\begin{array}{l}\text { Education, age, age- } \\
\text { squared, sex, race, } \\
\text { labor force } \\
\text { participation, family } \\
\text { size, metropolitan, } \\
\text { holiday indicator, and } \\
\text { fixed effects for day, } \\
\text { month, and state }\end{array}$ \\
\hline Raschke, $2012^{6}$ & $\begin{array}{l}\text { National } \\
\text { Participants aged 18- } \\
65 y \\
N=18,740\end{array}$ & $\begin{array}{l}\text { SES proxy: } \\
\text { Hourly market wage by } \\
\text { SNAP participation: } \\
\text { - SNAP participants } \\
(\mathrm{n}=935): \$ 10.90 / \mathrm{hr} \\
\text { - SNAP non- } \\
\text { participants } \\
(\mathrm{n}=17,805) \text { : } \\
\$ 21.01 / \mathrm{hr} \\
\text { Data source: ATUS, } \\
\text { Current Population } \\
\text { Survey - Food Security } \\
\text { Supplement (2003- } \\
\text { 2009) }\end{array}$ & $\begin{array}{l}\text { Home food production } \\
\text { (min/d), which includes } \\
\text { food preparation, } \\
\text { presentation, and } \\
\text { clean up } \\
\text { Data source: ATUS } \\
\text { (2003-2009) }\end{array}$ & $\begin{array}{l}\text { Mean time (min/day) in home food production, } \\
\text { Welch's t-test, } p<0.05 \\
\text { SNAP participants (lower income, } \mathrm{n}=\mathbf{9 3 5} \text { ): } \\
\mathbf{6 6 . 9 5} \\
\text { SNAP non-participants (higher income, } \\
\mathbf{n}=\mathbf{1 7 , 8 0 5 ) : ~} \mathbf{5 3 . 5 2}\end{array}$ & None \\
\hline Restrepo, $2020^{7}$ & $\begin{array}{l}\text { National } \\
\text { Mean 39y, 54.4\% } \\
\text { female, } 68.5 \% \text { non- } \\
\text { Hispanic White, } 12.1 \% \\
\text { Hispanic, } 9.7 \% \text { non- } \\
\text { Hispanic Black } \\
\mathrm{N}=1,784\end{array}$ & $\begin{array}{l}\text { SES proxy: } \\
\text { - Worked away from } \\
\text { home } \\
\text { - Worked from home } \\
\text { Data source: Leave } \\
\text { and Job Flexibilities } \\
\text { Module (2017-2018) }\end{array}$ & $\begin{array}{l}\text { Food preparation } \\
\text { includes food and } \\
\text { drink preparation, food } \\
\text { presentation, kitchen } \\
\text { and food clean-up, } \\
\text { grocery shopping, and } \\
\text { travel to grocery store } \\
\text { Data source: ATUS } \\
(2017-2018)\end{array}$ & $\begin{array}{l}\text { Coefficient estimate (SE) food preparation in } \\
\text { minutes/d, } p<0.10 \\
\text { Worked away from home (lower income, } \\
\mathrm{n}=1637): 30.3(1.216) \\
\text { Worked from home (higher income, } n=147) \text { : } \\
40.7 \text { (5.433) }\end{array}$ & None \\
\hline
\end{tabular}




\begin{tabular}{|c|c|c|c|c|c|}
\hline \multirow[t]{2}{*}{ Sliwa, $2015^{9}$} & \multirow[t]{2}{*}{$\begin{array}{l}\text { National } \\
\text { Hispanic mothers with } \\
\text { at least } 1 \text { child }<13 y \text {; } \\
\text { mean age } 32.8 y \text {; } \\
66.2 \% \text { households } \\
\text { with child under } 6 \\
\text { ( }<<0.05 \text { between } \\
\text { exposure groups with } \\
\text { more US-born mothers } \\
\text { with children }<6 \text { than } \\
\text { im/migrant mothers); } \\
24 \% \text { single mother } \\
\text { household ( } p<0.05 \\
\text { between exposure } \\
\text { groups with more US- } \\
\text { born mothers having } \\
\text { higher \% of single } \\
\text { mother household) } \\
\end{array}$} & $\begin{array}{l}\text { SES proxy: } \\
\text { - Im/migrant } \\
(\mathrm{n}=2277): 52.8 \% \\
<=130 \% \text { of poverty } \\
\text { guideline; } 19.3 \% \\
>130-185 \% \text { of } \\
\text { poverty guideline; } \\
27.9 \%>185 \% \text { of } \\
\text { poverty guideline } \\
\text { - US-born ( } \mathrm{n}=1345) \text { : } \\
36.6 \%<=130 \% \text { of } \\
\text { poverty guideline; } \\
16.6 \%>130-185 \% \\
\text { of poverty guideline; } \\
46.7 \%>185 \% \text { of } \\
\text { poverty guideline }\end{array}$ & $\begin{array}{l}\text { Food preparation } \\
\text { defined as total } \\
\text { minutes spent } \\
\text { preparing, cooking, } \\
\text { serving food, clean up } \\
\text { (e.g., putting away } \\
\text { food and drinks, } \\
\text { tidying the kitchen) } \\
\frac{\text { Data source: ATUS }}{(2003-2011)}\end{array}$ & $\begin{array}{l}\text { Mean (SE) daily food preparation (minutes), } \\
\text { adjusted Wald test, } p<0.001 \\
\text { Im/migrant (lower income, } \mathbf{n = 2 2 7 7 ) : ~} \mathbf{1 0 7 . 8} \\
(\mathbf{2 . 0}) \\
\text { US-born (higher income, } \mathbf{n = 1 3 4 5 ) : ~} \mathbf{7 0 . 8}(\mathbf{2 . 1})\end{array}$ & \multirow[t]{2}{*}{$\begin{array}{l}\text { Hours worked/8, } \\
\text { worked late hours, } \\
\text { Nativity X origin } \\
\text { interaction, Education, } \\
\text { Single mother, } \\
\text { Number children in } \\
\text { HH, presence of child } \\
<6, \text { maternal age, } \\
\text { weekend diary day, } \\
\text { and survey year }\end{array}$} \\
\hline & & & & & \\
\hline
\end{tabular}

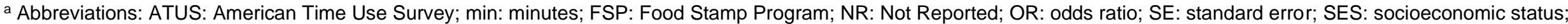
SNAP: Supplemental Nutrition Assistance Program; WIC: Special Supplemental Nutrition Program for Women, Infants and Children

Bold indicates statistically significant findings 
Table 4-d. Risk of bias for observational studies examining income and time spent on food-at-home-related activities ${ }^{a}$

\begin{tabular}{|c|c|c|c|c|c|c|c|}
\hline Article & Confounding & $\begin{array}{l}\text { Selection of } \\
\text { participants }\end{array}$ & $\begin{array}{l}\text { Classification of } \\
\text { exposures }\end{array}$ & $\begin{array}{l}\text { Deviations from } \\
\text { intended } \\
\text { exposures }\end{array}$ & Missing data & $\begin{array}{c}\text { Outcome } \\
\text { measurement }\end{array}$ & $\begin{array}{l}\text { Selection of the } \\
\text { reported result }\end{array}$ \\
\hline Bauer, $2012^{13}$ & MODERATE & LOW & LOW & MODERATE & LOW & MODERATE & MODERATE \\
\hline Dunn, $2015^{1}$ & MODERATE & MODERATE & LOW & LOW & MODERATE & MODERATE & MODERATE \\
\hline Forrester, $2018^{2}$ & SERIOUS & LOW & SERIOUS & LOW & $\begin{array}{c}\text { NO } \\
\text { INFORMATION }\end{array}$ & MODERATE & MODERATE \\
\hline Gough, $2019^{3}$ & MODERATE & LOW & LOW & LOW & MODERATE & MODERATE & MODERATE \\
\hline Hamrick, $2011^{4}$ & SERIOUS & LOW & LOW & LOW & LOW & MODERATE & MODERATE \\
\hline Kim, $2020^{5}$ & MODERATE & LOW & LOW & LOW & LOW & MODERATE & MODERATE \\
\hline Monsivais, $2014^{12}$ & SERIOUS & LOW & LOW & LOW & MODERATE & MODERATE & MODERATE \\
\hline Raschke, $2012^{6}$ & SERIOUS & LOW & LOW & SERIOUS & LOW & MODERATE & MODERATE \\
\hline Restrepo, $2020^{7}$ & SERIOUS & MODERATE & MODERATE & SERIOUS & MODERATE & MODERATE & MODERATE \\
\hline Senia, $2017^{8}$ & MODERATE & LOW & LOW & LOW & LOW & MODERATE & MODERATE \\
\hline Sliwa, $2015^{9}$ & SERIOUS & LOW & MODERATE & SERIOUS & MODERATE & MODERATE & MODERATE \\
\hline Smith, 2014 10 & MODERATE & LOW & LOW & LOW & MODERATE & MODERATE & MODERATE \\
\hline Wolfson, $2019^{11}$ & MODERATE & LOW & LOW & LOW & MODERATE & MODERATE & MODERATE \\
\hline
\end{tabular}


a Possible ratings of low, moderate, serious, critical, or no information determined using the "Risk of Bias for Nutrition Observational Studies" tool (RoB-NObs) (Dietary Guidelines Advisory Committee. 2020. Scientific Report of the 2020 Dietary Guidelines Advisory Committee: Advisory Report to the Secretary of Agriculture and the Secretary of Health and Human Services. U.S. Department of Agriculture, Agricultural Research Service, Washington, DC.) 


\section{References of the articles included in the income and time spent on food-at-home-related activities rapid review}

1. Bauer KW, Hearst MO, Escoto K, Berge JM, Neumark-Sztainer D. Parental employment and work-family stress: associations with family food environments. Soc Sci Med. 2012;75(3):496-504. doi:10.1016/j.socscimed.2012.03.026.

2. Dunn RA. Labor supply and household meal production among working adults in the Health and Retirement Survey. Review of Economics of the Household. 2013;13(2):437-457. doi:10.1007/s11150-013-9223-8.

3. Forrester K, Klein J. An analysis of female labor supply, home production, and household consumption expenditures. $J$ Demogr Econ. 2018;84(3):257-307. doi:10.1017/dem.2018.8.

4. Gough M, Lippert AM, Martin MA. The role of time use behaviors in the risk of obesity among low-income mothers. Women's Health Issues. 2019;29(1):23-30. doi:10.1016/j.whi.2018.10.002.

5. Hamrick KS, Andrews M, Guthrie J, Hopkins D, McClelland K. How much time do Americans spend on food? US Department of Agriculture, Economic Research Service. 2011;EIB-86.

6. Kim J, Rabbitt MP, Tuttle C. Changes in low-income households' spending and time use patterns in response to the 2013 sunset of the ARRA-SNAP benefit. Applied Economic Perspectives and Policy. 2019;42(4):777-795. doi:10.1093/aepp/ppz007.

7. Monsivais P, Aggarwal A, Drewnowski A. Time spent on home food preparation and indicators of healthy eating. Am J Prev Med. 2014;47(6):796-802. doi:10.1016/j.amepre.2014.07.033.

8. Raschke C. Food stamps and the time cost of food preparation. Review of Economics of the Household. 2011;10(2):259-275. doi:10.1007/s11150-011-9128-3.

9. Restrepo BJ, Zeballos E. The effect of working from home on major time allocations with a focus on food-related activities. Rev Econ Househ. 2020:1-23. doi:10.1007/s11150-020-09497-9.

10. Senia MC, Jensen $\mathrm{HH}$, Zhylye vs.kyy O. Time in eating and food preparation among single adults. Review of Economics of the Household. 2014;15(2):399-432. doi:10.1007/s11150-014-9258-5.

11. Sliwa SA, Must A, Perea F, Economos CD. Maternal employment, acculturation, and time spent in food-related behaviors among Hispanic mothers in the United States. Evidence from the American Time Use Survey. Appetite. 2015;87:10-19. doi:10.1016/j.appet.2014.10.015.

12. Smith LP, Ng SW, Popkin BM. Resistant to the recession: Low-income adults' maintenance of cooking and away-from-home eating behaviors during times of economic turbulence. Am J Public Health. 2014;104(5):840-846. doi:10.2105/AJPH.2013.301677.

13. Wolfson JA, Ramsing R, Richardson CR, Palmer A. Barriers to healthy food access: Associations with household income and cooking behavior. Prev Med Rep. 2019;13:298-305. doi:10.1016/j.pmedr.2019.01.023. 


\section{Chapter 5 - What factors influence the purchase and/or consumption of at-home convenience foods? How are these foods described in the literature?}

Sara Scinto-Madonich, MS, ${ }^{a}$ Laural Kelly English, PhD, ${ }^{a}$ Molly Higgins, MLIS, ${ }^{b}$ Marlana Bates, MPH, RD, ${ }^{a}$ Julie Nevins,

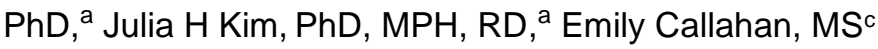

\section{Specific methods to conduct the evidence scan}

\section{Develop a protocol}

The research question, "What factors influence the purchase and/or consumption of at home-convenience foods?" was addressed with an evidence scan. Similar to the rapid reviews, a protocol was developed and followed. However, results were not extracted and no risk of bias assessment was completed. The following section describes the volume and characteristics of articles that address the purchase and/or consumption of at home-convenience foods.

The analytic framework for the evidence scan examining the relationship between different factors and the purchase and/or consumption of at-home convenience foods is presented in Figure 5-a. This analytic framework visually represents the overall scope of the evidence scan question, and depicts the contributing elements that were examined and evaluated. The intervention or exposure of interest is any factor in U.S. households or populations. The comparator is a different factor or level or factor, or no comparator. The outcomes are purchase and/or consumption of at-home convenience foods in U.S. households or populations. There are no key confounders. The other factors to be considered are how at-home convenience foods are described in the literature and may impact the relationships of interest.

\footnotetext{
a Analyst, NESR team; Panum Group, under contract with the FNS, USDA

b Librarian, NESR team; Panum Group, under contract with the FNS, USDA

${ }^{c}$ Project Lead, NESR team, NGAD, CNPP, FNS, USDA
} 
Figure 5-a. Analytic framework for the evidence scan on the purchase/consumption of at-home convenience foods

\begin{tabular}{|c|c|c|}
\hline Intervention[s]/exposure[s] & Comparator[s] & Outcome[s] \\
\hline \multirow{2}{*}{$\begin{array}{l}\text { Factor (e.g., socioeconomic status, } \\
\text { time, knowledge, skill, household } \\
\text { characteristics) }\end{array}$} & $\begin{array}{l}\text { Different factor or level of factor } \\
\text { No comparator }\end{array}$ & $\begin{array}{l}\text { Purchase and/or consumption of at- } \\
\text { home convenience foods }\end{array}$ \\
\hline & Population: U.S. households or populations & Population: U.S. households or \\
\hline & $\rightarrow$ & \\
\hline
\end{tabular}

Key definitions

Food-at-home: Food that is prepared at home and includes ready-to-eat and non-ready-to-eat foods that are brought from grocery stores, food pantries, super centers, mass merchandisers, convenience stores, drug stores, farmers markets, and food co-ops (ERS, 2018)

Food-away-from-home: Food prepared outside of home and includes food from full-service and fastfood restaurants (ERS, 2018)

Fast-food restaurants: Eating places where consumers pay before they eat (e.g., bakery, burger restaurant, and sandwich or coffee shop) (ERS, 2018)

Full-service restaurants: Eating places where consumers eat before they pay (ERS, 2018)

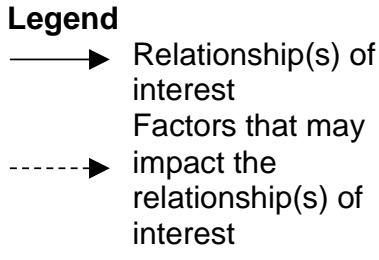

Relationship(s) of interest impact the interest

\section{Search for and select studies}

The following outlines any departures from the search and select studies project methods for this specific evidence scan:

- Scopus was searched instead of Web of Science because of the overwhelming number of results from Web of Science. This decision was made because the two databases cover similar topic areas and because this was an evidence scan.

- $80 \%$ of all records were single-screened at title, abstract, and full-text levels and $20 \%$ of all records were dual-screened, independently at each of these levels.

- A manual search was not completed.

NESR analysts worked jointly with NEAT staff to establish the final inclusion and exclusion criteria and literature search strategy, which are detailed in Table 5-a and Appendix 5-a, respectively. 
Table 5-a. Inclusion and exclusion criteria for the evidence scan on the purchase/consumption of at-home convenience foods

Category Inclusion Criteria

\begin{tabular}{|c|c|c|}
\hline Study design & $\begin{array}{l}\text { - Any study design, including qualitative, that is not a } \\
\text { narrative review, systematic review, or meta- } \\
\text { analysis }\end{array}$ & 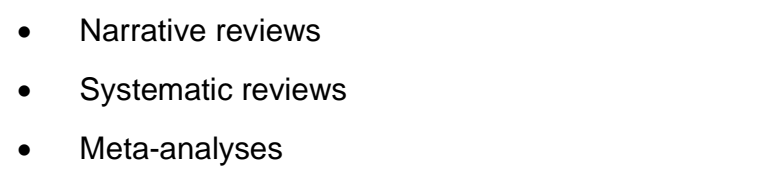 \\
\hline $\begin{array}{l}\text { Intervention/ } \\
\text { exposure }\end{array}$ & $\begin{array}{l}\text { - Any factor (e.g., socioeconomic status, time, } \\
\text { knowledge, skill, household characteristics) }\end{array}$ & - $\quad \mathrm{N} / \mathrm{A}$ \\
\hline Comparator & $\begin{array}{l}\text { - Different factor or level of factor } \\
\text { - } \quad \text { No comparator }\end{array}$ & - $\quad N / A$ \\
\hline Outcomes & $\begin{array}{l}\text { - Purchase and/or consumption of at-home } \\
\text { convenience foods that are: } \\
\circ \text { Ready-to-eat } \\
\circ \text { Ready-to-heat } \\
\circ \text { Ready-to-cook/bake } \\
\circ \text { Other }\end{array}$ & $\begin{array}{l}\text { - Purchase and/or consumption of at-home foods } \\
\text { that do not fit into the inclusion categories } \\
\text { - Purchase and/or consumption of food-away-from- } \\
\text { home, including fast-food and full-service } \\
\text { restaurants } \\
\text { - Purchase and/or consumption of beverages only }\end{array}$ \\
\hline $\begin{array}{l}\text { Publication } \\
\text { date }\end{array}$ & $\begin{array}{l}\text { - Jan } 2008 \text { - May } 2021 \\
\text { - Data inclusive of } 2008 \text { (e.g., 2000-2012; 2008- } \\
\text { 2009) }\end{array}$ & $\begin{array}{l}\text { - Before Jan 2008, after May } 2021 \\
\text { - } \quad \text { Data prior to } 2008 \text { (e.g., 2000-2007; 1999-2005) }\end{array}$ \\
\hline $\begin{array}{l}\text { Publication } \\
\text { status }\end{array}$ & $\begin{array}{l}\text { - } \quad \text { Articles that have been peer-reviewed } \\
\text { - Grey literature: reports that have not been peer- } \\
\text { reviewed but are available from government and } \\
\text { nongovernmental organizations }\end{array}$ & $\begin{array}{l}\text { - Articles that have not been peer reviewed and are } \\
\text { not published in peer-reviewed journals, other than } \\
\text { reports from government and nongovernmental } \\
\text { organizations }\end{array}$ \\
\hline Language & - Articles published in English & - Articles published in languages other than English \\
\hline Country & - $\quad$ Studies conducted in the U.S. & - $\quad$ Studies conducted outside the U.S. \\
\hline $\begin{array}{l}\text { Study } \\
\text { participants }\end{array}$ & - Human participants/ populations & $\begin{array}{l}\text { - Non-human participants (e.g., animal studies, in- } \\
\text { vitro models) }\end{array}$ \\
\hline
\end{tabular}

\section{Extract data}

NESR analysts extracted data from each included article to objectively describe the body of evidence available to inform the evidence scan. The following outlines any departures from the extract data and assess risk of bias project methods for this specific question:

- Basic data extraction occurred at the full-text screening level, and therefore $80 \%$ of the articles were extracted by 1 analyst and $20 \%$ of the articles were extracted independently by 2 analysts and compared for agreement. 
- The following data elements were extracted or bucketed into categories by the NESR analysts: publication year, study design, intervention/exposure category (factor), outcome categories (level(s) of convenience, food group(s), purchase and/or consumption), and any other notes.

- Level of convenience groupings used to categorize included articles:

- Ready-to-eat (RTE): foods that require no preparation before consumption

- Ready-to-heat (RTH): foods that are already cooked, but require a change in temperature before consumption.

- Ready-to-cook (RTC) or ready-to-bake (RTB): foods that are somewhat pre-prepared, but still require cooking or baking.

- Ready-to-prepare (RTP): foods which require preparation of multiple ingredients, as well as cooking or baking

- The specific ready-to-prepare level of convenience outcome category was added during the evidence scan process as we observed how convenience foods were being described in the literature. We listed an "Other" level of convenience outcome category in original protocol to allow for this specific situation.

- Food groups used to categorize included articles

- Vegetables

- Fruit

- Grains

- Proteins

- Dairy

- Snacks

- Sweets

- Multi-component foods/meals

- Other

- Only factors and purchase and/or consumption outcome categories were extracted for qualitative studies. This was because the qualitative data was often not clear enough to determine the level of convenience and/or food groups.

- For both qualitative and quantitative studies, factors and purchase and/or consumption categories were extracted. Level of convenience and food group(s) examined was also extracted for quantitative studies because the qualitative data was often not clear enough to determine the level of convenience and/or food groups.

- $\quad$ No results were extracted from the included articles

- No risk of bias assessment was completed 
Describe the evidence

NESR analysts summarized the volume and characteristics of included studies to inform the question, what factors influence the purchase and/or consumption of at home-convenience foods? The NESR analysts summarized the data using evidence tables and figures. The results of this evidence scan do not answer the question, since no results were extracted, however it describes the landscape of available evidence pertaining to this topic.

\section{Recommend future research}

Recommendations for future research evaluating at home-convenience foods were determined based on the gaps and limitations observed during data extraction and the description of the evidence, as previously described in the project methods. Future work addressing these gaps and limitations may contribute to the body of evidence contributing to this topic.

\section{Results}

\section{Literature search and screening results}

The literature search yielded 12,618 search results after the removal of duplicates (see Figure 5-b). Dualscreening resulted in the exclusion of 11,911 titles, 428 abstracts, and 190 full-text articles. Reasons for fulltext exclusion are in Appendix 5-b. A manual search was not conducted and all included articles were obtained through the electronic database search. The body of evidence included 89 articles: 
Figure 5-b. Literature search and screen flowchart for the evidence scan on the purchase/consumption of at-home convenience foods

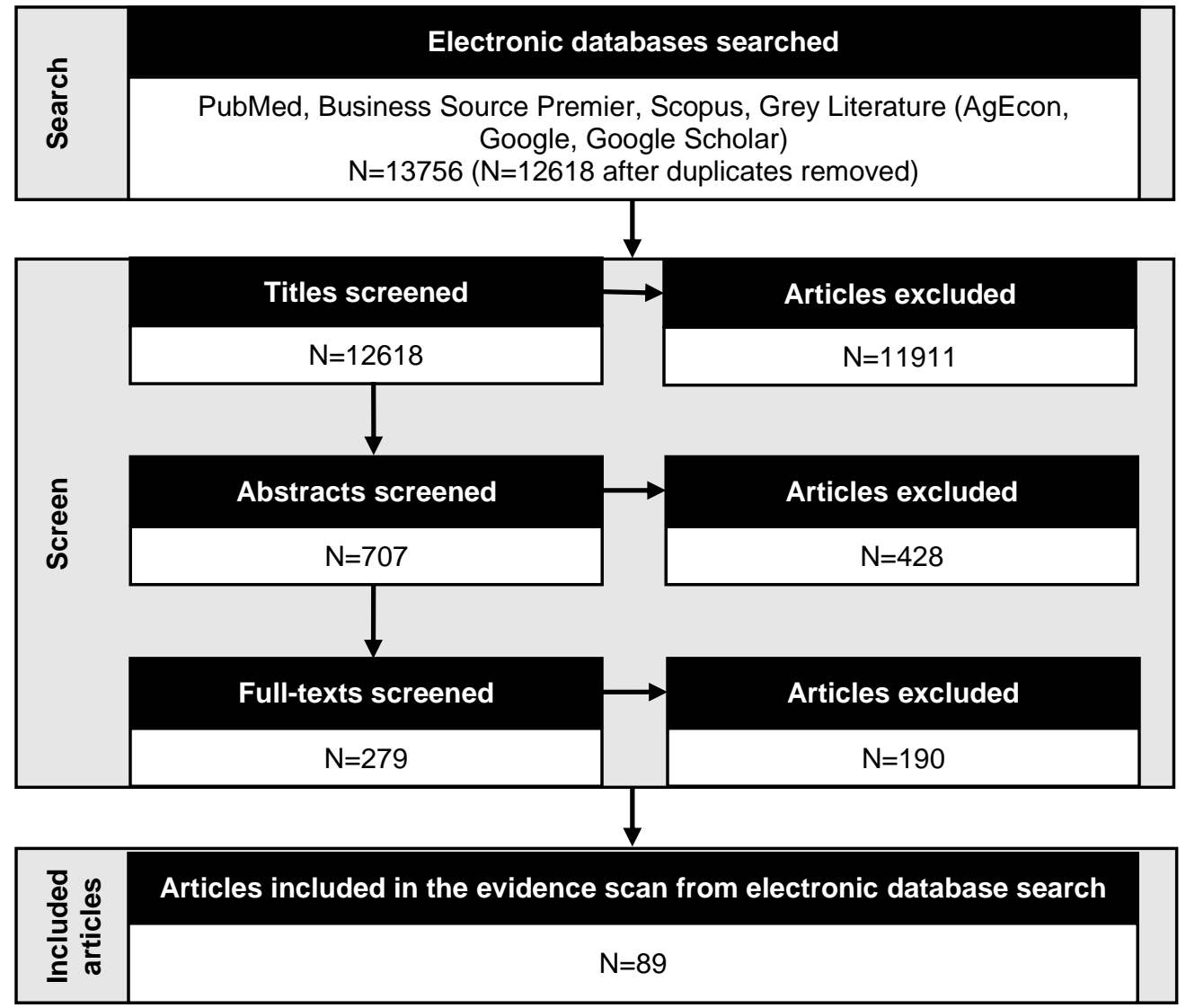

\section{Description of the evidence}

This evidence scan included 89 articles that examined the relationship between different factors and the purchase and/or consumption of at-home convenience foods. Sixty-five articles included cross-sectional data, ${ }^{1-}$ 6510 included qualitative data, ${ }^{1,15,66-73} 5$ each were prospective cohort ${ }^{74-78}$ and uncontrolled before-and-after studies, ${ }^{79-83}$ and 3 each were non-RCTs ${ }^{84-86}$ and RCTs. ${ }^{87-89}$ Two articles included both cross-sectional and qualitative data. ${ }^{1,15}$

\section{Intervention/exposure characteristics}

Ten articles included qualitative data ${ }^{1,15,66-73}$ and 81 articles included quantitative data. ${ }^{1-65,74-89}$ Within each article, 1 or more factors were identified or examined in relation to purchase and/or consumption of at-home convenience foods. Factors were identified by the study participants themselves in qualitative studies, while researchers selected which factors to study in relation to at-home convenience foods in quantitative studies.

\section{Qualitative studies}

The most common factor identified by study participants that influenced the purchase and/or consumption of at-home convenience foods was:

- $\quad$ price of food, ${ }^{15,68-70,73}$

- $\quad$ time, ${ }^{15,66,72,73}$ 
- healthfulness of the food, ${ }^{15,66,68}$

- family preferences, ${ }^{15,67}$

- federal assistance program participation/eligibility (such as SNAP or WIC), ${ }^{15,68}$

- $\quad$ ease of preparation, ${ }^{15,69}$

- $\quad$ and level of satisfaction. ${ }^{69,72}$

The less common factors identified included:

- age, ${ }^{73}$

- food security, ${ }^{15}$

- number of people in the household, ${ }^{68}$

- $\quad$ SES factor, ${ }^{68}$

- $\quad$ knowledge/skill, ${ }^{71}$

- $\quad$ shopping frequency, ${ }^{1}$

- day of the week (weekend v. weekday), ${ }^{72}$

- $\quad$ and meal skipping. ${ }^{72}$

Figure 5-c shows the more common factors identified in qualitative studies in relation to at-home convenience foods. 
Figure 5-c. Qualitative study factors identified related to the purchase/consumption of at-home convenience foods

\section{Number of articles}

2

Federal assistance program participation/eligibility

Ease

Level of satisfaction

\section{Quantitative studies}

The most common factors examined in quantitative studies in relation to the purchase and/or consumption of at-home convenience foods was:

- income, - $^{2,4,7,10,16,17,19-21,23,26,29-31,34,38,45,47,53,54,56,59,60,62,65,77,78}$

- race/ethnicity, $2,7,8,10,11,14-17,19-22,24,25,31,34,37-39,43,44,53,56,65,77$

- $\quad$ age, ${ }^{7,10,16,17,19,21,28-30,34,38,42,45,47,50,53,54,65}$

- $\quad \operatorname{sex},{ }^{7,10,16,17,19,21,30,34,37,38,47,53,55,65}$

- $\quad \operatorname{year}($ e.g., 2008, 2009, 2010), 2,29,31,35,40,41,46,49,51,59,63,64,75

- $\quad$ education, ${ }^{2,10,16,17,29,34,47,54,56,60,65}$

- household characteristics (e.g., number of children in the household, marriage status, language spoken at home), ${ }^{7,15,29,30,34,47,54,56,62,65,77}$

- federal assistance program participation/eligibility, 5,18,26,27,32-34,45,62,65

- food security, ${ }^{1,9,15,30,52,53,58,61,74}$

- intervention (e.g., dietary behavior change intervention, price discount intervention, in-store healthy foods promotion intervention), ${ }^{79,80,82,83,85,87-89}$ 
- $\quad$ price of food, ${ }^{11,24,30,31,36,77,78}$

- $\quad$ and BMI. ${ }^{10,34,37,45,76}$

Figure 5-d shows the more common factors examined in quantitative studies in relation to purchase/consumption of at-home convenience foods.

Figure 5-d. Quantitative study factors examined related to the purchase/consumption of at-home convenience foods

Number of articles

0

5

10

15

20

25

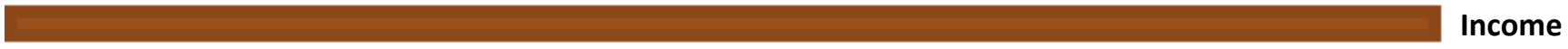

Race/ethnicity

Age

Sex

Year

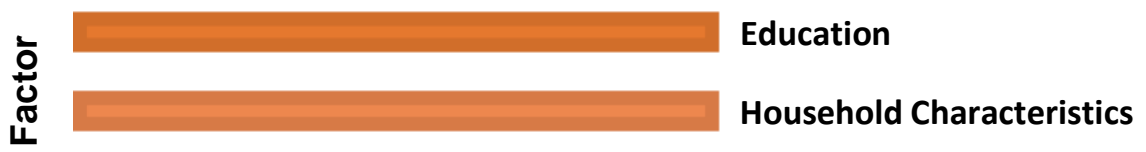

Federal assistance program participation/eligibility

Food security

Intervention

Price

BMI

The less commonly examined factors were:

- lifestyle factors (e.g., smoking status, alcohol intake, stress/stress management, time, physical activity, breakfast consumption (yes or no), tradition/habit, shopping frequency, times cooking from scratch per day, identification as a healthy eater/cook), 3,11,16,17,19,21,24,30,34,36-38,42,74

- SES factors (e.g., overall SES, access/distance to a store, work hours, car ownership/access, quality of the food environment), ${ }^{29,34,48,57,62,65,75,86}$

- personal characteristics (e.g., depressed mood, birthplace (US versus non-US), language(s) spoken, acculturation, knowledge/skill, food agency, family preferences), ${ }^{7,11,13,24,36,47,74}$ 
- food characteristics (e.g., taste, brand, quality/healthfulness of food, package size, ease of preparation), ${ }^{11,24,30,36,77,84}$

- location (e.g., urban versus rural/suburban, geographic region, city), ${ }^{4,29,56,57,63,75}$

- federal assistance program-related factors (e.g., WIC food package revisions, amount of time since receiving SNAP benefits, WIC eligibility of item, use of WICShopper app), $, 5,6,12,27,81$

- $\quad$ and other factors (e.g., store type, month of the year). ${ }^{4,26,39,41,59}$

\section{Outcome characteristics}

At-home convenience foods were categorized based on the level of convenience, the food group(s) examined, and whether purchase and/or consumption was studied. The most commonly studied (and most convenient) category was RTE foods, followed by RTH foods, RTC or RTB foods, and ending with the least commonly studied (and least convenient) category of RTP foods:

- Seventy-two articles studied RTE foods, ${ }^{1-6,8,9,11,12,14-21,23-27,29-34,37-41,43-65,74,76-89 ~}$

- 45 articles studied foods that were RTH, ${ }^{1,2,4,5,7,8,10,12,13,15,20,22,25-29,31-33,35-37,39-41,43-47,51,52,54,60,62,63,65,74-76,81,87-}$ 89

- 19 articles studied RTC or RTB foods, $2,4,26,32,33,36,39-41,43,44,46,51,60,63,64,74,76,87$

- $\quad$ and 11 articles studied foods that were RTP. 2,4,12,20,26,33,39,40,43,44,60

The most commonly studied foods were sweets, followed by grains, snacks, vegetables, fruit, multi-component foods/meals, proteins, dairy, and other foods that did not fit into any of the listed groupings:

- Thirty-seven articles studied at-home convenience foods that were sweets; $; 2,4,8,12,15,20,21,23,26,27,29,31-34,37,39$ $41,43,44,46,49-52,58,60,63-65,74,76,79,85-87$

- $\quad 32$ articles studied grains; ;,8,12,15,17,19-21,27,30-32,39-41,43,44,46,49-51,53,55,56,61,62,65,74,77,79,83,89

- 30 articles studied snacks; ;,4,15,20,23,26,27,29,31-34,37,39-41,43,44,46,49-52,60,63,65,74,80,82,86,87

- 28 articles each studied vegetables, $1,2,4,5,8,12,26,28,29,31,33,38-40,43-46,59-62,65,75,79,81,87,88$

- 28 articles studied fruit, $1,2,4,5,8,16,26,28,29,31,33,38,40,43-46,60,62,63,65,75,78,79,81,85,87,88$

- 28 articles studied multi-component foods/meals; ;,4,7,10,12,20,22,25,29,32,35-37,40,41,43-47,52,60,62-64,74,76,89

- 26 articles studied proteins; $;^{2-4,11,14,15,24,26,29,32,33,35,39-41,43-46,49,51,62,65,76,84,87}$

- 14 articles studied dairy; 6 , $15,32,33,39,40,43,44,46,62-65,76$

- $\quad$ and 13 articles studied other foods. $9,12,13,18,25,27,29,32,44,46,48,54,57$

Lastly, 59 articles examined purchase of at-home convenience foods ${ }^{1-6,8,9,11,12,14,18,23,24,26,27,29-33,35,36,39-}$ $41,43,46,49,52,54,56,57,59-68,70,73,75-84,86-89$ and 38 articles examined consumption of at-home convenience foods. ${ }^{1,7,10,13,15-17,19-22,24,25,28,30,34,37,38,42,44,45,47,48,50,51,53,55,58,66,67,69-74,85,86}$

Ready-to-eat food groups

Of the RTE foods, the most common group was: 
- $\quad$ sweets (e.g., candy, cookies, cupcakes), $2,4,8,12,15,20,21,23,26,27,29,31-34,37,39-41,43,44,46,49-52,58,60,63-65,74,76,79,85-87$

- grains (e.g., bread, cereal), $, 6,8,15,17,19-21,27,30-32,39-41,43,44,46,49-51,53,55,56,61,62,65,74,77,79,83,89$

- $\quad$ snacks (e.g., granola bars, chips, crackers), $2,4,15,20,23,26,27,29,31-34,37,39-41,43,44,46,49-52,60,63,65,74,80,82,86,87$

- fruit (e.g., canned fruit, apples, bananas), ${ }^{1,2,4,5,8,16,26,29,31,33,38,40,43-46,60,62,63,65,78,79,81,85,87,88}$

- $\quad$ vegetables (e.g., canned vegetables, bagged salad, baby carrots), 1,2,4,5,8,26,29,31,33,38,39,43-46,59-62,65,79,81,87,88

- $\quad$ proteins (e.g., canned beans/tuna, peanut butter, deli meat), ${ }^{2-4,11,14,15,24,26,29,32,33,39,41,43-46,49,51,62,65,76,84,87}$

- dairy (e.g., yogurt, cheese), 6,15,32,33,39,40,43,44,46,62-65,76

- $\quad$ other (e.g., condiments, unspecified), 9,18,25,27,29,32,44,46,48,54,57

- and finally multi-component foods/meals. ${ }^{29,32,44,46,47,63,64}$

Figure 5-e shows the breakdown of RTE food groups, which was fairly mixed.

Figure 5-e. Ready-to-Eat Food Groups

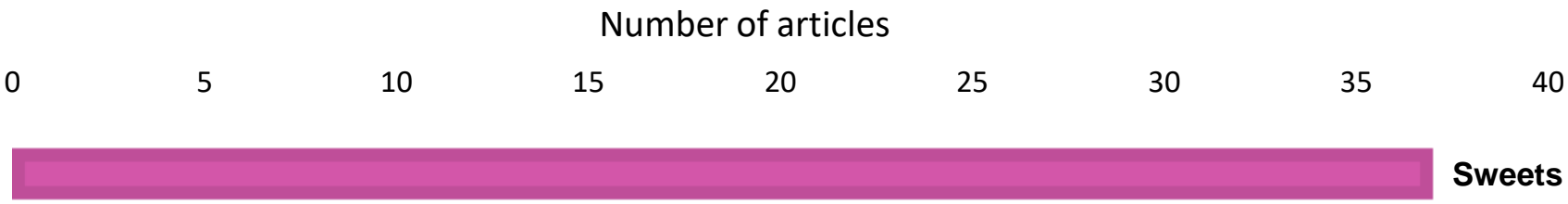

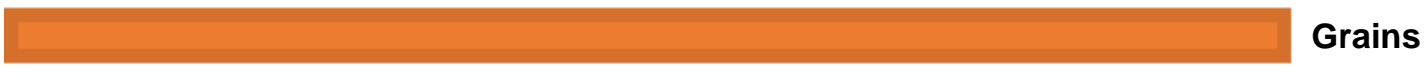

Snacks

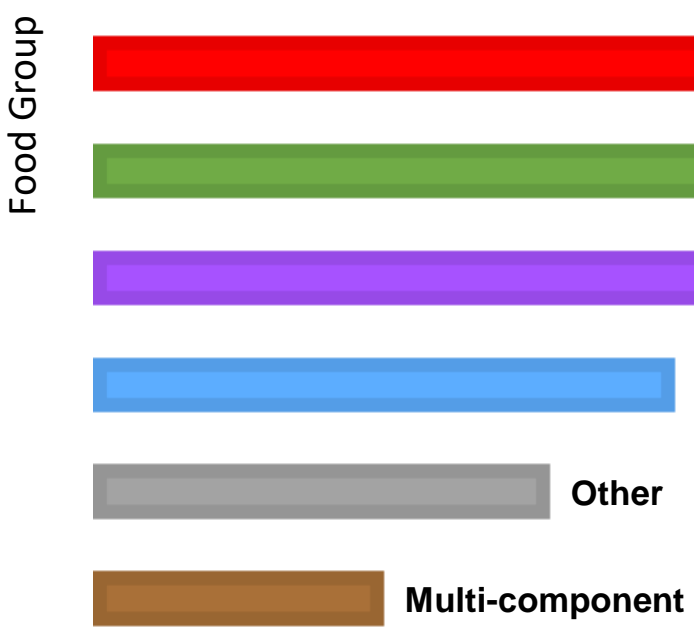

Fruit

Vegetables

Proteins

Dairy

Ready-to-heat food groups

The most common RTH group was: 
- multi-component foods/meals (e.g., frozen or chilled pre-cooked meals), $, 2,4,7,10,12,20,22,25,29,32,35-37,40,41,43-$ $47,52,60,62,63,74,76,89$

- $\quad$ vegetables (e.g., frozen vegetables), ${ }^{1,2,4,5,8,12,26,28,29,31,33,39,40,43,44,46,60,65,75,81,87,88}$

- fruit (e.g., frozen fruit), $1,2,4,5,8,26,28,29,31,33,43,44,46,60,75,81,87,88$

- proteins (e.g., frozen or chilled pre-cooked meats/fish), ${ }^{2,4,15,26,32,33,35,39,41,43,44,46,51,76,87}$

- $\quad$ other (e.g., sauces, broth, unspecified), ${ }^{12,13,27,29,44,46,54}$

- $\quad$ sweets (e.g., frozen cakes/pies), ${ }^{26,33,43,46}$

- grains (e.g., frozen pancakes/waffles, instant rice), ${ }^{12,43,46}$

- $\quad$ snacks (e.g., frozen snacks), ${ }^{40,43,46}$

- $\quad$ and ending with dairy (e.g., frozen whipped topping, cheese dip). ${ }^{46}$

Figure 5-f shows the breakdown of RTH food groups. Compared to the more convenient RTE food group breakdown, the share for multi-component foods/meals increased substantially and the shares for grains, snacks, sweets, and dairy decreased substantially.

Figure 5-f. Ready-to-Heat Food Groups

Number of articles

0

5

10

15

20

25

30

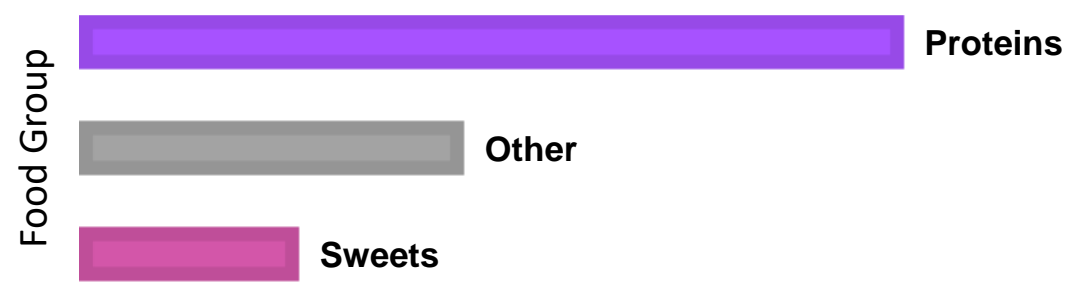

Grains

\section{Snacks}

\section{Dairy}


Ready-to-cook and ready-to-bake food groups

For the RTC/RTB foods, the most common category became:

- $\quad$ proteins (e.g., processed meat), $2,4,26,32,33,39-41,51,76,87$

- multi-component foods/meals (e.g., instant mashed potatoes), ${ }^{36,43,44,46,60,63,64,74}$

- grains (e.g., microwave popcorn), ${ }^{43,44,46}$

- snacks,$^{63}$

- $\quad$ sweets (e.g., cookie dough, RTB desserts), $33,39,43,46,63$

- $\quad$ and vegetables (e.g., pre-cut fresh vegetables). ${ }^{26}$

Figure 5-g shows the breakdown of RTC/RTB food groups. The share for proteins increased for this category, mainly because bacon was included in the processed meat category of many articles. The shares for vegetables and snacks decreased, and the dairy, fruit, and other categories were not represented in the RTC/RTB level of convenience.

Figure 5-g. Ready-to-Cook/Ready-to-Bake Food Groups

\begin{tabular}{llccccc}
\multicolumn{7}{c}{ Number of articles } \\
0 & 2 & 4 & 6 & 8 & 10 & 12
\end{tabular}

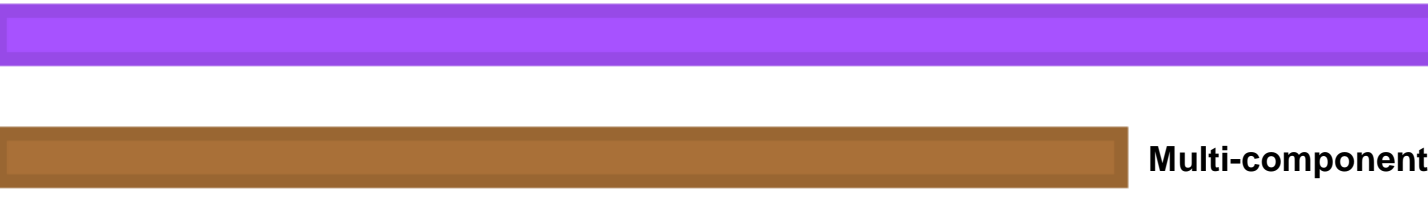

Proteins
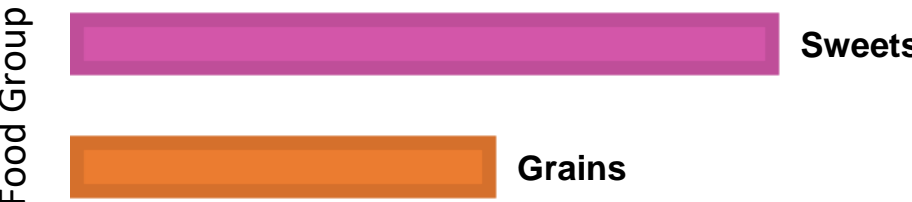

Sweets

\section{Vegetables}

Ready-to-prepare food groups

There were only 3 groups represented in the RTP category. From most to least common:

- $\quad$ sweets (e.g., baking mixes), $, 2,4,26,33,39,40,44,60$

- grains (e.g., pancake mix), ${ }^{12,40,43}$

- $\quad$ and multi-component foods/meals (e.g., boxed mac and cheese). ${ }^{20}$ 
Figure 5-h shows the breakdown of RTP food groups. The share for sweets dominated this category, the share for multi-component foods/meals decreased substantially, and RTP vegetables, snacks, and proteins were not found in the literature.

Figure 5-h. Ready-to-Prepare Food Groups

\section{Number of articles}

0

1

2

3

4

5

6

7

8

Sweets

\section{ปั}

Grains

\section{Research recommendations}

1. Establish and use standard definitions for at-home convenience foods, RTE, RTH, RTP, RTC, and RTB to improve their identification, as well as the ability to compare results between studies.

2. Provide sufficient detail about specific foods included in a food category to help determine whether the outcome fits the eligibility criteria of at-home convenience foods. 


\section{References of the articles included in the convenience food evidence scan}

1. Litton MM, Beavers AW. The relationship between food security status and fruit and vegetable intake during the covid-19 pandemic. Nutrients. 2021;13(3):1-14. doi: 10.3390/nu13030712.

2. Lacko A, Maselko J, Popkin B, $\mathrm{Ng} \mathrm{SW}$. Socioeconomic and racial/ethnic disparities in the nutritional quality of packaged food purchases in the U.S., 2008-2018. Public Health Nutrition. 2021. doi: 10.1017/S1368980021000367.

3. Winham DM, Davitt ED, Heer MM, Shelley MC. Pulse knowledge, attitudes, practices, and cooking experience of midwestern us university students. Nutrients. 2020;12(11):1-13. doi: 10.3390/nu12113499.

4. Lacko A, Ng SW, Popkin B. Urban vs.. Rural socioeconomic differences in the nutritional quality of household packaged food purchases by store type. International Journal of Environmental Research and Public Health. 2020;17(20):1-22. doi: 10.3390/ijerph17207637.

5. Tseng M, Mastrantonio C, Glanz H, Volpe RJ, lii N, D. B N. Fruit and Vegetable Purchasing Patterns and Supplemental Nutrition Assistance Program Participation: Findings From a Nationally Representative Survey. Journal of the Academy of Nutrition and Dietetics. 2020;120(10):1633-1642. doi: 10.1016/j.jand.2020.05.016.

6. Zhang Q, Zhang J, Park K, Tang C. Association between usage of an app to redeem prescribed food benefits and redemption behaviors among the special supplemental nutrition program for women, infants, and children participants: Cross-sectional study. JMIR mHealth and uHealth. 2020;8(10). doi: 10.2196/20720.

7. Kwon S, Wang-Schweig M, Kandula NR. Body composition, physical activity, and convenience food consumption among asian american youth: 2011-2018 NHANES. International Journal of Environmental Research and Public Health. 2020;17(17):1-13. doi: 10.3390/ijerph17176187.

8. Palmer SM, Winham DM. Midwest consumer shopping habits, nutrition knowledge, and latino tienda use. Health Behavior and Policy Review. 2020;7(2):79-91. doi: 10.14485/HBPR.7.2.1.

9. Lyonnais MJ, Rafferty AP, Pitts SJ, Blanchard RJ, Kaur AP. Examining shopping patterns, use of food-related resources, and proposed solutions to improve healthy food access among food insecure and food secure Eastern North Carolina residents. International Journal of Environmental Research and Public Health. 2020;17(10). doi: 10.3390/ijerph17103361.

10. Overcash F, Davey C, Zhang Y, Reicks M. Evening meal types and family meal characteristics: Associations with demographic characteristics and food intake among adolescents. Nutrients. 2020;12(4). doi: 10.3390/nu12040886.

11. Heer MM, Winham DM. Bean preferences vary by acculturation level among latinas and by ethnicity with non-hispanic white women. International Journal of Environmental Research and Public Health. 2020;17(6). doi: 10.3390/ijerph17062100.

12. Rex SM, Trabulsi J, Baker S, Bodt B, Robson SM. Food Purchasing Behaviors of WIC Participants: What Non-WIC Eligible Foods Items Are Being Purchased. American Journal of Health Promotion. 2020;34(3):307-310. doi: $10.1177 / 0890117119892765$.

13. Wolfson JA, Lahne J, Raj M, Insolera N, Lavelle F, Dean M. Food agency in the united states: Associations with cooking behavior and dietary intake. Nutrients. 2020;12(3). doi: 10.3390/nu12030877.

14. Heer MM, Winham DM. Food behaviors, health, and bean nutrition awareness among low-income men: A pilot study. International Journal of Environmental Research and Public Health. 2020;17(3). doi: 10.3390/ijerph17031039.

15. Palmer SM, Knoblauch ST, Winham DM, Hiller MB, Shelley MC. Putting knowledge into practice: Low-income women talk about food choice decisions. International Journal of Environmental Research and Public Health. 2020;17(14):1-16. doi: 10.3390/ijerph17145092.

16. Sullivan VK, Na M, Proctor DN, Kris-Etherton PM, Petersen KS. Consumption of Dried Fruits Is Associated with Greater Intakes of Underconsumed Nutrients, Higher Total Energy Intakes, and Better Diet Quality in US Adults: A Cross-Sectional Analysis of the National Health and Nutrition Examination Survey, 2007-2016. Journal of the Academy of Nutrition and Dietetics. 2020. doi: 10.1016/j.jand.2020.08.085.

17. Zhu Y, Jain N, Vanage V, Holschuh N, Agler AH, Smith JD. Association between ready-to-eat cereal consumption and nutrient intake, nutritional adequacy, and diet quality in adults in the national health and nutrition examination survey 2015-2016. Nutrients. 2019;11(12). doi: 10.3390/nu11122952.

18. Franckle RL, Thorndike AN, Moran AJ, et al. Supermarket Purchases Over the Supplemental Nutrition Assistance Program Benefit Month: A Comparison Between Participants and Nonparticipants. American Journal of Preventive Medicine. 2019;57(6):800-807. doi: 10.1016/j.amepre.2019.07.025.

19. Smith JD, Zhu Y, Vanage V, Jain N, Holschuh N, Agler AH. Association between ready-to-eat cereal consumption and nutrient intake, nutritional adequacy, and diet quality among infants, toddlers, and children in the national health and nutrition examination survey 2015-2016. Nutrients. 2019;11(9). doi: 10.3390/nu11091989.

20. Fertig AR, Loth KA, Trofholz AC, et al. Compared to Pre-prepared Meals, Fully and Partly Home-Cooked Meals in Diverse Families with Young Children Are More Likely to Include Nutritious Ingredients. Journal of the Academy of Nutrition and Dietetics. 2019;119(5):818-830. doi: 10.1016/j.jand.2018.12.006.

21. Fulgoni VL, lii B, M F, L C. Oatmeal-containing breakfast is associated with better diet quality and higher intake of key food groups and nutrients compared to other breakfasts in children. Nutrients. 2019;11(5). doi: 10.3390/nu11050964. 
22. Bowen ME, Casola AR, Coleman C, Monahan L. Community Food Pantry (CFP) Recipients' Food Challenges: Latino Households with at Least One Member Working as Farm Worker Compared to Other CFP Households. Journal of Hunger and Environmental Nutrition. 2019;14(1-2):128-140. doi:

23. French SA, Tangney CC, Crane MM, Wang Y, Appelhans BM. Nutrition quality of food purchases varies by household income: The SHoPPER study. BMC Public Health. 2019;19(1). doi: 10.1186/s12889-019-6546-2.

24. Winham DM, Tisue ME, Palmer SM, Cichy KA, Shelley MC. Dry bean preferences and attitudes among midwest hispanic and non-hispanic white women. Nutrients. 2019;11(1). doi: 10.3390/nu11010178.

25. Babatunde OT, Briley PM, White BM, Fang X, Ellis C. Dietary Practices Among Stroke-survivors-Racial/Ethnic Differences. Journal of Stroke and Cerebrovascular Diseases. 2018;27(11):2926-2931. doi: 10.1016/j.jstrokecerebrovasdis.2018.06.026.

26. Taillie LS, Grummon AH, Miles DR. Nutritional Profile of Purchases by Store Type: Disparities by Income and Food Program Participation. American Journal of Preventive Medicine. 2018;55(2):167-177. doi: 10.1016/j.amepre.2018.04.024.

27. $\mathrm{Ng}$ SW, Hollingsworth BA, Busey EA, Wandell JL, Miles DR, Poti JM. Federal Nutrition Program Revisions Impact Low-income Households' Food Purchases. American Journal of Preventive Medicine. 2018;54(3):403-412. doi: 10.1016/j.amepre.2017.12.003.

28. Storey M, Anderson P. Total fruit and vegetable consumption increases among consumers of frozen fruit and vegetables. Nutrition. 2018;46:115-121. doi: 10.1016/j.nut.2017.08.013.

29. Kornrich S, Roberts A. Household Income, Women's Earnings, and Spending on Household Services, 1980-2010. Journal of Marriage and Family. 2018;80(1):150-165. doi: 10.1111/jomf.12450.

30. Dominick SR, Bir C, Widmar NO, Acharya L, Holly Wang H, Wilcox M. Exploring preferences beyond the (cereal) box: Readyto-eat breakfast cereal buying behaviors. International Food and Agribusiness Management Review. 2018;21(8):1185-1201. doi: 10.22434/IFAMR2017.0113.

31. Taillie LS, Ng SW, Xue Y, Harding M. Deal or no deal? The prevalence and nutritional quality of price promotions among U.S. food and beverage purchases. Appetite. 2017;117:365-372. doi: 10.1016/j.appet.2017.07.006.

32. Franckle RL, Moran A, Hou T, et al. Transactions at a Northeastern Supermarket Chain: Differences by Supplemental Nutrition Assistance Program Use. American Journal of Preventive Medicine. 2017;53(4):e131-e138. doi: 10.1016/j.amepre.2017.06.019.

33. Grummon AH, Taillie LS. Nutritional profile of Supplemental Nutrition Assistance Program household food and beverage purchases. American Journal of Clinical Nutrition. 2017;105(6):1433-1442. doi: 10.3945/ajcn.116.147173.

34. Gustat J, Lee YS, O'Malley K, et al. Personal characteristics, cooking at home and shopping frequency influence consumption. Preventive Medicine Reports. 2017;6:104-110. doi: 10.1016/j.pmedr.2017.02.007.

35. Surathkal P, Dey MM, Engle CR, Chidmi B, Singh K. Consumer demand for frozen seafood product categories in the United States. Aquaculture Economics and Management. 2017;21(1):9-24. doi: 10.1080/13657305.2017.1265020.

36. Horning ML, Fulkerson JA, Friend SE, Story M. Reasons Parents Buy Prepackaged, Processed Meals: It Is More Complicated Than "I Don't Have Time". Journal of Nutrition Education and Behavior. 2017;49(1):60-66.e61. doi: 10.1016/j.jneb.2016.08.012.

37. Errisuriz VL, Pasch KE, Perry CL. Perceived stress and dietary choices: The moderating role of stress management. Eating Behaviors. 2016;22:211-216. doi: 10.1016/j.eatbeh.2016.06.008.

38. Freedman MR, Fulgoni VL. Canned Vegetable and Fruit Consumption Is Associated with Changes in Nutrient Intake and Higher Diet Quality in Children and Adults: National Health and Nutrition Examination Survey 2001-2010. Journal of the Academy of Nutrition and Dietetics. 2016;116(6):940-948. doi: 10.1016/j.jand.2015.10.013.

39. Stern D, Poti JM, Ng SW, Robinson WR, Gordon-Larsen P, Popkin BM. Where people shop is not associated with the nutrient quality of packaged foods for any racial-ethnic group in the United States. American Journal of Clinical Nutrition. 2016;103(4):1125-1134. doi: 10.3945/ajcn.115.121806.

40. Taillie LS, Ng SW, Popkin BM. Walmart and Other Food Retail Chains: Trends and Disparities in the Nutritional Profile of Packaged Food Purchases. American Journal of Preventive Medicine. 2016;50(2):171-179. doi: 10.1016/j.amepre.2015.07.015.

41. Stern D, Ng SW, Popkin BM. The Nutrient Content of U.S. Household Food Purchases by Store Type. American Journal of Preventive Medicine. 2016;50(2):180-190. doi: 10.1016/j.amepre.2015.07.025.

42. Wolfson JA, Bleich SN, Smith KC, Frattaroli S. What does cooking mean to you?: Perceptions of cooking and factors related to cooking behavior. Appetite. 2016;97:146-154. doi: 10.1016/j.appet.2015.11.030.

43. Poti JM, Mendez MA, Ng SW, Popkin BM. Highly processed and ready-to-eat packaged food and beverage purchases differ by race/ethnicity among US households. Journal of Nutrition. 2016;146(9):1722-1730. doi: 10.3945/jn.116.230441.

44. Eicher-Miller HA, Fulgoni VL, lii K. Processed food contributions to energy and nutrient intake differ among US children by race/ethnicity. Nutrients. 2015;7(12):10076-10088. doi: 10.3390/nu7125503.

45. Comerford KB. Frequent canned food use is positively associated with nutrient-dense food group consumption and higher nutrient intakes in US children and adults. Nutrients. 2015;7(7):5586-5600. doi: 10.3390/nu7075240.

46. Poti JM, Mendez MA, Ng SW, Popkin BM. Is the degree of food processing and convenience linked with the nutritional quality of foods purchased by US households? American Journal of Clinical Nutrition. 2015;101(6):1251-1262. doi: 10.3945/ajcn.114.100925.

47. Langellier BA, Brookmeyer R, Wang MC, Glik D. Language use affects food behaviours and food values among Mexicanorigin adults in the USA. Public Health Nutrition. 2015;18(2):264-274. doi: 10.1017/S1368980014000287.

48. Leslie T, Pawloski L, Kallman-Price J, et al. Survey of health status, nutrition and geography of food selection of chronic liver disease patients. Annals of Hepatology. 2014;13(5):533-540. doi: 10.1016/s1665-2681(19)31253-0. 
49. Ford CN, Ng SW, Popkin BM. Are food and beverage purchases in households with preschoolers changing?: A longitudinal analysis from 2000 to 2011. American Journal of Preventive Medicine. 2014;47(3):275-282. doi:

10.1016/j.amepre.2014.05.007.

50. Reicks M, Jonnalagadda S, Albertson AM, Joshi N. Total dietary fiber intakes in the US population are related to whole grain consumption: Results from the National Health and Nutrition Examination Survey 2009 to 2010. Nutrition Research. 2014;34(3):226-234. doi: 10.1016/j.nutres.2014.01.002.

51. Slining MM, Mathias KC, Popkin BM. Trends in Food and Beverage Sources among US Children and Adolescents: 19892010. Journal of the Academy of Nutrition and Dietetics. 2013;113(12):1683-1694. doi: 10.1016/j.jand.2013.06.001.

52. Nackers LM, Appelhans BM. Food insecurity is linked to a food environment promoting obesity in households with children. Journal of Nutrition Education and Behavior. 2013;45(6):780-784. doi: 10.1016/j.jneb.2013.08.001.

53. Albertson AM, Franko DL, Thompson DR, Tuttle C, Holschuh NM. Ready-to-Eat Cereal Intake is Associated with an Improved Nutrient Intake Profile among Food Insecure Children in the United States. Journal of Hunger and Environmental Nutrition. 2013;8(2):200-220. doi: 10.1080/19320248.2013.786664.

54. Ma Y, Ailawadi KL, Grewal D. Soda versus cereal and sugar versus fat: Drivers of healthful food intake and the impact of diabetes diagnosis. Journal of Marketing. 2013;77(3):101-120. doi: 10.1509/jm.11.0443.

55. Albertson AM, Wold AC, Joshi N. Ready-to-eat cereal consumption patterns: The relationship to nutrient intake, whole grain intake, and body mass index in an older American population. Journal of Aging Research. 2012;2012. doi: $10.1155 / 2012 / 631310$

56. Castetbon K, Harris JL, Schwartz MB. Purchases of ready-to-eat cereals vary across US household sociodemographic categories according to nutritional value and advertising targets. Public Health Nutrition. 2012;15(8):1456-1465. doi:

57. Hearst MO, Pasch KE, Laska MN. Urban v. suburban perceptions of the neighbourhood food environment as correlates of adolescent food purchasing. Public Health Nutrition. 2012;15(2):299-306. doi: 10.1017/S1368980011002114.

58. Cunningham TJ, Barradas DT, Rosenberg KD, May AL, Kroelinger CD, Ahluwalia IB. Is maternal food security a predictor of food and drink intake among toddlers in Oregon? Maternal and child health journal. 2012;16 Suppl 2:339-346. doi: 10.1007/s10995-012-1094-8.

59. Kuchler F. Is it food quality or quantity that responds to changing income? Applied Economic Perspectives and Policy. 2011;33(2):205-221. doi: 10.1093/aepp/ppr002.

60. Lacko A, Delamater P, Gordon-Larsen P, Wen Ng S. Geographic patterns and socioeconomic differences in the nutritional quality of household packaged food purchases in the United States. Health Place. 2021;69:102567. doi: 10.1016/j.healthplace.2021.102567.

61. Larson N, Laska MN, Neumark-Sztainer D. Food Insecurity, Diet Quality, Home Food Availability, and Health Risk Behaviors Among Emerging Adults: Findings From the EAT 2010-2018 Study. American Journal of Public Health. 2020;110(9):14221428. doi: 10.2105/AJPH.2020.305783.

62. Rahko vs.ky I, Jo Y. Higher Incomes and Greater Time Constraints Lead to Purchasing More Convenience Foods. 2018;June 2018(05). doi:

63. Okrent AM, Kumcu A. U.S. Households' Demand for Convenience Foods. 2016:40. doi:

64. Okrent A. Purchases of Foods by Convenience Type Driven by Prices, Income, and Advertising. 2016(10):1. doi:

65. Rahko vs.ky I, Jo Y, Carlson A. Consumers Balance Time and Money in Purchasing Convenience Foods. 2018. doi:

66. Hammons A, Olvera N, Teran-Garcia M, Villegas E, Fiese B. Mealtime resistance: Hispanic mothers' perspectives on making healthy eating changes within the family. Appetite. 2021;159. doi: 10.1016/j.appet.2020.105046.

67. Trofholz A, Richardson K, Mohamed N, Vang C, Berge JM. How a Racially/Ethnically Diverse and Immigrant Sample Qualitatively Describes the Role of Traditional and Non-traditional Foods in Feeding Their Children. Journal of Immigrant and Minority Health. 2020;22(6):1155-1162. doi: 10.1007/s10903-020-00999-3.

68. Askelson NM, Meier C, Baquero B, Friberg J, Montgomery D, Hradek C. Understanding the Process of Prioritizing Fruit and Vegetable Purchases in Families With Low Incomes: "A Peach May Not Fill You Up as Much as Hamburger". Health Education and Behavior. 2018;45(5):817-823. doi: 10.1177/1090198117752790.

69. Palmer SM, Winham DM, Oberhauser AM, Litchfield RE. Socio-ecological barriers to dry grain pulse consumption among lowincome women: A mixed methods approach. Nutrients. 2018;10(8). doi: 10.3390/nu10081108.

70. Ugalde M, Brand L, Beltran A, et al. Mommio's recipe box: Assessment of the cooking habits of mothers of preschoolers and their perceptions of recipes for a video game. JMIR Serious Games. 2017;5(4). doi: 10.2196/games.8142.

71. Tobey LN, Koenig HF, Brown NA, Manore MM. Reaching low-income mothers to improve family fruit and vegetable intake: Food hero social marketing campaign—research steps, development and testing. Nutrients. 2016;8(9). doi: 10.3390/nu8090562.

72. Griffith DM, Wooley AM, Allen JO. "I'm Ready to Eat and Grab Whatever I Can Get": Determinants and Patterns of African American Men's Eating Practices. Health Promotion Practice. 2013;14(2):181-188. doi: 10.1177/1524839912437789.

73. DiSantis KI, Grier SA, Odoms-Young A, et al. What "price" means when buying food: Insights from a multisite qualitative study with Black Americans. American Journal of Public Health. 2013;103(3):516-522. doi: 10.2105/AJPH.2012.301149.

74. Berge JM, Fertig AR, Trofholz A, Neumark-Sztainer D, Rogers E, Loth K. Associations between parental stress, parent feeding practices, and child eating behaviors within the context of food insecurity. Preventive Medicine Reports. 2020;19. doi: 10.1016/j.pmedr.2020.101146.

75. Winkler MR, Lenk KM, Erickson DJ, Caspi CE, Laska MN. Longitudinal fruit and vegetable sales in small food retailers: Response to a novel local food policy and variation by neighborhood socioeconomic status. International Journal of Environmental Research and Public Health. 2020;17(15):1-15. doi: 10.3390/ijerph17155480. 
76. Chen D, Jaenicke EC, Volpe RJ. The Healthfulness of Food-at-Home Expenditures, the Local Food Environment, and Childhood Obesity. American Journal of Health Promotion. 2019;33(3):412-419. doi: 10.1177/0890117118786871.

77. Rahko vs.ky I, Lin BH, Lin CTJ, Lee JY. Effects of the Guiding Stars Program on purchases of ready-to-eat cereals with different nutritional attributes. Food Policy. 2013;43:100-107. doi: 10.1016/j.foodpol.2013.08.013.

78. Weatherspoon DD, Oehmke JF, Coleman MA, Dembele AS, Weatherspoon LJ. Will Long Term Food Desert Consumers Purchase Fresh Fruits and Vegetables? 2012;27(3):5. doi:

79. Cassinat RA, Bruening M, Crespo NC, et al. Effects of a community-based pilot intervention on home food availability among U.S. households. International Journal of Environmental Research and Public Health. 2020;17(22):1-11. doi: 10.3390/ijerph17228327.

80. Pharis ML, Colby L, Wagner A, Mallya G. Sales of healthy snacks and beverages following the implementation of healthy vending standards in City of Philadelphia vending machines. Public Health Nutrition. 2018;21(2):339-345. doi: $10.1017 /$ S1368980017001914.

81. Andreyeva T, Luedicke J. Incentivizing fruit and vegetable purchases among participants in the Special Supplemental Nutrition Program for Women, Infants, and Children. Public Health Nutrition. 2015;18(1):33-41. doi: 10.1017/S1368980014000512.

82. Dannefer R, Williams DA, Baronberg S, Silver L. Healthy bodegas: Increasing and promoting healthy foods at corner stores in New York City. American Journal of Public Health. 2012;102(10):e27-e31. doi: 10.2105/AJPH.2011.300615.

83. Sutherland LA, Kaley LA, Fischer L. Guiding Stars: The effect of a nutrition navigation program on consumer purchases at the supermarket. American Journal of Clinical Nutrition. 2010;91(4):1090S-1094S. doi: 10.3945/ajcn.2010.28450C.

84. Çakır M, Balagtas JV, Okrent AM, Urbina-Ramirez M. Effects of Package Size on Household Food Purchases. Applied Economic Perspectives and Policy. 2021;43(2):781-801. doi: 10.1093/aepp/ppz019.

85. Whiteside-Mansell L, Swindle TM. Evaluation of together we inspire smart eating: Pre-school fruit and vegetable consumption. Health Education Research. 2019;34(1):72-83. doi: 10.1093/her/cyy048.

86. Rogus S, Athens J, Cantor J, Elbel B. Measuring Micro-Level Effects of a New Supermarket: Do Residents Within 0.5 Mile Have Improved Dietary Behaviors? Journal of the Academy of Nutrition and Dietetics. 2018;118(6):1037-1046. doi: 10.1016/j.jand.2017.06.360.

87. Moran A, Thorndike A, Franckle R, et al. Financial incentives increase purchases of fruit and vegetables among lower-income households with children. Health Affairs. 2019;38(9):1557-1566. doi: 10.1377/hlthaff.2018.05420.

88. Polacsek M, Moran A, Thorndike AN, et al. A Supermarket Double-Dollar Incentive Program Increases Purchases of Fresh Fruits and Vegetables Among Low-Income Families With Children: The Healthy Double Study. Journal of Nutrition Education and Behavior. 2018;50(3):217-228.e211. doi: 10.1016/j.jneb.2017.09.013.

89. Foster GD, Karpyn A, Wojtanowski AC, et al. Placement and promotion strategies to increase sales of healthier products in supermarkets in low-income, ethnically diverse neighborhoods: A randomized controlled trial. American Journal of Clinical Nutrition. 2014;99(6):1359-1368. doi: 10.3945/ajcn.113.075572. 


\section{Acknowledgments and funding}

The NESR team members were involved in: establishing all aspects of the protocol, which presented the plan for examining the scientific evidence, including the inclusion and exclusion criteria; reviewing all studies that met the criteria they set; deliberating on the body of evidence for each question. The NESR team, with assistance from NEAT and Project Leadership, facilitated, executed, and documented the work necessary to ensure the reviews were completed in accordance with NESR methodology. NESR staff thanks NESR Lead Nutritionist Julie Obbaggy for her consultation and review of materials.

NESR staff thanks USDA's NEAT, specifically TusaRebecca Pannucci, Clarissa (Claire) Brown, Hazel Hiza, Kristin Koegel, Kevin Kuczynski, Mark Lino, Emily Madan, Verena McClain, and Kevin Meyers Mathieu for their collaboration on all aspects of question protocols to ensure that the reviews completed as part of this project would be able to inform USDA's Food Plans. NESR thanks them for their time and expertise.

NESR staff thanks USDA's Director of NGAD Eve Stoody for her guidance, leadership, and support throughout this project.

NESR staff thank USDA's Economic Research Service, specifically, Debbie Rubas, Andrea Carlson, Jordan Jones, Matthew MacLachlan, and Sabrina Young for their review of the literature search strategy for the rapid review on income and price of food, which subsequently informed the other evidence scans and rapid reviews. NESR thanks them for their time and expertise.

NESR staff thank Gisela Butera and Nancy Terry from National Institute of Health Library, Division of Library Services in the Office of Research Services for developing the initial literature search strategy for the rapid review on income and price of food. NESR thanks them for their time and expertise.

Funding: United States Department of Agriculture, Food and Nutrition Service, Center for Nutrition Policy and Promotion, Alexandria, VA 


\section{Appendices}

\section{Appendix 0-a: Abbreviations}

\begin{tabular}{|c|c|}
\hline Abbreviation & Full name \\
\hline ATUS & American Time Use Survey \\
\hline BMI & Body Mass Index \\
\hline CACFP & Child and Adult Care Food Program \\
\hline CNPP & Center for Nutrition Policy and Promotion \\
\hline CSFII & Continuing Survey of Food Intakes by Individuals II \\
\hline DGA & Dietary Guidelines for Americans \\
\hline FNS & Food and Nutrition Service \\
\hline FSP & Food Stamp Program \\
\hline HANDLS & Healthy Aging in Neighborhoods of Diversity across the Life Span Study \\
\hline HEl & Healthy Eating Index \\
\hline NEAT & Nutrition and Economic Analysis Team \\
\hline NEMS-S & Nutrition Environment Measures Survey in stores \\
\hline NESR & Nutrition Evidence Systematic Review team \\
\hline NGAD & Nutrition Guidance and Analysis Division \\
\hline NHANES & National Health and Nutrition Examination Survey \\
\hline NSLP & National School Lunch Program \\
\hline PCS & Prospective Cohort Study \\
\hline $\mathrm{PICO}$ & Population, Intervention, Comparator, Outcome \\
\hline PIR & Poverty Index Ratio \\
\hline $\mathrm{RCT}$ & Randomized Controlled Trial \\
\hline $\mathrm{ROB}$ & Risk of bias \\
\hline RTB & Ready-to-bake \\
\hline RTC & Ready-to-cook \\
\hline
\end{tabular}




\begin{tabular}{|c|c|}
\hline Abbreviation & Full name \\
\hline RTE & Ready-to-eat \\
\hline RTH & Read-to-heat \\
\hline RTP & Ready-to-prepare \\
\hline SBP & School Breakfast Program \\
\hline SE & Standard Error \\
\hline SES & Socioeconomic status \\
\hline SNAP & Supplemental Nutrition Assistance Program \\
\hline SOS III & Seattle Obesity Study III \\
\hline SSI & Supplemental Security Income \\
\hline TFP & Thrifty Food Plan \\
\hline U.S. & United States \\
\hline USDA & United States Department of Agriculture \\
\hline WIC & Special Supplemental Nutrition Program for Women, Infants, and Children \\
\hline
\end{tabular}




\section{Appendix 0-b: Risk of Bias for Nutrition Observational Studies (ROB-NObS) Tool*}

\section{Bias due to confounding}

1.1 Is there potential for confounding of the effect of exposure in this study?

If $N$ or PN: skip all remaining questions (1.2 to 1.8) and go to Bias due to confounding: Risk of bias judgement; the study can be considered to be at low risk of bias due to confounding and no further signalling questions need be considered.

If $Y$ or $P Y$, answer question 1.2 to determine whether there is a need to assess time-varying confounding.

1.2. If $Y$ or $P Y$ to 1.1: Was the analysis based on splitting follow-up time according to exposure received?

If $N$ or PN, skip 1.3 and answer questions 1.4 to 1.6, which relate to baseline confounding.

If $Y$ or $P Y$, go to question 1.3.

1.3. If $Y$ or $P Y$ to 1.2: Were exposure discontinuations or switches likely to be related to factors that are prognostic for the outcome?

If $N$ or PN, answer questions 1.4 to 1.6, which relate to baseline confounding only. Do not answer 1.7 and 1.8 , which relate to both baseline and time-varying confounding.

If $Y$ or PY, skip questions 1.4 to 1.6, and answer questions 1.7 and 1.8, which relate to both baseline confounding and time-varying confounding.

1.4. If $N$ or $P N$ to 1.2 or 1.3: Did the authors use an appropriate analysis method that adjusted for all the critically important confounding variables at baseline?

Go to 1.5

1.5. Were confounders that were adjusted for measured validly and reliably by the variables available in this study?

Go to 1.6

1.6. Did the authors avoid adjusting for post-exposure variables?

(Skip to Bias due to confounding: Risk of bias judgement)

Questions related to baseline and time-varying confounding

1.7. If $Y$ or $P Y$ to 1.3: Did the authors use an appropriate analysis method that adjusted for all the critically important confounding variables, including baseline and time-varying confounding?

If $N$ or PN to 1.7, skip to Bias due to confounding: Risk of bias judgement.

If $Y$ or $P Y$ to 1.7 , answer question 1.8

1.8. If $Y$ or $P Y$ to 1.3 and $Y$ or $P Y$ to 1.7: Were confounders that were adjusted for measured validly and reliably by the variables available in this study?

Bias due to confounding: Risk of bias judgement 
Low risk of bias (the study is comparable to a well-performed randomized trial with regard to this domain)

Moderate risk of bias (the study is sound for an observational study with regard to this domain but cannot be considered comparable to a well-performed randomized trial)

Serious risk of bias (the study has some important problems)

Critical risk of bias (the study is too problematic to provide any useful evidence on the effects of intervention) No information on which to base a judgement about risk of bias for this domain
No confounding expected.

(i) Confounding expected, all known important confounding domains appropriately measured and controlled for; and

(ii) Reliability and validity of measurement of important domains were sufficient, such that we do not expect serious residual confounding.

(i) At least one key confounder was not appropriately measured, or not controlled for;

or

(ii) Reliability or validity of measurement of a key confounder was low enough that we expect serious residual confounding.

(i) Confounding is inherently not controllable; or

(ii) The use of negative controls strongly suggests unmeasured confounding. No information on whether confounding might be present.

\section{Bias in selection of participants into the study}

2.1. Was selection of participants into the study or into the analysis based on participant characteristics observed after the start of exposure?

If $N$ or PN, go to 2.4 (skip 2.2 and 2.3).

If $Y$ or $P Y$, go to 2.2 and 2.3.

2.2. If $Y$ or $P Y$ to 2.1: Were the post-exposure variables that influenced selection of participants (into the study or analysis) associated with exposure?

\section{Go to 2.3}

2.3. If $Y$ or $P Y$ to 2.1: Were the post-exposure variables that influenced selection of participants (into the study or analysis) associated with the outcome?

Go to 2.4

2.4. Do start of follow-up and start of exposure coincide for most participants?

If $N$ or $P N$ to 2.4 , answer 2.5.

If $Y$ or PY to 2.4, go to Bias in selection of participants into the study: Risk of bias judgement.

2.5 If $Y$ or $P Y$ to 2.2 and 2.3, or $N$ or $P N$ to 2.4: Were adjustment techniques that were likely to correct for the presence of selection biases used?

Go to Bias in selection of participants into the study: Risk of bias judgement.

Bias in selection of participants into the study: Risk of bias judgement 
Low risk of bias (the study is comparable to a well-performed randomized trial with regard to this domain)

Moderate risk of bias (the study is sound for an observational study with regard to this domain but cannot be considered comparable to a well-performed randomized trial)

Serious risk of bias (the study has some important problems) (i) All participants who would have been eligible for the target trial were included in the study;

and

(ii) For each participant, start of follow up and start of exposure coincided.

(i) Selection into the study may have been related to exposure and outcome; and

The authors used appropriate methods to adjust for the selection bias; or

(ii) Start of follow up and start of exposure do not coincide for all participants; and

(a) the proportion of participants for which this was the case was too low to induce important bias;

or

(b) the authors used appropriate methods to adjust for the selection bias;

or

(c) the review authors are confident that the rate (hazard) ratio for the effect of exposure remains constant over time.

(i) Selection into the study was related (but not very strongly) to exposure and outcome;

\section{and}

This could not be adjusted for in analyses;

or

(ii) Start of follow up and start of exposure do not coincide;

and

A potentially important amount of follow-up time is missing from analyses;

and

The rate ratio is not constant over time.

Critical risk of bias (the study is too problematic to provide any useful evidence on the effects of intervention)

No information on which to base a judgement about risk of bias for this domain (i) Selection into the study was very strongly related to exposure and outcome;

and Or

This could not be adjusted for in analyses;

(ii) A substantial amount of follow-up time is likely to be missing from analyses;

and

The rate ratio is not constant over time.

No information is reported about selection of participants into the study or whether start of follow up and start of exposure coincide.

\section{Bias in classification of exposures}

3.1. Is the exposure that was assessed clearly defined?

3.2. Does the exposure that was assessed represent the exposure of interest?

3.3. Were the methods used to assess the exposure clearly described? 
3.4. Were the methods used to measure the exposure valid and/or reliable?

3.5. Were the same methods used to assess the exposure status for all participants/groups?

3.6. Were the methods used to define exposure status for participants/groups clearly described?

3.7. Were the methods used to define exposure status for participants/groups likely to result in minimal random or systematic exposure misclassification?

3.8. Could classification of exposure status been affected by the presence of the outcome, knowledge of the outcome or risk of the outcome?

If $Y$ or $P Y$, there may be serious risk of bias.

Go to Bias in classification of exposures: Risk of bias judgement. Bias in classification of exposures: Risk of bias judgement

Low risk of bias (the study is comparable to a well-performed randomized trial with regard to this domain)

Moderate risk of bias (the study is sound for a, observational study with regard to this domain but cannot be considered comparable to a well-performed randomized trial)

Serious risk of bias (the study has some important problems) (i) The exposure and the methods used to assess the exposure were well defined and represent the exposure of interest; and

(ii) Methods were valid, reliable, the same across groups, and likely to result in minimal random or systematic exposure misclassification.

\section{and}

(iii) Exposure status was not affected by the presence of the outcome, knowledge of the outcome or risk of the outcome

(i) The exposure and the methods used to assess the exposure are defined and represent the exposure of interest;

and

(ii) Methods were valid, reliable, the same across groups, and likely to result in minimal random or systematic exposure misclassification. or

Exposure status was not affected by the presence of the outcome, knowledge of the outcome or risk of the outcome

(i) Exposure status or the methods used to assess the exposure are not well defined or do not represent the exposure of interest; and

(ii) Methods were not valid and reliable, the same across groups, or were likely to result in some degree of random or systematic exposure misclassification. or

Exposure status was affected by the presence of the outcome, knowledge of the outcome or risk of the outcome

Critical risk of bias (the study is too problematic to provide any useful evidence on the effects of intervention)

(i) Exposure status and the methods used to assess the exposure are not well defined or do not represent the exposure of interest;

and

(ii) Methods were not valid and reliable, were not the same across groups, and were likely to result in substantial random or systematic exposure misclassification.

and

(iii) Exposure status was affected by the presence of the outcome, knowledge of the outcome or risk of the outcome

No information on which to base a judgement about risk of bias for this domain
No definition of exposure or no explanation of the source of information about exposure status is reported. 
4.1. Is there concern that changes in exposure status occurred among participants that were unbalanced across groups and likely to impact the outcome?

4.2. Were any critical co-exposures that occurred unbalanced between exposure groups and likely to impact the outcome?

4.3. If $Y$ or $P Y$ to 4.1, or 4.2: Were adjustment techniques that are likely to correct for these issues (i.e., changes in exposure status and/or unbalanced co-exposures) used?

Go to Bias due to departures from intended exposures: Risk of bias judgement.

\section{Bias due to departures from intended exposures: Risk of bias judgement}

Low risk of bias (the study is comparable to a well-performed randomized trial with regard to this domain)

Moderate risk of bias (the study is sound for an observational study with regard to this domain but cannot be considered comparable to a well-performed randomized trial)

Serious risk of bias (the study has some important problems)

Critical risk of bias (the study is too problematic to provide any useful evidence on the effects of intervention)

No information on which to base a judgement about risk of bias for this domain
There were no changes in the exposure status that were likely to impact the outcome, and any important co-exposures were balanced across intervention groups.

(i) There were changes in exposures status or important coexposures were not balanced across groups and

(ii) the impact on the outcome is expected to be slight or measurement and/or adjustment techniques were used to correct for the issues

(i) There were changes in exposure status or important co-exposures were not balanced across groups that were likely to impact the outcome, and

(ii) no or inappropriate measurement and/or adjustment techniques were used to correct for the issues

(i) There were substantial changes in exposures status, or important co-exposures were not balanced across groups, that were likely to impact the outcome, and

(ii) no or inappropriate measurement and/or adjustment techniques were used to correct for the issues.

No information is reported on whether there is deviation from the intended exposure.

\section{Bias due to missing data}

5.1. Were there missing outcome data?

5.2. Were participants excluded due to missing data on exposure status?

5.3. Were participants excluded due to missing data on other variables (besides outcome data and exposure status) needed for the analysis?

5.4. If $Y$ or $P Y$ to 5.1, 5.2 or 5.3: Are the proportion of participants and reasons for missing data similar across exposure groups?

5.5. If $Y$ or $P Y$ to 5.1, 5.2 or 5.3: Were appropriate statistical methods used to account for missing data?

Go to Bias due to missing data: Risk of bias judgement

\section{Bias due to missing data: Risk of bias judgement}
Low risk of bias (the study is
(i) Data were reasonably complete;

comparable to a well-performed

or 
randomized trial with regard to this domain) (ii) Proportions of and reasons for missing participants were similar across exposure groups;

or

(iii) The analysis addressed missing data and is likely to have removed any risk of bias.

(i) Proportions of and reasons for missing participants differ slightly across exposure groups;

and

(ii) The analysis is unlikely to have removed the risk of bias arising from the missing data.

to a well-performed randomized trial)

Serious risk of bias (the study has some important problems)

Critical risk of bias (the study is too problematic to provide any useful evidence on the effects of intervention)

No information on which to base a judgement about risk of bias for this domain (i) Proportions of missing participants differ substantially across exposures;

or

Reasons for missingness differ substantially across exposures; and

(ii) The analysis is unlikely to have removed the risk of bias arising from the missing data;

or

Missing data were addressed inappropriately in the analysis; or

The nature of the missing data means that the risk of bias cannot be removed through appropriate analysis.

(i) (Unusual) There were critical differences between exposures in participants with missing data;

and

(ii) Missing data were not, or could not, be addressed through appropriate analysis.

No information is reported about missing data or the potential for data to be missing.

\section{Bias in measurement of outcomes}

6.1. Could the outcome measure have been influenced by knowledge of the exposure received?

6.2. Were outcome assessors aware of the exposure received by study participants?

6.3. Were the methods of outcome assessment the same across exposure groups?

6.4. Were any systematic errors during measurement of the outcome related to exposure received?

Go to Bias in measurement of outcomes: Risk of bias judgement

Bias in measurement of outcomes: Risk of bias judgement

Low risk of bias (the study is comparable to a well-performed randomized trial with regard to this domain) (i) The methods of outcome assessment were comparable across exposure groups;

and

(ii) The outcome measure was unlikely to be influenced by knowledge of the exposure received by study participants (i.e. is objective) or the outcome assessors were unaware of the exposure received by study participants; 


\begin{tabular}{|c|c|}
\hline & $\begin{array}{l}\text { and } \\
\text { (iii) Any error in measuring the outcome is unrelated to exposure status. }\end{array}$ \\
\hline $\begin{array}{l}\text { Moderate risk of bias (the study is } \\
\text { sound for an observational study } \\
\text { with regard to this domain but } \\
\text { cannot be considered comparable to } \\
\text { a well-performed randomized trial) }\end{array}$ & $\begin{array}{l}\text { (i) The methods of outcome assessment were comparable across } \\
\text { exposure groups; } \\
\text { and } \\
\text { (ii) The outcome measure is only minimally influenced by knowledge of } \\
\text { the exposure received by study participants; } \\
\text { and } \\
\text { (iii) Any error in measuring the outcome is only minimally related to exposure } \\
\text { status. }\end{array}$ \\
\hline $\begin{array}{l}\text { Serious risk of bias (the study has } \\
\text { some important problems) }\end{array}$ & $\begin{array}{l}\text { (i) The methods of outcome assessment were not comparable across } \\
\text { exposure groups; } \\
\text { or } \\
\text { (ii) The outcome measure was subjective (i.e. vulnerable to influence by } \\
\text { knowledge of the exposure received by study participants); } \\
\text { and } \\
\text { The outcome was assessed by assessors aware of the exposure } \\
\text { received by study participants; } \\
\text { or } \\
\text { (iii) Error in measuring the outcome was related to exposure status. }\end{array}$ \\
\hline $\begin{array}{l}\text { Critical risk of bias (the study is too } \\
\text { problematic to provide any useful } \\
\text { evidence on the effects of } \\
\text { intervention) }\end{array}$ & $\begin{array}{l}\text { The methods of outcome assessment were so different that they cannot } \\
\text { reasonably be compared across intervention groups. }\end{array}$ \\
\hline $\begin{array}{l}\text { No information on which to base a } \\
\text { judgement about risk of bias for this } \\
\text { domain }\end{array}$ & No information is reported about the methods of outcome assessment. \\
\hline
\end{tabular}

\section{Bias in selection of reported result}

7.1. Is the reported effect estimate likely to be selected on the basis of the results from multiple outcome measurements within the outcome domain?

7.2. Is the reported effect estimate likely to be selected on the basis of the results from multiple analyses of the exposure-outcome relationship?

7.3. Is the reported effect estimate likely to be selected on the basis of the results from different subgroups?

Go to Bias in selection of reported result: Risk of bias judgement

\section{Bias in selection of reported result: Risk of bias judgement}

\section{Low risk of bias (the study is} comparable to a well-performed randomized trial with regard to this domain)

Moderate risk of bias (the study is sound for an observational study with regard to this domain but cannot be considered comparable to a well-performed randomized trial)
There is clear evidence (usually through examination of a pre-registered protocol or statistical analysis plan) that all reported results correspond to all intended outcomes, analyses and sub-cohorts.

(i) The outcome measurements and analyses are consistent with an a priori plan; or are clearly defined and both internally and externally consistent;

and

(ii) There is no indication of selection of the reported analysis from among multiple analyses;

and

(iii) There is no indication of selection of the cohort or subgroups for analysis and reporting on the basis of the results. 
Serious risk of bias (the study has some important problems) (i) Outcomes are defined in different ways in the methods and results sections, or in different publications of the study; or

(ii) There is a high risk of selective reporting from among multiple analyses;

or

(iii) The cohort or subgroup is selected from a larger study for analysis and appears to be reported on the basis of the results.

Critical risk of bias (the study is too problematic to provide any useful evidence on the effects of intervention)

No information on which to base a judgement about risk of bias for this domain.

*NESR created the RoB-NObs by making modifications to the ROBINS-I and a preliminary instrument designed to assess risk of bias in non- randomized studies of exposures. ${ }^{*} \dagger$ These modifications were made to ensure that the tool was applicable to observational studies of food, nutrition, and public health. $\neq \S$

\footnotetext{
*Morgan, R.L., Thayer, K.A., Santesso, N., Holloway, A.C., Blain, R., Eftim, S.E., Goldstone, A.E., Ross, P., Guyatt, G., Schunemann, H.J., 2018a. Evaluation of the risk of bias in non-randomized studies of interventions (ROBINS-I) and the 'target experiment'concept in studies of exposures: rationale and preliminary instrument development. Environ. Int. 120, 382-387.

† Morgan RL, Thayer KA, Santesso N, Holloway AC, Blain R, Eftim SE, Goldstone AE, Ross P, Ansari M, Akl E, Filippini T, Hansell A, Meerpohl JJ, Mustafa RA, Verbeek J, Vinceti M, Whaley P, Schünemann HJ; GRADE Working Group. A risk of bias instrument for nonrandomized studies of exposures: A users' guide to its application in the context of GRADE. Environ Int. 2019 Jan;122:168-184. doi: 10.1016/j.envint.2018.11.004. Epub 2018 Nov 22 PMID: 30473382

‡ Hörnell A, Berg C, Forsum E, Larsson C, Sonestedt E, Åkesson A, Lachat C, Hawwash D, Kolsteren P, Byrnes G, De Keyzer W, Van Camp J, Cade JE, Greenwood DC, Slimani N, Cevallos M, Egger M, Huybrechts I, Wirfält E. Perspective: An Extension of the STROBE Statement for Observational Studies in Nutritional Epidemiology (STROBE-nut): Explanation and Elaboration. Adv Nutr. 2017;8(5):652678. PMID: $\underline{28916567}$

$\S$ Bero, Lisa \& Chartres, Nicholas \& Diong, Joanna \& Fabbri, Alice \& Ghersi, Davina \& Lam, Juleen \& Lau, Agnes \& McDonald, Sally \& Mintzes, Barbara \& Sutton, Patrice \& Turton, Jessica \& Woodruff, Tracey. (2018). The risk of bias in observational studies of exposures (ROBINS-E) tool: Concerns arising from application to observational studies of exposures. Systematic Reviews. 7. 10.1186/s13643-
} 018-0915-2. 


\title{
Appendix 1-a: Literature search strategy for the rapid review on income and food prices
}

\author{
Database: PubMed \\ Vendor: National Library of Medicine \\ Date of Search: February 8, 2021 \\ Limits Used: Filters: Language English; Publication Dates 1995 - 2021 \\ Total $=4,265$
}

\begin{tabular}{|c|c|c|c|}
\hline Search \# & Concept & Search String & $\mathbf{N}$ \\
\hline$\# 1$ & Food/Beverages & 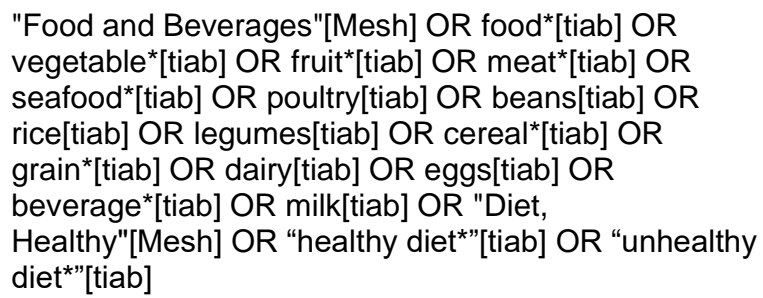 & $1,376,771$ \\
\hline \multirow[t]{2}{*}{ \#2 } & Price/Cost & $\begin{array}{l}\text { "Costs and Cost Analysis"[Mesh] OR cost }{ }^{\star}[\text { tiab] OR } \\
\text { price }{ }^{\star}\left[\text { tiab] OR affordab*[tiab] OR expense }{ }^{\star}[\text { tiab] OR }\right. \\
\text { expenditure*[tiab] OR budget*[tiab] OR purchas* }{ }^{\star}[\text { tiab] } \\
\text { OR cash[tiab] OR money[tiab] OR monetary[tiab] OR } \\
\text { monies[tiab] }\end{array}$ & 918,203 \\
\hline & $\begin{array}{l}\text { Income/social economic } \\
\text { factors }\end{array}$ & 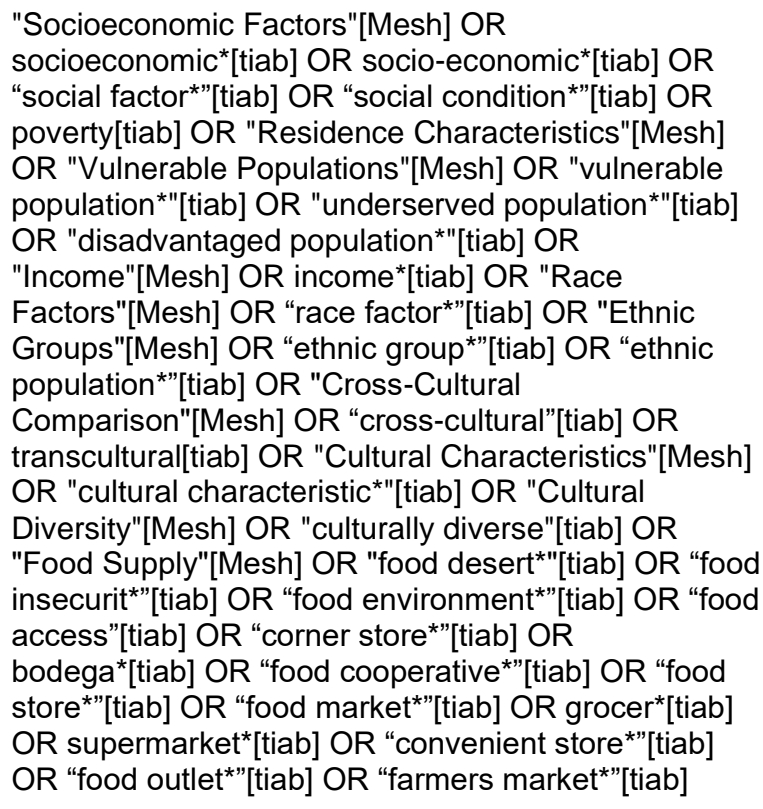 & 873,818 \\
\hline \#3 & & \#1 AND \#2 AND \#3 & 11,345 \\
\hline \#4 & Non-United States & $\begin{array}{l}\text { \#1 AND \#2 AND \#3 NOT ("Developing } \\
\text { Countries"[Mesh] OR "developing countr" OR "Under } \\
\text { Developed Nation*” OR "low income countr" OR } \\
\text { "middle income countr*"OR “low-middle-income } \\
\text { countr*" OR LMIC[tiab] OR "Europe"[Mesh] OR } \\
\text { "Australia"[Mesh] OR "Asia"[Mesh] OR "Africa"[Mesh] }\end{array}$ & 5,916 \\
\hline
\end{tabular}




\begin{tabular}{|c|c|c|c|}
\hline & & $\begin{array}{l}\text { OR "Mexico"[Mesh] OR "Islands"[Mesh] OR "Central } \\
\text { America"[Mesh] OR "Latin America"[Mesh] OR "South } \\
\text { America"[Mesh]) }\end{array}$ & \\
\hline$\# 4$ & Publication Excludes & $\begin{array}{l}\text { NOT (letter[ptyp] OR editorial[ptyp] OR comment[ptyp] } \\
\text { OR news[ptyp] OR "Congress"[Publication Type] OR } \\
\text { "Consensus Development Conference"[Publication } \\
\text { Type] OR editorial[tiab] OR commentary[tiab] OR } \\
\text { "conference abstract""[tiab] OR "systematic } \\
\text { review*"[ti] OR "meta-analysis"[ptyp] OR "meta- } \\
\text { analysis"[ti] OR "meta-analyses"[ti] OR } \\
\text { "Review"[Publication Type] OR "Systematic } \\
\text { Review"[Publication Type] OR "conference } \\
\text { proceeding*"[tiab] OR "retracted publication"[ptyp] OR } \\
\text { "retraction of publication"[ptyp] OR "retraction of } \\
\text { publication"[tiab] OR "retraction notice"[ti] OR } \\
\text { "retracted publication"[tiab] OR "Published } \\
\text { Erratum"[Publication Type] OR corrigenda[tiab] OR } \\
\text { corrigendum[tiab] OR errata[tiab] OR erratum[tiab] OR } \\
\text { protocol[ti] OR protocols[ti] OR "case report"[ti] OR } \\
\text { "case series"[ti] OR "Case Reports" [Publication } \\
\text { Type]) }\end{array}$ & 4,766 \\
\hline \#5 & Animal Excludes & $\begin{array}{l}\text { NOT ("Animals"[Mesh] NOT ("Animals"[Mesh] AND } \\
\text { "Humans"[Mesh])) }\end{array}$ & 4,570 \\
\hline \#6 & Limits: Language/Dates & Filters: English, from 1995 - 2021 & 4,265 \\
\hline
\end{tabular}

Database: Cochrane Central Register of Controlled Trials (CENTRAL)

Vendor: John Wiley \& Sons, Inc.

Date of Search: February 9, 2021

Limits Used: Filters: Trials; Publication Dates 1995 - 2021

Total $=847$

\begin{tabular}{|c|c|c|c|}
\hline Search \# & Concept & Search String & $\mathbf{N}$ \\
\hline \#1 & Food/Beverages & $\begin{array}{l}\text { [mh "Food and Beverages"] OR food* OR vegetable* } \\
\text { OR fruit* OR meat* OR seafood* OR poultry OR } \\
\text { beans OR rice OR legumes OR cereal* OR grain* OR } \\
\text { dairy OR eggs OR beverage* OR milk OR [mh "Diet, } \\
\text { Healthy"] OR "healthy diet*" OR "unhealthy diet*" }\end{array}$ & 96,092 \\
\hline \#2 & Price/Cost & $\begin{array}{l}\text { [mh "Costs and Cost Analysis"] OR cost* OR price* } \\
\text { OR affordab* OR expense* OR expenditure* OR } \\
\text { budget }^{\star} \text { OR purchas }{ }^{*} \text { OR cash OR money OR } \\
\text { monetary OR monies }\end{array}$ & 99,584 \\
\hline \#3 & $\begin{array}{l}\text { Income/social economic } \\
\text { factors }\end{array}$ & $\begin{array}{l}\text { [mh "Socioeconomic Factors"] OR socioeconomic* } \\
\text { OR socio-economic* OR "social factor*" OR "social } \\
\text { condition*" OR poverty OR [mh "Residence } \\
\text { Characteristics"] OR [mh "Vulnerable Populations"] } \\
\text { OR "vulnerable population*" OR "underserved } \\
\text { population*" OR "disadvantaged population*" OR [mh } \\
\text { "Income"] OR income* OR [mh "Race Factors"] OR } \\
\text { "race factor*" OR [mh "Ethnic Groups"] OR "ethnic } \\
\text { group*" OR "ethnic population*" OR [mh "Cross- } \\
\text { Cultural Comparison"] OR "cross-cultural" OR } \\
\text { transcultural OR [mh "Cultural Characteristics"] OR }\end{array}$ & 32,995 \\
\hline
\end{tabular}




\begin{tabular}{|l|l|l|l|}
\hline & $\begin{array}{l}\text { "cultural characteristic* OR [mh "Cultural Diversity"] } \\
\text { OR "culturally diverse" OR [mh "Food Supply"] OR } \\
\text { "food desert" OR "food insecurit" OR "food } \\
\text { environment*" OR "food access" OR "corner store*" } \\
\text { OR bodega* OR "food cooperative*" OR "food store*" } \\
\text { OR "food market" OR grocer* OR supermarket* OR } \\
\text { "convenient store" OR "food outlet" OR "farmers } \\
\text { market*" }\end{array}$ & $\begin{array}{l}\text { \#1 AND \#2 AND \#3 } \\
\text { \#4 }\end{array}$ \\
\hline Non-United States & $\begin{array}{l}\text { [mh "Developing Countries"] OR "developing countr*" } \\
\text { OR "under developed nation*" OR "low income } \\
\text { countr" OR "middle income countr" OR "low-middle- } \\
\text { income countr" OR LMIC OR [mh "Europe"] OR [mh } \\
\text { "Australia"] OR [mh "Asia"] OR [mh "Africa"] OR [mh } \\
\text { "Mexico"] OR [mh "Islands"] OR [mh "Central } \\
\text { America"] OR [mh "Latin America"] OR [mh "South } \\
\text { America"] }\end{array}$ & 5,916 \\
\hline \#6 & $\begin{array}{l}\text { \#4 NOT \#5" with Publication Year from 1995 to 2021, } \\
\text { in Trials (Word variations have been searched) }\end{array}$ & 847 \\
\hline
\end{tabular}

Database: Business Source Premier

Vendor: EBSCO

Date of Search: February 9, 2021

Limits Used: Filters: Language English, Peer Reviewed, Academic Journal; Publication, Geographic United States, Dates 1995 - 2021

Total $=471$

\begin{tabular}{|c|c|c|c|}
\hline Search \# & Concept & Search String & $\mathbf{N}$ \\
\hline \#S1 & Food/Beverages & $\begin{array}{l}\text { (DE "BEVERAGE consumption") OR (DE "FOOD } \\
\text { consumption forecasting") OR (DE "FOOD } \\
\text { consumption statistics") OR food* OR vegetable* OR } \\
\text { fruit* OR meat* OR seafood* OR poultry OR beans } \text { OR rice OR legumes OR cereal* OR grain* OR dairy } \\
\text { OR eggs OR beverage* OR milk OR "healthy diet"” } \\
\text { OR “unhealthy diet*” } \\
\text { Limiters - Scholarly (Peer Reviewed) Journals; } \\
\text { Published Date: 19950101-20211231; Publication } \\
\text { Type: Academic Journal; Document Type: Article }\end{array}$ & 115,0411 \\
\hline \#S2 & Price/Cost & $\begin{array}{l}\text { (DE "FOOD prices") OR cost* OR price* OR affordab* } \\
\text { OR expense* OR expenditure* OR budget* OR } \\
\text { purchas* OR cash OR money OR monetary OR } \\
\text { monies } \\
\text { Limiters - Scholarly (Peer Reviewed) Journals; } \\
\text { Published Date: } 19950101-20211231 \text {; Publication } \\
\text { Type: Academic Journal; Document Type: Article }\end{array}$ & 526,897 \\
\hline \#S3 & $\begin{array}{l}\text { Income/social economic } \\
\text { factors }\end{array}$ & $\begin{array}{l}\text { (DE "SOCIOECONOMIC factors") OR } \\
\text { socioeconomic* OR socio-economic* OR "social } \\
\text { factor" OR "social condition*" OR (DE "POVERTY") } \\
\text { OR poverty OR "vulnerable population*" OR }\end{array}$ & 200,523 \\
\hline
\end{tabular}




\begin{tabular}{|c|c|c|c|}
\hline & & 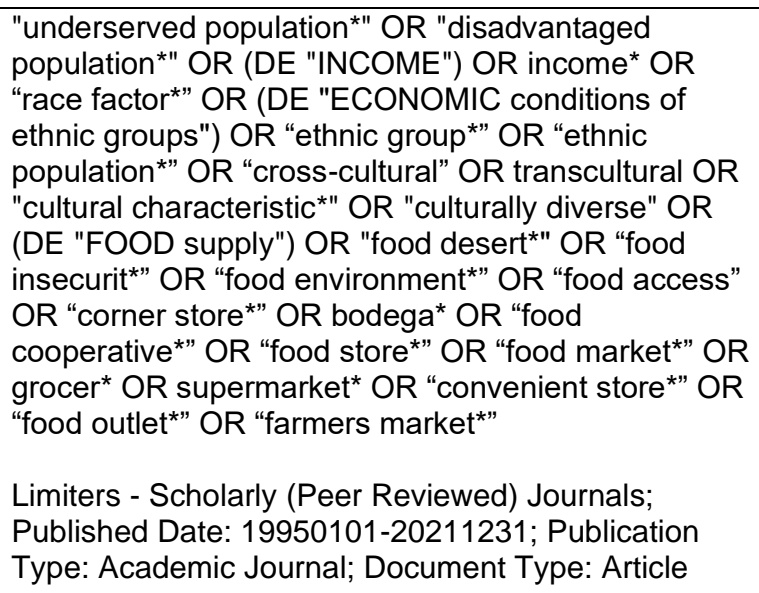 & \\
\hline \#S3 & & S1 AND S2 AND S3 & 6,977 \\
\hline \#S4 & Non-United States & $\begin{array}{l}\text { S1 AND S2 AND S3 } \\
\text { Limiters - Scholarly (Peer Reviewed) Journals; } \\
\text { Published Date: 19950101-20211231; Publication } \\
\text { Type: Academic Journal; Document Type: Article } \\
\text { Geographic: - united states }\end{array}$ & 471 \\
\hline
\end{tabular}

Database: Web of Science: Core Collection

Vendor: Clarivate Analytics

Date of Search: February 9, 2021

Limits Used: Filters: Language English; Publication Dates 1995 - 2021

Total $=4,040$

\begin{tabular}{|c|c|c|c|}
\hline Search \# & Concept & Search String & $\mathbf{N}$ \\
\hline$\# 1$ & Food \& Beverages & 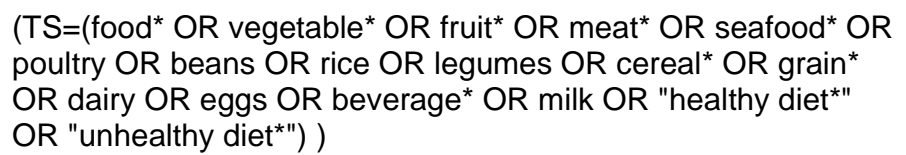 & $2,246,131$ \\
\hline$\# 2$ & Price/Cost & 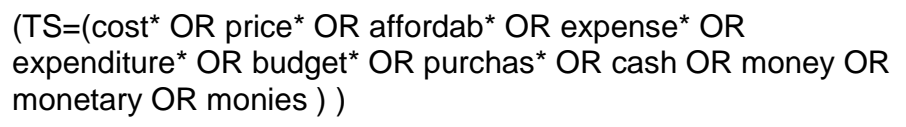 & $1,902,030$ \\
\hline \#3 & $\begin{array}{l}\text { Income/social } \\
\text { economic factors }\end{array}$ & 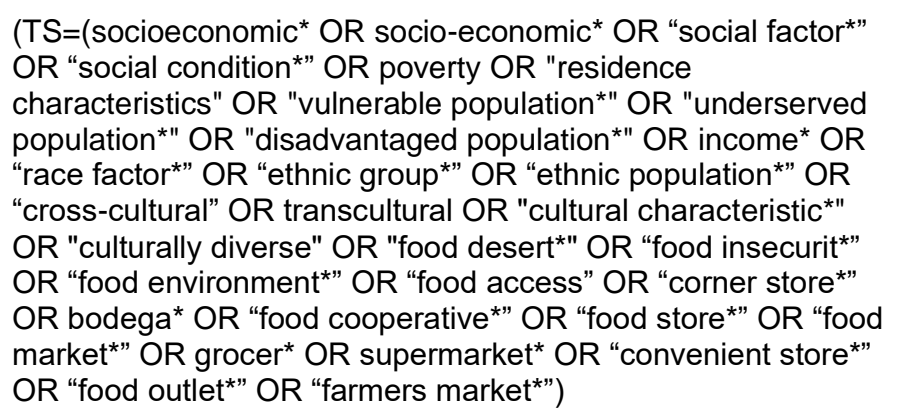 & 562,183 \\
\hline$\# 4$ & & \#1 AND \#2 AND \#3 & 17,069 \\
\hline$\# 5$ & Non-United States & $\begin{array}{l}\text { CU=("developing countr"*" OR "under developed nation" OR "lo } \\
\text { w income countr" OR "middle income }\end{array}$ & $2,281,865$ \\
\hline
\end{tabular}




\begin{tabular}{|l|l|l|l|}
\hline & & $\begin{array}{l}\text { countr" OR "low-middle income count*" OR LMIC } \\
\text { OR Europe OR Australia OR Asia OR Africa OR Mexico OR Isl } \\
\text { ands OR "Central America" OR "Latin America" OR "South Am } \\
\text { erica") }\end{array}$ & 15,059 \\
\hline$\# 6$ & Publication Excludes & $\begin{array}{l}\text { \#4 NOT \#5 } \\
\text { Onference proceeding*"[tiab] OR "retraction of publication" OR " } \\
\text { retracted publication" OR corrigenda[tiab] OR corrigendum[tiab] } \\
\text { OR errata OR erratum OR "case reports" ) OR TI=("systematic } \\
\text { review*" OR "meta-analysis" } \\
\text { OR "meta analyses" OR protocol OR protocols } \\
\text { OR "retraction notice" OR "case report" OR } \\
\text { "case series") }\end{array}$ & 731,825 \\
\hline$\# 8$ & $\begin{array}{l}\text { Language/Dates } \\
\text { AND NOT \#7 } \\
\text { (Article) Refined by: COUNTRIES/REGIONS: (USA) } \\
\text { Indexes=SCI-EXPANDED, SSCI Timespan=1995-2021 }\end{array}$ & 4040 \\
\hline
\end{tabular}

\section{Grey literature Search}

\section{Database: Google Scholar}

(Food AND beverages OR "food basket" OR groceries) (Price OR cost OR expenditure OR budget OR money OR "exact price index") AND (Income OR Poverty OR socioeconomic OR neighborhood OR city OR county)

\section{Limits:}

Date Searched: 4/26/2021

Results: 130 , limited to 13 pages

\section{Database: Google}

site:.gov pdf AND (Food AND beverages OR "food basket" OR groceries) (Price OR cost OR expenditure OR budget OR money OR "exact price index") AND (Income OR Poverty OR socioeconomic OR neighborhood OR city OR county)

Limits:

Date Searched: 4/26/2021

Results: 30 , limited to 3 pages

\section{Database: AgEcon}

\section{Search A}

Any of the words: food beverage basket grocer ${ }^{*}$

AND

Any of the words: cost price

AND

Any of the words: income

Limits:

Date Searched: 4/27/2021

Results: 100 , limited to 10 pages

\section{Search B}

Any of the words: food beverage basket grocer ${ }^{*}$ AND 


\section{USDA United States \\ Department of \\ Agriculture}

Any of the words: cost price

AND

Any of the words: neighborhood

Limits:

Date Searched: 4/27/2021

Results: 40 , limited to 4 pages

\section{Search C}

Any of the words: food beverage basket grocer* AND

Any of the words: cost price

AND

Any of the words: poverty

Limits:

Date Searched: 4/27/2021

Results: 110, limited to 11 pages

\section{Search D}

Any of the words: food beverage basket grocer* AND

Any of the words: cost price

AND

Any of the words: socioeconomic

Limits:

Date Searched: 4/27/2021

Results: 60 , limited to 6 pages 


\section{Appendix 1-b: Excluded articles for the rapid review on income and food prices}

The following table lists the articles excluded after full-text screening for this rapid review question. At least 1 reason for exclusion is provided for each article, though this may not reflect all possible reasons. Information about articles excluded after title and abstract screening is available upon request.

\section{Citation} CONSUMER EXPENDITURES -2019. 2020.

\begin{tabular}{|c|c|c|}
\hline 1. & CONSUMER EXPENDITURES -2019. 2020. & Outcome \\
\hline 2. & Vermont Basic Needs Budgets and Livable Wage. 2021. & Study Design \\
\hline 3. & $\begin{array}{l}\text { LONG-TERM BENEFITS OF THE SUPPLEMENTAL NUTRITION ASSISTANCE PROGRAM. } \\
2015 .\end{array}$ & Outcome \\
\hline 4. & Milwaukee Fresh Food Access Report. 2019. 86. & Outcome \\
\hline 5. & USDA Food Plans: Cost of Food Reports (monthly reports) | USDA-FNS. 2021. & Intervention/Exposure \\
\hline 6. & NC DHHS: Food and Nutrition Services Food Stamps. 2021. & Study Design \\
\hline 7. & $\begin{array}{l}\text { Ollinger, M, Guthrie,. Volume of Purchases and Regional Location Have Strong Effects on Food } \\
\text { Costs for School Meals. 2019. April 2019. doi:10.22004/ag.econ.302701. }\end{array}$ & Intervention/Exposure \\
\hline 8. & $\begin{array}{l}\text { Aaron, GJ, Keim, NL, Drewnowski, A, Townsend, MS. Estimating dietary costs of low-income } \\
\text { women in California: a comparison of } 2 \text { approaches. Am J Clin Nutr. 2013. 97:835-41. } \\
\text { doi:10.3945/ajcn.112.044453. }\end{array}$ & Intervention/Exposure \\
\hline 9. & $\begin{array}{l}\text { Aggarwal, A, Cook, AJ, Jiao, J, Seguin, RA, Vernez Moudon, A, Hurvitz, PM, Drewnowski, A. } \\
\text { Access to supermarkets and fruit and vegetable consumption. Am J Public Health. } 2014 . \\
\text { 104:917-23. doi:10.2105/ajph.2013.301763. }\end{array}$ & Outcome \\
\hline 11. & $\begin{array}{l}\text { Aggarwal, A, Monsivais, P, Cook, AJ, Drewnowski, A. Positive attitude toward healthy eating } \\
\text { predicts higher diet quality at all cost levels of supermarkets. J Acad Nutr Diet. 2014. 114:266- } \\
\text { 72. doi:10.1016/j.jand.2013.06.006. }\end{array}$ & Outcome \\
\hline 12. & $\begin{array}{l}\text { Aggarwal, A, Monsivais, P, Drewnowski, A. Nutrient intakes linked to better health outcomes are } \\
\text { associated with higher diet costs in the US. PLoS One. 2012. 7:e37533. } \\
\text { doi:10.1371/journal.pone.0037533. }\end{array}$ & Outcome \\
\hline 13. & $\begin{array}{l}\text { Aggarwal, A, Rehm, CD, Monsivais, P, Drewnowski, A. Importance of taste, nutrition, cost and } \\
\text { convenience in relation to diet quality: Evidence of nutrition resilience among US adults using } \\
\text { National Health and Nutrition Examination Survey (NHANES) 2007-2010. Prev Med. } 2016 . \\
\text { 90:184-92. doi:10.1016/j.ypmed.2016.06.030. }\end{array}$ & Intervention/Exposure \\
\hline 14. & $\begin{array}{l}\text { Alemu, R, Block, SA, Headey, D, Bai, Y, Masters, WA. Why are nutritious foods so expensive? } \\
\text { Economic development and the cost of nutritious diets. 2018. 32. doi:10.22004/ag.econ.281163. }\end{array}$ & Country \\
\hline
\end{tabular}

\section{Reason for exclusion}

nesr.usda.gov | 194 
15. Allcott, H, Diamond, R, Dubé, J-P, Handbury, J, Rahko vs.ky, I, Schnell, M. Food Deserts and the Causes of Nutritional Inequality. Quarterly Journal of Economics. 2019. 134:1793-1844. doi:10.1093/qje/qjz015.

16. Alston, JM, Pardey, PG. Agricultural R\&D, Food Prices, Poverty and Malnutrition Redux. $2014 . \quad$ Study Design 45. doi:10.22004/ag.econ.162413.

17. Anderson, K, Cockburn, J, Martin, W. Agricultural price distortions, inequality, and poverty.

Outcome 2010.

18. Andrews, M, Kantar, LS, Lino, M, Ripplinger, D. Using the USDA's Thrifty Food Plan to assess food availability and affordability. 24. 2001. 45-53.

19. Andreyeva, T, Luedicke, J, Middleton, AE, Long, MW, Schwartz, MB. Positive influence of the

Comparator revised Special Supplemental Nutrition Program for Women, Infants, and Children food packages on access to healthy foods. J Acad Nutr Diet. 2012. 112:850-8. doi:10.1016/j.jand.2012.02.019.

20. Anekwe, TD, Rahko vs.ky, I. The association between food prices and the blood glucose level Intervention/Exposure of US adults with type 2 diabetes. Am J Public Health. 2014. 104:678-85 doi:10.2105/ajph.2013.301661.

21. Appelhans, BM, Milliron, BJ, Woolf, K, Johnson, TJ, Pagoto, SL, Schneider, KL, Whited, MC

Outcome Ventrelle, JC. Socioeconomic status, energy cost, and nutrient content of supermarket food purchases. Am J Prev Med. 2012. 42:398-402. doi:10.1016/j.amepre.2011.12.007.

22. Ard, JD, Fitzpatrick, S, Desmond, RA, Sutton, BS, Pisu, M, Allison, DB, Franklin, F, Baskin, ML. The impact of cost on the availability of fruits and vegetables in the homes of schoolchildren in Birmingham, Alabama. Am J Public Health. 2007. 97:367-72. doi:10.2105/ajph.2005.080655.

23. Askelson, NM, Meier, C, Baquero, B, Friberg, J, Montgomery, D, Hradek, C. Understanding the Process of Prioritizing Fruit and Vegetable Purchases in Families With Low Incomes: "A Peach Intervention/Exposure May Not Fill You Up as Much as Hamburger". Health Educ Behav. 2018. 45:817-823. doi:10.1177/1090198117752790.

24. Basu, S, Wimer, C, Seligman, H. Moderation of the Relation of County-Level Cost of Living to Intervention/Exposure Nutrition by the Supplemental Nutrition Assistance Program. Am J Public Health. 2016. 106:2064-2070. doi:10.2105/ajph.2016.303439.

25. Beheshti, R, Igusa, T, Jones-Smith, J. Simulated Models Suggest That Price per Calorie Is the Dominant Price Metric That Low-Income Individuals Use for Food Decision Making. J Nutr. 2016. 146:2304-2311. doi:10.3945/jn.116.235952.

26. Berkowitz, SA, Basu, S, Meigs, JB, Seligman, HK. Food Insecurity and Health Care

Outcome Expenditures in the United States, 2011-2013. Health Serv Res. 2018. 53:1600-1620. doi:10.1111/1475-6773.12730.

27. Bertoni, AG, Foy, CG, Hunter, JC, Quandt, SA, Vitolins, MZ, Whitt-Glover, MC. A multileve assessment of barriers to adoption of Dietary Approaches to Stop Hypertension (DASH) among African Americans of low socioeconomic status. J Health Care Poor Underserved. 2011. 22:1205-20. doi:10.1353/hpu.2011.0142. 
28. Beydoun, MA, Fanelli-Kuczmarski, MT, Allen, A, Beydoun, HA, Popkin, BM, Evans, MK,

Zonderman, AB. Monetary Value of Diet Is Associated with Dietary Quality and Nutrient

Adequacy among Urban Adults, Differentially by Sex, Race and Poverty Status. PLoS One.

2015. 10:e0140905. doi:10.1371/journal.pone.0140905.

29. Beydoun, MA, Nkodo, A, Fanelli-Kuczmarski, MT, Maldonado, Al, Beydoun, HA, Popkin, BM

Evans, MK, Zonderman, AB. Longitudinal Associations between Monetary Value of the Diet,

DASH Diet Score and the Allostatic Load among Middle-Aged Urban Adults. Nutrients. 2019.

11:doi:10.3390/nu11102360.

30. Blecher, E, Liber, AC, Drope, JM, Nguyen, B, Stoklosa, M. Global Trends in the Affordability of Comparator Sugar-Sweetened Beverages, 1990-2016. Preventing Chronic Disease. 2017.

14:doi:10.5888/pcd14.160406.

31. Blisard, N, Stewart, H, Jolliffe, D. Low-income households' expenditures on fruits and

Other Exclude vegetables. 2004

32. Blisard, N, Smallwood, D, Lutz, S. Food Cost Indexes for Low-Income Households and the General Population. 1999. 29. doi:10.22004/ag.econ.156813.

33. Blisard, N, Stewart, H. How Low-Income Households Allocate Their Food Budget Relative to the Comparator Cost of the Thrifty Food Plan. 2006. 29. doi:10.22004/ag.econ.7239.

34. $\quad$ Blisard, N, Stewart, H. Food Spending in American Households, 2003-04. 2007. 108. Comparator doi:10.22004/ag.econ.59033.

35. Blitstein, JL, Snider, J, Evans, WD. Perceptions of the food shopping environment are associated with greater consumption of fruits and vegetables. Public Health Nutr. 2012.

Outcome 15:1124-9. doi:10.1017/s1368980012000523.

36. Bluthenthal, RN, Cohen, DA, Farley, TA, Scribner, R, Beighley, C, Schonlau, M, Robinson, PL.

Outcome

Alcohol availability and neighborhood characteristics in Los Angeles, California and southern

Louisiana. J Urban Health. 2008. 85:191-205. doi:10.1007/s11524-008-9255-1.

37. Boehm, R, Ver Ploeg, M, Wilde, PE, Cash, SB. Greenhouse gas emissions, total food spending

Outcome and diet quality by share of household food spending on red meat: results from a nationally representative sample of US households. Public Health Nutr. 2019. 22:1794-1806. doi:10.1017/s136898001800407x.

38. Breck, A, Kiszko, KM, Abrams, C, Elbel, B. Spending at mobile fruit and vegetable carts and

Outcome using SNAP benefits to pay, Bronx, New York, 2013 and 2014. Prev Chronic Dis. 2015. $12:$ E87. doi:10.5888/pcd12.140542.

39. Breyer, B, Voss-Andreae, A. Food mirages: geographic and economic barriers to healthful food Intervention/Exposure access in Portland, Oregon. Health Place. 2013. 24:131-9. doi:10.1016/j.healthplace.2013.07.008.

40. Brinkley, C, Chrisinger, B, Hillier, A. Tradition of healthy food access in low-income Intervention/Exposure neighborhoods: Price and variety of curbside produce vending compared to conventiona retailers. J Agric Food Syst Community Dev. 2013. 4:155-169. doi:10.5304/jafscd.2013.041.011.

41. Bronchetti, ET, Christensen, G, Hoynes, HW. Local food prices, SNAP purchasing power, and Intervention/Exposure child health. J Health Econ. 2019. 68:102231. doi:10.1016/j.jhealeco.2019.102231. 
Brown, C. Consumers' preferences for locally produced food: A study in southeast Missouri.

Comparator

American Journal of Alternative Agriculture. 2003. 18:213-224. doi:10.1079/ajaa200353.

43. Budd, N, Cuccia, A, Jeffries, JK, Prasad, D, Frick, KD, Powell, L, Katz, FA, Gittelsohn, J. B'More Study Design

Healthy: Retail Rewards--design of a multi-level communications and pricing intervention to improve the food environment in Baltimore City. BMC Public Health. 2015. 15:283. doi:10.1186/s12889-015-1616-6.

44. Burns, C, Cook, K, Mavoa, H. Role of expendable income and price in food choice by low income families. Appetite. 2013. 71:209-17. doi:10.1016/j.appet.2013.08.018.

45. Buszkiewicz, J, House, C, Aggarwal, A, Long, M, Drewnowski, A, Otten, JJ. The Impact of a City-Level Minimum Wage Policy on Supermarket Food Prices by Food Quality Metrics: A Two-

Year Follow Up Study. Int J Environ Res Public Health. 2019. 16:doi:10.3390/ijerph16010102.

46. Byker Shanks, C, Ahmed, S, Smith, T, Houghtaling, B, Jenkins, M, Margetts, M, Schultz, D,

Stephens, L. Availability, Price, and Quality of Fruits and Vegetables in 12 Rural Montana Counties, 2014. Prev Chronic Dis. 2015. 12:E128. doi:10.5888/pcd12.150158.

47. Cakir, M, Beatty, TKM, Boland, MA, Park, TA, Snyder, S, Wang, YH. SPATIAL AND TEMPORAL VARIATION IN THE VALUE OF THE WOMEN, INFANTS, AND CHILDREN PROGRAM'S FRUIT AND VEGETABLE VOUCHER. American Journal of Agricultural Economics. 2018. 100:691-706. doi:10.1093/ajae/aay002.

48. $\quad$ Canto, Amber, Brown, LE, Deller, SC. Rural Poverty, Food Access, and Public Health Outcomes. 2014. 29:5. doi:10.22004/ag.econ.182113.

49. Carlson, A, Page, E, Mentzer RM. USDA's Purchase to Plate Price Tool Estimates Food Costs for National Food Intake Data. 2020. 2020:doi:10.22004/ag.econ.307281.

50. Carnahan, LR, Zimmermann, K, Peacock, NR. What Rural Women Want the Public Health Community to Know About Access to Healthful Food: A Qualitative Study, 2011. Prev Chronic Dis. 2016. 13:E57. doi:10.5888/pcd13.150583.

51. Caspi, CE, Pelletier, JE, Harnack, LJ, Erickson, DJ, Lenk, K, Laska, MN. Pricing of Staple Foods at Supermarkets versus Small Food Stores. Int J Environ Res Public Health. 2017. 14:doi:10.3390/ijerph14080915.

52. Caswell, JA, Yaktine, AL, On Examination of the Adequacy of Food Resources, Snap Allotments, Committee, Board, Food, Nutrition, On National Statistics, Committee, Of Medicine, Institute, Council, National Research. Individual, Household, and Environmental Factors Affecting Food Choices and Access. Supplemental Nutrition Assistance Program: Examining the Evidence to Define Benefit Adequacy. 2013.

53. Cavanaugh, E, Mallya, G, Brensinger, C, Tierney, A, Glanz, K. Nutrition environments in corner Comparator stores in Philadelphia. Prev Med. 2013. 56:149-51. doi:10.1016/j.ypmed.2012.12.007.

54. Cerin, E, Frank, LD, Sallis, JF, Saelens, BE, Conway, TL, Chapman, JE, Glanz, K. From neighborhood design and food options to residents' weight status. Appetite. 2011. 56:693-703. doi:10.1016/j.appet.2011.02.006.

55. Chea, M, Mobley, AR. Factors Associated with Identification and Consumption of Whole-Grain Foods in a Low-Income Population. Curr Dev Nutr. 2019. 3:nzz064. doi:10.1093/cdn/nzz064. Intervention/Exposure

\section{Country}

Intervention/Exposure

Outcome

Intervention/Exposure

Comparator

Comparator

Intervention/Exposure

Comparator

Study Design

Intervention/Exposure 
56. Chen, D, Jaenicke, EC, Volpe, RJ. Food Environments and Obesity: Household Diet

Outcome

Expenditure Versus Food Deserts. Am J Public Health. 2016. 106:881-8. doi:10.2105/ajph.2016.303048.

57. Choi, HJ, Wohlgenant, MK, Zheng, XY. Household-Level Welfare Effects of Organic Milk Introduction. American Journal of Agricultural Economics. 2013. 95:1009-1028. doi:10.1093/ajae/aat021.

58. Chouinard, HH, Davis, DE, LaFrance, JT, Perloff, JM. Milk Marketing Order Winners and Losers. Applied Economic Perspectives and Policy. 2010. 32:59-76. doi:10.1093/aepp/ppp002.

59. Clauson, AL. Despite Higher Food Prices, Percent of U.S. Income Spent on Food Remains Constant. 2008. 1. doi:10.22004/ag.econ.124033.

60. Cliff, BQ, Townsend, T, Wolfson, JA. Examining Household Changes in Produce Purchases Among New Parents. J Nutr Educ Behav. 2019. 51:798-805. doi:10.1016/j.jneb.2019.04.010

61. Connell, CL, Zoellner, JM, Yadrick, MK, Chekuri, SC, Crook, LB, Bogle, ML. Energy density, nutrient adequacy, and cost per serving can provide insight into food choices in the lower Mississippi Delta. J Nutr Educ Behav. 2012. 44:148-53. doi:10.1016/j.jneb.2011.02.003.

62. Coughenour, C, Bungum, TJ, Regalado, MN. Healthy Food Options at Dollar Discount Stores Are Equivalent in Quality and Lower in Price Compared to Grocery Stores: An Examination in Las Vegas, NV. Int J Environ Res Public Health. 2018. 15:doi:10.3390/ijerph15122773.

63. Crandall, PG, Seideman, S, Ricke, SC, O'Bryan, CA, Fanatico, AF, Rainey, R. Organic poultry:

Study Design

Consumer perceptions, opportunities, and regulatory issues. Journal of Applied Poultry Research. 2009. 18:795-802. doi:10.3382/japr.2009-00025.

64. Damon, AL, King, RP, Leibtag, E. First of the month effect: Does it apply across food retail channels? Food Policy. 2013. 41:18-27. doi:10.1016/j.foodpol.2013.04.005.

65. Daniel, C. Is healthy eating too expensive?: How low-income parents evaluate the cost of food. Comparator Soc Sci Med. 2020. 248:112823. doi:10.1016/j.socscimed.2020.112823.

66. Darmon, N, Lacroix, A, Muller, L, Ruffieux, B. Food price policies improve diet quality while increasing socioeconomic inequalities in nutrition. Int J Behav Nutr Phys Act. 2014. 11:66. doi:10.1186/1479-5868-11-66.

67. Darmon, Nicole, Lacroix, Anne, Muller, Laurent, Ruffieux, Bernard. Food price policies improve Country diet quality while increasing socioeconomic inequalities in nutrition. International Journal of Behavioral Nutrition and Physical Activity. 2014. 11:1-12.

68. Davis, CG, Blayney, DP, Yen, ST, Cooper, J. An analysis of at-home demand for ice cream in the United States. J Dairy Sci. 2009. 92:6210-6. doi:10.3168/jds.2009-2536.

69. Davis, DE. Prices Dominate Interstate Variation in WIC Food Costs. 2005. 1. doi:10.22004/ag.econ.130597.

70. DiSantis, KI, Grier, SA, Oakes, JM, Kumanyika, SK. Food prices and food shopping decisions of Outcome black women. Appetite. 2014. 77:104-12. doi:10.1016/j.appet.2014.02.016.

71. DiSantis, KI, Grier, SA, Odoms-Young, A, Baskin, ML, Carter-Edwards, L, Young, DR, Lassiter, Comparator $\mathrm{V}$, Kumanyika, SK. What "price" means when buying food: insights from a multisite qualitative 
study with Black Americans. Am J Public Health. 2013. 103:516-22.

doi:10.2105/ajph.2012.301149.

72. Dong, D, Lin, B-H. Price Reductions Have Little Effect on Fruits and Vegetable Consumption by Comparator Low-Income Americans. 2009. 1. doi:10.22004/ag.econ.124213.

73. Dong, D, Lin, B-H. Fruit and Vegetable Consumption by Low-Income Americans: Would a Price Outcome Reduction Make a Difference? 2009. 17. doi:10.22004/ag.econ.55835.

74. Drewnowski, A. Nutrition Economics: How to Eat Better for Less. J Nutr Sci Vitaminol (Tokyo). Study Design 2015. 61 Suppl:S69-71. doi:10.3177/jnsv.61.S69.

75. Drewnowski, A, Aggarwal, A, Hurvitz, PM, Monsivais, P, Moudon, AV. Obesity and supermarket Other Exclude access: proximity or price? Am J Public Health. 2012. 102:e74-80. doi:10.2105/ajph.2012.300660.

76. Drewnowski, A, Moudon, AV, Jiao, J, Aggarwal, A, Charreire, H, Chaix, B. Food environment and socioeconomic status influence obesity rates in Seattle and in Paris. International Journal of Obesity. 2014. 38:306-314. doi:10.1038/ijo.2013.97.

77. Drewnowski, Adam, Darmon, Nicole. Food choices and diet costs: an economic analysis. The Study Design Journal of nutrition. 2005. 135:900-904.

78. Drichoutis, AC, Lazaridis, Panagiotis. What Influences Tastes? An Analysis of the Determinants Comparator of Consumers' Demand for Tastes in Food. 2009. 09:15. doi:10.22004/ag.econ.93803.

79. Elleby, C. Poverty and Price Transmission. 2014. 14. doi:10.22004/ag.econ.182722.

Comparator

80. Emond, JA, Madanat, HN, Ayala, GX. Do Latino and non-Latino grocery stores differ in the Intervention/Exposure availability and affordability of healthy food items in a low-income, metropolitan region? Public Health Nutr. 2012. 15:360-9. doi:10.1017/s1368980011001169.

81. Ethan, D, Basch, CH, Rajan, S, Samuel, L, Hammond, RN. A comparison of the nutritional Intervention/Exposure quality of food products advertised in grocery store circulars of high- versus low-income New York City zip codes. Int J Environ Res Public Health. 2013. 11:537-47. doi:10.3390/ijerph110100537.

82. Ethan, D, Samuel, L, Basch, CH. An analysis of Bronx-based online grocery store circulars for Outcome nutritional content of food and beverage products. J Community Health. 2013. 38:521-8. doi:10.1007/s10900-012-9643-z.

83. Fan, LL, Baylis, K, Gundersen, C, Ver Ploeg, M. Does a nutritious diet cost more in food Outcome deserts? Agricultural Economics. 2018. 49:587-597. doi:10.1111/agec.12444.

84. $\quad$ Fielding-Singh, P, Wang, J. Table talk: How mothers and adolescents across socioeconomic status discuss food. Soc Sci Med. 2017. 187:49-57. doi:10.1016/j.socscimed.2017.06.016.

85. Finke, MS, Chern, WS, Fox, JJ. Do the Urban Poor Pay More for Food? Issues in Measurement. Advancing the Consumer Interest. 1997. 9:13-17.

86. Flint, E, Cummins, S, Matthews, S. Do perceptions of the neighbourhood food environment doi:10.1016/j.healthplace.2013.07.005. 
87. French, MT, Browntaylor, D, Bluthenthal, RN. Price elasticity of demand for malt liquor beer:

Outcome findings from a US pilot study. Soc Sci Med. 2006. 62:2101-11. doi:10.1016/j.socscimed.2005.10.012.

88. French, SA, Tangney, CC, Crane, MM, Wang, Y, Appelhans, BM. Nutrition quality of food

Outcome purchases varies by household income: the SHoPPER study. BMC Public Health. 2019. 19:231. doi:10.1186/s12889-019-6546-2.

89. Glanz, K, Sallis, JF, Saelens, BE, Frank, LD. Nutrition Environment Measures Survey in stores Outcome (NEMS-S): development and evaluation. Am J Prev Med. 2007. 32:282-9. doi:10.1016/j.amepre.2006.12.019.

90. Glanz, Karen, Basil, Michael, Maibach, Edward, Goldberg, Jeanne, Snyder, DAN. Why Americans eat what they do: taste, nutrition, cost, convenience, and weight control concerns as influences on food consumption. Journal of the American Dietetic Association. 1998. 98:11181126.

91. Golan, Elise H, Stewart, Hayden, Kuchler, Fred, Dong, Diansheng. Can low-income Americans afford a healthy diet? 2008.

92. Gordon-Larsen, P, Guilkey, DK, Popkin, BM. An economic analysis of community-level fast food prices and individual-level fast food intake: a longitudinal study. Health Place. 2011. 17:1235-41. doi:10.1016/j.healthplace.2011.07.011.

93. Gorham, G, Dulin-Keita, A, Risica, PM, Mello, J, Papandonatos, G, Nunn, A, Gorham, S, Roberson, M, Gans, KM. Effectiveness of Fresh to You, a Discount Fresh Fruit and Vegetable Market in Low-Income Neighborhoods, on Children's Fruit and Vegetable Consumption, Rhode Island, 2010-2011. Prev Chronic Dis. 2015. 12:E176. doi:10.5888/pcd12.140583.

94. Goryakin, Y, Monsivais, P, Suhrcke, M. Soft drink prices, sales, body mass index and diabetes: Evidence from a panel of low-, middle- and high-income countries. Food Policy. 2017. 73:88-94. doi:10.1016/j.foodpol.2017.09.002.

95. Gouri Suresh, SS, Schauder, SA. Income Segregation and Access to Healthy Food. Am J Prev Med. 2020. 59:e31-e38. doi:10.1016/j.amepre.2020.02.009.

96. Govindasamy, Ramu, Purduri, Venkata, Kelley, Kathleen, Simon, JamesE. Influence of Consumer Demographics on the Demand for Locally Grown Ethnic Greens and Herbs Because of Food Miles Concerns: A Logit Model Analysis. 2012. 43:2. doi:10.22004/ag.econ.139446.

97. Grindal, T, Wilde, P, Schwartz, G, Klerman, J, Bartlett, S, Berman, D. Does food retail acces moderate the impact of fruit and vegetable incentives for SNAP participants? Evidence from western Massachusetts. Food Policy. 2016. 61:59-69. doi:10.1016/j.foodpol.2016.02.002.

98. Gupta, S, Rose, CM, Buszkiewicz, J, Ko, LK, Mou, J, Cook, A, Aggarwal, A, Drewnowski, A. Characterising percentage energy from ultra-processed foods by participant demographics, diet quality and diet cost: findings from the Seattle Obesity Study (SOS) III. Br J Nutr. 2020. 1-9. doi:10.1017/s0007114520004705 
100. Han, E, Powell, LM. Effect of food prices on the prevalence of obesity among young adults.

Public Health. 2011. 125:129-35. doi:10.1016/j.puhe.2010.11.014.

101. Han, Euna, Powell, LM. FAST FOOD PRICES AND ADULT BODY WEIGHT OUTCOMES:

Outcome

EVIDENCE BASED ON LONGITUDINAL QUANTILE REGRESSION MODELS. Contemporary

Economic Policy. 2013. 31:528-536. doi:10.1111/j.1465-7287.2012.00322.x.

102. Hanson, GD, Herrmann, RO, Dunn, JW. Determinants of seafood purchase behavior:

Study Design

Consumers, restaurants, and grocery stores. American Journal of Agricultural Economics. 1995.

77:1301-1305. doi:10.2307/1243365.

103. Hanson, KL, Garner, J, Connor, LM, Jilcott Pitts, SB, McGuirt, J, Harris, R, Kolodinsky, J, Wang, Comparator

W, Sitaker, M, Ammerman, A, Seguin, RA. Fruit and Vegetable Preferences and Practices May

Hinder Participation in Community-Supported Agriculture Among Low-Income Rural Families. J Nutr Educ Behav. 2019. 51:57-67. doi:10.1016/j.jneb.2018.08.006.

104. Harwood, EM, Erickson, DJ, Fabian, LE, Jones-Webb, R, Slater, S, Chaloupka, FJ. Effects of communities, neighborhoods and stores on retail pricing and promotion of beer. J Stud Alcohol. 2003. 64:720-6. doi:10.15288/jsa.2003.64.720.

105. Hausman, J, Leibtag, E. Consumer benefits from increased competition in shopping outlets: Measuring the effect of Wal-Mart. Journal of Applied Econometrics. 2007. 22:1157-1177. doi:10.1002/jae.994.

106. Haynes-Maslow, L, Auvergne, L, Mark, B, Ammerman, A, Weiner, BJ. Low-Income Individuals Perceptions About Fruit and Vegetable Access Programs: A Qualitative Study. J Nutr Educ Behav. 2015. 47:317-24.e1. doi:10.1016/j.jneb.2015.03.005.

107. Haynes-Maslow, L, Parsons, SE, Wheeler, SB, Leone, LA. A qualitative study of perceived barriers to fruit and vegetable consumption among low-income populations, North Carolina, 2011. Prev Chronic Dis. 2013. 10:E34. doi:10.5888/pcd10.120206.

108. Hendrickson, D, Smith, C, Eikenberry, N. Fruit and vegetable access in four low-income food Comparator deserts communities in Minnesota. Agriculture and Human Values. 2006. 23:371-383. doi:10.1007/s10460-006-9002-8.

109. Hillier, A, McLaughlin, J, Cannuscio, CC, Chilton, M, Krasny, S, Karpyn, A. The impact of WIC

Outcome food package changes on access to healthful food in 2 low-income urban neighborhoods. J Nutr Educ Behav. 2012. 44:210-6. doi:10.1016/j.jneb.2011.08.004.

110. Hinrichs, CC. Embeddedness and local food systems: notes on two types of direct agricultural Intervention/Exposure market. Journal of rural studies. 2000. 16:295-303.

111. Hirsch, J A, Hillier, A. Exploring the role of the food environment on food shopping patterns in Philadelphia, PA, USA: a semiquantitative comparison of two matched neighborhood groups.

Comparator International journal of environmental research and public health. 2013. 10:295-313.

112. Hirvonen, K, Bai, Y, Headey, D, Masters, WA. Affordability of the EAT-Lancet reference diet: a Comparator global analysis. Lancet Glob Health. 2020. 8:e59-e66. doi:10.1016/s2214-109x(19)30447-4.

113. Hoenink, JC, Beulens, JWJ, Harbers, MC, Boer, JMA, Dijkstra, SC, Nicolaou, M, van der Schouw, YT, Sluijs, I, Verschuren, WMM, Waterlander, W, Mackenbach, JD. To what extent do 
dietary costs explain socio-economic differences in dietary behavior? Nutr J. 2020. 19:88.

doi:10.1186/s12937-020-00608-x.

114. Hu, A, Acosta, A, McDaniel, A, Gittelsohn, J. Community perspectives on barriers and strategies Comparator for promoting locally grown produce from an urban agriculture farm. Health Promot Pract. 2013. 14:69-74. doi:10.1177/1524839911405849.

115. Huang, CL, Lin, BH. A hedonic analysis of fresh tomato prices among regional markets. Review Outcome of Agricultural Economics. 2007. 29:783-800. doi:10.1111/j.1467-9353.2007.00387.x.

116. Huang, KS. Nutrient elasticities in a complete food demand system. American Journal of Agricultural Economics. 1996. 78:21-29. doi:10.2307/1243775.

117. Huang, KS, Huang, SW. Consumer welfare effects of increased food and energy prices. Applied Outcome Economics. 2012. 44:2527-2536. doi:10.1080/00036846.2011.566182.

118. Huang, M-H, Hahn, DE, Jones, Eugene. A SOCIOECONOMIC APPROACH TO ASSESSING PRICE COMPETITION BETWEEN PRIVATE LABELS AND NATIONAL BRANDS: THE CASE OF SHREDDED CHEESE. 2003. 26. doi:10.22004/ag.econ.21993.

119. Ismail, MS, Ver Ploeg, M, Chomitz, VR, Wilde, P. Differences in Food-at-Home Spending for SNAP and Non-SNAP Households Given Geographic Price Variation. J Acad Nutr Diet. 2020. 120:1142-1150.e12. doi:10.1016/j.jand.2019.12.017.

120. Ivanic, MA, Martin, W. Short- and Long-Run Impacts of Food Price Changes on Poverty. Short- Country and Long-Run Impacts of Food Price Changes on Poverty. . doi:10.1596/1813-9450-7011.

121. Jetter, KM, Adkins, J, Cortez, S, Hopper, GK, Jr, Shively, V, Styne, DM. Yes We Can: Eating Intervention/Exposure Healthy on a Limited Budget. J Nutr Educ Behav. 2019. 51:268-276. doi:10.1016/j.jneb.2018.12.002.

122. Jetter, KM, Cassady, DL. The availability and cost of healthier food alternatives. Am J Prev Med. 2006. 30:38-44. doi:10.1016/j.amepre.2005.08.039.

123. Jetter, KM, Cassady, Diana. EXPLAINING DISPARITIES IN THE COST OF HEALTHIER Study Design FOOD. 2004. 17. doi:10.22004/ag.econ.20181.

124. Jiao, J, Moudon, AV, Ulmer, J, Hurvitz, PM, Drewnowski, A. How to identify food deserts: measuring physical and economic access to supermarkets in King County, Washington. Am J Public Health. 2012. 102:e32-9. doi:10.2105/ajph.2012.300675.

125. Jilcott, SB, Hurwitz, J, Moore, JB, Blake, C. Qualitative perspectives on the use of traditional Outcome and nontraditional food venues among middle- and low-income women in Eastern North Carolina. Ecol Food Nutr. 2010. 49:373-89. doi:10.1080/03670244.2010.507438.

126. Johnson, DS, Rogers, JM, Tan, Lucilla. A Century of Family Budgets in the United States. Outcome Monthly Labor Review. 2001. 18.

127. Johnson, JS, Nobmann, ED, Asay, E. Factors related to fruit, vegetable and traditional food consumption which may affect health among Alaska Native People in Western Alaska. Int $\mathrm{J}$ Circumpolar Health. 2012. 71:17345. doi:10.3402/ijch.v71i0.17345.

128. Jones, E. An analysis of consumer food shopping behavior using supermarket scanner data: Differences. American Journal of Agricultural Economics. 1997. 79:1437. doi:10.2307/1244358.

Outcome 
129. Jones, E. Consumer demand for carbohydrates: A look across products and income classes.

Outcome Agribusiness. 1997. 13:599-612. doi:10.1002/(SICI)1520-6297(199711/12)13:6<599::AIDAGR5>3.0.CO;2-Z.

130. Karp, RJ, Wong, G, Orsi, M. Demonstrating Nutrient Cost Gradients: A Brooklyn Case Study. Int Comparator J Vitam Nutr Res. 2014. 84:244-51. doi:10.1024/0300-9831/a000210.

131. Kaufman, PR, MacDonald, JM, Lutz, SM, Smallwood, DM. Do the poor pay more for food? Item Other Exclude selection and price differences affect low-income household food costs. 1997. Agricultural Economic Report 759.

132. Kaufman, PR. ASSESSMENT OF WIC COST-CONTAINMENT PRACTICES: FOOD ASSISTANCE RESEARCH BRIEF. 2003. 2. doi:10.22004/ag.econ.33855.

133. Keim, NL, Forester, SM, Lyly, M, Aaron, GJ, Townsend, MS. Vegetable variety is a key to improved diet quality in low-income women in California. J Acad Nutr Diet. 2014. 114:430-5. doi:10.1016/j.jand.2013.07.026.

134. Kern, DM, Auchincloss, AH, Stehr, MF, Roux, AVD, Moore, LV, Kanter, GP, Robinson, LF. Neighborhood Prices of Healthier and Unhealthier Foods and Associations with Diet Quality: Evidence from the Multi-Ethnic Study of Atherosclerosis. Int J Environ Res Public Health. 2017. 14:doi:10.3390/ijerph14111394.

135. Kershaw, KN, Klikuszowian, E, Schrader, L, Siddique, J, Van Horn, L, Womack, VY, Zenk, SN. Assessment of the influence of food attributes on meal choice selection by socioeconomic status and race/ethnicity among women living in Chicago, USA: A discrete choice experiment. Appetite. 2019. 139:19-25. doi:10.1016/j.appet.2019.04.003.

136. Khan, R, Misra, K, Singh, V. Will a Fat Tax Work? Marketing Science. 2016. 35:10-26. Outcome doi:10.1287/mksc.2015.0917.

137. Khan, T, Powell, LM, Wada, R. Fast food consumption and food prices: evidence from panel data on 5th and 8th grade children. J Obes. 2012. 2012:857697. doi:10.1155/2012/857697.

138. King, RP, Leibtag, ES, Behl, AS. SUPERMARKET CHARACTERISTICS AND OPERATING COSTS IN LOW-INCOME AREAS. 2004. 26. doi:10.22004/ag.econ.20361.

139. Kinsey, JD. The economics of federal food programs: Weighing the costs and benefits Executive Summary. 2013. 3. doi:10.22004/ag.econ.156194.

140. Kinsey, JD. The economics of federal food programs: Weighing the costs and benefits. 2013. 20. doi:10.22004/ag.econ.156193.

141. Ko, LK, Enzler, C, Perry, CK, Rodriguez, E, Mariscal, N, Linde, S, Duggan, C. Food availability Outcome and food access in rural agricultural communities: use of mixed methods. BMC Public Health 2018. 18:634. doi:10.1186/s12889-018-5547-x.

142. Koelkebeck, KW, Bell, DD, Carey, JB, Anderson, KE, Darre, MJ. Egg marketing in national supermarkets: Products, packaging, and prices - Part 3. Poultry Science. 2001. 80:396-400. doi:10.1093/ps/80.4.396.

143. Krebs-Smith, SM, Kantor, LS. Choose a variety of fruits and vegetables daily: understanding the Intervention/Exposure complexities. J Nutr. 2001. 131:487s-501s. doi:10.1093/jn/131.2.487S. 
144. Krukowski, RA, West, DS, Harvey-Berino, J, Elaine Prewitt, T. Neighborhood impact on healthy

Outcome

food availability and pricing in food stores. J Community Health. 2010. 35:315-20. doi:10.1007/s10900-010-9224-y.

145. Kuhns, A, Levin, D. Retail Food Price Inflation Varies Geographically. 2016. 1. doi:10.22004/ag.econ.244275.

146. Kumcu, A, Volpe, R III. Disaggregated Retail Food Price Indices Using Homescan Data: An
Application to Income Levels and SNAP Benefits. 2013. 6. doi:10.22004/ag.econ.150985.

147. Kwon, S-O, Oh, S-Y. Associations of household food insecurity with socioeconomic measures, Language health status and nutrient intake in low income elderly. Journal of Nutrition and Health. 2007. 40:762-768.

148. Kyureghian, G, Nayga, RM. FOOD STORE ACCESS, AVAILABILITY, AND CHOICE WHEN PURCHASING FRUITS AND VEGETABLES. American Journal of Agricultural Economics. 2013. 95:1280-1286. doi:10.1093/ajae/aat043.

149. Laraia, BA, Leak, TM, Tester, JM, Leung, CW. Biobehavioral Factors That Shape Nutrition in Low-Income Populations: A Narrative Review. American Journal of Preventive Medicine. 2017. 52:S118-S126. doi:10.1016/j.amepre.2016.08.003

150. Larsen, K, Gilliland, J. A farmers' market in a food desert: Evaluating impacts on the price and Country availability of healthy food. Health Place. 2009. 15:1158-62. doi:10.1016/j.healthplace.2009.06.007.

151. Larson, NI, Story, MT, Nelson, MC. Neighborhood environments: disparities in access to healthy Study Design foods in the US. American journal of preventive medicine. 2009. 36:74-81. e10.

152. Lear, SA, Gasevic, D, Schuurman, N. Association of supermarket characteristics with the body Country mass index of their shoppers. Nutr J. 2013. 12:117. doi:10.1186/1475-2891-12-117.

153. Lee, RE, Heinrich, KM, Medina, AV, Regan, GR, Reese-Smith, JY, Jokura, Y, Maddock, JE. A Intervention/Exposure picture of the healthful food environment in two diverse urban cities. Environ Health Insights. 2010. 4:49-60. doi:10.4137/ehi.s3594.

154. Leibtag, E. Where you shop matters: Store formats drive variation in retail food prices. Amber Comparator Waves. 2005. 3:12-18.

155. Lent, MR, Vander Veur, SS, McCoy, TA, Wojtanowski, AC, Sandoval, B, Sherman, S, Komaroff, Outcome $\mathrm{E}$, Foster, GD. A randomized controlled study of a healthy corner store initiative on the purchases of urban, low-income youth. Obesity (Silver Spring). 2014. 22:2494-500. doi:10.1002/oby.20878.

156. Leone, LA, Beth, D, Ickes, SB, Macguire, K, Nelson, E, Smith, RA, Tate, DF, Ammerman, AS. Attitudes Toward Fruit and Vegetable Consumption and Farmers' Market Usage Among LowIncome North Carolinians. J Hunger Environ Nutr. 2012. 7:64-76. doi:10.1080/19320248.2012.651386.

157. Li, Y, Zhang, D, Thapa, JR, Madondo, K, Yi, S, Fisher, E, Griffin, K, Liu, B, Wang, Y, Pagán, JA. Assessing the role of access and price on the consumption of fruits and vegetables across New York City using agent-based modeling. Prev Med. 2018. 106:73-78. doi:10.1016/j.ypmed.2017.10.014. 
158. Libman, K. Has New York City fallen into the local trap? Public Health. 2015. 129:310-7.

Outcome doi:10.1016/j.puhe.2014.12.016

159. Locher, JL, Ritchie, CS, Roth, DL, Sen, B, Vickers, KS, Vailas, LI. Food choice among Intervention/Exposure homebound older adults: motivations and perceived barriers. J Nutr Health Aging. 2009. 13:65964. doi:10.1007/s12603-009-0194-7.

160. Lopez, E, Lopez, RA. Demand for Differentiated Milk Products: Implications for Price Intervention/Exposure Competition. Agribusiness. 2009. 25:453-465. doi:10.1002/agr.20219.

161. Lucan, SC, Barg, FK, Long, JA. Promoters and barriers to fruit, vegetable, and fast-food consumption among urban, low-income African Americans--a qualitative approach. Am J Public Health. 2010. 100:631-5. doi:10.2105/ajph.2009.172692.

162. Lucan, SC, Maroko, AR, Sanon, O, Frias, R, Schechter, CB. Urban farmers' markets: accessibility, offerings, and produce variety, quality, and price compared to nearby stores. Appetite. 2015. 90:23-30. doi:10.1016/j.appet.2015.02.034.

163. Lunsford, J, Brunt, A, Foote, J, Rhee, Y, Strand, M, Segall, M. Analysis of Availability, Quality, and Price of Food Options in Denver, CO Grocery Stores. Journal of hunger \& environmental nutrition. 2020. doi:10.1080/19320248.2020.1741482.

164. Lusk, JL, Tonsor, GT. How Meat Demand Elasticities Vary with Price, Income, and Product Category. Applied Economic Perspectives and Policy. 2016. 38:673-711. doi:10.1093/aepp/ppv050.

165. MacNell, L. A geo-ethnographic analysis of low-income rural and urban women's food shopping Comparator behaviors. Appetite. 2018. 128:311-320. doi:10.1016/j.appet.2018.05.147.

166. Mancino, L, Kuchler, F. Demand for Whole-grain Bread Before and After the Release of Dietary Outcome Guidelines. Applied Economic Perspectives and Policy. 2012. 34:76-101. doi:10.1093/aepp/ppr035.

167. Marcy, TR, Britton, ML, Harrison, D. Identification of barriers to appropriate dietary behavior in Outcome low-income patients with type 2 diabetes mellitus. Diabetes Ther. 2011. 2:9-19. doi:10.1007/s13300-010-0012-6.

168. Martin, KS, Ghosh, D, Page, M, Wolff, M, McMinimee, K, Zhang, M. What role do local grocery Intervention/Exposure stores play in urban food environments? A case study of Hartford-Connecticut. PLoS One. 2014. 9:e94033. doi:10.1371/journal.pone.0094033.

169. Martin-Neuninger, R, Ruby, MB. What Does Food Retail Research Tell Us About the Study Design Implications of Coronavirus (COVID-19) for Grocery Purchasing Habits? Front Psychol. 2020. 11:1448. doi:10.3389/fpsyg.2020.01448.

170. Masters, MA, Stanek Krogstrand, KL, Eskridge, KM, Albrecht, JA. Race/ethnicity and income in Outcome relation to the home food environment in US youth aged 6 to 19 years. J Acad Nutr Diet. 2014. 114:1533-43. doi:10.1016/j.jand.2014.04.023.

171. Mayer, SE, Leone, MP. What money can't buy: Family income and children's life chances. $1997 . \quad$ Study Design

172. McDowell, DR, Allen-Smith, JE, McLean-Meyinsse, PE. Food expenditures and socioeconomic Outcome characteristics: Focus on income class. American Journal of Agricultural Economics. 1997. 79:1444-1451. doi:10.2307/1244359. 
173. McGuirt, JT, Huebner, G, Ward, R, Jilcott Pitts, SB. Food and Beverage Options at Highway Rest Areas in North Carolina: A Mixed-Methods Audit and Geospatial Approach. Prev Chronic Dis. 2019. 16:E142. doi:10.5888/pcd16.190129.

174. McGuirt, JT, Pitts, SBJ, Hanson, KL, DeMarco, M, Seguin, RA, Kolodinsky, J, Becot, F, Ammerman, AS. A modified choice experiment to examine willingness to participate in a Community Supported Agriculture (CSA) program among low-income parents. Renewable Agriculture and Food Systems. 2020. 35:140-157. doi:10.1017/s1742170518000364.

175. McLaughlin, PW. Specialized Stores Serving WIC Customers in California Improve Food Access Without Raising Food Costs. 2019. May 2019:doi:10.22004/ag.econ.302709.

176. McLaughlin, PW, Martinez, S. Specialized Stores Serving Participants in USDA's Special Supplemental Nutrition Program for Women, Infants, and Children (WIC) Can Reduce Program Food Costs and Increase Food Store Access. 2021. 2020:doi:10.22004/ag.econ.310091.

177. Meade, B, Muhammad, A. The Influence of Income and Prices on Global Dietary Patterns by Country, Age, and Gender. 2017. doi:10.22004/ag.econ.266027. 178. Meyer, BD, Sullivan, JX. Five decades of consumption and income poverty. 2009.

Comparator

Intervention/Exposure

Intervention/Exposure

Comparator

Comparator

Comparator

179. Meyer, KA, Guilkey, DK, Ng, SW, Duffey, KJ, Popkin, BM, Kiefe, Cl, Steffen, LM, Shikany, JM, Outcome Gordon-Larsen, P. Sociodemographic differences in fast food price sensitivity. JAMA Intern Med. 2014. 174:434-42. doi:10.1001/jamainternmed.2013.13922.

180. Monsivais, P, Aggarwal, A, Drewnowski, A. Are socio-economic disparities in diet quality Outcome explained by diet cost? J Epidemiol Community Health. 2012. 66:530-5. doi:10.1136/jech.2010.122333.

181. Monsivais, P, Drewnowski, A. Lower-energy-density diets are associated with higher monetary costs per kilocalorie and are consumed by women of higher socioeconomic status. J Am Diet Assoc. 2009. 109:814-22. doi:10.1016/j.jada.2009.02.002.

182. Monsivais, P, Perrigue, MM, Adams, SL, Drewnowski, A. Measuring diet cost at the individual Outcome level: a comparison of three methods. Eur J Clin Nutr. 2013. 67:1220-5. doi:10.1038/ejcn.2013.176

183. Mook, K, Laraia, BA, Oddo, VM, Jones-Smith, JC. Food Security Status and Barriers to Fruit Outcome and Vegetable Consumption in Two Economically Deprived Communities of Oakland,

California, 2013-2014. Prev Chronic Dis. 2016. 13:E21. doi:10.5888/pcd13.150402.

184. Moore, Latetia V, Diez Roux, Ana V. Associations of neighborhood characteristics with the Outcome location and type of food stores. American journal of public health. 2006. 96:325-331.

185. Morland, K, Filomena, S. The utilization of local food environments by urban seniors. Prev Med. Intervention/Exposure 2008. 47:289-93. doi:10.1016/j.ypmed.2008.03.009.

186. Morland, K, Wing, S, Roux, AD, Poole, C. Neighborhood characteristics associated with the Outcome location of food stores and food service places. American journal of preventive medicine. 2002. 22:23-29.

187. Mulik, K, Haynes-Maslow, L. The Affordability of MyPlate: An Analysis of SNAP Benefits and the Intervention/Exposure Actual Cost of Eating According to the Dietary Guidelines. J Nutr Educ Behav. 2017. 49:623631.e1. doi:10.1016/j.jneb.2017.06.005 
188. Mushi-Brunt, C, Haire-Joshu, D, Elliott, M. Food spending behaviors and perceptions are

Outcome associated with fruit and vegetable intake among parents and their preadolescent children. $J$ Nutr Educ Behav. 2007. 39:26-30. doi:10.1016/j.jneb.2006.06.004.

189. Neckerman, KM, Lovasi, L, Yousefzadeh, P, Sheehan, D, Milinkovic, K, Baecker, A, Bader, MD, Outcome Weiss, C, Lovasi, GS, Rundle, A. Comparing nutrition environments in bodegas and fast-food restaurants. J Acad Nutr Diet. 2014. 114:595-602. doi:10.1016/j.jand.2013.07.007.

190. Nelson, E, Fitzgerald, J, Tefft, N. The distributional impact of a green payment policy for organic Outcome fruit. PLoS One. 2019. 14:e0211199. doi:10.1371/journal.pone.0211199.

191. Nelson, JP. Economic and Demographic Factors in U.S. Alcohol Demand: A Growth-Accounting Study Design Analysis. Empirical Economics. 1997. 22:83-102. doi:10.1007/BF01188171.

192. Nord, M. Food Spending Declined and Food Insecurity Increased for Middle-Income and Low- Outcome Income Households From 2000 to 2007. 2009. 19. doi:10.22004/ag.econ.56627.

193. Nord, M, Hopwood, H. Can Food Stamps Do More to Improve Food Choices? An Economic

Comparator Perspective--Higher Cost of Food in Some Areas May Affect Food Stamp Households' Ability To Make Healthy Food Choices. 2007. 4. doi:10.22004/ag.econ.59429.

194. O'Connell, M, Buchwald, DS, Duncan, GE. Food access and cost in American Indian Intervention/Exposure communities in Washington State. J Am Diet Assoc. 2011. 111:1375-9. doi:10.1016/j.jada.2011.06.002.

195. Oliveira, Victor. Differences in Per-Person Food Costs for SNAP and WIC Have Widened Over Comparator Time. 2014. 1. doi:10.22004/ag.econ.210864

196. Omar, MA, Coleman, G, Hoerr, S. Healthy eating for rural low-income toddlers: caregivers' Comparator perceptions. J Community Health Nurs. 2001. 18:93-106. doi:10.1207/s15327655jchn1802_03.

197. Onufrak, SJ, Zaganjor, H, Pan, L, Lee-Kwan, SH, Park, S, Harris, DM. Foods and Beverages Outcome Obtained at Worksites in the United States. J Acad Nutr Diet. 2019. 119:999-1008. doi:10.1016/j.jand.2018.11.011.

198. Otten, JJ, Buszkiewicz, J, Tang, W, Aggarwal, A, Long, M, Vigdor, J, Drewnowski, A. The Impact of a City-Level Minimum-Wage Policy on Supermarket Food Prices in Seattle-King County. Int J Environ Res Public Health. 2017. 14:doi:10.3390/ijerph14091039.

199. Owens, MM, Ray, LA, MacKillop, J. Behavioral economic analysis of stress effects on acute motivation for alcohol. J Exp Anal Behav. 2015. 103:77-86. doi:10.1002/jeab.114.

200. Park, JL, Holcomb, RB, Raper, KC, Capps, O. A demand systems analysis of food commodities Outcome by US households segmented by income. American Journal of Agricultural Economics. 1996. 78:290-300. doi:10.2307/1243703.

201. Pearson, T, Russell, J, Campbell, MJ, Barker, ME. Do 'food deserts' influence fruit and Outcome vegetable consumption?--A cross-sectional study. Appetite. 2005. 45:195-7. doi:10.1016/j.appet.2005.04.003.

202. Pechey, R, Monsivais, P. Supermarket Choice, Shopping Behavior, Socioeconomic Status, and Country Food Purchases. Am J Prev Med. 2015. 49:868-77. doi:10.1016/j.amepre.2015.04.020. 
203. Pechey, R, Monsivais, P, Ng, YL, Marteau, TM. Why don't poor men eat fruit? Socioeconomic

Country differences in motivations for fruit consumption. Appetite. 2015. 84:271-9. doi:10.1016/j.appet.2014.10.022.

204. Pechey, R, Monsivais, P. Socioeconomic inequalities in the healthiness of food choices: Exploring the contributions of food expenditures. Preventive medicine. 2016. 88:203-209.

205. Peñalvo, JL, Cudhea, F, Micha, R, Rehm, CD, Afshin, A, Whitsel, L, Wilde, P, Gaziano, T, Pearson-Stuttard, J, O'Flaherty, M, Capewell, S, Mozaffarian, D. The potential impact of food taxes and subsidies on cardiovascular disease and diabetes burden and disparities in the United States. BMC Med. 2017. 15:208. doi:10.1186/s12916-017-0971-9.

206. Peng, K, Kaza, N. Association between Neighborhood Food Access, Household Income, and

Outcome Purchase of Snacks and Beverages in the United States. Int J Environ Res Public Health. 2020. 17:doi:10.3390/ijerph17207517.

207. Powell, LM. Fast food costs and adolescent body mass index: evidence from panel data. J Outcome Health Econ. 2009. 28:963-70. doi:10.1016/j.jhealeco.2009.06.009.

208. Powell, LM, Auld, MC, Chaloupka, FJ, O'Malley, PM, Johnston, LD. Access to fast food and Outcome food prices: relationship with fruit and vegetable consumption and overweight among adolescents. Adv Health Econ Health Serv Res. 2007. 17:23-48.

209. Powell, LM, Bao, Y. Food prices, access to food outlets and child weight. Econ Hum Biol. 2009. Outcome 7:64-72. doi:10.1016/i.ehb.2009.01.004.

210. Powell, LM, Han, E. The costs of food at home and away from home and consumption patterns Outcome among U.S. adolescents. J Adolesc Health. 2011. 48:20-6. doi:10.1016/j.jadohealth.2010.06.006.

211. Powell, LM, Han, E, Chaloupka, FJ. Economic Contextual Factors, Food Consumption, and Study Design Obesity among US Adolescents. Journal of Nutrition. 2010. 140:1175-1180. doi:10.3945/jn.109.111526

212. Powell, LM, Jones, K, Duran, AC, Tarlov, E, Zenk, SN. The price of ultra-processed foods and beverages and adult body weight: Evidence from U.S. veterans. Econ Hum Biol. 2019. 34:3948. doi:10.1016/j.ehb.2019.05.006.

213. Powell, LM, Kumanyika, SK, Isgor, Z, Rimkus, L, Zenk, SN, Chaloupka, FJ. Price promotions for Intervention/Exposure food and beverage products in a nationwide sample of food stores. Prev Med. 2016. 86:106-13. doi:10.1016/j.ypmed.2016.01.011.

214. Powell, LM, Wada, R, Krauss, RC, Wang, Y. Ethnic disparities in adolescent body mass index in Outcome the United States: the role of parental socioeconomic status and economic contextual factors. Soc Sci Med. 2012. 75:469-76. doi:10.1016/j.socscimed.2012.03.019.

215. Powell, LM, Zhao, Z, Wang, Y. Food prices and fruit and vegetable consumption among young Outcome American adults. Health Place. 2009. 15:1064-70. doi:10.1016/j.healthplace.2009.05.002.

216. Powell, LM, Slater, S, Mirtcheva, D, Bao, Y, Chaloupka, FJ. Food store availability and neighborhood characteristics in the United States. Preventive medicine. 2007. 44:189-195. 
217. Powell, LM Han, EEuna. Adult Obesity and the Price and Availability of Food in the United

Outcome

States. American Journal of Agricultural Economics. 2011. 93:378-384. doi:10.1093/ajae/aaq106.

218. Ramezani, CA, Rose, D, Murphy, S. AGGREGATION, FLEXIBLE FORMS, AND ESTIMATION OF FOOD-CONSUMPTION PARAMETERS. American Journal of Agricultural Economics. 1995. 77:525-532. doi:10.2307/1243221.

219. Raper, KC, Wanzala, M Namakhoye, Nayga, RM. Food expenditures and household demographic composition in the US: a demand systems approach. Applied Economics. 2002. 34:981-992. doi:10.1080/00036840110061959.

220. Reed, J, Frazão, E, Itskowitz, R. How much do Americans pay for fruits and vegetables? 2004. Intervention/Exposure

221. Rehm, CD, Monsivais, P, Drewnowski, A. The quality and monetary value of diets consumed by Outcome adults in the United States. Am J Clin Nutr. 2011. 94:1333-9. doi:10.3945/ajcn.111.015560.

222. Rose, CM, Gupta, S, Buszkiewicz, J, Ko, LK, Mou, J, Cook, A, Moudon, AV, Aggarwal, A, Drewnowski, A. Small increments in diet cost can improve compliance with the Dietary

Outcome Guidelines for Americans. Soc Sci Med. 2020. 266:113359. doi:10.1016/j.socscimed.2020.113359.

223. Rose, D. Access to healthy food: a key focus for research on domestic food insecurity. J Nutr. 2010. 140:1167-9. doi:10.3945/in.109.113183. 224. Rummo, PE, Meyer, KA, Green Howard, A, Shikany, JM, Guilkey, DK, Gordon-Larsen, P. Fast
food price, diet behavior, and cardiometabolic health: Differential associations by neighborhood SES and neighborhood fast food restaurant availability in the CARDIA study. Health Place. 2015. 35:128-35. doi:10.1016/j.healthplace.2015.06.010.

225. Sanjeevi, N, Freeland-Graves, JH. Association of Grocery Expenditure Relative to Thrifty Food Plan Cost with Diet Quality of Women Participating in the Supplemental Nutrition Assistance Program. J Acad Nutr Diet. 2018. 118:2315-2323. doi:10.1016/j.jand.2018.07.015.

226. Semega, J, Kollar, M, Creamer, J, Mohan, A. Income and Poverty in the United States: 2018. 2020. 88.

227. Shannon, J. Beyond the supermarket solution: Linking food deserts, neighborhood context, and Outcome everyday mobility. Annals of the American Association of Geographers. 2016. 106:186-202.

228. Shaver, ER, Sadler, RC, Hill, AB, Bell, K, Ray, M, Choy-Shin, J, Lerner, J, Soldner, T, Jones, $A D$. The Flint Food Store Survey: combining spatial analysis with a modified Nutrition

Environment Measures Survey in Stores (NEMS-S) to measure the community and consumer nutrition environments. Public Health Nutr. 2018. 21:1474-1485. doi:10.1017/s1368980017003950.

229. Shikany, JM, Carson, TL, Hardy, CM, Li, Y, Sterling, S, Hardy, S, Walker, CM, Baskin, ML. Assessment of the nutrition environment in rural counties in the Deep South. J Nutr Sci. 2018. 7:e27. doi:10.1017/jns.2018.18.

230. Singleton, CR, Fouché, S, Deshpande, R, Odoms-Young, A, Chatman, C, Spreen, C. Barriers to fruit and vegetable consumption among farmers' market incentive programme users in Illinois, USA. Public Health Nutr. 2018. 21:1345-1349. doi:10.1017/s1368980018000101.

\section{Study Design}

Outcome

Intervention/Exposure

\section{Outcome}

Outcome

Comparator 
231. Smith, C, Butterfass, J, Richards, R. Environment influences food access and resulting

Other factors

shopping and dietary behaviors among homeless Minnesotans living in food deserts. Agriculture and Human Values. 2010. 27:141-161. doi:10.1007/s10460-009-9191-z.

232. Smith, Travis A, Huang, Chung L, Lin, Biing-Hwan. Does price or income affect organic choice? Outcome Analysis of US fresh produce users. 2009.

233. Spoden, AL, Buszkiewicz, JH, Drewnowski, A, Long, MC, Otten, JJ. Seattle's minimum wage Intervention/Exposure ordinance did not affect supermarket food prices by food processing category. Public Health Nutr. 2018. 21:1762-1770. doi:10.1017/s1368980017004037.

234. Stallings, TL, Gazmararian, JA, Goodman, M, Kleinbaum, D. Agreement between the Perceived Intervention/Exposure and Actual Fruit and Vegetable Nutrition Environments among Low-Income Urban Women. J Health Care Poor Underserved. 2015. 26:1304-18. doi:10.1353/hpu.2015.0109.

235. Steenhuis, IH, Waterlander, WE, de Mul, A. Consumer food choices: the role of price and pricing strategies. Public Health Nutr. 2011. 14:2220-6. doi:10.1017/s1368980011001637.

236. Stegelin, F. Is Being Big Better? Shoppers Compare Food Merchandisers. 2016. 47:2. doi:10.22004/ag.econ.232317.

237. Steptoe, A, Pollard, TM, Wardle, J. Development of a measure of the motives underlying the Country selection of food: the food choice questionnaire. Appetite. 1995. 25:267-84. doi:10.1006/appe.1995.0061.

238. Stewart, $\mathrm{H}$, Blisard, N. Who pays more for food? Journal of Agricultural Economics. 2008. 59:150-168. doi:10.1111/j.1477-9552.2007.00139.x.

239. Stewart, H, Blisard, N. The Thrifty Food Plan and low-income households in the United States: What food groups are being neglected? Food Policy. 2006. 31:469-482. doi:10.1016/j.foodpol.2005.12.002.

240. Stewart, H, Hyman, J, Frazão, E, Buzby, JC, Carlson, A. Can low-income Americans afford to satisfy MyPyramid fruit and vegetable guidelines? J Nutr Educ Behav. 2011. 43:173-9. doi:10.1016/.j.jneb.2010.08.011.

241. Sturm, R, Datar, A. Regional price differences and food consumption frequency among elementary school children. Public Health. 2011. 125:136-41. doi:10.1016/j.puhe.2010.11.016.

242. Sturm, R, Datar, A. Body mass index in elementary school children, metropolitan area food prices and food outlet density. Public Health. 2005. 119:1059-68. doi:10.1016/j.puhe.2005.05.007.

243. Sullivan, CM, Pencak, JA, Freedman, DA, Huml, AM, León, JB, Nemcek, J, Theurer, J, Sehgal, AR. Comparison of the Availability and Cost of Foods Compatible With a Renal Diet Versus an Unrestricted Diet Using the Nutrition Environment Measures Survey. J Ren Nutr. 2017. 27:183186. doi:10.1053/j.jrn.2016.12.008.

244. Tach, L, Amorim, M. Constrained, Convenient, and Symbolic Consumption: Neighborhood Food Intervention/Exposure Environments and Economic Coping Strategies among the Urban Poor. J Urban Health. 2015. 92:815-34. doi:10.1007/s11524-015-9984-X.

245. Taylor, R, Villas-Boas, SB. FOOD STORE CHOICES OF POOR HOUSEHOLDS: A DISCRETE Outcome CHOICE ANALYSIS OF THE NATIONAL HOUSEHOLD FOOD ACQUISITION AND 
PURCHASE SURVEY (FOODAPS). American Journal of Agricultural Economics. 2016. 98:513-

532. doi:10.1093/ajae/aaw009.

246. Townsend, MS, Aaron, GJ, Monsivais, P, Keim, NL, Drewnowski, A. Less-energy-dense diets of Intervention/Exposure low-income women in California are associated with higher energy-adjusted diet costs. Am J Clin Nutr. 2009. 89:1220-6. doi:10.3945/ajcn.2008.26916.

247. Trapl, ES, Pike, SN, Borawski, E, Flocke, SA, Freedman, DA, Walsh, CC, Schneider, C, Yoder, Comparator L. Food Melt in Consumer Food Environments in Low-income Urban Neighborhoods. Am J Health Behav. 2017. 41:710-718. doi:10.5993/ajhb.41.6.5.

248. Treno, AJ, Gruenewald, PJ, Wood, DS, Ponicki, WR. The price of alcohol: a consideration of Outcome contextual factors. Alcohol Clin Exp Res. 2006. 30:1734-42. doi:10.1111/j.15300277.2006.00207.x.

249. Tschirley, DL, Rose, D. Developing Cost Effective Methods for Estimating Household Income Country and Nutrient Intake Adequacy. 2000. 6. doi:10.22004/ag.econ.11330.

250. Valera, P, Gallin, J, Schuk, D, Davis, N. "Trying to Eat Healthy" A Photovoice Study About Women's Access to Healthy Food in New York City. Affilia. 2009. 24:300-314.

251. Valluri, S, French, SA, Elbel, B, Oakes, JM, Rydell, SA, Harnack, LJ. Within- and BetweenHousehold Variation in Food Expenditures Among Low-Income Households Using a Novel Simple Annotated Receipt Method. Front Nutr. 2020. 7:582999. doi:10.3389/fnut.2020.582999.

252. Ver Ploeg, M, Rahko vs.ky, I. Recent Evidence on the Effects of Food Store Access on Food Outcome Choice and Diet Quality. 2016. 1. doi:10.22004/ag.econ.244274.

253. Vogel, C, Ntani, G, Inskip, H, Barker, M, Cummins, S, Cooper, C, Moon, G, Baird, J. Education Country and the Relationship Between Supermarket Environment and Diet. Am J Prev Med. 2016. 51:e27-e34. doi:10.1016/j.amepre.2016.02.030.

254. Volpe, R. WIC Foods Cost More in Smaller Stores. 2014. 1. doi:10.22004/ag.econ.210848. Intervention/Exposure

255. Wada, R, Han, EN, Powell, LM. Associations between soda prices and intake: Evidence from Outcome 24-h dietary recall data. Food Policy. 2015. 55:54-60. doi:10.1016/j.foodpol.2015.05.009.

256. Walker, RE, Fryer, CS, Butler, J, Keane, CR, Kriska, A, Burke, JG. Factors influencing food

Comparator buying practices in residents of a low-income food desert and a low-income food oasis. Journal of Mixed Methods Research. 2011. 5:247-267.

257. Walker, TA, Lee, JS. Changes in key food purchasing practices of Supplemental Nutrition Comparator Assistance Program (SNAP)-eligible older adults following SNAP benefit receipt. Transl Behav Med. 2020. 10:1286-1296. doi:10.1093/tbm/ibaa029.

258. Waterlander, WE, de Haas, WE, van Amstel, I, Schuit, AJ, Twisk, JWR, Visser, M, Seidell, JC, Steenhuis, IHM. Energy density, energy costs and income-how are they related? Public health nutrition. 2010. 13:1599-1608.

259. Weatherspoon, D, Oehmke, J, Dembélé, A, Coleman, M, Satimanon, T, Weatherspoon, L. Price Intervention/Exposure and Expenditure Elasticities for Fresh Fruits in an Urban Food Desert. Urban Studies (Sage Publications, Ltd.). 2013. 50:88-106. doi:10.1177/0042098012448555. 
260. Webber, CB, Sobal, J, Dollahite, JS. Shopping for fruits and vegetables. Food and retail qualities of importance to low-income households at the grocery store. Appetite. 2010. 54:297303. doi:10.1016/j.appet.2009.11.015.

261. Weber, JA. Increasing food costs for consumers and food programs straining pocketbooks. Am Diet Assoc. 2008. 108:615-7. doi:10.1016/j.jada.2008.02.010.

262. Wiig, K, Smith, C. The art of grocery shopping on a food stamp budget: factors influencing the food choices of low-income women as they try to make ends meet. Public Health Nutr. 2009. 12:1726-34. doi:10.1017/s1368980008004102.

263. Wilde, PE, Andrews, MS. The Food Stamp Program in an Era of Welfare Reform: Electronic Benefits and Changing Sources of Cash Income. Journal of Consumer Affairs. 2000. 34:31. doi:10.1111/j.1745-6606.2000.tb00082.x.

264. Winham, DM, Knoblauch, ST, Heer, MM, Thompson, SV, Der Ananian, C. African-American Views of Food Choices and Use of Traditional Foods. Am J Health Behav. 2020. 44:848-863. doi:10.5993/ajhb.44.6.9.

265. Winicki, J, Gundersen, C, Jolliffe, D. ISSUES IN FOOD ASSISTANCE - HOW DO FOOD ASSISTANCE PROGRAMS IMPROVE THE WELL-BEING OF LOW-INCOME FAMILIES? 2002. 4. doi:10.22004/ag.econ.262255.

266. Yen, ST, Lin, B-H, Smallwood, DM, Andrews, M. Demand for Nonalcoholic Beverages: The Case of Low-Income Households. Agribusiness. 2004. 20:309-321. doi:10.1002/agr.20015.

267. Young, CM, Batch, BC, Svetkey, LP. Effect of socioeconomic status on food availability and cost of the Dietary Approaches to Stop Hypertension (DASH) dietary pattern. J Clin Hypertens (Greenwich). 2008. 10:603-11. doi:10.1111/j.1751-7176.2008.08199.x.

268. Zeballos, E, Sinclair, W. Average Share of Income Spent on Food in the United States Remained Relatively Steady From 2000 to 2019. 2020. 2020:doi:10.22004/ag.econ.307278.

269. Zenk, SN, Schulz, AJ, Israel, BA, James, SA, Bao, S, Wilson, ML. Fruit and vegetable access differs by community racial composition and socioeconomic position in Detroit, Michigan. Ethn Dis. 2006. 16:275-280.

270. Zenk, SN, Schulz, AJ, Lachance, LL, Mentz, G, Kannan, S, Ridella, W, Galea, S. Multilevel correlates of satisfaction with neighborhood availability of fresh fruits and vegetables. Ann Behav Med. 2009. 38:48-59. doi:10.1007/s12160-009-9106-7.

271. Zhang, G, You, W, Carlson, A, Lin, B-H. The Impact of Regional Food Cost Differences on the Comparator TFP Recommendations. 2010. 2. doi:10.22004/ag.econ.61643.

272. Zhang, Q, Chen, Z, Diawara, N, Wang, Y. Prices of unhealthy foods, Food Stamp Program participation, and body weight status among U.S. low-income women. J Fam Econ Issues. 2011. 32:245-256. doi:10.1007/s10834-010-9228-x.

273. Zhang, Q, Jones, S, Ruhm, CJ, Andrews, M. Higher food prices may threaten food security status among American low-income households with children. J Nutr. 2013. 143:1659-65. doi:10.3945/jn.112.170506.

Comparator

\section{Comparator}

Study Design

Outcome

Outcome

Outcome

Outcome

\section{Outcome}

Intervention/Exposure

Intervention/Exposure

Outcome

Comparator

Outcome 


\section{USDA United States \\ Department of \\ Agriculture}

274.
Zhao, AW, McGowan, CC, Zenk, SN, Kershaw, KN. Associations of the consumer food environment with eating behaviours and BMI. Public Health Nutr. 2020. 23:3197-3203. doi:10.1017/s1368980020002633.
USDA Food Plans Rapid Reviews and Evidence Scans

Intervention/Exposure 


\section{Appendix 2-a: Literature search strategy for the rapid review on income and $\mathrm{HEl}$}

Database: PubMed

Vendor: National Library of Medicine

Date of Search: 5/11/2021

Limits Used: Filters: Language English Publication Dates 2008 - 2021

Total $=4,718$

\begin{tabular}{|c|c|c|c|}
\hline Search \# & Concept & Search String & $\mathbf{N}$ \\
\hline$\# 1$ & Income & 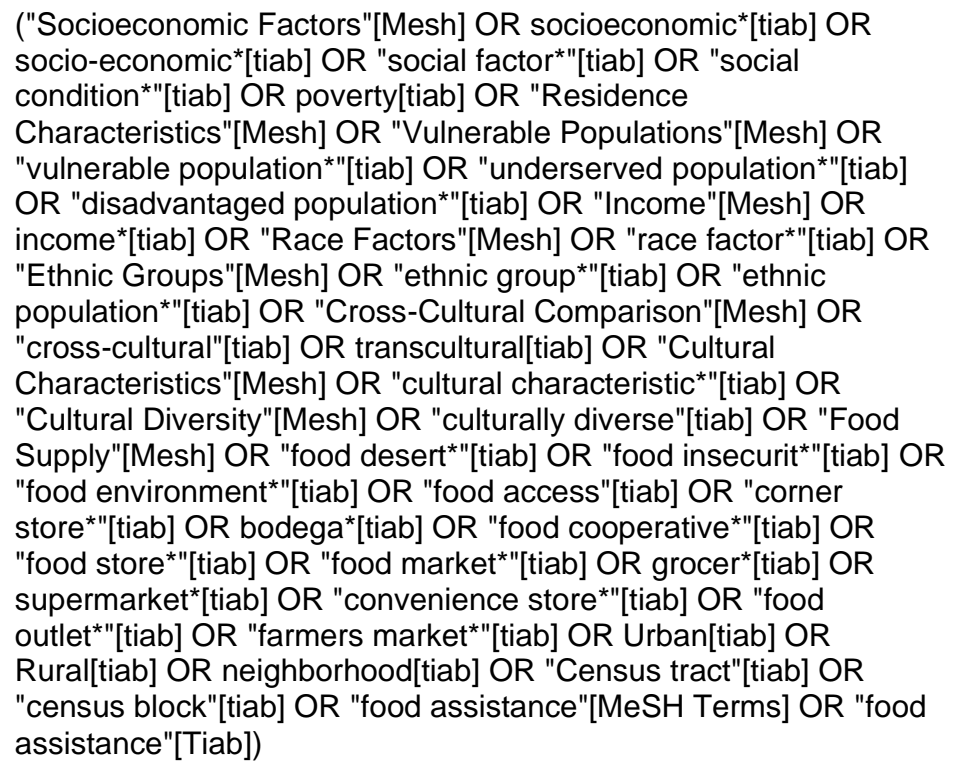 & $1,087,878$ \\
\hline \#2 & Dietary Patterns & 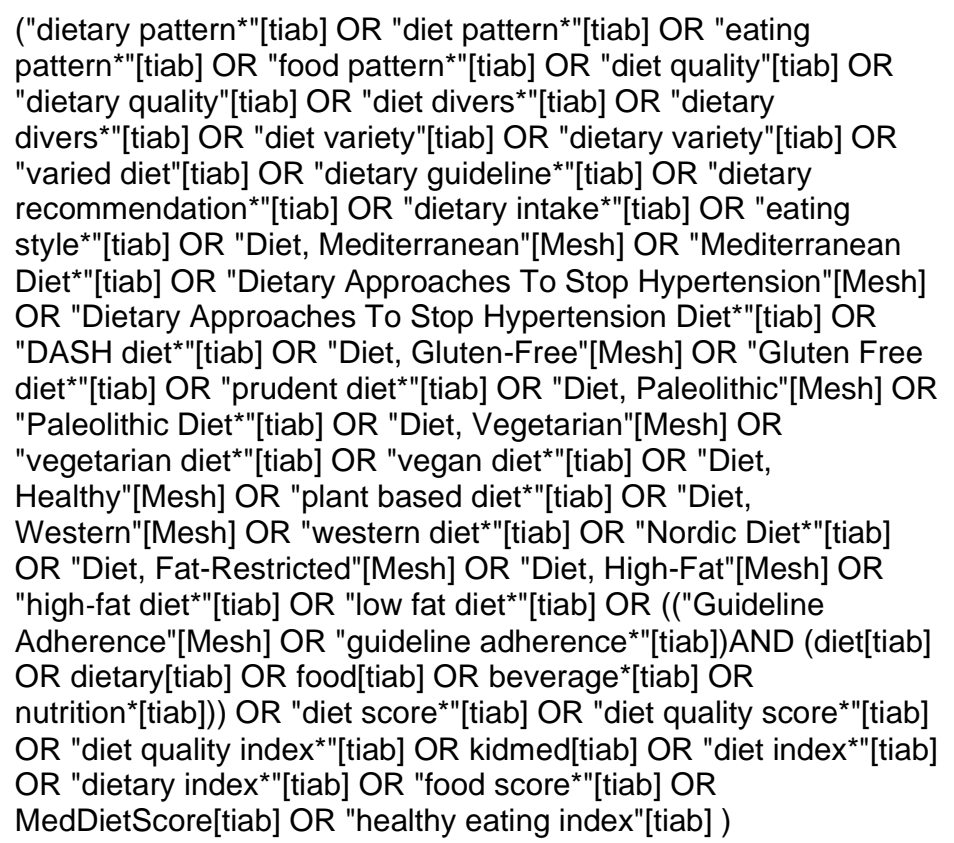 & 113,841 \\
\hline
\end{tabular}




\begin{tabular}{|c|c|c|c|}
\hline \#4 & $\begin{array}{l}\text { Publication, } \\
\text { Geography, and } \\
\text { species excludes }\end{array}$ & $\begin{array}{l}\text { \#1 AND \#2 NOT } \\
\text { (letter[ptyp] OR editorial[ptyp] OR comment[ptyp] OR news[ptyp] } \\
\text { OR "Congress"[Publication Type] OR "Consensus Development } \\
\text { Conference"[Publication Type] OR editorial[tiab] OR } \\
\text { commentary[tiab] OR "conference abstract*"[tiab] OR "systematic } \\
\text { review*"[ti] OR "meta-analysis"[ptyp] OR "meta-analysis"[ti] OR } \\
\text { "meta-analyses"[ti] OR "Review"[Publication Type] OR "Systematic } \\
\text { Review"[Publication Type] OR "conference proceeding*"[tiab] OR } \\
\text { "retracted publication"[ptyp] OR "retraction of publication"[ptyp] OR } \\
\text { "retraction of publication"[tiab] OR "retraction notice"[ti] OR } \\
\text { "retracted publication"[tiab] OR "Published Erratum"[Publication } \\
\text { Type] OR corrigenda[tiab] OR corrigendum[tiab] OR errata[tiab] } \\
\text { OR erratum[tiab] OR protocol[ti] OR protocols[ti] OR "case } \\
\text { report"[ti] OR "case series"[ti] OR "Case Reports"[Publication } \\
\text { Type]) } \\
\text { NOT } \\
\text { ("Developing Countries"[Mesh] OR "developing countr*" OR "Under } \\
\text { Developed Nation*" OR "low income countr" OR "middle income } \\
\text { countr*"OR "low-middle-income countr*" OR LMIC[tiab] OR } \\
\text { "Europe"[Mesh] OR "Australia"[Mesh] OR "Asia"[Mesh] OR } \\
\text { "Africa"[Mesh] OR "Mexico"[Mesh] OR "Islands"[Mesh] OR "Central } \\
\text { America"[Mesh] OR "Latin America"[Mesh] OR "South } \\
\text { America"[Mesh]) } \\
\text { NOT } \\
\text { ("Animals"[Mesh] NOT } \\
\text { ("Animals"[Mesh] AND "Humans"[Mesh]) } \\
\text { ) }\end{array}$ & 6,174 \\
\hline \#6 & Filters & Filters: Language: English; Publication Dates: 2008-2021 & 4,718 \\
\hline
\end{tabular}

Database: Business Source Premier

Vendor: EBSCO

Date of Search: 5/11/2021

Limits Used: Scholarly (Peer Reviewed) Journals; Published Date: 20080101-20211231; Document Type: Article; Language: English

Total $=1,044$

\begin{tabular}{|c|c|c|c|}
\hline Search \# & Concept & Search String & $\mathbf{N}$ \\
\hline \#1 & Income & $\begin{array}{l}\text { (DE "SOCIOECONOMIC factors") OR socioeconomic* OR socio- } \\
\text { economic* OR "social factor*" OR "social condition*" OR (DE } \\
\text { "POVERTY") OR poverty OR "vulnerable population*" OR } \\
\text { "underserved population*" OR "disadvantaged population*" OR } \\
\text { (DE "INCOME") OR income* OR "race factor*" OR (DE } \\
\text { "ECONOMIC conditions of ethnic groups") OR "ethnic group*” OR } \\
\text { "ethnic population" OR "cross-cultural" OR transcultural OR } \\
\text { "cultural characteristic*" OR "culturally diverse" OR (DE "FOOD } \\
\text { supply") OR "food desert*" OR "food insecurit*" OR "food } \\
\text { environment*" OR "food access" OR "corner store*" OR bodega* } \\
\text { OR DE "FOOD cooperatives" OR "food cooperative*" OR "food } \\
\text { store*" OR "food market*" OR (DE "GROCERY shopping") OR } \\
\text { (DE "GROCERY industry") OR grocer* OR (DE } \\
\text { "SUPERMARKETS") OR supermarket* OR (DE "CONVENIENCE }\end{array}$ & $1,403,085$ \\
\hline
\end{tabular}




\begin{tabular}{|c|c|c|c|}
\hline & & $\begin{array}{l}\text { stores") OR "convenience store*" OR "food outlet" OR (DE } \\
\text { "FARMERS' markets") OR "farmers market*"OR (DE } \\
\text { "METROPOLITAN areas") OR Urban OR Rural OR neighborhood } \\
\text { OR "Census tract" OR "census block" OR "food assistance" }\end{array}$ & \\
\hline \#2 & Dietary Patterns & 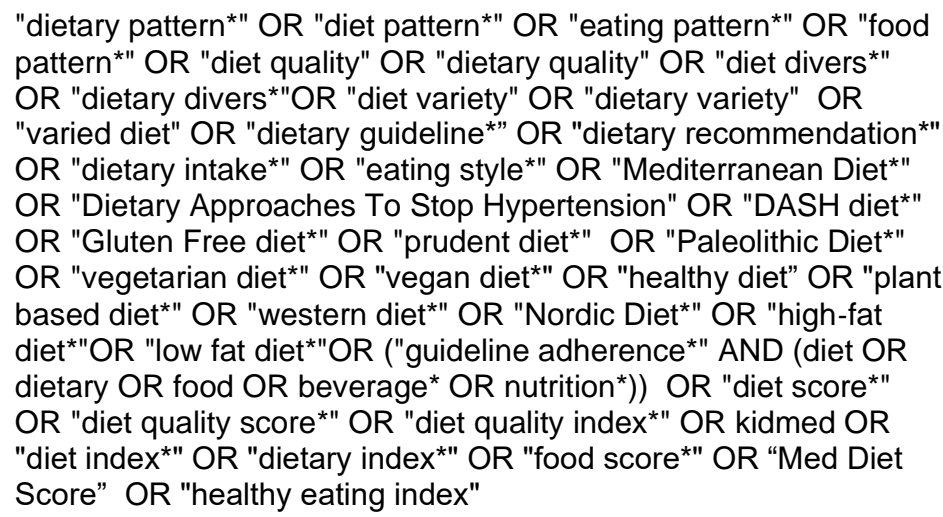 & 13,149 \\
\hline \#3 & \#1 AND \#2 & & 3,225 \\
\hline$\# 4$ & Filters & $\begin{array}{l}\text { Limiters - Scholarly (Peer Reviewed) Journals; Published Date: } \\
\text { 20080101-20211231; Document Type: Article; Language: English }\end{array}$ & 1,044 \\
\hline
\end{tabular}

Database: Web of Science: Core Collection

Vendor: Clarivate Analytics

Date of Search: 5/11/2021

Limits Used: Years: 2008-2021; Publication Types: Articles, Early Access; Language: English

Total $=7,300$

\begin{tabular}{|c|c|c|c|}
\hline Search \# & Concept & Search String & $\mathbf{N}$ \\
\hline$\# 1$ & Income & $\begin{array}{l}\text { TS=(socioeconomic* OR socio-economic* OR "social factor"” OR } \\
\text { "social condition*" OR poverty OR "residence characteristics" OR } \\
\text { "vulnerable population*" OR "underserved population*" OR } \\
\text { "disadvantaged population*" OR income* OR "race factor" OR } \\
\text { "ethnic group*" OR "ethnic population*" OR "cross-cultural" OR } \\
\text { transcultural OR "cultural characteristic*" OR "culturally diverse" } \\
\text { OR "food desert" OR "food insecurit*" OR "food environment*" OR } \\
\text { "food access" OR "corner store*" OR bodega* OR "food } \\
\text { cooperative*" OR "food store*" OR "food market*" OR grocer* OR } \\
\text { supermarket* OR "convenience store*" OR "food outlet*" OR } \\
\text { "farmers market*" OR Urban OR Rural OR neighborhood OR } \\
\text { "Census tract" OR "census block" OR "food assistance") }\end{array}$ & $1,036,318$ \\
\hline \#2 & Dietary Patterns & 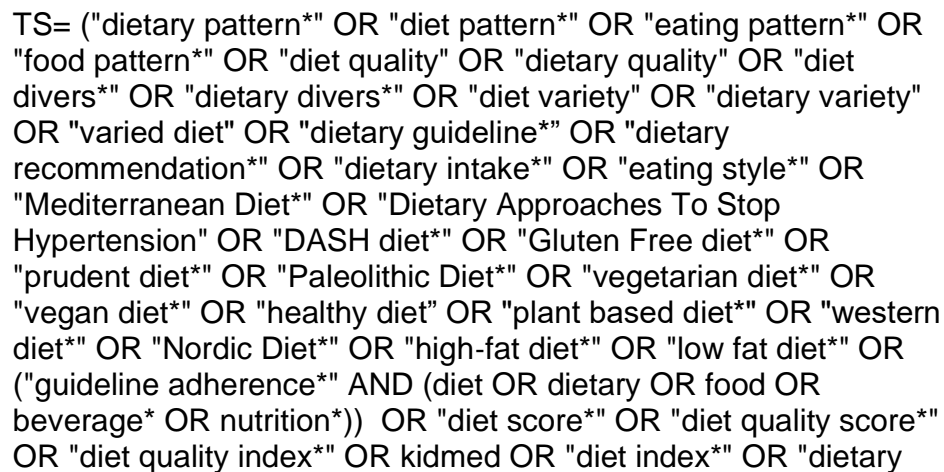 & 122,259 \\
\hline
\end{tabular}




\begin{tabular}{|c|c|c|c|}
\hline & & $\begin{array}{l}\text { index*" OR "food score*" OR "Med Diet Score" OR "healthy eating } \\
\text { index") }\end{array}$ & \\
\hline \#3 & \#1 AND \#2 & & 11,878 \\
\hline \#4 & $\begin{array}{l}\text { Non-United States } \\
\text { Excludes }\end{array}$ & $\begin{array}{l}\text { CU=("developing countr*" OR "under developed nation*" OR "low i } \\
\text { ncome countr*" OR "middle income countr*" OR "low-middle } \\
\text { income countr*" OR LMIC } \\
\text { OR Europe OR Australia OR Asia OR Africa OR Mexico OR Island } \\
\text { s OR "Central America" OR "Latin America" OR "South America") }\end{array}$ & $2,040,699$ \\
\hline \#5 & \#3 NOT \#4 & & 10,403 \\
\hline \#6 & $\begin{array}{l}\text { Publication } \\
\text { Excludes }\end{array}$ & $\begin{array}{l}\text { TS=(editorial OR commentary OR "conference abstract*" OR "conf } \\
\text { erence proceeding""[tiab] OR "retraction of publication" OR "retract } \\
\text { ed publication" OR corrigenda[tiab] OR corrigendum[tiab] OR errat } \\
\text { a OR erratum OR "case reports" ) OR TI=("systematic review"” OR } \\
\text { "meta-analysis" } \\
\text { OR "meta analyses" OR protocol OR protocols } \\
\text { OR "retraction notice" OR "case report" OR } \\
\text { "case series") }\end{array}$ & 710,063 \\
\hline$\# 7$ & \#5 NOT \#6 & & 10,151 \\
\hline \#8 & & $\begin{array}{l}\text { Years: 2008-2021; Publication Types: Articles, Early Access; } \\
\text { Language: English }\end{array}$ & 7,300 \\
\hline
\end{tabular}

\section{Grey Literature Search}

\section{Google Scholar}

Google Scholar's search has a character limit of 256. To accommodate all of the unique terms in this search strategy, the search has been split and run as three searches.

\section{Search A}

(Income OR resources OR poverty OR socioeconomic OR urban OR neighborhood) AND ("dietary pattern" OR "food pattern" OR "diet quality" OR "dietary diversity" OR "diet variety" OR "dietary guideline" OR "dietary recommendation" OR "dietary intake" OR "eating style")

Limits: Date Published: 2008-2021;

Date Searched: $5 / 17 / 2021$

Results: 80 , limited to 8 pages

\section{Search B}

(Income OR resources OR poverty OR socioeconomic OR urban OR neighborhood)AND ("Mediterranean Diet" OR "Dietary Approaches To Stop Hypertension" OR "DASH diet" OR "western diet" OR "Nordic diet")

Limits: Date Published: 2008-2021;

Date Searched: 5/17/2021

Results: 20, limited to 2 pages

\section{Search C}

(Income OR resources OR poverty OR socioeconomic OR urban OR neighborhood) AND ("Gluten Free diet" OR "prudent diet" OR "Paleolithic Diet" OR "vegetarian diet" OR "vegan diet" OR "healthy diet" OR "plant based diet")

Limits: Date Published: 2008-2021;

Date Searched: 5/17/2021

Results: 20 , limited to 2 pages

Total: 120 


\section{Google}

Google limits queries to 32 words (from Google notification, 5/17/21). To accommodate all of the unique terms in this search strategy, the search has been split and run as three searches.

\section{Search A}

site:.gov AND (Income OR resources OR poverty OR socioeconomic OR urban OR neighborhood) AND ("dietary pattern" OR "food pattern" OR "diet quality" OR "dietary diversity" OR "diet variety" OR "dietary guideline" OR "dietary recommendation" OR "dietary intake" OR "eating style")

Limits: Similar results omitted

Date Searched: 5/17/2021

Results: 12

\section{Search B}

site:.gov AND (Income OR resources OR poverty OR socioeconomic OR urban OR neighborhood) AND ("Mediterranean Diet" OR "Dietary Approaches To Stop Hypertension" OR "DASH diet" OR "western diet" OR "Nordic diet")

Limits: Similar results omitted

Date Searched: $5 / 17 / 2021$

Results: 10, limited to 1 page

\section{Search C}

site:.gov AND (Income OR resources OR poverty OR socioeconomic OR urban OR neighborhood) AND ("Gluten Free diet" OR "prudent diet" OR "Paleolithic Diet" OR "vegetarian diet" OR "vegan diet" OR "healthy diet" OR "plant based diet")

Limits: Similar results omitted

Date Searched: 5/17/2021

Results: 20 , limited to 2 pages

Total: 42

\section{AgEcon}

Any of the words: Income resources poverty socioeconomic urban neighborhood AND

Any of the words: "dietary pattern" "food pattern" "diet quality" "dietary diversity" "diet variety" "dietary guideline" "dietary recommendation" "dietary intake" "eating style" "Mediterranean Diet" "Dietary Approaches To Stop Hypertension" "DASH diet" "western diet" "Nordic diet" OR "Gluten Free diet" "prudent diet" "Paleolithic Diet" "vegetarian diet" "vegan diet" "healthy diet" "plant based diet"

Limits: added since 2008

Date Searched: $5 / 17 / 2021$

Results: 50 , results are limited to 5 pages

Results after Deduplication:

- $\quad$ Google Scholar: 120

- $\quad$ Google: 40

- AgEcon: 59 


\section{Appendix 2-b: Excluded articles for the rapid review on income and $\mathrm{HEl}$}

The following table lists the articles excluded after full-text screening for this rapid review question. At least 1 reason for exclusion is provided for each article, though this may not reflect all possible reasons. Information about articles excluded after title and abstract screening is available upon request.

\# Citation

\begin{tabular}{ll}
\hline 1 & . Access to Foods that Support Healthy Eating Patterns | Healthy People 2020. 2021. \\
\hline 2 & . Appendix E-2.37 | health.gov. 2021. \\
\hline 3 & . Eating Vegetarian | Nutrition.gov. 2021. \\
\hline 4 & . Food Pattern Modeling | Dietary Guidelines for Americans. 2021. \\
\hline 5 & $\begin{array}{l}\text {. Multicultural Healthy Diet to Reduce Cognitive Decline \& Alzheimer's Disease Risk | National } \\
\text { Institute on Aging. 2021. }\end{array}$
\end{tabular}

6

7

8

. Vegetarian Diet. 2021.$$
1
$$

10 . Vegetarian Nutrition | Food and Nutrition Information Center | NAL | USDA. 2021.

11 Aggarwal, A.,Drewnowski, A.. Plant- and animal-protein diets in relation to sociodemographic drivers, quality, and cost: findings from the Seattle Obesity Study. Am J Clin Nutr. 2019. 110:451-460

12 Aggarwal, A.,Monsivais, P.,Cook, A. J.,Drewnowski, A.. Does diet cost mediate the relation between socioeconomic position and diet quality?. Eur J Clin Nutr. 2011. 65:1059-66

13 Alexis, T. D.,Unruh, D.,Wang, W.,Dave, J. M.,Miketinas, D. C.,Chen, T. A.,Moore, C. E.. Implementation of a food scholarship program improves nutrient intake and dietary quality of college students. J Am Coll Health. 2020. :1-8

14 Anderson, S. E., Kaye, G.,Andridge, R.,Smathers, C.,Peng, J.,Pirie, P.. Interrelationships of More Healthful and Less Healthful Aspects of Diet Quality in a Low-Income Community Sample of Preschool-Aged Children. Matern Child Health J. 2015. 19:2663-72

15 Anderson, S. E.,Ramsden, M.,Kaye, G.. Diet qualities: healthy and unhealthy aspects of diet quality in preschool children. Am J Clin Nutr. 2016. 103:1507-13

16 Andreyeva, T.,Tripp, A. S.. The healthfulness of food and beverage purchases after the federal food package revisions: The case of two New England states. Prev Med. 2016. 91:204-210

17 Appelhans, B. M.,French, S. A.,Tangney, C. C.,Powell, L. M.,Wang, Y.. To what extent do food purchases reflect shoppers' diet quality and nutrient intake?. Int J Behav Nutr Phys Act. 2017; $14(1): 46$.

18 Arimond, Mary ,Wiesmann, Doris,Becquey, Elodie ,Carriquiry, Alicia ,Daniels, Melissa ,Deitchler, Megan ,Fanou, Nadia,Ferguson, Elaine ,Joseph, Maria ,Kennedy, Gina ,MartinPrével, Yves ,Elin Torheim, Liv . Dietary Diversity as a Measure of the Micronutrient Adequacy of Women's Diets in Resource-Poor Areas: Summary of Results from Five Sites. 2011.

19 Auchincloss, A. H.,Riolo, R. L.,Brown, D. G.,Cook, J.,Diez Roux, A. V.. An agent-based model of income inequalities in diet in the context of residential segregation. Am J Prev Med. 2011. 40:303-11
Exclusion rationale

Study design

Study design

Study design

Study design;

Publication

Status

Study design;

Publication

Status

Study design

Study design

Study design

Intervention/

Exposure;

Study design

Study design

Intervention/

Exposure

Outcome

Intervention/

Exposure

Intervention/

Exposure

Data date

range

Outcome

Outcome

Country

Outcome 
Exclusion rationale

20 Baraldi, L. G.,Martinez Steele, E.,Canella, D. S.,Monteiro, C. A.. Consumption of ultraprocessed foods and associated sociodemographic factors in the USA between 2007 and 2012: evidence from a nationally representative cross-sectional study. BMJ Open. 2018. 8:e020574

21 Basu, S., Gardner, C. D.,White, J. S.,Rigdon, J.,Carroll, M. M.,Akers, M.,Seligman, H. K.. Effects Of Alternative Food Voucher Delivery Strategies On Nutrition Among Low-Income Adults. Health Aff (Millwood). 2019. 38:577-584

22 Bauer, K. W.,Widome, R.,Himes, J. H.,Smyth, M.,Rock, B. H.,Hannan, P. J.,Story, M.. High food insecurity and its correlates among families living on a rural American Indian Reservation. Am J Public Health. 2012. 102:1346-52

23 Beasley, J. M.,Sevick, M. A.,Kirshner, L.,Mangold, M.,Chodosh, J.. Congregate Meals: Opportunities to Help Vulnerable Older Adults Achieve Diet and Physical Activity Recommendations. J Frailty Aging. 2018. 7:182-186

24 Bedrick, B. S.,Eskew, A. M.,Chavarro, J. E.,Jungheim, E. S.. Dietary Patterns, Physical Activity, and Socioeconomic Associations in a Midwestern Cohort of Healthy Reproductive-Age Women. Matern Child Health J. 2020. 24:1299-1307

25 Bergmans, R. S.,Palta, M.,Robert, S. A.,Berger, L. M.,Ehrenthal, D. B.,Malecki, K. M.. Associations between Food Security Status and Dietary Inflammatory Potential within LowerIncome Adults from the United States National Health and Nutrition Examination Survey, Cycles 2007 to 2014. Journal of the Academy of Nutrition and Dietetics. 2018. 118:994-1005 Bernstein, A. M.,Bloom, D. E.,Rosner, B. A.,Franz, M.,Willett, W. C.. Relation of food cost to healthfulness of diet among US women. American Journal of Clinical Nutrition. 2010. 92:11971203

27 Beydoun, M. A.,Wang, Y.. Do nutrition knowledge and beliefs modify the association of socioeconomic factors and diet quality among US adults?. Prev Med. 2008. 46:145-53

28 Beydoun, M. A.,Wang, Y.. How do socio-economic status, perceived economic barriers and nutritional benefits affect quality of dietary intake among US adults?. Eur J Clin Nutr. 2008. 62:303-13

29 Bishop, N. J.,Zuniga, K. E.,Ramirez, C. M.. Latent profile analysis of dietary intake in a community-dwelling sample of older Americans. Public Health Nutr. 2020. 23:243-253

30 Blake, C. E.,Wethington, E.,Farrell, T. J.,Bisogni, C. A.,Devine, C. M.. Behavioral contexts, food-choice coping strategies, and dietary quality of a multiethnic sample of employed parents. J Am Diet Assoc. 2011. 111:401-7

31 Bleiweiss-Sande, R.,Sacheck, J. M.,Chui, K.,Goldberg, J. P.,Bailey, C.,Evans, E. W.. Processed food consumption is associated with diet quality, but not weight status, in a sample of low-income and ethnically diverse elementary school children. Appetite. 2020. 151:104696

32 Bodnar, L. M.,Simhan, H. N.,Parker, C. B.,Meier, H.,Mercer, B. M., Grobman, W. A.,Haas, D. M.,Wing, D. A.,Hoffman, M. K.,Parry, S.,Silver, R. M.,Saade, G. R.,Wapner, R.,lams, J. D.,Wadhwa, P. D.,Elovitz, M.,Peaceman, A. M.,Esplin, S.,Barnes, S.,Reddy, U. M.. Racial or Ethnic and Socioeconomic Inequalities in Adherence to National Dietary Guidance in a Large Cohort of US Pregnant Women. J Acad Nutr Diet. 2017. 117:867-877.e3

33 Boehm, R.,Ver Ploeg, M.,Wilde, P. E.,Cash, S. B.. Greenhouse gas emissions, total food spending and diet quality by share of household food spending on red meat: results from a nationally representative sample of US households. Public Health Nutr. 2019. 22:1794-1806

34 Boone-Heinonen, J.,Gordon-Larsen, P.,Kiefe, C. I.,Shikany, J. M.,Lewis, C. E.,Popkin, B. M.. Fast food restaurants and food stores: longitudinal associations with diet in young to middleaged adults: the CARDIA study. Arch Intern Med. 2011. 171:1162-70

35 Bottino, C. J.,Fleegler, E. W.,Cox, J. E., Rhodes, E. T.. The Relationship Between Housing Instability and Poor Diet Quality Among Urban Families. Acad Pediatr. 2019. 19:891-898

Intervention/

Exposure

Intervention/

Exposure

Intervention/

Exposure

Data date

range

Data date

range

Data date

range

Outcome

Intervention

Exposure;

Data date

range

Comparator

Boutté, A. K.,Turner-McGrievy, G. M.,Eberth, J. M.,Wilcox, S.,Liu, J.,Kaczynski, A. T.. Healthy

Food Density is Not Associated With Diet Quality Among Pregnant Women With

Overweight/Obesity in South Carolina. J Nutr Educ Behav. 2021. 53:120-129

$\begin{aligned} & \text { Intervention/ } \\ & \text { Exposure }\end{aligned}$
$\begin{aligned} & \text { Data date } \\ & \text { range }\end{aligned}$
$\begin{aligned} & \text { Intervention/ } \\ & \text { Exposure }\end{aligned}$
$\begin{aligned} & \text { Intervention/ } \\ & \text { Exposure }\end{aligned}$


Exclusion rationale

37 Boynton, A.,Neuhouser, M. L.,Sorensen, B.,McTiernan, A.,Ulrich, C. M.. Predictors of diet quality among overweight and obese postmenopausal women. J Am Diet Assoc. 2008. 108:125-30

38 Brantley, K. D.,Hartman, T. J.,Patel, A. V.,Gapstur, S. M.,Flanders, W. D.,McCullough, M. L.. Test-Retest Reproducibility of Adult-Reported High School Diet Varies among Racially and Ethnically Diverse US Men and Women. J Nutr. 2018. 148:599-606

39 Brewster, P. J.,Durward, C. M.,Hurdle, J. F.,Stoddard, G. J.,Guenther, P. M.. The Grocery Purchase Quality Index-2016 Performs Similarly to the Healthy Eating Index-2015 in a National Survey of Household Food Purchases. J Acad Nutr Diet. 2019. 119:45-56

$40 \quad$ Bruening, M.,McClain, D.,Moramarco, M.,Reifsnider, E.. The Role of SNAP in Home Food Availability and Dietary Intake among WIC Participants Facing Unstable Housing. Public Health Nurs. 2017. 34:219-228

$41 \quad$ Bruening, M.,van Woerden, I.,Todd, M.,Laska, M. N.. Hungry to learn: the prevalence and effects of food insecurity on health behaviors and outcomes over time among a diverse sample of university freshmen. Int J Behav Nutr Phys Act. 2018. 15:9

42 Camacho-Rivera, M.,Rosenbaum, E., Yama, C., Chambers, E.. Low-Income Housing Rental Assistance, Perceptions of Neighborhood Food Environment, and Dietary Patterns among Latino Adults: the AHOME Study. J Racial Ethn Health Disparities. 2017. 4:346-353

43 Campbell, S.,Chen, J. J.,Boushey, C. J.,Eicher-Miller, H.,Zhu, F. Q.,Fialkowski, M. K.. Food Security and Diet Quality in Native Hawaiian, Pacific Islander, and Filipino Infants 3 to 12 Months of Age. Nutrients. 2020. 12:18

44 Cantor, J.,Beckman, R.,Collins, R. L.,Dastidar, M. G.,Richardson, A. S.,Dubowitz, T.. SNAP Participants Improved Food Security And Diet After A Full-Service Supermarket Opened In An Urban Food Desert. Health Aff (Millwood). 2020. 39:1386-1394

45 Caspi, C. E.,Lenk, K.,Pelletier, J. E.,Barnes, T. L.,Harnack, L.,Erickson, D. J.,Laska, M. N.. Association between store food environment and customer purchases in small grocery stores, gas-marts, pharmacies and dollar stores. Int J Behav Nutr Phys Act. 2017. 14:76

46 Caspi, C. E.,Lenk, K.,Pelletier, J. E.,Barnes, T. L.,Harnack, L., Erickson, D. J.,Laska, M. N.. Food and beverage purchases in corner stores, gas-marts, pharmacies and dollar stores. Public Health Nutr. 2017. 20:2587-2597

47 Chang, Y.,Hickman, H.. Food Insecurity and Perceived Diet Quality Among Low-Income Older Americans with Functional Limitations. J Nutr Educ Behav. 2018. 50:476-484

48 Chen, L.,Zhu, H., Gutin, B.,Dong, Y.. Race, Gender, Family Structure, Socioeconomic Status, Dietary Patterns, and Cardiovascular Health in Adolescents. Curr Dev Nutr. 2019. 3:nzz117

49 Chen, M.,Creger, T.,Howard, V.,Judd, S. E.,Harrington, K. F.,Fontaine, K. R.. Geospatial analysis of Mediterranean diet adherence in the United States. Public Health Nutr. 2020. :1-9

50 Chen, Y.,Lin, B. H.,Mancino, L.,Ploeg, M. V.,Zhen, C.. Nutritional quality of retail food purchases is not associated with participation in the Supplemental Nutrition Assistance Program for nutrition-oriented households. Plos One. 2020. 15:14

51 Chenarides, Lauren,Grebitus, Carola,Lusk, Jayson L.,Printezis, Iryna. Food consumption behavior during the COVID-19 pandemic. Agribusiness. 2021. 37:44-81

52 Cleary, Rebecca,Bonanno, Alessandro,Ghazaryan, Armen,Bellows, Laura,McCloskey, Morgan. School meals and quality of household food acquisitions. Applied Economic Perspectives \& Policy. 2021; (\#issue\#):1. \#doi\#.

53 Clements, Kenneth W.,Si, Jiawei. ENGEL'S LAW, DIET DIVERSITY, AND THE QUALITY OF FOOD CONSUMPTION. American Journal of Agricultural Economics. 2018. 100:1-22

54 Collins, A. M.,Klerman, J. A.. Improving Nutrition by Increasing Supplemental Nutrition Assistance Program Benefits. Am J Prev Med. 2017. 52:S179-s185

55 Cooksey Stowers, K.,Jiang, Q.,Atoloye, A.,Lucan, S.,Gans, K.. Racial Differences in Perceived Food Swamp and Food Desert Exposure and Disparities in Self-Reported Dietary Habits. Int J Environ Res Public Health. 2020. 17:
Data date

range

Intervention/

Exposure

Outcome

(Purchase

data)

Outcome

Outcome

Outcome

Intervention/

Exposure

Intervention/

Exposure

Intervention/

Exposure

Intervention/

Exposure

Intervention/

Exposure

Intervention/

Exposure

Intervention/

Exposure

Outcome

(Purchase

data)

Intervention/

Exposure;

Outcome

Outcome

(Purchase

data)

Study design;

Country

Outcome

Outcome 
Exclusion rationale

56 Côté-Lussier, C.,Kakinami, L.,Danieles, P. K.. Ego-centered relative neighborhood deprivation Country and reported dietary habits among youth. Appetite. 2019. 132:267-274

57 Courtemanche, Charles,Denteh, Augustine,Tchernis, Rusty. Estimating the Associations between SNAP and Food Insecurity, Obesity, and Food Purchases with Imperfect Administrative Measures of Participation. Southern Economic Journal. 2019. 86:202-228

58 Crane, M. M.,Tangney, C. C.,French, S. A.,Wang, Y.,Appelhans, B. M.. Gender Comparison of the Diet Quality and Sources of Food Purchases Made by Urban Primary Household Food Purchasers. J Nutr Educ Behav. 2019. 51:199-204

59 Crews, D. C.,Kuczmarski, M. F.,Miller, E. R., 3rd,Zonderman, A. B.,Evans, M. K.,Powe, N. R.. Dietary habits, poverty, and chronic kidney disease in an urban population. J Ren Nutr. 2015. 25:103-10

60 Cullen, K. W.,Chen, T. A.. The contribution of the USDA school breakfast and lunch program meals to student daily dietary intake. Prev Med Rep. 2017. 5:82-85

61 Cummins, Steven,Flint, Ellen,Matthews, Stephen A.. New Neighborhood Grocery Store Increased Awareness Of Food Access But Did Not Alter Dietary Habits Or Obesity. Health Affairs. 2014. 33:283-291

62 Cutler, G. J.,Flood, A.,Hannan, P.,Neumark-Sztainer, D.. Multiple sociodemographic and socioenvironmental characteristics are correlated with major patterns of dietary intake in adolescents. J Am Diet Assoc. 2011. 111:230-40

63 Dammann, K. W.,Smith, C.. Race, Homelessness, and Other Environmental Factors Associated with the Food-Purchasing Behavior of Low-Income Women. Journal of the American Dietetic Association. 2010. 110:1351-1356

64 Darmon, N.,Lacroix, A.,Muller, L.,Ruffieux, B.. Food price policies improve diet quality while increasing socioeconomic inequalities in nutrition. Int J Behav Nutr Phys Act. 2014. 11:66

65 Darmon, N.,Lacroix, A.,Muller, L.,Ruffieux, B.. Food Price Policies May Improve Diet but Increase Socioeconomic Inequalities in Nutrition. Hidden Hunger: Malnutrition and the First 1,000 Days of Life: Causes, Consequences and Solutions. 2016. 115:36-45

66 Davis, N. J.,Schechter, C. B.,Ortega, F.,Rosen, R.,Wylie-Rosett, J.,Walker, E. A.. Dietary patterns in Blacks and Hispanics with diagnosed diabetes in New York City's South Bronx. Am J Clin Nutr. 2013. 97:878-85

67 Dennisuk, L. A.,Coutinho, A. J.,Suratkar, S.,Surkan, P. J.,Christiansen, K.,Riley, M.,Anliker, J. A.,Sharma, S.,Gittelsohn, J.. Food expenditures and food purchasing among low-income, urban, African-American youth. Am J Prev Med. 2011. 40:625-8

68 Deshmukh-Taskar, P. R.,O'Neil, C. E.,Nicklas, T. A.,Yang, S. J.,Liu, Y.,Gustat, J.,Berenson, G. S.. Dietary patterns associated with metabolic syndrome, sociodemographic and lifestyle factors in young adults: the Bogalusa Heart Study. Public Health Nutr. 2009. 12:2493-503

69 Dhakal, C. K.,Khadka, S.. Heterogeneities in Consumer Diet Quality and Health Outcomes of Consumers by Store Choice and Income. Nutrients. 2021. 13

70 Dharod, J. M.,Croom, J. E.,Sady, C. G.. Food Insecurity: Its Relationship to Dietary Intake and Body Weight among Somali Refugee Women in the United States. Journal of Nutrition Education and Behavior. 2013. 45:47-53

71 Diep, C. S.,Leung, R.,Thompson, D. I.,Gor, B. J.,Baranowski, T.. Culture and Diet Among Chinese American Children Aged 9-13 Years: A Qualitative Study. Journal of Nutrition Education and Behavior. 2017. 49:275-284

72 Dondero, M.,Van Hook, J.. Generational status, neighborhood context, and mother-child resemblance in dietary quality in Mexican-origin families. Soc Sci Med. 2016. 150:212-20

73 Dubowitz, T.,Ghosh-Dastidar, M.,Cohen, D. A.,Beckman, R.,Steiner, E. D.,Hunter, G. P.,Flórez, K. R.,Huang, C.,Vaughan, C. A.,Sloan, J. C.,Zenk, S. N.,Cummins, S.,Collins, R. L.. Diet And Perceptions Change With Supermarket Introduction In A Food Desert, But Not Because Of Supermarket Use. Health Aff (Millwood). 2015. 34:1858-68
Comparator

Intervention/

Exposure

Outcome

Intervention/

Exposure;

Outcome

Outcome

Data date

range

Outcome

Country

Country

Outcome

Outcome

Data date

range

Outcome

(Purchase

data)

Outcome

Outcome

Intervention/

Exposure

Intervention/

Exposure 
Exclusion rationale

74 Dubowitz, T.,Zenk, S. N.,Ghosh-Dastidar, B.,Cohen, D. A.,Beckman, R.,Hunter, G.,Steiner, E. D.,Collins, R. L.. Healthy food access for urban food desert residents: examination of the food environment, food purchasing practices, diet and BMI. Public Health Nutr. 2015. 18:2220-30

75 Duffy, P.,Zizza, C.,Jacoby, J.,Tayie, F. A.. Diet quality is low among female food pantry clients in Eastern Alabama. J Nutr Educ Behav. 2009. 41:414-9

76 Egeland, G. M.,Williamson-Bathory, L.,Johnson-Down, L.,Sobol, I.. Traditional food and monetary access to market-food: correlates of food insecurity among Inuit preschoolers. Int $\mathrm{J}$ Circumpolar Health. 2011. 70:373-83

77 Eicher-Miller, H. A.,Boushey, C. J.,Bailey, R. L.,Yang, Y. J.. Frequently Consumed Foods and Energy Contributions among Food Secure and Insecure U.S. Children and Adolescents. Nutrients. 2020. 12

78 Eicher-Miller, H. A.,Fulgoni, V. L., 3rd,Keast, D. R.. Energy and Nutrient Intakes from Processed Foods Differ by Sex, Income Status, and Race/Ethnicity of US Adults. J Acad Nutr Diet. 2015. 115:907-18.e6

79 Eicher-Miller, H. A.,Khanna, N.,Boushey, C. J.,Gelfand, S. B.,Delp, E. J.. Temporal Dietary Patterns Derived among the Adult Participants of the National Health and Nutrition Examination Survey 1999-2004 Are Associated with Diet Quality. J Acad Nutr Diet. 2016. 116:283-91

80 Epstein, L. H.,Finkelstein, E.,Raynor, H.,Nederkoorn, C.,Fletcher, K. D.,Jankowiak, N.,Paluch, R. A.. Experimental analysis of the effect of taxes and subsides on calories purchased in an online supermarket. Appetite. 2015. 95:245-51

$81 \quad$ Ervin, R. B.. Healthy Eating Index scores among adults, 60 years of age and over, by sociodemographic and health characteristics: United States, 1999-2002. Adv Data. 2008. :1-16

82 Esmaili, H.,Mohd Yusof, R.,Abu Saad, H.,Ghaemian, A.,Darani Zad, N.. Association of dietary patterns with sociodemographic and health-related factors among coronary artery disease (CAD) patients. Ecol Food Nutr. 2015. 54:4-19

83 Estradé, M.,Trude, A. C. B.,Pardilla, M.,Jock, B. W. I.,Swartz, J.,Gittelsohn, J.. Sociodemographic and Psychosocial Factors Associated With Diet Quality in 6 Rural Native American Communities. J Nutr Educ Behav. 2021. 53:10-19

84 Fabian, C.,Pagan, I.,Rios, J. L.,Betancourt, J.,Cruz, S. Y.,Gonzalez, A. M.,Palacios, C.,Gonzalez, M. J.,Rivera-Soto, W. T.. Dietary Patterns and their Association with Sociodemographic Characteristics and Perceived Academic Stress of College Students in Puerto Rico. Puerto Rico Health Sciences Journal. 2013. 32:36-43

85 Fan, Linlin,Baylis, Kathy,Gundersen, Craig,Ver Ploeg, Michele. Does a Nutritious Diet Cost More in Food Deserts?. 2016. :46

86 Fanelli Kuczmarski, M.,Beydoun, M. A.,Cotugna, N.,Schwenk, E.,Evans, M. K.,Zonderman, A. B.. The Relationship of Diet Quality with Proportion of Daily Energy Contributed by Sandwiches Varies by Age over Adulthood in Racially and Socioeconomically Diverse Adults. Nutrients. 2020. 12

87 Fanelli Kuczmarski, M.,Brewer, B. C.,Rawal, R.,Pohlig, R. T.,Zonderman, A. B.,Evans, M. K. Aspects of Dietary Diversity Differ in Their Association with Atherosclerotic Cardiovascular Risk in a Racially Diverse US Adult Population. Nutrients. 2019; 11 (5) Fanelli Kuczmarski, M.,Brewer, B. C.,Rawal, R.,Pohlig, R. T.,Zonderman, A. B.,Evans, M. K.. Aspects of Dietary Diversity Differ in Their Association with Atherosclerotic Cardiovascular Risk in a Racially Diverse US Adult Population. Nutrients. 2019; 11 (5).

88 Fanelli Kuczmarski, M.,Hossain, S.,Beydoun, M. A.,Maldonando, A.,Evans, M. K.,Zonderman, A. B.. Association of DASH and Depressive Symptoms with BMI over Adulthood in Racially and Socioeconomically Diverse Adults Examined in the HANDLS Study. Nutrients. 2019. 11

89 Fanelli Kuczmarski, M.,Stave Shupe, E.,Pohlig, R. T.,Rawal, R.,Zonderman, A. B.,Evans, M. K.. A Longitudinal Assessment of Diet Quality and Risks Associated with Malnutrition in Socioeconomic and Racially Diverse Adults. Nutrients. 2019. 11:

$90 \quad$ Fang Zhang, F.,Liu, J.,Rehm, C. D.,Wilde, P.,Mande, J. R.,Mozaffarian, D.. Trends and Disparities in Diet Quality Among US Adults by Supplemental Nutrition Assistance Program Participation Status. JAMA Netw Open. 2018. 1:e180237

Intervention

Exposure

Data date

range

Country

Outcome

Outcome

Data date

range

Intervention/

Exposure

Data date

range

Country

Comparator

Outcome

Outcome

Comparator

Outcome

Intervention/

Exposure

Outcome

Outcome 
Exclusion rationale

91 Farmer, N.,Wallen, G. R.,Yang, L.,Middleton, K. R.,Kazmi, N.,Powell-Wiley, T. M.. Household Cooking Frequency of Dinner Among Non-Hispanic Black Adults is Associated with Income and Employment, Perceived Diet Quality and Varied Objective Diet Quality, HEI (Healthy Eating Index): NHANES Analysis 2007-2010. Nutrients. 2019. 11:

92 Ferranti, E. P.,Dunbar, S. B.,Higgins, M.,Dai, J.,Ziegler, T. R.,Frediani, J. K.,Reilly, C.,Brigham, K. L.. Psychosocial factors associated with diet quality in a working adult population. Res Nurs Health. 2013; 36 (3):242-56. \#doi\#.

93 Ferranti, E. P.,Narayan, K. M.,Reilly, C. M.,Foster, J.,McCullough, M.,Ziegler, T. R.,Guo, Y.,Dunbar, S. B.. Dietary self-efficacy predicts AHEI diet quality in women with previous gestational diabetes. Diabetes Educ. 2014. 40:688-99

94 Fitzgerald, N.,Damio, G.,Segura-Perez, S.,Perez-Escamilla, R.. Nutrition knowledge, food label use, and food intake patterns among Latinas with and without type 2 diabetes. Journal of the American Dietetic Association. 2008. 108:960-967

95 Ford, D. W.,Hartman, T. J.,Still, C.,Wood, C.,Mitchell, D. C.,Bailey, R.,Smiciklas-Wright, H.,Coffman, D. L.,Jensen, G. L.. Diet quality and body mass index are associated with health care resource use in rural older adults. J Acad Nutr Diet. 2014. 114:1932-8

96 Forrestal, S.,Potamites, E., Guthrie, J.,Paxton, N.. Associations among Food Security, School Meal Participation, and Students' Diet Quality in the First School Nutrition and Meal Cost Study. Nutrients. 2021. 13:

97 Fowles, E. R.,Stang, J.,Bryant, M.,Kim, S.. Stress, depression, social support, and eating habits reduce diet quality in the first trimester in low-income women: a pilot study. J Acad Nutr Diet. 2012. 112:1619-25

98 Franckle, R. L.,Moran, A.,Hou, T.,Blue, D.,Greene, J.,Thorndike, A. N.,Polacsek, M.,Rimm, E. B.. Transactions at a Northeastern Supermarket Chain: Differences by Supplemental Nutrition Assistance Program Use. American Journal of Preventive Medicine. 2017. 53:E131-E138

99 Franckle, R. L.,Thorndike, A. N.,Moran, A. J.,Hou, T.,Blue, D.,Greene, J. C.,Bleich, S. N.,Block, J. P.,Polacsek, M.,Rimm, E. B.. Supermarket Purchases Over the Supplemental Nutrition Assistance Program Benefit Month: A Comparison Between Participants and Nonparticipants. Am J Prev Med. 2019. 57:800-807

100 Franco, M.,Diez-Roux, A. V.,Nettleton, J. A.,Lazo, M.,Brancati, F.,Caballero, B.,Glass, T.,Moore, L. V.. Availability of healthy foods and dietary patterns: the Multi-Ethnic Study of Atherosclerosis. Am J Clin Nutr. 2009. 89:897-904

101 Fransen, H. P.,Boer, J. M. A.,Beulens, J. W. J.,de Wit, G. A.,Bueno-de-Mesquita, H. B.,Hoekstra, J.,May, A. M.,Peeters, P. H. M.. Associations between lifestyle factors and an unhealthy diet. Eur J Public Health. 2017. 27:274-278

102 Freedman, D. A.,Bell, B. A.,Clark, J.,Ngendahimana, D.,Borawski, E.,Trapl, E.,Pike, S.,Sehgal, A. R.. Small Improvements in an Urban Food Environment Resulted in No Changes in Diet Among Residents. J Community Health. 2021. 46:1-12

103 French, S. A.,Rydell, S. A.,Mitchell, N. R.,Oakes, J. M.,Elbel, B.,Harnack, L.. Financial incentives and purchase restrictions in a food benefit program affect the types of foods and beverages purchased: results from a randomized trial. International Journal of Behavioral Nutrition and Physical Activity. 2017. 14:10

104 French, S. A.,Tangney, C. C.,Crane, M. M.,Wang, Y.,Appelhans, B. M.. Nutrition quality of food purchases varies by household income: the SHoPPER study. BMC Public Health. 2019. 19:231

105 Frongillo, E. A.,Wolfe, W. S.. Impact of participation in Home-Delivered Meals on nutrient intake, dietary patterns, and food insecurity of older persons in New York state. J Nutr Elder. 2010. 29:293-310

106 Garner, J. A., Jilcott Pitts, S. B.,Hanson, K. L.,Ammerman, A. S.,Kolodinsky, J.,Sitaker, M. H.,Seguin-Fowler, R. A.. Making community-supported agriculture accessible to low-income families: findings from the Farm Fresh Foods for Healthy Kids process evaluation. Transl Behav Med. 2021. 11:754-763
Intervention/

Exposure

Intervention/

Exposure

Outcome

Intervention/

Exposure

Intervention/

Exposure

Intervention/

Exposure

Outcome

Outcome

Data date

range

Country;

Data date range

Intervention/

Exposure

Outcome

Outcome

(Purchase

data)

Outcome;

Data date

range Intervention/ Exposure 
Exclusion rationale

107 Gavrieli, A.,Farr, O. M.,Davis, C. R.,Crowell, J. A.,Mantzoros, C. S.. Early life adversity and/or posttraumatic stress disorder severity are associated with poor diet quality, including consumption of trans fatty acids, and fewer hours of resting or sleeping in a US middle-aged population: A cross-sectional and prospective study. Metabolism. 2015. 64:1597-610

108 Gills, S. M. H.,Auld, G.,Hess, A.,Guenther, P. M.,Baker, S. S.. Positive Change in Healthy Eating Scores Among Adults With Low Income After Expanded Food and Nutrition Education Program Participation. J Nutr Educ Behav. 2021.

109 Golan, Elise H.,Stewart, Hayden, Kuchler, Fred,Dong, Diansheng. Can Low-Income Americans Afford a Healthy Diet?. 2008. :8

110 Greatwood, H. C.,Daly-Smith, A.,McGregor, S.,McKenna, J.. Year 7 dietary intake: a comparison of two schools with middle-high socio-economic status. J Hum Nutr Diet. 2013. 26:563-9

111 Greenfield, Russell. The DASH Diet. 2020

112 Gregory, Christian ,Ver Ploeg, Michele, Andrews, Margaret, Coleman-Jensen, Alisha. Supplemental Nutrition Assistance Program (SNAP) Participation Leads to Modest Changes in Diet Quality. 2013; 36.

113 Guenther, P. M.,Luick, B. R.. Improved Overall Quality of Diets Reported by Expanded Food and Nutrition Education Program Participants in the Mountain Region. J Nutr Educ Behav. 2015. 47:421-6.e1

114 Gupta, S.,Rose, C. M.,Buszkiewicz, J.,Ko, L. K.,Mou, J.,Cook, A.,Aggarwal, A.,Drewnowski, A.. Characterising percentage energy from ultra-processed foods by participant demographics, diet quality and diet cost: findings from the Seattle Obesity Study (SOS) III. Br J Nutr. 2020. :1-9

115 Gupta, S.,Rose, C. M.,Buszkiewicz, J.,Otten, J.,Spiker, M. L.,Drewnowski, A.. Inedible Food Waste Linked to Diet Quality and Food Spending in the Seattle Obesity Study SOS III. Nutrients. 2021. 13:

116 Guthrie, J. F.,Anater, A. S.,Hampton, J. C.,Catellier, D. J.,Eldridge, A. L.,Johnson, W. L., Quann, E. E.. The Special Supplemental Nutrition Program for Women, Infants, and Children is Associated with Several Changes in Nutrient Intakes and Food Consumption Patterns of Participating Infants and Young Children, 2008 Compared with 2016. Journal of Nutrition. 2020. 150:2985-2993

117 Guthrie, J. F.,Catellier, D. J.,Jacquier, E. F.,Eldridge, A. L.,Johnson, W. L.,Lutes, A. C.,Anater, A. S.,Quann, E. E.. WIC and non-WIC Infants and Children Differ in Usage of Some WICProvided Foods. J Nutr. 2018. 148:1547s-1556s

118 Guthrie, Joanne F.,Variyam, Jayachandran N.. Can Food Stamps Do More to Improve Food Choices? An Economic Perspective-Nutrition Information: Can It Improve the Diets of LowIncome Households?. 2007; 4.

119 Harnack, L.,Oakes, J. M.,Elbel, B.,Beatty, T.,Rydell, S.,French, S.. Effects of Subsidies and Prohibitions on Nutrition in a Food Benefit Program: A Randomized Clinical Trial. JAMA Intern Med. 2016. 176:1610-1618

120 Harrington, J.,Fitzgerald, A. P.,Layte, R.,Lutomski, J.,Molcho, M.,Perry, I. J.. Sociodemographic, health and lifestyle predictors of poor diets. Public Health Nutrition. 2011. 14:2166-2175

121 Hattori, A.,An, R.,Sturm, R.. Neighborhood food outlets, diet, and obesity among California adults, 2007 and 2009. Prev Chronic Dis. 2013. 10:E35

122 Hidaka, B. H.,Kerling, E. H.,Thodosoff, J. M.,Sullivan, D. K.,Colombo, J.,Carlson, S. E.. Dietary patterns of early childhood and maternal socioeconomic status in a unique prospective sample from a randomized controlled trial of Prenatal DHA Supplementation. BMC Pediatr. 2016. 16:191

123 Hilmers, A.,Chen, T. A.,Cullen, K. W.. Household food insecurity and dietary intake among Mexican-American women participating in federal food assistance programs. Am $\mathrm{J}$ Health Promot. 2014. 28:e146-54 Study design

Intervention/

Exposure

Comparator

Outcome

Country

Outcome

Intervention/

Exposure; Comparator Comparator

Intervention/

Exposure

Outcome

Outcome

Intervention/

Exposure

Intervention/

Exposure

Country

Outcome

Intervention/

Exposure

Outcome 
Exclusion rationale

124 Hilmers, A.,Chen, T. A.,Dave, J. M.,Thompson, D.,Cullen, K. W.. Supplemental Nutrition Assistance Program participation did not help low income Hispanic women in Texas meet the dietary guidelines. Prev Med. 2014. 62:44-8

125 Hiza, H. A.,Casavale, K. O.,Guenther, P. M.,Davis, C. A.. Diet quality of Americans differs by age, sex, race/ethnicity, income, and education level. J Acad Nutr Diet. 2013. 113:297-306

126 Hsiao, P. Y.,Mitchell, D. C.,Coffman, D. L.,Allman, R. M.,Locher, J. L.,Sawyer, P.,Jensen, G. L.,Hartman, T. J.. Dietary patterns and diet quality among diverse older adults: the University of Alabama at Birmingham Study of Aging. J Nutr Health Aging. 2013. 17:19-25

127 Hurley, K. M.,Black, M. M.. Commercial Baby Food Consumption and Dietary Variety in a Statewide Sample of Infants Receiving Benefits from the Special Supplemental Nutrition Program for Women, Infants, and Children. Journal of the American Dietetic Association. 2010. 110:1537-1541

128 lacobucci, Dawn. Part II: The Marketing Research Perspective: Chapter 2: Marketing Research: Consumer Behavior--Food Purchasing and Consumption. Foundations \& Trends in Marketing. 2019. 13:89-91

129 lacobucci, Dawn. Part II: The Marketing Research Perspective: Chapter 2: Marketing Research: Consumer Behavior--Food Purchasing and Consumption: 2.1: Grocery Shopping. Foundations \& Trends in Marketing. 2019. 13:91-112

130 Jackson, J. A.,Smit, E.,Manore, M. M.,John, D.,Gunter, K.. The Family-Home Nutrition Environment and Dietary Intake in Rural Children. Nutrients. 2015. 7:9707-20

131 Jansen, E. C.,Kasper, N.,Lumeng, J. C.,Brophy Herb, H. E.,Horodynski, M. A.,Miller, A. L.,Contreras, D.,Peterson, K. E.. Changes in household food insecurity are related to changes in BMI and diet quality among Michigan Head Start preschoolers in a sex-specific manner. Soc Sci Med. 2017. 181:168-176

132 Jansen, E. C.,Peterson, K. E.,Lumeng, J. C.,Kaciroti, N.,LeBourgeois, M. K.,Chen, K.,Miller, A. L.. Associations between Sleep and Dietary Patterns among Low-Income Children Attending Preschool. J Acad Nutr Diet. 2019. 119:1176-1187

133 Jilcott Pitts, S. B.,Keyserling, T. C.,Johnston, L. F.,Smith, T. W.,McGuirt, J. T., Evenson, K. R.,Rafferty, A. P.,Gizlice, Z.,Garcia, B. A.,Ammerman, A. S.. Associations between neighborhood-level factors related to a healthful lifestyle and dietary intake, physical activity, and support for obesity prevention polices among rural adults. J Community Health. 2015. 40:276-84

134 Jilcott Pitts, S. B.,Wu, Q.,Truesdale, K. P.,Rafferty, A. P.,Haynes-Maslow, L.,Boys, K. A.,McGuirt, J. T.,Fleischhacker, S.,Johnson, N.,Kaur, A. P.,Bell, R. A.,Ammerman, A. S.,Laska, M. N.. A four-year observational study to examine the dietary impact of the North Carolina Healthy Food Small Retailer Program, 2017-2020. Int J Behav Nutr Phys Act. 2021. 18:44

135 Joyce, J. M.,Rosenkranz, R. R.,Rosenkranz, S. K.. Evaluation of Variability in Dietary Quality of School Lunches Meeting National School Lunch Program Guidelines by Socioeconomic Status and Rurality. Int J Environ Res Public Health. 2020. 17.

136 Jun, S.,Catellier, D. J.,Eldridge, A. L.,Dwyer, J. T.,Eicher-Miller, H. A.,Bailey, R. L.. Usual Nutrient Intakes from the Diets of US Children by WIC Participation and Income: Findings from the Feeding Infants and Toddlers Study (FITS) 2016. J Nutr. 2018. 148:1567s-1574s

137 Jun, S.,Cowan, A. E.,Dodd, K. W.,Tooze, J. A.,Gahche, J. J.,Eicher-Miller, H. A.,Guenther, P. M.,Dwyer, J. T.,Potischman, N.,Bhadra, A.,Forman, M. R.,Bailey, R. L.. Association of food insecurity with dietary intakes and nutritional biomarkers among US children, National Health and Nutrition Examination Survey (NHANES) 2011-2016. Am J Clin Nutr. 2021.

138 Jun, S.,Zeh, M. J.,Eicher-Miller, H. A.,Bailey, R. L.. Children's Dietary Quality and Micronutrient Adequacy by Food Security in the Household and among Household Children. Nutrients. 2019. 11:

139 Juul, F.,Simões, B. D. S.,Litvak, J.,Martinez-Steele, E.,Deierlein, A., Vadiveloo, M.,Parekh, N.. Processing level and diet quality of the US grocery cart: is there an association?. Public Health Nutr. 2019. 22:2357-2366
Outcome;

Data date

range

Data date

range

Data date

range

Outcome

Intervention/

Exposure

Study design

Outcome

Intervention/

Exposure

Intervention/

Exposure

Intervention/

Exposure

Intervention/

Exposure

Outcome

Outcome

Intervention/

Exposure

Intervention/

Exposure

Outcome

(Purchase

data) 
Exclusion rationale

140 Jyväkorpi, S. K.,Urtamo, A.,Strandberg, T. E.. Self-Perception of Economic Means Is Associated with Dietary Choices, Diet Quality and Physical Health in the Oldest Old Men from the Highest Socioeconomic Group. J Nutr Health Aging. 2019. 23:60-62

141 Kamdar, N.,Hughes, S. O.,Chan, W.,Power, T. G.,Meininger, J.. Indirect Effects of Food Insecurity on Body Mass Index Through Feeding Style and Dietary Quality Among Low-Income Hispanic Preschoolers. J Nutr Educ Behav. 2019. 51:876-884

142 Kang, M.,Park, S. Y.,Shvetsov, Y. B.,Wilkens, L. R.,Marchand, L. L.,Boushey, C. J.,Paik, H. Y.. Sex differences in sociodemographic and lifestyle factors associated with diet quality in a multiethnic population. Nutrition. 2019. 66:147-152

143 Kant, A. K.,Graubard, B. I.. Secular trends in regional differences in nutritional biomarkers and self-reported dietary intakes among American adults: National Health and Nutrition Examination Survey (NHANES) 1988-1994 to 2009-2010. Public Health Nutr. 2018. 21:927-939

144 Karimbeiki, R.,Pourmasoumi, M.,Feizi, A.,Abbasi, B.,Hadi, A.,Rafie, N.,Safavi, S. M.. Higher dietary diversity score is associated with obesity: a case-control study. Public Health. 2018. 157:127-134

145 Karpyn, A.,Young, C. R.,Collier, Z.,Glanz, K.. Correlates of Healthy Eating in Urban Food Desert Communities. Int J Environ Res Public Health. 2020. 17

146 Kay, M. C.,Wasser, H.,Adair, L. S., Thompson, A. L.,Siega-Riz, A. M.,Suchindran, C. M.,Bentley, M. E.. Consumption of key food groups during the postpartum period in low-income, nonHispanic black mothers. Appetite. 2017. 117:161-167

147 Kegler, M. C.,Prakash, R.,Hermstad, A.,Anderson, K.,Haardörfer, R.,Raskind, I. G.. Food Acquisition Practices, Body Mass Index, and Dietary Outcomes by Level of Rurality. J Rural Health. 2020.

148 Keita, A. D.,Casazza, K.,Thomas, O.,Fernandez, J. R.. Neighborhood-level disadvantage is associated with reduced dietary quality in children. J Am Diet Assoc. 2009. 109:1612-6

149 Kell, K. P.,Judd, S. E.,Pearson, K. E.,Shikany, J. M.,Fernández, J. R.. Associations between socio-economic status and dietary patterns in US black and white adults. Br J Nutr. 2015. 113:1792-9

150 Kharmats, A. Y.,Jones-Smith, J. C.,Cheah, Y. S.,Budd, N.,Flamm, L.,Cuccia, A.,Mui, Y.,Trude, A.,Gittelsohn, J.. Relation between the Supplemental Nutritional Assistance Program cycle and dietary quality in low-income African Americans in Baltimore, Maryland. Am J Clin Nutr. 2014. 99:1006-14

151 Kilanowski, J. F.,Moore, L. C.. Food security and dietary intake in midwest migrant farmworker children. J Pediatr Nurs. 2010. 25:360-6

152 Kilanowski, J. F.. Patterns and correlates of nutrition among migrant farm-worker children. West J Nurs Res. 2012. 34:396-416

153 Kolodinsky, Jane M.,Sitaker, Marilyn,Morgan, Emily H.,Connor, Leah M.,Hanson, Karla L.,Becot, Florence,Pitts, Stephanie B. Jilcott,Ammerman, Alice S.,Seguin, Rebecca A.. Can CSA Cost-Offset Programs Improve Diet Quality for Limited Resource Families?. 2017. 32:10

154 Kranz, S.,McCabe, G. P.. Examination of the five comparable component scores of the diet quality indexes $\mathrm{HEI}-2005$ and RC-DQI using a nationally representative sample of 2-18 year old children: NHANES 2003-2006. J Obes. 2013. 2013:376314

155 Lacko, A.,Delamater, P.,Gordon-Larsen, P.,Wen Ng, S.. Geographic patterns and socioeconomic differences in the nutritional quality of household packaged food purchases in the United States. Health Place. 2021. 69:102567

156 Lacko, A.,Ng, S. W.,Popkin, B.. Urban vs.. Rural Socioeconomic Differences in the Nutritional Quality of Household Packaged Food Purchases by Store Type. Int J Environ Res Public Health. 2020. 17

157 Larson, N.,Laska, M. N.,Neumark-Sztainer, D.. Food Insecurity, Diet Quality, Home Food Availability, and Health Risk Behaviors Among Emerging Adults: Findings From the EAT 20102018 Study. Am J Public Health. 2020. 110:1422-1428
Country

Intervention/

Exposure

Intervention/

Exposure

Intervention/

Exposure

Country

Intervention/

Exposure

Outcome

Outcome

Outcome

Data date

range

Outcome

Data date

range

Intervention/

Exposure

Study design

Data date

range

Outcome

(Purchase

data)

Outcome

Outcome;

Comparator 
158 LeCroy, M. N.,Nicastro, H. L.,Truesdale, K. P.,Matheson, D. M.,levers-Landis, C. E.,Pratt, C.

A.,Jones, S.,Sherwood, N. E.,Burgess, L. E.,Robinson, T. N.,Yang, S.,Stevens, J.. Dietary patterns and associations with BMI in low-income, ethnic minority youth in the USA according to baseline data from four randomised controlled trials. Br J Nutr. 2020. :1-11

159 LeDoux, T. F.,Vojnovic, I.. Examining the role between the residential neighborhood food environment and diet among low-income households in Detroit, Michigan. Applied Geography. 2014. 55:9-18

Outcome

160 Lee, J.,Kubik, M. Y.,Fulkerson, J. A.. Diet Quality and Fruit, Vegetable, and Sugar-Sweetened Beverage Consumption by Household Food Insecurity among 8- to 12-Year-Old Children during Summer Months. J Acad Nutr Diet. 2019. 119:1695-1702

161 Lee, Jonq-Ying. Food Assistance Programs and Healthy Diet among Low-Income Individuals. 2009. :5

162 Lee, R.,Zhai, F.,Han, W. J.,Brooks-Gunn, J.,Waldfogel, J.. "Head Start and Children's Nutrition, Weight, and Health Care Receipt". Early Child Res Q. 2013. 28

163 Leung, C. W.,Cluggish, S.,Villamor, E.,Catalano, P. J.,Willett, W. C.,Rimm, E. B.. Few changes in food security and dietary intake from short-term participation in the Supplemental Nutrition Assistance Program among low-income Massachusetts adults. J Nutr Educ Behav. 2014. 46:68-74

164 Leung, C. W.,Epel, E. S., Ritchie, L. D.,Crawford, P. B.,Laraia, B. A.. Food insecurity is inversely associated with diet quality of lower-income adults. J Acad Nutr Diet. 2014. 114:1943-53.e2 Leung, C. W.,Tester, J. M.. The Association between Food Insecurity and Diet Quality Varies by Race/Ethnicity: An Analysis of National Health and Nutrition Examination Survey 2011-2014 Results. J Acad Nutr Diet. 2019. 119:1676-1686

166 Leung, C. W.,Wolfson, J. A.,Lahne, J.,Barry, M. R.,Kasper, N.,Cohen, A. J.. Associations between Food Security Status and Diet-Related Outcomes among Students at a Large, Public Midwestern University. J Acad Nutr Diet. 2019. 119:1623-1631

167 Leung, C. W.,Wolfson, J. A.. Food Insecurity Among Older Adults: 10-Year National Trends and Associations with Diet Quality. J Am Geriatr Soc. 2021. 69:964-971

Intervention/

Exposure

Data date

range

Data date

range

Outcome

Intervention/

Exposure

Intervention/

Exposure

Outcome

Intervention/

Exposure

168 Lin, Biing-Hwan. Diet Quality Usually Varies by Income Status. 2005. :2

169 Lin, D.,Zickgraf, H.,Butt, M.,Rigby, A.. Food insecurity is linked to poorer dietary quality in prebariatric surgery patients. Surg Obes Relat Dis. 2021. 17:263-270

170 Link, L. B.,Jacobson, J. S.. Factors affecting adherence to a raw vegan diet. Complement Ther Clin Pract. 2008. 14:53-9

171 Lipsky, L. M.,Nansel, T. R.,Haynie, D. L.,Liu, D.,Li, K.,Pratt, C. A., Iannotti, R. J.,Dempster, K. W.,Simons-Morton, B.. Diet quality of US adolescents during the transition to adulthood: changes and predictors. Am J Clin Nutr. 2017. 105:1424-1432

172 Litvak, J.,Parekh, N.,Juul, F.,Deierlein, A.. Food assistance programs and income are associated with the diet quality of grocery purchases for households consisting of women of reproductive age or young children. Prev Med. 2020. 138:106149

173 Liu, J.,Micha, R.,Li, Y.,Mozaffarian, D.. Trends in Food Sources and Diet Quality Among US Children and Adults, 2003-2018. JAMA Netw Open. 2021. 4:e215262

174 Liu, Y.,Zhang, Y.,Remley, D. T.,Eicher-Miller, H. A.. Frequency of Food Pantry Use Is Associated with Diet Quality among Indiana Food Pantry Clients. J Acad Nutr Diet. 2019. 119:1703-1712

175 Lyerly, R.,Rummo, P.,Amin, S.,Evans, W.,Cohen, E. D.,Lawson, E.,Hallett, E.,De-Oliveira, S.,Rose, J.,Sutten Coats, C.,Nunn, A.. Effectiveness of mobile produce markets in increasing access and affordability of fruits and vegetables among low-income seniors. Public Health Nutr. 2020. 23:3226-3235

176 Ma, C.,Ho, S. K. M.,Singh, S.,Choi, M. Y.. Gender Disparities in Food Security, Dietary Intake, and Nutritional Health in the United States. Am J Gastroenterol. 2021. 116:584-592
Outcome

Data date range Intervention/ Exposure

Outcome

(Purchase data) Outcome Intervention/ Exposure

Outcome

Outcome 
Exclusion rationale

177 Madrigal, J. M.,Cedillo-Couvert, E.,Ricardo, A. C.,Appel, L. J.,Anderson, C. A. M.,Deo, R.,Hamm, L. L.,Cornish-Zirker, D.,Tan, T. C.,Sha, D.,Hsu, J. Y.,Zenk, S. N.,Saunders, M. R.,Persky, V.,Lash, J. P.. Neighborhood Food Outlet Access and Dietary Intake among Adults with Chronic Kidney Disease: Results from the Chronic Renal Insufficiency Cohort Study. J Acad Nutr Diet. 2020. 120:1151-1162.e3

178 Mancino, Lisa ,Gregory, Christian A.. Food-Insecure Households Score Lower on Diet Quality Compared to Food-Secure Households. 2020; March 2020 (02)

179 Mancino, Lisa, Guthrie, Joanne. SNAP Households Must Balance Multiple Priorities To Achieve a Healthful Diet. 2014; (10):1.

180 Marmash, D.,Ha, K.,Sakaki, J. R.,Gorski, I.,Rule, B.,Foster, J.,Puglisi, M.,Chun, O. K.. Diet Quality, Nutritional Adequacy, and Sociodemographic Characteristics of Mobile Food Pantry Users in Northeastern Connecticut. Nutrients. 2021. 13

181 Mayne, S. L., Virudachalam, S.,Fiks, A. G.. Clustering of unhealthy behaviors in a nationally representative sample of U.S. children and adolescents. Prev Med. 2020. 130:105892

182 McClain, A. C.,Tucker, K. L.,Falcon, L. M.,Mattei, J.. Food insecurity and dietary intake by Supplemental Nutrition Assistance Program participation status among mainland US Puerto Rican adults after the 2009 American Recovery and Reinvestment Act. Public Health Nutrition. 2019. 22:2989-2998

183 Merhout, F.,Doyle, J.. Socioeconomic Status and Diet Quality in College Students. J Nutr Educ Behav. 2019. 51:1107-1112

184 Metzgar, M.,Rideout, T. C.,Fontes-Villalba, M.,Kuipers, R. S.. The feasibility of a Paleolithic diet for low-income consumers. Nutr Res. 2011. 31:444-51

185 Millstein, R. A.,Yeh, H. C.,Brancati, F. L.,Batts-Turner, M.,Gary, T. L.. Food availability, neighborhood socioeconomic status, and dietary patterns among blacks with type 2 diabetes mellitus. Medscape J Med. 2009. 11:15

186 Misyak, S. A.,Hedrick, V. E.,Pudney, E.,Serrano, E. L.,Farris, A. R.. Reliability of a Market Basket Assessment Tool (MBAT) for Use in SNAP-Ed Healthy Retail Initiatives. J Nutr Educ Behav. 2018. 50:511-515

187 Molitor, F.,Doerr, C.,Pugliese, J.,Whetstone, L.. Three-year trends in dietary behaviours among mothers, teenagers and children from SNAP-Ed (Supplemental Nutrition Assistance ProgramEducation) eligible households across California. Public Health Nutr. 2020. 23:3-12

188 Molitor, F.,Sugerman, S. B.,Sciortino, S.. Fruit and Vegetable, Fat, and Sugar-Sweetened Beverage Intake Among Low-Income Mothers Living in Neighborhoods With Supplemental Nutrition Assistance Program-Education. J Nutr Educ Behav. 2016. 48:683-690.e1

189 Monsivais, P.,Drewnowski, A.. Lower-energy-density diets are associated with higher monetary costs per kilocalorie and are consumed by women of higher socioeconomic status. J Am Diet Assoc. 2009. 109:814-22

190 Monsivais, P.,Rehm, C. D.,Drewnowski, A.. The DASH diet and diet costs among ethnic and racial groups in the United States. JAMA Intern Med. 2013. 173:1922-4

191 Moore, L. V.,Diez Roux, A. V.,Nettleton, J. A.,Jacobs, D. R., Jr.. Associations of the local food environment with diet quality--a comparison of assessments based on surveys and geographic information systems: the multi-ethnic study of atherosclerosis. Am J Epidemiol. 2008. 167:91724

192 Mousa, T. Y.,Freeland-Graves, J. H.. Food security of food recipients of a food pantry and soup kitchen. Public Health Nutr. 2019. 22:1451-1460

193 Muhammad, J. N.,Fernandez, J. R.,Clay, O. J.,Saag, M. S.,Overton, E. T.,Willig, A. L.. Associations of food insecurity and psychosocial measures with diet quality in adults aging with HIV. AIDS Care. 2019. 31:554-562
Intervention/

Exposure

Outcome

Outcome

Outcome

Intervention/

Exposure;

Outcome;

Comparator

Outcome

Outcome

Comparator;

Data date

range

Data date

range

Intervention/

Exposure

Intervention/

Exposure

Intervention/

Exposure

Data date

range

Data date

range

Data date

range

Intervention/

Exposure

Intervention/

Exposure 
Exclusion rationale

194 Mulik, K.,Haynes-Maslow, L.. The Affordability of MyPlate: An Analysis of SNAP Benefits and the Actual Cost of Eating According to the Dietary Guidelines. J Nutr Educ Behav. 2017. 49:623-631.e1

195 Mullany, B.,Neault, N.,Tsingine, D.,Powers, J.,Lovato, V.,Clitso, L.,Massey, S.,Talgo, A.,Speakman, K.,Barlow, A.. Food insecurity and household eating patterns among vulnerable American-Indian families: associations with caregiver and food consumption characteristics. Public Health Nutr. 2013. 16:752-60

196 Mullie, P.,Clarys, P.,Hulens, M.,Vansant, G.. Dietary patterns and socioeconomic position. Eur J Clin Nutr. 2010. 64:231-8

197 Newby, P. K.,Noel, S. E.,Grant, R.,Judd, S.,Shikany, J. M.,Ard, J.. Race and region have independent and synergistic effects on dietary intakes in black and white women. Nutr J. 2012. $11: 25$

198 Ng, S. W.,Poti, J. M.,Popkin, B. M.. Trends in racial/ethnic and income disparities in foods and beverages consumed and purchased from stores among US households with children, 20002013. Am J Clin Nutr. 2016. 104:750-9

199 Nguyen, B. T.,Han, X.,Jemal, A.,Drope, J.. Diet quality, risk factors and access to care among low-income uninsured American adults in states expanding Medicaid vs.. states not expanding under the affordable care act. Prev Med. 2016. 91:169-171

200 Nnakwe, Nweze E.. Dietary Patterns and Prevalence of Food Insecurity Among Low-Income Families Participating in Community Food Assistance Programs in a Midwest Town. Family \& Consumer Sciences Research Journal. 2008. 36:229-242

201 Of Health, Mississippi State Department. Nutrition, Weight Loss and Healthy Eating Mississippi State Department of Health. 2021.

202 Ozcan, B. A., Yesilkay, B.,Yaldiz, N.,Pehliva, M.. Factors affecting diet quality in adolescents: the effect of sociodemographic characteristics and meal consumption. Progress in Nutrition. 2020. $22: 8$

203 Palmer, S. M.,Knoblauch, S. T.,Winham, D. M.,Hiller, M. B.,Shelley, M. C.. Putting Knowledge into Practice: Low-Income Women Talk about Food Choice Decisions. Int J Environ Res Public Health. 2020. 17

204 Park, S. Y.,Shvetsov, Y. B.,Kang, M.,Setiawan, V. W., Wilkens, L. R., Le Marchand, L.,Boushey, C. J.. Changes in Diet Quality over 10 Years Are Associated with Baseline Sociodemographic and Lifestyle Factors in the Multiethnic Cohort Study. J Nutr. 2020. 150:1880-1888

205 Park, Y.,Neckerman, K.,Quinn, J.,Weiss, C.,Jacobson, J.,Rundle, A.. Neighbourhood immigrant acculturation and diet among Hispanic female residents of New York City. Public Health Nutr. 2011. 14:1593-600

206 Parker, H. W.,Tovar, A.,McCurdy, K.,Vadiveloo, M.. Socio-economic and racial prenatal diet quality disparities in a national US sample. Public Health Nutr. 2020. 23:894-903

Outcome Intervention/ Exposure

Data date range

Study design

Country

Outcome

Intervention/

Exposure

Data date range

Data date range

207 Perkins, S.,Daley, A.,Yerxa, K.,Therrien, M.. The Effectiveness of the Expanded Food and Nutrition Education Program (EFNEP) on Diet Quality as Measured by the Healthy Eating Index. Am J Lifestyle Med. 2020. 14:316-325

208 Pfledderer, C. D.,Gren, L. H.,Metos, J.,Brusseau, T. A.,O'Toole, K.,Buys, S. S.,Daly, M. B.,Frost, C. J.. Mothers' Diet and Family Income Predict Daughters' Healthy Eating. Prev Chronic Dis. 2021. 18:E24

209 Pooler, J. A.,Srinivasan, M.,Wong, K.,Blitstein, J. L.. Food Skills Education and Low-Income Adults' Healthy Food Choices. Int Q Community Health Educ. 2021. :272684×211004941

210 Poskute, A. S.,Nzesi, A.,Geliebter, A.. Changes in food intake during the COVID-19 pandemic in New York City. Appetite. 2021. 163:105191

211 Ralston, P. A.,Cohen, N. L.,Wickrama, K.,Kwag, K.. Social Support and Dietary Quality in Older African American Public Housing Residents. Research on Aging. 2011. 33:688-712
Comparator

Country

Intervention/

Exposure; Comparator Outcome

Data date range 
Exclusion rationale

212 Raskind, I. G.,Kegler, M. C.,Girard, A. W.,Dunlop, A. L.,Kramer, M. R.. An activity space Outcome approach to understanding how food access is associated with dietary intake and BMI among urban, low-income African American women. Health Place. 2020. 66:102458

213 Rawal, R.,Kuczmarski, M. F.,Cotugna, N.,Brewer, B. C.,Beydoun, M. A.,Hughes, V. C.,Zonderman, A. B.,Evans, M. K.. Aspects of Dietary Diversity Changes across Adulthood in Racially Diverse Adults. Nutrients. 2020; 12 (8)

214 Rehm, C. D.,Monsivais, P.,Drewnowski, A.. Relation between diet cost and Healthy Eating Index 2010 scores among adults in the United States 2007-2010. Prev Med. 2015. 73:70-5

215 Rex, S. M.,Kopetsky, A.,Bodt, B.,Robson, S. M.. Relationships Among the Physical and Social Home Food Environments, Dietary Intake, and Diet Quality in Mothers and Children. J Acad Nutr Diet. 2021.

216 Richardson, A. S.,Collins, R. L.,Ghosh-Dastidar, B.,Ye, F.,Hunter, G. P.,Baird, M. D.,Schwartz, H.,Sloan, J. C.,Nugroho, A.,Beckman, R.,Troxel, W. M.,Gary-Webb, T. L., Dubowitz, T.. Improvements in Neighborhood Socioeconomic Conditions May Improve Resident Diet. Am J Epidemiol. 2021. 190:798-806

217 Rifas-Shiman, S. L.,Rich-Edwards, J. W.,Kleinman, K. P.,Oken, E.,Gillman, M. W.. Dietary quality during pregnancy varies by maternal characteristics in Project Viva: a US cohort. J Am Diet Assoc. 2009. 109:1004-11

218 Rivera, R. L.,Zhang, Y.,Wang, Q.,Maulding, M. K.,Tooze, J. A.,Wright, B. N.,Craig, B. A.,Bailey, R. L.,Eicher-Miller, H. A.. Diet Quality and Associations with Food Security among Women Eligible for Indiana Supplemental Nutrition Assistance Program-Education. J Nutr. 2020. 150:2191-2198

219 Rose, C. M.,Gupta, S.,Buszkiewicz, J.,Ko, L. K.,Mou, J.,Cook, A.,Moudon, A. V.,Aggarwal, A.,Drewnowski, A.. Small increments in diet cost can improve compliance with the Dietary Guidelines for Americans. Soc Sci Med. 2020. 266:113359

220 Rose, D.,Heller, M. C.,Willits-Smith, A. M.,Meyer, R. J.. Carbon footprint of self-selected US diets: nutritional, demographic, and behavioral correlates. Am J Clin Nutr. 2019. 109:526-534

\section{Outcome}

Exposure

Exposure

\section{Data date}

range

Exposure

Exposure

Exposure;
Intervention/

Intervention/

Comparator

Intervention/

Intervention/

Intervention/

Outcome

Outcome Pediatr Obes. 2016. 11:187-93

222 Rummo, P. E.,Meyer, K. A.,Boone-Heinonen, J.,Jacobs, D. R., Jr.,Kiefe, C. I.,Lewis, C. E.,Steffen, L. M.,Gordon-Larsen, P.. Neighborhood availability of convenience stores and diet quality: findings from 20 years of follow-up in the coronary artery risk development in young adults study. Am J Public Health. 2015. 105:e65-73

223 Sanjeevi, N.,Freeland-Graves, J. H.. Association of Grocery Expenditure Relative to Thrifty Food Plan Cost with Diet Quality of Women Participating in the Supplemental Nutrition Assistance Program. J Acad Nutr Diet. 2018. 118:2315-2323

224 Sanjeevi, N.,Freeland-Graves, J.,Hersh, M.. Food insecurity, diet quality and body mass index of women participating in the Supplemental Nutrition Assistance Program: The role of intrapersonal, home environment, community and social factors. Appetite. 2018. 125:109-117

225 Sanjeevi, N.,Freeland-Graves, J.. Monthly Variations in Dietary Intake of Women Participating in the Supplemental Nutrition Assistance Program. J Acad Nutr Diet. 2019. 119:261-271

Data date range

Comparator

Intervention/

Exposure

Intervention/

Exposure

226 Saxe-Custack, A.,LaChance, J.,Hanna-Attisha, M.,Ceja, T.. Fruit and Vegetable Prescriptions for Pediatric Patients Living in Flint, Michigan: A Cross-Sectional Study of Food Security and Dietary Patterns at Baseline. Nutrients. 2019. 11

227 Shah, B. S.,Freeland-Graves, J. H.,Cahill, J. M.,Lu, H.,Graves, G. R.. Diet quality as measured by the healthy eating index and the association with lipid profile in low-income women in early postpartum. J Am Diet Assoc. 2010. 110:274-9

228 Sharkey, J. R.,Nalty, C.,Johnson, C. M.,Dean, W. R.. Children's very low food security is associated with increased dietary intakes in energy, fat, and added sugar among Mexican-origin children (6-11 y) in Texas border Colonias. BMC Pediatr. 2012. 12:16
Intervention/

Exposure;

Outcome

Data date range

Outcome 
Exclusion rationale

229 Sharpe, P. A.,Whitaker, K.,Alia, K. A.,Wilcox, S.,Hutto, B.. Dietary Intake, Behaviors and Psychosocial Factors Among Women from Food-Secure and Food-Insecure Households in the United States. Ethn Dis. 2016. 26:139-46

230 Shiao, S. P. K.,Grayson, J.,Lie, A.,Yu, C. H.. Predictors of the Healthy Eating Index and Glycemic Index in Multi-Ethnic Colorectal Cancer Families. Nutrients. 2018. 10

Intervention/

Exposure

Intervention/

Exposure

231 Shin, Dayeon,Lee, Kyung Won,Song, Won O.. Pre-Pregnancy Weight Status Is Associated with Diet Quality and Nutritional Biomarkers during Pregnancy. Nutrients. 2016; 8 (3):162.

232 Silveira, B. K. S.,de Novaes, J. F.,Vieira, S. A.,Rocha, Dmup,Leal, A. C. G.,Hermsdorff, H. H. M.. Sociodemographic characteristics and dietary patterns in cardiometabolic risk subjects. British Food Journal. 2019. 121:2780-2790

233 Spees, C. K.,Clark, J. E.,Hooker, N. H.,Watowicz, R. P.,Taylor, C. A.. Dietary Intake Contributions of Food and Beverages by Source and Food Security Status in US Adults. J Nutr Educ Behav. 2017. 49:667-673.e1

234 Stein, C.,Cunha-Cruz, J.,Hugo, F. N.. Is dietary pattern a mediator of the relationship between socioeconomic status and dental caries?. Clin Oral Investig. 2021. :

235 Stephenson, B. J. K.,Sotres-Alvarez, D.,Siega-Riz, A. M.,Mossavar-Rahmani, Y.,Daviglus, M. L., Van Horn, L.,Herring, A. H.,Cai, J.. Empirically Derived Dietary Patterns Using Robust Profile Clustering in the Hispanic Community Health Study/Study of Latinos. J Nutr. 2020. 150:28252834

236 Surkan, P. J.,Coutinho, A. J.,Christiansen, K.,Dennisuk, L. A.,Suratkar, S.,Mead, E.,Sharma, S.,Gittelsohn, J.. Healthy food purchasing among African American youth: associations with child gender, adult caregiver characteristics and the home food environment. Public Health Nutrition. 2011. 14:670-677

237 Taillie, L. S.,Ng, S. W.,Xue, Y.,Harding, M.. Deal or no deal? The prevalence and nutritional quality of price promotions among U.S. food and beverage purchases. Appetite. 2017. 117:365372

238 Tan, M. L.,Laraia, B.,Madsen, K. A.,Au, L. E.,Frongillo, E. A.,Ritchie, L. D.. Child Food Insecurity Is Associated with Energy Intake among Fourth- and Fifth-Grade Girls. J Acad Nutr Diet. 2019. 119:1722-1731.e2

239 Taylor, Christopher A.,Spees, Colleen K.,Markwordt, Alayna M.,Watowicz, Rosanna P.,Clark, Jill K.,Hooker, Neal H.. Differences in US Adult Dietary Patterns by Food Security Status. Journal of Consumer Affairs. 2017. 51:549-565

240 Teufel-Shone, N. I.,Jiang, L. H.,Beals, J.,Henderson, W. G.,Zhang, L. J.,Acton, K. J.,Roubideaux, Y.,Manson, S. M.. Demographic characteristics and food choices of participants in the Special Diabetes Program for American Indians Diabetes Prevention Demonstration Project. Ethnicity \& Health. 2015. 20:327-340

241 Thompson, T. L., Singleton, C. R.,Springfield, S. E.,Thorpe, R. J., Jr.,Odoms-Young, A.. Differences in Nutrient Intake and Diet Quality Between Non-Hispanic Black and Non-Hispanic White Men in the United States. Public Health Rep. 2020. 135:334-342

242 Thomson, J. L., Onufrak, S. J.,Connell, C. L.,Zoellner, J. M.,Tussing-Humphreys, L. M.,Bogle, M. L.,Yadrick, K.. Food and beverage choices contributing to dietary guidelines adherence in the Lower Mississippi Delta. Public Health Nutr. 2011. 14:2099-109

243 Thomson, J. L.,Zoellner, J. M.,Tussing-Humphreys, L. M.,Goodman, M. H.. Moderators of intervention dose effects on diet quality and physical activity changes in a church-based, multicomponent, lifestyle study: Delta Body and Soul III. Health Educ Res. 2016. 31:339-49

244 Todd, Jessica E.. Changes in Eating Patterns and Diet Quality Among Working-Age Adults, 2005-2010. 2014

245 Torres-Aguilar, P.,Teran-Garcia, M.,Wiley, A.,Raffaelli, M.,Morales, M.. Factors Correlated to Protective and Risk Dietary Patterns in Immigrant Latino Mothers in Non-metropolitan Rural Communities. J Immigr Minor Health. 2016. 18:652-659

Outcome

Country

Intervention/

Exposure

Intervention/

Exposure

Intervention/

Exposure

Outcome

Outcome

Intervention/

Exposure

Intervention/

Exposure

Data date

range

Comparator

Data date range

Intervention/

Exposure

Outcome

Outcome 
Exclusion rationale

246 Townsend, M. S.,Aaron, G. J.,Monsivais, P.,Keim, N. L., Drewnowski, A.. Less-energy-dense diets of low-income women in California are associated with higher energy-adjusted diet costs. Am J Clin Nutr. 2009. 89:1220-6

247 Tran, L. T.,Brewster, P. J.,Chidambaram, V.,Hurdle, J. F.. Towards Measuring the Food Quality of Grocery Purchases: an Estimation Model of the Healthy Eating Index-2010 Using only Food Item Counts. Procedia Food Sci. 2015. 4:148-159

248 Trapp, C. M.,Burke, G.,Gorin, A. A.,Wiley, J. F.,Hernandez, D.,Crowell, R. E.,Grant, A.,Beaulieu, A.,Cloutier, M. M.. The relationship between dietary patterns, body mass index percentile, and household food security in young urban children. Child Obes. 2015. 11:148-55

249 Treviño, R. P.,Vasquez, L.,Shaw-Ridley, M.,Mosley, D.,Jechow, K.,Piña, C.. Outcome of a food observational study among low-income preschool children participating in a family-style meal setting. Health Educ Behav. 2015. 42:240-8

250 Trude, A. C. B.,Black, M. M.,Surkan, P. J.,Hurley, K. M.,Wang, Y.. Maternal anxiety and diet quality among mothers and toddlers from low-income households. Matern Child Nutr. 2020. 16:e12992

251 Truesdale, K. P.,Matheson, D. M.,JaKa, M. M.,McAleer, S.,Sommer, E. C.,Pratt, C. A.. Baseline diet quality of predominantly minority children and adolescents from households characterized by low socioeconomic status in the Childhood Obesity Prevention and Treatment Research (COPTR) Consortium. BMC Nutr. 2019. 5:38

252 Vadiveloo, M. K.,Parker, H. W.,Juul, F.,Parekh, N.. Sociodemographic Differences in the Dietary Quality of Food-at-Home Acquisitions and Purchases among Participants in the U.S. Nationally Representative Food Acquisition and Purchase Survey (FoodAPS). Nutrients. 2020. 12:

253 Vadiveloo, M.,Guan, X.,Parker, H. W.,Perraud, E.,Buchanan, A.,Atlas, S., Thorndike, A. N.. Effect of Personalized Incentives on Dietary Quality of Groceries Purchased: A Randomized Crossover Trial. JAMA Netw Open. 2021. 4:e2030921

254 Vadiveloo, M.,Perraud, E.,Parker, H. W.,Juul, F.,Parekh, N.. Geographic Differences in the Dietary Quality of Food Purchases among Participants in the Nationally Representative Food Acquisition and Purchase Survey (FoodAPS). Nutrients. 2019. 11:

255 Ver Ploeg, Michele,Rahko vs.ky, llya. Recent Evidence on the Effects of Food Store Access on Food Choice and Diet Quality. 2016. :1

256 Wang, D. D.,Leung, C. W.,Li, Y.,Ding, E. L.,Chiuve, S. E.,Hu, F. B.,Willett, W. C.. Trends in dietary quality among adults in the United States, 1999 through 2010. JAMA Intern Med. 2014. 174:1587-95

257 Wang, Y.,Chen, X.. How much of racial/ethnic disparities in dietary intakes, exercise, and weight status can be explained by nutrition- and health-related psychosocial factors and socioeconomic status among US adults?. J Am Diet Assoc. 2011. 111:1904-11

258 Wang, Y.,Jahns, L., Tussing-Humphreys, L.,Xie, B., Rockett, H.,Liang, H.,Johnson, L.. Dietary intake patterns of low-income urban african-american adolescents. J Am Diet Assoc. 2010. 110:1340-5

259 Weinfield, N. S.,Borger, C.,Au, L. E.,Whaley, S. E.,Berman, D.,Ritchie, L. D.. Longer Participation in WIC Is Associated with Better Diet Quality in 24-Month-Old Children. J Acad Nutr Diet. 2020. 120:963-971

260 Wen, X.,Kong, K. L.,Eiden, R. D.,Sharma, N. N.,Xie, C.. Sociodemographic differences and infant dietary patterns. Pediatrics. 2014. 134:e1387-98

261 Whiteman, E. D.,Chrisinger, B. W.,Hillier, A.. Diet Quality Over the Monthly Supplemental Nutrition Assistance Program Cycle. Am J Prev Med. 2018. 55:205-212

262 Wilson, Magdalena M.,Reedy, Jill,Krebs-Smith, Susan M.. American Diet Quality: Where It Is, Where It Is Heading, and What It Could Be. Journal of the Academy of Nutrition and Dietetics. 2016. 116:302-310.e1
Data date

range

Intervention/

Exposure

Outcome

Intervention/

Exposure;

Outcome;

Comparator

Comparator

Intervention/

Exposure

Outcome

(Purchase

data)

Intervention/

Exposure

Outcome

(Purchase

data)

Outcome;

Study design

Outcome

Data date

range

Intervention/

Exposure

Intervention/

Exposure

Data date

range

Outcome

(Purchase

data)

Intervention/

Exposure 
\# Citation

Exclusion rationale

263 Woodruff, R. C.,Haardörfer, R.,Raskind, I. G.,Hermstad, A.,Kegler, M. C.. Comparing food Outcome desert residents with non-food desert residents on grocery shopping behaviours, diet and BMI: results from a propensity score analysis. Public Health Nutr. 2020. 23:806-811

264 Wright, B. N.,Bailey, R. L.,Craig, B. A.,Mattes, R. D.,McCormack, L.,Stluka, S.,Franzen-Castle, L.,Henne, B.,Mehrle, D.,Remley, D.,Eicher-Miller, H. A.. Daily Dietary Intake Patterns Improve after Visiting a Food Pantry among Food-Insecure Rural Midwestern Adults. Nutrients. 2018.

Intervention/

Exposure 10:

265 Wright, B. N.,Tooze, J. A.,Bailey, R. L.,Liu, Y.,Rivera, R. L.,McCormack, L., Stluka, S.,FranzenCastle, L.,Henne, B.,Mehrle, D.,Remley, D.,Eicher-Miller, H. A.. Dietary Quality and Usual Intake of Underconsumed Nutrients and Related Food Groups Differ by Food Security Status for Rural, Midwestern Food Pantry Clients. J Acad Nutr Diet. 2020. 120:1457-1468

266 Wright, B. N.,Vasquez-Mejia, C. M.,Guenther, P. M.,McCormack, L.,Stluka, S.,Franzen-Castle, L.,Henne, B.,Mehrle, D.,Remley, D.,Eicher-Miller, H. A.. Fruit and Vegetable Healthy Eating Index Component Scores of Distributed Food Bags Were Positively Associated with Client Diet Scores in a Sample of Rural, Midwestern Food Pantries. J Acad Nutr Diet. 2021. 121:74-83

267 Young, C. M.,Batch, B. C.,Svetkey, L. P.. Effect of socioeconomic status on food availability and cost of the Dietary Approaches to Stop Hypertension (DASH) dietary pattern. J Clin Hypertens (Greenwich). 2008. 10:603-11

268 Zarnowiecki, D.,Ball, K.,Parletta, N.,Dollman, J.. Describing socioeconomic gradients in children's diets - does the socioeconomic indicator used matter?. Int J Behav Nutr Phys Act. 2014. 11:44

269 Zhang, Q.,Wang, Y. F.. Socioeconomic and Racial/Ethnic Disparity in Americans' Adherence to Study design Federal Dietary Recommendations. Journal of the Academy of Nutrition and Dietetics. 2012. 112:614-616

270 Zimmer, M. C.,Rubio, V.,Kintziger, K. W.,Barroso, C.. Racial/Ethnic Disparities in Dietary Intake Outcome of U.S. Children Participating in WIC. Nutrients. 2019. 11

271 Zimmer, M. C.,Vernarelli, J. A.. Select Food Group Intake of US Children Aged 2 to 4 Years by Outcome WIC Participation Status and Income. J Acad Nutr Diet. 2020. 120:2032-2038.e1 


\section{Appendix 3-a: Literature search strategy for the rapid review on diet cost and $\mathrm{HEl}$}

\section{Database: PubMed}

Vendor: National Library of Medicine

Date of Search: June 18, 2021

Limits Used: Filters: Language English; Publication Dates 2008 - 2021

Total $=1,152$

\begin{tabular}{|c|c|c|c|}
\hline Search \# & Concept & Search String & $\mathrm{N}$ \\
\hline$\# 1$ & Diet & 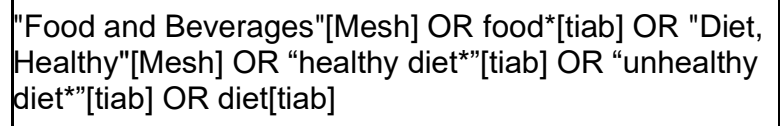 & $1,283,793$ \\
\hline \#2 & Price/Cost & $\begin{array}{l}\text { "Costs and Cost Analysis"[Mesh] OR cost*[tiab] OR } \\
\text { price*[tiab] OR pricing*[tiab] OR affordab*[tiab] OR } \\
\text { expense*[tiab] OR expenditure*[tiab] OR budget*[tiab] } \\
\text { OR purchas*[tiab] OR cash[tiab] OR money[tiab] OR } \\
\text { monetary[tiab] OR monies[tiab] }\end{array}$ & 945,938 \\
\hline$\# 3$ & $\begin{array}{l}\text { HEI (including dietary } \\
\text { patterns terms) }\end{array}$ & $\begin{array}{l}\text { HEI OR "healthy eating index" OR "diet quality"[tiab] OR } \\
\text { "dietary quality"[tiab] OR "dietary guidelines" OR "dietary } \\
\text { recommendation*"[tiab] OR "dietary intake*"[tiab] OR } \\
\text { "dietary consumption"[tiab] OR "eating style*"[tiab] OR } \\
\text { "Guideline Adherence"[Mesh] OR "guideline } \\
\text { adherence*"[tiab] OR "diet score*"[tiab] OR "diet quality } \\
\text { score*"[tiab] OR "diet quality inde**"[tiab] OR "diet } \\
\text { index*"[tiab] OR "dietary inde**"[tiab] OR "food } \\
\text { score*"[tiab] OR "dietary pattern*"[tiab] OR "diet } \\
\text { pattern*"[tiab] OR "eating pattern*"[tiab] OR "food } \\
\text { pattern*"[tiab] }\end{array}$ & 88,968 \\
\hline$\# 4$ & & $\# 1$ AND \#2 AND \#3 & 3,188 \\
\hline$\# 5$ & Non-United States & $\begin{array}{l}\text { \#1 AND \#2 AND \#3 NOT ("Developing } \\
\text { Countries"[Mesh] OR “developing countr" OR “Under } \\
\text { Developed Nation*” OR “low income countr" OR } \\
\text { "middle income countr*”OR “low-middle- } \\
\text { income countr"” OR LMIC[tiab] OR "Europe"[Mesh] } \\
\text { OR "Australia"[Mesh] OR "Asia"[Mesh] OR } \\
\text { "Africa"[Mesh] OR "Mexico"[Mesh] OR } \\
\text { "Islands"[Mesh] OR "Central America"[Mesh] OR "Latin } \\
\text { America"[Mesh] OR "South America"[Mesh]) }\end{array}$ & 2,146 \\
\hline$\# 6$ & Publication Excludes & 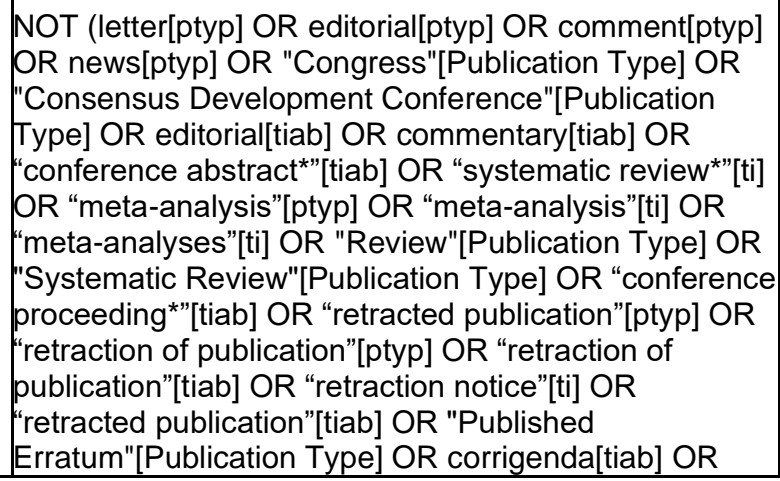 & 1,657 \\
\hline
\end{tabular}




\begin{tabular}{|l|l|l|l|} 
& & $\begin{array}{l}\text { corrigendum[tiab] OR errata[tiab] OR erratum[tiab] OR } \\
\text { protocol[ti] OR protocols[ti] OR “case report"[ti] OR } \\
\text { "case series"[ti] OR "Case Reports" [Publication } \\
\text { Type]) }\end{array}$ & 1,562 \\
\hline$\# 7$ & Animal Excludes & $\begin{array}{l}\text { NOT ("Animals"[Mesh] NOT ("Animals"[Mesh] AND } \\
\text { "Humans"[Mesh])) }\end{array}$ & 1,152 \\
\hline$\# 8$ & Limits: Language/Dates & Filters: English, from $2008-2021$ & 1,10 \\
\hline
\end{tabular}

Database: Business Source Premier Vendor: EBSCO

Date of Search: June 18, 2021

Limits Used: Scholarly (Peer Reviewed) Journals; Published Date: 20080101-20211231; Document Type: Article; Language: English

Total $=887$

\begin{tabular}{|c|c|c|c|}
\hline Search \# & Concept & Search String & $\mathbf{N}$ \\
\hline$\# 1$ & Diet & $\begin{array}{l}\text { (DE "BEVERAGE consumption") OR (DE "FOOD } \\
\text { consumption forecasting") OR (DE "FOOD } \\
\text { consumption statistics") OR food* OR "healthy diet"” } \\
\text { OR "unhealthy diet*" }\end{array}$ & 704,148 \\
\hline$\# 2$ & Price/Cost & $\begin{array}{l}\text { (DE "FOOD prices") OR cost* OR price* OR pricing } \\
\text { OR affordab* OR expense* OR expenditure* OR } \\
\text { budget* OR purchas* OR cash OR money OR } \\
\text { monetary OR monies }\end{array}$ & $3,680,852$ \\
\hline \#3 & $\begin{array}{l}\text { HEI (including dietary } \\
\text { patterns terms) }\end{array}$ & $\begin{array}{l}\text { HEI OR "healthy eating index" OR "diet quality" OR "dietary } \\
\text { quality" OR "dietary guidelines" OR "dietary } \\
\text { recommendation*" OR "dietary intake*" OR "dietary } \\
\text { consumption" OR "eating style*" OR "guideline } \\
\text { adherence*" OR "diet score*" OR "diet quality score*" OR } \\
\text { "diet quality index*" OR "diet index*" OR "dietary index*" } \\
\text { OR "food score*" OR "dietary pattern*" OR "diet pattern*" } \\
\text { OR "eating pattern*" OR "food pattern*" }\end{array}$ & 11,319 \\
\hline$\# 4$ & & \#1 AND \#2 AND \#3 & 2,269 \\
\hline$\# 5$ & Filters & $\begin{array}{l}\text { Limiters - Scholarly (Peer Reviewed) Journals; } \\
\text { Published Date: 20080101-20211231; Document } \\
\text { Type: Article; Language: English }\end{array}$ & 887 \\
\hline
\end{tabular}

Database: Web of Science: Core Collection

Vendor: Clarivate Analytics

Date of Search: 6/18/2021

Limits Used: Years: 2008-2021; Publication Types: Articles, Early Access; Language: English

Total $=2,022$

\begin{tabular}{|l|l|l|l|}
\hline Search \# & Concept & Search String & N \\
\hline$\# 1$ & Diet & (TS=(food* OR "healthy diet*" OR "unhealthy diet*") ) & 824,277 \\
\hline
\end{tabular}




\begin{tabular}{|c|c|c|c|}
\hline \#2 & Price/Cost & $\begin{array}{l}\text { (TS }=\left(\text { cost }^{*} \text { OR price* OR affordab* OR expense* OR expenditure* }\right. \\
\text { OR budget* OR purchas* OR cash OR money OR monetary OR } \\
\text { monies ) ) }\end{array}$ & $1,873,881$ \\
\hline \#3 & $\mathrm{HEI}$ & $\begin{array}{l}\text { (TS=( HEI OR "healthy eating index" OR "diet quality" OR "dietary quality" } \\
\text { OR "dietary guidelines" OR "dietary recommendation*" OR "dietary } \\
\text { intake*" OR "dietary consumption" OR "eating style*" OR "guideline } \\
\text { adherence*" OR "diet score*" OR "diet quality score*" OR "diet quality } \\
\text { index*" OR "diet index*" OR "dietary index*" OR "food score*" OR } \\
\text { "dietary pattern*" OR "diet pattern*" OR "eating pattern*" OR "food } \\
\text { pattern*")) }\end{array}$ & 64,270 \\
\hline \#4 & $\begin{array}{l}\text { \#1 AND \#2 AND } \\
\# 3\end{array}$ & & 3,559 \\
\hline \#5 & $\begin{array}{l}\text { Non-United States } \\
\text { Excludes }\end{array}$ & $\begin{array}{l}\text { CU=("developing countr*" OR "under developed nation*" OR "low i } \\
\text { ncome countr"" OR "middle income } \\
\text { countr*" OR "low-middle income countr*" OR LMIC } \\
\text { OR Europe OR Australia OR Asia OR Africa OR Mexico OR Island } \\
\text { s OR "Central America" OR "Latin America" OR "South America") }\end{array}$ & $2,061,484$ \\
\hline \#6 & \#4 NOT \#5 & & 3,137 \\
\hline$\# 7$ & $\begin{array}{l}\text { Publication } \\
\text { Excludes }\end{array}$ & $\begin{array}{l}\text { TS=(editorial OR commentary OR "conference abstract*" OR "conf } \\
\text { erence proceeding*”[tiab] OR "retraction of publication" OR "retract } \\
\text { ed publication" OR corrigenda[tiab] OR corrigendum[tiab] OR errat } \\
\text { a OR erratum OR "case reports" ) OR TI=("systematic review" OR } \\
\text { "meta-analysis" } \\
\text { OR "meta analyses" OR protocol OR protocols } \\
\text { OR "retraction notice" OR "case report" OR } \\
\text { "case series") }\end{array}$ & 721,284 \\
\hline \#8 & \#6 NOT \#7 & & 3,054 \\
\hline \#9 & & $\begin{array}{l}\text { Years: 2008-2021; Publication Types: Articles, Early Access; } \\
\text { Language: English }\end{array}$ & 2,022 \\
\hline
\end{tabular}

\section{Grey Literature Search:}

\section{Google Scholar}

(Food OR diet) AND (Price OR cost OR budget OR money) AND (HEI OR "healthy eating index" OR dietary)

Limits: Date Published: 2008-2021;

Date Searched: 6/18/2021

Results: 50 , limited to 5 pages

\section{Google}

site:.gov AND (diet OR food) AND (cost OR price) AND "healthy eating index"

Limits:

Date Searched: 6/18/2021

Results: Date Published: 30, limited to 3 pages

\section{AgEcon}

Any of the words: food diet AND

Any of the words: cost price 


\section{USDA United States \\ Department of \\ Agriculture}

AND

Any of the words: HEI "healthy eating index" dietary

Limits: Added/Modified since: 2008;

Date Searched: 6/21/2021

Results: Date Published: 40 , limited to 4 pages 


\section{Appendix 3-b: Excluded articles for the rapid review on diet cost and $\mathrm{HEl}$}

The following table lists the articles excluded after full-text screening for this rapid review question. At least 1 reason for exclusion is provided for each article, though this may not reflect all possible reasons. Information about articles excluded after title and abstract screening is available upon request.

\# Bibliography

1 affordable healthy food: Topics by Science.gov, 2021

$2 \quad$ Federal Register, Volume 85 Issue 228 (Wednesday, November 25, 2020). 2020

3 Healthy Eating Index (HEI) | USDA-FNS. 2021

$4 \quad$ Research Rundown: USDA School Nutrition and Meal Cost Study. 2019;

5 TFCO Access to Healthy Affordable Food

Acheampong, I.,Haldeman, L. Are nutrition knowledge, attitudes, and beliefs

associated with obesity among low-income Hispanic and African American women

6 caretakers?. J Obes. 2013; 2013 :123901. doi: 10.1155/2013/123901.

Aggarwal, A.,Drewnowski, A. Plant- and animal-protein diets in relation to sociodemographic drivers, quality, and cost: findings from the Seattle Obesity Study.

$7 \quad$ Am J Clin Nutr. 2019; 110 (2):451-460. doi: 10.1093/ajcn/nqz064. Aggarwal, A.,Monsivais, P.,Cook, A. J.,Drewnowski, A. Does diet cost mediate the relation between socioeconomic position and diet quality?. Eur J Clin Nutr. 2011; 65

8 (9):1059-66. doi: 10.1038/ejcn.2011.72. Aggarwal, A.,Monsivais, P.,Cook, A. J.,Drewnowski, A. Positive attitude toward healthy eating predicts higher diet quality at all cost levels of supermarkets. J Acad

$9 \quad$ Nutr Diet. 2014; 114 (2):266-72. doi: 10.1016/j.jand.2013.06.006. Aggarwal, A.,Monsivais, P.,Drewnowski, A. Nutrient intakes linked to better health outcomes are associated with higher diet costs in the US. PLoS One. 2012; 7

10 (5):e37533. doi: 10.1371/journal.pone.0037533. Aggarwal, A.,Rehm, C. D.,Monsivais, P.,Drewnowski, A. Importance of taste, nutrition, cost and convenience in relation to diet quality: Evidence of nutrition resilience among US adults using National Health and Nutrition Examination Survey (NHANES) 2007-2010. Prev Med. 2016; 90 :184-92. doi:

11 10.1016/j.ypmed.2016.06.030. Amenyenu, Anonya,Tegegne, Fisseha,Singh, Surendra P.,Ekanem, Enefiok. Knowledge of 2005 Dietary Guidelines and Food Consumption Habits of African-

12 Americans in Tennessee. Journal of Food Distribution Research. 2010; 41 (1):1-4. Appelhans, B. M.,French, S. A.,Tangney, C. C.,Powell, L. M.,Wang, Y. To what extent do food purchases reflect shoppers' diet quality and nutrient intake?. Int $\mathrm{J}$

13 Behav Nutr Phys Act. 2017; 14 (1):46. doi: 10.1186/s12966-017-0502-2. Appelhans, B. M.,Milliron, B. J.,Woolf, K.,Johnson, T. J.,Pagoto, S. L.,Schneider, K. L.,Whited, M. C., Ventrelle, J. C. Socioeconomic status, energy cost, and nutrient content of supermarket food purchases. Am J Prev Med. 2012; 42 (4):398-402. doi:

$14 \quad$ 10.1016/j.amepre.2011.12.007. Appelhans, B. M.,Tangney, C. C.,French, S. A.,Crane, M. M.,Wang, Y. Delay discounting and household food purchasing decisions: The SHoPPER study. Health

15 Psychol. 2019; 38 (4):334-342. doi: 10.1037/hea0000727. Basu, S.,Gardner, C. D.,White, J. S.,Rigdon, J.,Carroll, M. M.,Akers, M.,Seligman, H. K. Effects Of Alternative Food Voucher Delivery Strategies On Nutrition Among LowIncome Adults. Health Aff (Millwood). 2019; 38 (4):577-584. doi:

$16 \quad 10.1377 /$ hlthaff.2018.05405. Basu, S.,Seligman, H.,Bhattacharya, J. Nutritional policy changes in the supplemental nutrition assistance program: a microsimulation and cost-effectiveness

\section{Exclusion rationale}

Publication status

Publication status

Publication status

Pubilcation status

Outcome, Study design

Intervention/Exposure, Outcome

Outcome

Outcome

Outcome

Outcome

Intervention/Exposure, Data date range

Intervention/Exposure

Intervention/Exposure Intervention/Exposure Intervention/Exposure 
Baudry, J.,Pointereau, P.,Seconda, L., Vidal, R.,Taupier-Letage, B.,Langevin, B.,Alles,

B.,Galan, P.,Hercberg, S.,Amiot, M. J.,Boizot-Szantai, C.,Hamza, O.,Cravedi, J.

P.,Debrauwer, L.,Soler, L. G.,Lairon, D.,Kesse-Guyot, E. Improvement of diet sustainability with increased level of organic food in the diet: findings from the BioNutriNet cohort. American Journal of Clinical Nutrition. 2019; 109 (4):1173-1188.

18 doi: 10.1093/ajen/nqy361.

Beheshti, R.,Jones-Smith, J. C., Igusa, T. Taking dietary habits into account: A

Country computational method for modeling food choices that goes beyond price. PLoS One.

19 2017; 12 (5):e0178348. doi: 10.1371/journal.pone.0178348.

Bernstein, A. M.,Bloom, D. E.,Rosner, B. A.,Franz, M.,Willett, W. C. Relation of food cost to healthfulness of diet among US women. Am J Clin Nutr. 2010; 92 (5):119720 203. doi: 10.3945/ajcn.2010.29854.

Outcome, Data date range

Data date range

Bessems, Kmhh,Linssen, E.,Lomme, M.,Van Assema, P. The Effectiveness of the Good Affordable Food Intervention for Adults with Low Socioeconomic Status and Small Incomes. International Journal of Environmental Research and Public Health.

$212020 ; 17$ (7) doi: 10.3390/ijerph17072535.

Beydoun, M. A.,Nkodo, A.,Fanelli-Kuczmarski, M. T.,Maldonado, A. I.,Beydoun, H. A.,Popkin, B. M.,Evans, M. K.,Zonderman, A. B. Longitudinal Associations between Monetary Value of the Diet, DASH Diet Score and the Allostatic Load among Middle-

22 Aged Urban Adults. Nutrients. 2019; 11 (10) doi: 10.3390/nu11102360.

Outcome

Beydoun, M. A.,Powell, L. M.,Chen, X.,Wang, Y. Food prices are associated with dietary quality, fast food consumption, and body mass index among U.S. children and adolescents. J Nutr. 2011; 141 (2):304-11. doi: 10.3945/jn.110.132613.

Intervention/Exposure, Data date range

Beydoun, M. A.,Powell, L. M.,Wang, Y. Reduced away-from-home food expenditure and better nutrition knowledge and belief can improve quality of dietary intake among US adults. Public Health Nutr. 2009; 12 (3):369-81. doi:

24 10.1017/S1368980008002140.

Intervention/Exposure, Data date range

Beydoun, M. A.,Powell, L. M.,Wang, Y. The association of fast food, fruit and vegetable prices with dietary intakes among US adults: is there modification by family income?. Soc Sci Med. 2008; 66 (11):2218-29. doi:

25 10.1016/j.socscimed.2008.01.018.

Intervention/Exposure, Data date range

Beydoun, M. A.,Wang, Y. How do socio-economic status, perceived economic barriers and nutritional benefits affect quality of dietary intake among US adults?. Eur

26 J Clin Nutr. 2008; 62 (3):303-13. doi: 10.1038/sj.ejcn.1602700.

Data date range

Bouis, H. E.,Eozenou, P.,Rahman, A. Food prices, household income, and resource allocation: Socioeconomic perspectives on their effects on dietary quality and nutritional status. Food and Nutrition Bulletin. 2011; 32 (1):S14-S23. doi:

$27 \quad 10.1177 / 15648265110321$ S103.

Country

Brewster, P. J.,Durward, C. M.,Hurdle, J. F.,Stoddard, G. J.,Guenther, P. M. The Grocery Purchase Quality Index-2016 Performs Similarly to the Healthy Eating Index2015 in a National Survey of Household Food Purchases. J Acad Nutr Diet. 2019; 28119 (1):45-56. doi: 10.1016/j.jand.2018.08.165. Brewster, P. J.,Guenther, P. M.,Jordan, K. C.,Hurdle, J. F. The Grocery Purchase Quality Index-2016: An innovative approach to assessing grocery food purchases. Journal of Food Composition and Analysis. 2017; 64 :119-126. doi:

$29 \quad$ 10.1016/j.jfca.2017.07.012.

Intervention/Exposure

Carlson, A.,Dong, D. S.,Lino, M. Association between Total Diet Cost and Diet Quality Is Limited. Journal of Agricultural and Resource Economics. 2014; 39 (1):4768.

Data date range

Carlson, A.,Frazao, E. Food costs, diet quality and energy balance in the United States. Physiology \& Behavior. 2014; 134 :20-31. doi:

31 10.1016/j.physbeh.2014.03.001.

Data date range 
Carlson, Andrea,Dong, Diansheng,Lino, Mark. ARE THE TOTAL DAILY COST OF FOOD AND DIET QUALITY RELATED: A RANDOM EFFECTS PANEL DATA

32 ANALYSIS. . 2010; :25. doi: 10.22004/ag.econ.116395. Carlson, Andrea,Lino, Mark,Fungwe, Thomas V.,Guenther, Patricia M. Eating a

33 Healthy Diet: Is Cost a Major Factor?. . 2009; doi: 10.22004/ag.econ.49259.

Data date range

Caspi, C. E.,Lenk, K.,Pelletier, J. E.,Barnes, T. L.,Harnack, L.,Erickson, D. J.,Laska,

M. N. Association between store food environment and customer purchases in small grocery stores, gas-marts, pharmacies and dollar stores. Int J Behav Nutr Phys Act.

34 2017; 14 (1):76. doi: 10.1186/s12966-017-0531-x.

Intervention/Exposure

Chen, Xiu,Kaiser, Harry M.,Rickard, Bradley J. The Salience of Excise vs.. Sales

Taxes on Healthy Eating: An Experimental Study. . 2014; :39. doi:

35 10.22004/ag.econ.180111.

Chrisinger, B. W.,Kallan, M. J.,Whiteman, E. D.,Hillier, A. Where do U.S. households

purchase healthy foods? An analysis of food-at-home purchases across different

types of retailers in a nationally representative dataset. Prev Med. 2018; 112 :15-22.

36 doi: 10.1016/j.ypmed.2018.03.015.

Clark, R. L.,Famodu, O. A.,Barr, M. L.,Hagedorn, R. L., Ruseski, J.,White, J.

Intervention/Exposure

A.,Warner, C. M.,Morrell, A. M.,Murray, P. J.,Olfert, I. M.,McFadden, J. W.,Downes,

M. T.,Colby, S. E.,Olfert, M. D. Monetary Cost of the MyPlate Diet in Young Adults:

Higher Expenses Associated with Increased Fruit and Vegetable Consumption. J Nutr

37 Metab. 2019; 2019 :2790963. doi: 10.1155/2019/2790963.

Outcome

Collins, A. M.,Klerman, J. A. Improving Nutrition by Increasing Supplemental Nutrition

Assistance Program Benefits. Am J Prev Med. 2017; 52 (2S2):S179-S185. doi:

38 10.1016/j.amepre.2016.08.032.

Outcome

Courtemanche, Charles,Denteh, Augustine,Tchernis, Rusty. Estimating the

Associations between SNAP and Food Insecurity, Obesity, and Food Purchases with

Imperfect Administrative Measures of Participation. Southern Economic Journal.

39 2019; 86 (1):202-228. doi: 10.1002/soej.12364.

Intervention/Exposure

Crane, M. M.,Tangney, C. C.,French, S. A.,Wang, Y.,Appelhans, B. M. Gender

Comparison of the Diet Quality and Sources of Food Purchases Made by Urban

Primary Household Food Purchasers. J Nutr Educ Behav. 2019; 51 (2):199-204. doi:

$40 \quad$ 10.1016/j.jneb.2018.07.016.

Intervention/Exposure

D'Angelo, H.,Suratkar, S.,Song, H. J.,Stauffer, E.,Gittelsohn, J. Access to food

source and food source use are associated with healthy and unhealthy food-

purchasing behaviours among low-income African-American adults in Baltimore City.

41 Public Health Nutrition. 2011; 14 (9):1632-1639. doi: 10.1017/S1368980011000498.

Outcome

Darmon, N.,Lacroix, A.,Muller, L.,Ruffieux, B. Food price policies improve diet quality while increasing socioeconomic inequalities in nutrition. Int J Behav Nutr Phys Act.

42 2014; $11: 66$. doi: 10.1186/1479-5868-11-66.

Outcome

Davis, G. C.,Carlson, A. The inverse relationship between food price and energy density: is it spurious?. Public Health Nutr. 2015; 18 (6):1091-7. doi:

43 10.1017/S1368980014001098.

Outcome

Deierlein, A. L.,Morland, K. B.,Scanlin, K.,Wong, S.,Spark, A. Diet quality of urban

older adults age 60 to 99 years: the Cardiovascular Health of Seniors and Built

Environment Study. J Acad Nutr Diet. 2014; 114 (2):279-87. doi:

$44 \quad 10.1016 / j . j a n d .2013 .09 .002$.

Intervention/Exposure

Dellava, Jocilyn E,Bulik, Cynthia M,Popkin, Barry M. Price changes alone are not adequate to produce long-term dietary change. The Journal of nutrition. 2010; 140

45 (10):1887-1891.

Dhakal, C. K.,Khadka, S. Heterogeneities in Consumer Diet Quality and Health

Outcomes of Consumers by Store Choice and Income. Nutrients. 2021; 13 (4) doi: 
Drewnowski, A. Nutrient density: addressing the challenge of obesity. Br J Nutr.
$472018 ; 120$ (s1):S8-S14. doi: 10.1017/S0007114517002240.

Study design

Drewnowski, A. Nutrition Economics: How to Eat Better for Less. J Nutr Sci Vitaminol

48 (Tokyo). 2015; 61 Suppl :S69-71. doi: 10.3177/jnsv.61.S69.

Study design

Drewnowski, A. The economics of food choice behavior: why poverty and obesity are

49 linked. Nestle Nutr Inst Workshop Ser. 2012; 73 :95-112. doi: 10.1159/000341303.

Outcome, Study design

Drewnowski, A.,Kawachi, I. Diets and Health: How Food Decisions Are Shaped by

Biology, Economics, Geography, and Social Interactions. Big Data. 2015; 3 (3):193-

50 197. doi: 10.1089/big.2015.0014.

Study design

D'Souza, Anna,Jolliffe, Dean. Food Insecurity in Vulnerable Populations: Coping with

Food Price Shocks in Afghanistan. American Journal of Agricultural Economics.

$51 \quad$ 2014; 96 (3):790-812. doi: 10.1093/ajae/aat089.

Country

Duffey, K. J.,Gordon-Larsen, P.,Shikany, J. M.,Guilkey, D.,Jacobs, D. R., Jr.,Popkin,

B. M. Food price and diet and health outcomes: 20 years of the CARDIA Study. Arch

52 Intern Med. 2010; 170 (5):420-6. doi: 10.1001/archinternmed.2009.545.

Data date range

Egeland, G. M.,Williamson-Bathory, L.,Johnson-Down, L.,Sobol, I. Traditional food

and monetary access to market-food: correlates of food insecurity among Inuit

preschoolers. Int J Circumpolar Health. 2011; 70 (4):373-83. doi:

53 10.3402/ijch.v70i4.17836.

Country

Emond, J. A.,Madanat, H. N.,Ayala, G. X. Do Latino and non-Latino grocery stores

differ in the availability and affordability of healthy food items in a low-income,

metropolitan region?. Public Health Nutrition. 2012; 15 (2):360-369. doi:

54 10.1017/S1368980011001169.

Intervention/Exposure,

Epstein, L. H.,Finkelstein, E. A.,Katz, D. L.,Jankowiak, N.,Pudlewski, C.,Paluch, R. A.

Effects of nutrient profiling and price changes based on $\mathrm{NuVal}(\mathrm{R})$ scores on food

purchasing in an online experimental supermarket. Public Health Nutr. 2016; 19

55 (12):2157-64. doi: 10.1017/S1368980015002931.

Outcome

Ford, C. N.,Poti, J. M.,Ng, S. W.,Popkin, B. M. SSB taxes and diet quality in US

preschoolers: estimated changes in the 2010 Healthy Eating Index. Pediatr Obes.

56 2017; 12 (2):146-154. doi: 10.1111/ijpo.12121.

Forrestal, S.,Potamites, E.,Guthrie, J.,Paxton, N. Associations among Food Security,

School Meal Participation, and Students' Diet Quality in the First School Nutrition and

57 Meal Cost Study. Nutrients. 2021; 13 (2) doi: 10.3390/nu13020307.

Franckle, R. L., Thorndike, A. N.,Moran, A. J.,Hou, T.,Blue, D., Greene, J. C.,Bleich, S.

N.,Block, J. P.,Polacsek, M.,Rimm, E. B. Supermarket Purchases Over the

Supplemental Nutrition Assistance Program Benefit Month: A Comparison Between

Participants and Nonparticipants. Am J Prev Med. 2019; 57 (6):800-807. doi:

58 10.1016/j.amepre.2019.07.025.

Freedman, D. A.,Bell, B. A.,Clark, J.,Ngendahimana, D.,Borawski, E.,Trapl, E.,Pike,

Outcome

S.,Sehgal, A. R. Small Improvements in an Urban Food Environment Resulted in No

Changes in Diet Among Residents. J Community Health. 2021; 46 (1):1-12. doi:

59 10.1007/s10900-020-00805-z.

Intervention/Exposure

French, S. A., Tangney, C. C.,Crane, M. M.,Wang, Y.,Appelhans, B. M. Nutrition

quality of food purchases varies by household income: the SHoPPER study. BMC

60 Public Health. 2019; 19 (1):231. doi: 10.1186/s12889-019-6546-2.

French, S. A.,Wall, M.,Mitchell, N. R.,Shimotsu, S. T.,Welsh, E. Annotated receipts capture household food purchases from a broad range of sources. Int J Behav Nutr

61 Phys Act. 2009; $6: 37$. doi: 10.1186/1479-5868-6-37.

Intervention/Exposure

Outcome

Fulgoni, V., 3rd,Drewnowski, A. An Economic Gap Between the Recommended

Healthy Food Patterns and Existing Diets of Minority Groups in the US National

Health and Nutrition Examination Survey 2013-14. Front Nutr. 2019; 6 :37. doi: 
Gao, Zhifeng,Yu, Xiaohua,Lee, Jonq-Ying. Consumer demand for diet quality: evidence from the healthy eating index Consumer demand for diet quality: evidence from the healthy eating index. Australian Journal of Agricultural \& Resource

63 Economics. 2013; 57 (3):301-319. doi: 10.1111/j.1467-8489.2012.00619.x. Intervention/Exposure Glickman, A. R.,Clark, J. K.,Freedman, D. A. A relational approach to evaluate food environments finds that the proximate food environment matters for those who use it.

64 Health Place. 2021; 69 :102564. doi: 10.1016/j.healthplace.2021.102564. Intervention/Exposure Gregory, Christian ,Ver Ploeg, Michele ,Andrews, Margaret ,Coleman-Jensen, Alisha . Supplemental Nutrition Assistance Program (SNAP) Participation Leads to Modest

65 Changes in Diet Quality. . 2013; :36. doi: 10.22004/ag.econ.262225. Intervention/Exposure Guenther, P. M.,Luick, B. R. Improved Overall Quality of Diets Reported by Expanded Food and Nutrition Education Program Participants in the Mountain

66 Region. J Nutr Educ Behav. 2015; 47 (5):421-6 e1. doi: 10.1016/j.jneb.2015.05.001. Comparator Gustafson, A.,Jilcott Pitts, S.,McDonald, J.,Ford, H.,Connelly, P.,Gillespie, R.,Liu, E.,Bush, H.,Brancato, C.,Babatande, T.,Mullins, J. Direct Effects of the Home, School, and Consumer Food Environments on the Association between Food Purchasing Patterns and Dietary Intake among Rural Adolescents in Kentucky and North Carolina, 2017. Int J Environ Res Public Health. 2017; 14 (10) doi:

$67 \quad 10.3390 /$ ijerph14101255. Outcome Hakansson, A.,Andersson, H. S.,Granfeldt, Y. Diet inequality prevails among consumers interested and knowledgeable in nutrition. Food Nutr Res. 2015; 59

$68 \quad$ :27601. doi: 10.3402/fnr.v59.27601. Hamad, R.,Templeton, Z. S.,Schoemaker, L.,Zhao, M.,Bhattacharya, J. Comparing demographic and health characteristics of new and existing SNAP recipients: application of a machine learning algorithm. Am J Clin Nutr. 2019; 109 (4):1164-

69 1172. doi: 10.1093/ajen/nqy355. Han, H. Y.,Paquet, C.,Dube, L.,Nielsen, D. E. Diet Quality and Food Prices Modify Associations between Genetic Susceptibility to Obesity and Adiposity Outcomes.

70 Nutrients. 2020; 12 (11) doi: 10.3390/nu12113349. Harnack, L.,Oakes, J. M.,Elbel, B.,Beatty, T.,Rydell, S.,French, S. Effects of Subsidies and Prohibitions on Nutrition in a Food Benefit Program: A Randomized Clinical Trial. JAMA Intern Med. 2016; 176 (11):1610-1618. doi:

71 10.1001/jamainternmed.2016.5633. Hatzenbuehler, Patrick L.,Gillespie, Jeffrey M.,O'Neil, Carol E. The Cost of Dietary Variety: A Case of Fruit and Vegetables. Journal of Food Distribution Research.

$72 \quad 2011 ; 42(3): 1-13$.

Hilmers, A.,Chen, T. A.,Dave, J. M.,Thompson, D.,Cullen, K. W. Supplemental Nutrition Assistance Program participation did not help low income Hispanic women in Texas meet the dietary guidelines. Prev Med. 2014; 62 :44-8. doi:

73 10.1016/j.ypmed.2014.01.016. Huffman, F. G.,Vaccaro, J. A.,Zarini, G. G.,Dixon, Z. Comparison of Two Indices of Diet Quality with Acculturation Factors and Demographics in Haitian Americans. Ecology of Food and Nutrition. 2014; 53 (1):42-57. doi:

$74 \quad 10.1080 / 03670244.2013 .774674$. Hyder, J. A., Thomson, C. A.,Natarajan, L.,Madlensky, L.,Pu, M.,Emond, J.,Kealey, S.,Rock, C. L.,Flatt, S. W.,Pierce, J. P.,Whel Study Group. Adopting a plant-based diet minimally increased food costs in WHEL Study. Am J Health Behav. 2009; 33

75 (5):530-9. doi: 10.5993/ajhb.33.5.6. Jahns, L.,McDonald, L.,Wadsworth, A.,Morin, C.,Liu, Y.,Nicklas, T. Barriers and facilitators to following the Dietary Guidelines for Americans reported by rural, Northern Plains American-Indian children. Public Health Nutr. 2015; 18 (3):482-9. doi: $10.1017 / S 136898001400041 \mathrm{X}$.

Country

Intervention/Exposure, Outcome

Intervention/Exposure, Outcome Intervention/Exposure

Outcome, Data date range

Intervention/Exposure, Outcome 
Jetter, K. M.,Adkins, J.,Cortez, S.,Hopper, G. K., Jr.,Shively, V.,Styne, D. M. Yes We Can: Eating Healthy on a Limited Budget. J Nutr Educ Behav. 2019; 51 (3):268-276. doi: 10.1016/j.jneb.2018.12.002.

Intervention/Exposure, Outcome Jilcott Pitts, S. B.,Wu, Q., Truesdale, K. P.,Rafferty, A. P.,Haynes-Maslow, L.,Boys, K. A.,McGuirt, J. T.,Fleischhacker, S.,Johnson, N.,Kaur, A. P.,Bell, R. A.,Ammerman, A. S.,Laska, M. N. A four-year observational study to examine the dietary impact of the North Carolina Healthy Food Small Retailer Program, 2017-2020. Int J Behav Nutr

78 Phys Act. 2021; 18 (1):44. doi: 10.1186/s12966-021-01109-8. Intervention/Exposure Keim, N. L.,Forester, S. M.,Lyly, M.,Aaron, G. J.,Townsend, M. S. Vegetable variety is a key to improved diet quality in low-income women in California. J Acad Nutr Diet. 79 2014; 114 (3):430-5. doi: 10.1016/j.jand.2013.07.026.

Intervention/Exposure, Outcome Kell, K. P.,Judd, S. E.,Pearson, K. E.,Shikany, J. M.,Fernandez, J. R. Associations between socio-economic status and dietary patterns in US black and white adults. British Journal of Nutrition. 2015; 113 (11):1792-1799. doi:

$80 \quad 10.1017 /$ S0007114515000938.

Intervention/Exposure, Outcome

Kern, D. M.,Auchincloss, A. H.,Robinson, L. F.,Stehr, M. F.,Pham-Kanter, G. Healthy and Unhealthy Food Prices across Neighborhoods and Their Association with Neighborhood Socioeconomic Status and Proportion Black/Hispanic. Journal of Urban Health-Bulletin of the New York Academy of Medicine. 2017; 94 (4):494-505.

81 doi: 10.1007/s11524-017-0168-8.

Outcome

Kern, D. M.,Auchincloss, A. H.,Stehr, M. F.,Roux, A. V. D.,Moore, L. V.,Kanter, G. P.,Robinson, L. F. Neighborhood Prices of Healthier and Unhealthier Foods and Associations with Diet Quality: Evidence from the Multi-Ethnic Study of Atherosclerosis. Int J Environ Res Public Health. 2017; 14 (11) doi:

82 10.3390/ijerph14111394. Klassen, A. C.,Smith, K. C.,Black, M. M.,Caulfield, L. E. Mixed method approaches to understanding cancer-related dietary risk reduction among public housing residents. J

83 Urban Health. 2009; 86 (4):624-40. doi: 10.1007/s11524-009-9352-9. Kroshus, E. Gender, marital status, and commercially prepared food expenditure. J

84 Nutr Educ Behav. 2008; 40 (6):355-60. doi: 10.1016/j.jneb.2008.05.012.

Intervention/Exposure, Comparator

Intervention/Exposure, Data date range Leone, A. F.,Rigby, S.,Betterley, C.,Park, S.,Kurtz, H.,Johnson, M. A.,Lee, J. S. Store type and demographic influence on the availability and price of healthful foods, Leon 85 County, Florida, 2008. Prev Chronic Dis. 2011; 8 (6):A140.

Outcome

Outcome Liese, A. D.,Ma, X.,Hutto, B.,Sharpe, P. A.,Bell, B. A.,Wilcox, S. Food Shopping and Acquisition Behaviors in Relation to BMI among Residents of Low-Income Communities in South Carolina. Int J Environ Res Public Health. 2017; 14 (9) doi: $86 \quad 10.3390 /$ ijerph14091075. Lin, Biing-Hwan. Nutrition and Health Characteristics of Low-Income Populations:

87 Healthy Eating Index. . 2005; :4. doi: 10.22004/ag.econ.33617.

Outcome Litvak, J.,Parekh, N.,Juul, F.,Deierlein, A. Food assistance programs and income are associated with the diet quality of grocery purchases for households consisting of women of reproductive age or young children. Prev Med. 2020; 138 :106149. doi:

88 10.1016/j.ypmed.2020.106149. Mabli J, Castner L, Ohls J, Fox MK, Crepinsek MK, Condon E. Food Expenditures

89 and Diet Quality Among Low-Income Households and Individuals. . 2010; Maillot, M.,Drewnowski, A. Energy allowances for solid fats and added sugars in nutritionally adequate U.S. diets estimated at $17-33 \%$ by a linear programming model.

90 J Nutr. 2011; 141 (2):333-40. doi: 10.3945/jn.110.131920. Mancino, Lisa,Todd, Jessica E.,Scharadin, Benjamin. USDA's National Household Food Acquisition and Purchase Survey: Methodology for Imputing Missing Quantities To Calculate Healthy Eating Index-2010 Scores and Sort Foods Into ERS Food 91 Groups. . 2018; doi: 10.22004/ag.econ.276252.

Intervention/Exposure, Comparator 
Masset, G.,Monsivais, P.,Maillot, M.,Darmon, N.,Drewnowski, A. Diet optimization methods can help translate dietary guidelines into a cancer prevention food plan. J

92 Nutr. 2009; 139 (8):1541-8. doi: 10.3945/jn.109.104398.

Outcome

McClain, A. C.,Tucker, K. L.,Falcon, L. M.,Mattei, J. Food insecurity and dietary

intake by Supplemental Nutrition Assistance Program participation status among

mainland US Puerto Rican adults after the 2009 American Recovery and

Reinvestment Act. Public Health Nutrition. 2019; 22 (16):2989-2998. doi:

93 10.1017/S1368980019002209.

Intervention/Exposure

McCurley, J. L.,Levy, D. E.,Rimm, E. B.,Gelsomin, E. D.,Anderson, E. M.,Sanford, J.

M.,Thorndike, A. N. Association of Worksite Food Purchases and Employees' Overall

Dietary Quality and Health. Am J Prev Med. 2019; 57 (1):87-94. doi:

94 10.1016/j.amepre.2019.02.020.

Intervention/Exposure

McDaniel, J. C.,Belury, M. A. Are young adults following the dietary guidelines for

Americans?. Nurse Pract. 2012; 37 (5):1-9. doi:

95 10.1097/01.NPR.0000413484.90121.d8.

McDermott, A. J.,Stephens, M. B. Cost of eating: whole foods versus convenience

96 foods in a low-income model. Fam Med. 2010; 42 (4):280-4.

Outcome

Middaugh, A. L.,Fisk, P. S.,Brunt, A., Rhee, Y. S. Few Associations between Income and Fruit and Vegetable Consumption. Journal of Nutrition Education and Behavior.

97 2012; 44 (3):196-203. doi: 10.1016/j.jneb.2011.10.003.

Outcome

Intervention/Exposure,

Molitor, F.,Doerr, C.,Pugliese, J.,Whetstone, L. Three-year trends in dietary

behaviours among mothers, teenagers and children from SNAP-Ed (Supplemental

Nutrition Assistance Program-Education) eligible households across California. Public

98 Health Nutr. 2020; 23 (1):3-12. doi: 10.1017/S1368980019003197.

Intervention/Exposure

Monsivais, P.,Aggarwal, A.,Drewnowski, A. Following federal guidelines to increase

nutrient consumption may lead to higher food costs for consumers. Health Aff

99 (Millwood). 2011; 30 (8):1471-7. doi: 10.1377/hlthaff.2010.1273.

Outcome

Monsivais, P.,Drewnowski, A. Lower-energy-density diets are associated with higher monetary costs per kilocalorie and are consumed by women of higher socioeconomic

100 status. J Am Diet Assoc. 2009; 109 (5):814-22. doi: 10.1016/j.jada.2009.02.002.

Monsivais, P.,Perrigue, M. M.,Adams, S. L.,Drewnowski, A. Measuring diet cost at the individual level: a comparison of three methods. Eur J Clin Nutr. 2013; 67

101 (11):1220-5. doi: 10.1038/ejcn.2013.176.

Mulik, K.,Haynes-Maslow, L. The Affordability of MyPlate: An Analysis of SNAP

Benefits and the Actual Cost of Eating According to the Dietary Guidelines. J Nutr

102 Educ Behav. 2017; 49 (8):623-631 e1. doi: 10.1016/j.jneb.2017.06.005.

Mulik, Kranti,Haynes Maslow, Lindsey. Is MyPlate really Affordable? An analysis of

SNAP Benefits and the actual cost of eating according to the dietary guidelines. .

Outcome, Data date

range

Outcome

2016; doi: 10.22004/ag.econ.235924.

Nicklas, T. A.,Jahns, L.,Bogle, M. L.,Chester, D. N.,Giovanni, M.,Klurfeld, D.

M.,Laugero, K.,Liu, Y.,Lopez, S.,Tucker, K. L. Barriers and facilitators for consumer

adherence to the dietary guidelines for Americans: the HEALTH study. J Acad Nutr

104 Diet. 2013; 113 (10):1317-31. doi: 10.1016/j.jand.2013.05.004.

Outcome

O'Keeffe, M.,Jansen, C.,Martin, L.,Williams, M.,Seamark, L.,Staudacher, H. M.,Irving,

P. M.,Whelan, K.,Lomer, M. C. Long-term impact of the low-FODMAP diet on

gastrointestinal symptoms, dietary intake, patient acceptability, and healthcare

utilization in irritable bowel syndrome. Neurogastroenterol Motil. 2018; 30 (1) doi:

105 10.1111/nmo.13154.

Outcome

Parker, H. W.,de Araujo, C.,Thorndike, A. N.,Vadiveloo, M. K. The utility of household

Grocery Purchase Quality Index scores as an individual diet quality metric. Br J Nutr.

106 2020; :1-9. doi: 10.1017/S0007114520004833.

Parum, Faith,Dharmasena, Senarath. U.S. Consumers' Intake of Food at Home

Outcome, Multiple food groups

Intervention/Exposure,

Outcome

$(\mathrm{FAH})$ and Food Away from Home (FAFH) As a Complex Economic System. Journal

107 of Food Distribution Research. 2021; 52 (1):77-85.

Intervention/Exposure,

Outcome

Intervention/Exposure

Outcome 
Ranjit, N.,Macias, S.,Hoelscher, D. Factors related to poor diet quality in food insecure populations. Transl Behav Med. 2020; 10 (6):1297-1305. doi:

108 10.1093/tbm/ibaa028. Rehm, C. D.,Drewnowski, A. Replacing American Breakfast Foods with Ready-ToEat (RTE) Cereals Increases Consumption of Key Food Groups and Nutrients among US Children and Adults: Results of an NHANES Modeling Study. Nutrients. 2017; 9

109 (9) doi: 10.3390/nu9091010.

Rehm, C. D.,Monsivais, P.,Drewnowski, A. The quality and monetary value of diets consumed by adults in the United States. Am J Clin Nutr. 2011; 94 (5):1333-9. doi:

110 10.3945/ajcn.111.015560.

Richardson, A. S.,Collins, R. L.,Ghosh-Dastidar, B.,Ye, F.,Hunter, G. P.,Baird, M. D.,Schwartz, H.,Sloan, J. C.,Nugroho, A.,Beckman, R., Troxel, W. M.,Gary-Webb, T. L.,Dubowitz, T. Improvements in Neighborhood Socioeconomic Conditions May Improve Resident Diet. Am J Epidemiol. 2021; 190 (5):798-806. doi:

$111 \quad$ 10.1093/aje/kwaa220.

Robert Wood Johnson Foundation. Improving the Health of All Americans through Intervention/Exposure Study design,

112 Better Nutrition . . nd; Pubilcation status

Robinson, Courtney N.,Baker, Gregory A.,Harwood, Michael J.,Diekmann, Lucy O.

Food expenditures and consumption by food bank clients in Silicon Valley.

International Food \& Agribusiness Management Review. 2020; 23 (4):619-632. doi:

113 10.22434/IFAMR2019.0125.

Outcome

Rogus, S. Examining the influence of perceived and objective time constraints on the quality of household food purchases. Appetite. 2018; 130 :268-273. doi:

114 10.1016/j.appet.2018.08.025.

Ryden, P. J.,Hagfors, L. Diet cost, diet quality and socio-economic position: how are they related and what contributes to differences in diet costs?. Public Health Nutrition.

115 2011; 14 (9):1680-1692. doi: 10.1017/S1368980010003642.

Comparator

Data date range

Scharadin, B.,Yu, Y.,Jaenicke, E. C. Household time activities, food waste, and diet quality: the impact of non-marginal changes due to COVID-19. Rev Econ Househ.

1162021 ; :1-30. doi: 10.1007/s11150-021-09555-w. Schreiner, N.,Perazzo, J.,Digenarro, S.,Currie, J.,Daly, B.,Webel, A. Examining the Association between Item Specific Treatment Burden and Adherence in People Living

117 with HIV. West J Nurs Res. 2020; 42 (7):495-502. doi: 10.1177/0193945919880317. Sheldon, M.,Gans, K. M.,Tai, R.,George, T.,Lawson, E.,Pearlman, D. N. Availability, affordability, and accessibility of a healthful diet in a low-income community, Central

118 Falls, Rhode Island, 2007-2008. Prev Chronic Dis. 2010; 7 (2):A43. Silver, L. D.,Ng, S. W.,Ryan-Ibarra, S.,Taillie, L. S.,Induni, M.,Miles, D. R.,Poti, J. M.,Popkin, B. M. Changes in prices, sales, consumer spending, and beverage consumption one year after a tax on sugar-sweetened beverages in Berkeley, California, US: A before-and-after study. PLoS Med. 2017; 14 (4):e1002283. doi:

119 10.1371/journal.pmed.1002283.

Outcome

Smith, T. A., Valizadeh, P.,Lin, B. H.,Coats, E. What is driving increases in dietary quality in the United States?. Food Policy. 2019; 86 doi:

120 10.1016/j.foodpol.2019.05.003. Sogari, Giovanni,Velez-Argumedo, Catalina,Gómez, Miguel I.,Mora, Cristina. College Students and Eating Habits: A Study Using An Ecological Model for Healthy

121 Behavior. . 2019; doi: 10.22004/ag.econ.300040. Intervention/Exposure Sturm, R.,Datar, A. Regional price differences and food consumption frequency among elementary school children. Public Health. 2011; 125 (3):136-41. doi: 122 10.1016/j.puhe.2010.11.016.

Outcome 
Surkan, P. J.,Coutinho, A. J.,Christiansen, K.,Dennisuk, L. A.,Suratkar, S.,Mead,

E.,Sharma, S.,Gittelsohn, J. Healthy food purchasing among African American youth:

associations with child gender, adult caregiver characteristics and the home food environment. Public Health Nutrition. 2011; 14 (4):670-677. doi:

123 10.1017/S136898001000251X

Outcome

Tiwari, A.,Aggarwal, A.,Tang, W.,Drewnowski, A. Cooking at Home: A Strategy to Comply With U.S. Dietary Guidelines at No Extra Cost. Am J Prev Med. 2017; 52

124 (5):616-624. doi: 10.1016/j.amepre.2017.01.017.

Comparator

Tran, L. T.,Brewster, P. J.,Chidambaram, V.,Hurdle, J. F. Towards Measuring the Food Quality of Grocery Purchases: an Estimation Model of the Healthy Eating Index2010 Using only Food Item Counts. Procedia Food Sci. 2015; 4 :148-159. doi:

125 10.1016/j.profoo.2015.06.020.

Vadiveloo, M. K.,Parker, H. W.,Juul, F.,Parekh, N. Sociodemographic Differences in

Intervention/Exposure the Dietary Quality of Food-at-Home Acquisitions and Purchases among Participants in the U.S. Nationally Representative Food Acquisition and Purchase Survey

126 (FoodAPS). Nutrients. 2020; 12 (8) doi: 10.3390/nu12082354. Intervention/Exposure Vadiveloo, M.,Guan, X.,Parker, H. W.,Perraud, E.,Buchanan, A.,Atlas, S.,Thorndike, A. N. Effect of Personalized Incentives on Dietary Quality of Groceries Purchased: A Randomized Crossover Trial. JAMA Netw Open. 2021; 4 (2):e2030921. doi:

127 10.1001/jamanetworkopen.2020.30921.

Intervention/Exposure, Vadiveloo, M.,Perraud, E.,Parker, H. W.,Juul, F.,Parekh, N. Geographic Differences in the Dietary Quality of Food Purchases among Participants in the Nationally Representative Food Acquisition and Purchase Survey (FoodAPS). Nutrients. 2019;

12811 (6) doi: 10.3390/nu11061233.

Intervention/Exposure Vilaro, M. J.,Barnett, T. E.,Mathews, A.,Pomeranz, J.,Curbow, B. Income differences in social control of eating behaviors and food choice priorities among southern rural women in the US: A qualitative study. Appetite. 2016; 107 :604-612. doi:

129 10.1016/j.appet.2016.09.003. Vogel, C.,Ntani, G., Inskip, H.,Barker, M.,Cummins, S.,Cooper, C.,Moon, G.,Baird, J. Education and the Relationship Between Supermarket Environment and Diet. Am J

130 Prev Med. 2016; 51 (2):e27-e34. doi: 10.1016/j.amepre.2016.02.030. Volpe, Richard,Cai, Xiaowei,Schroeter, Christiane,Mancino, Lisa. Adherence to Dietary Recommendations and Food Retail Market Structure: Is There a Connection?. Journal of Agricultural \& Food Industrial Organization. 2020; :1. doi: 10.1515/jafio-

131 2019-0035.

Wang, M.,Levi, R.,Seligman, H. New SNAP Eligibility in California Associated With Improved Food Security and Health. Prev Chronic Dis. 2021; 18 :E28. doi:

$13210.5888 /$ pcd18.200587. Weatherspoon, D. D.,Miller, S. R.,Steele, M. E.,Newkirk, C. J.,Santiago, O.,Dembele, Outcome A. S.,Hoerr, S. L. What Social, Program, and Behavioral Factors Influence the Healthy Eating Index for EFNEP and SNAP-Ed Adult Participants?. Am J Lifestyle

133 Med. 2017; 11 (4):344-353. doi: 10.1177/1559827615607194. Intervention/Exposure Whiteman, E. D.,Chrisinger, B. W.,Hillier, A. Diet Quality Over the Monthly Supplemental Nutrition Assistance Program Cycle. Am J Prev Med. 2018; 55 (2):205-

134 212. doi: 10.1016/j.amepre.2018.04.027. Wilcox, S.,Sharpe, P. A.,Liese, A. D.,Dunn, C. G.,Hutto, B. Socioeconomic factors associated with diet quality and meeting dietary guidelines in disadvantaged neighborhoods in the Southeast United States. Ethn Health. 2020; 25 (8):1115-1131.

135 doi: 10.1080/13557858.2018.1493434. Wilde, Parke E.,Llobrera, Joseph. Using the Thrifty Food Plan to Assess the Cost of a Nutritious Diet. Journal of Consumer Affairs. 2009; 43 (2):274-304. doi:

136 10.1111/j.1745-6606.2009.01140.x.

Outcome

Intervention/Exposure, Outcome

Country

Outcome


Willits-Smith, A.,Aranda, R.,Heller, M. C.,Rose, D. Addressing the carbon footprint, healthfulness, and costs of self-selected diets in the USA: a population-based crosssectional study. Lancet Planet Health. 2020; 4 (3):e98-e106. doi: 10.1016/S2542-

137 5196(20)30055-3.

You, W.,Zhang, G.,Davy, B. M.,Carlson, A.,Lin, B. H. Food consumed away from

Intervention/Exposure home can be a part of a healthy and affordable diet. J Nutr. 2009; 139 (10):1994-9.

138 doi: $10.3945 /$ jn.109.107615.

Young, C. M.,Batch, B. C.,Svetkey, L. P. Effect of socioeconomic status on food availability and cost of the Dietary Approaches to Stop Hypertension (DASH) dietary pattern. J Clin Hypertens (Greenwich). 2008; 10 (8):603-11. doi: 10.1111/j.1751-

Data date range 7176.2008.08199.x. 


\title{
Appendix 4-a: Literature search strategy for the rapid review on income and time spent on food-at-home-related activities
}

\author{
Database: PubMed \\ Vendor: National Library of Medicine \\ Date of Search: 5/3/2021 \\ Limits Used: Filters: Language English Publication Dates 2008 - 2021 \\ Total $=2,401$
}

\begin{tabular}{|c|c|c|c|}
\hline Search \# & Concept & Search String & $\mathbf{N}$ \\
\hline \#1 & Income & $\begin{array}{l}\text { ( "Income"[Mesh] OR income*[tiab] OR } \\
\text { "Socioeconomic Factors"[Mesh] OR } \\
\text { socioeconomic*[tiab] OR socio-economic*[tiab] OR } \\
\text { "social facto*"[tiab] OR "social condition*"[tiab] OR } \\
\text { poverty[tiab] OR "Residence Characteristics"[Mesh] } \\
\text { OR "Vulnerable Populations"[Mesh] OR "vulnerable } \\
\text { population*"[tiab] OR "underserved population*"[tiab] } \\
\text { OR "disadvantaged population*"[tiab] OR "Race } \\
\text { Factors"[Mesh] OR "race factor*"[tiab] OR "Ethnic } \\
\text { Groups"[Mesh] OR "ethnic group*"[tiab] OR "ethnic } \\
\text { population*"[tiab] OR "Cross-Cultural } \\
\text { Comparison"[Mesh] OR "cross-cultural"[tiab] OR } \\
\text { transcultural[tiab] OR "Cultural Characteristics"[Mesh] } \\
\text { OR "cultural characteristic*"[tiab] OR "Cultural } \\
\text { Diversity"[Mesh] OR "culturally diverse"[tiab] OR "Food } \\
\text { Supply"[Mesh] OR "food desert*"[tiab] OR "food } \\
\text { insecurit*"[tiab] OR "food environment*"[tiab] OR "food } \\
\text { access"[tiab] OR Urban[tiab] OR Rural[tiab] OR } \\
\text { neighborhood[tiab] OR "Census tract"[tiab] OR } \\
\text { "census block"[tiab] OR "food assistance"[MeSH } \\
\text { Terms] OR "food assistance"[Tiab]) }\end{array}$ & $1,082,156$ \\
\hline \#2 & Time & $\begin{array}{l}\text { ("Time Factors"[MeSH] OR "Time Management"[MeSH] OR } \\
\text { Time[tiab]) }\end{array}$ & $4,181,306$ \\
\hline \#3 & $\begin{array}{l}\text { Food Related } \\
\text { Activities }\end{array}$ & $\begin{array}{l}\text { (home*[tiab] OR domestic[tiab] OR family[tiab] OR families[tiab] } \\
\text { OR house*[tiab]) AND ("Feeding Behavior"[Mesh] OR } \\
\text { cooking[MeSH] OR Eating[MeSH] OR Food[MeSH] OR cook*[tiab] } \\
\text { Or eat[tiab] OR eats[tiab] OR eating[tiab] OR eaten[tiab] OR } \\
\text { Food[tiab] OR meal*[tiab] OR kitchen[tiab] OR clean*[tiab] OR } \\
\text { dishwash*[tiab] OR (wash*[tiab] AND (dish[tiab] OR dishes[tiab])) }\end{array}$ & 74,178 \\
\hline \#4 & $\begin{array}{l}\# 1 \text { AND \#2 AND } \\
\# 3\end{array}$ & & 3,718 \\
\hline$\# 5$ & $\begin{array}{l}\text { Publication, } \\
\text { Geography, and } \\
\text { species excludes }\end{array}$ & $\begin{array}{l}\text { \#1 AND \#2 AND \#3 NOT ( } \\
\text { (letter[ptyp] OR editorial[ptyp] OR comment[ptyp] OR news[ptyp] } \\
\text { OR "Congress"[Publication Type] OR "Consensus Development } \\
\text { Conference"[Publication Type] OR editorial[tiab] OR } \\
\text { commentary[tiab] OR "conference abstract*"[tiab] OR "systematic } \\
\text { review*"[ti] OR "meta-analysis"[ptyp] OR "meta-analysis"[ti] OR }\end{array}$ & 3,465 \\
\hline
\end{tabular}




\begin{tabular}{|c|c|c|c|}
\hline & & $\begin{array}{l}\text { "meta-analyses"[ti] OR "Review"[Publication Type] OR "Systematic } \\
\text { Review"[Publication Type] OR "conference proceeding*"[tiab] OR } \\
\text { "retracted publication"[ptyp] OR "retraction of publication"[ptyp] OR } \\
\text { "retraction of publication"[tiab] OR "retraction notice"[ti] OR } \\
\text { "retracted publication"[tiab] OR "Published Erratum"[Publication } \\
\text { Type] OR corrigenda[tiab] OR corrigendum[tiab] OR errata[tiab] } \\
\text { OR erratum[tiab] OR protocol[ti] OR protocols[ti] OR "case } \\
\text { report"[ti] OR "case series"[ti] OR "Case Reports" [Publication } \\
\text { Type]) } \\
\text { NOT } \\
\text { ("Developing Countries"[Mesh] OR "developing countr*" OR "Under } \\
\text { Developed Nation*" OR "low income countr*" OR "middle income } \\
\text { count*"OR "low-middle-income countr*" OR LMIC[tiab] OR } \\
\text { "Europe"[Mesh] OR "Australia"[Mesh] OR "Asia"[Mesh] OR } \\
\text { "Africa"[Mesh] OR "Mexico"[Mesh] OR "Islands"[Mesh] OR "Central } \\
\text { America"[Mesh] OR "Latin America"[Mesh] OR "South } \\
\text { America"[Mesh]) } \\
\text { ) } \\
\text { NOT } \\
\text { ("Animals"[Mesh] NOT } \\
\text { ("Animals"[Mesh] AND "Humans"[Mesh]) } \\
\text { ) }\end{array}$ & \\
\hline \#6 & Filters & Filters: Language: English; Publication Dates: 2008-2021 & 2,401 \\
\hline
\end{tabular}

Database: Business Source Premier

Vendor: EBSCO

Date of Search: 5/3/2021

Limits Used: Scholarly (Peer Reviewed) Journals; Published Date: 20080101-20211231; Document Type: Article; Language: English

Total $=950$

\begin{tabular}{|c|c|c|c|}
\hline Search \# & Concept & Search String & $\mathbf{N}$ \\
\hline$\# 1$ & Income & $\begin{array}{l}\text { (DE "SOCIOECONOMIC factors") OR socioeconomic* } \\
\text { OR socio-economic* OR "social factor" OR "social } \\
\text { condition*" OR (DE "POVERTY") OR poverty OR } \\
\text { "vulnerable population*" OR "underserved population*" } \\
\text { OR "disadvantaged population*" OR (DE "INCOME") } \\
\text { OR income* OR "race factor" OR (DE "ECONOMIC } \\
\text { conditions of ethnic groups") OR "ethnic group*” OR } \\
\text { "ethnic population*” OR "cross-cultural" OR } \\
\text { transcultural OR "cultural characteristic*" OR "culturally } \\
\text { diverse" OR (DE "FOOD supply") OR "food desert*" } \\
\text { OR "food insecurit*" OR "food environment" OR "food } \\
\text { access" OR (DE "METROPOLITAN areas") OR Urban } \\
\text { OR Rural OR neighborhood OR "Census tract" OR } \\
\text { "census block" OR "food assistance" }\end{array}$ & $1,177,425$ \\
\hline \#2 & Time & (DE "TIME management" OR Time) & $1,359,692$ \\
\hline
\end{tabular}




\begin{tabular}{|c|c|c|c|}
\hline \#3 & $\begin{array}{l}\text { Food Related } \\
\text { Activities }\end{array}$ & $\begin{array}{l}\text { ((home* OR domestic OR family OR families OR house*) AND (DE } \\
\text { "FOOD safety" OR cook* OR eat* OR Food OR meal }{ }^{*} \text { OR kitchen } \\
\text { OR clean* OR dishwash* OR (wash* AND (dish OR dishes))) }\end{array}$ & 127,582 \\
\hline$\# 4$ & $\begin{array}{l}\text { \#1 AND \#2 AND } \\
\# 3\end{array}$ & & 1,856 \\
\hline \#5 & Filters & $\begin{array}{l}\text { Limiters - Scholarly (Peer Reviewed) Journals; Published Date: } \\
\text { 20080101-20211231; Document Type: Article; Language: English }\end{array}$ & 950 \\
\hline
\end{tabular}

Database: Web of Science: Core Collection

Vendor: Clarivate Analytics

Date of Search: 5/3/2021

Limits Used:

Total $=3,545$

\begin{tabular}{|c|c|c|c|}
\hline Search \# & Concept & Search String & $\mathbf{N}$ \\
\hline$\# 1$ & Income & $\begin{array}{l}\text { TS=(socioeconomic* OR socio-economic* OR "social } \\
\text { factor*" OR "social condition*” OR poverty OR } \\
\text { "residence characteristics" OR "vulnerable population*" } \\
\text { OR "underserved population*" OR "disadvantaged } \\
\text { population*" OR income* OR "race factor*" OR "ethnic } \\
\text { group*" OR "ethnic population*" OR "cross-cultural" } \\
\text { OR transcultural OR "cultural characteristic*" OR } \\
\text { "culturally diverse" OR "food desert*" OR "food } \\
\text { insecurit*" OR Urban OR Rural OR neighborhood OR } \\
\text { "Census tract" OR "census block" OR "food } \\
\text { assistance") }\end{array}$ & $1,019,047$ \\
\hline \#2 & Time & TS=time & $6,476,056$ \\
\hline \#3 & $\begin{array}{l}\text { Food Related } \\
\text { Activities }\end{array}$ & $\begin{array}{l}\left.\text { TS=((home* OR domestic OR family OR families OR house }{ }^{\star}\right) \text { AND } \\
\text { ("FOOD safety" OR cook* OR eat* OR Food OR meal* OR kitchen } \\
\text { OR clean* OR dishwash* OR (wash* AND (dish OR dishes)))) }\end{array}$ & 119,957 \\
\hline \#4 & $\begin{array}{l}\text { \#1 AND \#2 AND } \\
\text { \#3 }\end{array}$ & & 5,569 \\
\hline \#5 & Non-United States & $\begin{array}{l}\text { CU=("developing countr*" OR "under developed nation*" OR "low i } \\
\text { ncome countr"" OR "middle income } \\
\text { countr*" OR "low-middle income countr*" OR LMIC } \\
\text { OR Europe OR Australia OR Asia OR Africa OR Mexico OR Island } \\
\text { s OR "Central America" OR "Latin America" OR "South America") }\end{array}$ & $2,037,499$ \\
\hline \#6 & \#4 NOT \#5 & & 4,920 \\
\hline \#7 & $\begin{array}{l}\text { Publication } \\
\text { Excludes }\end{array}$ & $\begin{array}{l}\text { TS=(editorial OR commentary OR "conference abstract*" OR "conf } \\
\text { erence proceeding*”[tiab] OR "retraction of publication" OR "retract } \\
\text { ed publication" OR corrigenda[tiab] OR corrigendum[tiab] OR errat } \\
\text { a OR erratum OR "case reports" ) OR TI=("systematic review" OR } \\
\text { "meta-analysis" }\end{array}$ & 708,261 \\
\hline
\end{tabular}




\begin{tabular}{|l|l|l|l|}
\hline & & $\begin{array}{l}\text { OR “meta analyses" OR protocol OR protocols } \\
\text { OR "retraction notice" OR “case report" OR } \\
\text { "case series") }\end{array}$ & \\
\hline \#8 & \#6 NOT \#5 & & 4,920 \\
\hline \#9 & & Years: 2008-2021; Publication Types: Articles, Early Access & 3,545 \\
\hline
\end{tabular}

\section{Grey Literature Search}

\section{Google Scholar}

(Income OR resources OR poverty OR socioeconomic) AND time AND ((home OR domestic OR family OR house) AND (eating OR meals OR cooking OR cleaning OR washing dishes))

Limits: Date published: 2008-2021;

Date Searched: 5/14/2021

Results: 40, limited to 4 pages

\section{Google}

site:.gov AND (Income OR resources OR poverty OR socioeconomic) AND (time OR time spent) AND ((home OR domestic OR family) AND (meal preparation OR meals OR cooking OR cleaning))

Limits: Include Omitted results

Date Searched: 5/14/2021

Results: 10, limited to 1 page

\section{Ag Econ}

Any of the words: Income resources poverty socioeconomic

AND

Any of the words: Time

AND

Any of the words: "Food at home" "at home meals" "meals at home" "cooking at home" "family cooking" "family meals" "meal preparation" "food preparation"

Limits: added since 2008

Date Searched: 5/14/2021

Results: 60 , limited to 6 pages 


\section{Appendix 4-b: Excluded articles for the rapid review on income and time spent on food-at-home-related activities}

The following table lists the articles excluded after full-text screening for this rapid review question. At least 1 reason for exclusion is provided for each article, though this may not reflect all possible reasons. Information about articles excluded after title and abstract screening is available upon request.

Bibliography

Rationale for exclusion

Álvarez, Begoña,Miles-Touya, Daniel. Gender imbalance in housework allocation: a question of time?. Review of Economics of the Household. 2019. 17. doi: 10.1007/s11150-019-09467-

1 w.

Archer, E.,Shook, R. P.,Thomas, D. M.,Church, T. S.,Katzmarzyk, P. T.,Hébert, J. R.,Mclver, K. L.,Hand, G. A.,Lavie, C. J.,Blair, S. N.. 45-Year trends in women's use of time and household management energy expenditure. PLoS One. 2013. 8. doi:

$2 \quad 10.1371 /$ journal.pone.0056620.

Country;

Outcome

Beatty, T. K.,Nanney, M. S.,Tuttle, C.. Time to eat? The relationship between food security

3 and food-related time use. Public Health Nutr. 2014. 17. doi: 10.1017/s1368980012005599. Beshara, M.,Hutchinson, A.,Wilson, C.. Preparing meals under time stress. The experience of

4 working mothers. Appetite. 2010. 55. doi: 10.1016/j.appet.2010.10.003.

Comparator;

Outcome

Biddle, Jeff E.,Hamermesh, Daniel S.. Income, wages and household production theory.

5 Economics Letters. 2020. 192. doi: 10.1016/j.econlet.2020.109188.

Exposure

Blitstein, Jonathan L.,Frentz, Florentine,Jilcott Pitts, Stephanie B.. A Mixed-method

Examination of Reported Benefits of Online Grocery Shopping in the United States and

Germany: Is Health a Factor?. Journal of Food Products Marketing. 2020. 26. doi:

$6 \quad 10.1080 / 10454446.2020 .1754313$.

Exposure

Bostic, S. M.,McClain, A. C.. Older adults' cooking trajectories: shifting skills and strategies.

7 British Food Journal. 2017. 119. doi: 10.1108/bfj-09-2016-0436.

Outcome

Bowen, Sarah,Elliott, Sinikka,Brenton, Joslyn. The Joy of Cooking?. Contexts. 2014. 13. doi:

$8 \quad 10.1177 / 1536504214545755$.

Carpio, C. E.,Kalenkoski, C. M.,Moyeda-Carabaza, A. F.,Murimi, M.. The effect of time use

Comparator

and food cost on dietary quality. Public Health Nutrition. 2020. 23. doi:

$910.1017 / \mathrm{s} 1368980020001615$.

Comparator

Cason-Wilkerson, R.,Goldberg, S.,Albright, K.,Allison, M.,Haemer, M.. Factors influencing

healthy lifestyle changes: a qualitative look at low-income families engaged in treatment for

10 overweight children. Child Obes. 2015. 11. doi: 10.1089/chi.2014.0147.

Outcome

Cawley, J.,Liu, F.. Maternal employment and childhood obesity: a search for mechanisms in

11 time use data. Econ Hum Biol. 2012. 10. doi: 10.1016/j.ehb.2012.04.009.

Exposure; Date

Christian, T. J.. Trade-offs between commuting time and health-related activities. J Urban

12 Health. 2012. 89. doi: 10.1007/s11524-012-9678-6.

Date;

Connelly, Rachel,Kimmel, Jean. Spousal Economic Factors in ATUS Parents' Time Choices.

13 Social Indicators Research. 2009. 93. doi: 10.1007/s11205-008-9403-8.

Connelly, Rachel,Kimmel, Jean. Spousal influences on parents' non-market time choices.

14 Review of Economics of the Household. 2009. 7. doi: 10.1007/s11150-009-9060-y.

Comparator

Daniels, S.,Glorieux, I.,Minnen, J.,van Tienoven, T. P.,Weenas, D.. Convenience on the

menu? A typological conceptualization of family food expenditures and food-related time

15 patterns. Soc Sci Res. 2015. 51. doi: 10.1016/j.ssresearch.2014.09.010.

Datar, A.,Nicosia, N.,Shier, V.. Maternal work and children's diet, activity, and obesity. Soc Sci

16 Med. 2014. 107. doi: 10.1016/j.socscimed.2013.12.022.

Davis, G. C.,You, W.. The Thrifty Food Plan is not thrifty when labor cost is considered. J Nutr.

17 2010. 140. doi: 10.3945/jn.109.119594.

Date; Outcome

Date; Outcome

Date; Country

Exposure;

Outcome

Date; Study

Design;

Outcome 
Davis, G. C.,You, W.. Estimates of returns to scale, elasticity of substitution, and the thrifty food plan meal poverty rate from a direct household meal production function. Food Policy.

18 2013. 43. doi: 10.1016/j.foodpol.2013.09.002.

Date

Davis, G. C., You, W.. Not enough money or not enough time to satisfy the Thrifty Food Plan?

A cost difference approach for estimating a money-time threshold. Food Policy. 2011. 36. doi:

Date; Exposure;

19 10.1016/j.foodpol.2010.09.001.

Outcome

Davis, George C.,You, Wen. The time cost of food at home: general and food stamp

20 participant profiles. Applied Economics. 2010. 42. doi: 10.1080/00036840801964468.

Date; Exposure

De Backer, Charlotte J. S.. Family meal traditions. Comparing reported childhood food habits

to current food habits among university students. Appetite. 2013. 69. doi:

21 https://doi.org/10.1016/j.appet.2013.05.013.

Outcome;

Devine, C. M.,Farrell, T. J.,Blake, C. E.,Jastran, M.,Wethington, E.,Bisogni, C. A.. Work

Country

Conditions and the Food Choice Coping Strategies of Employed Parents. Journal of Nutrition

22 Education and Behavior. 2009. 41. doi: 10.1016/j.jneb.2009.01.007.

Outcome

Do, B.,Wang, S. D.,Naya, C. H.,Dunton, G. F.,Mason, T. B.. Momentary and personal

characteristics predicting maternal fruit and vegetable preparation for children using ecological

23 momentary assessment. Eat Behav. 2021. 41. doi: 10.1016/j.eatbeh.2021.101492.

Outcome

Dong, K. R.,Tang, A. M.,Stopka, T. J.,Beckwith, C. G.,Must, A.. Food acquisition methods and correlates of food insecurity in adults on probation in Rhode Island. PLoS One. 2018. 13. doi:

24 10.1371/journal.pone.0198598.

Outcome

Dunaway, L. F.,Carton, T.,Ma, P.,Mundorf, A. R.,Keel, K.,Theall, K. P.. Beyond Food Access:

The Impact of Parent-, Home-, and Neighborhood-Level Factors on Children's Diets.

International Journal of Environmental Research and Public Health. 2017. 14. doi:

25 10.3390/ijerph14060662.

Outcome

Escoto, K. H.,Laska, M. N.,Larson, N.,Neumark-Sztainer, D.,Hannan, P. J.. Work Hours and

Perceived Time Barriers to Healthful Eating Among Young Adults. American Journal of Health

26 Behavior. 2012. 36. doi: 10.5993/ajhb.36.6.6.

Exposure

Farmer, N.,Wallen, G. R.,Yang, L.,Middleton, K. R.,Kazmi, N.,Powell-Wiley, T. M.. Household

Cooking Frequency of Dinner Among Non-Hispanic Black Adults is Associated with Income

and Employment, Perceived Diet Quality and Varied Objective Diet Quality, HEl (Healthy

27 Eating Index): NHANES Analysis 2007-2010. Nutrients. 2019. 11. doi: 10.3390/nu11092057.

Fisher, Kimberly,Robinson, John. Average Weekly Time Spent in 30 Basic Activities Across

2817 Countries. Social Indicators Research. 2009. 93. doi: 10.1007/s11205-008-9372-y.

Gelber, Alexander M.,Mitchell, Joshua W.. Taxes and Time Allocation: Evidence from Single

29 Women and Men. Review of Economic Studies. 2012. 79. doi: 10.1093/restud/rdr041.

Gershuny, Jonathan,Harms, Teresa Atttracta. Housework Now Takes Much Less Time: 85

30 Years of US Rural Women's Time Use. Social Forces. 2016. 95. doi: 10.1093/sf/sow073.

Graesch, Anthony. Material Indicators of Family Busyness. Social Indicators Research. 2009.

31 93. doi: 10.1007/s11205-008-9408-3.

Gupta, Nabanita Datta,Stratton, Leslie S.. Examining the impact of alternative power

measures on individual time use in American and Danish couple households. Review of

32 Economics of the Household. 2010. 8. doi: 10.1007/s11150-009-9073-6.

Date; Exposure

Gupta, Sanjiv,Ash, Michael. Whose money, whose time? A nonparametric approach to

modeling time spent on housework in the United States. Feminist Economics. 2008. 14. doi:

33 10.1080/13545700701716664.

Henry, J. L.,Trude, A. C. B.,Surkan, P. J.,Steeves, E. A.,Hopkins, L. C.,Gittelsohn, J..

Psychosocial Determinants of Food Acquisition and Preparation in Low-Income, Urban African

American Households. Health Education \& Behavior. 2018. 45. doi:

34 10.1177/1090198118760686.

Hobbes, Marieke,De Groot, Wouter T.,Van Der Voet, Ester,Sarkhel, Sukanya. Freely

Disposable Time: A Time and Money Integrated Measure of Poverty and Freedom. World

Outcome

Exposure

Date

Exposure

Outcome

Development. 2011. 39. doi: 10.1016/j.worlddev.2011.04.005.

Date; Outcome 
Horning, M. L.,Fulkerson, J. A.,Friend, S. E.,Story, M.. Reasons Parents Buy Prepackaged, Processed Meals: It Is More Complicated Than "I Don't Have Time". J Nutr Educ Behav. 2017.

36 49. doi: 10.1016/j.jneb.2016.08.012. Jarrett, R. L.,Bahar, O. S.,Kersh, R. T.. "When We Do Sit Down Together": Family Meal Times in Low-Income African American Families With Preschoolers. Journal of Family Issues. 2016.

37 37. doi: $10.1177 / 0192513 \times 14547417$.

Kant, A. K.,Graubard, B. I.. Family income and education were related with 30-year time trends in dietary and meal behaviors of American children and adolescents. J Nutr. 2013. 143.

38 doi: 10.3945/jn.112.165258. Kolodinsky, J. M.,Goldstein, A. B.. Time use and food pattern influences on obesity. Obesity

39 (Silver Spring). 2011. 19. doi: 10.1038/oby.2011.130.

Kolpashnikova, Kamila. American Househusbands: New Time Use Evidence of Gender

40 Display, 2003-2016. Social Indicators Research. 2018. 140. doi: 10.1007/s11205-017-1813-z.

Kornides, M. L.,Nansel, T. R.,Quick, V.,Haynie, D. L.,Lipsky, L. M.,Laffel, L. M.,Mehta, S. N..

Associations of family meal frequency with family meal habits and meal preparation characteristics among families of youth with type 1 diabetes. Child Care Health Dev. 2014. 40.

41 doi: 10.1111/cch.12078.

Kornrich, S.,Roberts, A.. Household Income, Women's Earnings, and Spending on Household

42 Services, 1980-2010. Journal of Marriage and Family. 2018. 80. doi: 10.1111/jomf.12450. Landefeld, J. Steven,Fraumeni, Barbara M.,Vojtech, Cindy M.. ACCOUNTING FOR HOUSEHOLD PRODUCTION: A PROTOTYPE SATELLITE ACCOUNT USING THE AMERICAN TIME USE SURVEY. Review of Income \& Wealth. 2009. 55. doi: 10.1111/j.1475- Date;

43 4991.2009.00319.x. Ly, D. P.,Jena, A. B.. Sex Differences in Time Spent on Household Activities and Care of Children Among US Physicians, 2003-2016. Mayo Clin Proc. 2018. 93. doi:

10.1016/j.mayocp.2018.02.018. Martell, Michael E.,Roncolato, Leanne. Share of Household Earnings and Time Use of Women in Same-Sex and Different-Sex Households. Eastern Economic Journal. 2020. 46.

45 doi: 10.1057/s41302-019-00145-4. McGuirt, J. T.,Wu, Q.,Laska, M. N.,Truesdale, K. P.,Rafferty, A. P.,Bell, R. A.,Ammerman, A. S., Jilcott Pitts, S. B.. Associations between shopping patterns, dietary behaviours and geographic information system-assessed store accessibility among small food store

46 customers. Public Health Nutr. 2020. . doi: 10.1017/s1368980020005017. Milkie, Melissa A.,Raley, Sara B.,Bianchi, Suzanne M.. Taking on the Second Shift: Time Allocations and Time Pressures of U.S. Parents with Preschoolers. Social Forces. 2009. 88.

47 doi: $10.1353 /$ sof.0.0268.

Mills, Susanna,Brown, Heather,Wrieden, Wendy,White, Martin,Adams, Jean. Frequency of eating home cooked meals and potential benefits for diet and health: cross-sectional analysis of a population-based cohort study. International Journal of Behavioral Nutrition and Physical

48 Activity. 2017. 14. doi: 10.1186/s12966-017-0567-y. Nepper, M. J.,Chai, W.. Parents' barriers and strategies to promote healthy eating among

49 school-age children. Appetite. 2016. 103. doi: 10.1016/j.appet.2016.04.012. Neumark-Sztainer, D.,MacLehose, R.,Loth, K.,Fulkerson, J. A.,Eisenberg, M. E.,Berge, J.. What's for dinner? Types of food served at family dinner differ across parent and family

50 characteristics. Public Health Nutrition. 2014. 17. doi: 10.1017/s1368980012004594. Neumark-Sztainer, D.,Wall, M.,Fulkerson, J. A.,Larson, N.. Changes in the frequency of family meals from 1999 to 2010 in the homes of adolescents: trends by sociodemographic

51 characteristics. J Adolesc Health. 2013. 52. doi: 10.1016/j.jadohealth.2012.06.004. Oleschuk, Merin. Expanding the joys of cooking: How class shapes the emotional experience

52 of family foodwork. Gender, Work \& Organization. 2020. . doi: 10.1111/gwao.12599. Pailhé, Ariane,Solaz, Anne,Stanfors, Maria. The Great Convergence: Gender and Unpaid Work in Europe and the United States. Population \& Development Review. 2021. 47. doi:

Comparator

Exposure;

Comparator Outcome; Date

Exposure;

Comparator

Date; Outcome

Date;

Comparator

Exposure

Outcome

Date; Outcome

Outcome

Outcome

Country

Date 
Pelletier, J. E.,Laska, M. N.. Balancing healthy meals and busy lives: associations between work, school, and family responsibilities and perceived time constraints among young adults. $\mathrm{J}$

54 Nutr Educ Behav. 2012. 44. doi: 10.1016/j.jneb.2012.04.001. Pepin, Joanna R.,Sayer, Liana C.,Casper, Lynne M.. Marital Status and Mothers' Time Use: Childcare, Housework, Leisure, and Sleep. Demography (Springer Nature). 2018. 55. doi:

Outcome 10.1007/s13524-018-0647-x.

Exposure; Quick, B. L.,Fiese, B. H.,Anderson, B.,Koester, B. D.,Marlin, D. W.. A formative evaluation of shared family mealtime for parents of toddlers and young children. Health Commun. 2011. 26.

56 doi: 10.1080/10410236.2011.561920.

Outcome

Rogus, S.. Examining the influence of perceived and objective time constraints on the quality

57 of household food purchases. Appetite. 2018. 130. doi: 10.1016/j.appet.2018.08.025.

Comparator; Outcome Schneider, Daniel,Hastings, Orestes P... Income Inequality and Household Labor. Social

58 Forces. 2017. 96. doi: 10.1093/sf/sox061.

Outcome Sen, Shuvro,Antara, Neel,Sen, Shusmita. Factors influencing consumers' to Take Ready-

59 made Frozen Food. Current Psychology. 2019. . doi: 10.1007/s12144-019-00201-4. Outcome; Date

Smith, L. P.,Ng, S. W.,Popkin, B. M.. Trends in US home food preparation and consumption: analysis of national nutrition surveys and time use studies from 1965-1966 to 2007-2008. Nutr

60 J. 2013. 12. doi: 10.1186/1475-2891-12-45.

Sonneville, K. R.,La Pelle, N.,Taveras, E. M.,Gillman, M. W.,Prosser, L. A.. Economic and other barriers to adopting recommendations to prevent childhood obesity: results of a focus

61 group study with parents. BMC Pediatr. 2009. 9. doi: 10.1186/1471-2431-9-81. Starmer, A. J.,Frintner, M. P.,Matos, K.,Somberg, C.,Freed, G.,Byrne, B. J.. Gender Discrepancies Related to Pediatrician Work-Life Balance and Household Responsibilities.

62 Pediatrics. 2019. 144. doi: 10.1542/peds.2018-2926. Taillie, L. S.. Who's cooking? Trends in US home food preparation by gender, education, and

63 race/ethnicity from 2003 to 2016. Nutr J. 2018. 17. doi: 10.1186/s12937-018-0347-9. Country

Tao, Hung-Lin. Informational Ambiguity and Survey Bias: Husbands' and Wives' Reports on Their Contribution to Their Families. Social Indicators Research. 2013. 111. doi:

64 10.1007/s11205-012-0029-5.

Tashiro, S.,Lo, C. P.. Gender Difference in the Allocation of Time PREPARING FOOD

Date;

Comparator COOKED AT HOME VERSUS PURCHASING PREPARED FOOD. Food Culture \& Society.

65 2012. 15. doi: 10.2752/175174412x13276629246000. Date; Outcome Tashiro, Sanae. Differences in Food Preparation by Race and Ethnicity: Evidence from the American Time Use Survey. Review of Black Political Economy. 2009. 36. doi:

66 10.1007/s12114-009-9045-3.

Exposure; Outcome Comparator; Outcome

Taveras, E. M.,McDonald, J.,O'Brien, A.,Haines, J.,Sherry, B.,Bottino, C. J.,Troncoso, K.,Schmidt, M. E.,Koziol, R.. Healthy Habits, Happy Homes: methods and baseline data of a randomized controlled trial to improve household routines for obesity prevention. Prev Med.

67 2012. 55. doi: 10.1016/j.ypmed.2012.08.016.

Tiedje, K.,Wieland, M. L.,Meiers, S. J.,Mohamed, A. A.,Formea, C. M.,Ridgeway, J. L.,Asiedu, G. B.,Boyum, G.,Weis, J. A.,Nigon, J. A.,Patten, C. A.,Sia, I. G.. A focus group study of healthy eating knowledge, practices, and barriers among adult and adolescent immigrants and refugees in the United States. Int J Behav Nutr Phys Act. 2014. 11. doi: 10.1186/1479-5868-

$68 \quad 11-63$.

Tiwari, A.,Aggarwal, A.,Tang, W.,Drewnowski, A.. Cooking at Home: A Strategy to Comply

With US Dietary Guidelines at No Extra Cost. American Journal of Preventive Medicine. 2017.

69 52. doi: 10.1016/j.amepre.2017.01.017.

Trofholz, A. C., Tate, A.,Keithahn, H., de Brito, J. N.,Loth, K.,Fertig, A.,Berge, J. M.. Family meal characteristics in racially/ethnically diverse and immigrant/refugee households by household food security status: A mixed methods study. Appetite. 2021. 157. doi:

70 10.1016/j.appet.2020.105000.

Tuttle, Charlotte. Changes in Food-At-Home Spending by SNAP Participants After the

71 Stimulus Act of 2009. . 2016. . doi: 10.22004/ag.econ.252645.

Exposure; Outcome Country

Date

Date

Comparator; Outcome

Outcome Outcome 


\section{Bibliography}

Rationale for exclusion

Virudachalam, S.,Chung, P. J.,Faerber, J. A.,Pian, T. M.,Thomas, K.,Feudtner, C.. Quantifying parental preferences for interventions designed to improve home food preparation and home food environments during early childhood. Appetite. 2016. 98. doi:

72 10.1016/j.appet.2015.11.007. Virudachalam, S.,Long, J. A.,Harhay, M. O.,Polsky, D. E.,Feudtner, C.. Prevalence and patterns of cooking dinner at home in the USA: National Health and Nutrition Examination Survey (NHANES) 2007-2008. Public Health Nutrition. 2014. 17. doi:

73 10.1017/s1368980013002589.

Wolfson, J. A.,Bleich, S. N.,Smith, K. C.,Frattaroli, S.. What does cooking mean to you?:

Perceptions of cooking and factors related to cooking behavior. Appetite. 2016. 97. doi:

74 10.1016/j.appet.2015.11.030.

Wolfson, J. A.,Leung, C. W.,Richardson, C. R.. More frequent cooking at home is associated with higher Healthy Eating Index-2015 score. Public Health Nutrition. 2020. 23. doi:

75 10.1017/s1368980019003549. Wulff Pabilonia, Sabrina,Younghwan, Song. Single Mothers' Time Preference, Smoking, and Enriching Childcare: Evidence from Time Diaries. Eastern Economic Journal. 2013. 39. doi:

76 10.1057/eej.2013.7.

Date

Yenerall, J.,You, W.,Hill, J.. Beyond the supermarket: analyzing household shopping trip patterns that include food at home and away from home retailers. BMC Public Health. 2020.

77 20. doi: 10.1186/s12889-020-09882-0.

Exposure; Outcome

You, W, Davis, G,C,. Household food expenditures, parental time allocation, and childhood overweight: An integrated two-stage collective model with an empirical application and test.

78 American Journal of Agricultural Economics. 2010. 92. doi: 10.1093/ajae/aap031. Date Zeballos, Eliana,Restrepo, Brandon. Working From Home Leads to More Time Spent

79 Preparing Food, Eating at Home. . 2021. 2020. doi: 10.22004/ag.econ.309609. Exposure 


\section{Appendix 5-a: Literature search strategy for the evidence scan on factors that influence the purchase and/or consumption of convenience foods}

Database: PubMed

Vendor: National Library of Medicine

Date of Search: 5/20/2021

Limits Used: Filters: Language English Publication Dates 2008 - 2021

Total $=3,201$

\begin{tabular}{|c|c|c|c|}
\hline Search \# & Concept & Search String & $\mathbf{N}$ \\
\hline$\# 1$ & Convenience Foods & $\begin{array}{l}\text { (("ready to eat"[tiab] OR "ready to heat"[tiab] OR } \\
\text { "ready to cook"[tiab] OR "ready to bake"[tiab] OR "pre } \\
\text { prepared"[tiab] OR preprepared[tiab] OR "pre } \\
\text { made"[tiab] OR } \\
\text { premade[tiab] OR "pre cooked"[tiab] OR } \\
\text { precooked[tiab] OR "pre cut"[tiab] OR precut[tiab] OR } \\
\text { "fresh cut"[tiab] OR boxed[tiab] OR frozen[tiab] OR } \\
\text { canned[tiab] OR dehydrated[tiab] OR tinned[tiab] OR } \\
\text { bagged[tiab] OR jarred[tiab] OR "ready made"[tiab] } \\
\text { OR instant[tiab] OR prepackaged[tiab] OR "pre- } \\
\text { packaged"[tiab] OR "shelf stable"[tiab] OR "single } \\
\text { serve"[tiab] OR "single serving"[tiab] OR "pre } \\
\text { washed"[tiab] OR prewashed[tiab] OR "partially } \\
\text { prepared"[tiab] OR packaged[tiab] OR "easy to } \\
\text { prepare"[tiab]) } \\
\text { AND } \\
\text { (food[MeSH] OR food*[tiab] OR goods[tiab] OR } \\
\text { meal*[tiab] OR snack*[tiab] OR fruit*[tiab] OR } \\
\text { vegetable*[tiab])) } \\
\text { OR } \\
\text { ("convenient food*”[tiab] OR "convenience food*”[tiab] } \\
\text { OR "convenience meal*"[tiab] OR "ready meal”[tiab] } \\
\text { OR "food at home"[tiab] OR "fresh cut produce"[tiab])) }\end{array}$ & 16,186 \\
\hline \#2 & & $\begin{array}{l}\text { \#1 NOT (letter[ptyp] OR editorial[ptyp] OR } \\
\text { comment[ptyp] OR news[ptyp] OR } \\
\text { "Congress"[Publication Type] OR "Consensus } \\
\text { Development Conference"[Publication Type] OR } \\
\text { editorial[tiab] OR commentary[tiab] OR "conference } \\
\text { abstract*"[tiab] OR "systematic review*"[ti] OR "meta- } \\
\text { analysis"[ptyp] OR "meta-analysis"[ti] OR "meta- } \\
\text { analyses"[ti] OR "Review"[Publication Type] OR } \\
\text { "Systematic Review"[Publication Type] OR } \\
\text { "conference proceeding*"[tiab] OR "retracted } \\
\text { publication"[ptyp] OR "retraction of publication"[ptyp] } \\
\text { OR "retraction of publication"[tiab] OR "retraction } \\
\text { notice"[ti] OR "retracted publication"[tiab] OR } \\
\text { "Published Erratum"[Publication Type] OR } \\
\text { corrigenda[tiab] OR corrigendum[tiab] OR errata[tiab] } \\
\text { OR erratum[tiab] OR protocol[ti] OR protocols[ti] OR } \\
\text { "case report"[ti] OR "case series"[ti] OR "Case } \\
\text { Reports" [Publication Type]) }\end{array}$ & 3,201 \\
\hline
\end{tabular}




\begin{tabular}{|c|c|c|}
\hline & & $\begin{array}{l}\text { NOT } \\
\text { ("Developing Countries"[Mesh] OR "developing } \\
\text { countr*" OR "Under Developed Nation*" OR "low } \\
\text { income countr" OR "middle income countr*"OR "low- } \\
\text { middle-income countr*" OR LMIC[tiab] OR } \\
\text { "Europe"[Mesh] OR "Australia"[Mesh] OR } \\
\text { "Asia"[Mesh] OR "Africa"[Mesh] OR "Mexico"[Mesh] } \\
\text { OR "Islands"[Mesh] OR "Central America"[Mesh] OR } \\
\text { "Latin America"[Mesh] OR "South America"[Mesh]) } \\
\text { ) } \\
\text { NOT } \\
\text { ("Animals"[Mesh] NOT } \\
\text { ("Animals"[Mesh] AND "Humans"[Mesh]) } \\
\text { ) Filters: English, from } 2008 \text { - 2021 }\end{array}$ \\
\hline
\end{tabular}

Database: Business Source Premiere Vendor: EBSCO

Date of Search: 5/20/2021

Limits Used: Scholarly (Peer Reviewed) Journals; Published Date: 20080101-20211231; Document Type: Article; Language: English

Total $=6,181$

\begin{tabular}{|c|c|c|c|}
\hline Search \# & Concept & Search String & $\mathbf{N}$ \\
\hline$\# 1$ & Convenience Foods & $\begin{array}{l}\text { ((("ready to eat" OR "ready to heat" OR "ready to } \\
\text { cook" OR "ready to bake" OR "pre prepared" OR } \\
\text { preprepared OR "pre made" OR premade OR "pre } \\
\text { cooked" OR precooked OR "pre cut" OR precut OR } \\
\text { "fresh cut" OR boxed OR frozen OR canned OR } \\
\text { dehydrated OR tinned OR bagged OR jarred OR } \\
\text { "ready made" OR instant OR prepackaged OR "pre- } \\
\text { packaged" OR "shelf stable" OR "single serve" OR } \\
\text { "single serving" OR "pre washed" OR prewashed OR } \\
\text { "partially prepared" OR packaged OR "easy to } \\
\text { prepare") } \\
\text { AND } \\
\text { (food* OR goods OR meal* OR snack* OR fruit* OR } \\
\text { vegetable*)) } \\
\text { OR } \\
\text { ("convenient food" OR "convenience food*" OR } \\
\text { "convenience meal*” OR "ready meal*" OR "food at } \\
\text { home" OR "fresh cut produce")) }\end{array}$ & 107,790 \\
\hline \#2 & & $\begin{array}{l}\text { Limiters - Scholarly (Peer Reviewed) Journals; } \\
\text { Published Date: 20080101-20211231; Document } \\
\text { Type: Article; Language: English }\end{array}$ & 6,181 \\
\hline
\end{tabular}


Total $=\mathbf{4 , 1 1 4}$

\begin{tabular}{|c|c|c|c|}
\hline Search \# & Concept & Search String & $\mathbf{N}$ \\
\hline$\# 1$ & $\begin{array}{l}\text { Convenience } \\
\text { Foods }\end{array}$ & $\begin{array}{l}\text { TITLE-ABS-KEY ( "convenience food" OR "convenient food" OR } \\
\text { "ready meal" OR "convenience meal" OR "food at home" OR "fresh } \\
\text { cut produce" ) } \\
\text { OR ( TITLE-ABS-KEY ( "ready to eat" OR "ready to heat" OR "ready } \\
\text { to cook" OR "ready to bake" OR "pre prepared" OR preprepared } \\
\text { OR "pre made" OR premade OR "pre cooked" OR precooked OR } \\
\text { "pre cut" OR precut OR "fresh cut" OR boxed OR frozen OR } \\
\text { canned OR dehydrated OR tinned OR bagged OR jarred OR } \\
\text { "ready made" OR instant OR "pre packaged" OR prepackaged OR } \\
\text { "shelf stable" OR "single serve" OR "single serving" OR "pre } \\
\text { washed" OR prewashed OR "partially prepared" OR packaged OR } \\
\text { "easy to prepare" ) } \\
\text { AND TITLE-ABS-KEY ( food OR goods OR meal OR snack OR } \\
\text { fruit OR vegetable) ) }\end{array}$ & 40,946 \\
\hline \#2 & Limiters & $\begin{array}{l}\text { ( LIMIT-TO ( PUBYEAR, } 2021 \text { ) OR LIMIT-TO ( PUBYEAR, } 2020 \text { ) } \\
\text { OR LIMIT-TO ( PUBYEAR, 2019) OR LIMIT-TO ( PUBYEAR, } \\
2018 \text { ) OR LIMIT-TO ( PUBYEAR, } 2017 \text { ) OR LIMIT-TO ( } \\
\text { PUBYEAR, 2016 ) OR LIMIT-TO ( PUBYEAR, 2015 ) OR LIMIT- } \\
\text { TO ( PUBYEAR, 2014 ) OR LIMIT-TO ( PUBYEAR, 2013 ) OR } \\
\text { LIMIT-TO ( PUBYEAR, 2012 ) OR LIMIT-TO ( PUBYEAR, 2011) } \\
\text { OR LIMIT-TO ( PUBYEAR, 2010) OR LIMIT-TO ( PUBYEAR, } \\
2009 \text { ) OR LIMIT-TO ( PUBYEAR, 2008 )) } \\
\text { AND ( LIMIT-TO ( DOCTYPE, "ar" ) } \\
\text { AND ( LIMIT-TO ( AFFILCOUNTRY, "United States" ) OR LIMIT-TO } \\
\text { ( AFFILCOUNTRY, "Undefined" ) } \\
\text { AND ( LIMIT-TO ( SRCTYPE, "j" ) OR LIMIT-TO ( SRCTYPE , } \\
\text { "Undefined" ) } \\
\text { AND ( LIMIT-TO ( LANGUAGE , "English" ) }\end{array}$ & 4,114 \\
\hline
\end{tabular}

\section{Grey Literature Search}

\section{Google Scholar}

Convenience "ready meal" OR "food at home" OR "fresh cut produce" OR "ready to eat" OR "ready to heat" OR "ready to cook" OR "ready to bake" OR "pre made" OR premade OR "pre cooked" OR "pre cut" OR precut OR "fresh cut" OR boxed OR frozen OR canned OR dehydrated OR tinned OR bagged OR jarred OR "ready made" OR instant OR "pre packaged" OR prepackaged OR "shelf stable" OR "single serve" OR "single serving" OR "pre washed" OR prewashed OR "partially prepared" OR packaged OR "easy to prepare"

Limits: Publication Date: 2008-2021;

Date Searched: $5 / 26 / 2021$

Results: 110, limited to 11 pages

\section{Google}

site:.gov AND Convenience AND "ready meal" OR "food at home" OR "fresh cut produce" OR "ready to eat" OR "ready to heat" OR "ready to cook" OR "ready to bake" OR "pre made" OR premade OR "pre cooked" OR "pre cut" OR precut OR "fresh cut" OR boxed OR frozen OR canned OR dehydrated OR tinned OR bagged OR jarred OR "ready made" OR instant OR "pre packaged" OR prepackaged OR "shelf stable" OR "single serve" OR "single serving" OR "pre washed" OR prewashed OR "partially prepared" OR packaged OR "easy to prepare"

Limits:

Date Searched: $5 / 27 / 2021$ 


\section{USDA Unansument \\ Department of \\ Agriculture}

USDA Food Plans Rapid Reviews and Evidence Scans

Results: 30 , limited to 3 pages

\section{Ag Econ}

Any of the words: "ready to eat" "ready to heat" "ready to cook" "ready to bake" "pre prepared" preprepared "pre made" premade "pre cooked" precooked "pre cut" precut "fresh cut" boxed frozen canned dehydrated tinned bagged jarred "ready made" instant "pre packaged" prepackaged "shelf stable" "single serve" "single serving" "pre washed" prewashed "partially prepared" packaged "easy to prepare"

AND

Any of the words: food goods meal snack fruit vegetable

OR

Any of the words: "convenience food" "convenient food" "ready meal" "convenience meal" "food at home" "fresh cut produce"

Limits: Added since 2008

Date Searched: $5 / 26 / 2021$

Results: 120, limited to 12 pages 


\section{Appendix 5-b: Excluded articles for the evidence scan on factors that influence the purchase and/or consumption of convenience foods}

The following table lists the articles excluded after full-text screening for this evidence scan question. At least 1 reason for exclusion is provided for each article, though this may not reflect all possible reasons. Information about articles excluded after title and abstract screening is available upon request.

Citation

1. . Are canned fruits and vegetables a healthy alternative to fresh produce? The Johns Hopkins medical letter health after 50. 2013. 25:7.

2. . Convenience food and drink sector. Nutrition \& Food Science. 2010. 40:173-178. doi:10.1108/nfs.2010.01740dab.022.

3. . FASTLANE CONVENIENCE. 2021.

4. . Fresh or frozen produce? The health benefit is all in the mix. Relying on a mix of fresh and frozen can help you get your five-to-nine daily servings of fruits and vegetables. Harvard men's health watch. 2014. 18:6.

5. . From Other Blogs: National Immunization Awareness Month, convenience foods, disaster recovery \& more. Live Healthy SC. 2018.

6. . International chefs' circle promotes quality ready meals. Food Australia. 2008. 60:94.

7. . ready-to-eat food samples: Topics by Science.gov. 2021.

8. Ailawadi, K, Ma, Y, Grewal, D. The club store effect: Impact of shopping in warehouse club stores on consumers' packaged food purchases. Journal of Marketing Research. 2018. 55:193-207. doi:10.1509/jmr.16.0235.

9. Albuquerque, P, Bronnenberg, BJ. Estimating demand heterogeneity using aggregated data: An application to the frozen pizza category. Marketing Science. 2009. 28:356-372. doi:10.1287/mksc.1080.0403.

10. Alpaugh, M, Pope, L, Trubek, A, Skelly, J, Harvey, J. Cooking as a health behavior: Examining the role of cooking classes in a weight loss intervention. Nutrients. 2020. 12:1-13. doi:10.3390/nu12123669.

11. Andrews, SandraL, O'Reilly, Donna. Storing Designer And Convenience Foods. Extension Bulletin E-2297 Cooperative Extension Service. 1991. 6.

12. Anesbury, Zachary William, Talbot, Danielle, Day, Chanel Andrea, Bogomolov, Tim, Bogomolova, Svetlana. The fallacy of the heavy buyer: Exploring purchasing frequencies of fresh fruit and vegetable categories. Journal of Retailing \& Consumer Services. 2020. 53:N.PAG-N.PAG. doi:10.1016/j.jretconser.2019.101976.

13. Anselmsson, Johan, Bondesson, Niklas Vestman, Johansson, Ulf. Brand image and customers' willingness to pay a price premium for food brands. Journal of Product \& Brand Management. 2014. 23:90-102. doi:10.1108/JPBM-10-2013-0414.

14. Arentz, L. Kidney-Friendly Frozen Meals Update: Quick and Convenient Options for Chronic Kidney Disease Patients. Journal of Renal Nutrition. 2016. 26:e15-e17. doi:10.1053/j.jrn.2016.02.004.

15. Aviles, M Victoria, Naef, Elisa Fernanda, Abalos, Rosa Ana, Lound, Liliana H, Olivera, Daniela F, García-Segovia, Purificación. Effect of familiarity of ready-to-eat animal-based meals on consumers' perception and consumption motivation. International Journal of Gastronomy and Food Science. 2020. 21:100225.

16. Ayala, GX, Baquero, B, Laraia, BA, Ji, M, Linnan, L. Efficacy of a store-based environmental change intervention compared with a delayed treatment control condition on store customers' intake of fruits and vegetables. Public Health Nutrition. 2013. 16:1953-1960. doi:10.1017/S1368980013000955.
Reason for exclusion

Outcome

Country

Outcome

Outcome

Study design

Country; Publication status

Other

Outcome

Intervention/Exposure; Data date range

Outcome

Outcome

Intervention/Exposure

Country

Outcome

Country

Outcome 
Citation

17. Baker, SL, McCabe, SD, Swithers, SE, Payne, CR, Kranz, S. Do healthy, child-friendly fruit and vegetable snacks appeal to consumers? A field study exploring adults' perceptions and purchase intentions. Food Quality and Preference. 2015. 39:202-208. doi:10.1016/j.foodqual.2014.07.013.

18. Balzan, S, Fasolato, L, Cardazzo, B, Berti, G, Novelli, E. Cold Chain and Consumers' Practices: Exploratory Results of Focus Group Interviews. Ital J Food Saf. 2014. 3:4516. doi:10.4081/ijfs.2014.4516.

19. Barska, Anetta. Millennial consumers in the convenience food market. Konsumenci generacji Y na rynku żywności wygodnej.. 2018. 22:251-264. doi:10.2478/manment-2018-0018.

20. Baumhofer, NK, Panapasa, SV, Francis Cook, E, Roberto, CA, Williams, DR. Sociodemographic factors influencing island foods consumption in the Pacific Islander Health Study. Ethnicity and Health. 2020. 25:305-321. doi:10.1080/13557858.2017.1418300.

21. Berge, JM, Tate, A, Trofholz, A, Loth, K, Miner, M, Crow, S, Neumark-Sztainer, D. Examining variability in parent feeding practices within a low-income, racially/ethnically diverse, and immigrant population using ecological momentary assessment. Appetite. 2018. 127:110118. doi:10.1016/j.appet.2018.04.006.

22. Binkley, JK, Liu, Y. Food at Home and away from Home: Commodity Composition, Nutrition Differences, and Differences in Consumers. Agricultural and Resource Economics Review. 2019. 48:221-252. doi:10.1017/age.2019.1.

23. Bird Jernigan, Valarie Blue, Salvatore, AliciaL, Williams, Mary, Wetherill, Marianna, Taniguchi, Tori, Jacob, Tvli, Cannady, Tamela, Grammar, Mandy, Standridge, Joy, Fox, Jill, Tingle Owens, JoAnna, Spiegel, Jennifer, Love, Charlotte, Teague, Travis, Noonan, Carolyn. A Healthy Retail Intervention in Native American Convenience Stores: The THRIVE Community-Based Participatory Research Study. American Journal of Public Health. 2019. 109:132-139. doi:10.2105/AJPH.2018.304749.

24. Bishop, L, Goeddeke-Merickel, CM. Kidney-Friendly Frozen Meal Tips and Suggestions "In A Pinch". Journal of Renal Nutrition. 2012. 22:e43-e45. doi:10.1053/j.jrn.2012.06.002.

25. Bodor, JN, Hutchinson, PL, Rose, D. Car ownership and the association between fruit and vegetable availability and diet. Preventive Medicine. 2013. 57:903-905.

doi:10.1016/j.ypmed.2013.10.003.

26. Bosworth, RC, Bailey, D, Curtis, KR. Consumer Willingness to Pay for Local Designations: Brand Effects and Heterogeneity at the Retail Level. Journal of Food Products Marketing. 2015. 21:274-292. doi:10.1080/10454446.2013.843488.

27. Bower, Patrick. Forecasting New Products in Consumer Goods. Journal of Business Forecasting. 2012. 31:4-30.

28. Brauchla, M, Fulgoni, VL. Cost-effective Options for Increasing Consumption of Underconsumed Food Groups \& Nutrients in the United States. Public Health Nutrition. 2021. doi:10.1017/S1368980021000537.

29. Briefel, RR, Chojnacki, GJ, Gabor, V, Forrestal, SG, Kleinman, R, Cabili, C, Gleason, PM. A Cluster Randomized Controlled Trial of a Home-Delivered Food Box on Food Security in Chickasaw Nation. Journal of the Academy of Nutrition and Dietetics. 2021. 121:S46-S58. doi:10.1016/j.jand.2020.07.021.

30. Briefel, RR, Collins, AM, Wolf, A, Gordon, AR, Cabili, CL, Klerman, JA. Nutrition impacts in a randomized trial of summer food benefits to prevent childhood hunger in U.S. schoolchildren. Journal of Hunger and Environmental Nutrition. 2018. 13:304-321. doi:10.1080/19320248.2017.1393366.

31. Briefel, RR, Wilson, A, Gleason, PM. Consumption of Low-Nutrient, Energy-Dense Foods and Beverages at School, Home, and Other Locations among School Lunch Participants and Nonparticipants. Journal of the American Dietetic Association. 2009. 109:S79-S90. doi:10.1016/j.jada.2008.10.064.

32. Burani, J. Home cooking. Eat healthy, save money!. Diabetes self-management. 2010. 27:

33. Camire, ME, Savoie, K, Perry, J, Calder, B. Preliminary assessment of maine consumers' educational preferences for fermenting foods at home. Food Protection Trends. 2019. 39:116126.
Reason for exclusion

Outcome

Country

Country

Outcome

Outcome

Intervention/Exposure

Outcome

Outcome; Study

design

Outcome

Outcome

Outcome

Outcome

Outcome

Outcome

Data date range

Publication status

Outcome

nesr.usda.gov | 263 
Citation

34. Canuto, R, Garcez, A, Spritzer, PM, Olinto, MTA. Associations of perceived stress and salivary cortisol with the snack and fast-food dietary pattern in women shift workers. Stress. 2021. 1-9. doi:10.1080/10253890.2021.1919615.

35. Caspi, CE, Lenk, K, Pelletier, JE, Barnes, TL, Harnack, L, Erickson, DJ, Laska, MN. Association between store food environment and customer purchases in small grocery stores, gas-marts, pharmacies and dollar stores. International Journal of Behavioral Nutrition and Physical Activity. 2017. 14:doi:10.1186/s12966-017-0531-x.

36. Chae, Mi-Jin, Bae, Hyun-Joo. A survey on preference and satisfaction of the customers purchasing ready-to-eat foods. Korean Journal of Food and Cookery Science. 2008. 24:788800.

37. Chen, Danhong, Jaenicke, EdwardC. Composition of Food-at-Home Expenditures and Childhood Obesity. 2017. doi:10.22004/ag.econ.258343.

38. Chen, Y, Lin, BH, Mancino, L, Ploeg, MV, Zhen, C. Nutritional quality of retail food purchases is not associated with participation in the Supplemental Nutrition Assistance Program for nutrition-oriented households. PLoS ONE. 2020. 15:doi:10.1371/journal.pone.0240263.

39. Chonpracha, P, Ardoin, R, Gao, Y, Waimaleongoraek, P, Tuuri, G, Prinyawiwatkul, W. Effects of intrinsic and extrinsic visual cues on consumer emotion and purchase intent: A case of ready-to-eat salad. Foods. 2020. 9:doi:10.3390/foods9040396.

40. Chu, J, Chintagunta, P, Cebollada, J. A comparison of within-household price sensitivity across online and offline channels. Marketing Science. 2008. 27:283-299. doi:10.1287/mksc.1070.0288.

41. Cioffi, CE, Levitsky, DA, Pacanowski, CR, Bertz, F. A nudge in a healthy direction. The effect of nutrition labels on food purchasing behaviors in university dining facilities. Appetite. 2015. 92:7-14. doi:10.1016/j.appet.2015.04.053.

42. Cleary, R, Bonanno, A, Ghazaryan, A, Bellows, L, McCloskey, M. School meals and quality Outcome of household food acquisitions. Applied Economic Perspectives and Policy. 2021. doi:10.1002/aepp.13130.

43. Coffman, MA, Camire, ME. Perceived Barriers to Increased Whole Grain Consumption by Older Adults in Long-Term Care. Journal of Nutrition in Gerontology and Geriatrics. 2017. 36:178-188. doi:10.1080/21551197.2017.1385564.

44. Colasanti, KJA, Matts, C, Hamm, MW. Results from the 2009 Michigan Farm to School Survey: Participation Grows from 2004. Journal of Nutrition Education and Behavior. 2012. 44:343-349. doi:10.1016/j.jneb.2011.12.003.

45. Combs, Susan. Local Sales Tax and Use Bulletin: Ready-To-Eat Food . 2007.

46. Conrad, Z, Chui, K, Jahns, L, Peters, CJ, Griffin, TS. Characterizing trends in fruit and vegetable intake in the USA by self-report and by supply-And-disappearance data: 2001-2014. Public Health Nutrition. 2017. 20:3045-3050. doi:10.1017/S1368980017002385.

47. Contini, Caterina, Romano, Caterina, Scozzafava, Gabriele, Casini, Leonardo. Food habits and the increase in ready-to-eat and easy-to-prepare products. Food hygiene and toxicology in ready-to-eat foods. 2016. 3-14.

48. Cook, R. Fresh-cut/value-added produce marketing trends. UC Davis freshcut products workshop: maintaining quality and safety. 2016.

49. Cornwell, TB, Setten, E, Paik, SHW, Pappu, R. Parents, Products, and the Development of Preferences: Child Palate and Food Choice in an Obesogenic Environment. Journal of Public Policy and Marketing. 2020. doi:10.1177/0743915620939581.

50. Dallinger, I, Magnini, VP. Chefs' perceptions of using convenience food products versus scratch cooking. Journal of Foodservice Business Research. 2017. 20:34-49. doi:10.1080/15378020.2016.1192892.

51. Dannefer, R, Bryan, E, Osborne, A, Sacks, R. Evaluation of the Farmers' Markets for Kids programme. Public Health Nutrition. 2016. 19:3397-3405. doi:10.1017/S1368980016001725.

52. Davis, GC, You, W, Yang, Y. Are SNAP benefits adequate? A geographical and food expenditure decomposition. Food Policy. 2020. 95:doi:10.1016/j.foodpol.2020.101917.
Data date range

Reason for exclusion

Country

Outcome

Country; Data date range

Publication status

Outcome

Outcome

Country

Outcome; Other

Outcome

Outcome

Intervention/Exposure

Study design

Study design

Outcome

Outcome

Outcome

Outcome

nesr.usda.gov | 264 
Citation

53. Dettmann, RL, Dimitri, C. Who's buying organic vegetables? Demographic characteristics of U.S. consumers. Journal of Food Products Marketing. 2010. 16:79-91. doi:10.1080/10454440903415709.

54. DeWeese, RS, Ohri-Vachaspati, P. Cost of Children's Healthy vs. Unhealthy Snacks Does Not Differ at Convenience Stores. Journal of Nutrition Education and Behavior. 2017. 49:241243.e1. doi:10.1016/j.jneb.2016.11.006.

55. Dhir, Bhavya, Singla, Neerja. Consumption Pattern and Health Implications of Convenience Foods: A Practical Review. Current Journal of Applied Science and Technology. 2019. 1-9.

56. Di Noia, J, Monica, D, Cullen, KW, Pérez-Escamilla, R, Gray, HL, Sikorskii, A. Differences in fruit and vegetable intake by race/ethnicity and by hispanic origin and nativity among women in the special supplemental nutrition program for women, infants, and children, 2015.

Preventing Chronic Disease. 2016. 13:doi:10.5888/pcd13.160130.

57. Didinger, $\mathrm{C}$, Thompson, $\mathrm{H}$. Motivating pulse-centric eating patterns to benefit human and environmental well-being. Nutrients. 2020. 12:1-12. doi:10.3390/nu12113500.

58. Disantis, KI, Grier, SA, Oakes, JM, Kumanyika, SK. Food prices and food shopping decisions of black women. Appetite. 2014. 77:104-112. doi:10.1016/j.appet.2014.02.016.

59. Dong, Diansheng, Kaiser, HarryM. Investigating household food interpurchase behavior through market segmentation. Agribusiness. 2010. 26:389-404. doi:10.1002/agr.20230.

60. Espinoza-Orias, Namy, Azapagic, Adisa. Understanding the impact on climate change of convenience food: Carbon footprint of sandwiches. Sustainable Production and Consumption. 2018. 15:1-15.

61. Findholt, NE, Izumi, BT, Nguyen, T, Pickus, H, Chen, Z. Availability of healthy snack foods and beverages in stores near high-income urban, low-income urban, and rural elementary and middle schools in Oregon. Childhood Obesity. 2014. 10:342-348. doi:10.1089/chi.2014.0020.

62. Gabrielli, Veronica, Cavazza, Nicoletta. The influence of in-store product holders on orientation towards the product and on purchase intention. International Review of Retail, Distribution \& Consumer Research. 2014. 24:311-327. doi:10.1080/09593969.2013.862507.

63. Gajda, R, Bronkowska, M. Dietary patterns of health sciences students in regarding to physical activity levels and somatic indicators of nutritional status. Rocz Panstw Zakl Hig. 2020. 71:271-278. doi:10.32394/rpzh.2020.0124.

64. Ghosh Roy, P, Jones, KK, Martyn-Nemeth, P, Zenk, SN. Contextual correlates of energydense snack food and sweetened beverage intake across the day in African American women: An application of ecological momentary assessment. Appetite. 2019. 132:73-81. doi:10.1016/j.appet.2018.09.018.

65. Graham, DJ, Mohr, GS. When zero is greater than one: Consumer misinterpretations of nutrition labels. Health Psychology. 2014. 33:1579-1587. doi:10.1037/hea0000080.

66. Guan, X, Atlas, SA, Vadiveloo, M. Targeted retail coupons influence category-level food purchases over 2-years 11 Medical and Health Sciences 1117 Public Health and Health Services. International Journal of Behavioral Nutrition and Physical Activity. 2018. 15:doi:10.1186/s12966-018-0744-7.

67. Gumirakiza, JD, Curtis, KR, Bosworth, R. Who attends farmers' markets and why? Understanding consumers and their motivations. International Food and Agribusiness Management Review. 2014. 17:65-82.

68. Guthrie, J, Mancino, L, Lin, CTJ. Nudging consumers toward better food choices: Policy approaches to changing food consumption behaviors. Psychology and Marketing. 2015. 32:501-511. doi:10.1002/mar.20795.

69. Guthrie, Joanne, Lin, Biing-Hwan . Both At Home and Away, Americans Are Choosing More Lower Fat Foods Than They Did 35 Years Ago. 2018. October 2018:doi:10.22004/ag.econ.302659.

70. Ha, EJ, Caine-Bish, N. Effect of Nutrition Intervention Using a General Nutrition Course for Promoting Fruit and Vegetable Consumption among College Students. Journal of Nutrition Education and Behavior. 2009. 41:103-109. doi:10.1016/j.jneb.2008.07.001.

71. Haire, C, Raynor, HA. Weight status moderates the relationship between package size and food Intake. Journal of the Academy of Nutrition and Dietetics. 2014. 114:1251-1256. doi:10.1016/j.jand.2013.12.022.
Reason for exclusion

Data date range

Outcome

Country

Outcome

Study design

Outcome

Data date range

Outcome

Outcome

Country

Country

Other

Intervention/Exposure; Outcome

Data date range

Outcome

Study design

Outcome

Data date range

Outcome

nesr.usda.gov | 265 
Citation

72. Henderson, Steven. September, 20171 Comparing Global questions and answers to results from detailed specific questions: Data on Food Expenditures from the Consumer Expenditure Survey, 1998 - 2016. 2017. 5.

73. Hillier, A, McLaughlin, J, Cannuscio, CC, Chilton, M, Krasny, S, Karpyn, A. The Impact of WIC Food Package Changes on Access to Healthful Food in 2 Low-Income Urban

Neighborhoods. Journal of Nutrition Education and Behavior. 2012. 44:210-216.

doi:10.1016/j.jneb.2011.08.004.

74. Hirekenchanagoudar, Renuka. Consumer behaviour towards ready-to-eat food products. 2008.

75. Holloman, EL, Newman, MC. A community-based assessment of seafood consumption along the lower James River, Virginia, USA: Potential sources of dietary mercury exposure.

Environmental Research. 2010. 110:213-219. doi:10.1016/j.envres.2010.01.002.

76. Holzmeister, LA. Supermarket smarts. Fresh, frozen, and canned poultry. Diabetes selfmanagement. 2008. 25:73, 75, 77-78, 80-81, 84-85.

77. Holzmeister, LA. Vegetarian frozen entrées. Diabetes self-management. 2010. 27:52, 54, 56- Publication status 60.

78. Hoseini Siahdashti, Seyed Jaber. Investigating the Role of Food Packaging in Terms of Design and Color in Consumer Purchasing Behavior. International Journal of Management, Accounting \& Economics. 2019. 6:542-550.

79. Hosler, AS, Rajulu, DT, Fredrick, BL, Ronsani, AE. Assessing retail fruit and vegetable availability in urban and rural underserved communities. Preventing Chronic Disease. 2008. 5:

80. Huffman, WE. Household production and the demand for food and other inputs: U.S. Evidence. Journal of Agricultural and Resource Economics. 2011. 36:465-487.

81. Hull, MV, Jagim, AR, Oliver, JM, Greenwood, M, Busteed, DR, Jones, MT. Gender differences and access to a sports dietitian influence dietary habits of collegiate athletes. Journal of the International Society of Sports Nutrition. 2016. 13:doi:10.1186/s12970-0160149-4.

82. Huyghe, Elke, Verstraeten, Julie, Geuens, Maggie, Van Kerckhove, Anneleen. Clicks as a Healthy Alternative to Bricks: How Online Grocery Shopping Reduces Vice Purchases. Journal of Marketing Research (JMR). 2017. 54:61-74. doi:10.1509/jmr.14.0490.

83. Idowu, Atinuke O, Omobuwajo, TO, Falade, KO. Production proximate analysis and shelf life Country studies of ready-to-eat rice and kilishi. African Journal of Food Science. 2010. 4:264-268.

84. llyuk, V, Block, L. The effects of single-serve packaging on consumption closure and judgments of product efficacy. Journal of Consumer Research. 2016. 42:858-878. doi:10.1093/jcr/ucv059.

85. Imtiyaz, H, Soni, P, Yukongdi, V. Investigating the Role of Psychological, Social, Religious and Ethical Determinants on Consumers' Purchase Intention and Consumption of Convenience Food. Foods. 2021. 10:doi:10.3390/foods10020237.

86. Ismail, MS, Ver Ploeg, M, Chomitz, VR, Wilde, P. Differences in Food-at-Home Spending for SNAP and Non-SNAP Households Given Geographic Price Variation. Journal of the Academy of Nutrition and Dietetics. 2020. 120:1142-1150.e12. doi:10.1016/j.jand.2019.12.017.

87. Jamal, Ahmad, Peattie, Sue, Peattie, Ken. Ethnic minority consumers' responses to sales promotions in the packaged food market. Journal of Retailing \& Consumer Services. 2012. 19:98-108. doi:10.1016/j.jretconser.2011.10.001.

88. Jenny Sun, $\mathrm{CH}$, Chiang, FS, Owens, M, Squires, D. Will American consumers pay more for eco-friendly labeled canned tuna? Estimating US consumer demand for canned tuna varieties using scanner data. Marine Policy. 2017. 79:62-69. doi:10.1016/j.marpol.2017.02.006.

89. Jilcott, SB, Laraia, BA, Evenson, KR, Ammerman, AS. Perceptions of the community food environment and related influences on food choice among midlife women residing in rural and urban areas: A qualitative analysis. Women and Health. 2009. 49:164-180. doi:10.1080/03630240902915085.
Reason for exclusion

Outcome

Outcome

Country

Intervention/Exposure

Publication status

Outcome

Data date range

Outcome

Outcome

Country

Outcome

Country

Outcome

Country

Intervention/Exposure

Outcome; Data date

range 
Citation

90. Jock, BW, Roche, KB, Caldas, SV, Redmond, L, Fleischhacker, S, Gittelsohn, J. Latent class analysis offers insight into the complex food environments of native american communities: Findings from the randomly selected OPREVENT2 trial baseline sample. International Journal of Environmental Research and Public Health. 2020. 17:doi:10.3390/ijerph17041237.

91. Jones, SA, Walter, J, Soliah, L, Phifer, JT. Perceived motivators to home food preparation: Focus group findings. Journal of the Academy of Nutrition and Dietetics. 2014. 114:15521556. doi:10.1016/j.jand.2014.05.003.

92. KC Healthy Kids. The incidence of the inclusion of food at home preparation in the sales tax base. . 9.

93. Keller, KL, Kuilema, LG, Lee, N, Yoon, J, Mascaro, B, Combes, AL, Deutsch, B, Sorte, K, Outcome Halford, JCG. The impact of food branding on children's eating behavior and obesity. Physiology and Behavior. 2012. 106:379-386. doi:10.1016/j.physbeh.2012.03.011.

94. Kern, DM, Auchincloss, AH, Robinson, LF, Stehr, MF, Pham-Kanter, G. Healthy and Unhealthy Food Prices across Neighborhoods and Their Association with Neighborhood Socioeconomic Status and Proportion Black/Hispanic. Journal of Urban Health. 2017. 94:494505. doi:10.1007/s11524-017-0168-8.

95. Kim, J, Rabbitt, MP, Tuttle, C. Changes in Low-Income Households' Spending and Time Use Patterns in Response to the 2013 Sunset of the ARRA-SNAP Benefit. Applied Economic Perspectives and Policy. 2020. 42:777-795. doi:10.1093/aepp/ppz007.

96. Kumar, Arvind. Shopping Orientations and Their Inter-Relatedness: A Study on the Poor for CPGs. Journal of Global Marketing. 2020. 33:289-304. doi:10.1080/08911762.2020.1733729.

97. Lacy, K, Huffman, WE. Consumer demand for potato products andwillingness-to-pay for lowacrylamide, sulfite-free fresh potatoes and dices: Evidence from lab auctions. Journal of Agricultural and Resource Economics. 2016. 41:116-137.

98. Laguna, L, Gómez, B, Garrido, MD, Fiszman, S, Tarrega, A, Linares, MB. Do Consumers Change Their Perception of Liking, Expected Satiety, and Healthiness of a Product If They Know It Is a Ready-to Eat Meal?. Foods. 2020. 9:doi:10.3390/foods9091257.

99. Lee, Jonq-Ying, Kilmer, RichardL. At-Home Convenience Food Consumption and BMI. 2010. 29. doi:10.22004/ag.econ.56428.

100. Lee, JY, Lin, BH. A Study of the Demand for Convenience Food. Journal of Food Products Marketing. 2013. 19:1-14. doi:10.1080/10454446.2013.739120.

101. Lee, SH, Hoffman, VA, Bleich, SN, Gittelsohn, J. Frequency of Visiting and Food Dollars Spent at Carryouts Among Low-Income, Urban African American Adults. Journal of Hunger and Environmental Nutrition. 2013. 7:459-467. doi:10.1080/19320248.2012.735220.

102. Lin, BH, Dong, D, Carlson, A, Rahko vs.ky, I. Potential dietary outcomes of changing relative prices of healthy and less healthy foods: The case of ready-to-eat breakfast cereals. Food Policy. 2017. 68:77-88. doi:10.1016/j.foodpol.2017.01.004.

103. Liu, Y, Balachander, S. How long has it been since the last deal? Consumer promotion timing expectations and promotional response. Quantitative Marketing and Economics. 2014. 12:85126. doi:10.1007/s11129-013-9141-3.

104. Locher, JL, Ritchie, CS, Roth, DL, Sen, B, Vickers, KS, Vailas, LI. Food choice among homebound older adults: Motivations and perceived barriers. Journal of Nutrition, Health and Aging. 2009. 13:659-664. doi:10.1007/s12603-009-0194-7.

105. Lodolce, ME, Harris, JL, Schwartz, MB. Sugar as part of a balanced breakfast? What cereal advertisements teach children about healthy Eating. Journal of Health Communication. 2013. 18:1293-1309. doi:10.1080/10810730.2013.778366.

106. Loose, Simone Mueller, Peschel, Anne, Grebitus, Carola. Quantifying effects of convenience and product packaging on consumer preferences and market share of seafood products: The case of oysters. Food Quality and Preference. 2013. 28:492-504.

107. Lotade-Manje, Justus, Dunn, RichardA, Nayga, RodolfoM, Jr, Sharkey, JosephR. Determinants of Affordability of Healthy Food in the Rural Counties: case of the Brazos Valley Area. The relationship between neighborhood characteristics and the affordability of fresh fruits and vegetables. 2009. 26. doi:10.22004/ag.econ.49511.

Outcome
Reason for exclusion Intervention/Exposure

Outcome

Data date range

Outcome

Outcome

Country

Outcome

Outcome

Data date range

Data date range

Outcome

Data date range

Outcome

Outcome

Outcome

Country 
Citation

108. Lucan, SeanC, Barg, FrancesK, Long, JudithA. Promoters and Barriers to Fruit, Vegetable, and Fast-Food Consumption Among Urban, Low-Income African Americans--A Qualitative Approach. American Journal of Public Health. 2010. 100:631-635. doi:10.2105/AJPH.2009.172692.

109. Marckhgott, Eva, Kamleitner, Bernadette. Matte matters: when matte packaging increases perceptions of food naturalness. Marketing Letters. 2019. 30:167-178. doi:10.1007/s11002019-09488-6.

110. Martin-Belloso, Olga, Soliva Fortuny, Robert. Advances in fresh-cut fruits and vegetables processing. 2019.

111. McDermott, AJ, Stephens, MB. Cost of eating: Whole foods versus convenience foods in a low-income model. Family Medicine. 2010. 42:280-284.

112. McGill, CR, Birkett, A, Fulgonii, VL, III. Healthy Eating Index-2010 and food groups consumed by US adults who meet or exceed fiber intake recommendations NHANES 20012010. Food and Nutrition Research. 2016. 60:doi:10.3402/fnr.v60.29977.

113. McLean-Meyinsse, PatriciaE, Taylor, SherviaS, Gager, JanetV. Self-Reported Consumption of Fast-Food Meals by University Students. Journal of Food Distribution Research. 2015. 46:23-29.

114. Melo, G, Zhen, C, Colson, G. Does point-of-sale nutrition information improve the nutritional quality of food choices?. Economics and Human Biology. 2019. 35:133-143. doi:10.1016/j.ehb.2019.07.001.

115. Melo, Grace, Rabinowitz, AdamN. Food Choices of SNAP/WIC Participants at Convenience Stores and Larger Stores. 2018. doi:10.22004/ag.econ.273844.

116. Miller, SR, Knudson, WA. Nutrition and Cost Comparisons of Select Canned, Frozen, and Fresh Fruits and Vegetables. American Journal of Lifestyle Medicine. 2014. 8:430-437. doi:10.1177/1559827614522942.

117. Moore, LV, Pinard, CA, Yaroch, AL. Features in Grocery Stores that Motivate Shoppers to Buy Healthier Foods, ConsumerStyles 2014. Journal of Community Health. 2016. 41:812-817. doi:10.1007/s10900-016-0158-x.

118. Morrissey, TW, Jacknowitz, A, Vinopal, K. Local food prices and their associations with children's weight and food security. Pediatrics. 2014. 133:422-430. doi:10.1542/peds.20131963.

119. Muhamad, Ida Idayu, Karim, Norsuhada Abdul. Trends, convenience, and safety issues of ready meals. Minimally Processed Foods. 2015. 105-123.

120. Mulik, K, Haynes-Maslow, L. The Affordability of MyPlate: An Analysis of SNAP Benefits and the Actual Cost of Eating According to the Dietary Guidelines. Journal of Nutrition Education and Behavior. 2017. 49:623-631.e1. doi:10.1016/j.jneb.2017.06.005.

121. Muth, MK, Karns, SA, Zmuda, M, Coglaiti, MC, Koyanagi, M, Duffey, K, Dunn, C, Jensen, $\mathrm{HH}$, Gregory, C. Price, nutrition, time, and other trade-offs: A web-based food value analysis application to compare foods at different levels of preparation and processing. Nutrition Today. 2014. 49:176-184. doi:10.1097/NT.0000000000000039.

122. Nakano, S, Washizu, A. Aiming for better use of convenience food: an analysis based on meal production functions at home. J Health Popul Nutr. 2020. 39:3. doi:10.1186/s41043-0200211-3.

123. Närvänen, Elina, Saarijärvi, Hannu, Simanainen, Olli. Understanding consumers' online conversation practices in the context of convenience food. International Journal of Consumer Studies. 2013. 37:569-576. doi:10.1111/ijcs.12021.

124. Ng, SW, Poti, JM, Popkin, BM. Trends in racial/ethnic and income disparities in foods and beverages consumed and purchased from stores among US households with children, 20002013. American Journal of Clinical Nutrition. 2016. 104:750-759. doi:10.3945/ajcn.115.127944.

125. Nicola, Silvana, Fontana, Emanuela. Fresh-cut produce quality: implications for a systems approach. Postharvest handling. 2014. 217-273.

126. O'Dare Wilson, K. The effect of poverty-influenced, food-related consumer behaviors on obesity: An analysis of the NHANES flexible consumer behavioral module. Social Work in Health Care. 2017. 56:400-411. doi:10.1080/00981389.2017.1279704.
Reason for exclusion

Outcome

Outcome

Study design

Outcome

Outcome

Outcome

Intervention/Exposure

Outcome

Outcome

Outcome

Data date range

Study design

Outcome

Outcome

Country

Country

Outcome

Study design; Publication status Intervention/Exposure 
Citation

127. Olsen, Nina Veflen, Sijtsema, Siet J, Hall, Gunnar. Predicting consumers' intention to consume ready-to-eat meals. The role of moral attitude. Appetite. 2010. 55:534-539.

128. Olsen, Nina Veflen. The convenience consumer's dilemma. British Food Journal. 2012.

129. Page, R, Montgomery, $K$, Ponder, A, Richard, A. Targeting children in the cereal aisle: Promotional techniques and content features on ready-to-eat cereal product packaging.

American Journal of Health Education. 2008. 39:272-282. doi:10.1080/19325037.2008.10599050.

130. Park, Ji Young, Kim, Ji-Na, Hong, Wan-Soo, Shin, Weon-Sun. Survey on Present Use and Future Demand for the Convenience Food in the Elderly Group. Korean J Community Nutr. 2012. 17:81-90.

131. Payne, C, Niculescu, M. Can healthy checkout end-caps improve targeted fruit and vegetable Outcome purchases? Evidence from grocery and SNAP participant purchases. Food Policy. 2018. 79:318-323. doi:10.1016/j.foodpol.2018.03.002.

132. Payne, CR, Niculescu, M, Barney, CE. Consumer consumption intentions of smaller packaged snack variants. International Journal of Consumer Studies. 2014. 38:238-242. doi:10.1111/ijcs.12090.

133. Peltner, Jonas, Thiele, Silke. Convenience-based food purchase patterns: Identification and associations with dietary quality, sociodemographic factors and attitudes. Public health nutrition. 2018. 21:558-570.

134. Peterson, SL, Dodd, KM, Kim, K, Roth, SL. Food cost perceptions and food purchasing practices of uninsured, low-income, rural adults. Journal of Hunger and Environmental Nutrition. 2010. 5:41-55. doi:10.1080/19320240903578073.

135. Phan, MM, Stodolska, M. What Impacts Leisure Activity and Diet among Immigrants? Mexican Immigrants' Leisure Participation and Food Patterns in the Midwestern U.S. Leisure Sciences. 2019. doi:10.1080/01490400.2019.1656119.

136. Phil, Harris, Silva, Andrés, Von Hausen, Nicolas, Magaña-Lemus, David. Effect of food insecurity on food purchases at home. Journal of Public Affairs (14723891). 2019. 19:N.PAGN.PAG. doi:10.1002/pa.1852.

137. Phipps, EJ, Braitman, LE, Stites, SD, Singletary, SB, Wallace, SL, Hunt, L, Axelrod, S, Glanz, K, Uplinger, N. Impact of a rewards-based incentive program on promoting fruit and vegetable purchases. American Journal of Public Health. 2015. 105:166-172. doi:10.2105/AJPH.2013.301752.

138. Phipps, EJ, Wallace, SL, Stites, SD, Uplinger, N, Brook Singletary, S, Hunt, L, Axelrod, S, Glanz, K, Braitman, LE. Using rewards-based incentives to increase purchase of fruit and vegetables in lower-income households: Design and start-up of a randomized trial. Public Health Nutrition. 2013. 16:936-941. doi:10.1017/S1368980012004934.

139. PLATTA, ANNA, PUKSZTA, TOMASZ . ELDERLY PEOPLE‘S PERCEPTION OF NEW AND Country CONVENIENCE FOODS WITH HEALTH BENEFITS. 2019. 2019:doi:10.22004/ag.econ.293920.

140. Poti, Jennifer, Mendez, Michelle, Ng, Shu Wen, Popkin, Barry. Are Food Processing and Convenience Linked with the Nutritional Quality of Foods Purchased by US Households?. The FASEB Journal. 2015. 29:587.9. doi:https://doi.org/10.1096/fasebj.29.1_supplement.587.9.

141. Powell, LM, Han, E. The costs of food at home and away from home and consumption patterns among U.S. adolescents. Journal of Adolescent Health. 2011. 48:20-26. doi:10.1016/j.jadohealth.2010.06.006.

142. Rahko vs.ky, llya, Jo, Young, Carlson, Andrea. What Drives Consumers to Purchase Convenience Foods?. USDA Blog. 2021.

143. Restrepo, BJ, Zeballos, E. The effect of working from home on major time allocations with a focus on food-related activities. Review of Economics of the Household. 2020. 18:1165-1187. doi:10.1007/s11150-020-09497-9.

144. Richards, R, Brown, LB, Williams, DP, Eggett, DL. Developing a Questionnaire to Evaluate College Students' Knowledge, Attitude, Behavior, Self-efficacy, and Environmental Factors Related to Canned Foods. Journal of Nutrition Education and Behavior. 2017. 49:117-124.e1. doi:10.1016/j.jneb.2016.10.004.
Reason for exclusion

Country

Country

Data date range

Publication language

Outcome

Country

Data date range

Outcome

Outcome; Country

Intervention/Exposure; Outcome

Study design

Publication status

Data date range

Country; Other

Outcome

Outcome 
Citation

145. Rogus, S. Examining the influence of perceived and objective time constraints on the quality of household food purchases. Appetite. 2018. 130:268-273. doi:10.1016/j.appet.2018.08.025.

146. Rohatgi, KW, Tinius, RA, Cade, WT, Steele, EM, Cahill, AG, Parra, DC. Relationships between consumption of ultra-processed foods, gestational weight gain and neonatal outcomes in a sample of US pregnant women. PeerJ. 2017. 2017:doi:10.7717/peerj.4091.

147. Rudi, Jeta, Davis, GeorgeC, You, Wen. The Goods-Time Elasticity of Substitution in Home Food Production for Food Stamp/SNAP Participants. 2012. 2. doi:10.22004/ag.econ.124707.

148. Scharadin, B, Jaenicke, EC. Time spent on childcare and the household Healthy Eating Index. Review of Economics of the Household. 2020. 18:357-386. doi:10.1007/s11150-02009482-2.

149. Schäufele, I, Janssen, M. How and Why Does the Attitude-Behavior Gap Differ Between Product Categories of Sustainable Food? Analysis of Organic Food Purchases Based on Household Panel Data. Front Psychol. 2021. 12:595636. doi:10.3389/fpsyg.2021.595636.

150. Sen, Shuvro, Antara, Neel, Sen, Shusmita. Factors influencing consumers' to Take Readymade Frozen Food. Current Psychology. 2019. 1-10. doi:10.1007/s12144-019-00201-4.

151. Senia, MC, Jensen, $\mathrm{HH}$, Zhylye vs.kyy, $\mathrm{O}$. Time in eating and food preparation among single adults. Review of Economics of the Household. 2017. 15:399-432. doi:10.1007/s11150-0149258-5.

152. Shamim, K, Ahmad, S, Alam, MA. COVID-19 health safety practices: Influence on grocery shopping behavior. J Public Aff. 2021. e2624. doi:10.1002/pa.2624.

153. Sharkey, JR, Horel, S, Dean, WR. Neighborhood deprivation, vehicle ownership, and potential spatial access to a variety of fruits and vegetables in a large rural area in Texas. International Journal of Health Geographics. 2010. 9:doi:10.1186/1476-072X-9-26.

154. Sheely, M. Global adoption of convenience foods. American Journal of Agricultural Economics. 2008. 90:1356-1365. doi:10.1111/j.1467-8276.2008.01231.x.

155. Shen, W, Long, LM, Shih, CH, Ludy, MJ. A humanities-based explanation for the effects of emotional eating and perceived stress on food choice motives during the COVID-19 pandemic. Nutrients. 2020. 12:1-18. doi:10.3390/nu12092712.

156. Short, Gianna, Peterson, Hikaru. Does time spent preparing food affect consumers' food choices?. 2016. doi:10.22004/ag.econ.244990.

157. Smith, LP, Ng, SW, Popkin, BM. Trends in US home food preparation and consumption: Analysis of national nutrition surveys and time use studies from 1965-1966 to 2007-2008. Nutrition Journal. 2013. 12:doi:10.1186/1475-2891-12-45.

158. Song, HJ, Simon, JR, Patel, DU. Food Preferences of Older Adults in Senior Nutrition Programs. Journal of Nutrition in Gerontology and Geriatrics. 2014. 33:55-67. doi:10.1080/21551197.2013.875502.

159. Speight, KC, Schiano, AN, Harwood, WS, Drake, MA. Consumer insights on prepackaged Cheddar cheese shreds using focus groups, conjoint analysis, and qualitative multivariate analysis. Journal of Dairy Science. 2019. 102:6971-6986. doi:10.3168/jds.2018-16209.

160. Stallings, TL, Gazmararian, JA, Goodman, M, Kleinbaum, D. Agreement between the perceived and actual fruit and vegetable nutrition environments among low-income Urban women. Journal of Health Care for the Poor and Underserved. 2015. 26:1304-1318. doi:10.1353/hpu.2015.0109.

161. Stanley, K. Frugal cooking. Using canned goods. Diabetes self-management. 2010. 27:17 20.

162. Sutin, A, Robinson, E, Daly, M, Terracciano, A. Weight discrimination and unhealthy eatingrelated behaviors. Appetite. 2016. 102:83-89. doi:10.1016/j.appet.2016.02.016.

163. Taber, DR, Chriqui, JF, Chaloupka, FJ. State laws governing school meals and disparities in fruit/vegetable intake. American Journal of Preventive Medicine. 2013. 44:365-372. doi:10.1016/j.amepre.2012.11.038.

164. Taillie, LS, Ng, SW, Popkin, BM. Global growth of "big box" stores and the potential impact on human health and nutrition. Nutrition Reviews. 2016. 74:83-97. doi:10.1093/nutrit/nuv062.
Reason for exclusion

Outcome

Outcome

Publication status

Outcome

Country

Country

Outcome

Country

Data date range

Data date range

Outcome

Data date range

Outcome

Outcome; Other

Intervention/Exposure; Outcome

Outcome

Publication status

Outcome

Outcome

Outcome 
Citation

165. Tate, EB, Unger, JB, Chou, CP, Spruijt-Metz, D, Pentz, MA, Riggs, NR. Children's Executive Function and High-Calorie, Low-Nutrient Food Intake: Mediating Effects of ChildPerceived Adult Fast Food Intake. Health Education and Behavior. 2015. 42:163-170. doi:10.1177/1090198114547811.

166. Tripathi, Jyoti, Gupta, Sumit, Kumar, Vivekanand, Chatterjee, Suchandra, Variyar, Prasad $\mathrm{S}$, Sharma, Arun. Processing Food for Convenience: Challenges and Potentials.

167. Trudel, R, Murray, KB, Kim, S, Chen, S. The impact of traffic light color-coding on food health perceptions and choice. Journal of Experimental Psychology: Applied. 2015. 21:255275. doi:10.1037/xap0000049.

168. Tu, Juan, Qiu, Feng, Yang, Meng. The value of healthy eating vs.. the value of convenience: Investigating the willingness to pay for living in food swamps. 2020. doi:10.22004/ag.econ.304260.

169. Untari, Asih, Safira, Anya. DETERMINANTS OF NON-MUSLIM CONSUMERS' PURCHASE BEHAVIOR TOWARD HALAL PACKAGED FOOD. ASEAN Marketing Journal. 2020. 12:6068. doi:10.21002/amj.v12i1.12892.

170. Vadiveloo, MK, Parker, HW, Juul, F, Parekh, N. Sociodemographic differences in the dietary quality of food-at-home acquisitions and purchases among participants in the U.S. nationally representative food acquisition and purchase survey (foodaps). Nutrients. 2020. 12:1-18. doi:10.3390/nu12082354.

171. Variyam, JN. Do nutrition labels improve dietary outcomes?. Health Economics. 2008. 17:695-708. doi:10.1002/hec.1287.

172. Vickner, StevenS. Estimating the Implicit Price of Convenience: A Hedonic Analysis of the US Breakfast Sausage Market. Agribusiness. 2015. 31:281-292. doi:10.1002/agr.21404.

173. Vidal, Leticia, Ares, Gastón, Giménez, Ana. Projective techniques to uncover consumer perception: Application of three methodologies to ready-to-eat salads. Food Quality and Preference. 2013. 28:1-7. doi:https://doi.org/10.1016/j.foodqual.2012.08.005.

174. Webb, R. Healthy eating. Canned heat. A simple broth becomes a delicious meal. Diabetes forecast. 2008. 61:

175. Wells, Pamela, Dunn-Jensen, LindaM, Yang, Inae. But I Can't Eat That: Should Babcock Ice Cream Change its Ingredients?. Journal of Critical Incidents. 2019. 12:23-26.

176. Wetherill, MS, Williams, MB, Taniguchi, T, Salvatore, AL, Jacob, T, Cannady, T, Grammar, M, Standridge, J, Fox, J, Spiegel, J, Blue Bird Jernigan, V. A Nutrition Environment Measure to Assess Tribal Convenience Stores: The THRIVE Study. Health Promotion Practice. 2020. 21:410-420. doi:10.1177/1524839918800968.

177. Wilde, $\mathrm{P}$, Ismail, $\mathrm{M}$, Ver Ploeg, $M$. The Quality of the Food Retail Environment When Consumers May Be Mobile. Applied Economic Perspectives and Policy. 2021. 43:701-715. doi:10.1002/aepp.13147.

178. Williams, BM, O'Neil, CE, Keast, DR, Cho, S, Nicklas, TA. Ready-to-Eat Cereal Breakfasts Are Associated with Improved Nutrient Intake and Dietary Adequacy but Not Body Mass Index in Black Adolescents. American Journal of Lifestyle Medicine. 2009. 3:500-508. doi:10.1177/1559827609342063.

179. Williams, MB, Wang, W, Taniguchi, T, Salvatore, AL, Groover, WK, Wetherill, M, Love, C Cannady, T, Grammar, M, Standridge, J, Fox, J, Jernigan, VBB. Impact of a Healthy Retail Intervention on Fruits and Vegetables and Total Sales in Tribally Owned Convenience Stores: Findings From the THRIVE Study. Health Promotion Practice. 2020. doi:10.1177/1524839920953122.

180. Wilson, NLW, Just, DR, Swigert, J, Wansink, B. Food pantry selection solutions: A randomized controlled trial in client-choice food pantries to nudge clients to targeted foods. Journal of Public Health (United Kingdom). 2017. 39:366-372. doi:10.1093/pubmed/fdw043.

181. Wolf, RL, Lepore, SJ, Vandergrift, JL, Wetmore-Arkader, L, McGinty, E, Pietrzak, G, Yaroch, AL. Knowledge, Barriers, and Stage of Change as Correlates of Fruit and Vegetable Consumption among Urban and Mostly Immigrant Black Men. Journal of the American Dietetic Association. 2008. 108:1315-1322. doi:10.1016/j.jada.2008.05.011.
Reason for exclusion

Outcome

Outcome

Outcome

Publication status

Country

Outcome

Data date range

Outcome

Country

Study design;

Publication status

Outcome; Study

design

Outcome

Outcome

Data date range

Outcome

Outcome

Outcome 
Citation

182. Yan, D, Sengupta, J, Wyer Jr, RS. Package size and perceived quality: The intervening role of unit price perceptions. Journal of Consumer Psychology. 2014. 24:4-17. doi:10.1016/j.jcps.2013.08.001.

183. Yi, Na-Young, Choi, Bo-Ram, Chang, Hye-Ja. Opinion of commercialization of ready-to-eat Korean foods by food-related lifestyle segments in Koreans and non-Koreans. Journal of the Korean Society of Food Science and Nutrition. 2016. 45:602-612.

184. Yoon, Sungeun, Gao, Zhifeng, House, LisaA. Analysis of Healthy and Convenient Food: The Example of Meal Kit Delivery Services. 2019. doi:10.22004/ag.econ.290854.

185. Zarychta, K, Banik, A, Kulis, E, Boberska, M, Radtke, T, Chan, CKY, Lobczowska, K, Luszczynska, A. Do Parent-Child Dyads with Excessive Body Mass Differ from Dyads with Normal Body Mass in Perceptions of Obesogenic Environment?. Nutrients. 2020. 12:doi:10.3390/nu12072149.

186. Zeballos, E, Mancino, L, Lin, BH. Does how you pay influence the share of healthy items that you Buy? Assessing differences in nutritional quality of food purchases by payment type. Food Policy. 2020. 92:doi:10.1016/j.foodpol.2020.101886.

187. Zhen, C, Finkelstein, EA, Karns, SA, Leibtag, E, Zhang, C. Scanner Data-Based Panel Price Indexes. Am J Agric Econ. 2019. 101:311-329. doi:10.1093/ajae/aay032.

188. Zheng, Yuqing, Dong, Diansheng, Burney, Shaheer, Kaiser, HarryM. Eat at Home or Away from Home? The Role of Grocery and Restaurant Food Sales Taxes. 2019. 44:doi:10.22004/ag.econ.281315.

189. Zhu, C, Lopez, RA, Liu, X. Information Cost and Consumer Choices of Healthy Foods. American Journal of Agricultural Economics. 2016. 98:41-53. doi:10.1093/ajae/aav057.

190. Zhylye vs.kyy, O, Jensen, HH, Garasky, SB, Cutrona, CE, Gibbons, FX. Effects of family, friends, and relative prices on fruit and vegetable consumption by African Americans. Southern Economic Journal. 2013. 80:226-251. doi:10.4284/0038-4038-2011.277.
Reason for exclusion

Country

Country

Publication status

Outcome; Country

Outcome

Outcome

Intervention/Exposure

Intervention/Exposure

Outcome; Data date range 